\title{
El problema de la lengua literaria: disputas y condiciones de transformación en la Argentina de 1920
}

\section{Mariano Javier Oliveto}

\author{
Tesis de doctorado en Letras \\ Directora: Dra. Geraldine Rogers (UNLP) \\ Codirector: Dr. José Maristany (UNLPam)
}




\section{ÍNDICE}

INTRODUCCIÓN

\section{CAPÍTULO I}

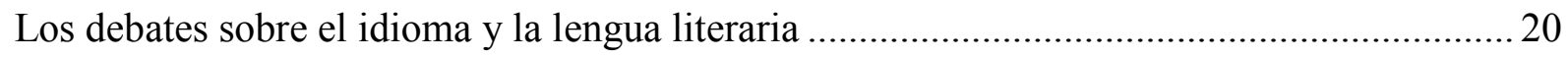

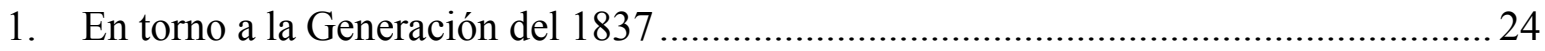

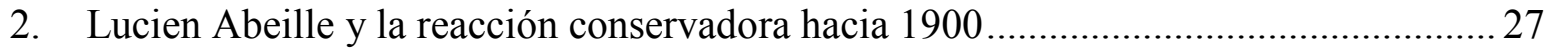

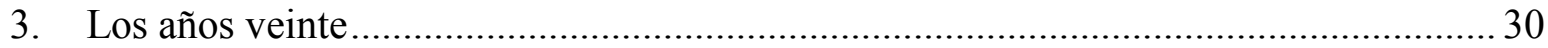

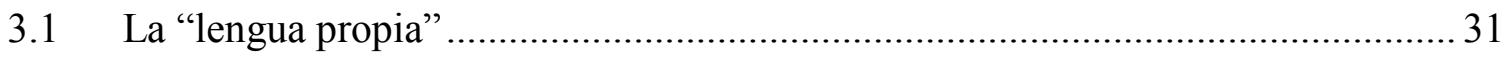

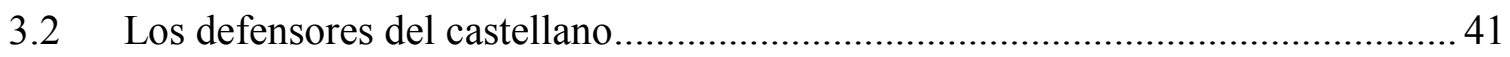

4. Gramática, ortografía y corrección en los debates sobre el idioma ..............................53

\section{CAPÍTULO II}

La lengua literaria y los escritores de izquierda: Elías Castelnuovo, César Tiempo y Álvaro Yunque

1. Escritores de izquierda y martinfierrismo: lenguajes y vanguardismos en los años

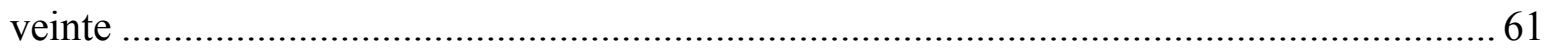

1.1 Hipercorrección y voces populares en Tinieblas de Elías Castelnuovo...................69

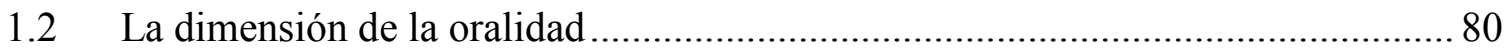

1.3 Clara Beter, la mujer que no se puede nombrar............................................... 88

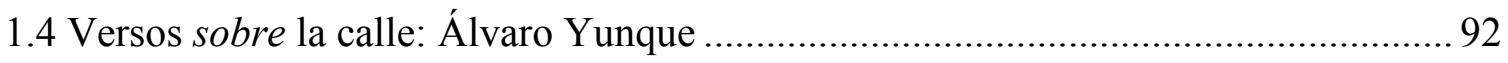

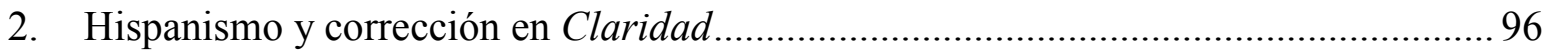

\section{CAPÍTULO III}

Prensa masiva, lunfardo y mercado.

1. A propósito de una encuesta del diario Crítica: ¿Llegaremos a tener un idioma propio?

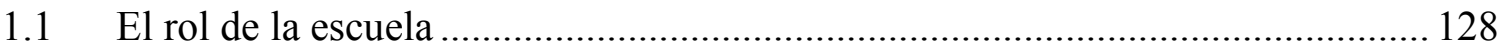

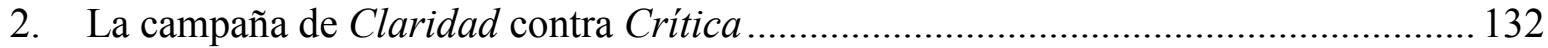

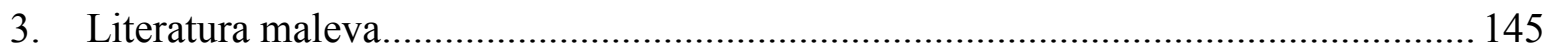

\section{CAPÍTULO IV}

Lengua literaria en el proyecto creador en Nicolás Olivari ................................................ 154

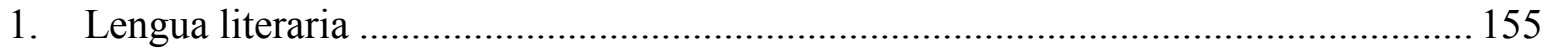

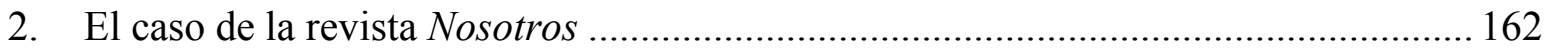

3. Nicolás Olivari y Martín Fierro: desencuentros y acuerdos................................... 171

4. La subversión del lenguaje como novedad ................................................................ 183

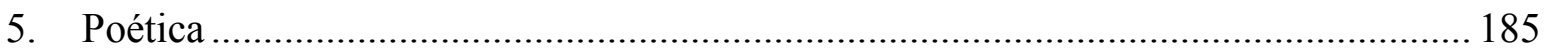




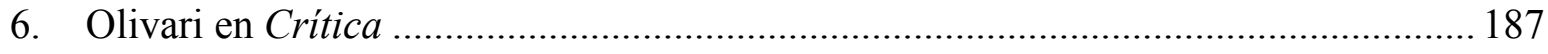

\section{CAPÍTULO V}

Roberto Arlt: el "idioma porteño" como lengua literaria................................................... 195

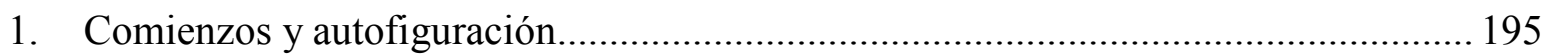

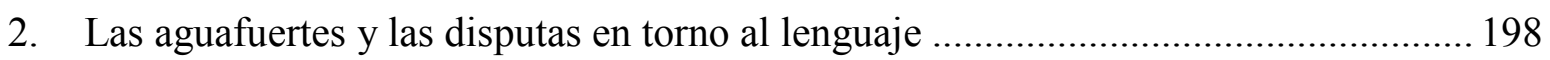

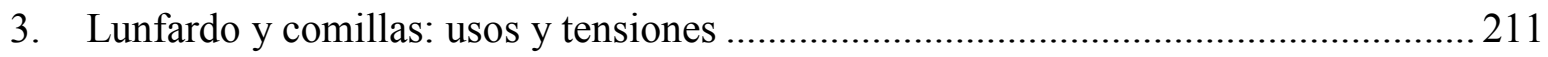

4. Lunfardo y corrección en un pasaje de El juguete rabioso ........................................ 223

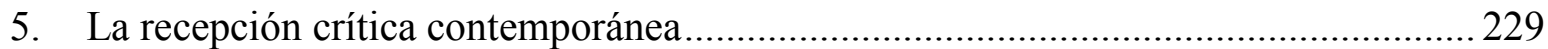

5.1 La izquierda literaria y Roberto Arlt: entre el rechazo y la aceptación ...............2230

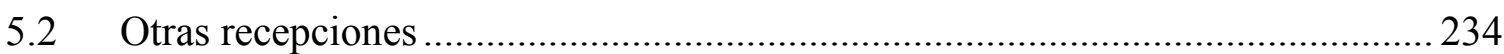

\section{CAPÍTULO VI}

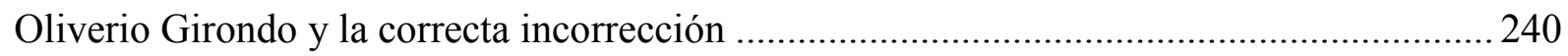

1. Entre la renovación estética y el conservadurismo idiomático ................................. 241

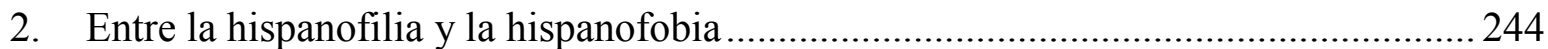

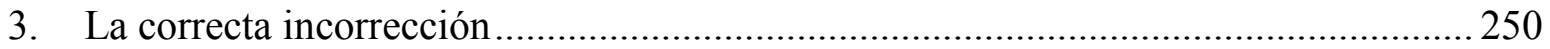

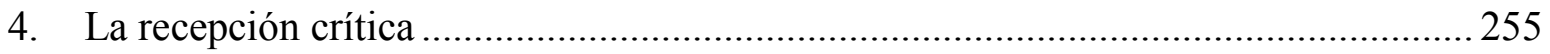

\section{CAPÍTULO VII}

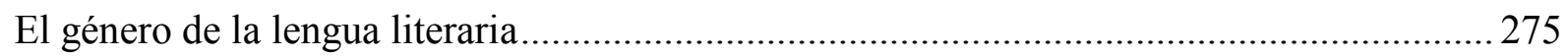

1. Las polémicas sobre el lenguaje y el "discurso literario femenino" .......................... 275

2. Norah Lange: regulaciones y transgresiones de la lengua literaria ............................277

2.1 Entre la vanguardia y las narraciones semanales ....................................................... 286

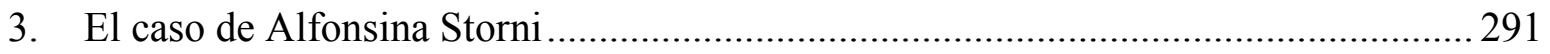

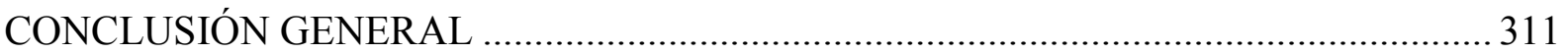

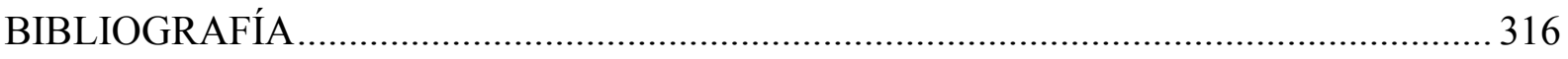

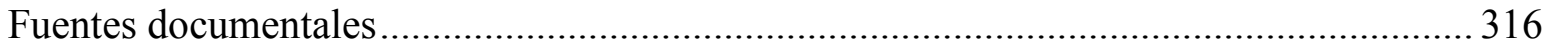

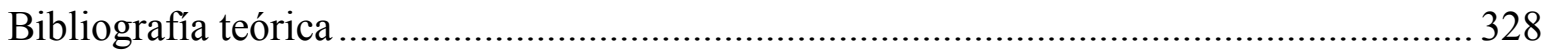

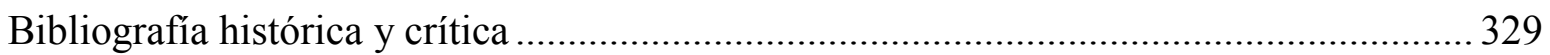




\section{INTRODUCCIÓN}

1.

Jorge Panesi señala que existen polémicas que son constitutivas de una cultura. $\mathrm{Su}$ olvido o superación en determinados momentos de la historia es sólo aparente puesto que, más tarde o más temprano, regresan y dan forma a un juego en el que, a través del tiempo, se van anexando formas de discusión, se cancelan otras y se reabren viejos debates (2003: 7). Estas polémicas componen la punta visible de una fractura oculta y vasta: son reinscripciones de puntos no soldados de la historia. Vale decir, entonces, que representan las huellas de las modalidades en que la cultura, o una franja determinada de ella, se ha conformado a lo largo del tiempo. Entre estas "polémicas ocultas", el crítico menciona la dicotomía sarmientina "civilización-barbarie", intervención polémica que abre una brecha de largo alcance, revisitada y reinterpretada en los contextos de crisis política. También brinda el ejemplo de las polémicas nacionalistas que tuvieron lugar en las décadas del treinta y del cuarenta, como así también las valoraciones revisionistas de los tiempos de Rosas. Pero, sin lugar a dudas, una de las polémicas más importantes es la que se construye en torno a los problemas de la lengua. Desde la primera mitad del siglo XIX, en los albores de la nación, hasta los días de la actualidad, los problemas referidos al idioma han gozado de una notable vigencia en Argentina, con períodos de meseta o aplacamiento, propios de las "polémicas ocultas", como en el momento de la organización nacional. Pero también con coyunturas críticas, como las que se abren a fines del siglo XIX, a partir de la primera oleada inmigratoria. En este sentido, la década de 1920 representa uno de estos momentos de auge de los debates en torno al idioma y a la lengua literaria. Este fenómeno no es casual, puesto que es durante estos años cuando los escritores comienzan a mostrar una aspiración a la independencia que se manifiesta, antes que nada, en proyectos que suponen un uso algo más autónomo de la lengua literaria.

Conviene hacer aquí la distinción entre lengua literaria y lengua o idioma ${ }^{1}$, conceptos que estarán funcionando a lo largo de toda la tesis. Para ello, tomaremos en cuenta el modo en que estos términos son abordados por algunos teóricos: los formalistas rusos distinguen entre la lengua poética y la lengua prosaica o cotidiana. Esa distinción se basa en que la primera, a diferencia de la segunda, es una "construcción”, un artificio (Eichembaum 1991: 32). La lengua cotidiana es un mero instrumento, un "elemento técnico", que no interviene ni participa del objeto estético (51). Este autor, por su parte, distingue entre lenguaje poético y

\footnotetext{
${ }^{1}$ Utilizaremos "lengua" e "idioma" como sinónimos.
} 
lenguaje lingüístico. A diferencia de cualquier otro dominio de la cultura, la literatura se sirve del lenguaje lingüístico en su totalidad. Por ejemplo, la ciencia no necesita la especificidad compleja de los sonidos de las palabras, pero la poesía sí (Bajtín 1991: 51). En tanto, Mukarovsky (2000) discrimina entre lenguaje poético y lenguaje comunicativo, y advierte: se debe evitar "el repetido error" de identificar el lenguaje poético con el comunicativo. El primero es una expresión poética, un acto creativo individual valorado de acuerdo con la tradición poética vigente, por un lado, y sobre el trasfondo del lenguaje comunicativo de la época, por otro. Por este motivo, las tensiones a la que está sometida la lengua literaria se explican a partir de la intervención de fuerzas que tienen que ver tanto con las discusiones acerca del idioma como con las tentativas de ruptura y de autonomización de la lengua literaria. Para este autor, el acercamiento de la expresión poética al lenguaje comunicativo se debe a una reacción contra la tradición poética dada. Estas tensiones son las que se ponen de manifiesto con particular intensidad en los años veinte, en Argentina, y resultan uno de los vectores principales de los desplazamientos y polémicas sobre la lengua literaria.

A partir de 1880, se puede observar un vínculo entre el Estado y los nuevos “escritores-artistas" (Rama 1984). Según Miguel Dalmaroni, durante la modernización de la literatura argentina (1880-1920), algunos desearon y creyeron que planificar el Estado era una misión de las nuevas letras, y que esa tarea los justificaría como modernos (2006: 16). Esta relación alcanza su punto más alto alrededor del Centenario, con nombres como Ricardo Rojas, Leopoldo Lugones, Paul Groussac, Joaquín V. González, Manuel Gálvez. La organización del Estado implicó el impulso de fuertes iniciativas culturales y educativas en las que se vieron involucrados directamente: "ciertos literatos, que ya no son generales, ministros, presidentes ni embajadores, se hacen pedagogos del nacionalismo del Estado o de los saberes del buen gobierno". De este modo, se constituyen en "proveedores discursivos o espirituales de las políticas del Estado" (35).

El desarrollo del sistema escolar en Argentina estableció cierto tipo de literatura como modelo de lengua general, sobre todo después de la llegada masiva de la inmigración. Con la enseñanza de la literatura, la escuela procuró construir una norma estético-lingüística escolar que cumpliera una función modeladora frente a las prácticas lingüísticas "amenazantes" de un sujeto social conflictivo: el inmigrante, potencial agente de corrupción lingüística (Bombini 2004: 89-90). ${ }^{2}$ El Estado educador reconocía a los intelectuales como portadores de una

\footnotetext{
${ }^{2}$ En una conferencia de 1903, Calixto Oyuela señala a la lengua literaria como el modelo de lengua: “...los buenos escritores representan la lengua en su forma literaria más pura, y por qué desde tiempo inmemorial se ha citado su testimonio como la manifestación más respetable de su uso...” (Bombini 2004: 106).
} 
verdad cultural de la nación y parecía pedirles que dieran letra a los políticos (Dalmaroni 4344).

Para los representantes del hispanismo, "la política escolar de la lengua establecerá que la lengua literaria escrita constituya el 'modelo' en el ámbito del aula" (Bombini 107). Teniendo presente este dato central, cobra vital importancia para nuestro trabajo la noción de corrección, ${ }^{4}$ puesto que no sólo resultó el baremo con el que se valoraron los diversos lenguajes literarios, sino que además establece relaciones complejas con los procesos de autonomización relativa de la lengua literaria.

Nos interesa sumar a estas apreciaciones los aportes que realiza Pascale Casanova. La lengua es un conjunto de leyes y normas impuestas por instituciones políticas (2001). ${ }^{5} \mathrm{~A}$ su vez, la lengua tiene la función de servir como estandarte nacional y, en este sentido, puede ser utilizada con fines nacionales, nacionalistas o populistas. Por otra parte, la lengua literaria supone el uso estético del idioma y su grado de autonomía está vinculado, entre otras cosas, con la no injerencia, en la praxis artística, de los mandatos de corrección gramatical y/o ortográfica. Una lengua literaria autónoma ${ }^{6}$ no admite tampoco las exigencias de legibilidad más comunes e inmediatas. El lenguaje literario verdaderamente independiente de todos estos factores no obedecería más que a los imperativos dictados por la creación estética en sí misma, pero eso difícilmente ocurre en la práctica. Por otra parte, la noción de lengua literaria ha sufrido cambios a lo largo de la historia. La acumulación de recursos literarios, la invención de una libertad y una especificidad literarias hicieron que la esfera de lo literario tendiera a reconfigurarse según los parámetros de la modernización. Por esta razón, no resulta posible brindar una definición única y ahistórica de esta categoría. Precisamente eso constituye uno de los principales justificativos de esta tesis, localizada en Argentina y centrada en una etapa de notables transformaciones en su historia literaria: la década de 1920.

\footnotetext{
${ }^{3}$ Ricardo y José María Monner Sans, Arturo Costa Álvarez, Juan Selva, Arturo Capdevila, entre otros, conforman un grupo de catedráticos, en cierta medida hegemónico, de raíces hispánicas, con una fuerte influencia en el ambiente de la formación de profesores y de la educación secundaria (Bombini 2004: 109).

${ }^{4}$ Entendemos la corrección como la cualidad, que asumen los textos, de respeto y/o apego a las normas lingüísticas emanadas desde las academias, el sistema escolar y aquellas instituciones que se ocupan de legislar y controlar los usos del idioma.

5 "La lengua [es] concebida como un conjunto de leyes y de normas impuestas por las instituciones políticas y que contribuyen a someter a los escritores a las normas nacionales de la lengua nacional" (Casanova 2001: 445).

${ }^{6}$ Entendemos el concepto de autonomía no en un sentido estricto, plenamente realizado, sino más bien como una tendencia y/o aspiración, es decir como algo que no siempre se consigue en la práctica. Como veremos a lo largo de este trabajo, en la literatura del período abundan los casos en que, por ejemplo, la gramática y las normas de corrección intervienen el grado de autonomía de muchos lenguajes literarios.
} 
En 1965, Jaime Rest se refirió a la lengua literaria culta, canónica, como una lingua communis (2010). ${ }^{7}$ Por su parte, Casanova afirma que la autonomía literaria implica, justamente, romper con esa lengua común, y para ello es preciso la utilización, por parte del escritor, de un nuevo lenguaje, pensado como libre de cualquier tipo de servidumbre. En este sentido, la lengua literaria se entiende como una construcción o elaboración estética llevada a cabo en el plano del lenguaje. Las lenguas literarias son sumamente sensibles puesto que sus definiciones y alcances cambian en función de las nuevas concepciones sobre la literatura y sobre la lengua. Los años veinte, en Argentina, expresan un momento de reconfiguración, movilizado por tensiones y disputas, de un concepto más antiguo o tradicional de la lengua literaria.

En 1974, Rodolfo Borello definió el dilema del escritor argentino, en lo que respecta a la elaboración de un lenguaje literario: su labor se encuentra atravesada por el sentimiento de "inseguridad" y por "la conciencia de oponerse" a la tradición literaria española, tradición que percibe "como propia y al mismo tiempo 'otra"” (1974: 11). Este autor expresó la vacilación que muchos escritores experimentaron al momento de escribir literatura; una vacilación que determinó las tensiones que afectaron la lengua literaria argentina desde siempre, pero -según la hipótesis central de nuestra tesis- con notable intensidad durante la década de 1920.

Desde la perspectiva de Borello, los conflictos y tensiones se definen a partir de la intersección problemática de la oralidad y la literatura. Tradicionalmente, el lenguaje literario encarna un prestigio internacional y una persistencia conservadora que lo pone por encima de las diferencias locales o nacionales. En nuestras letras, este crítico lo designa con el nombre de "koiné hispánica internacional". Como hemos dicho, un concepto similar había utilizado Jaime Rest, "lingua communis", para referirse a la lengua literaria que se uniforma de acuerdo con regulaciones gramaticales y estéticas que la fijan dentro de cánones conservadores. Dicha "koiné", o "lingua communis", no sólo da origen a las posturas puristas, sino a lo que Ángela Di Tullio (2003) denomina la "tradición de la queja": la cercanía con la oralidad en la literatura conlleva formas que son "condenadas sistemáticamente por gramáticas y gramáticos, por la escuela y por todos los encargados de dictar normas lingüísticas concretas" (Borello 12).

La conformación de modalidades de la lengua literaria o, mejor dicho, las fuerzas que intervienen en su constitución y que definen en buena medida las tensiones y disputas que analizaremos en esta tesis, responden a un proceso complejo que involucra, en primer lugar, a todo el pasado escrito. A esto se le debe sumar, en segundo término, la influencia que ejercen

\footnotetext{
7 "La lengua literaria tiende a uniformarse de acuerdo con regulaciones gramaticales y estéticas que la fijan dentro de los cánones conservadores y la convierten en una suerte de lingua communis" (Rest 2010: 134-135).
} 
"la lengua hablada coetánea, la lengua escrita de su época y, sobre todas las cosas, el habla concreta del mundo nacional en el cual [el escritor] vive" (14). En esa relación intensa con el pasado y el presente radica la dimensión histórica del problema que abordamos.

Desde los tiempos de la Revolución de Mayo, dos son las fuerzas opuestas que intervienen en la creación literaria: por un lado, un uso lingüístico conservador, que propicia el exclusivo manejo de formas cultas ya reconocidas; por el otro, la búsqueda de vitalidad en una mayor cercanía con la lengua hablada (Rest 2010).

Los problemas en torno al idioma constituyen uno de los marcos de las tensiones y transformaciones que se producen en la lengua literaria. La cuestión del idioma representa un dilema de grandes proporciones con numerosas aristas que se vinculan de distinto modo y en diferentes situaciones con el lenguaje literario. En ocasiones, la lengua nacional encuentra en la lengua literaria un modelo idiomático; otras veces se producen colisiones o distancias cuando algunos autores se apartan de los usos lingüísticos "correctos". Resulta imposible, entonces, referirse a los problemas y disputas entablados en relación con los textos literarios sin hacer referencia a las cuestiones de la lengua, puesto que la naturaleza y la lógica que gobierna las polémicas sobre el lenguaje literario muchas veces derivan de ese marco más amplio que las sustenta. Ya en el origen, las intervenciones de los románticos sobre la cuestión del idioma implicaron aspectos vinculados con la literatura. Es decir, desde el comienzo, el discurso literario aparece como un catalizador de toda polémica desatada en torno al idioma, puesto que la literatura durante mucho tiempo fue pensada como modelo de diversas pautas idiomáticas, fueran éstas dominantes o no. La lengua literaria, entonces, guarda una estrecha relación con las actitudes lingüísticas generales (Blanco de Margo 1991), puesto que muchas evaluaciones literarias se realizan a partir de valoraciones previas sobre el idioma y sobre la función social y política que se le asigna en el marco nacional. Esto constituye un límite al proceso de autonomización señalado por Casanova.

\section{2.}

Las disputas en torno a la lengua literaria y sus condiciones de transformación, en la Argentina de los años veinte, constituyen el objeto de estudio de esta tesis. El propósito principal que la guía es el de conformar un corpus significativo de intervenciones polémicas en torno al lenguaje literario durante el período 1920-1930, y analizarlo a la luz de la bibliografía crítica y teórica. Por este motivo, la metodología que se sigue hace fuerte hincapié en el relevamiento de fuentes documentales, las cuales nos permiten conocer no sólo las dimensiones que adquirieron las querellas sobre la lengua literaria en esa etapa, sino 
también reunir una porción importante ${ }^{8}$ de documentos hasta ahora inadvertidos o poco explorados, así como reponer la discursividad propia de la época en torno a este problema, a partir de los intercambios llevados a cabo por diversos agentes del campo literario (Bourdieu 1995). Dada la diversidad, complejidad y extensión del espacio letrado de la década del veinte, resulta obligado realizar un recorte a los fines de abordar con más orden y detenimiento la problemática, con plena conciencia de que no será este un trabajo exhaustivo sobre la literatura de la década de 1920, ni siquiera sobre sus zonas más conocidas (algunas de las cuales han sido muy investigadas) ${ }^{9}$ sino sobre una selección parcial pero significativa de la misma.

El fenómeno vanguardista en Argentina no puede entenderse si no consideramos el acelerado, profundo y desigual proceso de modernización que sufre la ciudad de Buenos Aires durante las décadas de 1920 y 1930. Se produce, a instancias de ella, una cultura de mezcla (Sarlo 2007) en un mismo espacio urbano que conjuga los signos de la transformación (alumbrado eléctrico, medios de transporte, etc.) con aquellos otros más residuales (poca edificación en las afueras de la ciudad, calles sin veredas, etc.). Pero, en el plano literario, la mezcla también implica la convivencia, en el marco de un campo literario cada vez más definido y diversificado, de dos órdenes opuestos: el de los escritores centrales, legitimados, y el de aquellos autores recién llegados al campo letrado, de origen inmigratorio, de formación no tradicional. En la constitución de un campo literario moderno, con relativa autonomía, interviene la emergencia de estos nuevos escritores quienes, durante las décadas de 1910 y 1920, reclaman su lugar en el panorama de las letras argentinas.

La emergencia de un mercado cultural constituye un rasgo central del proceso modernizador del espacio letrado (Sarlo 1997b). Las redefiniciones de un mercado literario que se amplía y moderniza en este período, incluye la creación de editoriales (Tor, Claridad, Babel) cuyos proyectos, al apuntar a un público popular, propician la edición de libros baratos. A esto se le agrega la aparición de nuevas publicaciones periodístico-literarias diseñadas especialmente para este lectorado emergente (Sarlo 1985). Las empresas culturales que llevaron adelante esos proyectos editoriales orientaron los gustos e intereses del nuevo público al mismo tiempo que permitieron la conformación de su sensibilidad. Los libros

\footnotetext{
${ }^{8}$ Cabe señalar, no obstante, que las exploraciones biblio y hemerográficas no son exhaustivas debido a la profusión de documentos que contemplan directa o indirectamente la temática en cuestión.

${ }^{9}$ Ya sea debido a que la crítica se ha ocupado con mucha frecuencia a determinados autores, o bien debido a la amplitud y las lógicas particulares de funcionamiento de algunas zonas del campo literario de los años veinte, las cuales exceden los propósitos de esta tesis, existe una amplia porción del panorama literario del período que no hemos abordado. Tal es el caso del teatro criollo, las narraciones semanales, y numerosos escritores de la época que no aportan elementos significativos referidos a nuestro objeto de estudio. Además, sobre algunos autores abundan los trabajos sobre su obra desde la perspectiva que ofrecen los problemas de la lengua literaria, como por ejemplo el caso de Borges.
} 
baratos no sólo formaron la biblioteca del pobre, sino que también constituyeron uno de los elementos configuradores de la cultura de los sectores populares (Gutiérrez- Romero 1995). Un nuevo público emergió y desbarató el antiguo orden de los "señores" lectores (Prieto 1956, Barcia 1981, Gutiérrez-Romero 1995, Rivera 1998, Sarlo 2007). Pero también la modernización del espacio letrado implicó la emergencia de un nuevo periodismo que encontró en estos nuevos lectores su público privilegiado. Este es el caso de, por ejemplo, los diarios Crítica y El Mundo, en los que numerosos e importantes escritores del período tuvieron una participación relevante (Saitta 1998, 2008, 2009). Este nuevo periodismo y la literatura de vanguardia, sumamente vinculados, configuran una variante moderna del escritor profesional (Sarlo 2007).

Junto a estos nuevos lectores aparece un campo profesional asociado en el que se destacan no sólo escritores, sino también periodistas, imprenteros, editores, libreros, críticos, etc. La prensa escrita se multiplica y transforma notablemente: los diarios y revistas dejan de tener una circulación restringida y de estar dirigida únicamente a los miembros de la élite letrada. El periodismo comercial y masivo, regulado por leyes propias, amplía notablemente los ámbitos en los que jóvenes escritores, sin linaje ni dinero, procedentes de clases medias y populares, encuentran fuentes de trabajo y ensayan una variante moderna del escritor profesional: el escritor-periodista. Sin embargo, la existencia de un público potencial no garantiza nuevos lectores: es necesario captar el interés de ese público. Por tal motivo, diarios y revistas elaboran estrategias de interpelación que los diferencia de la "prensa seria", a través de nuevos formatos periodísticos, acorde con los recién llegados al mundo de la cultura letrada (Saítta 2009).

Las capas medias y populares se convierten en destinatarios privilegiados de un mercado que se construye en función de sus gustos, intereses y modalidades de lectura. A su vez, si la librería era un reducto minoritario hacia 1910, a partir de allí, se generan nuevos circuitos de consumos culturales en los que este nuevo público comienza a encontrar libros y revistas en quioscos, peluquerías, estaciones de tren y de subte, etc. (Sarlo 1985; Rivera 1998; De Diego 2006, 2009).

La ampliación y diversificación del público lector produjo una crisis en la hegemonía cultural que mantenían los sectores de la élite letrada, puesto que no sólo un gran número de personas accedieron al patrimonio cultural que este sector creía como propio, sino que además nuevos escritores, portando nuevas formas estéticas, comienzan a disputarle espacios en el campo literario el cual, en consecuencia, asume rasgos democratizadores (Rogers 2008). Las innovaciones en la lengua literaria, y las tensiones a las que estuvo sometida durante este 
período no pueden ser entendidas sin tomar en cuenta estas transformaciones culturales de suma relevancia.

La emergencia de un campo intelectual en Argentina constituye parte de un proceso de modernización mucho más vasto que afecta al conjunto de la sociedad (Altamirano-Sarlo 1997). Este incipiente proceso -que tiene lugar, aproximadamente, entre 1890 y 1930-, sumado al fenómeno inmigratorio, despertó en buena parte de la intelectualidad diversas respuestas frente a una realidad compleja: por un lado, la búsqueda de una identidad nacional; por el otro, y concomitante con lo anterior, la necesidad de redefinir la relación con España.

Entre fines del siglo XIX y comienzos del XX, se produce un nuevo fenómeno: la constitución de ideologías de artista. El gentleman-escritor (Viñas 2005b) tiende a dejar paso al escritor profesional: los escritores comienzan a definirse como tales, empiezan a concebir su actividad como una ocupación central, de manera autónoma, es decir, no sujeta a ninguna otra esfera de actividad, como sucedía en el pasado en la que los escritores eran antes que nada políticos o militares, y la literatura se ejercía como una actividad lateral (Viñas 8; Altamirano-Sarlo 168). Como se sabe, se trata de un momento de transición: en el campo letrado, conviven formas arcaicas y novedosas. A las tramas familiares, los vínculos políticos y amicales que regulaban, en el pasado, las relaciones en la república de las letras, se suman ahora nuevas formas de iniciación cultural que conectan, a través de la universidad o el periodismo, a jóvenes escritores, hijos de inmigrantes, con los intelectuales tradicionales, cosa impensada en el panorama de las letras del siglo XIX.

La elección del período 1920-1930 para abordar este tema se justifica en que en esa etapa de modernización cultural y estética, la literatura, como hemos dicho, atraviesa una importante fase de transformación, inédita hasta ese entonces. Las influencias vanguardistas, el contacto de lenguas ocasionado por la inmigración, el auge de la prensa masiva y del mercado cultural, que suponen una ampliación inédita del lectorado, la diversificación del campo literario a partir del ingreso a la práctica literaria de nuevos escritores y escritoras, de formación no tradicional, producen una pluralidad de lenguas literarias que no sólo muchas veces batallan entre sí, sino que además se enfrentan contra las estéticas tradicionales y las instituciones legitimadoras, además de cuestionar la idea de un lenguaje literario modélico de los usos idiomáticos. 
3.

A los efectos de abordar el problema de la lengua literaria en el marco de la variadísima y heterogénea situación del campo letrado de los años veinte, hemos decidido organizar la exposición de esta tesis a partir de ciertas "zonas" o espacios de confluencia y producción cultural que es posible identificar o relevar en la ciudad de Buenos Aires. Eso nos permite establecer un orden relativo en los diversos sectores en los que nos hemos detenido con el objeto de analizar las polémicas y las nuevas configuraciones de la lengua literaria.

Apenas se comienza a indagar en el campo literario, se puede apreciar que existen escritores o publicaciones que -tanto diacrónica como sincrónicamente- participan de distintas "zonas". Estas podrían pensarse de manera afín a las formas rizomáticas ${ }^{10}$, es decir como estructuras abiertas, conectables unas con otras, con ciertas características identificables y una unidad relativa, aunque también con líneas de desterritorialización, es decir con rupturas que establecen líneas de fuga. Vale decir entonces que el campo literario de la década del veinte puede ser presentado como un mapa de dimensiones abiertas y conectables. Con esto, ponemos en cuestión la idea de que los autores, publicaciones y agrupaciones intelectuales se distribuyan en espacios homogéneos, estancos y cerrados; el caso paradigmático que ilustra esa idea, reproducida por gran parte de la crítica literaria durante años, es el par "Boedo/Florida" cuyos participantes no siempre se mantuvieron en los límites estéticos e ideológicos que la dicotomía parecía encerrar. Pensar, en cambio, en zonas relativamente indentificables pero a la vez conectadas y desmontables permite visibilizar fenómenos complejos y relevantes que ayudan a comprender la dinámica circulación cultural en aquella etapa.

Existen autores que circulan "entre" zonas, con mayor o menor intensidad en su relación con cada una de ellas: por ejemplo, Nicolás Olivari transita entre la izquierda literaria, la vanguardia estética y el mercado. Algo similar ocurre con Roberto Arlt quien tiene sus vínculos con la revista de izquierda Claridad $^{11}$ (1926-1941) y a la vez escribe cotidianamente en periódicos destinados al circuito masivo como Crítica y El Mundo y está muy cerca del martinfierrismo, al punto que da a conocer avances de su primera novela en la revista Proa. En Crítica, entre 1926 y 1927, convergen en el staff del diario Arlt y la mayoría

\footnotetext{
${ }^{10}$ Deleuze y Guattari toman el concepto de rizoma como modelo descriptivo en el que se privilegia la multiplicidad, la heterogeneidad y la desjerarquización de elementos: "a diferencia de los árboles o de sus raíces, el rizoma conecta cualquier punto con otro punto cualquiera (...) El rizoma no se deja reducir ni a lo Uno ni a lo Múltiple. No es lo Uno que deviene en dos, ni tampoco en tres, cuatro o cinco, etc. No está hecho de unidades, sino de dimensiones, o más bien de direcciones cambiantes. No tiene principio ni tiene fin, siempre tiene un medio por el que crece y desborda (...) el rizoma es un sistema acentrado, no jerárquico y no significante, sin General, sin memoria organizadora o autómata central, definido únicamente por una circulación de estados" (Deleuze - Guattari 1997: 25-26).

${ }^{11}$ Este aspecto se desarrolla en el capítulo V.
} 
de los escritores del llamado grupo de Florida. ${ }^{12}$ Frente a estos casos que la crítica había considerado como "de frontera", "francotiradores", "casos raros", etc., algunos críticos más recientes -Carlos Giordano (1986), Sylvia Saítta (1998), Ojeda-Carbone (2006) (2008) (2012) - ${ }^{13}$ los describen como un espacio intermedio, una "tercera zona" o "zona alternativa" a la polaridad de Boedo y Florida.

En ese mapa de dimensiones abiertas y conectables, podemos entonces identificar las siguientes zonas significativas del campo literario de esos años: la vanguardia estética, la vanguardia de izquierda, el circuito de mercado, y el circuito "culto" tradicional.

La primera zona está regida por una lógica de modernización estética, y encuentra en publicaciones como Martín Fierro (1924-1927) y Proa (1924-1926) sus principales órganos de difusión. Como se sabe, esta zona de la vanguardia se propone renovar las artes. La heterogeneidad es una de sus propiedades, dado que participan escritores de muy diversa índole en lo que respecta a los temas, influencias y, sobre todo, al uso de la lengua literaria. Cabe destacar que mantiene contactos con otras zonas, como por ejemplo el mercado, a través de las publicidades que encontramos en sus revistas, de los emprendimientos editoriales que llevan adelante, como así también de los vínculos que establece con espacios que funcionan de acuerdo con la lógica del mercado cultural, como el diario Crítica. También entabla zonas de contacto con el circuito "culto" tradicional, como por ejemplo el lugar que la revista Nosotros le brinda a los jóvenes ultraístas a comienzos de la década de 1920.

La segunda zona se define por ciertos rasgos que se vinculan con la militancia ideológica de izquierda y con una concepción de la literatura como herramienta de cambio político-social. Tal es el caso de los emprendimientos editoriales de Antonio Zamora, cuyas publicaciones principales son Los Pensadores (1922-1926) y Claridad.

La zona del circuito de mercado contempla un segmento de la industria cultural que, a partir de las transformaciones modernizadoras junto con la relativa autonomización de la literatura, en los años veinte encuentra su momento de mayor auge. Una cantidad significativa de publicaciones periódicas surgen o se afianzan en esa etapa (revistas de canciones y de

\footnotetext{
${ }^{12}$ Otros casos similares pueden ser los de Roberto Mariani, Enrique y Raúl González Tuñón, Luis Emilio Soto, etc.

${ }^{13}$ Ojeda y Carbone definen a la "tercera zona" como aquella en la que se agrupan los escritores "que no están ni en Boedo ni en Florida sino en un lugar de 'indefinición' estética entre estos dos extremos" (2012: 71). Cabe destacar que el concepto de "tercera zona" consolida la dicotomía "Boedo y Florida", puesto que no pretende, o no consigue, desarmar esa bipolaridad, esparcirla, otorgarle la complejidad que los escritores de los años veinte presentan al momento de ubicarlos en grupos o espacios según características comunes. Al menos, desde la perspectiva de la lengua literaria, se presentan muchos problemas cuando se libran operaciones como la señalada. Además, cabe preguntarse ¿por qué habría un rasgo de "indefinición" solamente en los escritores integrantes de la "tercera zona? ¿En ese caso, los escritores de "Boedo y Florida" presentarían rasgos unívocos y homogéneos? Por estas cuestiones, resulta necesario poner más insistencia sobre una heterogeneidad circulante que conecta y hace permeables, difusas, a las zonas literarias.
} 
teatro, magazines semanales, diarios como Crítica y, hacia fines de la década, El Mundo) así como distintos proyectos editoriales que difunden folletos y libros baratos entre una emergente franja popular de lectores. A su vez, izquierda literaria y mercado entran en un contacto estrecho a partir de proyectos editoriales como los de Claridad (Montaldo 2006b).

El circuito "culto", por último, es una categoría que utiliza Dalmaroni (2006) para referirse al conjunto de poéticas, escritores, formaciones e instituciones culturalmente más autorizadas, que con el tiempo irán ocupando la tradición dominante de la "literatura argentina". Bourdieu (2003) los denominó "los conservadores de la cultura". ${ }^{14}$ Allí se concentran los agentes o sistemas de agentes poseedores de una autoridad "extensa y extendida" que ejercen o pretenden ejercer sobre otros agentes y que, merced a ella, ocupan espacios centrales del campo literario. Se trata de agentes que intervinieron en calidad de árbitros en la competencia por la consagración y la legitimidad intelectuales (Bourdieu 265). En la Argentina de los años veinte, este sector se concentra en algunas publicaciones como la revista Nosotros (1907-1934) y en el suplemento cultural del diario La Nación; en algunos sectores universitarios; y en la SADE, fundada en 1928. Autores con prestigio y autoridad en el campo de los temas de la lengua son, por ejemplo, Arturo Costa Álvarez, Ernesto Quesada, Ricardo Monner Sans y Arturo Capdevila, entre otros, quienes a lo largo de los años veinte han publicado textos fundamentales sobre la cuestión del idioma y los problemas de la lengua literaria.

El caso de las mujeres escritoras del período, a las que nos vamos a referir, puede ser pensado en relación con los vínculos que establecen o las formas en que circulan por estas zonas que acabamos de relevar. Entre ellas no existen propiedades similares u homogéneas, en lo que respecta a sus preferencias estéticas o sus praxis literarias. Lo que las aúna, en todo caso, es una situación mujer que resulta significativa para considerar la relación entre sus prácticas de escritura y las disputas en torno a la lengua literaria en los años veinte. Este concepto expresa las condiciones socioculturales bajo las cuales las mujeres desarrollaron sus actividades literarias desde el período colonial hasta la década de 1960, en América Latina (Rivero 1994-95). La situación mujer implica una determinada subalternidad de las prácticas literarias femeninas, una práctica "diferente a la norma, ex-céntrica y, por ende, con la marginalidad de lo secundario" (23). Existen textos femeninos "porque hay una situación

\footnotetext{
14 "Ya sea que se trate de las clases altas, que sancionan por su rango social el rango de las obras que consumen en la jerarquía de obras legítimas; ya se trate de instituciones específicas (...); ya se trate incluso de grupos literarios o artísticos como los cenáculos (...) existe casi siempre, hasta cierto punto, una pluralidad de potencias sociales (...) las cuales, en virtud de su poder económico o político, o de las garantías institucionales que disponen, están en condiciones de imponer sus normas culturales a una fracción más o menos amplia del campo intelectual y reivindican una legitimidad cultural" (Bourdieu 2003: 265).
} 
femenina, no porque haya necesariamente una esencia femenina" (25). El énfasis en la unicidad que pareciera plantear la situación mujer no debe tomarse necesariamente como admisión de homogeneidad. ${ }^{15}$ Lo que une a las escritoras que analizaremos en este trabajo (Norah Lange y Alfonsina Storni) son sus diversas estrategias discursivas para instalar su palabra literaria por fuera de las prescripciones falocéntricas, ${ }^{16}$ fenómeno que contribuyó a la emergencia de tensiones y nuevas configuraciones de la lengua literaria durante la década del veinte. Al mismo tiempo, cada una de estas escritoras participa en algunas de las zonas que hemos relevado. Por ejemplo, Norah Lange forma parte de la vanguardia estética, mientras que Alfonsina Storni también rozó esa zona en su obra poética tardía, a la vez que participó en el circuito de mercado.

Con respecto a los recortes, se ha privilegiado la selección de aquellos autores y/o publicaciones más significativos de cada una de las zonas. Es decir, hemos procurado cartografiar, aunque de manera no exhaustiva, los puntos neurálgicos en los que afloran las tensiones que atraviesan el campo letrado en relación con la problemática de la lengua literaria. Los criterios que guiaron la selección de autores y/o publicaciones para analizar se fundamentan en la intención de reconstruir el escenario de las polémicas, tensiones, indecisiones y ambigüedades, reinstalando y dando nueva visibilidad a sus protagonistas más relevantes. Las fuentes consultadas son de dos tipos: por un lado, materiales editados en publicaciones periódicas, donde predominantemente los debates fueron expuestos en la esfera pública; y por el otro, textos literarios, donde se observan las prácticas concretas, en contrapunto con las intervenciones polémicas llevadas a cabo en diarios y revistas.

\section{4.}

La hipótesis general de nuestro trabajo sostiene que la lengua literaria durante los años veinte atraviesa una transformación sin precedentes. En este período, emerge con mayor claridad que en etapas previas la pretensión de crear modalidades de lengua específicamente literarias, relativamente autónomas de cualquier esfera ajena a ellas, es decir un lenguaje literario con una "voluntad de soberanía en su propio campo" (Rogers 2011a: 1). Una parte de

\footnotetext{
${ }^{15}$ Es decir, más allá de las condiciones socioculturales en las que estuvieron inmersas las mujeres durante mucho tiempo, se debe pensar lo femenino como "un término pluralizador, analítico tanto como descriptivo, que pueda entenderse como amalgama de factores comunes de construcción cultural, pero que no ignore las perspectivas sopesadas por etnia, clase social, orígenes nacionales, y preferencia sexual, diferencias todas ellas representadas por las mujeres que viven, piensan y escriben en nuestros países del centro y del sur continentales" (Rivero 1994-95: 28).

${ }^{16}$ A la lengua literaria legítima se le puede adjudicar género (gender), puesto que se la representa como "viril" y "masculina", a la vez que muchas otras escrituras son tildadas de "femeninas", "afeminadas" o del "tercer sexo". La izquierda literaria, por ejemplo, ha hecho uso de este tipo de argumentos para mostrar su rechazo hacia diversos escritores. Ver, por ejemplo, "Vaselina, vaselina" (1926), Doll (1928), Lavagnino (1930), Alcazar Civit (1931), etc. Todos estos artículos serán abordados a lo largo de este trabajo.
} 
los escritores modernos cuestionó la asociación de la literatura con las "bellas letras" y con la idea de un discurso literario modélico del idioma y de determinadas pautas de corrección. En este sentido, la autonomía postulada por estos escritores implicó una considerable oposición hacia los gramáticos y normalizadores de la lengua. Esa voluntad de soberanía no resultó pacífica, ni necesariamente exitosa, dado que diversas concepciones acerca de lo que la lengua literaria debía ser entraron en pugna. Frente a este panorama, la escritura del período se tensiona: la voluntad de innovación se cruza con el eje más conservador que despliegan los agentes centrales del campo literario; pero también con otras zonas que bregan por la innovación, sólo que guiados por otras coordenadas estéticas y lingüísticas. Sin embargo, la distribución de esas tensiones no resulta ordenada y esquemática. Dado que la implicancia entre "lengua literaria", "modelo de lengua" y "corrección idiomática" se encontraba todavía muy vigente en una época en que escolarización y movilidad social ascendente estaban implicadas (Bertoni 2001; Sarlo 1997) no es extraño entonces encontrar nuevas tensiones, matices y vacilaciones aún en los escritores más innovadores, quienes elaboran una escritura sintomática de las transformaciones que la propia lengua literaria atraviesa por aquellos años. Esta problemática reorganiza la configuración del campo letrado: la desestabilización de ciertos presupuestos (entre los que se cuenta la función normalizadora de la lengua literaria) permite al sector más moderno de los autores cuestionar, al menos en parte, la autoridad de los escritores más tradicionales. Las prácticas literarias que ponen en cuestión la validez y legitimidad de las normas son paralelas a la emergencia de nuevas figuras y nuevos proyectos creadores en el campo literario. Los espacios adyacentes al circuito "culto" tradicional intentan desbaratar el centro, lo ponen en cuestión, lo rechazan y horizontalizan. Y es así que los debates en torno a la lengua literaria se convierten en arena de lucha entre los diversos agentes que buscan ganar posiciones (o recuperar las perdidas), aunque con otros criterios de legitimación. Finalmente, cabe agregar que no existe un vínculo simple entre sectores del campo letrado y posturas determinadas con respecto al idioma y a la lengua literaria, en función de las afinidades estéticas e ideológicas. Una percepción de ese tipo implicaría correspondencias demasiado automáticas entre las relaciones o "posiciones" de los sujetos y las concepciones y prácticas literarias en torno a la lengua. Por esta razón, sostenemos que dada la diversidad de factores en el escenario cultural del período, se puede apreciar una heterogeneidad notable y tensiones en materia de opiniones estéticas e idiomáticas, aún dentro de una misma zona, y a veces incluso en un mismo autor. Uno de los propósitos centrales de este trabajo consiste en explicar, en la medida de lo posible, a qué responden estas tensiones. 
5.

Cabe destacar también la importancia que "lo popular" tiene en relación con el problema de la lengua literaria en los años veinte. La relevancia de esa categoría cobra una dimensión fundamental en primer lugar porque la literatura argentina, por aquellos años, asume un nuevo punto de vista sobre los marginales y los pobres (Sarlo 2007).

Resulta más rico pensar "lo popular" no como una categoría que reúne objetos culturales, sino como una "dimensión del mundo simbólico" (Sarlo 1983). Es decir, lo popular no se definiría por dichos objetos en sí mismos, sino por las prácticas en las cuales están implicados. El concepto de dimensión permite no presuponer la existencia de una sustancia que define lo popular, contenida en un todo homogéneo y excluyente. La oposición cultura de élite - cultura popular, si bien permite un orden inicial, no resulta funcional puesto que presupone "la estabilidad de la élite $\mathrm{y}$, lo que es quizás más grave, también su homogeneidad ideológica y estética" (Sarlo 5). Desde esta concepción, la cultura dominante en la Argentina no es siempre la cultura de elite.

Por su parte, Stuart Hall (1984) señala que lo que mejor define "lo popular" son las tensiones permanentes que establece con la cultura dominante. Cuando hablamos de "lenguaje popular" nos referimos a la relación compleja entre determinados usos lingüísticos y los sectores populares. Estos no se definen, necesariamente, por la clase, puesto que no hay una relación de uno a uno entre una clase y determinada forma o práctica cultural. Los términos "clase" y "popular" están profundamente relacionados, pero no pueden ser asociados de manera simple. No hay "culturas" totalmente separadas que estén paradigmáticamente unidas a clases enteras específicas. Sin embargo, "lo popular" se vincula con la cultura de los oprimidos, los grupos excluidos, contrapuestos por definición, no a otra clase entera, sino a esa otra alianza de clases, estratos y fuerzas sociales que constituyen lo que no es "el pueblo" y tampoco las clases populares: la cultura del bloque de poder (Hall). ${ }^{17}$

En el Buenos Aires de las primeras décadas del siglo XX, el lenguaje popular es un conjunto de "modalidades" lingüísticas que han surgido y se desarrollan de manera espontánea, nutridas por la atmósfera social de los estratos más vastos y típicos de la región

\footnotetext{
${ }^{17}$ Para reflexionar sobre los conceptos y categorías vinculados a lo popular en el contexto de nuestro trabajo nos servimos de los aportes de Leandro Gutiérrez y Luis Alberto Romero (1995) y de Jorge Rivera (1996): hacia finales de siglo XIX, merced al desarrollo capitalista y a la masiva inmigración, se produce una "reconstrucción" de la sociedad argentina y de los sectores populares los cuales, en muchos sentidos, pueden ser mirados como nuevos. Según Gutiérrez-Romero, resulta imposible pensar en "un sujeto popular claramente recortado, de bordes precisos y estables", como así tampoco en una cultura popular cerrada en sí misma, definida en términos esenciales (1995: 15). El fin de siglo marca la emergencia del vínculo entre la literatura y una incipiente cultura popular urbana cuya génesis se encuentra en cuatro factores estructurales confluyentes: la inmigración masiva, el proceso de alfabetización, el crecimiento de infraestructuras citadinas que contribuyeron de manera directa al desarrollo de una cultura popular urbana, y el proceso de modernización global de las sociedades rioplatenses (Rivera 1996).
} 
(Rest 2010: 135). Desde los tiempos de la Revolución de Mayo, existe una doble tendencia que atraviesa nuestra historia literaria: por un lado, la lengua literaria culta, concebida como uniforme y "correcta"; y por el otro, la lengua popular, que encuentra su punto de partida en la oralidad $^{18}$ (Rest).

El lenguaje popular en la literatura supone una reelaboración por parte de la cultura letrada. En este sentido, resultan de utilidad teórico-metodólogica los aportes de Josefina Ludmer (2000) en relación con el género gauchesco pero que, no obstante, en nuestro caso sirven para iluminar la categoría de "lo popular" en la lengua literaria de la década de 1920. Cuando nos referimos al "lenguaje popular" en los textos literarios hay que tener presente que ese registro verbal se constituye en literatura merced a los procesos de reelaboración que supone el trabajo estético del escritor. Entre el lenguaje popular "real" y su correlato literario existe una mediación: el "uso" en la representación escrita de ese registro (Ludmer 30). El uso letrado de la voz popular, que para Ludmer define al género gauchesco, resulta muy productivo para pensar la categoría de "lo popular" en la literatura en general, ya que la dimensión verbal de "lo popular" en la literatura se configura como una "ficción de reproducción escrita de la palabra oral del otro" (66). El registro popular es una "voz escrita" y "traducida" (53). La idea de traducción supone un alejamiento del original, pero sobre todo una construcción verbal nueva que no se puede poner en relación directa y mimética con su modelo "real". 19

El lenguaje popular, construido con las formas idiomáticas usadas corrientemente en la conversación diaria, encuentra una "modalidad arrabalera", en las primeras décadas del siglo XX, definida por los usos de los estratos populares y suburbanos de la ciudad (Ludmer). El arrabal y sus tipos literarios cobran, entonces, nuevas significaciones y modos de representación. ${ }^{20}$ Ingresan a la literatura, como nunca antes, la lengua popular -“espuria" o "auténtica" -, que los escritores recrean abriendo así un amplio debate en el cual la lengua literaria se convierte en el problema central.

Por otro lado, desde comienzos de siglo, pero con notable intensidad en los años veinte, el mercado cultural usa la categoría de "lo popular" para interpelar a los consumidores

\footnotetext{
${ }^{18}$ Las tensiones que genera el habla en nuestras letras han sido estudiadas con especial cuidado por Rodolfo Borello (1974). Cabe hacer mención también a los modelos de oralidad en la literatura argentina, estudiados por Walter Berg (1999).

${ }^{19}$ En 1965, Jaime Rest (2010) afirmaba que el habla popular constituye, por excelencia, un lenguaje oral, que es recogido por la letra impresa de manera incompleta y deformada. En otras palabras, la literatura sólo puede utilizar el lenguaje popular a condición de un proceso de reelaboración a cargo del escritor, que lo deforma y lo aleja de su original.

${ }^{20}$ Si bien el costumbrismo ya había contemplado a los sectores populares, Sarlo señala que su perspectiva no superaba la "notación centrada en el color local". Los años veinte brindan nuevos pactos de lectura y nuevas franjas de público que habilitan la posibilidad de abordar el espacio social popular "de un modo menos exterior, incorporando dimensiones personales y biográficas" (2007: 179).
} 
de sus productos culturales, a través de elementos "populares" en el lenguaje literario y periodístico. Caras y Caretas a principios de siglo funda una suerte de populismo de mercado (Rogers 2008) que se intensificará con el diario Crítica y otras publicaciones destinadas al circuito masivo durante la década de $1920 .^{21}$

Por todos estos motivos, los años veinte son una etapa significativa para analizar las intensas disputas en torno a la lengua literaria, en las diversas zonas propuestas.

6.

El primer capítulo de la tesis repasa las principales líneas del problema del idioma en Argentina, marco general que encuadra parcialmente los referidos a la lengua literaria. Ofrece un recorrido histórico de "la cuestión del lenguaje", desde sus inicios durante la primera mitad del siglo XIX hasta la década de 1920, siguiendo los aportes realizados sobre el tema (Rosenblat 1961; Vidal de Battini 1966; Narvaja de Arnoux-Bein 1999; Bordelois-Di Tullio 2002; Verdevoye 2002b; Di Tulio 2003, 2006, 2009; Oviedo2005; Ennis 2008; Alfón 2008a, 2008b, 2013; etc. ) a partir de un corpus de ensayos y artículos escritos por filólogos, gramáticos y/o intelectuales abocados a este asunto, y cuyas intervenciones afectan de modo directo las disputas y prácticas en torno de la lengua literaria. En ese marco, daremos cuenta de uno de los tópicos centrales resurgidos en estas disputas: la existencia o no de un idioma privativo de los argentinos, independiente de la evolución y de las normas del castellano peninsular. En este sentido, haremos un repaso de las principales intervenciones puristas, tendientes a negar la existencia de un idioma argentino en formación y a afirmar la vigencia del idioma de España. Este capítulo se justifica y asume importancia puesto que es imprescindible conocer los antecedentes de estas querellas en torno a la lengua a los efectos de lograr una mejor comprensión de las discusiones que se generan en la década de 1920 con respecto a la escritura literaria. Sin embargo, queremos adelantar que si bien las disputas y tensiones referidas al lenguaje literario encuentran en la cuestión del idioma nacional un espacio productivo importante, existen otras dimensiones fundamentales de las que se ocupa esta tesis. Los apartados siguientes muestran lógicas específicas del campo literario vinculadas con la emergencia de formas más "modernas" de escritura, las cuales suponen para la literatura un avance en materia de autonomía. Por otro lado, se mostrará la relevancia de las lógicas mercantiles, elementos clave para comprender la aparición de usos "plebeyos" del lenguaje, incorporados al periodismo y la literatura a través de "géneros populares".

\footnotetext{
${ }^{21}$ El 18 de abril de 1923, y con motivo de la celebración del primer aniversario de la aparición de la $5^{\circ}$ edición, Crítica se autoproclama como "la voz del pueblo". En un artículo aparecido ese día, se puede leer: “... pensamos con la mente del pueblo y proclamamos poderosamente su pensamiento, hablamos con su voz y es su alma, grande y noble, la que presta elocuencia a nuestra voz" ("Hoy hace un año...” 1923, destacado nuestro).
} 
El segundo capítulo está dedicado a la vanguardia de izquierda y a las tensiones que atraviesan tanto a las concepciones en torno a la lengua literaria como a las prácticas literarias mismas. Se analizará, en algunos autores que frecuentan esta zona, el lenguaje literario que se pliega a las normas de corrección idiomática y se afirma en franco rechazo de registros y vocabularios provenientes de o adjudicados a los sectores populares. Pero no sólo eso: las aspiraciones de estos escritores a la alta cultura; la corrección y el apego a las normas lingüísticas; las modulaciones de la oralidad; las tensiones entre la claridad y la sencillez frente a los lenguajes "embrollados" o "complicados"; los saberes del pobre, entre otras cuestiones, definen, de manera compleja y muchas veces ambigua, un lenguaje literario preñado de fuerzas en tensión que requiere ser revisado. Este capítulo explora además los vínculos que Claridad establece con el hispanismo argentino ya que en el año 1927, la revista publica algunos artículos que expresan concepciones filohispánicas y reseña libros de autores vinculados con el purismo idiomático casticista.

El tercer capítulo se ocupa de analizar las actitudes y valoraciones en relación con el lunfardo, en el marco del circuito popular de mercado. Para ello, hemos puesto el foco en dos publicaciones periódicas -el diario Crítica y la revista Claridad-vinculadas por la polémica sobre esa modalidad de la lengua. En primer lugar, se aborda una encuesta realizada por el diario de Botana a mediados de 1927, cuyo propósito era averiguar si realmente existía la posibilidad de conformación de un "idioma propio" en Argentina, para lo cual consultó a numerosas figuras del campo literario del momento. El objetivo de esta primera parte es analizar las intervenciones polémicas de los intelectuales que participaron de esta encuesta, en relación con los problemas de la lengua literaria. En segundo término, se analiza la campaña de desprestigio que llevó a cabo la revista Claridad contra Crítica, a mediados de la década del veinte. En dicha campaña, la cuestión del lenguaje literario resulta central. El caso expresa el rechazo que la izquierda manifiesta hacia determinadas formas populares del lenguaje literario y periodístico.

Los capítulos cuarto y quinto analizan, respectivamente, dos de las figuras paradigmáticas de la "mala escritura" (Di Tullio 2009, Ojeda-Carbone 2012): Nicolás Olivari y Roberto Arlt, quienes no sólo reivindican sus propias escrituras en oposición a las estéticas y lenguajes dominantes en el escenario literario de aquellos años, sino que además conciben sus lenguas literarias como la expresión más genuina de un (supuesto) idioma nacional, argentino o sencillamente porteño en ciernes.

Con respecto a Olivari, analizaremos la recepción de su obra, con el objeto de mostrar que sus apuestas poéticas representaron fuertes intervenciones en la reconfiguración de la 
lengua literaria de su época. Indagaremos también en las propiedades de ese lenguaje y veremos de qué modo, junto con las evaluaciones críticas, contribuyen con la creación de su particular figura de autor, que encuentra en el rechazo y en el fracaso los valores y fundamentos de un proyecto estético deliberado.

En el caso de Arlt, se plantea como hipótesis principal el hecho de que, pese a que realiza una fervorosa defensa de lo que él llama "idioma porteño", su literatura muestra ciertas tensiones, en el plano del lenguaje, determinadas por la relación ambigua que este escritor establece tanto con el público y el mercado como con los sectores pertenecientes al circuito "culto" tradicional. Dichas tensiones o ambigüedades se observan en la coexistencia, en sus textos, de un estilo que se pretende "culto" con otro más cercano a los usos "populares". También pueden verse en la utilización de comillas y marcas textuales tendientes a distanciarse de las formas populares, particularmente, del lunfardo. La literatura de Arlt manifiesta, tal vez mejor que la de ningún otro escritor, la situación crítica de una lengua literaria que oscila entre la conservación de ciertas formas estéticas e idiomáticas y su innovación a partir de la incorporación de un coloquialismo urbano y popular. Otra hipótesis del capítulo, y que involucra tanto a Arlt como a Olivari, señala que aquello que fue leído y valorado contemporáneamente (y aún por la crítica más reciente) como "mala escritura" lenguaje popular o "plebeyo", ripios ortográficos y gramaticales, etc.- deriva de una intención deliberada por parte de los autores de elaborar una lengua literaria autónoma y por eso más moderna, mientras que la noción de "mala escritura" representa el rechazo conservador de aquellas nuevas escrituras que ponían en entredicho los supuestos que regían el lenguaje literario hasta entonces.

El sexto capítulo se ocupa de la lengua literaria en Oliverio Girondo. Si bien la crítica ha dado sobrada cuenta de las particularidades de su estilo, en este capítulo se indagan sus innovaciones estéticas en el marco más amplio que ofrecen estas disputas, lo que posibilita pensar su escritura en relación con otras, en un panorama signado por las tensiones y reconfiguraciones del lenguaje literario. A su vez, con el objeto de revisar la recepción crítica de sus libros durante la década, y así reponer el marco de discusiones a la que estuvo sujeta su obra, se procedió a la exploración y análisis de diversas fuentes documentales, muchas de ellas poco consultadas. Una de las hipótesis centrales que guía este capítulo sostiene que las radicales innovaciones que propone la escritura de Girondo se realizan dentro de ciertas normas que no alteran sustancialmente las reglas de la gramática y del "buen decir". El "mal decir" o, mejor dicho, la "mala escritura" se asocia a los lenguajes que contravienen las prescripciones del castellano y los presupuestos estéticos y literarios. Por lo general, se refiere a las escrituras "plebeyas" producto de la mezcla lingüística, practicadas por escritores 
nuevos, con una formación no tradicional y de escaso capital cultural. El caso de Girondo es interesante, y singular, porque descentra el eje sobre el cual se asientan las intervenciones más renovadoras en torno al lenguaje literario: el poeta propone una nueva estética, una lengua literaria alternativa a la del circuito "culto" tradicional, pero evitando recurrir a lo "plebeyo" y "popular" de los lenguajes "bajos", como lo hacen otros escritores que incorporan innovaciones estilísticas.

Por último, el séptimo capítulo parte de que las lenguas literarias tienen género (gender), y que éste rige las relaciones literarias. De este modo, las lenguas literarias más legitimadas y dominantes asumen rasgos masculinos, mientras que la escritura realizada por mujeres se define por su condición subalterna. La hipótesis que guía esta parte del trabajo señala que las escritoras de los años veinte no siempre se ajustaron a las normas estéticas e idiomáticas correspondientes a los preceptos androcéntricos. Por el contrario, algunas de ellas, $\mathrm{y}$ en determinados momentos de su producción literaria, los contravienen y dan forma a textualidades novedosas no sólo en relación con los mandatos de género, sino también con las estéticas emergentes de la década. El capítulo se centra en las figuras de Alfonsina Storni y Norah Lange, y su propósito consiste en brindar un marco explicativo de las condiciones que determinan el grado de aceptación y/o subversión de las prescripciones de género para estas escrituras. La crítica que ha abordado los problemas de la lengua literaria muy pocas veces ha incluido en ese marco la labor de las escritoras; injustificada omisión si tenemos en cuenta la importancia que tuvieron sus intervenciones en las disputas y en las condiciones de transformación del lenguaje literario. 


\section{CAPÍTULO I}

\section{Los debates sobre el idioma y la lengua literaria}

En la historia de las polémicas acerca del idioma y la lengua literaria se destacan tres o cuatro momentos principales. El primer núcleo de debates se encuentra en la primera mitad del siglo XIX, a partir de los aportes generados por los hombres del 37. Estos intelectuales afirmaban que la revolución política, conquistada en mayo de 1810, debía ser completada por una revolución cultural de gran alcance. Sus escritos dan cuenta de ello, y en ese marco pensaron que la fundación de una nación implicaba la creación de una de sus piedras angulares: una literatura. Qué lengua debía utilizarse para que la nueva nación escribiera su literatura es una de las cuestiones sobre la que trabajó mucho esta primera generación intelectual del Río de la Plata. Pierre Bourdieu afirma que la lengua oficial se constituye en estrecha vinculación con el Estado, puesto que cuando éste comienza a conformarse se crea "un mercado lingüístico unificado y dominado por la lengua oficial", la cual se convierte en la norma teórica con que se miden objetivamente todas las prácticas lingüísticas (1985: 19). La generación del 37 pensaba la conformación del Estado y brindaba un espacio muy importante a la lengua y la literatura en esa construcción. ${ }^{22}$ Cuando estos intelectuales escribieron sus primeros textos, la norma idiomática estaba marcada por los preceptos hispánicos. Ellos, en cambio, proponían una lengua americana, que diera cuenta de la realidad diversa en la que se encontraban. $^{23}$ Se delimitan, entonces, desde muy temprano, los dos paradigmas que, interpretados no siempre del mismo modo, dan forma a los extremos del debate sobre el idioma y la lengua literaria: por un lado, el rupturismo, que se propone romper con la hegemonía peninsular y fomenta la idea de un idioma de los argentinos y/o americanos. Por otro lado, el casticismo o purismo idiomático, el cual sostiene que la identidad nacional se manifiesta en una lengua libre de extranjerismos o "desviaciones" americanas, y encuentra en España, y en su legislación sobre el idioma, la fuente de nuestras tradiciones.

Un segundo momento se ubica hacia 1880, cuyos hombres, en principio, fueron continuadores de los preceptos forjados por la generación anterior. La Generación del 80 mantuvo gran parte de las idea de sus predecesores: a la libertad frente al préstamo siguió un poliglotismo declarado que se detentó como señal distintiva del nivel cultural del grupo (Di Tullio 2003).

\footnotetext{
${ }^{22}$ Esta percepción también es compartida por Andrés Bello para quien la gramática resulta un discurso fundacional del Estado moderno. Según este autor, y dada la diversidad lingüística de América Latina, la gramática es un discurso capaz de imponer una estructura normativa unificadora (Ramos 1995: 10).

${ }^{23}$ Blanco de Margo (1991), Borello (1974), Feinmann (2004), Myers (1999), Rosenblat (1961), Rama (1977), Viñas (2005a).
} 
Como se sabe, la inmigración produjo desencanto en las élites, puesto que no estaba conformada por los europeos que pensaron Sarmiento y Alberdi -vale decir, ingleses, alemanes, holandeses-, sino por europeos del sur a los que, lejos del progreso invocado, se les atribuía rasgos retardatarios y amenazantes. ${ }^{24}$ Frente a un escenario no deseado -crecimiento urbano desmesurado, exclusivo interés en objetivos económicos, formación de movimientos obreros, etc.-, la dicotomía que sirvió de guía para la construcción de la nación -civilización y barbarie- sufrió una inversión que obligó a las clases dirigentes a repensar los fundamentos de la nacionalidad. El inmigrante, antes considerado agente del progreso y la civilización, se convirtió en un elemento de corrupción identitaria que amenazaba la nación (Onega 1982; Svampa 2006).

La definición de una nacionalidad implica la elaboración de un relato de identidad, en donde la lengua constituye uno de los ingredientes fundamentales. Explica Juan Antonio Ennis que

la reflexión sobre la lengua, sobre la propia lengua y las ajenas (...) constituye una parte importante de la construcción de la propia identidad. Aristóteles (...) hacía su mentada distinción entre griegos y barbaroi -comportando esta última palabra una designación del otro a partir nada menos que de la diferencia lingüística (2008: 86).

Como señala Ennis, la barbarización del otro a partir de la diferencia lingüística se constituye en un lugar común de las intervenciones que dan lugar a lo que se dio en llamar "la cuestión del idioma" (Di Tullio 2003).

En el año 1900, Lucien Abeille, profesor francés radicado en Buenos Aires, publicó Idioma nacional de los argentinos, y dió lugar a una polémica de tal magnitud que su edición es considerada como punto de inflexión en los debates en torno a la lengua. La tesis fundamental del francés consiste en la convicción de que la constitución de la nueva raza argentina debía producirse a partir del contacto y la mezcla lingüística y cultural, tanto la ya producida entre colonizadores españoles y aborígenes como la que debía generarse a partir de la llegada masiva de inmigrantes (Ennis 2008). Esa nueva raza sería dueña de un idioma propio, forjado en condiciones únicas. No tardaron en aparecer las respuestas airadas de Miguel Cané, Eduardo Wilde, Paul Groussac, Carlos O. Bunge, Juan B. Terán, Ricardo Monner Sans, Mariano de Vedia, Manuel Ugarte, y desde ya, Ernesto Quesada. Estas reacciones constituyeron la primera oleada de recepción de la obra. Se puede agregar que

\footnotetext{
${ }^{24}$ A partir de 1880, momento en que la élite se aisla de "la masa innominada de trabajadores descontentos", mudándose al sector norte de la ciudad de Buenos Aires, se desarrolla en relación con el inmigrante "toda una retórica sobre el materialismo, la ausencia de espíritu, el cosmopolitismo, la torre de Babel, los valores amenazados y el mercantilismo" (Onega 1982: 19).
} 
estas intervenciones anticipan algunas de las posturas que se tornarán más claras y definidas en los hombres del Centenario. Después de 1902 las resonancias se volvieron dilatadas e intermitentes y reaparece la polémica con el estudio panorámico de Arturo Costa Álvarez, Nuestra Lengua, en 1922.

Como se sabe, hacia 1910 surge lo que se conoció como "primer nacionalismo" o "nacionalismo cultural" (Payá-Cárdenas 1978). Un conjunto de intelectuales elaboraron un sistema discursivo tendiente a neutralizar la presencia del inmigrante y lo que ellos juzgaban sus efectos negativos y disolventes para la nacionalidad. La más significativa de las reacciones suscitadas por la transformación del cuerpo social giró en torno al tema de la “identidad nacional” (Altamirano-Sarlo 1997). En lo que respecta al idioma, el horizonte ideológico de ese nacionalismo estaba dado por un "espíritu de conciliación hacia España y reconsideración de la herencia española” (165). Ricardo Rojas, por ejemplo, reivindicaba la identificación romántica entre lengua y nación, y sostenía que la cultura del idioma sería el freno para la corrupción que la inmigración infligía a la lengua ${ }^{25}$ (Di Tullio, 2003). En España y su tradición, los nacionalistas encontraron la manera de diferenciarse de los recién llegados, hallaron un nuevo origen al cual apelar, en virtud del fracaso que significaron algunos postulados de la generación previa. La reacción nacionalista del Centenario implicó un viraje respecto de los valores que presidieron la construcción de la Argentina moderna (Altamirano y Sarlo 1997).

En la década de 1920, los debates en torno al lenguaje, como acabamos de ver, cuentan con una larga tradición. A su vez, el campo literario comienza a complejizarse: Graciela Montaldo (1987a) indica que, hasta este momento, había sabido controlar sus fisuras, y una identidad semejante, no idéntica, mantuvo unidos a la mayoría de sus miembros activos. Ya a partir de la generación del Centenario, y con mayor intensidad en los años veinte, esa cohesión se rompe: si, hasta los primeros años del siglo $\mathrm{XX}$, de las letras se ocuparon los letrados, poco tiempo después, jóvenes de procedencia y formación no tradicional, salen a exigir su derecho a la escritura. La literatura comienza a desempeñar un rol activo dentro de estos debates, quizás mucho más que antes en la medida en que sus posibilidades formales y enunciativas se astillan y pluralizan. De esta manera, la lengua literaria comienza a reclamar su especificidad literaria. La inmigración, desde comienzos de siglo, transforma la ciudad y sus pautas culturales, sociales y políticas; y, en el terreno

\footnotetext{
${ }^{25}$ Herder resultó decisivo para el romanticismo y para la formación de las nuevas literaturas nacionales, configuradas en torno a una lengua y tradición originarias capaces de generar sentimiento de pertenencia. Este pensamiento incidió también en el romanticismo argentino, y en la difícil negociación entre la búsqueda de un suelo firme adonde edificar la literatura nacional y las condiciones reales de contar con una lengua y una cultura de trasplante y con una tradición originaria dispersa o inexistente (Gramuglio 2013).
} 
lingüístico, aparecen usos de la lengua que las élites comienzan a percibir como un "babelismo" que afecta la identidad nacional. De esta manera, un conjunto de otredades son sometidas a procesos de legitimación y exclusión. Si Lugones, en sus conferencias de 1913, reivindicó la figura del gaucho a partir de un pacto que sintetiza una raza, un tipo social y una literatura, también excluyó del proyecto de nación a esos “otros", los nuevos bárbaros, quienes se diferenciaban en el terreno de la lengua. ${ }^{26}$ Jorge Monteleone (1988) advierte que la literatura que surge en la década del veinte, y que se distingue de la producida por los escritores de la élite, no resulta homogénea en muchos niveles, pero sobre todo en lo que se refiere a las modalidades discursivas de la alusión o de la elusión de la voz del otro inmigrante. Si seguimos el artículo de Monteleone, veremos que tanto Jorge Luis Borges como Carlos de la Púa, César Tiempo o Raúl González Tuñón utilizan distintos procedimientos para referirse a otro, enunciar como otro o inventar voces de otros, y en esas operaciones sientan posiciones con respecto al idioma y a la lengua literaria.

El propósito de este capítulo es elaborar una cartografía documental; conseguir un relevamiento, lo suficientemente representativo, de los discursos que instalaron la cuestión del idioma y los problemas de la lengua literaria desde la primera mitad del siglo XIX hasta la década de 1920. Pero además de esto, nos proponemos trazar un recorrido histórico por los hitos que ambas temáticas, muchas veces entrelazadas, marcaron desde los albores de la nación.

En este primer capítulo se recorta un corpus más bien ensayístico, adonde el discurso literario cede su espacio preponderante en nuestro trabajo a los aportes provenientes de los gramáticos y filólogos los cuales, no obstante, incluyen a la literatura como el modelo de lengua a seguir, el ejemplo de "buen decir". Tanto las gramáticas como los manuales de lengua recurren a la literatura canónica para brindar ejemplos acerca de la "correcta" forma de expresión escrita y/u oral. Para tal caso -y luego de la exposición de algunos antecedentes de estos debates-, hemos decidido ordenar la presentación de las fuentes en cuatro ejes: los dos primeros comprenden a los grandes antagonistas de la "cuestión de la lengua" en Argentina: por un lado, tenemos a los autores que velan por la formación y consolidación de una lengua "propia" de los argentinos; por otro lado, se encuentran los cultores del hispanismo y del purismo idiomático. En tercer lugar, cabe señalar que, en el marco de estos debates, la función de las gramáticas y de los diccionarios recibió mucha atención por parte de algunos sectores. Una buena porción del corpus relevado se refiere exclusivamente a esta temática, y por tal

\footnotetext{
${ }^{26}$ Lugones, en su libro Las fuerzas extrañas, tematiza la problemática de la educación y las condiciones de integración de los inmigrantes. Al respecto, consultar el análisis de Miguel Dalmaroni en "Las bestias extrañas" (2006).
} 
motivo se optó por reservar para esta cuestión un espacio independiente. Por último, el lunfardo en los años veinte adquiere una relevancia vinculada, principalmente, con el auge y la extensión que presenta en diversas manifestaciones culturales como en el tango o en cierto tipo de literatura. En el marco de los debates en torno a la lengua, el lunfardo se constituye en uno de los actores principales dado que se lo ha juzgado, con alarmas y esperanzas, como el sustrato privilegiado de ese nuevo idioma en ciernes.

\section{En torno a la Generación del $\mathbf{1 8 3 7}$}

Las polémicas del lenguaje en Argentina tienden un arco que parte desde los años de la Revolución de Mayo hasta, por lo menos, la década de 1930.

La generación de los independentistas de 1810 reaccionó políticamente contra sus padres: fue revolucionaria y proclamó la Independencia, pero se mantuvo fiel a las formas culturales y lingüísticas que había heredado (Rosenblat 1961). Durante los momentos inmediatos a la emancipación, la posición de Argentina y de América Latina, en materia idiomática, siguió siendo monocéntrica (Blanco de Margo 1991). Sin embargo, es posible observar en este período voces que plantean una lengua muy diferente a la emanada desde la metrópoli: Bartolomé Hidalgo, además de fundar el género gauchesco y con ello la literatura rioplatense, ${ }^{27}$ propuso una lengua literaria alternativa al español peninsular. Con Hidalgo ingresa, y nace, la lengua popular en la literatura argentina, principalmente a partir de la intervención de dos coordenadas: en primer lugar, el uso letrado de las formas orales y populares de la campaña bonaerense (Ludmer 2000); y en segundo término el rechazo explícito a todo lo que proviene de España. El desacato de Hidalgo no sólo fue político, sino también lingüístico: "es en la gauchesca donde encontramos un esfuerzo coherente, por humilde que se defina, para acompañar la independencia política con una paralela independencia lingüística, que es bastante anterior a los intentos reformistas de Sarmiento o de Bello" (Rama 1977). La opción del habla dialectal "rompe bruscamente la sujeción con los modelos europeos", dotando al escritor de una "rigurosa libertad" en la construcción de la lengua literaria, "para lo cual carece de fórmulas o de tradiciones estatuidas" (Rama XXIX).

\footnotetext{
${ }^{27}$ La tesis corresponde a Ángel Rama quien afirma sobre Hidalgo: "Primer poeta de la patria, primer cantor de la gesta artiguista, primer director patrio de la Casa de Comedias, primer versificador de los gauchos orientales, este Bartolomé Hidalgo no es un poeta, sino una piedra fundacional. Sobre ella se yergue una literatura con 150 años de trabajos para constituirse independiente, original, nacional..." (1982: 44). Sin embargo, otros críticos, prefieren encontrar el origen de nuestras letras en la literatura culta. Este es el caso de David Viñas, quien sostiene que "la literatura argentina comienza como una violación" (2005a), poniendo a "El matadero" como el texto fundacional de la literatura argentina. Piglia, por su parte, encuentra en la violencia del relato de Echeverría y de la primera página del Facundo la génesis de la ficción argentina (1998: 23).
} 
Desde este momento fundacional de la literatura rioplatense, se puede apreciar que la cuestión del lenguaje se encuentra asociada a las formulaciones literarias.

El problema del idioma nacional, eje vertebral de los debates sobre la lengua en Argentina, se inaugura a mediados de 1828, cuando Juan Cruz Varela llama la atención sobre "el mal trato" que se le brinda al idioma español (Alfón 2008b: 43). Varela publica, en el diario El Tiempo, un artículo llamado "Literatura Nacional” en el que además sostiene que no cree que exista una literatura nacional ni cosa semejante. No obstante, aguardaba un movimiento cultural, una pléyade o un conjunto de obras que la inicien, y en ese deseo preanuncia la aparición de la generación de los románticos del 37. Para Varela, no se puede forjar una literatura nacional sin conocer a fondo el idioma que se habla; y recomienda preservarlo y custodiarlo en la medida en que representa un vínculo entre la antigua metrópoli y la América hispana (Alfón 2008b).

Para Varela, la nacionalidad argentina constituye una suerte de apéndice de España y, por lo tanto, el español peninsular debe cumplir un rol fundamental en la formación de la literatura argentina. Esta idea, contradictoria a primera vista, pero que encuentra su sentido en la concepción que Varela tiene de la nacionalidad, se repetirá más de una vez a lo largo de las diferentes fases de la polémica sobre la lengua. Así, por ejemplo, este razonamiento vuelve a aparecer en un texto de la década de 1920, de Arturo Capdevila:

en mi viaje a España, veinte días había navegado el vapor (...) Era, sin embargo, real y efectivamente como si no hubiéramos salido de la patria; pues que aun hablábamos el mismo nativo idioma. (...) Yo siento el orgullo de esta confraternidad sin fronteras y me sobrecoge el entusiasmo ante esa gigantesca extensión de que es capaz el espíritu. (1954:16).

En momentos en que la nación comienza a diseñarse discursivamente, la lengua forma parte del programa socio-político de los hombres de la Generación del 37. Convencidos de que una revolución cultural e intelectual debía acompañar a la ya lograda revolución política de 1810, ellos asumirán esa responsabilidad. Escribirán textos destinados, entre otras cosas, a la fundación de aquello que juzgan esencial de una nación: una literatura. Otros escritos sentarán las bases acerca de la variedad de español que debe utilizarse para que la nueva nación la escriba. En definitiva, lo que busca la generación del 37 es la articulación de una cultura propia. Esa tarea se centra en completar la independencia con respecto a España en los terrenos en los que se mantenía la tutela hispánica: la lengua y la literatura (Di Tullio 2003).

Con la Generación del 37 surge un pensamiento que se ocupa de pensar y sistematizar los problemas de la lengua que la reconfiguración política e institucional post-revolucionaria 
depara. Juan Bautista Alberdi, Domingo Faustino Sarmiento, Esteban Echeverría y Juan María Gutiérrez son los cuatro autores principales que se encargan de pensar, con sumo detenimiento, en la formación de una lengua que nos diferencie de España. Las tradiciones que nos unían con ese país comienzan a romperse con la Revolución de Mayo y, en las dos décadas siguientes, y como parte del mismo proceso, los jóvenes intelectuales, bajo el signo del historicismo romántico, sintieron el desafío de forjar una lengua americana. La propuesta encerraba la paradoja que se desprende de la mirada estrábica ${ }^{28}$ de nuestros románticos: proponer el francés como lengua modélica sobre la cual erigir una lengua americana.

La fundación de un canon no podía orientarse en ese momento a ningún pasado prestigioso, no sólo porque la actividad cultural en el Río de La Plata era escasa, sino también porque, según estos jóvenes intelectuales, no había nada ejemplar que ver en ese tiempo. Sin ese pasado prestigioso, la tendencia de los grupos liberales es la de programar un futuro que revierta las condiciones de un presente cuyo aspecto desfavorable es atribuido al pasado. Se trata de sentar los pilares de una antitradición (Ennis 2006).

Para la Generación del 37, la emancipación no significa necesariamente la formación de una lengua nueva, de un idioma propio -exigencia que sí cumplirá un rol protagónico a partir de fines del siglo XIX-, sino cierta reivindicación del derecho de propiedad sobre la lengua, el derecho a legislar sobre ella, de reformarla cuando sea preciso, sin necesidad de ser autorizado por instituciones peninsulares. Este programa de ruptura con España se complementa con la adscripción a otras culturas prestigiosas: Francia, en tanto modelo cultural para estos intelectuales, desempeñó un papel fundamental en cuanto a las posturas adoptadas con respecto a la lengua. El español, para Alberdi, debía someterse a un proceso por el cual el francés oficiaría de modelador del idioma, a los fines de convertirlo en una lengua apta para la ciencia y las culturas modernas. De esta manera, al preferir el francés por sobre el español, al adoptar la "orientación romántica” (Rama 1977: XXVII-XXIX), la Generación del 37 reemplaza un vasallaje por otro (Rosenblat 1984).

Con los hombres del 80, la esfera de lo político, que todo lo invadía, y que tan estrechamente estuvo vinculada con la literatura durante prácticamente todo el siglo XIX, comienza a separarse, a ganar una senda que culminará en la relativa autonomía literaria de las primeras décadas del siglo XX. Escritores como Miguel Cané, Eduardo Wilde, Lucio V. Mansilla, Lucio V. López o Eugenio Cambaceres escriben con intenciones mucho más

\footnotetext{
${ }^{28}$ En el Dogma socialista, Esteban Echeverría escribe: “el mundo de nuestra vida intelectual será a la vez nacional y humanitario; tendremos siempre un ojo clavado en el progreso de las naciones y el otro en las entrañas de nuestra sociedad" (1958: 188-189). Piglia toma esta cita y elabora la noción de "mirada estrábica" para definir el doble vínculo del escritor del siglo XIX, vínculo que funda una verdadera tradición nacional: "un ojo mira el pasado, el otro ojo está puesto en lo que vendrá” (1998: 22).
} 
"literarias", puesto que están mucho más interesados en dejar un testimonio de sí mismos que en influir sobre la realidad política (Borello 1974). Y la manera privilegiada de lograr ese cometido será a través de sus tareas como escritores. El surgimiento de una figura de autor que comienza a emanciparse de la adyacente imagen del político, conlleva un fenómeno significativo: emerge la novela como género en el Río de la Plata; de este modo, novelas y novelistas aparecen hacia 1880 (Esposito 2009). La modernización literaria que se da a partir del ochenta consiste, principalmente, en la elaboración de una lengua literaria nutrida de otras lenguas literarias, en cuyos países de origen, los europeos, se había conseguido ya hacía décadas "una separación institucionalizada de las prácticas y las categorías literarias" (Piglia 1998: 21).

\section{Lucien Abeille y la reacción conservadora hacia 1900}

El problema de la lengua en Argentina tiene dos extremos antagónicos: el de los casticistas, que postulan un idioma fiel al de España y libre de los elementos "espurios" ${ }^{29}$ que el contacto de lenguas trae aparejados; y el de los progresistas o evolucionistas, quienes no sólo proponen la "modernización, intelectualización y flexibilización" de la lengua, sino que son además los que promueven la creación de un idioma propio, aspiración que resulta una de las aristas centrales de la cuestión del idioma en Argentina (Di Tullio 2003).

Como es sabido, el antihispanismo independentista que había guiado las tesis de la generación de 37, hacia 1880 cambia de signo y deviene en un hispanismo purificador de la lengua nacional. El primer foco del purismo lo encontramos en el Estado: los dirigentes piensan medidas para contrarrestar el efecto "negativo" que la inmigración tiene sobre la integridad nacional. Se genera así un nacionalismo lingüístico asociado al hispanismo que se traduce en políticas estatales claras: se diseñan marcos institucionales para que la escuela se convierta en el ámbito privilegiado de acción para llevar a cabo la tarea de "erradicar todo vestigio de los rasgos de la inmigración" (Di Tullio 5). El objetivo fue lograr un estado unicultural y monoglósico.

Sin lugar a dudas, el epicentro de la cuestión del idioma se encuentra hacia el año 1900, cuando un profesor francés llamado Lucien Abeille publica, en Francia, un voluminoso libro titulado Idioma nacional de los argentinos. Abeille hace suya la idea de que la identidad de un pueblo se encuentra en su lengua. Sin embargo, dicha idea es antigua y por lo tanto

\footnotetext{
${ }^{29}$ Según Blanco de Margo, el purismo "considera a la lengua como un bien inalterado e inalterable que debe preservarse de todo cambio. Parte de la errónea creencia en la posibilidad de fijar el idioma en algún punto de su evolución. Esta posición conservadora del idioma produce el surgimiento de lo que algunos autores llaman "guardianes públicos del uso", es decir escritores, intelectuales, hombres públicos, que muchas veces se erigen a sí mismos en preceptistas de la lengua" (1991: 2).
} 
preexistente al surgimiento del nacionalismo moderno que se produce hacia fines del siglo XVIII y comienzos del XIX en Europa (Blanco de Margo 1997). Este nacionalismo lingüístico que inaugura Abeille en Argentina y que repite, aunque de manera extrema, las tesis de los liberales decimonónicos, es opuesto al que por ese entonces se delineaba a favor del hispanismo y en contra de las influencias idiomáticas provenientes de la inmigración. Si bien el nacionalismo lingüístico conduce, por lo general, hacia actitudes lingüísticas conservadoras que preconizan la pureza idiomática, también sucede que reenvía hacia la defensa de formas vernáculas a las que se le otorga el rango de lengua nacional, "generando, en consecuencia (...), la búsqueda de un idioma nacional distintivo" (Blanco de Margo 121). Con el libro de Abeille no sólo se sientan las bases de un paradigma opuesto al purismo, sino que se actualiza y se propone, de una manera nunca antes ensayada, la futura formación de un idioma propio.

Cuando Abeille publica su libro, la mayoría de los intelectuales se encontraban lejos de las tesis autoctonistas postuladas por el francés, de allí que puede entenderse su propuesta como una "rehabilitación anómala del programa romántico juvenilista del 37" (Oviedo 2005: 31). Por esta razón, se produce un rechazo contundente del libro en todo el arco intelectual argentino, dominado por un hispanismo en pleno auge. Los sectores conservadores del campo letrado llevaron a cabo un proceso de nacionalización del habla "españolizando", dado que la mayor parte de la clase dirigente patricia era de origen español (Rubione 1983: 36). Esta postura hizo que desecharan las propuestas argentinizantes y consideraran el libro de Abeille como un verdadero "disparate" (Rubione 37). Para esta época, ser argentino significaba ser profundamente español, y eso implicaba una lealtad incorruptible hacia la lengua española, lo que a su vez suponía una visión monolítica del castellano. Ese sentido de la nacionalidad perdurará en los años veinte, momento en que algunos autores conservadores reproducirán explícitamente esta idea como, por ejemplo, Arturo Capdevila en su libro Babel y el castellano (1928).

Aquello que molestó de la obra de Abeille fue "su intención manifiesta de servir a la causa romántica populista del nacionalismo lingüístico" (Oviedo 2005: 24). Su criollismo idiomático proponía la exclusión de la gramática y daba fueros patrios al habla coloquial, lo cual generó un malestar tan grande que los debates en torno al idioma estallaron en diarios y publicaciones de la época.

Las polémicas en torno al libro de Abeille se entroncan con una problemática previa que también preocupó notablemente a los "conservadores de la cultura": hacia 1880, surge la literatura criollista. Al respecto, en 1881, en el Anuario Bibliográfico de la República Argentina, dirigido por Alberto Navarro Viola, se sostiene: "no caben dos opiniones sobre 
estos vulgares folletines: es la literatura más perniciosa y malsana que se ha producido en el país..." (Prieto 2006: 56). De acuerdo con el Anuario, estas novelas, además de la catadura moral de sus personajes y de la "vulgaridad" de sus escenarios, tenían el defecto de estar escritas con un vocabulario "recogido en los corrales y enriquecido en los conventillos y en las cárceles" (56). Es decir, escritas con una fuerte dosis de cocoliche y lunfardo. En el Anuario se advierte que es precisamente el libro de Abeille el que legitima estas "jergas" y las convierte en una suerte de "neogauchesco", principal componente del idioma de los argentinos propuesto por el francés. ${ }^{30}$ Oportunamente, Abeille rechazó esta acusación, y en una carta que le escribiera a Pellegrini afirma: "algunas personas me atribuyen ideas que solo a ellas les pertenecen. Me hacen decir que el idioma nacional de los argentinos es el gaucho. El inventor de la supuesta teoría es el señor Ernesto Quesada. El doctor Cané la repite" (Rubione 1983: 248).

Quesada sostiene que, desde fines del siglo XIX, Argentina se encuentra sumida en un "caos lingüístico" producido por diversos factores como la deficiencia en la enseñanza, las pésimas traducciones y la circunstancia de que cada colectividad que llega al país trae su escuela, y, naturalmente, la proliferación del dialecto gauchesco emanado de las publicaciones criollistas. A esto se le suma el hecho de que, ya sobre el filo del siglo XX, se percibe una “tendencia desafortunada" que considera argentino lo que es criollista (Rubione 39).

La reacción contra el libro de Abeille provino principalmente del grupo de autores hispanistas. Sin dudas, el texto más importante que nació de esa reacción pertenece a Ernesto Quesada, quien supo sistematizar y brindar consistencia argumentativa al pensamiento que dominaba en buena parte de los puristas finiseculares. Nos referimos a El 'criollismo' en la literatura argentina (1902). Desde la perspectiva de Quesada, la "barbarie" idiomática prolifera gracias a la presencia de la inmigración, que vino a adulterar un estado de lengua relativamente estable y puro. De esta manera, por ejemplo, Quesada aprueba el género gauchesco, puesto que posee una "raigambre española" (1983: 114); sin embargo, con la masiva llegada de extranjeros al país el género se convirtió en una "influencia literaria perniciosa en alto grado" dado que "ha desnaturalizado el tipo gaucho, enardeciendo al compadrito, y ha pervertido a los inmigrantes acriollados" (138). A través de la literatura criollista, los inmigrantes encontraron en la jerga criolla una estrategia de integración cultural (Prieto 2006), sin embargo, como sabemos, el Estado, que también persigue la asimilación de los extranjeros, encuentra en las formas gauchescas un lenguaje no apto para tal fin: el sistema

\footnotetext{
${ }^{30}$ En su libro El 'criollismo' en la literatura argentina (1902), Quesada sostiene: "la tendencia del criollismo [es creer] que el dialecto gauchesco es el verdadero idioma nacional” (1983: 177).
} 
escolar prescribirá la enseñanza de una lengua y una literatura ceñidas fuertemente a las tradiciones españolas.

Como puede observarse, el vínculo que se establece entre la literatura y los problemas referidos al idioma se hace evidente en estas polémicas de comienzos de siglo XX. Sin embargo, es durante la década de 1920 cuando los problemas en torno a la lengua literaria asumirán una especial intensificación.

\section{Los años veinte}

Durante la década del veinte, los debates acerca del idioma, lejos de aplacarse, se convierten en un tópico casi obligado en numerosas publicaciones y en los intercambios entre diversos intelectuales. Varios son los motivos que hacen de los problemas de la lengua uno de los rasgos más definitorios de esa década en lo que respecta a materia cultural y literaria. En primer lugar, la inmigración europea se manifiesta no sólo en el creciente proceso de "babelización" que experimenta Buenos Aires desde fines del siglo anterior, sino también en diversos objetos y consumos culturales. En este sentido, y en segundo lugar, podríamos señalar el auge del teatro, el tango, las narraciones semanales y una amplia gama de escritores subalternos que utilizan las formas lingüísticas excluidas por "los conservadores de la cultura" para elaborar sus textos literarios. Cada una de estas manifestaciones culturales presupone la inmigración, en la medida en que están atravesadas por numerosos fenómenos lingüísticos producto del contacto de lenguas. En tercer término, durante los años veinte tiene lugar otro hecho relevante: el apogeo del nacionalismo lingüístico, cuyo período podría establecerse entre 1910 y 1930. Frente al nacionalismo de elite, caracterizado por su marcado casticismo y el rechazo hacia el cosmopolitismo ${ }^{31}$, aparece el grupo diferente que abreva en las ideas emancipadoras de los románticos decimonónicos y en las doctrinas de Abeille. Los miembros

\footnotetext{
${ }^{31}$ En términos de un ideal, el cosmopolitismo significaría el "interés por lo universal y el respeto por las legítimas diferencias". En términos más estrictamente históricos, cabría referir el concepto a las grandes etapas de la cultura occidental, para advertir la creciente intensificación del interés y la necesidad del intercambio y el mejor conocimiento de los otros, indiscutiblemente ligados, a partir del siglo XVI, a las empresas de conquista y colonización y a la expansión comercial, hasta alcanzar hoy lo que se denomina "cosmopolitismo global". El cosmopolitismo es una cuestión concerniente a lo que Carlos Altamirano en sus trabajos llama elites intelectuales o, en otras palabras, el "cosmopolitismo activo" de las minorías que buscan acrecentar la literatura nacional y ponerla en el mapa literario mundial (Gramuglio 2013: 371).

Desde las primeras décadas del siglo XX, las lenguas extranjeras en Argentina no poseen un sentido unívoco. Por un lado, encontramos las lenguas extranjeras que leen y escriben los letrados; y por el otro, están las lenguas extranjeras de la inmigración. Las primeras, son una expresión de la "alta" cultura, del bilingüismo prestigioso; las segundas, están asociadas a lo precario, lo bárbaro y a los acentos exóticos que deforman el español. Como correlato de esta situación, la noción se escinde en un cosmopolitismo legítimo, el asociado a las élites, y otro babélico, vinculado con la inmigración (Sarlo 1997a: 274, Di Tullio 2003: 57). Frente a esta situación, el poliglotismo y el cosmopolitismo pasan a ser sospechosos y, por lo tanto, surge el mandato de volver a las fuentes de la lengua y la literatura españolas (Di Tullio 59).
} 
de este grupo se denominan a sí mismo también "nacionalistas" 32 pero divergen del nacionalismo hispanófilo de la élite intelectual (Blanco de Margo 1991). Durante los años veinte, sobre todo al final de la década, aparece una serie de obras destinadas a poner en evidencia la formación efectiva de un idioma diferente al castellano, privativo de Argentina. $\mathrm{Al}$ respecto, Blanco de Margo asegura que

este grupo parte de la mal interpretación del proceso de policentrismo lingüístico y por tanto, cree que la norma argentina debería ser la única válida. Al igual que el hispano-nacionalismo postula, entonces, una estandarización monocéntrica, cuyo foco único en este caso, sería la norma rioplatense (89).

Algunos de los representantes de este nacionalismo popular son Vicente Rossi y Ramón Carriegos.

\subsection{La "lengua propia"}

Sin lugar a dudas, uno de los representantes más importantes de la tendencia antipurista es Vicente Rossi. Hijo de padre genovés y madre argentina, nacido en Santa Lucía, Uruguay, en 1871, Rossi se instala en la ciudad de Córdoba, en la cual fundará una imprenta Imprenta Argentina- en la que editará la mayor parte de su prédica a favor de un idioma rioplatense. Si bien la argumentación acerca de una lengua propia del Río de la Plata cobra madurez y solidez hacia fines de los años veinte, cuando publica sus Folletos lenguaraces (1927-1931), Rossi ya se había ocupado del tema algunos años antes. En 1910, publica Teatro nacional rioplatense. Contribución a su análisis y a su historia, en el que efectúa un pormenorizado estudio acerca de los orígenes y propiedades del género en el Río de la Plata. Una parte de este libro está dedicada al lenguaje, y es allí adonde Rossi postula las tesis que luego, en los años veinte, profundizará y explayará en los Folletos. Los aportes fundamentales de este autor se completan con su libro Cosas de negros (1926), obra que si bien versa sobre los orígenes del tango, dedica una parte al tema del idioma. Allí sostendrá la idea de que los rioplatenses contamos con un idioma propio, y denuncia que "el interés por nuestro castellano no es nuestro, es íbero, bajo la pretensión de mantenernos en perpetua dependencia, que llaman 'conquista espiritual', quienes ignoran hasta nuestra posición jeográfica (sic)" (1926: 402).

\footnotetext{
${ }^{32}$ Di Tullio se refiere a este nacionalismo como popular (2003: 65).
} 
Rossi señala que cuando "nuestro pueblo" se decidió a fundar su teatro "tuvo necesariamente que darle su lenguaje". No faltaron, entonces, quienes pensaron en que ese lenguaje debía ser "muy castizo o castizo del todo" (1969: 120). Para Rossi, esa amenaza, lejos de desaparecer, continuaba muy presente. Sin embargo, "nuestros mejores autores" se han preservado de caer en el "vicio" del purismo y aplicar a sus obras "otro lenguaje que no fuera el que en el Río de la Plata se habla" (120). El castellano puro en el teatro nacional no hace más que "adulterarlo" y "desfigurarlo", en la medida en que es un lenguaje "con el que se escribe [pero] no se habla" (120). Aquí Rossi invierte una matriz conceptual, forjada por la cultura conservadora e hispanófila, que vinculaba las formas vernáculas con el orden de la deformación idiomática. Al invertir la estrategia argumentativa, Rossi se sirve de los mismos conceptos que utilizan los puristas para referirse al lunfardo y a todas aquellas voces que caen fuera de la órbita del castellano normado.

Las tesis de Rossi abrevan en los postulados de Abeille. De hecho, creemos que es uno de sus mejores continuadores. El uruguayo parte de argumentos afines a los del francés. Para Abeille, la raza y el idioma constituyen una unidad; por lo tanto, si en Argentina se ha formado una nueva raza, merced al aporte indígena y cosmopolita, resulta lógico que el castellano peninsular "evolucione" hasta formar un "idioma nuevo" (2005: 136). Rossi retoma esta idea cuando afirma que el castellano resulta "arcaico, áspero y arbitrario" y, sobre todo, “ajeno a nuestra raza y espiritualidad” (1928a: 7). A su vez, también parte de una suerte de darwinismo lingüístico al afirmar que el castellano se encuentra "en desaparición evolutiva" frente a un "idioma nacional" que resulta "superior a sus fuentes en todo sentido" (1969:123). De hecho, cuando realiza estas afirmaciones en su Teatro nacional rioplatense, coloca una nota a pie de página para referirse al libro de Abeille como de "inapreciable" importancia al respecto. En los Folletos lenguaraces, se extiende un poco más en consideraciones acerca del profesor francés: con respecto a Idioma nacional de los argentinos señala que es "el primer y único trabajo serio, de alto valor científico, desarrollado con profundos conocimientos en tan compleja ciencia lingüística, y con clara percepción del alma nacional” (1928a: 14). Y agrega que el libro representa "una revelación y consagración de nuestra independencia idiomática" (15).

Los Folletos lenguaraces representan, después del libro de Abeille, el soporte argumentativo más fuerte y analítico acerca de la formación de una lengua propia en el Río de la Plata. Pero, además de esto, y a diferencia de la obra del francés, Rossi despliega allí todo un arsenal discursivo destinado a desacreditar y agredir a sus adversarios idiomáticos, los puristas. Más arriba, hemos señalado que los grupos rupturistas se apropiaron del concepto de nacionalismo para invertir el sentido otorgado por la cultura conservadora. Si en esta esfera lo 
nacional estaba vinculado, en parte, al restablecimiento de las relaciones con España y a la asunción de una lengua apegada a sus preceptos académicos, el nacionalismo idiomático de hombres como Rossi significa justamente todo lo contrario: se es nacional en la medida en que se le brinda cabida a las formas culturales e idiomáticas propias de estas regiones y, en ese mismo gesto, se procede a negar cualquier tipo de tutela foránea, principalmente española. Según Rossi, los pueblos del Plata hace tiempo que se han creado un lenguaje propio, que él denomina "Idioma Nacional Rioplatense" (6). Esta lengua no es más que el producto de la "nacionaliza(ción) (d)el idioma", acción que para los "derrotistas nativos" -así llama a los puristas argentinos- constituye un "grave delito" (6). De acuerdo con Rossi, uno de los postulados básicos del "derrotismo" es catalogar de "inculto al que pretenda ser nacional", mientras que los cultos son aquellos que permanecen fieles al castellano (6).

Rossi no niega el castellano de modo completo, sino que sostiene que se lo debe “anexar a lo nacional”, pero "conservando su procedencia, no ocultándola como es la costumbre académica con infinidad de americanismos" (10). De esta manera, se agrega a los otros aportes que conforman los insumos principales de la lengua rioplatense: el aporte autóctono, vale decir indígena; el europeo no español y la creatividad propia. Sin embargo, hace mucho hincapié en que el grueso del "idioma nacional" deriva en buena parte del español hablado por los inmigrantes y de las invenciones idiomáticas de los sectores populares del Río de la Plata. El castellano queda reducido a la mera función de "idioma auxiliar" que vehiculiza las influencias de otros idiomas sobre él. En términos cronológicos, el proceso de formación de la "lengua propia" cuenta con dos fases, según Rossi: el período inicial, en el que destaca los aportes del indígena y del negro colono; y luego, el segundo período comprende "la babel europea" en nuestro medio (1929c: 26).

Rossi no se queda en formulaciones teóricas y argumentativas. En sus Folletos lenguaraces ensaya ese "idioma argentino-uruguayo" a partir de la consecución de su propia reforma ortográfica: unifica los sonidos con las grafías, elimina acentos y signos de puntuación, como así también los de interrogación y exclamación. ${ }^{33}$ En cada uno de los folletos, Rossi aclara que "la irregular o ausente acentuación obedece a un plan de entrenamiento para suprimirla paulatinamente, probando que, con muy raras excepciones, es

\footnotetext{
${ }^{33}$ El proyecto idiomático de Rossi se integra a un conjunto conformado por otras propuestas de reforma de la lengua, las cuales no se limitan al contexto argentino, sino que, a partir de mediados del siglo XIX y hasta por lo menos la década de 1920, se llevan a cabo en distintos lugares de América Latina. Por ejemplo, el proyecto de "el idioma de los argentinos" de Borges; el dialecto inventado por Xul Solar, basado en el castellano y el portugués, conocido como "neocriollo", y su utopía lingüística denominada "panlengua"; la recuperación de algunos rasgos de las lenguas indígenas en el proyecto del peruano Fransisqo Chuqiwanka Ayulo. Otros autores que expresaron su preocupación por la defensa de una lengua americana opuesta al conservadurismo de las academias son Mario de Andrade, Manuel González Prada, José de Alencar. En el siglo XIX, cabe destacar la radical propuesta de reforma ortográfica de Simón Rodríguez, y la controversia entre Sarmiento y Andrés Bello, en 1842. Jorge Schwartz (2002a) realiza un completo repaso de todos estos proyectos.
} 
innecesaria" (1928a: 6). La idea es que, al mismo tiempo que se le brinda sustento argumentativo, los folletos propagan "el Idioma Nacional Rioplatense [que] es el que hablamos y escribimos actualmente" (7). Esta conclusión responde a los pormenorizados análisis cuantitativos del vocabulario que realiza al final de cada uno de los folletos, los cuales arrojan el resultado de que un ochenta por ciento de las voces que se empleaban por aquellos años en Argentina correspondían al español rioplatense, en detrimento de la variedad peninsular.

Durante los años veinte, muchos creyeron ver en el lunfardo uno de los insumos centrales, cuando no el único, del idioma nacional. Los conservadores lo juzgaron siempre como una amenaza: Ernesto Quesada, Arturo Costa Álvarez y Ricardo Monner Sans, por mencionar sólo algunos, lo combatieron enérgicamente. Sin embargo, en los postulados de los dos representantes más importantes del paradigma de la lengua propia -Abeille y Rossi-, el lunfardo no tiene demasiado protagonismo. El profesor francés, "alude apenas a algunos términos del vocabulario lunfardo", pero jamás lo hace por su nombre (Conde 2011: 30). Por su parte, Rossi quiere dejar en claro que el "idioma nacional [que] hablamos y escribimos actualmente" no se conforma sobre la "clave lunfarda ni el argot orillero". Rechaza la afirmación acerca de que "lo único nacional en el lenguaje es el lunfardo" (1928a: 6). ${ }^{34}$

El lunfardo resulta un elemento crucial en la historia de los debates en torno al lenguaje y en las condiciones de transformación de la lengua literaria. Entre fines del siglo XIX y comienzos del XX, el lunfardo estuvo asociado al vocabulario del delito. Ya en los años veinte comenzó a ser percibido, por algunos sectores del campo literario y de la sociedad como un elemento, o una influencia, importante del idioma, ${ }^{35}$ sobre todo de ese "idioma", independiente del castellano, ${ }^{36}$ al que aspiraban los sectores afines a la tendencia rupturista. A su vez, durante las primeras décadas del siglo XX, el lunfardo se constituye como una

\footnotetext{
${ }^{34}$ En Cosas de negros (1926) repite esta tesitura con respecto al lunfardo: "en todos los pueblos civilizados hay argot 'lunfardo' y no es el idioma nacional de ningún pueblo. No se hace, ni hacemos nosotros, idioma con argot, sino con el uso, abuso, creación y adopción de vocablos. (1926: 399 y 401). Por su parte, Borges en sus tesis sobre "el idioma de los argentino", también rechaza el lunfardo y el casticismo. Más adelante, se desarrollarán brevemente las ideas de Borges al respecto.

${ }^{35}$ Como veremos en el capítulo III, durante el año 1927, el diario Crítica lleva adelante una encuesta que se proponía dilucidar si “¿Llegaremos a tener un idioma propio?”. En casi todas las respuestas de los encuestados responden la consigna desde escritores conservadores hasta vanguardistas, gramáticos y estudiosos de la lenguael lunfardo está presente, ya sea para descartar o afirmar su rol protagónico en la constitución de un idioma argentino, aunque mejor sería decir rioplatense.

${ }^{36}$ Los primeros estudios sobre el lunfardo aparecen en 1878, cuando en el diario La Prensa aparece un suelto anónimo titulado "El dialecto de los ladrones". Un año después, Benigno Lugones, un escribiente del Departamento de Policía, publica en La Nación un artículo titulado "Los beduinos urbanos", en el que aborda el "caló de los ladrones". La continuación de este artículo de Lugones aparece unos meses después con el título"Los caballeros de industria". En 1883, La Crónica publica un artículo anónimo titulado "El conventillo Aravena”, el cual aporta la más antigua definición del término lunfardo (Conde 2011: 89). En 1888, Luis María Drago publica un ensayo de antropología criminal en el que hace referencias a este vocabulario. En 1894 aparece El idioma del delito, de Antonio Dellepiane, uno de los textos más importantes del período sobre el tema. La obra venía acompañada de un pequeño Diccionario lunfardo, el primero publicado.
} 
herramienta importante, entre otras, en la reconfiguración de la lengua literaria, puesto que poetas y escritores se sirvieron de él para renovar por completo un lenguaje literario que hasta no hacía mucho tiempo atrás se encontraba supeditado a la corrección que prescribían los diccionarios y las gramáticas.

Sin lugar a dudas, el diario Crítica fue uno de los difusores centrales del lunfardo en los años veinte, puesto que muchos de los poetas y escritores lunfardescos publicaban allí asiduamente sus poemas, columnas, relatos y glosas. Este fenómeno implica el pasaje de una modalidad propia de la oralidad a la escritura, lo cual redobla los motivos de alarma puesto que esta última era considerada como el reservorio de la corrección. ${ }^{37}$ El espacio que Crítica le brinda a estos autores fue motivo de ataques contra el diario por parte de sectores que veían al lunfardo como un "corruptor" del idioma y, en cierta medida, como una de las formas de la inmoralidad dada las temáticas -prostitución, juego, delincuencia, etc.- que parecían resultarle inherentes.

J. A. de Diego, en el "Estudio preliminar" que escribe para la primera reedición de Teatro Nacional Rioplatense, a fines de los años sesenta, señala que cuando el autor de Cosas de negros muere en 1945 "para esta época era ya inexplicablemente un olvidado" (De Diego 1969: 7). Borges, que ya presentía, con cierta ironía, ese destino en los años veinte, escribe una reseña del sexto volumen de los Folletos en la revista Síntesis (1927-1930), en donde afirma: "estoy previendo que este ahora inaudito y solitario Vicente Rossi va a ser descubierto algún día, con desprestigio de nosotros sus contemporáneos y escandalizada comprobación de nuestra ceguera" (1928a: 361). Las reediciones, en 2001 (Taurus) y 2008 (Aguilar), de Cosas de negros tal vez den por cumplidos los presagios borgeanos. ${ }^{38}$

Al mismo tiempo que Rossi se dedica a escribir y publicar sus Folletos, otro representante de los rupturistas, Ramón Carriegos, ${ }^{39}$ escribe su libro El porvenir del idioma

\footnotetext{
${ }^{37}$ Esta problemática ya había sido puesta de manifiesto por Ernesto Quesada (1983) y otros autores que, a principios de siglo, reaccionaron contra el "criollismo" de la literatura popular en la que se mezclaban los registros gauchesco, lunfardo y cocoliche.

38 A excepción de la reseña de Borges, la obra de Rossi no fue muy comentada en las revistas y periódicos de la época. Por esta razón, el texto de Borges resulta de suma importancia. Si bien no comparte plenamente las tesis de Rossi, la moderada simpatía que siente por este autor se recorta sobre el poderoso rechazo que despiertan en él los puristas.

${ }^{39}$ Ramón C. Carriegos es periodista, profesor y escritor. Nace en la ciudad de Corrientes, en donde comienza su actividad como periodista. Luego se traslada a la Capital Federal para desempeñarse como profesor. Más tarde, presta servicios docentes en Bahía Blanca, en el Colegio Nacional y Escuela Nacional de Comercio, hasta que es designado para desempeñar la Secretaría y una cátedra en la recién fundada Escuela Normal Mixta de la ciudad de Tandil, en el año 1910 (Homenajes tributados... 1947). Carriegos inicia su prédica a favor de un "idioma argentino" en los primeros años del siglo XX, cuando publica en 1906 una Gramática de la lengua castellana en coautoría con Juan Quevedo. En 1910 edita Minucias gramaticales. Entre otras cosas, en esta última obra explica por qué opta por escribir el nexo copulativo "y" con el grafema "i", una modificación que hicieron propia varios rupturistas: "La Real Academia, la científica corporación por uno de esos rasgos que sólo tiene su explicación en las leyes atávicas, apegada a las cosas ilógicas, ordena, manda que la vocal $i$ no siga la misma suerte de sus
} 
español en la República Argentina. Frases i palabras criollas (1928). Allí defiende la tesis de que en el país existe un "idioma argentino en formación” (22), producto de que España y Argentina han seguido "caminos diferentes en lo que respecta a la evolución del castellano" (19). La principal diferencia que encuentra Carriegos entre nuestro país y España es que Argentina es cosmopolita, condición que no se presenta en la Península Ibérica. Si en España intervienen el catalán, el vascuence, el gallego y el valenciano en el devenir del castellano, “estos factores no actúan en la República Argentina", por lo tanto "es lógico deducir que no puede dicho idioma seguir un mismo proceso en ambos países" (19). Los factores que influyen en nuestro medio tienen que ver, principalmente, con la inmigración aunque, al igual que Abeille y Rossi, incluye las lenguas indígenas como sustrato importante del nuevo idioma: "concurren también a la evolución del castellano en nuestro país los idiomas hablados por los aborígenes. El quichua, el guaraní y el araucano han contribuido a la formación del léxico criollo" (18).

Carriegos también ensaya una fuerte prédica anti purista: reacciona frente a aquellos "compatriotas que (...) se empeñan en conservar [el idioma] puro e intangible" (15). De esta manera, entabla una disputa con Costa Álvarez, quien había publicado en el diario La Prensa una "crítica cáustica" a su libro El porvenir del idioma español... También le responde a un autor anónimo que, en La Nación, publica un artículo en el que afirma que Carriegos "pregona un error o una utopía", en referencia a su tesis acerca de una evolución diferente del castellano a la que sigue en España, y propia de la Argentina (Carrriegos 1940). Al mismo tiempo, apoya a aquellos que "corrompen el castellano" (1928: 15) y lo conducen hacia los fueros vernáculos. Así, la acción de "corromper" el idioma, en Carriegos, pierde su sentido negativo y asume un valor necesario y progresista: el idioma nacional se realiza a fuerza de corromper el "rancio" castellano. Rossi también realiza esta suerte de inversiones cuando vindica el "hablar mal" en la medida en que esa es una "forma nacional de expresarse" (1929c: 4).

Como vemos, la idea de una lengua propia tuvo una presencia importante durante la década del veinte. En los años siguientes, las tesis hispanófilas y puristas, lejos de retroceder, inauguran otros capítulos significativos. ${ }^{40}$ No obstante, el debate en torno a un posible idioma nacional en los años veinte gana la prensa y numerosos intelectuales intervienen a través de

hermanas!.... (sic). ¿Se fundará en algo? ¡Qué esperanza! (...) Nosotros estamos harto curados de la fantasmagoría de la sapiencia académica" (1910: 9-12).

\footnotetext{
${ }^{40}$ Rosenblat sostiene que, en décadas posteriores a la de 1920, el purismo idiomático fue la nota que predominó: "en toda America, en la educación, en el periodismo, en la prosa didáctica, el purismo siguió siendo la nota dominante" (1984: 293). Ejemplo de esto, según el autor, es la prohibición del voseo por parte del Consejo Nacional de Educación en 1939. Sin embargo, agrega que, pese a este dominio, el habla popular "ha llegado honrosamente a nuestra literatura y le ha comunicado su savia" (293).
} 
artículos, libros y/o reseñas. Sin lugar a dudas, la cumbre de estos debates podemos encontrarla hacia 1927 cuando, entre otros eventos significativos de ese año, ${ }^{41}$ el diario Crítica lanza la ya mencionada encuesta titulada “¿Llegaremos a tener una lengua propia?”. Aunque la evidencia documental demuestre lo contrario, hacia 1927, Costa Álvarez declara que el problema de la lengua propia ya había quedado en el pasado y la revista El Hogar no hizo más que "resucitar" el tema (1927b: 192). El autor de Nuestra lengua se refiere a un artículo que publica Pescatore di Perle ${ }^{42}$ en su habitual columna de ese semanario, en marzo de 1927, cuyo título es el mismo con el que, cuatro meses después, Crítica bautizará su encuesta.

Sin abandonar el estilo humorístico que lo caracteriza, Pescatore se opone a la idea de la gestación de un idioma nacional. Señala que en 1927 "ya no podemos hacer lenguas propias. ¡Imposible, amigo!” (1927: 66). Para Pescatore, el "Idioma Nacional de los Argentinos" lejos de ser una realidad empírica, constituye un "invento" de Abeille; un invento encarnado en "cuatrocientas veintiocho páginas in octavo. ¡Una papa! Tan papa que nadie volvió a hablar del asunto hasta la fecha" (66). Pescatore tiene la tesis de que la humanidad se encamina hacia "los grandes sistemas homogéneos", es decir, una dirección inversa a los particularismos que suponen las lenguas vernáculas: “¿qué diablos vamos a conseguir inventando ahora el argentino, el chileno, y el boliviano" (66), se pregunta.

En septiembre de 1927, el español Américo Castro publica en La Nación un artículo titulado "En torno al posible idioma argentino", en el que afirma que el deseo de poseer un "lenguaje propio" resulta una cualidad típicamente americana (1927: 11). Este deseo se manifiesta en Argentina, siempre según Castro, primero en el "fracasado libro de Abeille" y luego "de vez en cuando en la prensa, como sucede en la encuesta a que vengo aludiendo" (11). Se refiere a la encuesta del diario Crítica. De hecho, el domingo siguiente a la publicación de este artículo aparece en el diario de Botana una nota titulada "La encuesta de Crítica: ¿Llegaremos a tener idioma propio? Y D. Américo Castro” en la que se acusa el golpe de Castro y se realiza una encendida defensa de la lengua propia, a contrapelo de los resultados arrojados por la encuesta en la que la mayoría de los escritores y estudiosos

\footnotetext{
${ }^{41}$ Entre esos eventos, podemos mencionar: la polémica en torno al meridiano intelectual de Hispanoamérica, que tuvo lugar principalmente en la revista Martín Fierro, entre junio y noviembre; la campaña contra el diario Crítica por parte de la revista Claridad (ver capítulo III), la conferencia de Borges sobre el idioma de los argentinos, en septiembre; y la publicación de algunas obras como los Folletos lenguaraces de Vicente Rossi; la publicación de los textos de Sarmiento, compilados por Armando Donoso; entre numeroso libros y artículos que hacían foco en los problemas del idioma.

42 "Pescatore di Perle" es el seudónimo de Francisco Ortiga Anckermann quien escribía, en los años veinte y en la revista El Hogar, la cómica sección "La paja en el ojo ajeno", en la cual se ocupaba de encontrar "perlas" literarias (plagios, incorrecciones gramaticales, barbarismos, etc.) en autores consumados.
} 
convocados "decidieron impugnar" a quienes bregan por "la formación del lenguaje en otra fuente que la hispana" (“La encuestas de Crítica...” 1927: 7). Castro se pregunta “¿con qué vamos a cargar nuestro deseo de una lengua propia? ¿Con lunfardismos y giros del arrabal porteño? ¿Dónde está su peculiaridad? Creen que diciendo 'davi' y no 'vida' se hace una lengua..." (1927: 11). En la aludida nota de Crítica, se desestima la subvaloración de los registros populares que hace Castro en su artículo. Para Crítica, en cambio, no se puede prescindir de la psicología de la numerosa cantidad de personas que hablan el lunfardo de manera cotidiana ("La encuesta de Crítica" 1927).

En 1928, la editorial de Samuel Glusberg, Babel, edita Seis ensayos en busca de nuestra expresión, de Pedro Henríquez Ureña, con el cual intervino de lleno "en el debate sobre la historia literaria y sobre la modernidad y los nacionalismos" (Díaz Quiñones 2006: 246). Además, elaboró sus concepciones a partir de la crítica del criollismo, el indigenismo y de las vanguardias. En este libro, se incluye el capítulo titulado "El descontento y la promesa", fechado en 1926. Dominicano, afincado en Buenos Aires desde 1924, ${ }^{43}$ Henríquez Ureña revisa en este capítulo uno de los problemas que ocupan a buena parte de la prensa y de la producción literaria y ensayística en esos años: el idioma nacional. El autor se pregunta si para los americanos escribir en lengua vernácula significa retomar las lenguas indígenas. Descarta esa posibilidad dado que, explica, el hombre de letras las ignora, además de que existe el problema de que la consecuencia final de su implementación sería "la reducción inmediata del público" (1928: 20). Henríquez Ureña recuerda que años atrás existió la idea de que íbamos embarcados en la "aleatoria tentativa de crear idiomas criollos", pero ese camino nos hubiese llevado, concluye, a una "empobrecida expresión dialectal mientras no apareciera el Dante creador" (21). Vale decir que para 1926, Ureña da por finalizada la posibilidad de la conformación de una lengua vernácula, al menos en los términos que había sido pensada por Abeille, o más bien por sus detractores. Recordemos que el profesor francés había dejado en claro que su tesis no consistía en que la lengua del gaucho es el idioma nacional de los argentinos, como le había sido imputado por Ernesto Quesada (1983). De este modo, Henríquez Ureña plantea que, para el Río de la Plata, el lenguaje gauchesco parecía ser la "sustancia principal" de ese idioma en ciernes, aunque ese registro presenta un problema: no contiene "la diversidad suficiente para erigirla siquiera en dialecto, como el de León o el de Aragón" (1928: 21). Cabe señalar que Henríquez Ureña no lleva más allá del gauchesco la

\footnotetext{
43 "Su traslado a la Argentina, en junio de 1924, fue una apuesta a la independencia, y al logro de las condiciones materiales necesarias para sus proyectos. En las décadas de 1920 y 1930, se encontró con un campo intelectual muy activo, estableció amistad con Alejandro Korn (1860-1936), frecuentó los círculos de escritores, colaboró en los diarios, y formó parte del equipo de la revista Sur" (Díaz Quiñones 2006: 211).
} 
problemática del idioma en Argentina, y en este texto no se refiere a las otras formas que se postulaban como sustratos lingüísticos de esa lengua propia. Para Henríquez Ureña el problema parte de que en América no se ha renunciado a escribir en español. La solución que parece encontrar es que el americano se ocupe de "acendrar nuestra nota expresiva, buscar el acento inconfundible", pero sin renegar de la lengua heredada. En cierta medida, esta idea será repetida por Borges quien luego de descartar las tendencias hispanizantes y aquellas otras conceptuadas como vernáculas -el lunfardo, el orillero- llega a la conclusión de que no hay una distinción muy marcada entre el castellano peninsular y nuestro español. La diferencia es sólo de "matiz" y ocurre "a nivel del significado de las palabras, que no ha cambiado en lo sustancial, pero sí en la connotación que tienen los términos" (1994: 146). La perspectiva de Henríquez Ureña sobre la lengua es la de un intelectual que pensaba que "ninguna revolución deja de recibir la herencia del régimen que cae", lo cual no sólo implicaba una adhesión explícita al hispanismo, ${ }^{44}$ sino también "una reserva ante el progreso y las vanguardias" (Díaz Quiñones 2006: 169). No sólo colaboró con Amado Alonso en el Instituto de Filología, ${ }^{45}$ sino que además junto a este intelectual publicó, en 1938 y 1939, los volúmenes I y II de la Gramática Castellana. Estos textos son los fundadores de "una tradición en la enseñanza de la lengua en la Argentina que se prolongó a lo largo de la segunda mitad del siglo XX" (Narvaja de Arnoux 2001: 53). ${ }^{46}$ Tanto Alonso como Henríquez Ureña partían de la existencia de un desorden lingüístico que caracterizaba a Buenos Aires, producto del aluvión inmigratorio. La Gramática es pensada entonces como una herramienta para restablecer el orden.

Mucho se ha escrito acerca de las tesis sobre el idioma que Borges sustenta durante la década del veinte. ${ }^{47}$ Por tal motivo, sólo expondremos sus ideas al respecto brevemente. En primer lugar, cabe señalar que su postura resulta muy particular en la medida en que, como hemos dicho, no adscribe a ninguna de las dos posturas dominantes en los debates en torno al idioma. La producción borgeana de los años veinte ha sido catalogada, de manera muy consensuada, como "criollista" (Olea Franco 1993). Ese criollismo consiste básicamente en el

\footnotetext{
44 “Como para Menéndez Pelayo, la tradición para Henríquez Ureña no era sólo el acto de transmisión, sino una herencia que imponía obligaciones" (Díaz Quiñones 2006: 167).

${ }^{45}$ La gestión de Amado Alonso frente al Instituto de Filología se extiende entre los años 1927 y 1946, y se considera como el período en el que el Instituto se afianza como el más importante centro de investigación en el ámbito de la filología hispánica. Para profundizar en la historia del Instituto de Filología en la década del veinte, ver Toscano y García (2009).

46 "La Gramática está destinada a ser el libro de texto de Castellano para los dos primeros años de la escuela secundaria, por lo cual amplía el alcance de la literatura ya que esta, además de suministrar muestras de lengua legítima, es modelo para las actividades de escritura, estímulo y control de la oralidad y espacio para la ejercitación gramatical" (Narvaja de Arnoux, 2001: 53).

${ }^{47}$ Barrenechea (1953, 1967), Borello (1974), Echavarría (1983), Masiello (1986), Olea Franco (1993), Farías (1994), Narvaja de Arnoux - Bein (1999), Bordelois-Di Tullio (2002), Di Tullio (2003, 2006, 2009), Ennis (2008), Rest (2010), Schäffauer (1999), etc.
} 
rechazo hacia la inmigración y en una impugnación de las políticas europeizantes de los hombres del 37.48 además implica una revalorización de la figura de Rosas e Yrigoyen. En materia lingüística, el criollismo borgeano se manifiesta en la aspiración a una "entonación argentina del castellano" que encuentra en la oralidad culta, próxima a la norma literaria, una de sus señas particulares (Narvaja de Arnoux-Bein 1999: 24); y, a su vez, en el simétrico rechazo del lunfardo-orillero y del español castizo. Su breve tesis de 1928 acerca del idioma argentino consiste en señalar que aún no está conformado. ${ }^{49} \mathrm{Y}$ agrega que lo que le falta, principalmente, es una obra literaria que lo "inmortalice". El ideal idiomático, para Borges, se encuentra en el pasado, de ninguna manera en el babélico presente. Por eso rescata a "nuestro mayores", quienes sin "arrogancia orillera" ni "malhumor" hispano, escribieron, con el "tono de su voz", "el dialecto usual de sus días". ${ }^{50}$ Acorralado por las coordenadas "seudo plebeya" y "seudo hispánica”, Borges critica al escritor argentino de los años veinte puesto que "el que no se aguaranga para escribir y se hace el peón de estancia o el matrero o el valentón, trata de españolarse" 51 (1994: 146). En síntesis, entre el español peninsular y el nuestro habría sólo "un matiz de diferenciación" lo bastante discreto como para "no entorpecer la circulación total del idioma" (146-147).

En 1928, mismo año que Borges edita su Idioma de los argentinos, Arturo Costa Álvarez publica un libro, titulado El castellano en la Argentina, ${ }^{52}$ que se constituye en uno de

\footnotetext{
${ }^{48}$ Borges (1993) culpa directamente a Sarmiento por habernos europeizado. No obstante, cabe aclarar que no rechaza toda la prédica de los liberales decimonónicos; muy por el contrario, reconoce en alguno de ellos un antecedente directo de su postura con respecto a la lengua. Por ejemplo, Borges retoma algunas ideas esbozadas por Juan Bautista Alberdi, quien hacia 1838 señala: "desde el instante en que los españoles pisaron las playas de América, nuestro suelo les impuso acentos nuevos a sus bocas" (Narvaja de Arnoux-Bein 1999: 24). La tesis de Borges es prácticamente la misma que la de Alberdi: piensa que en Argentina existe un español levemente transformado por referencias, connotaciones y sentidos nuevos.

${ }^{49}$ Además de varios artículos publicados en revistas y diarios de la época, dos son los libros que reúnen sus posiciones fundamentales sobre el idioma: El tamaño de mi esperanza (1926) y El idioma de los argentinos (1928). En ambos textos, sus argumentos no varían demasiado. En el primero, Borges se ocupa de desacreditar el lunfardo-orillero como posible sustrato del idioma nacional dado que esa "infame jerigonza" no es más que el lugar adonde "las repulsiones de muchos dialectos conviven y las palabras se insolentan" (1993: 122). Junto a esta influencia, que "milita contra un habla argentina" (1994: 134), Borges remarca la otra, la de "los casticistas o españolados que creen en lo cabal del idioma y en la impiedad o inutilidad de su refacción" (134). Borges afirma que el arrabalero, esa suerte de "decantación o divulgación del lunfardo", además de estar constituido por un "vocabulario misérrimo", no resulta muy utilizado: "el criollo no lo usa" y "la mujer lo habla sin ninguna frecuencia". Pensar que una "lengua técnica" como esta puede "arrinconar al castellano" resulta del todo inviable (137-138).

${ }_{50}$ Piensa, principalmente, en los escritores cultos del siglo XIX, representantes tanto de la Generación del 37 como la del 80 (menciona a Echeverría, Sarmiento, Vicente Fidel López, Mansilla, Wilde) (1994: 146). La crítica hacia la generación de intelectuales argentinos que promovió la inmigración -la "europeización"-, al igual que su rosismo de aquellos días, no disuaden a Borges para encontrar en estos escritores el tono del idioma que anhela y que ya poco encuentra entre sus contemporáneos.

${ }_{51}^{51}$ Menciona como excepciones a Eduardo Schiaffino y a Ricardo Güiraldes.

${ }^{52}$ El castellano en la Argentina se publica primero, en forma de artículo, en el número 219/220 de la revista Nosotros, en agosto de 1927. A su vez, una parte de este texto ya había sido editada en La obra de Monner Sans en nuestra lengua, un ensayo de 1927 con el cual pretende ubicar al gramático español por fuera de la actitud de "intransigencia de los puristas". Según Costa Álvarez, este autor fue un batallador en la tarea de "sostener la necesidad de legitimar las voces nuevas, es decir, los neologismos" (1927b: 8).
} 
los compendios argumentativos más interesantes y valiosos contra las tesis rupturistas. Si bien en Nuestra lengua (1922) ya había decretado la muerte de todas las tentativas a favor de una lengua vernácula, ante la persistencia de esas ideas Costa Álvarez parece verse en la necesidad de repetir y agudizar su postura en este libro. Según Costa Álvarez (1928b), todas aquellas publicaciones que postulan al castellano en Argentina como un idioma propio tropiezan con un problema: sostienen la emancipación de las formas castellanas a partir de una serie de reformas que se llevan a cabo dentro del castellano mismo. Los aportes de los rupturistas quedan reducidos, entonces, a la "desnaturalización” del castellano mediante la incorporación de formas extranjeras y "vulgarismos nacionales" (17). Para este autor, estas modificaciones no comportan en modo alguno la transformación de una lengua en otra puesto que, "por mucho localismo que injertemos" nuestro tronco idiomático común siempre será el castellano (18). Sin embargo, la postura de Costa Álvarez no es la de un purista recalcitrante puesto que reconoce las particularidades propias que presenta el castellano del Río de la Plata: "la base de nuestra cultura es la heredada tradición hispana; pero su estructura tiende a desarrollarse con caracteres propios, en armonía con nuestra idiosincrasia de pueblo nuevo" (63). No obstante, no por esto deja de ser un purista, puesto que si bien acepta el argumento de una lengua con características personales y diferenciadas, pervive la idea de que el castellano en estas tierras ha sido "desnaturalizado" y "vulgarizado" por algunos aportes indeseables. ${ }^{53}$ Más allá del reconocimiento de las particularidades del castellano en argentina, Costa Álvarez tiene la idea de que la lengua culta ha sido "dañada” y, ante esta situación, es necesario "restablecer[la]" (1928b: 64). Vale decir que si, por un lado, este autor y otros afines se oponen a la tesis de una lengua propia en formación, por el otro su prédica también se orienta a favor de la recomposición de una lengua que se ha visto seriamente comprometida y apartada de su estado "ideal". Por esta razón, durante los años veinte, aparecen textos destinados a señalar los errores más frecuentes en el uso de la lengua y a enmendarlos. ${ }^{54}$

\subsection{Los defensores del castellano}

Luego de la polémica que se genera alrededor del libro de Abeille, y que deriva en la disputa en torno al criollismo, las querellas se enfrían en los años subsiguientes. En la década del veinte, comienza a emerger un nuevo corpus de ensayos que, por un lado, realizan una revisión de ese pasado reciente y concluyen que el problema de la lengua ha dejado ya de

\footnotetext{
${ }^{53}$ Se refiere, principalmente, a las influencias del francés, por un lado; y por el otro al contacto entre las "clases altas" y "bajas", a partir de la apertura democrática del yrigoyenismo (Costa Álvarez 1928b).

${ }^{54}$ Sirva de ejemplo algunos libros de Ricardo Monner Sans, tales como Disparates usuales en la conversación diaria (1923) y Barbaridades que se nos escapan al hablar (1924); o bien la Guía del buen decir. Estudio de las transgresiones gramaticales más comunes (1925), de Juan Selva.
} 
serlo, puesto que "cualquier tendencia deliberadamente corruptora del idioma" se ha disipado (Quesada 1923: 11). Ernesto Quesada, quien da por finalizado el debate y proclama la victoria de una batalla iniciada un cuarto de siglo atrás, es el encargado de reseñar y festejar uno de los libros más importantes sobre el tema durante esa década: Nuestra lengua, de Arturo Costa Álvarez. Publicado en 1922, este libro puede considerarse como un texto inaugural o fundante en el sentido de que se inicia con él una nueva perspectiva en el abordaje de "la cuestión del idioma": hasta ese momento, quienes habían intervenido en el debate eran protagonistas en diferentes esferas de la vida intelectual e institucional; sin embargo, es Costa Álvarez quien aborda el tema en tanto objeto de reflexión y de estudio, y se erige como "el especialista" en dicha temática (Di Tullio 2006). Si bien forma parte de "la tradición de la queja" 55 -al igual que Ricardo Monner Sans, Juan B.Selva y otros--, su voluminoso libro no sólo representa una prolija argumentación contra quienes postulaban una lengua propia, sino también constituye una revisión del pasado idiomático del país al calor de los nuevos desafíos que el contexto de los años veinte ofrece.

Si bien es un acérrimo enemigo de las tesis rupturistas, su prédica nacionalista lo preserva de la idea de que se debe acatar servilmente las normas emanadas de la Real Academia Española. Sin embargo, la perspectiva de Costa Álvarez se encuadra en una defensa del castellano - con los límites ya señalados- y con la intención de codificar una lengua culta y nacional, purgada de todos aquellos elementos lingüísticos provenientes de la inmigración, en los cuales muchos creyeron adivinar el germen de un nuevo idioma. Costa Álvarez distingue muy bien las tendencias opuestas que existen dentro del concepto de nacionalismo. En las postrimerías del siglo XIX, afirma, se asiste al "triunfo" y a la "apoteosis" de la "incultura popular" en el lenguaje (1922: 89). Piensa en la literatura criollista, en el teatro criollo y en el colofón del siglo: el libro de Abeille, del cual afirma, principalmente, que favorece la corrupción de la lengua (Costa Álvarez). Sobre el período 1900-1920, Costa Álvarez sostiene que "la corrupción del idioma se ha hecho sistemática" debido a que se persigue un fin patriótico: nacionalizar el habla (89). Es aquí cuando distingue dos formas del nacionalismo: por un lado, el que se conduce por la "vía bárbara", que aglutina a todos aquellos "idiomólogos" y escritores cuya prédica tiene por objetivo "sustituir la lengua en la que escriben" (91). Ese patriotismo es el que coloca en su centro una "lengua artificial", cuyo vocabulario "será gauchesco, la construcción será francesa y del castellano no quedará sino lo indispensable para que el aparato no se venga abajo" (91). Por otro lado, se

\footnotetext{
55 "Lo que se observa en un primer momento, en cuanto a la lengua hablada, es un castellano casi nunca correcto" (Costa Álvarez 1922: 141).
} 
encuentra "la vía civilizada", la suya, que se basa en el respeto y la preservación del castellano "culto".

Frente a un contexto en el que prevalece un "caos" lingüístico producto de las influencias y mixturas que ejercen los grupos de inmigrantes en contacto con el español, "caos" que sirve a un conjunto de escritores e intelectuales para fundamentar la idea de una lengua "privativa" de la Argentina, Costa Álvarez recupera el valor que tiene el castellano para contrarrestar esta situación "indeseable”. Señala que, durante el siglo XIX, la lengua se torna cada vez menos castiza debido "al roce que se produce en los arrabales con el guirigay de los negros bozales, en los campos con el lenguaje gauchesco y en las lindes con las lenguas indígenas" (22). Es decir, los sectores populares, las minorías conformadas por los negros, indígenas y gauchos serían los agentes corruptores del lenguaje durante el gobierno de Juan Manuel de Rosas. Sin embargo, este y otros autores se encuentran con un problema a la hora de trazar una verdadera tradición nacional apoyada sobre la base del castellano hispánico: los liberales decimonónicos elaboraron sus proyectos de nación a partir de una profunda hispanofobia. Para otorgarle un fuerte respaldo al castellano "correcto" y lo suficientemente puro, Costa Álvarez debe recurrir a los padres de la patria puesto que la definición de un idioma legítimo siempre se realiza en consonancia con los fundamentos de la nacionalidad. Ahora bien, si los padres de la patria parecen sostener tesis que resultan adversas al momento de argumentar a favor de un castellano castizo, medianamente libre de las variaciones locales, no queda otro camino que transformar las tesis antihispánicas para poder vincular "nuestra lengua" con los pilares de la nacionalidad. Vale decir, entonces, que el desafío consiste en transformar el rechazo hacia España que sienten nuestros próceres y aproximarlos al español peninsular. Se impuso, entonces, la tarea de una revisión del pasado nacional a los fines de contrarrestar los "males" que aquejan al presente. Y este paso lo inicia Costa Álvarez en Nuestra lengua. De este modo, se ocupa de revisar las ideas que en materia idiomática sostuvieron los principales intelectuales del siglo XIX: Esteban Echeverría, Juan Bautista Alberdi, Domingo Faustino Sarmiento y Juan María Gutiérrez. A modo de ejemplo, y dada la vastedad de los análisis que lleva a cabo Costa Álvarez en su libro, sólo sintetizaremos la operación argumentativa que realiza sobre los dos primeros. Acerca de Echeverría, Costa Álvarez sostiene que pese a su postura contraria al dogma colonial y a favor de una doctrina estética genuina, es decir, americanista, el autor de El matadero "no predicó ni practicó el antiespañolismo furioso, ni el americanismo frenético" (25). El objetivo principal de Costa Álvarez es desdibujar la imagen de un Echeverría hispanófobo que pueda venir en auxilio de un presente que reclama, para ciertos grupos, una revalorización del castellano. Según este autor, existe una confusión cuando se piensa en los posicionamientos estéticos e idiomáticos 
de Echeverría en la medida en que su desdén no se dirige hacia el castellano, sino hacia las letras españolas de su tiempo. Y encuentra las palabras de Echeverría que lo redimen: "el único legado que los americanos pueden aceptar y aceptan de buen grado de la España es el idioma" (26). Con respecto a la figura de Alberdi, es conocida la hispanofobia de sus años de juventud. El problema se encuentra en que "preconiza al francés como mejor lengua a causa de su biblioteca literaria y científica” (35). Costa Álvarez va a cuestionar la idea alberdiana acerca de que el francés, al ser vehículo de grandes ideas, va a dotar al español de una mejor expresividad. La argumentación de Costa Álvarez no consiste tanto en "desdecir" a Alberdi, es decir en mostrar la tergiversación de la que fue objeto, como ocurre con el caso de Echverría, sino más bien en notar lo equivocado que estaba Alberdi en su juventud. Por esta razón, la argumentación tendrá por objeto matizar las posturas del prócer, y adjudicar su radicalidad a la "irresponsabilidad" e "ignorancia" propias de la juventud, la cual tiene sus "arrebatos y extravíos", excesos que se deben reconocer más tarde, como lo hizo Alberdi, quien admitió lo "apasionado e irrazonable de su aversión juvenil al castellano" (37). La muerte temprana de Echeverría impidió afirmaciones similares, y no hubo más remedio que sostener las tesis del extravío interpretativo. Las palabras del viejo Alberdi a favor del castellano serán también utilizadas por Arturo Capdevila en su libro Babel y el castellano (1928).

Al final de su análisis, Costa Álvarez hace coincidir los posicionamientos lingüísticos de Echeverría, Alberdi, Sarmiento y Gutiérrez de la siguiente manera: "los cuatro proclamaron en definitiva que nuestro idioma es el castellano, al que debemos limpiar de las impurezas con que lo afean en la lengua vulgar la inmigración cosmopolita, y en la lengua culta la lectura continua de libros extranjeros" (71). La conclusión, si bien está referida al contexto del siglo XIX, cobra una deliberada vigencia en los primeros años de la década del veinte, cuando se publica Nuestra lengua. La situación de fuerte contacto de lenguas explica la anacrónica y tendenciosa reflexión final a la que arriba Costa Álvarez: Echeverría muere en 1851, cuando todavía no había siquiera caído el rosismo. Resulta, por lo tanto, anacrónico decir que el autor de "El matadero" se propuso, junto con sus pares de generación, eliminar las impurezas que la inmigración cosmopolita iba depositando sobre la lengua, cuando todavía restaban varios años para que se pongan en marcha las políticas de promoción de la inmigración. A su vez, Costa Álvarez olvida o minimiza posicionamientos hispanófobos ostensibles que estos intelectuales tuvieron en relación con los problemas de la lengua: por ejemplo, Gutiérrez, en 1875, rechaza el diploma de "académico correspondiente extranjero" de la Real Academia Española, fundando su decisión en que la pluralidad de lenguas que se oyen en Buenos Aires y el "idioma nacional" en que se escriben los periódicos, se dictan las 
leyes y se comunican los porteños son fenómenos opuestos al purismo idiomático que pretende instalar la Academia en suelo argentino. ${ }^{56}$

Ahora bien, ¿cuál es la evaluación del estado de la lengua a comienzos de los años veinte para Costa Álvarez? En primer lugar, va a dejar muy en claro que el idioma nacional es el castellano, "la lengua de los manifiestos, proclamas y decretos de nuestra emancipación, de nuestro himno nacional, de nuestra acta de independencia, de nuestras constituciones, leyes y códigos", y la de todos aquellos escritores, poetas y publicistas que "han cuidado la forma de expresión" (142). La lengua nacional es, entonces, aquella que se encuentra institucionalizada y vinculada con los orígenes de la Patria, es decir, la lengua "culta" que proviene del español heredado. Existe, en efecto, una heterogeneidad lingüística en la Buenos Aires de los años veinte, pero para el autor este no es un fenómeno extraño puesto que "en ninguna parte de la Tierra la lengua general de una nación se habla uniformemente en todos los puntos de su territorio" (142). Y agrega que en cualquier lugar del mundo esta distinción que señala basta para establecer cuál es el idioma nacional; en cambio, en Argentina, eso no es suficiente puesto que "los idiomólogos han atribuido demasiada importancia a lo regional y/o local" (143). Ahora bien, la injerencia de las formas locales en el idioma nacional resulta prácticamente nula para Costa Álvarez, puesto que los lenguajes populares se encuentran "confinados a un círculo estrecho" (147). Por este motivo, ninguna variedad popular "afecta el fondo de nuestro castellano" (148). La causa de la corrupción del idioma no se encuentra únicamente en la inmigración, sino en la insuficiencia del sistema educativo nacional, el cual experimentó un doble fracaso -el de la ley Gómez (1894 y 1896) ${ }^{57}$ - en cuanto a la implementación del uso obligatorio del castellano como instrumento de enseñanza en las escuelas (Capdevila).

A fines de la década, poco antes de morir, Costa Álvarez publica "Groussac y la lengua”, un artículo aparecido en la revista Nosotros. Allí recupera una figura como la de Paul Groussac, presencia central del campo literario que tuvo un importante desempeño en los debates sobre la lengua hacia fines del siglo XIX. Groussac funciona en el esquema de Costa Álvarez como una buena cita de autoridad para refrendar la inviabilidad de la creación de un idioma nacional que no fuese el castellano. Allá por 1891, nos cuenta Costa Álvarez,

\footnotetext{
${ }^{56}$ Ver "Juan María Gutiérrez: consecuencias de un gesto" (Ennis 2008: 143-157).

${ }^{57}$ En 1894, el diputado por la provincia de Salta, Indalecio Gómez, presentó un proyecto de ley sobre la exclusividad del idioma nacional en todo tipo de escuelas. Lo que motiva este proyecto es el temor que despiertan las escuelas extranjeras, que impartían clase en los idiomas correspondientes a cada colectividad. Esto fue visto como una tendencia, por parte de estas escuelas, hacia la autonomía y la segregación del conjunto de la nación. Según Gómez, este tipo de escuelas no hacía otra cosa que formar "niños extraños a nosotros", en la medida en que "no hablan ni quieren hablar nuestro idioma". No obstante, el proyecto no es tratado en 1894 y se lo vuelve a presentar en 1896. Pese a que esta vez el proyecto es ampliamente debatido en Diputados, no alcanza los votos necesarios para su aprobación (Bertoni 2007).
} 
Groussac ya se había encargado de conjurar la amenaza que suponía la campaña criollista "en su propósito de inducirnos a sustituir el castellano mundial por una jerga local" (1929: 118). En aquel momento, Groussac no hizo más que postular, ante el Ministerio Nacional de Instrucción, que "no hay más idioma nacional que el castellano" (118). Pero Costa Álvarez convoca a Groussac porque, además de defender el castellano, reivindica la tradición hispánica y la vincula con la cultura americana: "necesitamos desde luego estudiar la historia y la lengua españolas, si queremos conocer a medias las tradiciones americanas y los antecedentes argentinos" (119). ${ }^{58}$

Casi inmediatamente después de la aparición de Nuestra lengua, Ernesto Quesada publica La evolución del idioma nacional (1922), folleto que luego reproducirá la revista Nosotros a comienzos de 1923. De alguna manera, el texto se propone como un encomio del libro de Costa Álvarez, el cual "viene a historiar las luchas pasadas y a proclamar el triunfo final de la sana doctrina" (1923a: 13). Para Quesada, Nuestra lengua es el último y victorioso eslabón del largo debate sobre la lengua en Argentina: “en ese momento verdaderamente crítico $^{59}$ se produjo la reacción, en la forma historiada por Costa Álvarez, y en la cual me correspondió la parte modesta, reconocida por éste: la lucha vivísima duró un par de lustros, encauzándose después, hasta que hoy por completo ha terminado con el triunfo del buen sentido" (13, destacado nuestro). El problema del idioma nacional ha dejado de ser un problema y, siempre según Quesada, a comienzos de los años veinte la "tendencia deliberadamente corruptora del idioma" se ha disipado en pos de "mantener incólume la pureza de la lengua" (11). Lejos del diagnóstico que describe Quesada, el libro de Costa Álvarez más que una pieza final y victoriosa resulta, según la perspectiva que ofrece la década del veinte, el inicio de una nueva faceta de las querellas en torno al idioma y la lengua literaria.

Al igual que Costa Álvarez, Quesada reproduce los argumentos que marcan la diferencia entre el Alberdi joven e hispanófobo del Alberdi viejo que valora el castellano.

\footnotetext{
${ }^{58}$ A su modo, Groussac es un purista: en el filo del siglo, cuando asumen protagonismo los debates acerca del idioma nacional, tiene un postura clara: “no existe tal 'idioma argentino' en formación. No hubo nunca, ni podrá haber entre nosotros, escritores de valía actual o virtual que desconociesen las leyes del pensamiento, hasta el punto de profesar el solecismo, pretendiendo expresar mejor en jerga de barbarie sus ideas de civilización" (Costa Álvarez 1929: 119). Para Groussac, el "idioma nacional" es el castellano, pero resulta necesario cortar con el dominio idiomático ejercido por España. Del español peninsular sólo se debe mantener "la corrección gramatical, base y fundamento del estilo" (125). Es decir, se muestra purista en lo que respecta a las normas de la lengua, pero su purismo no tiene que ver con una lealtad desmedida hacia el español. El idioma que él valora como el más evolucionado estéticamente es el francés. Recupera el castellano como idioma nacional, pero un castellano libre del atraso que significa la tutela española. Esta concepción del idioma se traslada a su mirada sobre la lengua literaria, a la cual piensa como un instrumento llano, apegado a las normas y libre de la "contaminación" de las "jergas bárbaras". Estas ideas explican los términos en que Groussac leyó, por ejemplo, Don Segundo Sombra (Ver "Conversaciones del momento. Paul Groussac al caer la tarde" 1926).

${ }^{59}$ Se refiere al momento en que Abeille publica su libro Idioma nacional de los argentinos, y la consecuente reacción que se produce entre los sectores intelectuales más conservadores.
} 
Vale decir que duplica y consolida la estrategia que se despliega en Nuestra lengua, que consiste en entroncar las raíces patrias, definidas en su momento por sus protagonistas como antihispánica, con las fuentes del español peninsular. Para Quesada, la prédica contra la lengua española en la que incurrieron los románticos decimonónicos era un simple resabio del odio a lo godo. Y agrega: "ninguno de aquellos cultos argentinos -como lo demuestra acabadamente Costa Álvarez - en realidad soñó con la suplantación del castellano por un dialecto casi indígena" (8, destacado nuestro). Si bien es cierto que ningún miembro de la Generación del 37 postuló el reemplazo del castellano por otro idioma, también es verdad que los rupturistas tampoco bregaron por ese objetivo seriamente. En todo caso, se opusieron a la variedad culta de España y a los deseos de mantenerla "pura"; y propusieron una apertura idiomática que contemplara la inclusión de diversas voces populares y americanas en el seno del español. Pensaron, eso sí, que los cambios serían tan radicales que la lengua en el Río de la Plata - por aquí se circunscribía el radio de los debates- cambiaría de tal forma que apenas unos pocos elementos la mantendrían vinculada al castellano.

Sin lugar a dudas, durante la década del veinte, uno de los principales exponentes de la “tradición de la queja” y del purismo idiomático es Ricardo Monner Sans. Por aquellos años, publica dos libros cuya intención prescriptiva en relación con los usos de la lengua en Argentina y la lealtad hacia el español peninsular resultan por demás evidentes. Disparates usuales en la conversación diaria (1923) y Barbaridades que se nos escapan al hablar (1924), como ya se desprende de los títulos, ponen en primer plano las formas impropias de una oralidad que, evidentemente, se aleja del modelo idiomático español y que, por consiguiente, es preciso corregir. Según Monner Sans, la lengua sufre un proceso de creciente corrupción debido al avance de la cultura popular, la cual deber regirse por los usos cultos: la corrección en el habla "es el más alto exponente de la cultura de un pueblo" (1923: 95). Y, a su vez -y en esto coincide con Costa Álvarez-, responsabiliza al Ministerio de Instrucción Pública por no cumplir del todo con su misión central de garantizar que "no se bastardee el heredado lenguaje" (95, destacado nuestro). Para este autor, esa cultura popular, responsable de imponer sus usos lingüísticos tanto en el habla como en la literatura configura la expresión de los "'elementos extranjerizos" responsables de "afear la belleza del heredado lenguaje" (96). Inficionados en diversos discursos sociales de la época, las extendidas formas populares alertan a Monner Sans quien reclama de las autoridades que se "revisen" desde los textos escolares hasta los carteles que aparecen en la vía pública debido a que muchos de estos soportes se encuentran "redactados en una jerigonza incomprensible" (96). El libro siguiente se encuentra en la misma sintonía que el anterior, sólo que los "disparates", purgados de la 
comicidad que parecen sugerir, se han convertido ahora en cosa seria, invasiva, al trocarse en elementos propios de la "barbarie".

Mientras Costa Álvarez publica Nuestra lengua, algunos fragmentos de lo que luego se convertirá en Eurindia (1924) comienzan a aparecer, en forma de artículos, en el suplemento dominical de La Nación. En 1924, Ricardo Rojas, figura preponderante del nacionalismo cultural, finalmente publica su libro en España. Sus tesis son por demás interesantes en la medida en que parecerían ubicarse en una zona vecina a la de Abeille, puesto que postulan, en apariencia, una cultura nacional y propia no a partir del rechazo y la negación de diversas influencias, sino más bien todo lo contrario: la cultura argentina debía ser el producto de la asimilación de componentes tanto exóticos como autóctonos. Sin embargo, las ideas de Rojas, por más que insistan en la necesidad de asimilar las diversas formas culturales e idiomáticas europeas e indígenas, no pueden ocultar la lealtad que el autor sentía hacia España; cuestión que lo ubica, en el marco de estos debates, en una suerte de purismo relativo, abierto a los localismo y extranjerismos, pero siempre supeditados al dominio de España.

Con respecto a los problemas concretos del idioma, Rojas (1980) afirma que la aparente gran dificultad de nuestra literatura es que no se encuentra escrita en idioma argentino. De la misma manera, las bases de nuestra nacionalidad tampoco están escritas en ese idioma: tanto nuestra literatura como el Himno Nacional, la Constitución de 1853 y los diversos documentos que dan origen a nuestra nación se encuentran escritos en castellano, pero esto no significa que debemos negarle los caracteres nacionales a todas estas formulaciones discursivas puesto que resultan fundantes de nuestra identidad como Nación. En este sentido, coincide con Costa Álvarez quien para demostrar la vigencia del castellano en nuestra cultura apela a este mismo argumento que lo ubica en las bases y orígenes de la Patria. Tanto Rojas como Costa Álvarez llegan a la misma conclusión: el pueblo argentino "no necesita crearse una lengua nueva para manifestar su genio social" (Rojas 42). De este modo, Rojas refuta las tesis rupturistas y refuerza la importancia del castellano en la conformación de una identidad nacional "autóctona", porque el hecho de que en América se hable castellano no significa que por ese solo motivo seamos españoles y no americanos. De esta manera, concluye que nuestro idioma nacional es el castellano. No obstante, no es un purista intransigente. Pese a su argumentación inclusiva de otras formaciones culturales (cosmopolitismo, indianismo), perdura el gesto de lealtad hacia todo lo relacionado con 
España. ${ }^{60}$ Sin lugar a dudas, para este autor, las influencias del país ibérico sobre nuestra cultura fueron de suma importancia. ${ }^{61}$

Rojas reconoce que para la conformación de la nación, además de cultivar el desierto y fundar ciudades, se ha necesitado también "reducir al indígena y civilizarlo" (65). En este sentido, apoya y justifica la tarea llevada a cabo por los representantes del liberalismo de la segunda mitad del siglo XIX. Si bien reconoce y reivindica el componente indígena que subyace en nuestro idioma y en nuestra cultura, eso no significa que se deba poner esa influencia al mismo nivel que funcionan las otras, como por ejemplo la hispánica. Se puede afirmar, entonces, que los elementos constitutivos del esquema cultural denominado "Eurindia" no tienen todos el mismo peso y valor. Si bien Rojas habla de "lo europeo" como el otro brazo de esa síntesis cultural que propone, existe en su argumentación una clara diferenciación: por un lado, se encuentra lo español, que no se define necesariamente como un elemento extranjero y no conlleva casi ningún tipo de valoración negativa; y por el otro, se encuentra lo europeo (inmigración francesa, inglesa, alemana, eslava, judía, etc.) en el sentido de lo foráneo, cuyos elementos "disgregadores" ponen a prueba la identidad nacional. Esta segunda acepción se compone de la llamada "inmigración cosmopolita” a la cual Rojas evalúa de una manera ambigua, puesto que si por un lado contribuye a la caracterización de nuestra raza, por el otro es la responsable directa de la corrupción idiomática que experimenta Buenos Aires durante el primer cuarto del siglo XX. ${ }^{62}$

En la introducción a su Historia de la literatura argentina (1917), Rojas (1948) advierte sobre el problema del idioma en el país y las implicancias que esto tiene sobre nuestra literatura. Para este autor existe una "conciencia declinante" de la lengua castellana en el Río de la Plata. Esto sucede porque la historia breve de Argentina no ha dado tiempo para que nuestras tradiciones e idioma se sedimenten en un todo orgánico, como sí sucedió en Europa. Si, como afirma Rojas, el suelo, la raza, el idioma y la literatura se funden en una sola unidad, en Argentina esa unidad es puesta en duda a partir del intenso cosmopolitismo que supuso la inmigración: muchos escritores argentinos, por "cuestiones de ambiente", escriben

\footnotetext{
${ }^{60}$ Para escritores como Ricardo Rojas, Manuel Gálvez, Emilio Becher, Manuel Ugarte, entre otros, el hispanismo resultó fundamental en la formulación de cierto nacionalismo cultural. Ver Payá-Cárdenas (1978).

${ }^{61}$ Para Rojas, a tal punto es determinante el influjo español en la formación cultural de nuestra región que, sostiene, “en América se desarrolló una España genuina” (1980: 32). Para este autor, la historia de la civilización en América no reenvía al conocimiento de las culturas precolombinas, como así tampoco a la injerencia que tuvieron los países centrales de Europa, sino "al conocimiento de la civilización española” (33).

62 “...mientras, el idioma nacional se corrompe en el conventillo, en el salón y en el teatro, mostrándose como nuevo signo de bastardía. En las clases obreras ha penetrado el socialismo, que no tiene patria, y en las clases adineradas el 'snobismo', que tampoco la tiene. Todo es en Buenos Aires exótico" (Rojas 1980: 88). Toscano y García (2009) señala que Rojas observa un "peligro" en la dialectalización del español, producto del intenso contacto de lenguas, y asigna al Instituto de Filología una función de control y regulación del uso de la lengua.
} 
en otras lenguas, como el francés, lo que supone el planteo de una serie de interrogantes no menores:

\begin{abstract}
¿Pues, cuál es el criterio con que un historiador de la literatura argentina debería considerar esos libros, ${ }^{63}$ argentinos por su asunto o por sus autores, y extranjeros por la lengua en que fueron escritos? ¿Qué causas de educación o de ambiente les movieron a abandonar el idioma nativo? ¿Hasta dónde el idioma de la nación define la argentinidad de su literatura, y hasta dónde se la define por la cuna de sus autores o la índole de sus obras? (Rojas 32).
\end{abstract}

En 1926, un argentino nacido en Rosario, de padre alemán, llamado Rudolf Grossmann publica un libro que se propone, en cierta medida, como una refutación al Idioma nacional de los argentinos de Lucien Abeille: El patrimonio lingüístico extranjero en el español del Río de la Plata. Con su libro, tiene el propósito de brindar su dictamen en relación con las querellas acerca de la lengua. Sin embargo, su intervención en estos debates es muy relativa puesto que el texto en sí tuvo muy escasa circulación: fue publicado en lengua alemana y en el extranjero (Alemania, Hamburgo) y recién fue traducido al español en el año 2008 (Biblioteca Nacional). Quien insertó el texto de Grossmann en el ambiente, y de manera bastante indirecta, fue Costa Álvarez (1928a, 1928b).

Si Abeille propone la emergencia de una lengua de los argentinos, gracias al paulatino alejamiento del español castizo debido a las múltiples influencias idiomáticas que provienen del extranjero y de las culturas autóctonas, Grossmann viene a demostrar la tesis opuesta: para este autor, pese al caótico panorama de la lengua en la cosmopolita Buenos Aires de los años veinte, no existe nada que pueda poner en peligro la unidad del castellano usual de la Argentina. Esta obra puede ser leída como el alegato al Idioma nacional de los argentinos: se puede entender como el libro que se le opuso en su mismo campo, el empírico, y dentro de un mismo marco, el de la lingüística de principios de siglo XX (Alfón 2008a, Ennis 2008). Como bien lo explicita Grossmann, el profesor francés procuró darle una base científica al tópico de la lengua nacional argentina y se vio en la necesidad de "pronosticar su futuro desarrollo sobre la base de los idiomas aborígenes" (Grossmann 2008: 71). Sin embargo, para Grossmann, el trabajo de Abeille resulta "pseudocientífico" y sus postulados, lejos de referirse a un nuevo idioma, no hacen otra cosa que elevar a la condición de idioma nacional "el patrimonio dialectal del español antiguo o meras faltas gramaticales" (71).

\footnotetext{
${ }^{63}$ Se refiere a algunas obras argentinas escritas en francés: Les races aryennes du Pérou (1871) de Vicente Fidel López, Les origines argentines (1881) de Roberto Levillier y Simplement ... (1911) de Delfina Bunge de Gálvez (Rojas 1948: 32).
} 
El contacto de lenguas que tiene lugar en la Buenos Aires cosmopolita de los años veinte propició el desarrollo de lo que Grossmann denomina "lenguas mixtas argentinoeuropeas". Se diferencian de los dialectos, principalmente, en que las "lenguas mixtas" no son constantes desde el punto de vista gramatical. Además, resulta imposible establecer un vocabulario unificado, principios fonéticos precisos y una morfología firmemente trazada, sostiene. Esto se debe a que este tipo de lenguas nunca son populares o nacionales, sino individuales por lo que su variabilidad hace que resulten sumamente inestables y mudables. Según Grossmann, las lenguas mixtas no son otra cosa que lenguas auxiliares, es decir que se ubican de manera paralela y supeditada a la lengua principal por lo que no influyen de ninguna manera sobre el español. Y agrega que tampoco deberían influir en la literatura "puesto que ningún escritor serio estaría dispuesto a integrarlas [a las lenguas mixtas] a sus obras” (268). Grossmann señala que muchos se vieron tentados en pensar estas lenguas mixtas como el germen de un nuevo idioma nacional argentino; pero el autor niega esa posibilidad argumentando que su "inconsistencia gramatical" las condena a la "extinción" (284).

En mayo de 1928, Arturo Costa Álvarez publica en la revista Valoraciones una de las pocas reseñas que recibe en Argentina El patrimonio... Allí señala que la influencia de la inmigración sobre la lengua -principal preocupación para Grossmann y para muchos otros "guardianes" del castellano- fue utilizada tanto por los "conservadores" como por los "revolucionarios" para demostrar "ora una degeneración en dialectismo que se debía contener, ora una evolución hacia un idioma propio que se debía estimular” (1928a: 241).

Uno de los libros que mejor expresa el purismo idiomático es el que Arturo Capdevila publica en 1928: Babel y el castellano. Ya desde su dedicatoria se puede apreciar la importancia que tendrá España y su cultura en la argumentación a favor de un castellano puro, sin las máculas que el pasado hispanófobo y el presente cosmopolita pretenden impregnar sobre la superficie del español. Capdevila dedicará el libro al "señor del castellano", Enrique Larreta, escritor argentino, ferviente admirador de España. Luego la dedicatoria se ocupa de vincular la idea de lo nacional con lo español, un esquema argumentativo que se repetirá varias veces a lo largo de la obra. ${ }^{64}$ Para Capdevila, España conserva, en relación con la Argentina, una tutela cultural e idiomática que la historia no pudo destruir, pese a los intentos de los liberales decimonónicos y de la tradición hispanófoba que fundan. Argentinos y españoles no sólo pertenecen a "una misma raza”, sino que además ambos son "ciudadanos

\footnotetext{
64 "Un orgullo ha dictado este libro argentino: el hablar castellano. Y una cosa querría patrióticamente el autor: comunicar este orgullo a toda la gente que lo habla." (Capdevila 1954: 10, destacado nuestro).
} 
de una misma nación, miembros de una sola y única familia" (11). La idea de una misma raza, pero sobre todo la de una nación compartida con los españoles, implica no sólo la relativización del pasado independentista argentino sino también la de un gran número de ciudadanos descendientes de las culturas autóctonas y de la inmigración no española. Según Capdevila, Argentina viene a ser una suerte de apéndice de España. Ambas naciones parecen compartir un mismo medio - cultural e idiomático- al punto tal de que si se viaja hacia la antigua metrópoli lo más probable es que uno se sienta "como si no hubiésemos salido de la patria; pues que aún hablábamos y nos hablaban en el mismo nativo idioma” (16).

En el nacionalismo hispanófilo (Cárdenas-Payá 1978, Devoto 2002) -del que participan la raza, la nacionalidad y la idea de familia común- la noción de una espiritualidad compartida termina por cerrar el estrecho vínculo que liga la cultura argentina con la española: "esa gigantesca extensión de que es capaz el espíritu" es la responsable de cimentar "esta confraternidad sin fronteras" que une a ambos países (16). Sin embargo, Capdevila llama la atención sobre el hecho de que "no siempre ha sido este que yo enuncio el sentimiento argentino", puesto que "la independencia debió dejar, y dejó, un sedimento de enconos" (16). Y recomienda que, en este terreno, a nuestra cultura le hace falta "mucho olvido" para poder "apaciguar" y revertir ese rencor que el padre supo legar en el hijo (16). La hispanofobia de la Generación del 37, continúa, ha sido la principal responsable de estos enconos hereditarios, particularmente las figuras de Alberdi, Sarmiento y Gutiérrez. La idea de una lengua propia nace con estos intelectuales, sin embargo, al igual que Costa Álvarez, Capdevila afirma que todas las ideas que postulan la emancipación o modificación idiomática se ubican en los discursos de juventud de estos intelectuales. Los rasgos particulares del español rioplatense son negados, o bien condenadas, por Capdevila. De este modo, por ejemplo, afirma que el voseo no es más que un "sucio mal” del que están "enfermos" los argentinos (64). En cuanto a los argentinismos, afirma que resultan "falsos" puesto que no provienen de ninguna cantera propia y original sino de la Península (84). Así concluye que el pueblo argentino ha creado poquísimas palabras y deja entrever que el grueso de nuestra lengua es enteramente heredada. Estas apreciaciones no son más que la antesala de la negación de todas aquellas tesis rupturistas que tienen un importante auge durante la década del veinte. Para Capdevila, el padre de la "peregrina" idea de una lengua propia no es otro que Lucien Abeille. De hecho, llama "abeillistas" a los rupturistas de aquellos años. Con respecto al autor del Idioma nacional de los argentinos, se pregunta si su tesis acerca de una lengua propia no responde a un intento de justificar "no sé qué desviaciones fonéticas en que él [Abeille] veía ya una lengua nueva" (27). Contrariamente a lo que pensaba el profesor 
francés, "una nueva patria no implica necesariamente una nueva lengua". De esa idea proviene "la ilusión de ambicionar una privativa lengua para la patria" (28).

\section{Gramática, ortografía y corrección en los debates sobre el idioma}

En un contexto de fuertes debates sobre el idioma, "los conservadores de la cultura", hispanófilos, se ocupan de reforzar las barreras que protegen al castellano de todas aquellas formas "espurias" del habla traídas principalmente por la inmigración. La proliferación de libros y artículos destinados a reforzar la supremacía del castellano sobre cualquier otra forma idiomática y a remarcar la vigencia de una herencia cultural, la española, por sobre la que pudiera otorgar la inmigración cosmopolita es una de las manifestaciones del purismo de los guardianes de la cultura. Pero también existieron otras estrategias para refrenar el avance de ese cosmopolitismo: desde fines del siglo XIX, se colocó en la escuela la función primordial de homogeneizar una población cultural e idiomáticamente heterogénea. Algunos, como Costa Álvarez o Quesada, proclamaron la victoria de las tendencias castizas gracias al rol llevado a cabo por el sistema educativo. Sin embargo, ahora quisiéramos referirnos a otra de las estrategias del purismo, muy vinculada con la escuela: el énfasis puesto en la corrección idiomática $\mathrm{y}$, sobre todo, en la gramática.

En el terreno literario, el casticismo realiza un importante recorte que deja fuera de la noción de literatura a casi todas las obras de cuño popular y moderno. Para los puristas, el lenguaje literario se considera un modelo idiomático $\mathrm{y}$, en consecuencia, toda aquella literatura que incorpora elementos locales, populares y extranjeros es rechazada. Esto explica por qué los problemas en torno al idioma se articulan con los de la lengua literaria y se retroalimentan de manera continua. Un buen ejemplo de la concepción de la literatura como modelo idiomático es el que brinda Ángel Acuña, ${ }^{65}$ en un pasaje de su libro Ensayos, publicado en 1932. Allí hay un capítulo titulado "Los factores de evolución de los idiomas", en el que señala que "no se puede negar que la lengua literaria fija y organiza, dando formas definitivas al idioma" (1932a: 44). Desestima el lenguaje popular al asegurar que en él "hay diversidad de normas en pugna, lo que imposibilita la estabilización de su estructura”. El lenguaje literario viene en auxilio de esta situación y determina el predominio de "la norma más apta”, dando unidad y sistematización (44). Desde la perspectiva de Acuña, los registros

\footnotetext{
${ }^{65}$ Ángel Acuña nació en la provincia de Corrientes, el 17 de abril de 1882. Estudió derecho en la Universidad de Buenos Aires. Fue senador por su provincia entre los años 1919-1921. En 1930, alcanza la presidencia del Consejo Nacional de Educación. Su tarea intelectual estuvo abocada a los estudios vinculados con la educación. Entre sus obras se destacan: Ensayos (3 series, 1926-1931), La disciplina escolar (1938), El analfabetismo y la función del Consejo Nacional de Educación (1939), La escuela en el régimen de la instrucción pública argentina (1939), Origen y evolución de las instituciones educativas (1939). (Santillán 1956).
} 
populares no pueden servir como materia literaria en la medida en que al ser plurales e inestables atentan contra la fijación del idioma, pero sobre todo contra las leyes que regulan la lengua "legítima". En este sentido, la gramática cobra un notable protagonismo para estos sectores en la medida en que constituye el compendio legislativo encargado de normalizar no sólo la lengua frente al avance del "babelismo", sino también el discurso literario de los escritores modernos que se proponen fundar una lengua literaria con un mayor grado de autonomía y de especificidad literaria (Rogers 2011a). En enero de 1930, Roberto Arlt realiza una de las impugnaciones más famosas a la gramática y los gramáticos cuando publica su aguafuerte "El idioma de los argentinos". Allí refuta unos dichos de José María Monner Sans, quien había sostenido, en El Mercurio de Chile, que ya nadie defendía la gramática y la Academia, aunque la tarea "depuradora" de los intelectuales argentinos ponía coto a la "amenaza" del lunfardo. ${ }^{66}$

Algunos escritores e intelectuales afines a las propuestas rupturistas del idioma marcan su posición a través de la violación de ciertas normas, la común de ellas es la ortográfica. En la revista Caras y Caretas, el reconocido crítico español José Gabriel, ${ }^{67}$ en 1927, escribe un artículo que pone de manifiesto el malestar ante la anomia que existe en las letras argentinas al respecto. Según José Gabriel, la complejidad ortográfica es la responsable de que se hayan originado las propuestas de reformar la ortografía; propuestas que hunden sus raíces en el siglo XIX, a partir de las tentativas de Sarmiento, y que se manifiestan en plena década del veinte. Por ejemplo, José Gabriel menciona un "reciente libro anónimo", titulado Ortografía racional, cuya propuesta hace que "todos los proyectos [previos] de reforma se queden cortos en comparación" (1927: 26).

La defensa que hace José Gabriel de la ortografía entra en colisión con las propuestas de algunos intelectuales como Vicente Rossi, quienes no sólo proponen sino que escriben de acuerdo con una reforma tendiente a simplificar la correspondencia entre los sonidos y los grafemas. En este marco, la publicación en 1927 de los ensayos que Sarmiento escribe en Chile en la década de 1840, que tratan precisamente sobre sus proyectos de reforma ortográfica, entre otros aspectos, no resulta casual ni inocente, sino que constituye una pieza más del mosaico de disputas sobre el idioma y la lengua literaria. La editorial Gleizer publica Sarmiento en el destierro (1927), cuyo prólogo, notas y edición están a cargo del ensayista, periodista y crítico chileno Armando Donoso. La reedición de estos textos de Sarmiento

\footnotetext{
${ }^{66}$ Ver el capítulo V, dedicado a Roberto Arlt.

${ }^{67}$ José Gabriel es el seudónimo de José Gabriel López Buisán. Nacido en España en 1896, vino a la Argentina en 1905. Tuvo una intensa participación en los medios gráficos argentinos: en los años veinte, se desempeñó en el periódico La Patria de Miguel Ugarte; en La Prensa y en la revista Caras y Caretas, entre otras publicaciones. Muere en 1957, en Buenos Aires.
} 
actualiza las disputas vigentes sobre el idioma en la década del veinte y, por lo tanto, resultan de gran interés y actualidad para los nuevos escritores (Rogers 2011a), los cuales perciben los problemas de la lengua como inherentes a su praxis literaria, dado que en ellos se dirime no sólo la legitimidad de determinadas escrituras, sino también diversos espacios dentro del campo literario. En la década del veinte, la figura de Sarmiento había sido revisitada en más de una oportunidad por los protagonistas de los debates en torno al lenguaje. Recordemos que, como hemos visto, Costa Álvarez en Nuestra lengua, como así también Ernesto Quesada en La evolución del idioma, repasan las tesis no sólo de Sarmiento sino de otros exponentes de la Generación del 37 que explicitaron políticas y proyectos lingüísticos. El prólogo de Donoso constituye un fuerte posicionamiento contra el purismo idiomático de los casticistas. La intencionalidad principal de Donoso es caracterizar a Sarmiento como un americanista; y eso lo consigue haciendo una semblanza del autor del Facundo desde una perspectiva con la cual, seguramente, Sarmiento no hubiese estado de acuerdo: Donoso invierte la polaridad de la dicotomía "civilización-barbarie" y define a Sarmiento desde lo que él entendía como la barbarie: lo caracteriza como un "gaucho" al que se debe vindicar por ser "el menos europeizado de los americanos" (1927: 8). Según el compilador, Sarmiento es "la expresión de la pampa libre y de la América bárbara, de esta América que es la más nuestra" (8). Frente a lo europeo, la barbarie cobra un renovado sentido positivo porque comprende el dominio que Donoso intenta ponderar: América. Si observamos bien, nos damos cuenta de que la operación de Donoso no es muy diferente a la llevada a cabo por Costa Álvarez, quien mediante un minucioso aparato argumentativo procura diluir la hispanofobia del prócer. Lo que cambia es el signo de la operación ya que Donoso intenta llevar la figura de Sarmiento hacia el extremo opuesto, y eso implica convertir todos aquellos elementos denostados por el propio Sarmiento en valores. De esta manera, si Sarmiento era un representante de la ciudad y la "civilización", en el prólogo de Donoso pasa a serlo "de la Pampa en toda su audacia acaudilladora. Era el gaucho que sabía dormir con un ojo abierto, portando en la vaina de la espada la pluma audaz" (9).

Para Donoso, las ideas de Sarmiento con respecto a la lengua eran bien claras:

observó que son los pueblos y no los tratadistas o los escritores quienes dan vida a las lenguas; señaló que la única función de los gramáticos y de las academias es codificar en sus diccionarios las nuevas voces y modismos que el pueblo sanciona, y afirmó que la ortografía debe corresponder a la pronunciación antes que a su etimología (17). 
Vale decir que Donoso muestra a Sarmiento como un rupturista -cosa que el propio Sarmiento plantea explícitamente- que pone en cuestión el dominio y la injerencia de la Real Academia en América, además de relativizar el poder de las gramáticas y diccionarios en lo que respecta a los usos de la lengua, asignando al pueblo, en este sentido, un valor y un poder que los puristas reducían a meras influencias perniciosas y corruptas sobre la lengua. Según Sarmiento, el castellano se encuentra en una fase de "anquilosamiento" que impacta "negativamente sobre la literatura". Esto se debe al "influjo de los gramáticos, el respeto a los admirables modelos [y al] temor a infringir las reglas" (17). Estas ideas no pueden ser más actuales ni más funcionales en un contexto en donde la discusión sobre la lengua posee renovada vigencia, en donde los gramáticos y el aparato preceptivo que desciende desde las instituciones españolas constituyen uno de los frentes de lucha de los rupturistas. Donoso retoma lo que Costa Álvarez pretendía dejar en el olvido, es decir, la prédica de Sarmiento contra el purismo. ${ }^{68}$

La propuesta de Sarmiento resulta afín a la que tienen algunos escritores modernos en los años veinte: "fundemos nuestra literatura naciente en la independencia" (20). La idea de que debe prevalecer la expresión, es decir el contenido del mensaje, por sobre su forma reglada o normada se convierte, en algunos escritores vanguardistas, en el precepto-guía de sus poéticas. Por ejemplo, Nicolás Olivari afirma que "el nuevo poema" va a surgir no sólo al margen de la corrección, sino en contra de ella. ${ }^{69}$ Sarmiento hacía declaraciones no muy diferentes a las de Olivari: “... escribid con amor (...) lo que se os antoje, que eso será bueno en el fondo, aunque la forma sea incorrecta, será apasionado aunque a veces sea inexacto; agradará al lector, aunque rabie Garcilaso” (Donoso 17-18).

Finalmente, cabe destacar que Sarmiento en el destierro está dedicado a Ricardo Rojas. La propuesta americanista que Donoso postula a través de los textos de Sarmiento parece encontrar en Rojas una suerte de aliado en el sentido en que, como hemos visto, el autor de La restauración nacionalista ya había formulado, en 1924, su tesis sobre Eurindia, que reservaba en el terreno de la lengua un lugar destacado a los aportes de las culturas autóctonas, ${ }^{70}$ a las cuales Donoso juzga como otro de los componentes de su americanismo. De hecho, en esa especie de "barbarie para la civilización" que diseña y con la cual

\footnotetext{
${ }^{68}$ Cabe aclarar que Costa Álvarez no niega la prédica hispanófoba de Sarmiento. Reconoce sus ataques contra los retóricos y puristas (1922: 46), las pretensiones de supresión total de las reglas gramaticales (46) y el rechazo hacia el estilo correcto y castizo en la literatura (46). Sin embargo, al igual que sucede en el caso de Alberdi, Costa Álvarez va a centrar su atención en las opiniones que Sarmiento desarrolla con posterioridad a 1853, cuando la "hostilidad" y "ojeriza" que muestra en 1842 desaparecen a punto tal de afirmar que "el español será la clave de la América del Sur (51).

${ }^{69}$ Ver el capítulo IV, dedicado a Nicolás Olivari.

${ }^{70}$ Cabe aclarar que estas ideas, si bien encuentran su desarrollo en Eurindia (1924), Rojas ya las había expuesto en 1917, cuando publica el primer tomo de la Historia de la literatura argentina (1917-1922).
} 
caracteriza a la figura de Sarmiento, el componente indígena no está excluido: "su ascendiente indígena parece rezumar en sus polémicas de gaucho bravío, que son como el necesario antecedente de su Facundo" (45-46).

Pero la prédica a favor de la gramática y la corrección es incesante durante estos años por parte de los puristas. En 1925 se reedita la Guía del buen decir, de Juan B. Selva, ${ }^{71}$ libro que había sido publicado originalmente en 1915. Para Selva el modelo del buen decir está dado por la literatura y por la gramática. ${ }^{72}$ El objetivo de Selva con este texto es el mismo que persiguen otros gramáticos, dando forma a lo que ya hemos mencionado como la tradición de la queja ${ }^{73}$ es decir, ponderar la gramática y la corrección idiomática, realizar un diagnóstico negativo del modo en que se habla y escribe en Buenos Aires, y prescribir medidas tendientes a revertir tal situación: “... cunde también de frondosa y lujuriante la cizaña, abundan los errores de toda laya, barbarismos vergonzoso y garrafales solecismos, y no es propio que en el siglo de la electricidad y de las luces sea siglo de descuido y errores para cuanto atañe al decir" (1925: VI). Con respecto a la literatura, sostiene que esta debe estar sustentada por un discurso correcto desde el punto de vista gramatical, además de ceñirse al uso estricto del castellano, evitando cualquier tipo de "contaminación": "la corrección gramatical ha de primar siempre; sin ella no hay elegancia posible ni literatura que valga dos cominos" (VIII). Naturalmente, todas estas manifestaciones a favor de la gramática y del respeto a la normativa no son sino más que la otra cara de la moneda de las propuestas acerca de la lengua propia. Es por eso que, sobre el final, Selva niega su existencia al afirmar que "no hay idioma argentino", como tampoco mexicano o español: "sólo hay idioma castellano" (XIII).

\footnotetext{
${ }^{71}$ Juan Bautista Selva fue un gramático y docente argentino. Nació en la ciudad de Dolores el 16 de febrero de 1874 en el hogar de don Juan Bautista Selva y doña Juana Concepción Rodríguez. Se recibió de maestro normal en 1891. Fue director de la Escuela Nro. 1 de Lomas de Zamora hasta el año 1893 en que se radicó definitivamente en su ciudad natal para consagrarse a la docencia. Fue secretario, profesor, vicerrector y director de la Escuela Normal de Dolores; Presidente del Consejo Escolar y miembro de diversas instituciones culturales de Dolores. Fue miembro de la Academia Argentina de Letras y de la Real Academia Española; Miembro Honorario de la Academia Hombres de Letras del Uruguay, y de la Academia de Letras de Chile, de la Academia Cultural Interamericana y de varias academias de letras extranjeras. Su obra fecunda consiste principalmente en estudios sobre gramática, ortografía y literatura. Falleció en Dolores el 29 de julio de 1962. Una escuela del distrito la $\mathrm{N}^{\circ} 16$ ubicada en Lomas de Roldán, como así otra de la ciudad de Mar del Plata, llevan su nombre (Selva 1967).

72 "Navegue en buena hora por el mar de las letras primorosas quien quiera remozar su estilo, dar pulidez y brillo a su decir; mas mírese bien que para alcanzar verdadera propiedad y corrección, y aun elegancia, resultará siempre muy eficaz, si no indispensable, la acción del gramático, que está llamado a señalar los más seguros derroteros, que advierte los escollos, que sirve de faro" (Selva 1925: V).

${ }^{73}$ Ya se trate de la gramática española o bien americana, lo cierto es que desde los sectores más conservadores del campo letrado se insiste en lo mal que se habla y se escribe en el país. Detrás de esa queja se esconde el desprecio hacia los sectores populares; hacia la inmigración cosmopolita; hacia cualquier tentativa de postular una lengua nacional fuera de las lindes del castellano; y hacia las nuevas concepciones de la literatura, tendientes a autonomizar al lenguaje literario de la norma gramatical. En síntesis, se oponen a la autonomía creativa tanto del pueblo como de los escritores.
} 
En un artículo publicado en la revista Nosotros, titulado "La gramática rediviva y el nuevo diccionario”, Ricardo Monner Sans afirma que si hay alguna nación de Sudamérica que necesita una férula gramatical es la Argentina debido a "la irrupción de gentes venidas de otras tierras ignorantes del Castellano", quienes ejercen una fuerza "persistente" y "corrosiva" sobre "la belleza de nuestra habla" (1926: 50). Los casticistas invocan la gramática como un antídoto frente a una anomia idiomática cada vez más extendida. Naturalmente que el discurso literario vio en las plasticidades lingüísticas que deparaba el contacto de lenguas la mejor alternativa para conseguir una lengua literaria autónoma y creativa, pero por sobre todas las cosas libre de los preceptos emanados de una autoridad -España- que ya había sido puesta en cuestión tiempo atrás. En un artículo publicado en La Nación, en 1929, Leopoldo Lugones lamenta la "incultura" que existe entre "decenas de autores, llamémoslos así, desprovistos no sólo de mediana instrucción, sino de la gramática más elemental indispensable para escribir una carta" (1929: 3). Sin lugar a dudas, Lugones piensa en aquellos escritores que escriben, casi siempre deliberadamente, contra la gramática y los "buenos" usos del lenguaje. Concluye diciendo que muchos autores definen a la gramática como "un reglamento inútil, por supuesto que a rigurosa condición de ignorar lo que se desprecia" (3). La gramática vendría ser inherente a la lengua literaria puesto que sin ella "no se puede escribir" (3).

Selva, Monner Sans, Lugones, Capdevila y todos aquellos "guardianes del buen decir" que veían en la gramática una preceptiva formal insoslayable con la cual se debía elaborar la lengua literaria, concebían una relación no problemática entre el escritor ideal y el gramático. Para estos autores, la literatura se pensaba como un modelo de lengua en donde se combinan armoniosamente ambas autoridades, la del gramático y la del escritor.

Como hemos explicitado en la introducción de este capítulo, el propósito de estas páginas ha sido el de reponer el mapa documental que trace las diversas líneas discursivas que instalaron y dieron forma a la cuestión del idioma y de los problemas de la lengua literaria, en las primeras décadas del siglo XX. Este recorrido también tiene por objeto posibilitar el abordaje, de manera contextualizada, de zonas específicas del campo literario a los fines de poder analizar el fenómeno que nos ocupa: la reconfiguración de la lengua literaria en los años veinte.

Nos hemos circunscripto a un ámbito -el del ensayo- que no es el específico de este trabajo - referido a la literatura-, pero que sin embargo lo contempla de manera directa dada la relación que existe entre las discusiones en torno al idioma y las condiciones de 
transformación de la lengua literaria en estos años. Como hemos dicho, nuestro objetivo es ver de qué manera estas discusiones acerca de la lengua dialogan con el discurso literario y con las relaciones que se establecen en el seno del espacio literario. La cartografía documental que hemos presentado demuestra que los debates en torno al idioma, lejos de aquietarse, cobran un renovado vigor durante los años veinte.

Uno de los ejes de nuestra tesis señala que los debates sobre la lengua no son para nada ajenas al discurso literario en la medida en que siempre se encuentra, de alguna manera, implicado y/o aludido. En este primer capítulo nos hemos ocupado de señalar cuál es el contexto discursivo en el cual los escritores del período publican sus obras y entran en la dinámica que propone el campo letrado. La literatura que se produce en aquellos años y su recepción se encuentran implicadas por las querellas en torno al idioma. Consideramos la literatura del período como una parte constitutiva de los problemas en torno al idioma; sin embargo, nuestro foco estará centrado en la manera en que el discurso literario, al mismo tiempo que alimenta un debate que lo excede, reconfigura las pautas estéticas e idiomáticas que le dan forma. En el centro de ese fenómeno se ubica el proceso de autonomización y especificidad relativas al lenguaje literario.

En los años veinte, el tópico del "idioma propio" se apoya sobre la plataforma construida por las polémicas de comienzos de siglo: Lucien Abeille, Vicente Rossi y Ramón Carriegos, por ejemplo, se ocupan de esta temática en la primera y segunda década del siglo. Si bien esta problemática representa una continuidad en la década de 1920, el auge del periodismo popular y de una literatura asociada a este periodismo y a la representación de los arrabales y los conventillos con la correspondiente recreación de sus modos particulares de habla, convierten al período en un momento de intenso debate en relación con la tesis de un idioma de los argentinos. Como hemos visto, las intervenciones de aquellos intelectuales afines al conservadurismo idiomático se centraron en desmontar el aparato argumentativo elaborado por los rupturistas que señalaba la emergencia, en el Río de la Plata, de un "idioma propio".

Para los puristas, la lengua legítima se definía en relación con las normas emanadas de España y con sus criterios de corrección y “buen decir”. Estos mismos parámetros son los que ponen en funcionamiento las élites intelectuales para legitimar o rechazar las diversas formas y géneros literarios. En este sentido, todos aquellos lenguajes identificados con lo popular se adscriben a categorías vinculadas con lo incorrecto, inculto y/o exótico.

Por último, una de las modalidades importantes que asumen los debates en torno a la lengua consiste en revisitar el pasado con el objetivo de recuperar figuras históricas que sirvan de cita de autoridad para los argumentos que se esgrimen en los años veinte. Esto sucede tanto 
del lado de los conservadores -Costa Álvarez o Quesada, por ejemplo-, como así también del de los rupturistas, como Armando Donoso.

A continuación, desarrollaremos los modos en que se manifestaron estas discusiones dentro del dominio estrictamente literario. Para ello no sólo se analizarán las obras en las que mejor se aprecien estos debates, sino también haremos hincapié en su recepción -a través de diversas fuentes documentales como reseñas, comentarios y artículos-dado que es allí en donde mejor aparecen las valoraciones y disputas referidas al lenguaje literario. 


\section{CAPÍTULO II}

\section{La lengua literaria y los escritores de izquierda: Elías Castelnuovo, César Tiempo y Álvaro Yunque}

\section{Escritores de izquierda y martinfierrismo: lenguajes y vanguardismos en los años veinte}

En referencia al panorama literario de los años veinte, durante mucho tiempo existieron presupuestos instalados que polarizaron un segmento del campo letrado en dos grupos antagónicos - Boedo y Florida-, lo cual dificultó la posibilidad de visualizar otros agentes intervinientes en este contexto de producción, además de vincular a los escritores con uno u otro de esos grupos. Además se instaló la idea de que las diferencias entre ambos sectores eran ideológicas, que se manifestaban en el terreno de la escritura, y que una de ellas -la de Florida- era preferible a la otra.

De este modo, desde el martinfierrismo, se pensó la escritura de Boedo como carente no sólo de aciertos literarios sino de las pautas de corrección gramatical y ortográfica, como una escritura "plebeya" y enrevesada de italianismos que "contaminan" la "pureza" del idioma. Por ejemplo, en una reseña que publica Martín Fierro sobre el libro de cuentos La levita gris (1924), de Samuel Glusberg, se señala :

\footnotetext{
El judío es en realidad bilingüe por las circunstancias de su vida y posee generalmente con igual perfección el idioma heredado y el del país adoptivo. Pero nunca -en el caso del escritor judío- el idioma originario llega a contaminar la pureza del adquirido, como les sucede, por ejemplo, en nuestro país, a los escritores noveles de la Boca y de Boedo, en cuyo lenguaje se siente como un tufo la influencia del arraigado italiano paterno, formándose así un castellano ‘al pesto’ que amenaza con asfixiarnos (H. C. 1924: 8, destacado nuestro). ${ }^{74}$
}

Cabe mencionar también la vigencia de esa línea de lectura en la crítica posterior, e incluso actual. Así, por ejemplo, Adolfo Prieto (1964) señala que los boedistas se sirvieron de viejas estéticas, como el realismo crítico y el lirismo tolstoiano. Por su parte, Guillermo Ara (1970) señala que Boedo tenía preocupaciones más sociales que literarias, mientras que Carlos Giordano (1986) considera la poesía de Boedo "estéticamente frustrada". Unos años

\footnotetext{
${ }^{74}$ Ortos artículos de Martín Fierro que expresan el rechazo hacia la inmigración: Méndez (1924c), "Suplemento explicativo a nuestro Manifiesto. A propósito de ciertas críticas" (1924c).
} 
después, Graciela Montaldo (2006b) expresa que estos escritores, en el plano estético, "no tienen elementos de interés". Muy probablemente, todo eso se manifiesta, por ejemplo, en las "torpezas poéticas" de los Versos de la calle (1924) de Álvaro Yunque, según Pablo Ansolabehere (2009: 64). En síntesis, en el balance de los aportes críticos que CandianoPeralta realizan acerca del grupo en su libro, Boedo: orígenes de una literatura militante, destacan esta suerte de desprecio, por parte de la crítica, de algunos escritores de izquierda:

en los críticos ajenos al Grupo de Boedo encontramos una aguda subestimación de su estética (...). Esto conlleva, a su vez, al hecho de que pocos críticos parecen haberse detenido en realizar un investigación profunda sobre un movimiento cuyos materiales de producción se encuentran dispersos y fragmentados... (2007: 73).

Este capítulo no pretende revisar la pertinencia de estos juicios. En principio, importa poner en entredicho esa segmentación dicotómica del campo literario de los años veinte. Ambos grupos resultan partes integrantes de una misma vanguardia que además de compartir un mismo período de surgimiento, consolidación y disolución ${ }^{75}$ establece canales de comunicación entre un grupo y otro. Naturalmente que con esto no se pretende subsumir las notorias diferencias que separan a ambas conformaciones, sino dar cuenta de la emergencia de nuevas y diversas escrituras que exceden la polaridad Boedo-Florida.

A su vez, estas páginas buscan poner en cuestión la idea de que los aspectos formales de la escritura no resultan un problema para los escritores de izquierda; es decir, que su foco de atención se encuentra puesto en la denuncia social, en una literatura que funciona principalmente como un compromiso con los sectores oprimidos de la sociedad, y en la cual el lenguaje es un mero medio de expresión que debe cumplir con las máximas de claridad y transparencia que requiere el público lector al cual se dirigen estos escritores. Por el contrario, cabe preguntarse hasta qué punto, en muchos casos, no existe un trabajo detenido sobre la lengua literaria, una búsqueda formal que, por momentos, aleja a estos escritores de los presupuestos estéticos y lingüísticos declarados. Teniendo en cuenta esto, también podemos

\footnotetext{
${ }^{75}$ Entre 1921 y 1922 podría señalarse un probable comienzo de la vanguardia en Argentina. El regreso de Borges al país y la publicación de su artículo "Ultraísmo" en Nosotros, la fundación de las primeras revistas vanguardistas, como Prismas (1921-1922) y Proa (primera época, 1922-1923), indican el comienzo del movimiento de vanguardia que se extenderá a lo largo de toda la década de 1920. En el ala de la izquierda literaria, también podemos encontrar una datación similar, puesto que en 1922 Antonio Zamora funda Los Pensadores (1922-1926), publicación que derivará luego en la Revista Claridad (1926-1941). A mediados de la década es cuando se concentra la mayor cantidad de publicaciones vanguardistas, correspondientes tanto a la vanguardia estética como a la izquierda literaria. Y, hacia 1927, es el momento en que se diluyen muchas de ellas: Martín Fierro (1924-1927), Proa (segunda época, 1924-1926), Inicial (1923-1927), La campana de palo (1925-1927), Revista del Pueblo (1926-1927). La revista Síntesis, vinculada a la vanguardia estética, resulta más tardía en relación con las citadas, puesto que se funda en el año en que muchas empezaban a dejar de existir, 1927, y culmina su vida hacia 1930.
} 
formularnos la pregunta de si algunos de los escritores de izquierda -aún los más centrales, como Elías Castelnuovo, por ejemplo- no participaron de una voluntad de renovación de la lengua literaria, objetivo que parecería exceder la zona en la que se incluyen estos autores y que guía, de manera mucho más clara, a los escritores nucleados en la vanguardia estética.

Francine Masiello habla de "la vanguardia de los años veinte" para referirse tanto a Boedo $^{76}$ como a Florida, e incluso sus aportes alcanzan a aquellos escritores que no respondieron a ninguno de esos grupos. ${ }^{77}$ Habría dos elementos que estabilizan y unifican a la vanguardia: por un lado, la voluntad de reclamar y luchar por una autoridad que se encontraba en los escritores pertenecientes a las generaciones anteriores; por el otro, y como complemento de lo primero, la necesidad de legitimar un conjunto de nuevas escrituras:

Mientras los historiadores de la literatura enfatizan en general las diferencias entre los poetas cosmopolitas y sus colegas del realismo social, sostengo en este libro que los escritores argentinos de la década del veinte tenían un objetivo unificado, destinado a identificar un yo soberano y reclamar la legitimidad de la escritura (...) La experiencia registra las voces marginales que claman desde la periferia del poder, donde giran en una interminable espiral de negaciones y deseos frustrados. (Masiello 1986: 24).

La idea de un lenguaje periférico en lucha con otro central estaría marcando para Masiello los movimientos y las dinámicas principales que tienen lugar en el campo literario de los años veinte:

el escritor de clase media de la década del veinte, se apropió de un discurso personalizante, utilizando su don de palabra para reclamar la autoridad social. Así, mientras escribía al margen del lenguaje oficial, sentía ansiedad por poseer un lenguaje que pudiera asegurarle el prestigio de su oficio. (23).

Cabe agregar que si bien esas nuevas escrituras entablaban luchas con diversos frentes ya constituidos y, dueños de autoridad, emplazados en los lugares centrales, también los

\footnotetext{
${ }^{76}$ Los escritores vinculados con la izquierda literaria se juzgaban a sí mismos como parte integrante de una vanguardia, incluso por sobre los martinfierristas, quienes eran considerados por este sector como "usurpadores" de esa denominación (Picone 1929: 22). "La verdadera vanguardia en lo económico, en lo político, en lo social, en lo cultural, por consiguiente en lo artístico y literario es el izquierdismo, o sea la posición que adoptan todos aquellos que se colocan frente a los intereses subalternos, a las convenciones sociales, al egoísmo y a la rutina, bajo una bandera de esperanza, de armonía, de ideal" (Picone 22).

77 "Ambos bandos (Boedo y Florida) se han comprometido en un programa común para reelaborar las premisas de la narrativa y de la identidad del personaje en el arte, y proponen sacudir el mundo social de la narrativa del Centenario y objetar sus procedimientos habituales." (Masiello 1986: 193-194).
} 
conflictos en materia de lenguajes se dirimían hacia adentro de ese conglomerado diverso que Masiello llama vanguardia.

Esta autora se opone a la imagen construida en torno a la noción de vanguardia que muestra a una "juventud ambiciosa que marcha contra la tradición". Si bien marca esa disputa -que implica una batalla permanente contra los modernistas y la generación del Centenariocomo una disputa primordial por la autoridad, también manifiesta cierta tensión en las prácticas de los vanguardistas. Por ejemplo, de Castelnuovo dirá:

se percibe una ávida adhesión al discurso 'oficial'; esto se corrobora en su concepto de 'verdad' y en su aceptación de los códigos éticos que emanan del estado. Hasta las clases de personajes que aparecen en los trabajos de Castelnuovo están firmemente entregados a esa convicción. (199).

Y agrega: "Mariani, al igual que Castelnuovo, no llega a escapar del todo a la ideología dominante de la ficción naturalista y sólo juega con resistencias menores para aprobar una rebelión parcial" (200). En sus memorias, Castelnuovo ofrece la imagen de un Mariani respetuoso de la gramática, que reprende a Arlt por desdeñarla: "pero, che, Roberto -le decía Mariani que cuidaba la integridad del idioma a despecho de haberse criado en La Boca-, ¿cuándo vas a aprender gramática?” (1974: 136, destacado nuestro).

Los escritores de izquierda, al igual que los martinfierristas, adjudicaban un alto valor a lo nuevo en relación con su práctica artística. Así, pese a la existencia de una literatura argentina de izquierda que podría haber funcionado como una suerte de tradición, imponen un corte con ese antecedente. Sustenta este gesto la convicción de que los escritores de izquierda del 900 adscribían a la estética predominante de la época, el modernismo. ${ }^{78}$ Para estos escritores, lo verdaderamente nuevo no es la anticuada práctica del preciosismo formal, sino la búsqueda de un arte del pueblo y para el pueblo (Ansolabehere 2009). Por otro lado, elaboran una literatura social, ${ }^{79}$ con lo cual desplazan algunos ejes de la literatura del momento: en primer lugar, el escritor no se ubica junto al proletariado, sino que forma parte de él. Sus experiencias personales se convierten en condición necesaria y valor primario para la escritura. Ellos alegaban que podían escribir de la manera en que lo hacían porque habían vivido y sufrido situaciones semejantes, o bien habían sido testigos (Candiano-Peralta 2007:

\footnotetext{
${ }^{78}$ Bajo su seudónimo Roland Chaves, Elías Castelnuovo afirma: "la literatura de hace 20 años, en líneas generales, era una literatura artificiosa y decadente. Se cultivaba la morfina y la declamación" (Chaves 1927c: 4).

${ }^{79}$ Como acabamos de señalar, si bien existen antecedentes de una literatura de izquierda en la Argentina (Giordano 1986: 25), la literatura de Boedo puede ser interpretada y analizada, según la definición de Adolfo Prieto, como "la primera experiencia colectiva de literatura social en nuestro país" (1964: 20).
} 
21). En este sentido, se habrían dado las condiciones para una relación de mayor proximidad entre la voz del autor y la voz de los otros. ${ }^{80}$ Esta situación, inevitablemente, produce determinadas elecciones en el plano del lenguaje. La lengua literaria utilizada por los escritores de izquierda es producto de un esfuerzo de adecuación en función del público lector al cual se dirigen; es decir, un lenguaje que pretende ser lo más parecido a los usos lingüísticos de los sectores populares. ${ }^{81}$ Sin embargo, como demostraremos luego, llevan a cabo una operación de "limpieza" de todos aquellos elementos lingüísticos que juzgaban perniciosos, como el lunfardo, por ejemplo.

Algunos autores hacen hincapié en el tono "oral-coloquial" que asume la escritura de Boedo:

Los miembros de Boedo utilizan un lenguaje simple porque pretenden escribir como oyen hablar en las calles y acercar el discurso escrito al oral haciendo uno de ambos. Para ello toman en sus producciones críticas palabras coloquiales de uso cotidiano en la oralidad como por ejemplo onomatopeyas o las formaciones léxicas ajenas a la escritura, es decir, incluyen en lo escrito las deformaciones del habla. (Candiano-Peralta 88).

\section{Según Candiano-Peralta, en las obras de Castelnuovo se observa}

la presencia de un lenguaje popular y coloquial y un uso sostenido de la hipérbole como procedimiento narrativo que está al servicio de la denuncia social (...) La simpleza de su escritura y las marcas de oralidad son otras de las características del autor, así como el rechazo

\footnotetext{
${ }^{80}$ Carlos Gamerro (1989) explica que hasta la década de 1880, la República conservadora no tiene una voz que cuestione su dominio. Ni la literatura de las campañas contra el indio ni la gauchesca marcan la irrupción de la voz del otro en el espacio de circulación del discurso de la elite dominante. Indios y gauchos, y su correspondiente voz, se encuentran representados, objetivados, en el discurso oficial. No dialogan, ni interpelan ni cuestionan: son mostrados. En todo caso, cuando una voz se levanta en defensa de alguno de estos grupos nunca es la propia, sino la de algún miembro o instancia de la cultura oficial, que en tanto voz central asume la reivindicación o la elegía. Es decir, la voz del otro se encontraba mediada por los intelectuales que respondían, en diverso grado, al discurso dominante. Con los anarquistas de fines de siglo XIX, esa relación con la voz del otro se modifica. Ellos se hacen escuchar, producen un discurso con sus propios medios y construyen un espacio de circulación y recepción que no depende de la cultura dominante. Este fenómeno iniciado por los anarquistas parece encontrar su continuación en la literatura de los escritores de izquierda de los años veinte puesto que, desde la perspectiva del grupo, sus escritores no son los mediadores de las voces de los otros, ya que ellos mismos se constituyen en esos otros con un discurso propio. Cabe agregar, además, que muchas veces esos otros son construcciones llevadas a cabo por estos escritores; el caso paradigmático es el de Clara Beter. Sin embargo, como veremos, el corpus literario con el que operan pertenece a la cultura hegemónica, al igual que muchas de sus pautas lingüísticas y literarias.

${ }^{81}$ Cabe recordar, no obstante, que los escritores de izquierda colocan estos usos populares en una relación de subordinación con respecto a la lengua estatal, normalizada (ver capítulo II). A diferencia de, por ejemplo, los poetas gauchescos del siglo XIX que también se dirigieron de manera prioritaria a los sectores populares de entonces, los escritores de izquierda no adaptan de manera completa el mensaje literario al público. En los gauchescos pesan más las intenciones de imitación de la lengua de los otros, mientras que en los autores de la vanguardia social de los años veinte la lengua "correcta" media o interfiere los registros populares.
} 
ante cualquier palabra o formación lingüística que pueda llegar a considerarse culta y lo que hemos llamado una utilización de la metáfora y de una adjetivación no lúdica (91).

No obstante, luego veremos que existen límites claros a esta supuesta "fiel reproducción" de los registros populares ya que -como ya hemos explicado haciendo uso de los aportes de Ludmer- debemos entender el discurso literario como una reelaboración de otros discursos, y nunca como una forma mimética o refleja.

A diferencia de Masiello, cuando Sarlo (1997b) se refiere a la vanguardia de la década del veinte piensa exclusivamente en el grupo nucleado en torno a la revista Martín Fierro. Esta autora afirma que la vanguardia es producto de un espacio cultural establecido, en la medida en que define su accionar a partir de la oposición hacia el centro del campo literario. Para Sarlo, habría dos cuestiones con las que pretende romper la vanguardia argentina: el modernismo y la generación del Centenario. A su vez, los martinfierristas dirimieron la supremacía del campo literario con la revista Nosotros, en tanto órgano de consagración y difusión de la cultura dominante. Desde este punto de vista, no habría razón para dejar afuera del concepto de vanguardia a Boedo, puesto que ambos sectores de la nueva generación coinciden en disputar esa autoridad a la que se refieren Masiello y Sarlo.

Según Sarlo, el moderatismo caracteriza a la vanguardia argentina de los años veinte. La autora explica que en el caso de Martín Fierro se manifestó en la represión sexual ${ }^{82}$ y moral, el apoliticismo, la disciplinada afirmación de la nacionalidad y el poder del Estado. Estas cuestiones se vinculan con ideologías sociales todavía tradicionales que producen una vanguardia poco cuestionadora del orden social. Martín Fierro no bromea con la familia, con la patria, con la religión ni con la autoridad (Sarlo 1997b).

$\mathrm{Si}$, desde la perspectiva de Masiello, la izquierda literaria forma parte del movimiento de vanguardia gestado hacia mediados de la década del veinte, cabe preguntarnos si este rasgo de moderatismo también puede ser aplicado a este grupo. Si es así, naturalmente que no se lo puede aplicar en el mismo sentido que lo hace Sarlo en referencia a Martín Fierro. Los escritores de izquierda pondrán en tela de juicio muchas cuestiones que el martinfierrismo deja sin tocar, sobre todo en el terreno de lo político. Creemos que el moderatismo de Boedo se pone de manifiesto en el terreno de la lengua literaria, en la asunción de una norma lingüística que tiende hacia la corrección y es refractaria a todas aquellas expresiones literarias no convencionales o no canónicas, tanto en lo referido a las experimentaciones

\footnotetext{
82 Habría que exceptuar el caso de Oliverio Girondo y de Nicolás Olivari. Ver capítulos IV y VI, respectivamente.
} 
formales propias de los vanguardismos europeos, como así también a los lenguajes "bajos" y/o "plebeyos", marcadamente orales.

Sarlo explica que dos ejes son los que definen la actitud martinfierrista frente a la literatura como mercancía: lucro-arte y argentinos-inmigrantes. Pese a los estrechos vínculos que los escritores de izquierda establecen con el mercado, al igual que el martinfierrismo, manifiestan un rechazo hacia el beneficio económico que proviene de la literatura ${ }^{83}$ cuestionan fuertemente la literatura de folletín-, aunque, pese a eso, no pueden escapar de las críticas de Florida en ese sentido. Literatura y mercado confluyen en Los Pensadores, publicación que en su primera época tuvo como finalidad editar "obras selectas", en un folleto de treinta y dos páginas escritas a doble columna, a muy bajo precio. Los escritores más representativos del martinfierrismo vieron con espanto esta empresa, la cual fue juzgada como una suerte de abaratamiento de la literatura, en la medida en que "la plebe iletrada se adueña del tesoro mental" (Méndez 1924c: 2) y así quedó expresado en el primer número de Martín Fierro, en el artículo "Rubén Darío, poeta plebeyo".

En el periódico de Florida, rápidamente se produce una asociación que resulta clave para los debates sobre la lengua: la unión de la condena moral ante el lucro y la refutación de una estética "inferior" (Sarlo 1997: 229). Cuando Martín Fierro se refiere a la literatura de folletín y señala su "baja" poética, retoma el tema de la pureza lingüística puesto que destaca la típica "deformidad de pronunciación" que aparece en esos textos, y en la que subyacen las formas provenientes de la inmigración. De alguna manera, Martín Fierro se coloca junto a los representantes del viejo purismo idiomático, y esa posición puede ser leída como un rasgo más del moderatismo conservador indicado por Sarlo. Esta autora demuestra que habría una línea de continuidad entre quienes sostenían la prueba de la pureza lingüística, como Lugones, y Martín Fierro, que se diferencia de la "jerga ramplona plagada de italianismos" $" 84$ (231).

No obstante, hay que tener presente que cuando nos referimos a Martín Fierro, y sobre todo en materia de lenguaje, lo hacemos en líneas generales puesto que no se presenta como una revista homogénea, sino que en su interior se despliega una polifonía evidenciada en ciertas voces disidentes con los preceptos idiomáticos más o menos conservadores, como por ejemplo las de Nicolás Olivari, Enrique González Tuñón o Santiago Ganduglia quienes producen una literatura nutrida de múltiples registros, muchos de ellos provenientes de los sectores inmigratorios rechazados por los escritores centrales del martinfierrismo. La propiedad sobre el lenguaje y la relación con el público "bajo" son pensados desde la

\footnotetext{
${ }^{83}$ El objetivo principal de la editorial Claridad no habría sido económico sino pedagógico-político. Al respecto, Zamora afirma: "Yo concebí que una editorial no debía ser una empresa comercial, sino una especie de universidad popular" (Montaldo 1987b: 41).

${ }^{84}$ Véase "Suplementos explicativo de nuestro Manifiesto" (1924).
} 
vanguardia estética como opuestos: ese público, del cual el martinfierrismo se separa, "contamina" el lenguaje, impone su pronunciación deformada.

De lo hasta aquí expuesto, surge la idea de que, a los rasgos aportados por Sarlo acerca del moderatismo martinfierrista, hay que sumar el que se manifiesta en el terreno del lenguaje. Sin embargo, cuando hablamos de los escritores de izquierda, y pese a encontrarnos en las atípodas en cuanto a sus concepciones con respecto a la lengua literaria, hallamos en sus textos ciertos límites, moderaciones, que matizan algunas de sus posturas radicales al respecto. Veamos cuál es la posición que algunos de estos autores tienen en estas disputas.

\section{Lengua literaria y escritores de izquierda: los casos de Elías Castelnuovo, César Tiempo y Álvaro Yunque}

En líneas generales, los escritores de izquierda de la década de 1920, al retratar en su literatura los márgenes sociales y geográficos de la ciudad, y al dirigirse a un público popular, optaron por una lengua pensada como sencilla y comprensible. De hecho, dicha opción quedó explicitada en sus propios textos. Un buen ejemplo es el de Castelnuovo quien, en el primer número de Izquierda (1927-1928), afirma:

\footnotetext{
Discrepamos con toda esa falange de jóvenes desorbitados que emplean palabras abstrusas, vulgarmente llamadas 'palabras sifilíticas'. O que se crean un léxico embrollado, recargado de esdrújulas y sobreesdrújulas, especie de alambrado de púas donde se ensarta la inocencia de los cerebros equilibrados. También discrepamos con la adjetivación viciosa. (...) Nosotros creemos que el que tiene algo que decir lo dice con claridad primero. Después, con la menor cantidad de palabras y con los términos más usuales y precisos del idioma. (1927: 47, destacado nuestro).
}

Castelnuovo realiza las elecciones idiomáticas $-\mathrm{o}$, en todo caso, las justifica, parcialmente- a partir de la oposición y diferenciación con respecto a la vanguardia estética. En el número siguiente de Izquierda, sostiene:

El hecho de que un término suene bien no significa que lo encajemos aquí a allí, venga o no venga al caso, que eso es lo que hace la nueva sensibilidad. Generalmente, se trata de llenar el vacío de las ideas con la charanga celestial de las palabras bonitas. (Chaves ${ }^{85}$ 1927b: 17)

Candiano-Peralta afirman el carácter oral y antiacadémico de los textos de los escritores de izquierda. Como hemos dicho, si bien es cierto que, en líneas generales, tenían la voluntad de

\footnotetext{
${ }^{85}$ Seudónimo de Elías Castelnuovo.
} 
expresarse de modo sencillo y transparente para el fácil acceso del público al que se dirigían, el lenguaje literario de estos escritores no siempre cumplió con los principios de claridad y comunicabilidad que se proponían como definición de su escritura. A su vez, ya sea en sus obras como en las críticas y teorizaciones que realizan dentro de distintas publicaciones, el rechazo de la lengua literaria popular, vigente en el mercado cultural, marca otra de las coordenadas de un lenguaje literario atravesado por tensiones y contradicciones que requieren ser revisadas. Para ello tomaremos algunos textos de Elías Castelnuovo, los cuales muchas veces distan bastante de ser sencillos y transparentes.

\subsection{Hipercorrección y voces populares en Tinieblas de Elías Castelnuovo}

Elías Castelnuovo se constituye como uno de los principales escritores de la izquierda literaria de los años veinte, y su libro Tinieblas, de 1923, es un texto representativo de esa zona del campo literario. La obra inaugura Los Nuevos, colección editada por Claridad cuyo principal objetivo era "conformar una biblioteca de autores que desarroll[en] un arte realista, de crítica social" (Candiano-Perlata 2007: 203). Pero no sólo eso, el libro de Castelnuovo es un texto que ya existía antes de la conformación del grupo de Boedo y que reúne en sí las condiciones necesarias y suficientes de lo que ellos llamaban literatura social, vale decir Tinieblas es

un texto de un trabajador que narra desde la perspectiva de su clase una serie de hechos y sentimientos propios. Allí radica su importancia central en la historia de Boedo y el motivo por el que se decidió que inaugurara formalmente el camino de esta colección... (Candiano-Peralta 2007: 206).

La claridad y la sencillez forman parte de la poética del grupo. Apoyados sobre esa base, reaccionan contra la vanguardia estética y su lenguaje cargado de palabras consideradas embrolladas y de difícil comprensión. Castelnuovo denomina "palabras sonoras" al lenguaje que no resulta sencillo y que despierta atracción por motivos "meramente musicales". Por eso se refiere a estos vocablos como "ruiditos": "el ruidito encanta y deleita a los poetas" (Chaves 1927b: 17). La "nueva sensibilidad" ha sido la que más provecho le ha sacado al "ruidito", a punto tal, afirma, que sin él "desaparecería" irremediablemente.

Por esta misma época, los martinfierristas también se molestaban por los "ruiditos" literarios: se referían a la rima. Borges, en El tamaño de mi esperanza (1926), se queja del 
"sonsonete de terminaciones iguales" 86 y refuta la rima por considerarla "la deleitación más burda de los oídos, y es hasta inmusical” (1993: 108). Al igual que Castelnuovo, para Borges privilegiar la sonoridad en la lengua literaria es un error propio de los rimadores, quienes "rebaja[n] el verso a pura dependencia de los oídos y no de la imaginativa y del corazón" (107). Pero Borges y Castelnuovo no están criticando lo mismo: en el caso del primero, los dardos apuntan contra Leopoldo Lugones y sus rimas modernistas: "la tribu de Rubén aún está vivita y coleando como luna nueva en pileta y este Romancero $^{87}$ es la prueba de ello. Prueba irreparable y penosa" (97). En cambio, los "ruiditos" que desdeña Castelnuovo son, precisamente, los que produce la vanguardia estética, que no tienen que ver con la rima sino con la utilización de un lenguaje literario poco comprensible y opaco, centrado en la forma y la sonoridad de las palabras. Para los escritores de izquierda -y Castelnuovo se ocupa de dejarlo bien en claro- lo que importa es el significado, el cual no tiene ninguna relación con el "barullo que la palabra produce" (Chaves 1927b: 17).

La dicotomía entre un lenguaje claro y otro embrollado asume también diversas formas metafóricas o alegóricas en el seno de la izquierda literaria. Citamos dos ejemplos: en primer lugar, quisiéramos hacer referencia a un par de sueltos sin firma aparecidos, en noviembre de 1926, en la revista Claridad bajo los títulos "Vaselina vaselina" y "Hay que escribir con dinamita". En el primero de ellos se afirma:

Sabemos cómo escribes tú. No lo sabemos por experiencia. Lo sabemos porque no nos chupamos el dedo. Tú escribes con vaselina. Tu estilo no es estilo: es vaselina. Has descubierto un tratamiento muy singular para lubrificar tus ideas... Tú no sabes concebir sin vaselina. Tu expresión es límpida y tersa, meliflua y amerengada. Para digerir lo que tú escribes no es preciso tener buena dentadura. Todo lo que tú escribes resbala por el cerebro del que te lee como las gotas de sebo sobre el candil. Tus palabras entran por un oído y salen por el otro sin dejar rastros. Eres un inmaculado (...) Tu estilo es el estilo común al tercer sexo o al sexo contrario. Estás en La Nación o en La Prensa o en el Para Ti. (...) Tienes el mismo lenguaje inconfundible, amanerado, fino, lleno de metáforas brillantes y vacío de pensamiento. Tu envoltura literaria es aparatosa y grandilocuente. (...) Juegas al ajedrez con las palabras lánguidas y bonitas. (...) Tú eres prudentito, delicadito, ordenadito. Sabes lo que cuesta decir la verdad y la dices a chorritos o la insinúas entre líneas de manera que se sepa y no se sepa a la vez o que se adivine. (...) El lenguaje directo, para ti, es el lenguaje de los brutos ("Vaselina, vaselina" 1926: 7).

\footnotetext{
${ }^{86}$ Estas, en verdad, son palabras de Milton, a quien Borges cita en uno de los textos que componen El tamaño de mi esperanza, "Milton y su condenación de la rima" (Borges 1993: 105-109).

${ }^{87}$ El Romancero de Lugones se publica en 1924.
} 
En el suelto aparece un nombre vinculado a la "vaselina": Martínez Zuviría, ${ }^{88}$ de quien Leónidas Barletta y Nicolás Olivari ya se habían ocupado en 1924, cuando firman un cartel con la consigna "Con Gálvez o con Martínez Zuviría”, para denunciar que el segundo falseaba "la vida y el amor" en sus novelas. El autor anónimo del suelto critica varias cosas: el estilo aparatoso que oculta y distorsiona "la verdad", la utilización de la metáfora, el lenguaje muy estetizado, poco claro, con el que se puede también estar aludiendo al modernismo. Todo esto desde una perspectiva misógina y homofóbica ${ }^{89}$ en la que se identifica a estas escrituras (afeminadas) con las textualidades de las mujeres escritoras. ${ }^{90}$ Lo que les molesta a los escritores de izquierda, en definitiva, es "el singular embrollo de la literatura sin sexo. Se usa y abusa de la literatura con fines nada literarios. Atrás de una metáfora se encuentra siempre una verdad que el autor dejó en el tintero" ("Vaselina, vaselina" 7, destacado nuestro). El lenguaje complicado no sólo es anti-pedagógico, sino que además encubre las "verdades" que la literatura debería sacar a la luz. En cambio, frente a la "vaselina", se ubica el lenguaje como "dinamita": "la dinamita suena y truena. Sólo resiste la mano de un varón fuerte que la maneje. (...) Nos gustan las palabras explosivas. Esas que hacen saltar y brincar y encender el rostro. Que cuando caiga una verdad, donde caiga, explota" ("Hay que escribir con dinamita" 1926: 7). Por oposición, habría entonces un lenguaje claro y conciso, viril, mediante el cual la literatura se convierte en un poderoso instrumento de denuncia, de crítica social pero, sobre todo, en un instrumento pedagógico.

El segundo ejemplo al que quisiéramos referirnos es el prólogo que escribe Alvaro Yunque para su libro Barcos de papel, en el cual a través de un texto alegórico plantea la dicotomía entre lo claro y lo opaco. Dada su brevedad, lo citamos completo:

\footnotetext{
${ }^{88} \mathrm{Si}$ pensamos el suelto exclusivamente desde el punto de vista del lenguaje y dejamos de lado las implicancias de "la verdad" y "falsedad" sobre la literatura, resulta llamativo que sea justamente Martínez Zuviría un ejemplo de "vaselina", de decir de un lenguaje "aparatoso y grandilocuente", puesto que sus novelas se caracterizan por la sencillez, rasgo con el que la izquierda literaria hubiera coincidido. Sobre la lengua literaria de Martínez Zuviría, Gramuglio señala: "la clave de bóveda de su poética de la novela era 'la máxima sencillez'. Esto significaba, para Wast, un rechazo explícito de los artificios retóricos, una total despreocupación por repeticiones y disonancias en la prosa y una confianza absoluta en la transparencia del lenguaje. Estos principios, que sintetizó en la fórmula 'hay que hacer desaparecer el estilo', rigieron siempre su producción escrita, y fueron especialmente característicos de sus novelas. Con toda evidencia, se trataba de eliminar cualquier dificultad o innovación que pudieran alejar al lector medio perteneciente al gran público de las primeras décadas del siglo XX” (Rapalo-Gramuglio 2001: 468). El estilo de Martínez Zuviría combina rasgos típicos de la novela semanal con detalles costumbristas (468).

${ }^{89}$ Manuel Gálvez, en El mal metafísico (1916), utiliza la expresión "vaselina" para señalar a la estética modernista. Se refiere a una escritura alejada de la realidad, con un lenguaje complicado, "afeminado"; es decir, Gálvez hace uso de este concepto con un sentido muy parecido al que años después pondrá en circulación la revista Claridad en el artículo citado: “Al principio había mirado con desprecio a los modernistas (...) Les llamó afeminados, fumistas, degenerados, pobres locos. Hablan de princesas y no conocían más princesas que las de Junín y Lavalle. No tenían el sentimiento de la mujer, de la patria, del heroísmo. Era la de ellos una poesía ¿poesía?- una 'cosa' de coldcream, de vaselina.” (Gálvez 1922: 85).

${ }^{90}$ Ver Capítulo VII.
} 
Al despertar vi, sorprendido, a mis pies un enorme lago de miel y leche. Ondulábase hablando, satisfecho de su propia abundancia. Era magnífico. Escuché su discurso. Me invitaba a arrojarme en él, a gozar su blanda dulzura.

-¿Dónde vas, lago de miel y leche? -lo interrogué. Me respondió:

- Soy el lago de la felicidad. No salgo de mí. Me gozo a mí mismo.

Le di la espalda.

$\mathrm{Y}$ vi a mis pies un ligero arroyo de aguas clarísimas. Cantaba. No comprendí bien el significado de sus musicales palabras rítmicas.

Y le pregunté:

-¿Dónde vas, arroyo?

- ¿Lo sé yo mismo, acaso? -me respondió el ligero arroyo -, quizás voy al mar amargo, quizás al sol rutilante, quizás...

No dudé un segundo. Con mi ensueño más hermoso, el más multicolor y brillante, hice un barco de papel. Lo arrojé a sus aguas. Y lo vi alejarse, ¿hacia dónde?, lo vi dichoso, confiado yo en el destino de mi barco de papel que sería el del ligero arroyo cantor de aguas clarísimas (1976: 7-8).

El texto plantea la oposición entre dos texturas, dos densidades: la del "lago de miel y leche" y la del "arroyo de aguas clarísimas". La dicotomía se entabla a partir de la relación opacidadclaridad. En primer lugar, se podría leer en la alegoría las diferentes formas de pensar el arte y la literatura que tienen los escritores de izquierda frente a otras lenguas literarias más formales. El prólogo parecería estar haciendo referencia a la vanguardia martinfierrista, la cual practica una estética encerrada en sí misma. El pasaje "me gozo a mí mismo” también brinda la clave de que la alegoría trabaja con la semivelada alusión al onanismo. Esto nuevamente nos remite a la vinculación entre las formas de hacer literatura y la moral sexual. En este sentido, la literatura onanista de la vanguardia estética se revelaría como un mero goce improductivo, algo muy alejado de la clara función social que la izquierda asigna de manera prioritaria tanto a la sexualidad como a los textos literarios.

La literatura de la izquierda sería transparente frente a la opacidad de la de Florida y de aquellas escrituras centradas fuertemente en la elaboración de una estética que remite al "arte por el arte", esquema dentro del cual obviamente también puede ser incluido el modernismo.

Para satisfacer la necesidad de claridad, los escritores de izquierda optan por apegarse a las normas de corrección y uso del español. El lenguaje literario debe estar construido a partir de cierta idea de vigencia o contemporaneidad de la lengua, puesto que las formas arcaicas o poco utilizadas comprometen la transparencia e inteligibilidad del mensaje literario. Por eso, Castelnuovo recomienda "eludir todas aquellas palabras que sin estar propiamente 
muertas, se hallan en las inmediaciones del cementerio de la lengua" (19). Sin embargo, en su propia lengua literaria, suelen aparecer términos hipercorrectos y cultos que opacan el mensaje, es decir que interfieren la pretendida sencillez de la prosa, y que provienen de diversas fuentes: en primer lugar, Castelnuovo utiliza vocablos derivados de la estética modernista o, en general, poéticamente "elevada". De este modo, encontramos palabras como “taciturnas" (Castelnuovo 2003: 57) o "mustias" (59), frecuentes en las obras de Rubén Darío, José Asunción Silva, Juan Ramón Jiménez, Leopoldo Lugones, ${ }^{91}$ etc.

En sus Memorias, Castelnuovo narra uno de sus primeros contactos con el lenguaje literario modernista. El episodio resulta sumamente esclarecedor y amerita citarlo extensamente por la riqueza de su contenido, a los efectos de comprender algunas de las tensiones que manifiesta su lenguaje:

Lo penoso de ello consistía en que el destino me había puesto, como quien dice, ante todo el conocimiento humano, -ciencia, literatura, filosofía-, completamente inerme. En el más trágico desamparo. Porque yo no conocía para empezar ni el forro de las tapas de tan opulento tesoro. No estaba al tanto siquiera de que existía un diccionario de la lengua y cada vez que alguien decía una palabra difícil, suponía que la inventaba él por su cuenta. No podía admitir que se hablase otro idioma que aquel que se hablase en mi barrio. Cuando se presentaba un dramaturgo como Víctor Pérez Petit o un filósofo como José Enrique Rodó, que editaban allí una revista, y empezaban a conversar entre ellos, por más que me empeñaba no conseguía nunca pescar el hilo de su discurso. Y se me antojaba que seguramente ellos estarían en posesión de algún secreto y que por eso se comunicaban así a fin de que nadie pudiese descubrir el enigma. Mi posición se resentía todavía más por cuanto, en líneas generales, esa promoción intelectual, en vez de buscar el lenguaje que la gente usaba para todo, buscaba el lenguaje que la gente no usaba para nada. (...). A veces, hurgaba afanosamente los estantes de la biblioteca en procura del alimento apetecido, como una carcoma hambrienta, cambiando a cada momento de autor, no por cambiar, sino porque a unos los comprendía a medias y a otros no los comprendía en absoluto.

Ciertos términos que empleaba Rubén Darío -hipsipila, palimpsesto, sicofante- lo confieso sin rubor, me dejaban estúpido.

Lentamente, sin embargo, me fui familiarizando con el vocabulario de mis lecturas, no así con su pronunciación, que me resultaba en muchos casos de una dificultad infranqueable. A veces,

\footnotetext{
${ }^{91}$ Algunos ejemplos: José Asunción Silva: "Tú, mustia, yerta y pálida entre la negra seda" (1985: 20). Leopoldo Lugones: "Era el silencio de la tarde mustia" (1959: 491). Rubén Darío: "mata la indiferencia taciturna" (1953: 645), "los cocheros taciturnos, en su quietud de indiferentes" $(1961,96)$. Antonio Machado: "es una tarde cenicienta y mustia..." (1919: 59).
} 
me subía a la azotea para estar solo y poder aprender a vocalizar sin que nadie me viese, contando las sílabas, palabras como metafísico, epistemológico y peripatético.

Omito decir que sudaba.

El problema que se me planteaba, por desgracia, no incidía únicamente en la terminología del saber. Incidía con el saber mismo. Con el contenido de la sabiduría, ante la cual, sin la menor preparación previa, de golpe, me hallaba en un cotejo dispar, mirando, asombrado, quién sabe dónde, como si estuviese ante un abismo insondable.

Era tal la angustia que padecía (...). Mis ansias de saber no guardaban ninguna relación con la exigua preparación que yo poseía para adquirirlo. Debía navegar (...) en un mar desconocido y arcano, sin una carta de ruta... (1974: 26-27, destacado nuestro).

Como se puede ver, Castelnuovo relata, muchos años después, el momento en que descubre su "inferioridad" cultural. Y percibe el lenguaje de la Cultura, el que hablaban Rodó y Pérez Petit, como un "enigma", un "secreto". Castelnuovo se piensa, retrospectivamente, como un excluido cultural -y social, claro- que encuentra en la lengua de la "alta" cultura un límite que se propone cruzar (traducir), no sólo como un desafío personal, sino también como la muestra fáctica de que los sujetos pueden mejorar a través de la educación y el acceso a los bienes culturales. Contra esta exclusión se propone dar batalla. Y esa batalla no es otra cosa que la aspiración al "opulento tesoro" de la Cultura. La biblioteca se convierte entonces en el medio y en el fin para conseguir estos objetivos, para saciar el "hambre" de conocimiento. Y es allí adonde encuentra el modernismo y ese lenguaje que lo dejaba "estúpido" de tan abstruso, pero que lejos de rechazar se empecina en dominar, en derrotar la "dificultad infranqueable" que le propone el vocabulario modernista. La escena de Castelnuovo en la azotea, en un escenario que ya de por sí comporta cierta idea de altura o elevación, tratando de articular las palabras que utiliza Darío en sus poemas, se configura como la representación más nítida e ilustrativa de sus aspiraciones culturales y, como señala Rogers (2013), de la difícil apropiación de la letra escrita.

El saber científico y técnico se encuentra muy presente en los textos de Castelnuovo. Por este motivo, una fuente importante no sólo de palabras, sino también de temas y de una estética realista particular, asociados a este saber, definen una parte de su lenguaje literario. Así como en los casos de Arlt o Quiroga, cuyos textos son construidos a partir de "pasiones técnicas" (Sarlo 1992), Castelnuovo se ubica en una perspectiva similar a la de estos autores en relación con la ciencia o la técnica. ${ }^{92}$ Sarlo explica que Arlt escribe a partir de un vacío que

\footnotetext{
${ }^{92}$ Cabe señalar, no obstante, que el uso de los saberes del pobre en Arlt y Castelnuovo es diferente: "como el límite de la literatura de Castelnuovo es siempre el mensaje moral y pedagógico, sólo registra aquellos saberes del pobre que no tienen huella de doblez o de astucia (...) La astucia, la traición y el robo, entonces, están siempre sujetos, si aparecen, a la sanción moral o al perdón” (Astutti 2002: 438).
} 
debe ser colmado con libros y autores, pero también intervienen en este proceso otros saberes: "los saberes técnicos aprendidos y ejercidos por los sectores populares" (2007: 52). La afirmación puede funcionar también para el caso de Castelnuovo quien, como Arlt, parte desde un "vacío cultural" "93 y, para autorizarse, encuentra en estos saberes una legitimidad parcial como escritor.

Durante los años veinte, existe una circulación masiva y popular de los conocimientos científicos y técnicos ${ }^{94}$; de hecho, la izquierda literaria participa de este fenómeno al publicar, por ejemplo, la Biblioteca Científica en la revista Claridad. La técnica se convierte en un instrumento más de la modernización, pero también representa para las clases populares la posibilidad de "notoriedad o ascenso social" (Sarlo 1992: 13). Los saberes del pobre, ${ }^{95}$ además de esta función de modernización cultural, se convierten en compensadores de diferencias culturales puesto que ocupan, para los sectores populares, el lugar de los saberes de la élite letrada, es decir, se le otorga a estos conocimientos "la respetabilidad y el prestigio que tienen las organizaciones más tradicionales del conocimiento" (13).

En Tinieblas podemos observar un vocabulario perteneciente al campo léxico de la ciencia (sobre todo la medicina) y de la técnica, como por ejemplo: "escoplo" (Castelnuovo 2003: 28), “arcos voltaicos” (30), “antimonio" (41), “hidrópico” (56), “sonámbulo”, “cráneo”, “córneas" (90), "sífilis", “wertheritis" (108), "bicloruro de mercurio" (109), "apetito genésico", "impulsión morbosa" (113), etc. En el caso de Castelnuovo, la procedencia de este léxico no se explica únicamente por la circulación popular del saber científico y/o técnico divulgado durante los años veinte. Según relata en sus Memorias, desde muy chico, se dedicó a tareas manuales en las que ciertos conocimientos técnicos se hacían indispensables para poder realizar diversas labores:

\footnotetext{
${ }^{93}$ Elías Castelnuovo nace en Montevideo en 1893. Su familia, de origen italiano, supo hacerse de una buena posición económica hasta que la crisis de 1890 la sume en la pobreza. Su padre muere prematuramente y deja a su madre y a los numerosos hijos (ocho) en una situación económica muy delicada. Pronto se las arreglan para subsistir: su hermana mayor se dedica a la costura y Castelnuovo desempeña múltiples trabajos durante su infancia. Sus primeros años de vida transcurren en un suburbio de Montevideo, en un "barrio de ratas", conocido con el nombre de La Playa, en el que primaba, según afirma el propio escritor, la ignorancia y la falta de cultura. En oposición con su medio, Castelnuovo desarrolla una fascinación por la lectura y el conocimiento que contrasta con su deficiente formación escolar: suspende sus estudios en cuarto grado de la escuela primaria para ingresar como obrero en un taller. No obstante, al mismo tiempo, asiste a tertulias literarias barriales y escucha lecturas de Las aventuras de Rocambole de Ponsón du Terrail; datos que recuerdan algunos tópicos de la biografía de Roberto Arlt. Cuando algunos poetas visitan el barrio, Castelnuovo entabla contacto, los admira y anhela parecerse a ellos: representan la "civilización" en un barrio que, "sin ninguna exageración", se parecía a la "plena Edad Media" (Castelnuovo 1974).

${ }^{94}$ La difusión del saber técnico y científico se lleva a cabo en diarios masivos, como Crítica y El Mundo, como así también en revistas especializadas, por ejemplo Ciencia Popular o Radio Revista (Sarlo 1992).

${ }_{95}$ "Se trata de saberes o prácticas que no tienen una legitimidad pública indiscutible, ni se integran del todo a una jerarquía socialmente aceptada de conocimientos; se trata de saberes que entrecruzan modernidad y arcaísmo, ciencia y paraciencia, empirismo y fantasías suprasensoriales. Son los saberes de los pobres y marginales, los únicos saberes que poseen quienes, por origen y formación, carecen de Saber” (Sarlo 1992: 55).
} 
Donde se fuera siempre se oía la misma cantilena. Y que cómo se componía la pava o la cacerola que se había agujereado. Y que cómo se arreglaba la gotera del techo que se llovía o la rotura de la canaleta que goteaba. Y que cuándo vendría un albañil que revocase el frente de la escuela, que daba lástima, y que reparase los baños del alumnado, que se venían abajo. Y que cuándo llegaría el ebanista que supiese por lo menos tallar una cuna de madera para los recién nacidos y un ataúd con tablas cepilladas para enterrar decorosamente a los que se morían. Y que cuándo esto y que cuándo aquello.

Fue así que ante el clamor de tan insistentes reclamaciones, me vi compelido a suplantar paulatinamente a todos aquellos artesanos de los cuales se carecía constituyéndome, también en forma paulatina, en un desfacedor de entuertos de cuanta avería o desaguisado se orinaba en cualquier sector del poblado (1974: 53).

Astutti (2002) afirma que este "saber artesanal" se retrata en sus novelas y cuentos, en los cuales el narrador/albañil-electricista-carpintero es el mejor ejemplo. Pero, por sobre todo, el léxico y los saberes médicos, que bien podrían ser pensados como el reverso de los saberes del pobre, provienen de su trabajo como linotipista, fuertemente tematizado en Tinieblas, en donde se familiariza con este vocabulario al "componer" las tesis médicas que editaba la imprenta en donde se desempeñaba:

Aunque se imprimían en el sótano libros y semanarios, el dueño de la empresa me había asignado el rubro más delicado de la tipografía, consistente en la composición de las tesis doctorales que debían presentar entonces obligatoriamente para optar al título los estudiantes de medicina. Munido de un diccionario de la especialidad, pronto conseguí dominar ampliamente la terminología (1974: 76).

Ya desde entonces, su afán normativo se manifiesta en el cuestionamiento hacia los estudiantes que, en el uso del vocabulario médico, a su juicio, incurrían en ocasiones en errores ortográficos y etimológicos. El diccionario, esta vez específico, se constituye en la instancia que dirime los debates:

... a menudo solía entablar controversias de orden ortográfico con los mismos autores del texto, algunos de los cuales, porque la palabra osteología se derivaba de hueso, exigían que se escribiese hosteología con hache, o porque la palabra cirujano se escribía con jota, pretendían también que le pusiese una jota a la palabra cirugía. Sin contar que ponían tifóidea en vez de tifoidea, o laparatomía en lugar de laparotomía como si esta última voz proviniera de aparato. Cuando no lograba disuadirlos con explicaciones verbales, recurría al mataburros, no de la Real Academia, que abarca las generales de la ley, sino al mataburros específico de la ciencia médica... (76-77). 
La familiaridad con la medicina es tal para Castelnuovo que, con el correr de los años, afirma, se convierte en "médico teórico o nominal", lo que posibilita, gracias a las amistades que genera en el medio, que el doctor Lelio Zeno lo lleve a Rosario para desempeñarse como ayudante de cirujano en el Hospital Centenario. Los saberes específicos de la medicina y los conocimientos técnicos no sólo se entraman en los campos léxicos que despliega Castelnuovo, sino que además en la práctica se encuentran muy relacionados puesto que, por ejemplo, el doctor Zeno lo convence de ser cirujano justamente a partir de sus destrezas manuales: "cortar es un oficio como cualquier otro. Y vos que aprendiste tantos, aprenderías a cortar en seguida..." (79). Y es el propio Castelnuovo quien corrobora esta suerte de continuidad entre saberes médicos y técnicos, puesto que pasa "sucesivamente de la cirugía estética que practicaba con los tachos a la cirugía general" (53).

$\mathrm{Su}$ discurso cientificista configura lo que Rodríguez Pérsico (2011) llama realismo teratológico. Lo monstruoso, el feísmo y el mal gusto convergen para brindarle una forma singular a su lengua literaria, la cual posibilita la representación de las zonas "enfermas" de la sociedad. ${ }^{96}$ Un ejemplo de esto es la unión (imposible) entre Luisa y el protagonista en el cuento "Tinieblas", la cual da como fruto un hijo monstruoso, que porta los males "deformantes" de la prostitución, el juego y la marginalidad presentes en los padres. ${ }^{97}$ En esta suerte de naturalismo extremo, Castelnuovo se sirve de cierta perspectiva cientificista que se puede observar con claridad en las descripciones de los personajes, los cual son presentados como casos. De esta manera, sus textos se configuran como "ficciones científicas del terror social" (Astutti 2002: 430). Debemos entender estas nuevas formas de realismo ${ }^{98}$ que propone el autor de Tinieblas en los albores de la década del 20 como una manifestación de las transformaciones que sufre el lenguaje literario, puesto que en estos excesos "reside la singularidad de su escritura" (Astutti 436). El conocimiento y el léxico científico-médico se

\footnotetext{
96 “...el morbo del que hablan sus textos no se detienen nunca donde cualquiera reconocería un límite: el del mal gusto, por ejemplo" (Astutti 2002: 430).

97 "Levanté las sábanas y descubrí un fenómeno macabro. La cabeza semejaba por sus planos un perro extraño y era tan chata que se sumergía hasta hacerse imperceptible en el cráter de una joroba quebrada en tres puntos. Su cuerpo estaba revestido de pelos largos; no tenía brazos y las piernas eran dos muñones horrorosos (...) El nene bajo las sábanas se revolvía como un gusano y lanzaba unos vagidos que me helaban el corazón (...) Luisa murió sin pronunciar una queja y el nene se ahogó en un lago de sangre" (Castelnuovo 2003: 45-46).

${ }^{98}$ El realismo ensayado por Castelnuovo tiene su antecedente en las ficciones naturalistas de fines del siglo XIX. Francine Masiello lee esa relación en clave paródica puesto que afirma que en uno de sus primeros libros, Notas de una novela naturalista (1923), el autor "cuestiona los excesos del naturalismo y sus propuestas de 'verdad' en la ficción" (1986: 196). No obstante, Castelnuovo reconsidera la lógica cientificista que rige los textos naturalistas y la utiliza en la construcción de algunos de sus narradores y personajes, sobre todo en aquellos vinculados temáticamente al frecuente tópico de la enfermedad y las degeneraciones. Como acabamos de señalar, Adriana Rodríguez Pérsico (2011) denomina "naturalismo teratológico" a los modos narrativos que practica Castelnuovo durante la década del veinte y treinta.
} 
integran a la aspiración de saber que define su proyecto intelectual y artístico. A su vez, lo dota de un sentido de modernidad.

Castelnuovo se forma leyendo traducciones españolas, puesto que no maneja segundas lenguas "prestigiosas", y de allí que el contacto con el conocimiento y la literatura en lengua no hispánica sea siempre de segunda mano. En este sentido, comparte la misma problemática que Arlt, quien la supo tematizar en el prólogo a Los lanzallamas. Muchas de esas traducciones españolas, que leía en las bibliotecas populares socialistas, eran ediciones baratas de la Casa Sempere. ${ }^{99}$ De estas y de otras lecturas, igualmente castizas, proviene ese registro culto que suele utilizar Castelnuovo. La utilización del verbo "coger" en la acepción del castellano peninsular es un claro ejemplo. ${ }^{100}$ Sin embargo, también se debe considerar la influencia lingüística que pudieron ejercer la gran cantidad de inmigrantes españoles que habitaban en la zona del Río de la Plata. Vale decir entonces que la "alta" cultura se tornó accesible al público y a los escritores populares durante las décadas de 1910 y 1920, gracias al mercado cultural y a la ampliación del lectorado. La literatura culta -por ejemplo, el modernismo- adquirió una difusión muy extensa que produjo el paradójico fenómeno de que aquello que se consideraba propio de la cultura de las élites se convirtió en repertorio de la cultura popular. Este fenómeno permitió que escritores como Castelnuovo, Arlt u Olivari, por ejemplo, accedan a ese tipo de literatura y se conviertan en lectores autodidactas a partir de que la misma cultura popular les franqueó el acceso a la literatura culta. La incidencia de este fenómeno en la reconfiguración de la lengua literaria en los años veinte es decisiva. De este modo, emergen escrituras que, como la de estos autores, mezclan los registros coloquiales con aquellos "refinados" o provenientes de la "alta" cultura.

Cabe preguntarse por qué Castelnuovo trabaja, en determinados momentos, con un lenguaje alejado de la sencillez y claridad que se propone como escritura ideal. El

\footnotetext{
${ }^{99}$ En 1898, el escritor valenciano Vicente Blasco Ibañez (1867-1928) funda la Editorial Sempere. Los textos publicados por esta empresa estaban orientados hacia los sectores populares, dado que se trataba de libros de muy bajo costo, muy accesibles. Entre sus propósitos se contaba el de difundir una cultura ilustrada, laica y científica. Editaron a autores tales como Zolá, Hugo, Gorki, Tolstoi, Ibsen, Nietzsche, Bakunin, etc. Editorial Sempere no sólo tuvo una gran difusión en España, sino también en América Latina. Sus libros influyeron en la cultura obrera y en el mundo intelectual hispanoamericanos. Ver Lluch-Prats (2008). La editorial Sempere resulta un proyecto muy similar al que Antonio Zamora pone en marcha en 1922, bajo el nombre de Claridad: público popular; libros baratos; circuitos de mercado alternativos a los tradicionales; difusión de clásicos de la literatura, la filosofía y las ciencias; privilegio de la dimensión política de la literatura; etc. Castelnuovo se formó intelectualmente, en parte, con las lecturas de Sempere, un proyecto editorial animado por un espíritu similar al de la, por entonces, futura editorial de Zamora: “Allí donde funcionaba una pequeña biblioteca popular, que si no pertenecía a un centro socialista, la fiscalizaba alguna agrupación ácrata, prolongaba mi estadía, y hasta que no leía todo el material subsistente en ella, no me retiraba de ese punto (...) Luego me saturaba bien el intelecto principalmente con las ediciones baratas de la Casa Sempere, que dirigía en Valencia el novelista Vicente Blasco Ibáñez..." (Castelnuovo 1974: 45).

100 "Me preguntó, cogiéndome de las manos si yo no acostumbraba a castigar" (Castelnuovo 2003: 33); "Entonces, cogía el pie con ambas manos..." (53); "Jerónimo, coge, temblando, un cuaderno manoseado..." (110), “... se levanta, coge a Jerónimo por una manga...” (210); “...me cogió del mentón amablemente...” (125).
} 
modernismo y las traducciones expresan sus aspiraciones culturales, es decir los modelos de alta cultura que anhela como forma compensatoria de su deficiente educación formal. ${ }^{101}$ Pero, en su caso, tanto uno como otras corresponden a circuitos culturales populares donde prima la cultura de mezcla, la ausencia de homogeneidad, el amasijo de restos: las lecturas las lleva a cabo en las bibliotecas que son producto de las organizaciones políticas de izquierda; en los libros baratos; y, por su parte, el modernismo se convierte en una "vulgata" gracias al canon escolar y a su difusión popular. ${ }^{102}$ Se trata, en suma, de la "alta" cultura, pero transformada en cultura popular, en cultura de divulgación. En los cruces entre el modernismo hispanoamericano y el naturalismo europeo, entre las tesis de medicina y el diario $L a$ protesta, entre los diccionarios y gramáticas y los textos de divulgación se fragua, al menos en una parte importante, las bases literarias y lingüísticas sobre las que Castelnuovo construye su imagen y sus prácticas de escritura. A su vez, el discurso científico y técnico -lengua oscura, muchas veces-, los saberes del pobre, no sólo tienen que ver con la aspiración al Conocimiento, sino también con el deseo de ser moderno, de adoptar un discurso que denota modernidad durante las primeras décadas del siglo XX.

La claridad y la sencillez son pensadas por Castelnuovo más que nada como el lenguaje literario ideal para las masas populares que se forman como lectores y conforman sus primeras bibliotecas con los emprendimientos editoriales que propone la izquierda. Sin embargo, los materiales culturales, estéticos y lingüísticos disponibles de los que Castelnuovo se sirve, de un modo famélico, ${ }^{103}$ con la finalidad de compensar sus pobrezas simbólicas no siempre contribuyen con un lenguaje transparente. Se podría pensar, entonces, el problema del lenguaje literario en este escritor como la resultante del conflicto que se presenta entre una lengua literaria concebida para los lectores populares y otra, diferente, con la cual se define y busca legitimidad como escritor. Es decir, habría un cierto estrabismo en Castelnuovo dado que si, por un lado, concibe una lengua literaria funcional a sus intereses pedagógicos con respecto al lectorado, por el otro no puede pensarse como escritor solamente a partir del parámetro de claridad didáctica: recurre a los registros mencionados en las páginas anteriores, los que a veces lo apartan de la diafanidad rectora de su escritura. Esta situación reenvía al problema de lo popular en la izquierda, puesto que su interpelación al pueblo iletrado,

\footnotetext{
${ }^{101}$ La falta o incompletud de una educación formal en estos escritores y su correlato, el autodidactismo, explican, en parte, las intenciones pedagógicas que asumió la izquierda en relación con el lectorado.

102 Sara Bosoer señala que "una lectura de los catálogos de las colecciones de literatura barata, en auge a comienzos de la década de 1920, evidencia la predilección por la poesía de Darío y Amado Nervo; y las novelas románticas". Y agrega que, según Noe Jitrik, la prensa periódica habría contribuido a la difusión y popularización del modernismo (2012: 11).

103 "Me apasionaba por toda manifestación de conocimiento: el arte escénico, la pintura, el dibujo, la música, la escultura, las letras, la arquitectura. Todo me gustaba..." (Castelnuovo 1974: 66).
} 
humillado y explotado suele realizarse tomando como punto de referencia la cultura establecida. Es decir, la "alta" cultura estaría funcionando como el horizonte que define los ideales igualitarios de la izquierda "hacia arriba"; o sea, planteando el acceso a la cultura como un ascenso que se define a partir del universo simbólico de las élites. La tensión entre lo popular y la alta cultura no sólo desafía la construcción del lenguaje literario en Castelnuovo, sino que además involucra los posicionamientos de la izquierda en el campo letrado.

\subsection{La dimensión de la oralidad}

Escritores como Castelnuovo definen las actitudes sobre la lengua literaria en una dimensión ético-estética, en la cual ciertos males sociales, inmorales en sí mismos, e indeseables para el desarrollo de una mejor sociedad -como por ejemplo, el juego, la prostitución y el mundo del delito-comportan lenguajes igualmente negativos. Pero también a todo aquello que distrae y atenta contra la educación general, en la cual el lenguaje resulta un aspecto central. Así, los géneros masivos -folletines, teatro popular, diarios de gran tirada, el tango- son rechazados por este sector. Cada uno de estos géneros se constituye a partir de formas de lengua específicas, en alianzas diversas con la oralidad. De este modo, por ejemplo, el lunfardo se constituye en un insumo importante para numerosos géneros y artistas. Este vocabulario, a lo largo de los años veinte, será muy combatido por la izquierda literaria en general; y por Castelnuovo, en particular. ${ }^{104}$ En Claridad, podemos leer "incorrecciones" en la redacción de los textos, en sus aspectos gramaticales, sintácticos u ortográficos. Sin embargo, debemos entender esto como las manifestaciones de las carencias de formación de los autores, provenientes de los márgenes, y no como una intencionalidad estética propia de un proyecto creador determinado.

La precariedad del capital cultural con que contaba un escritor como Castelnuovo ${ }^{105}$ explicaría su aspiración a una lengua literaria culta y la adhesión a normas de corrección idiomática. La ignorancia es lo aborrecido para estos escritores: lucharon duro para salir del "oscurantismo" producto de una escolarización incompleta y un ámbito socio-cultural precario y abocado al mundo del trabajo. Lo que les permitió superar esa precariedad es la lectura. Habría entonces, por parte de la izquierda literaria, una idealización de la cultura oficial y entendieron a la educación popular como vía de acceso al conocimiento y la "verdad". La posición insegura y distante que los escritores de izquierda mantuvieron con la

\footnotetext{
${ }^{104}$ Entre los años 1926 y 1927, la revista Claridad inicia una agresiva campaña contra el diario Crítica. La revista de Zamora lo acusa de inmoralidad, de utilizar lenguajes prostibularios como el lunfardo, y de fomentar un tipo de literatura que desde esta publicación se la denomina "literatura maleva". Ver capítulo III.

${ }^{105}$ Ver Memorias (1974).
} 
cultura escolar hizo que se aferren a sus reglas y normativas, y las hayan convertido en preceptos para la elaboración de sus lenguas literarias. Castelnuovo luchó contra la imagen que el circuito "culto" tradicional construyó de él, ${ }^{106}$ y trató de revertirla con estos posicionamientos culturales, literarios e idiomáticos.

Las traducciones cobran vital importancia para que los escritores, en vías de formación, accedan a los autores de la literatura universal. En el anverso de la literatura, encontramos las gramáticas y los diccionarios, que terminan de componer un lenguaje. Sin embargo, en la literatura de Castelnuovo, la oralidad no es un ingrediente segregado completamente, sino un principio activo que por momentos intenta entrar al texto, sólo que las normas del "buen decir" que priman hacen fracasar su ingreso, y convierten a la oralidad en un registro incompleto, abortado. En este sentido, la de Castelnuovo es una lengua literaria en tensión, bien propia de los años veinte, atravesada por fuerzas antagónicas que son, finalmente, las que le brindan su forma.

De este modo, en Tinieblas, existen voces provenientes del registro coloquial que, sin embargo, se encuentran filtradas por un registro literario apegado a cierta norma que impide su completo desarrollo, la cual se corresponde con una lengua "semejante y diferente al castellano rioplatense", que es el de las traducciones que publican Los Pensadores y Claridad; una lengua que se presenta como el modelo del lenguaje literario o culto, castiza, con muchos elementos arcaizantes ${ }^{107}$ (Montaldo 1987b).

Los relatos de Tinieblas están contados por un narrador cuyo registro se ajusta a ciertas normas de uso más o menos correctas del idioma. Sin embargo, y por este motivo, la oralidad se desdibuja cuando intenta aparecer en los diálogos, puesto que en su mayoría lo hace de manera ambigua, mezclada muchas veces con el registro escrito. Si por un lado, por ejemplo, se incorpora una suerte de lenguaje que remeda el registro oral -“¡Se paróooo!...” (Castelnuovo 2003: 26)-, por el otro aparecen largas parrafadas que colocan al registro escrito allí adonde debería primar el tono coloquial. Como por ejemplo en el siguiente diálogo, en el que aparece un tuteo frecuente tanto en los modelos literarios en los que se apoya (traducciones y textos españoles), como así también en la oralidad de los inmigrantes españoles:

\footnotetext{
${ }^{106}$ Por ejemplo, desde la revista Nosotros, Julio Noé, si bien mira con buenos ojos su libro de cuentos Tinieblas, no deja de exhibir su rusticidad cultural y la necesidad de pulir tanto su estilo como su espíritu: "Elías Castelnuovo (...) acaba de publicar un volumen de relatos titulado Tinieblas (...). Su libro es un diamante sin desbastar, como el propio espíritu del autor, pero entre una y otra arista sin pulimiento se advierte la luz de la piedra preciosa (1923: 473).

107 Dado que el grueso del lectorado al cual se dirigen los escritores de izquierda pertenece a un origen inmigratorio, las políticas lingüísticas que despliegan en sus publicaciones parecen estar en consonancia con las que se emanan desde el Estado y se aplican en el nivel educativo: un castellano regido por normas peninsulares cuyo objetivo es la instrucción y homogeneización lingüística.
} 
- ¿Sabes qué pensé hacer? No lo digas a nadie: pensé colocarme otra vez el hábito de la Virgen del Carmen...

- Sí, sí, el hábito oscuro, las sandalias negras... ¿te acuerdas? (48).

Sin embargo, el voseo no se encuentra totalmente desterrado de la escritura de este autor. Muy por el contrario, Castelnuovo vacila y utiliza alternativa e indistintamente el tuteo o el voseo en sus textos. En el mismo cuento al que pertenece la cita anterior, "Tinieblas", los mismos personajes -el protagonista y Luisa- hacen uso del voseo: “¿Por qué me hablás así entonces? ¿Por qué me decís eso a mí que te quiero tanto?” (42).

La presencia del tú en la literatura argentina del período, lejos de ser una forma en retroceso, se mantiene vigente. No sólo es utilizado por los autores más conservadores, sino también por los jóvenes escritores que tienen incluso una visión transgresora sobre el idioma y la lengua literaria. De este modo, por ejemplo, es posible encontrar un uso del tú no sólo en Manuel Gálvez o Enrique Larreta, sino también en Enrique González Tunóon, Nicolás Olivari o Ricardo Güiraldes; como así también en algunos géneros populares, tales como las narraciones semanales o las letras de tango. El vos y el tú conviven tanto en la literatura del período como en el heterogéneo habla del Río de la Plata, se tensionan en configuraciones estéticas diversas, convergen muchas veces en un mismo texto, como los de Arlt por ejemplo, elaborado, muchas veces, bajo una "dualidad de normas" (Borello 1974: 13). La persistencia del tú se entiende como la perseverancia de las tradicionales concepciones de la literatura que la entienden como modelo de lengua escrita y correcta. El vos, en cambio, es "el punto neurálgico en que se tocan las lenguas literarias y cotidiana y sus respectivos mundos" (Prieto 1956: 133). El uso o no del voseo es uno de los indicios que muestran las reconfiguraciones de la lengua literaria en los años veinte como oscilaciones, intercambios, negociaciones o disputas entre las representaciones de la escritura y la oralidad. ${ }^{108}$

El relato de Tinieblas que más se empeña en producir un efecto de oralidad es "De Profundis", y esto se nota cuando se insertan los pasajes correspondientes a los hablantes brasileros. ${ }^{109}$ En el siguiente ejemplo, observamos cómo además de dar con un portugués más fonético que ortográfico, se pretende imitar el tartamudeo del personaje: “Es... tou po... bre fillo me... u... Nao tenio nada para darte... na... da... na... da... Eu sin... to ter que dizerte isto as... $\operatorname{sim} . .$. assim..." (56). La deformidad o la "anormalidad" como manifestación del mal social parecería también querer encarnar en la versión de la oralidad que ofrece el texto,

\footnotetext{
${ }^{108}$ Los problemas en relación con el tú y el vos se abordan brevemente en los capítulos I y V.

109 "De profundis" narra el viaje iniciático del protagonista por tierras uruguayas y brasileras, cuando decide abandonar la casa familiar para sumirse en la dura aventura que le propone ese largo periplo. En el Brasil pasará buena cantidad de tiempo, y trabajará duramente. Por esta razón, en el cuento abundan las voces en portugués.
} 
como se puede observar en el tartamudeo de la cita. Pero el relato pronto regresa a un registro deliberadamente limpio de coloquialismos. Es decir, Castelnuovo se interesa por determinadas formas de la lengua, en la medida en que incorpora a sus relatos el portugués, el guaraní o la lengua oral del interior de la Argentina y del Uruguay; sin embargo, como bien lo señala Astutti, estas formas siempre se encuentran "separadas del discurso del narrador, recluidas en los diálogos y entrecomilladas" (2001: 437), separación característica de la literatura culta.

La confluencia de registros cultos y populares no es privativa de Castelnuovo ni de la izquierda literaria. Por ejemplo, Güiraldes, en su Don Segundo Sombra, hace hablar a sus reseros con un lenguaje acorde (gauchismos), pero también claramente diferenciado del lenguaje del narrador, mediante comillas o guiones de diálogo. Sobre este aspecto, Castelnuovo recomienda:

El lenguaje de cada individuo forma parte de su psicología. Tan falso resulta un personaje cuando habla bien porque el autor conoce el idioma, como cuando habla mal porque el autor lo desconoce. Porque el teatro nacional tiene dos especímenes de autores: el que habla falsamente bien y que habla falsamente mal. Cuando un personaje habla su lenguaje no se advierte ninguna de las dos cosas: ni de que habla bien ni de que habla mal porque habla lo justo (Chaves 1927a: 20, destacado nuestro).

En primer lugar, cabe señalar que la dicotomía "hablar bien" / "hablar mal" que utiliza Castelnuovo evidencia que, aun en estas instancias en las que parece defender la expresión genuina de los personajes, siempre se coloca en una norma estética e idiomática determinada desde la cual establece lo que debe considerarse como "buena" o "mala" escritura. Pero además imagina una lengua literaria sin mediaciones, es decir sin el artificio y las reelaboraciones que supone siempre la construcción literaria de una voz. Esta situación explica la imposibilidad de llevar a la práctica lo que recomienda en la cita, es decir, que el personaje hable con su propio lenguaje. En segundo lugar, la propuesta de Castelnuovo choca contra otro problema: el rechazo radical que tanto este autor como otros escritores de izquierda experimentan por determinadas formas de la "lengua popular", particularmente el lunfardo y el cocoliche. ${ }^{110} \mathrm{Si}$ bien existía un uso extendido en diversas capas de la sociedad rioplatense, estos registros corresponden también a una construcción del mercado periodístico, teatral y literario. Y, en este sentido, el rechazo de estos lenguajes por parte de los escritores de izquierda puede ser entendido, además de en su dimensión moral, como una disputa por el público.

\footnotetext{
${ }^{110}$ Ver Oliveto (2011), Rogers (2011b, 2012b).
} 
No sorprende que posicionados desde los parámetros de la corrección y el respeto por las normas del "buen decir", estos escritores hayan desplegado fuertes invectivas contra el lunfardo y contra todos aquellos que hacían uso de él en el periodismo y en la literatura. En el plano literario, Claridad bautizó con el nombre de "literatura maleva" a aquella que trabajaba con una lengua literaria basada en el lunfardo. En 1926, la revista de Zamora publica un artículo, que analizaremos más detenidamente en el capítulo siguiente, cuyo título es precisamente "Literatura maleva", en el que se afirma:

\footnotetext{
Desde un tiempo a esta parte se cultiva entre nosotros un género de literatura incalificable al que vamos a calificar eventualmente de literatura maleva. Dicha literatura pretende encarnar el alma del arrabal y reproducir su lenguaje característico (...) Digamos que lo más típico de semejante literatura es el léxico: "Piantá que te cacha el peine; quéhacés, qué hacés, tres veces qué hacés; salí de ay salí; manyá que te juno; cotorro, bulín, fianqueta, al vesre, funge, biaba, papusa, rantifusa, etc.” (“Literatura maleva” 1926: 1)
}

Como se puede observar, nos encontramos en presencia de otra tensión entre las conceptualizaciones de Castelnuovo y su práctica literaria concreta. El autor de Tinieblas queda encerrado en sus propios razonamientos porque si, por un lado, recomienda no falsear las voces de los personajes, por el otro le resulta inconcebible dar lugar al lunfardo en sus textos. Si rechaza explícitamente el "lenguaje popular" y la oralidad, ¿cómo solucionar entonces la contradicción que resulta de representar un personaje orillero, marginal, prescindiendo de las voces populares? ¿Cómo evitar esa "falsedad” sobre la que llama la atención si se escribe desde una norma dominante, monológica y jerárquica, que repele todo "hablar mal" del texto?

El cuento "Desamparados" narra el amor imposible entre una prostituta, Aurelia, y un vagabundo, Jerónimo. Luego de fracasar en el intento de conseguir un trabajo que aparte a Aurelia de su mala vida y reúna la pareja bajo un mismo techo, Jerónimo se entrega al mundo del crimen para conseguir dinero. De esta manera, culmina preso, mientras que Aurelia, ante la imposibilidad de volver a estar con su amado, se suicida. En la cárcel, Jerónimo trabaja en una imprenta. Allí le llega a sus manos una tesis médica, "El estado mental del suicida". Su función consiste en componer las galeras de un capítulo de ese trabajo: "El suicidio por la pasión amorosa". Leyendo ese texto se entera de la desgraciada historia de Aurelia. En la tesis confluyen las voces de Aurelia, a través de la transcripción de su cuaderno o diario íntimo, y la del médico que evalúa y juzga el caso. Jerónimo es quien administra y comenta las voces del texto. En el diario, Aurelia explica con detalle sus padecimientos y el motivo de su última 
decisión. Interesa este relato porque allí se observan con claridad las tensiones y desplazamientos que se producen en la lengua literaria de Castelnuovo.

Al comienzo, aparece la voz del médico, a través de la historia clínica de la paciente. No obstante, no se limita a la exposición del caso, sino que juzga la relación de la pareja y la conducta moral de Aurelia: “"Había llegado a querer con irresistible afecto a un hombre [Jerónimo] que no le correspondía por igual y en su triste condición de mujer libertina no le era posible exigir de nadie el perdón..." (2003: 109-110). A partir de allí, en el cuento predomina la voz de Aurelia (el cuaderno) mientras que la del médico (la tesis) aparece referida y comentada (casi siempre negativamente) por Jerónimo.

Lo que interesa de este relato es que en la narración directa de Aurelia, entrecomillada, no aparece ninguna marca idiolectal o del perfil lingüístico del personaje. El texto está escrito en un español depurado y correcto, del todo improbable para un personaje de las características de Aurelia. Sin embargo, las tensiones aparecen cuando se filtran unas pocas formas lingüísticas "incorrectas", orales, como por ejemplo: "pero vos vistes que aquí, en medio de tanta escoria, había un corazón noble (...) vos lo vistes desde el primer día..." (115, destacado nuestro), o bien "te perdona porque no fuistes vos que me matastes..." (118, destacado nuestro). También aquí tiene lugar el uso alternativo y vacilante del tú y el vos: "vos también pasarás dolores, muchos dolores por mi culpa (...) Escucha: no quiero morir aquí, eso sí que no..." (114-115, destacado nuestro).

Luego aparece un párrafo interesante que permite repensar la escritura de Aurelia: "Vienen unas reflexiones torvas, donde el autor [el médico] señala varias 'incorrecciones gramaticales', dejando traslucir que para suicidarse, es indispensable conocer gramática" (117). La cita habilita la posibilidad de que la transcripción del cuaderno se encuentre reformulada por el médico. Sin embargo, si este fuera el caso, no se comprendería la presencia simultánea de las “impropias" que aparecen en el cuaderno de modo aislado e infrecuente. Pero la cita también pone en evidencia que, efectivamente, en el texto de Aurelia existían marcas de su "propio" lenguaje (errores gramaticales) que han sido eliminados por el "buen decir" del médico. Sólo quedan, como marcas de la tensión señalada, los dos o tres ejemplos que hemos puesto de manifiesto. El médico asume la función de la voz culta que corrige la expresión oral del otro; de quien el narrador se distancia con ironía crítica en una escena que a partir de ese entrecruzamiento expresa uno de los dilemas de la literatura argentina: los vínculos problemáticos entre la cultura oral y la escrita. Si pensamos esta escena en serie literaria, podemos evocar el canto XVI de La vuelta de Martín Fierro (1879), 
cuando el segundo hijo de Fierro relata el delicado estado de salud de Vizcacha. ${ }^{111}$ En ese momento, uno de "ajuera", que estaba parado en la puerta, lo corrige en dos oportunidades: en primer lugar, le señala que no se dice "tabernáculo", sino "tubérculo"; y luego advierte que a las mujeres que curan no se las llaman "culandreras", sino "curanderas". El episodio ha sido finamente estudiado por Josefina Ludmer, ${ }^{112}$ para quien este momento del Poema marca la irrupción de "la escena didáctica de la corrección de la voz del gaucho" (Ludmer 2000: 236). El intercambio entre ese representante de la norma lingüística y el hijo de Fierro se configura como "una lección de lengua nacional", una lección que es también el choque entre dos culturas, la oral y la escrita. Dentro del género, hasta ese momento, nunca estas culturas habían tenido un duelo verbal tan fuerte (Schvartzman 2001).

A diferencia de lo que ocurre en el poema de Hernández, en donde resulta imposible que la palabra letrada se imponga puesto que de esa manera el género dejaría de existir, en el relato de Castelnuovo prevalece el registro escrito y prescriptivo. Nos encontramos aquí con la situación inversa a la del poema de Hernández: el género gauchesco sostiene la primacía de la voz oral y facilita una rápida eliminación del corrector. Sin embargo, en el texto de Castelnuovo, el registro de la oralidad se encuentra domeñado por la escritura: el médico vendría a tomar el lugar del "guey corneta" de Hernández, pero en lugar de estar "ajuera" y hablar desde "la puerta", el médico lo hace desde adentro del texto, desde el interior del cuaderno de Aurelia, en una clara situación de dominio discursivo. En este relato, el médico representa la institución estatal de la lengua letrada en la medida en que los escritores de izquierda, como hemos dicho, para escribir su literatura se afirman en la norma y en el valor del idioma de la institución escolar y de las gramáticas.

Este fragmento del cuento "Desamparados" ilustra bien las tensiones que se producen en la lengua literaria de Castelnuovo, quien queda torsionado, a medio camino, entre dos opciones: por un lado, la de perseguir una escritura "incorrecta", es decir darle una voz genuina al personaje de Aurelia y, por el otro, permanecer fiel a las pautas de corrección a las que somete todos los relatos de la obra. Es decir, junto a la lengua literaria correcta, clara y apegada a la norma, emergen los registros coloquiales y populares. No obstante ello, estos últimos aparecen interferidos por el "buen decir" que busca dominar en el texto. Castelnuovo

\footnotetext{
111 “Cuando el viejo cayó enfermo/viendo yo que se empioraba,/y que esperanza no daba/de mejorarse siquiera/le truje una culandrera/a ver si mejoraba/En cuanto lo vio me dijo: 'Este no aguanta el sogazo/muy poco le doy de plazo/nos va a dar un espectáculo,/porque debajo del brazo/le ha salido un tabernáculo'/Dice el refrán que en la tropa/nunca falta un güey corneta/uno que estaba en la puerta/le pegó el grito ahí no más:/‘Tabernáculo... qué bruto,/un tubérculo dirás'./Al verse ansí interrumpido/al punto dijo el cantor:/‘No me parece ocasión/de meterse los de ajuera,/tabernáculo, señor,/le decía la culandrera'./El de ajuera repitió/dándole otro chaguarazo/‘Allá va un nuevo bolazo/Copo y se lo gano en puerta:/a las mujeres que curan/se les llama curanderas"”. (Hernández 2001: 370-371)

${ }^{112}$ También fue abordado, brevemente, por Julio Schwartzman, en su Microcítica (1996: 168-171).
} 
asume como propias las normas estéticas e idiomáticas conservadoras (que aplica también cuando lee y juzga a escritores como Roberto Arlt). ${ }^{113}$ Los personajes pobres y marginales son los preferidos de Castelnuovo, sin embargo al adjudicarles una voz la norma que rige su lengua literaria obtura las posibilidades expresivas de estos personajes.

Como ya hemos mencionado, al igual que otros escritores de izquierda, Castelnuovo sostiene un discurso en el que se opone a la escritura literaria "embrollada", poco clara, al "ruidito" vanguardista y a todas aquellas estéticas en las que prevalece la forma por sobre el contenido que se quiere transmitir. También reacciona contra el lunfardo y contra las expresiones "incorrectas" del idioma. La mayoría de los autores que componen esta zona emergieron de un subsuelo cultural, puesto que se convirtieron en escritores con mucho trabajo, gracias a un aplicado autodidactismo, en el que las gramáticas y diccionarios cumplieron una tarea muy importante. $\mathrm{Y}$, en esos comienzos, en los que la lectura y el hambre de conocimientos cobran un lugar central en su vida, la gramática asume una importancia tal que, en sus recuerdos, adopta dimensiones épicas: narra la manera en que a los quince años abandona el hogar, a instancias del maltrato y explotación de su cuñado, y recorre el Uruguay y el Brasil. ${ }^{114}$ En todo su periplo, la gramática lo acompaña y se convierte en un símbolo de su lucha contra las adversidades, pero también en puente para alcanzar sus primeras experiencias laborales: ${ }^{115}$

... al final, tomé una resolución heroica y me largué a pie en procura de una colonia cercana, distante unos cien kilómetros del lugar, por un camino escarpado y desierto, llevando conmigo tan sólo la gramática (...) Marchaba siempre con la gramática a cuestas, chorreando lodo y agua, muerto de hambre y aterido de frío (47).

Escritores como Castelnuovo diseñaron estrategias "para autorizarse frente a un público inculto y masivo al que no se pretende servir como un esclavo sino elevar y educar" (Astutti, 422). En ese marco, el español sujeto a pautas de corrección será la variedad deseable para la lengua literaria de estos autores $\mathrm{y}$, por consiguiente, para este nuevo lectorado. Aunque esa

\footnotetext{
${ }^{113}$ Como se sabe, cuando Arlt le lleva los borradores de su primera novela, todavía llamada Vida puerca, con la intención de que la apruebe para ser publicada en la colección Los Nuevos, Castelnuovo le niega esa posibilidad arguyendo deficiencias en el estilo y en el lenguaje.

${ }_{114}$ Este episodio se encuentra tematizado en el cuento recién analizado "De profundis", perteneciente a Tinieblas.

${ }_{115}$ Castelnuovo refiere un episodio en el que cuenta cómo gracias a la gramática consigue un trabajo de escribiente. El libro llama la atención de sus futuros empleadores, los predispone de manera positiva dado que "un vagabundo con un libro bajo el brazo, seguramente infunde más confianza" (Castelnuovo 1974: 48). De esta manera, "gracias a la mediación accidental de la gramática (...) esa misma noche conseguí empleo de escribiente en la receptoría de rentas de la villa..." (49).
} 
elección, como hemos visto, no se encuentra desprovista de tensiones y contradicciones evidentes.

\subsection{Clara Beter, la mujer que no se puede nombrar}

En 1926 se publica, en la colección Los Nuevos de la editorial Claridad, Versos de una..., el poemario apócrifo que César Tiempo firmó con el seudónimo Clara Beter. Los poemas escritos por una prostituta, en los cuales daba cuenta de sus desgracias, sus sueños, el nostálgico pasado y las amargas condiciones de su marginación presente, resultaron de sumo interés para los escritores de izquierda, quienes vieron en Clara Beter el mejor ejemplo de una literatura testimonial que decía revelar las condiciones reales de existencia del oprimido. Para estos escritores, la experiencia resultaba un instrumento fundamental para justificar la escritura literaria. Por eso, los obreros son quienes mejor pueden dar cuenta del mundo del trabajo puesto que participan de esa experiencia (Candiano-Peralta 2007). Como se sabe, así se constituye lo que la vanguardia de izquierda denomina literatura social. Los versos de Clara Beter se configuran como otra arista de los testimonios del oprimido. Además, la obra constituye una pieza, si no rara, al menos singular en la medida en que quien se supone que escribe es una prostituta (pero no, es un hombre y escritor), una voz que no aparece con frecuencia en la literatura de la época ${ }^{116}$ pero que, sin embargo, constituía uno de los tópicos referenciales más visitados no sólo por la izquierda, sino también por casi todo el arco literario de los años veinte.

César Tiempo explica la génesis del fenómeno "Clara Beter” del siguiente modo:

Cierto día mi alter ego recibe un regalo inseperado, los Diálogos de Platón, editados por la Universidad Nacional de México. Y allí descubre la sentencia atribuida a Sócrates en "Felón o del Alma" (sic): "Un poeta, para ser un verdadero poeta no debe componer discursos en verso, sino inventar ficciones". Sugestionado por la recomendación y, sobre todo, ganoso de dar candonga a los camaradas mayores que se resistían a creer en los talentos del mequetrefe, el tal escribe una poesía dedicada a Tatiana Pavlova, la gran actriz ítalorusa que por aquel entonces arrebataba al público de Buenos Aires desde el escenario de un teatro porteño (1974: $17)$.

La primera ficción que inventa Tiempo al respecto consiste en la creación de la prostituta, Clara Beter; luego vendrán, uno en uno, sus poemas. El mismo autor se da cuenta

\footnotetext{
${ }^{116} \mathrm{Si}$ bien la prostituta resulta un tipo literario muy frecuente en la literatura de las décadas de 1910 y 1920 , raras veces se le cede la voz. Si tenemos en cuenta esto, se comprende mejor el interés que el libro de Tiempo había despertado en el grupo de Castelnuovo.
} 
de que esos versos "engarzan con puntualidad prefabricada en la estética redentorista de Boedo" (18), tal es así que le fue "fácil deslizar entre los originales de Claridad los versos firmados por Clara Beter" (18). La recepción de esos poemas, por parte de los escritores de izquierda, fue por demás auspiciosa: "Castelnuovo, el gran Castelnuovo, se desata en un elogio ardoroso" (18) que lo conduce a afirmar que esos versos "rezuman demasiada verdad", a tal punto que asegura la existencia de la poetisa y descarta rápidamente la peregrina idea de que puedan ser atribuidos a "una imaginación desgobernada" (18). Finalmente, Versos de una..., título escogido por sus editores, aparece en la colección Los Nuevos, y constituye su octavo volumen. Parejamente a que el fenómeno "Clara Beter" crece ${ }^{117}$ también lo hacen las sospechas del autor de Tinieblas, quien ya se había comprometido a escribir el prólogo de la obra. "La superchería asumía proporciones peligrosas para el autor" (22), y a lo ya señalado debe agregarse que los editores se empeñaron en que Beter escriba una novela. Cabe añadir también que el libro había sido inscripto en el Premio Municipal de Poesía por Carlos Serfaty, con su nombre (22). Por todo esto, César Tiempo decide develar el misterio. Y la reacción de Castelnuovo no se hizo esperar. Así lo recuerda el creador de Clara Beter: “...Elías Catelnuovo (...) cuando se enteró del engaño, publicó un artículo señalando que todos habían sido defraudados. Pues la tal prostituta había resultado un prostituto. El prostituto era yo" (24).

Los escritores de izquierda afirmaban que ellos no sólo representaban "la voz del pueblo", sino que eran esa voz, puesto que muchos provenían de las clases proletarias. Explica Castelnuovo en el prólogo a Versos de una...: "el núcleo de escritores al cual nos venimos refiriendo ha descendido al pueblo. Mejor dicho, no ha descendido: surgió del pueblo mismo. Probablemente los parió la calle como a Clara Beter o el conventillo como a Juan Palazzo" (Chaves 1998: 32). Sin embargo, en esta cita se puede apreciar la distancia que Castelnuovo establece entre el escritor y los sujetos a los que dice representar. Esa distancia se manifiesta en su lengua literaria, en las tensiones entre las pretensiones de claridad y las búsquedas formales que las traicionan. Bien miradas, estas palabras de Castelnuovo casi constituyen un lapsus que parece querer enmendar rápidamente, pero del cual no parece consciente del todo puesto que no las borra. Nos referimos a esa significativa contradicción entre el "descender" al pueblo y ser parte de él. La cita también pone en cuestión esa supuesta cercanía entre escritor y pueblo que pregona la izquierda literaria y en la cual fundan su diferenciación con otros sectores, principalmente con el martinfierrismo.

\footnotetext{
${ }^{117}$ El uruguayo Alberto Zum Felde escribe algunos artículos en El Día de Montevideo, e inventa una biografía de la poetisa; por su parte, Roberto Ibáñez le dedica un estudio en el mismo diario; las ventas del libro alcanzan cifras increíbles y se traduce al alemán con destino a una editorial suiza (Tiempo, 1974: 20).
} 
Más allá de la declaración de principios de los escritores reunidos en torno a Claridad, no era posible recrear la voz del pueblo en un sentido pleno: su lengua literaria estaba plagada de tensiones y contradicciones en la medida en que en ella coexistían diversas, y a veces incluso opuestas, normas estéticas y lingüísticas, aunque con un claro predominio de las normas prescriptas por gramáticas y diccionarios.

Por aquellos años, la voz del pueblo fue un objeto de disputa en distintas zonas del campo literario que alegaban afinidad con los sectores populares. Varios frentes pretendieron asumir la responsabilidad de esa representación. Por ejemplo, el diario Crítica, en su edición del día 18 de abril de 1923, se proclamaba como la voz del pueblo. En un artículo titulado "Hoy hace un año que apareció triunfalmente el primer número de las $5^{\circ}$ edición de Crítica", y en el tono de balance que la fecha ameritaba, se puede leer:

\footnotetext{
Nuestra única satisfacción (...) es la de haber entrado en el alma del pueblo (...) Pensamos con la mente del pueblo y proclamamos valerosamente su pensamiento: hablamos con su voz, y es su alma, grande y noble, la que presta elocuencia a nuestra voz ("Hoy hace un año...." 1923: 1, destacado nuestro).
}

En el famoso artículo publicado en Martín Fierro, "Martín Fierro y yo", y al cual se juzga iniciador de la polémica entre los denominados grupos de Boedo y Florida, Roberto Mariani señala a Nicolás Olivari como una voz de Buenos Aires: "he aquí una voz, una voz de muchacho porteño, de hoy y aquí: Nicolás Olivari” (1924b: 46). La vanguardia de izquierda reitera su propiedad sobre la voz de las clases explotadas en el prólogo que Elías Castelnuovo escribe para Versos de una...Allí, el autor de Tinieblas declara: "Clara Beter es la voz angustiosa de los lupanares" (Chaves 1998: 33).

La noción de voz implica, necesariamente, un determinado abanico de opciones en el plano del lenguaje. El libro de Clara Beter -igual que en Tinieblas de Castelnuovo- conserva la aspiración a un castellano ceñido a pautas de corrección refractarias a los registros y variedades populares. Estos escritores vieron en el referente -en los proletarios y marginados; en el suburbio; en la fábrica; en la narración de la explotación, la pobreza y la humillación- el insumo principal de esas voces, sin embargo desdeñaron las formas expresivas de los sectores que pretendían representar.

Juan Palazzo, autor de La casa por dentro (1921), novela en la que se relata las miserias de la vida en los conventillos porteños, es un precursor de los escritores de 
izquierda $^{118}$ (Giordano 1986) quienes sin embargo descartaron las formas lingüísticas usadas en los inquilinatos. En la mayoría de sus textos, no aparece ninguna elaboración del lenguaje de mezcla hablado en los espacios reales de la ciudad. Es más, desde las páginas de Claridad libraron campañas contra estos vocabularios y contra las publicaciones y autores que se servían de ellos. ${ }^{119}$ En este sentido, y paradójicamente, la izquierda encuentra en la lengua estatal el modelo para una lengua literaria "popular", colocándose a caballo entre los sectores populares y la cultura letrada. En esa intersección, en la que la educación a través de los libros como vehículo de la alta cultura cumple una función primordial en su modelo cultural y pedagógico, se dirimen sus posicionamientos con respecto al lenguaje literario.

Clara Beter es una prostituta ficcional que reúne ciertas condiciones que explican y contradicen, al mismo tiempo, la voz que enuncia en los poemas. En primer lugar, se trata de una inmigrante, su tierra natal es Ucrania. En segundo término, Clara, obviamente, sabe leer y escribir. Finalmente cabe agregar que vive en los arrabales de las grandes ciudades, ya sea en Buenos Aires -se menciona La Boca- o en Rosario -se refiere al barrio Echesortu-. Pese a estas coordenadas que definen a la poetisa inventada, Clara no recoge las voces de su medio, sino más bien todo lo contrario: utiliza un español culto -que abreva en el modernismo y en el tardoromanticismo- que se manifiesta en el uso de ciertas frases y en un vocabulario determinado: "vaso de acíbar" (Beter 1998: 39), "faz” (40) para referirse al rostro, "mustio" (40), “hogaño" (42), “estrépito” (42), “salacidad de fauno” (43), “escanció” (48), “caolín” (51), "hetaira" (51), "alacridad” (52), "grama” (52), "muellemente” (52), "lábaros" (55), “parvo" (58), "ruzafa” (63), "marisabidilla" (68) "fosco" (72), etc. Estas formas lingüísticas presuponen una lectora del canon poético accesible al lector popular, con cierto nivel de instrucción. $^{120}$

Como hemos dicho, Clara Beter es ucraniana ${ }^{121}$ y permaneció en su país hasta bien entrada la infancia: “¡Oh, los días felices de la infancia lejana / en el rincón humilde de la

\footnotetext{
118 “... Los integrantes del grupo de Boedo (lo) catalogaban como una de sus influencias literarias más notables dentro del país. Palazzo murió de tuberculosis poco tiempo antes de que surja Boedo, vivía en un 'conventillo infecto' como el de Lázaro y fue autor, en 1921, de La casa por dentro (...). La proximidad entre este escritor y el protagonista del cuento de Castelnuovo se manifiesta más profundamente cuando leemos que Lázaro ha escrito una obra llamada El conventillo por dentro." (Candiano-Peralta 2007: 219-220).

${ }^{119}$ Ver capítulo III, en el que se aborda la campaña de Claridad contra el diario Crítica.

120 En el poemario, existen numerosas referencias literarias: en un poema que alude explícitamente a su condición de lectora -"Leyendo" (Beter 1998: 45)- se menciona el "Cancionero" del español Enrique de Mesa. Otra referencia a la lectura aparece cuando dice que está "saboreando un libro de versos" (54). Además, hay un poema cuyo título es "Glosando a Bécquer" (58), el cual incluye un fragmento perteneciente a este autor: "mientras haya una mujer hermosa habrá poesía." Por último, hay una referencia a Rubén Darío, más precisamente al poema "Canción de otoño en primavera", incluido en Cantos de vida y esperanza, los cisnes y otros poemas (1905), cuando Clara expresa: "La vida es dura; amarga y pesa -dijo aquel lírico sutil.” (78).
}

$121 \mathrm{Su}$ inventor, Israel Zeitlin (César Tiempo), nació en Ucrania pero se trasladó a Buenos Aires muy tempranamente. 
Ukrania natal" (38). Si tenemos en cuenta este dato clave, resulta extraño no sólo el manejo "correcto" del español, sino la ausencia de marcas que evidencien su lengua materna, apenas esbozada en la toponimia y en los personajes que recorren su infancia.

El personaje-autor de Clara Beter reunía muchos aspectos, entre ellos una lengua literaria que no contravenía los presupuestos de la izquierda literaria, por lo cual el libro fue muy bien recibido por los escritores vinculados con ella. Uno de los postulados fundamentales de la vanguardia de izquierda consistió en que la literatura se legitima en función de lo vivido por el escritor, es decir, la literatura cobra sentido en función de un criterio de verdad que sólo puede darse cuando quien escribe ha tenido la experiencia directa de lo que narra. Castelnuovo es el primero que autoriza los versos de Beter al sentenciar que en ellos existe “demasiada verdad”. Los Versos de una ... tiene una escritura que resultaba verosímil para los parámetros ideológicos y estéticos de la izquierda; sin embargo, esta no se preocupó de que la verosimilitud estuviese sustentada por un uso del lenguaje literario acorde con las características de quien supuestamente escribía.

\subsection{Versos sobre la calle: Álvaro Yunque}

Como ocurre con otros textos de los autores nucleados en torno a Claridad, Versos de la calle de Álvaro Yunque -segundo volumen de la colección Los Nuevos- se rige bajo parámetros similares a los de las obras de los escritores de izquierda que lo precedieron y sucedieron. Enmarcado en una poesía realista y tradicional, este libro se propone como un recorrido por las calles de la ciudad de Buenos Aires. El suburbio y los conventillos configuran sus escenarios principales. Sin embargo, su mirada descriptiva y denunciante no se introduce lo suficiente en estos inquilinatos como para rescatar las "babélicas" voces que allí se dan cita:

Conventillo

Costra en los muros y opacos los vidrios;

faz de leproso es su fachada.

Tuberculosos, deformes y anémicos

su puerta, boca inmunda, traga.

Oh, lo que hacer no pudiera un milagro lo hizo la avaricia humana:

¡Ya consiguió que no fuesen de todos

ni el aire ni la luz ni el agua! (Yunque 1977: 14). 
En relación con los otros textos analizados hasta el momento, el de Yunque es el que evidencia una relación más estrecha con el español peninsular. Esto se manifiesta, por ejemplo, en la utilización del "vosotros" y sus correspondientes conjugaciones. ${ }^{122}$ Además, muchos vocablos remiten directamente al español peninsular, como por ejemplo: "gañán", "greña", "jumento" (54). También, como ya mencionamos, puede observarse la utilización del verbo "coger" con el sentido de "tomar" (110, 23, 67, etc.), rasgo que se repite en otros escritores de izquierda, producto de las traducciones españolas con las que se formaron como lectores y escritores, y de la probable influencia de la numerosa inmigración española.

Muchas veces, el poeta se queda a medio camino en la utilización del voseo, como si el español peninsular interfiriera en un registro porteño que, dicho sea de paso, jamás consigue aparecer: "Vos que, por sólo veinte centavos, quitáis el hambre" (25, destacado nuestro). Otra arista del vos reside en la tensión que lo enfrenta con el tú. Los escritores de la época alternaban el voseo y el tuteo en muchos de sus textos. Tanto Borges como Arlt, dos figuras diversas en todo sentido, pero sobre todo en materia de lenguaje, coinciden en sus escritos de la década del veinte en cuanto a vacilaciones y contradicciones en el uso del "vos y tú", "ustedes y vosotros"; así como, por arcaísmo, los dos suelen extender el empleo del pronombre en posición enclítica. Este fenómeno es producto de la incipiente estandarización del español rioplatense (Di Tullio 2009). Las tensiones que destacamos forman parte de un proceso fundamental que tiene lugar en el período: la radical transformación de la lengua literaria. En varios sectores del campo literario, se observan usos vacilantes en el lenguaje: Arlt se encuentra entre el tú y el vos; se enorgullece de escribir "en porteño" y de tener "profundos conocimientos de filología lunfarda" (Arlt 1998: 66), pero, al mismo tiempo que dice esto, entrecomilla las palabras de origen lunfardo como si, por alguna razón, no pudiese integrarlas a ese idioma porteño en el que escribe. ${ }^{123}$

Por aquellos años, un referente del rechazo del voseo es Arturo Capdevila, a quien ya nos hemos referido en el capítulo I. En su libro Babel y el castellano (1928), escribe: "los argentinos [estamos] enfermos de este sucio mal [el voseo], que ojalá no resulte incurable. (1954: 61). Y, recurriendo a la metáfora médica, sentencia que el voseo "es la viruela del idioma..." (64). Capdevila pone en relación este uso lingüístico con la noción de barbarie:

\footnotetext{
122 “Sois" (Yunque 1977: 15), "podríais" (21), "quitáis" (25), “domeñáis" (31), "proseguid” (63), "mostrásteis" (15), "exigíais" (15), "dadme" (31). También abundan los pronombres enclíticos: "hízoles" (69), "partiros" (15), "detiénese" (27), "impidiérales" (26), "propúsole" (26), "decíame" (27), "brindábales" (28), "suicidóse" (51), etc.

${ }^{123}$ Ver capítulo V, dedicado a Roberto Arlt.
} 
“todo el Buenos Aires culto de 1810 decía de tú; todo Córdoba también. Mas, venido que fue el Tirano, se retornó al voseo (...). ¡Victoria oscura de la barbarie sobre la cobardía!” (99).

La alusión a Rosas inicia una serie en la que Capdevila hilvana el voseo con los siguientes términos: federalismo-incultura-barbarie. Esta serie encuentra una segunda instancia histórica en el momento en que escribe su libro: "después, ¿cómo ignorarlo? Aluviones humanos de Italia, de Rusia, o de regiones dialectales de la propia España" (100).

De este modo, la barbarie se asocia con determinadas formas lingüísticas que se apartan de lo académicamente correcto y de la norma del español peninsular. La barbarización de algunos escritores se sustenta no sólo en el uso por parte de ellos del voseo, sino también a partir de la reelaboración literaria de los registros y variaciones populares.

Si evaluamos el poemario de Yunque en su totalidad, veremos que la lengua culta se impone sobre cualquier otra forma lingüística. Desde este punto de vista, los Versos de la calle resultan versos sobre la calle, en la medida en que no recogen los registros propios del lugar que representan, mayoritariamente, los poemas: el suburbio. ${ }^{124}$ No obstante, y como acabamos de señalarlo, existen fisuras en esa lengua "correcta" que se manifiestan, principalmente, de tres maneras diferentes: en primer lugar, cabe destacar la aparición, en dos oportunidades, de un vocablo proveniente del lunfardo: "atorrante" $(25,70)$. Hecho singular si se toma en cuenta el rechazo que la mayoría de los escritores de izquierda manifestaban por este vocabulario. En segundo lugar, y también en pocos momentos, aparece una suerte de registro escatológico que, no obstante, evita caer en vulgarismos. Por ejemplo: "y en la misma giróvaga danza, / enlodados y rotos, caerán: / al olvido cruel los ensueños, / y las hojas al tacho fecal" (44, destacado nuestro). Cabe aclarar que este registro escatológico, que por momentos se confunde con el miserabilismo y el "extremo realismo", es habitual en las ficciones de estos autores. De hecho, sobre estos usos lingüísticos Martín Fierro levantará sus críticas: “...el léxico que zarandean [los] redactores [de Extrema Izquierda] es de un extremado realismo: masturbación, prostitución, placas sifilíticas, piojos, pelandrunas, que lo parió, etc., etc... ¡Muy, muy realista!” (“Extrema izquierda” 1924: 8). En tercer lugar, aparecen a lo largo de la obra, de manera puntual y esporádica, algunos vocablos, no vulgares,

\footnotetext{
${ }^{124}$ Borges tampoco lo hará, pero su arrabal prescinde deliberadamente de los inmigrantes, mientras que Yunque ingresa en los conventillos. Conviene citar otro ejemplo en el que, al igual que Yunque, se utiliza al conventillo como espacio literario pero, no obstante, se eluden las voces propias de ese lugar. Nos referimos a la Nacha Regules (1919) de Manuel Gálvez, novela que se desarrolla, en buena parte, dentro de los conventillos y de los prostíbulos de Buenos Aires. Sin embargo, Gálvez no reproduce las voces de los habitantes de esos inquilinatos, o si lo hace utiliza un lenguaje desagregado de modismos populares: "Era un deparartamento bajo, al fondo de una casa de dos pisos (...) Salió a abrirle una vieja desdentada y repugnante (...) Monsalvat preguntó por la dueña de casa. La vieja le pidió disculpas en un castellano de conventillo, y le hizo entrar en una pieza..." (Gálvez 2010: 228-229, destacado nuestro).
} 
referidos a la sexualidad: “...da tu viril canto (...) / como a una hembra hermosa das tu fecundo semen” (Yunque, 1977: 13). O bien: “iSalve, máscula sonda / que adentras en un virgo y lo fecundas!" (49). Expresiones como "semen", "virgo", "máscula sonda" resultan materiales verbales que, observados desde la perspectiva de la época, podrían considerarse como "anti-poéticos" y que Yunque procura integrarlos como objetos estéticos, procedimiento que Oliverio Girondo ensayará de manera ostensible y definida algunos años después. ${ }^{125}$ Vale decir, entonces, que Yunque, sin hacer uso del registro lo popular, adelanta de manera muy sutil (si se lo compara con Girondo) nuevas formas estéticas que subvierten los supuestos de la lengua literaria dominante.

En todo el poemario, se registra una sola "mala palabra": "hombres que viven recogiendo mierda" (103). La leve alternancia entre una lengua culta y otra popular se manifiesta, por ejemplo, en algunos títulos; porque si a veces Yunque elige encabezar sus poemas con nombres como "Epinicio a un aeroplano"126, en otros momentos opta por denominaciones no tan literarias, como "Meaderos": “joh, mármol de meaderos, ay, triste; / ser mármol de una estatua pudiste.” (68). En el primer ejemplo se puede ver además, el contraste desublimador entre lo antiguo (epinicio) y lo moderno (aeroplano), mientras que en el segundo caso el contraste se produce tanto a nivel del sentido como del registro.

Al mismo tiempo que aparecen estos ejemplos, en los que Yunque cede a las voces que escucha constantemente en sus paseos por la ciudad moderna, una actitud opuesta se torna recurrente: el poeta continúa escuchando el lenguaje de la urbe, pero se resiste a utilizarlo; esto ocurre, sobre todo, con los insultos y/o vulgarismos. Se señala la utilización de este lenguaje, pero las voces de la calle jamás llegan a hablar dentro de los poemas. El poeta se limita a describir fenómenos lingüísticos populares, pero distanciándose de ellos: “allá chocó un tranvía contra un carro, y se dicen / motorman y carrero, qué frases..." (16, destacado nuestro). Otro ejemplo: "Es un café de los suburbios. / Hay palabrotas y bullicio; / y una guitarra y un piano / que fabrican sonidos" (62, destacado nuestro).

Por lo general, en los poemas no aparece otra voz que no sea la primera persona de un poeta culto. Como hemos visto, apenas emergen voces del suburbio. Estas ausencias cobran mucho más significado cuando observamos que el poeta construye una voz propia dentro de

\footnotetext{
${ }^{125}$ Ver capítulo VI, dedicado a Oliverio Girondo. Sobre el lenguaje anti-poético en este poeta, ver Speranza (2006).

${ }^{126} \mathrm{Si}$ bien nos estamos refiriendo a un escritor de izquierda, el título del poema resulta sumamente vanguardista, digno de algún poeta de la vanguardia estética. El procedimiento que se observa en este título nos reenvía nuevamente a un escritor como Oliverio Girondo. En su poesía, géneros o subgéneros literarios, estructuras y aspectos formales, o bien campos semánticos propios de la literatura culta convergen con objetos típicos de la vida material y moderna. Como veremos en el capítulo VI, Girondo configura su lengua literaria a partir de refentes y referencias poco ortodoxos, vinculados principalmente a la vida moderna de esos años. No se puede "expresar nuestras ideas modernas" con las lenguas literarias previas, afirma el autor de Calcomanías.
} 
los poemas; nos referimos, por supuesto, a su voz en un estilo directo, entrecomillado. En estos momentos, el español pretendidamente "correcto", predominante en toda la obra, se exacerba y se concentra no sólo a partir de la corrección en sí misma, sino a través del uso del cultismo: "yo: 'Dadme, les grito, dadme ese secreto / con el cual vosotros domeñáis el hierro"” (31, destacado nuestro). El poeta, a través del lenguaje correcto, gramatical, por momentos cultista, impone una distancia con respecto a su tema y a los sujetos que lo constituyen.

A pesar de la voluntad de apego a las normas de corrección en el lenguaje literario ${ }^{127}$ por parte de estos escritores de izquierda, los martinfierristas no dejan de señalar una y otra vez la falta de estilo y la "mala" escritura de los autores nucleados en Claridad. En una reseña de Versos de la calle, publicada en el número 8 y 9 del periódico de Florida, en referencia a Yunque, podemos leer: "nos han llamado la atención, en cambio, su negligencia constructiva y su predilección por expresiones de dudoso gusto" (C. I., 1924: 10). Las expresiones de "dudoso gusto" son, seguramente, las que se reparten entre las zonas escatológicas y las del lenguaje popular y vulgar. En el mismo artículo se advierte: "los versos rengueantes, torpes, duros o ingratos por cualquier motivo formal son censurables aun en el caso de expresar nobles pensamientos" (10).

En conclusión, más allá del grado de corrección de Versos de la calle, hay algo que resulta evidente: casi no se observan marcas de oralidad o de formas del español rioplatense. En todo caso, si estas formas del lenguaje aparecen, lo hacen de manera esporádica, y en una permanente tensión con otras configuraciones estilísticas dominantes.

\section{Hispanismo y corrección en Claridad}

En diciembre de 1927, Claridad publica un artículo de Carlos de Lucca, titulado "El ocaso de la retórica”, en el que impugna la presencia de ésta en el discurso literario, aunque sus afirmaciones no contienen la virulencia y radicalidad que podrían esgrimir en este caso los defensores de la lengua vernácula. El comienzo de su artículo bien podría ser una declaración de principios típicamente vanguardista, en la medida en que opone un presente de cambios novedosos frente a un pasado que se concibe como perimido y anquilosado:

\footnotetext{
${ }^{127}$ Cabe mencionar que la presencia de esa norma se hace mucho más evidente en los textos que forman parte de libros. Erratas, deficiencias constructivas, faltas de ortografía, repetición de palabras son mucho más comunes en los textos que se incluyen en las publicaciones periódicas como Los Pensadores o Claridad.
} 
Ahora que está en decadencia la vieja retórica, arrugada y fea después de ser manoseada por todos los escritores mediocres que han envilecido las letras, es justo que evoquemos por un momento el poema de su existencia, a modo de anticipado responso, que, nada más leal, le debemos nosotros, los hombres de hoy, que gustamos escribir desdeñando irrespetuosa, pero prudentemente la tentadora fastuosidad de su compañía (De Lucca 1927: 10).

En la "prudencia" del rechazo hacia la retórica se encuentra el moderatismo con que De Lucca se opone a una manera de escribir literatura. Sin embargo, esto no se encuentra reñido con los postulados de la izquierda, sino más bien todo lo contrario: liberarse de la retórica otorga claridad al mensaje literario ("nosotros amamos la claridad", enfatiza De Lucca). Según el articulista, el romanticismo francés la había entronizado, pero gracias a la aparición de un "artista de poderoso talento" se consigue desplazarla "de su trono resplandeciente de falsa pedrería" (10). Ese artista era Zola y, gracias a él, se comienza a llamar "las cosas por su verdadero nombre" y se conquistan los postulados del realismo (10). De Lucca pone en evidencia su disconformidad con los libros "académicamente vacíos" y a continuación realiza un encomio no sólo de la claridad, sino también de "la justeza del vocablo y la sencillez" (10), valores que representan la estética que persiguen los escritores nucleados en torno a Claridad. En síntesis, De Lucca reacciona contra lo académico, contra el lenguaje literario excesivamente artificioso; sin embargo, se puede apreciar que esa crítica es mesurada y no conduce a "irreverencias" contra la corrección idiomática, como así tampoco comporta una flexibilización pronunciada de las formas lingüísticas.

Unos meses antes, en mayo de 1927, Elías Castelnuovo publica bajo su seudónimo Roland Chaves, un artículo que lleva como título "La hora se acerca". Allí también reaccionará contra la "artificiosidad" de la literatura y verá en este rasgo signos de un cosmopolitismo consistente en el plagio de poetas franceses y españoles. Como una respuesta frente a esa retórica "vieja, arrugada y fea" (De Lucca 10), propone como forma de conocimiento y como insumo literario la experiencia directa, vivida, y no los libros como única fuente del saber. De esta manera, se culmina con una literatura "artificiosa y decadente", cultora de la "declamación" (Chaves 1927c: 4), afirma. Las ideas de Castelnuovo con respecto no sólo a la forma, sino también al contenido que debe tener la literatura se sustentan en un nacionalismo muy singular. $\mathrm{Si}$, como hemos visto, podemos identificar dos vertientes del nacionalismo lingüístico en los años veinte -por un lado, el de los puristas hispanófilos y, por otro, el de los rupturistas-, los aportes que hace al respecto en este artículo no parecen ajustarse a ninguna de ellas. Para este autor, la literatura practicada en ese momento es "de reflejo o de importación", puesto que consiste en la "repetición de lo que se escribía en Europa" (3). Por lo tanto, sostiene que "“nuestra literatura' no tiene nada de 
nuestra" puesto que no es el reflejo de "nuestras costumbres, de nuestro medio o de nuestros sentimientos, sino el reflejo de las indigestiones de nuestra cultura” (3). Para Castelnuovo, lo nacional va a estar vinculado, principalmente, con las costumbres populares y no con la lealtad -idiomática y cultural- hacia España, como así tampoco con las propuestas de una lengua vernácula. Los escritores de izquierda pretenden una lengua sin las "contaminaciones" lunfardas, pero eso no implica la adhesión al hispanismo. Simplemente, postulan una lengua que tiende hacia la norma, desagregada de lunfardismos y de voces populares que remitan a la inmigración, a los efectos de conseguir una "claridad" homogénea para sus textos.

Sin embargo, algunos elementos del hispanismo logran ingresar en Claridad. Si bien no se lo promueve como una forma prescriptiva para el discurso literario, la publicación de Zamora tiende lazos con el purismo idiomático. De este modo, por ejemplo, en julio de 1926, se reseña Pasatiempos lingüísticos de Ricardo Monner Sans. Alineada con la prédica hispánica y de "corrección” del gramático, Claridad comenta: "en amenísimo estilo, casi siempre humorístico, don Ricardo Monner Sans, que a los setenta años es todavía celoso centinela de nuestro idioma, nos da un nuevo libro..." (“Pasatiempos lingüísticos...” 1926: 43, destacado nuestro). Esta tendencia, que despunta de manera esporádica en Claridad, se ve reforzada con un artículo que publica J. Rivera Reyes en junio de 1927, titulado "Sobre hispanismo. En defensa del idioma”. Sin lugar a dudas, este texto es uno de los más radicales que publica Claridad, en cuanto a la exposición de un nacionalismo a ultranza basado en España como modelo racial e idiomático.

El artículo coincide con De Lucca y Castelnuovo puesto que también denuncia las influencias extranjeras vigentes en la cultura argentina, ${ }^{128}$ pero Rivera Reyes se diferencia de estos en que reafirma la filiación y el dominio de España sobre el español americano. No le interesa tanto reaccionar contra las "jergas" locales, como ocurre con los escritores de izquierda, sino más bien contra idiomas extranjeros como el inglés, a los que ve como una "seria amenaza". ${ }^{129}$

En suma, en estos textos de Claridad se puede apreciar que las posturas con respecto al idioma y a la lengua literaria son explícitas: las afirmaciones contra el lunfardo y a favor de una lengua diáfana y "correcta" resultan muy frecuentes y explícitas; a su vez, se pueden

\footnotetext{
128 “... en la América hispana (...) no procuramos tener nada propio, sino que preferimos todo lo extraño, lo que nos viene de afuera: mercancías, costumbres, modas, legislación, y hasta lo más sagrado e inapreciable que tenemos y que debemos conservar y defender con ahínco, como legado materno e instrumento de unión y de seguridad de todos los pueblos de raza íbera, lo exponemos ante el empuje avasallador de las influencias extrañas: la religión y el idioma." (Rivera Reyes 1927: 23, destacado nuestro).

129 “... se le merma el tiempo al aprendizaje del idioma patrio para dedicarlo a idiomas extraños; se trastorna antipedagógicamente el estudio de la gramática nuestra con las complicadas reglas de lenguas extranjeras; se despierta en la niñez el desprecio por nuestro lenguaje y la admiración por lo ajeno; se proporciona a la juventud un elemento de cultura, que es a la vez peligroso elemento de destrucción (...). Debilitamos, en suma, un símbolo de soberanía y un vínculo de unidad nacional y racial' (Rivera Reyes 1927: 23, destacado nuestro).
} 
apreciar posturas a favor de la hispanofilia revitalizada por los grupos dominantes, contra los cuales los escritores de izquierda reaccionan desde lo estético y lo político, aunque no desde lo idiomático. Esto permite que en Claridad ingresen perspectivas a favor de una lengua normalizada que se identifica acríticamente con el español peninsular. Este fenómeno se explica por la aspiración de los escritores de izquierda de ofrecer al lectorado una instrucción cercana a la que propone la cultura legitimada y hegemónica en materia idiomática, a través de la educación pública, en la que no tienen lugar las "jergas" vernáculas ni los registros de origen inmigratorio. $^{130}$

En la escritura de los escritores de izquierda no se juegan valores estéticos, sino más bien ideológicos y políticos (Montaldo 2006b). Sin embargo, a lo largo de este capítulo hemos mostrado de qué manera la elaboración de una lengua literaria en estos escritores se encuentra atravesada por tensiones que derivan de la problemática coexistencia de lo culto y lo popular, como así también de la relación entre oralidad/escritura. Lejos de configurarse como un núcleo no problemático, la lengua literaria se constituye, desde muy temprano, no sólo en una cuestión relativa a esas tensiones, sino que también es inherente a la legitimidad y a las figuras de autor que construyen.

Los escritores nucleados en torno a Claridad concibieron dos grandes líneas sobre las que sentaron su tarea intelectual: por un lado, el público, o mejor dicho la educación de un público masivo y popular, con escasa instrucción. Por el otro, la función de la literatura como práctica social. Durante mucho tiempo, la crítica ha insistido en señalar a la vanguardia estética como el frente principal contra el cual los escritores de izquierda confrontaron. Sin embargo existía otro contendiente contra el cual decían militar: los folletos semanales y la prensa masiva, cuyos escritores, sostenían, alimentaban las "bajas pasiones" del pueblo en lugar de educarlo.

A esto se le suma que también existió un problema de competencia de mercado en la medida en que las narraciones semanales no sólo se dirigen a un mismo público (sectores populares), sino que comparten circuitos de comercialización y los precios bajos de las

\footnotetext{
130 Ángela Di Tullio explica que la creación, en 1881, del Consejo Nacional de Educación; la reunión del Congreso Pedagógico Nacional, en 1882, cuyo objetivo consistió en trazar líneas de la política educativa; y la sanción de la Ley 1420, en 1884, forman parte del proceso, no exento de conflictividad, de construcción y reproducción de un ideario sobre la educación que ponía en primer plano la nacionalidad y la necesaria homogeneización de la población (Di Tullio 2003: 101). En 1881, en el diario La Nación, aparece un artículo "Noticias" - en el que se advierten las primeras inquietudes acerca de nacionalidad amenazada por el influjo de la inmigración. Allí se afirma la importancia que debe asumir la educación de los residentes extranjeros, una educación nacional, que priorice la historia patria y la enseñanza del idioma, con el objetivo de evitar una de las consecuencias culturales de la inmigración: la “corrupción” lingüística (Bertoni 2001: 41-77).
} 
publicaciones. De este modo, lengua literaria y mercado se interceptan, dando una mayor dimensión al problema. Los folletines y los diarios como Crítica incorporan los lenguajes "bajos" y "deformadores" de la realidad, como el lunfardo y el cocoliche. Pero, a su vez, estos registros comportan cierta inmoralidad dada por los temas y los tipos sociales a los que suelen estar asociados: prostitución, juego, delincuencia. ${ }^{131}$ Como veremos en el capítulo siguiente, en 1926-1927, la revista Claridad inicia una campaña contra el diario de Botana en la que lo acusa directamente de fomentar estas cuestiones.

El discurso de publicaciones como Los Pensadores y Claridad se encuadra muchas veces en una dimensión moral. Este rasgo no es menor dado que "la moral impregna todas las iniciativas culturales" emprendidas por la editorial Claridad (Montaldo 1987b: 42). Se entiende mejor, entonces, que esta esfera se desplace de manera muy significativa hacia las concepciones que los escritores de izquierda tenían con respecto al idioma y a la lengua literaria puesto que, como dijimos, muchas valoraciones lingüísticas se realizan desde esta perspectiva. Una de las principales inmoralidades para estos autores consiste en atentar contra la educación del lectorado, contra los objetivos pedagógicos y humanitaristas que se plantean. Según su perspectiva, precisamente eso es lo que hacen las formas lingüísticas rechazadas por estos escritores, principalmente el lunfardo y el cocoliche. La lengua literaria de esta zona debe entenderse como una de las opciones que se condice con la idea que tenían los escritores de izquierda con respecto a la formación cultural de los sectores populares. En este sentido, puede comprenderse por qué hacen uso de un lenguaje literario apegado a las normas de la lengua estándar. El problema para ellos no radica tanto en construir una lengua literaria determinada, sino en evitar ciertos registros y vocabularios que atentan contra sus metas principales.

"Yo hablo como escribo. No cuento con dos formas de expresión" (Zas 1968: 15), advierte Castelnuovo en una entrevista, en1968. En esta cita, el autor parecería querer revisar, años después, las contradicciones de las que estamos dando cuenta. Y no sólo eso, sino que

\footnotetext{
131 En 1923, el diario La Razón lanza una encuesta destinada a indagar la literatura folletinesca y sus vinculaciones con lo "pornográfico" y "obsceno". En abril, comienzan a publicarse las respuestas, bajo el título "Literatura pornográfica, ñoña o cursi. Nuestra encuesta para averiguar por qué el público, los autores y las editoriales facilitan su incremento". Nos interesa rescatar las intervenciones de Leopoldo Lugones y Ricardo Rojas, quienes vinculan el desconocimiento del idioma, existente entre lectores y autores, con el auge de esta literatura. Dice Lugones: "para incrementar lo cursi, lo pornográfico y lo insípido, ha influido nuestra atroz incultura del idioma" (Pierini 2002: 51). Por su parte, Rojas coincide con el diagnóstico de Lugones y agrega que "las causas de su auge (el de la literatura pornográfica) se ha de buscar en nuestro cosmopolitismo sin cultura y en nuestra educación sin severas disciplinas en cuanto atañe al idioma" (52). Rojas correlaciona cuatro núcleos: extranjeros - mala educación - mal gusto - mala literatura. Afirma que los extranjeros cuentan con una masa "aterradora" de analfabetos, la cual no habla el "idioma nacional". Se suma a esto la "acción escolar deficiente" que hace que "cuando llega la hora de escoger sus lecturas", el inmigrante o su hijo se decida por aquellas que "están más cerca de su sensibilidad" (53).
} 
además niega el apego a las normas de corrección que rigieron su lengua literaria durante la década de 1920. En primer lugar, Castelnuovo destaca que su escritura responde a las formas coloquiales y que, en segundo término, su lengua literaria no representa una construcción en sí misma, sino más bien una conformación sin mediaciones estéticas de ningún tipo. Ahora bien, ya hemos visto que esto no es así, y que su lengua literaria evidencia aspiraciones de elevación cultural. En la misma entrevista, el autor de Tinieblas continúa:

Todo lo que huele a literatura a mí sinceramente me apesta. Siempre que viene algún novicio a consultarme y me trae un original bien escrito, pulido, planchado, con esa terminología putrefacta que constituye el buen decir, lo primero que le aconsejo que tiene que hacer, es aprender a escribir mal (Zas 1968: 19)

La reivindicación del "escribir mal”, en los años sesenta, ya tiene más legitimidad como signo de ruptura que en la década de 1920. Recordemos, nuevamente, que Castelnuovo justifica el rechazo de la primera novela de Arlt precisamente por estar "mal" escrita. La cita resulta muy fructífera para poder apreciar la manera en que entran en tensión las formas literarias concretas con los juicios y valoraciones que el autor hace de ellas varias décadas después. Como hemos visto en el análisis de algunos de sus relatos, en la literatura de Castelnuovo los pares culto / popular, claridad / complicación, corrección / incorrección, y escritura / oralidad configuran un espacio conflictivo.

Versos de una... constituye otro ejemplo de cómo la norma, la corrección, la lengua más institucional y modélica, habitual en los escritores de izquierda, impide una construcción verosímil, "genuina", de una prostituta que ha transcurrido los años de escolarización primaria en Ucrania, y que a su vez, cuando se encuentra en Argentina, frecuenta los arrabales de las grandes ciudades, los cabarets y otros lugares donde eran usadas formas "plebeyas" e "impropias" de la lengua, sin que eso afectara los rasgos de la escritura. Se puede apreciar también la asimilación contradictoria, entre la atracción y el rechazo, hacia el lenguaje literario previo, del modernismo y el tardorromanticismo principalmente. Estéticas que se configuran como símbolos de una cultura elevada y refinada a la que autores como Castelnuovo aspiraban no sólo como compensación de sus deficiencias de formación, sino como un modelo de lengua literaria.

Algo similar sucede con Versos de la calle, los cuales, pese a tomar al conventillo e inquilinatos como escenarios principales, no recuperan o recrean bajo ninguna forma las particularidades lingüísticas de estos espacios, dominados por el fuerte contacto de lenguas ocasionado por la inmigración. Importa destacar, además, que también en esta obra de Yunque, al igual que en el caso de Castelnuovo, se filtran formas lingüísticas de uso 
peninsular, cuya procedencia evidente son las traducciones con las que Yunque también se formó como lector y escritor; además, por supuesto, de la posible influencia de la oralidad española que existía en la Buenos Aires del veinte debido a la inmigración.

Al contrario de lo que ocurre con el aspecto político e ideológico, en lo que respecta a la lengua y al corpus cultural, este sector se apega a lineamientos conservadores. Los escritores de izquierda nunca se plantearon el valor o la existencia de una cultura popular (Astutti 2002). En consecuencia, para cumplir con sus metas pedagógicas toman la "cultura con mayúscula" como modelo. Sobre esa cultura se formaron como escritores, construyeron sus saberes. Por esta razón, algunos de ellos, como Castelnuovo, adoptan una actitud de rechazo o de sospecha frente a todo lo relacionado con la cultura popular de mercado y los lenguajes asociados: el tango, los folletines, los diarios masivos.

Las discrepancias entre los rechazos y las preferencias estético-lingüísticos de Castelnuovo, en relación con sus prácticas literarias, no debe ser leída como una contradicción sin fundamentos, sin motivos que la expliquen en relación con la coyuntura que le propone el período. La década de 1920 se caracteriza, para decirlo con un concepto de Ángel Rama, por una "plasticidad cultural"132 (Rama 2008) en el sentido en que los escritores de estos años encuentran a su alcance múltiples y nutridas fuentes estéticas de las que se valen para construir sus lenguas literarias, muchas veces en franca contradicción con sus preferencias explícitas y declaradas. Este fenómeno que no es privativo de Castelnuovo, muestra que los procesos de configuración de los lenguajes literarios lejos de ser lineales y homogéneos son el resultado de la utilización, por parte del escritor, consciente o inconsciente, de los vocabularios, géneros y formas estéticas que intervinieron en su formación y que se encuentran disponibles en el momento de producción.

Las tensiones y disputas en torno a la lengua literaria constituyen la arena de lucha en las que se dirimen posiciones dentro del campo letrado. No siempre esas disputas se suscitan entre autores legitimados y escritores modernos y vanguardistas. Muchas veces los distintos espacios de la vanguardia buscan diferenciarse, precisamente, a partir de evaluaciones diversas sobre el lenguaje literario. De este modo, por ejemplo, las mismas críticas que Martín Fierro realiza a los escritores de izquierda -"escriben mal", "son unos bárbaros"estos las utilizan contra otros escritores, como Nicolás Olivari. ${ }^{133}$ La idea de la "mala

\footnotetext{
${ }^{132} \mathrm{Si}$ bien Rama utiliza este concepto para referirse a la transculturación en América Latina y a los conflictos entre regionalismo y modernización, puede resultarnos funcional en el sentido de que durante los años veinte existe también cierta plasticidad (en el lenguaje) dada por las tensiones que se producen entre los procesos modernizadores y los constructos culturales tradicionales, entre la oralidad y la escritura, entre lo culto y lo popular, etc. Ver Rama (2008: 83-133).

133 “.... Nicolás Olivari que pretendiendo imitar a los modernistas franceses dio en la ridiculez de un librito titulado La musa de la mala pata, lleno de barbarismos y pavadas. El caso de este autor merece considerarse por 
escritura" constituye, para los autores jóvenes, un valor de diferenciación con respecto a las zonas institucionalizadas. Sin embargo, como se verá en los capítulos que siguen, la transformación más fecunda de la lengua literaria en los años veinte es producto, en gran medida, de la mutua interferencia entre el "buen decir" y las textualidades "plebeyas" o "incorrectas".

tratarse de un hombre joven, reincidente. Ya cuando apareció La amada infiel, se le hicieron atinadas observaciones que echó en saco roto. (...) Esperamos con interés su regeneración" ("El año literario" 1926: 21, destacado nuestro). 


\section{CAPÍTULO III}

\section{Prensa masiva, lunfardo y mercado}

La vanguardia estética, la izquierda literaria y la industria cultural, si bien se configuran como zonas diferenciadas, se encuentran sumamente vinculadas durante este período. Por ejemplo, como se sabe, algunos martinfierristas se desempeñaron en la redacción del diario Crítica, hecho que motivará, parcialmente, los ataques que la revista Claridad inició hacia 1927 contra el diario de Botana.

El mercado es un actor fundamental en las modificaciones y tensiones que sufre la lengua literaria. El "lenguaje popular" en la literatura, como por ejemplo el lunfardo o el cocoliche, corresponden a la recreación o invención de diversos escritores, que el periodismo, el teatro, el tango, u otros formatos propios del mercado, ponen en circulación. Si Crítica se construye como una suerte de ventrílocuo de las hablas "populares", este procedimiento forma parte de sus estrategias de mercado.

Como hemos señalado en la introducción de este trabajo, el mercado constituye un actor fundamental del proceso de modernización que experimenta la cultura de Buenos Aires durante las primeras décadas del siglo veinte. Su crecimiento y diversificación implicó, de manera correlativa, la emergencia de nuevos géneros y nuevas formas de la lengua literaria; pero también se convirtió en escenario y vehículo, a través de las numerosas revistas y diarios, de las disputas y polémicas que tenían como eje el problema del idioma y la lengua literaria.

Entre 1880 y 1910, se produce la emergencia de un nuevo tipo de lector, producto de las masivas campañas de alfabetización con que el poder político buscó asegurar su estrategia de modernización (Prieto 2006). En treinta años, la Argentina redujo a un 4\% el porcentaje de analfabetismo, lo que implicó la aparición de un nuevo y amplio horizonte de lectores. En su gran mayoría, este nuevo lectorado provenía de sectores populares -nativos, extranjeros e hijos de extranjeros- lo que significa que se abría un nuevo espacio de cultura y se establecían zonas de fricción y contacto entre los circuitos letrado y popular.

La prensa periódica sirvió de práctica inicial a los nuevos contingentes de lectores y, previsiblemente, también creció con el ritmo en que éstos crecían (Prieto). De esta manera, la prensa provee un novedoso espacio de lectura para los sectores populares, pero también se convierte en un elemento importante de la profesionalización del escritor. A partir de los primeros años del siglo, y gracias no sólo al auge de los diarios sino también al de las revistas 
ilustradas populares -el caso emblemático es el de Caras y Caretas, fundada en 1898aparece un nuevo tipo de intelectual, el escritor periodista, que se incorpora a un incipiente mercado cultural (Rivera 1998). De este modo, jóvenes escritores y poetas, sin linaje y sin dinero, procedentes de las clases medias y populares de la Capital y del interior, encuentran nuevas fuentes de trabajo y se convierten en responsables del afianzamiento de una variante moderna del escritor profesional.

En el espacio de la cultura letrada, el libro continuó siendo la unidad vertebradora de su universo específico y durante estos treinta años cruciales apenas modificó sus dimensiones. Por su parte, en el circuito ampliado de la prensa periódica, el libro es un objeto impreso de pésima factura; la novela es folletín; el poema lírico, cancionero de circunstancias; el drama, representación circense. Y su comercialización se lleva a cabo por fuera de las librerías: quioscos, tabaquerías, salas de lustrar, barberías y lugares de esparcimiento (Prieto 2006). Estas nuevas formas de circulación de los textos literarios resulta concomitante con el auge de la prensa masiva, e inaugura una tradición que se prolongará en los grandes proyectos editoriales de los años veinte; entre los cuales, el de Antonio Zamora se constituye como el de mayor importancia y envergadura (De Diego 2009).

Por otra parte, debemos hacer referencia al fenómeno del auge de la prensa masiva, correlato del paulatino crecimiento de un lectorado popular. Con la fundación de los diarios La Razón (1905) y Crítica (1913), se consolida un nuevo periodismo en el campo cultural argentino: se trata de una prensa moderna, dirigida y escrita por periodistas profesionales que, en poco tiempo, logran diferenciarse de los diarios finiseculares y separarse formalmente del Estado. Cabe señalar, sin embargo, que la sola existencia de un público potencial no garantiza nuevos lectores; por lo tanto, para captar el interés de ese público, algunos diarios y revistas ensayaron estrategias de interpelación que los diferenciaran de la denominada "prensa seria" (Saítta 2009). Este es uno de los rasgos centrales para pensar el rol que cumplió la prensa masiva en el rediseño de las polémicas sobre el idioma y la lengua literaria, puesto que creó formatos y géneros periodísticos destinados a los recién llegados al mundo de la cultura letrada. De este modo, este tipo de periodismo registra la expansión del tango; difunde las viñetas costumbristas; y revela "los nombres de la marginalidad urbana en la galería de delincuentes de las secciones policiales"; pero, sobre todas las cosas, "capta las mínimas alteraciones en el uso de la lengua y explora día a día cómo se habla en la ciudad" (Saítta 247). La temática y los procedimientos ensayados por la prensa masiva para lograr una aproximación a ese gran abanico de nuevos lectores trajo aparejadas numerosas críticas por parte de los sectores más conservadores: tempranamente, en su estudio “El ‘criollismo' en la 
literatura argentina" (1902), Ernesto Quesada se queja ${ }^{134}$ de que en determinadas publicaciones periódicas, como por ejemplo Caras y Caretas, aparece el cocoliche mezclado con el dialecto orillero. Fray Mocho descuella en este terreno y "las gentes del pueblo devoran sus escritos" (Quesada 1983: 159-160). Por su parte, Arturo Costa Álvarez, en su libro Nuestra lengua (1922), señala la ruptura que significó, en el nivel de la lengua, la aparición de una prensa popular en la Argentina. Afirma que a fines del siglo XIX, la prensa argentina era “escrupulosa en su lenguaje, lo cuidaba especialmente en su más trivial exterioridad, la ortografía, considerándola buena muestra de cultura". Esto sucedía porque "en los principales diarios bonaerenses había un redactor español por lo menos, y la tarea de corrección de las pruebas era confiada algunas veces a literatos eximios". Sin embargo, años después, la prensa fue absorbida por otros intereses, y por ese motivo surgen en torno a ella, "como excrecencia pletórica de nuestro organismo social, los diarios y los semanarios populacheros" (Costa Álvarez 1922: 86-87). Semanarios y diarios “populacheros" incorporan, entonces, secciones con cuadros costumbristas en los que abundan el lunfardo y el cocoliche, lo cual significa para Costa Álvarez que "la corrupción no se enseña ya en el circo o una vez por semana en el periódico, sino cotidianamente en el diario" (99). Según este autor, durante los primeros años del siglo XX, la prensa "ha descuidado el estilo de sus cronistas" y no ha hecho más que “aplebeyar" la lengua (134).

En junio de 1932, Guillermo de Torre publica, en las páginas de El Sol de Madrid, un artículo titulado "La buena doctrina" en el que se refiere al rol desempeñado por la prensa en Argentina, en relación con el idioma. ${ }^{135}$ Según De Torre, los escritores fueron quienes, en la Argentina, promovieron la utopía del "idioma nacional argentino" (1954: 167). Cabe recordar que fue De Torre, precisamente, quien refutó esta idea en el marco de la polémica sobre "el meridiano intelectual de Hispanoamérica”, en 1927. En esta oportunidad, De Torre desea dejar en claro que el pueblo "no tomó aquí, ni en ningún sitio, la iniciativa" de promover esta tesis, sino que "se limitó a propagar el lunfardo vertido desde el teatro y el periódico" (167). Es decir, resultó "un movimiento de arriba abajo""136 el que impone "barbarismos e idiotismos, chulaperías, o lunfardismos". Son un Arniche y un Vacarezza quienes no sólo les dan categoría, sino hasta quienes crean los giros y vocablos que luego calcan chulos y malevos"

\footnotetext{
${ }^{134}$ La queja de Quesada es muy anterior al período que abordamos, sin embargo da cuenta de un proceso que si bien data de comienzos de siglo, se intensifica en la década de 1920.

${ }^{135}$ Este artículo se incluye, a modo de epílogo, en las reediciones de Babel y el castellano, de Arturo Capdevila (1954).

${ }^{136}$ Para De Torre, las clases más acomodadas son las responsables de corromper la lengua a partir de la utilización del lunfardo. En cambio, como hemos visto en su respuesta a la encuesta de Crítica, para Monner Sans (h) la culpa es de los sectores populares que, como si se tratase de una propagación infecciosa, enferman a los segmentos medios y altos de la sociedad.
} 
(167). De acuerdo con De Torre, la "corrupción" idiomática desciende desde ciertos sectores ilustrados (algunos escritores, la prensa y el teatro) hacia el pueblo que divulga formas "incorrectas". Sea como fuere, el rol que le adjudica De Torre a la prensa es, justamente, el de generar un medio propicio para las "peregrinas" ideas en torno a la formación de un idioma nacional o rioplatense. Resulta importante destacar que este autor pone de manifiesto una idea crucial para comprender la naturaleza de lo que denominamos "lengua popular" en el contexto de estos análisis: estas formas no corresponden, de manera automática, al habla del pueblo o de la gente real, sino más bien se trata, en gran medida, de una amplificación y/o reelaboración del circuito de mercado. Lo que nos interesa dejar en claro es que las críticas realizadas a la prensa masiva desde diversos ángulos coinciden en juzgar sus usos lingüísticos como reprobables. La polémica que, a mediados de los años veinte, entabla Claridad con Crítica debe ser entendida en el marco de esta concatenación de juicios y evaluaciones que los sectores más conservadores en cuestiones de lenguaje realizaron en torno a la emergente prensa popular.

A la par del desarrollo de la prensa masiva, tiene su auge, a partir de mediados de 1910 y durante toda la década del veinte, una literatura cuyos temas, personajes, lenguaje y escenarios remiten al arrabal y a la cultura popular urbana. Si por un lado existe el circuito de los folletines y novelas por entrega; por el otro, aparece el heterogéneo orbe de los libros baratos. Muchos correspondían a obras clásicas y universales, otros eran publicados por una cohorte de escritores recién llegados al campo literario, en su mayoría hijos de inmigrantes, que exploraban y configuraban representaciones literarias de los suburbios y recuperaban las jergas y las variedades populares del español rioplatense. A su vez, por esos años, aparecieron los grandes proyectos editoriales populares: en 1916, Juan Torrendell, un inmigrante de origen español, fundó la editorial Tor que publicaba, en ediciones descuidadas, en papel de baja calidad y a precios muy económicos, una amplia variedad de textos; a su vez, en 1922, Samuel Glusberg creó la editorial Babel que publicó a lo largo de diez años más de cien títulos de autores nacionales (De Diego 2009). En ese mismo año, nació la editorial Gleizer que reunía, en su amplio catálogo, autores tanto de la izquierda como del martinfierrismo, dando muestras de una convivencia que parece refutar la clásica visión dicotómica de la vanguardia. Sin embargo, el proyecto quizás más importante de la década es el que llevó adelante Antonio Zamora, ${ }^{137}$ otro inmigrante de origen español, quien fundó, en 1921, la Cooperativa Editorial Claridad. La característica relativamente novedosa del emprendimiento

\footnotetext{
137 "Ninguna empresa nacional editora de libros alcanzó entre nosotros, en su época, la extensión e importancia que caracterizó a la que difundió en todos los ámbitos del país y aún más allá de sus fronteras el nombre de 'Claridad' (Barcia 1981: 8).
} 
de Zamora radicaba en el bajo costo de los libros publicados ${ }^{138}$ que le permitió, en primer lugar, alcanzar un segmento de público amplio y hasta ese entonces no contemplado en las políticas editoriales; y en segundo lugar, combinar bajos niveles de ganancia con amplios márgenes de rentabilidad:

Presumo que debe haber sido la concurrencia simultánea de dos circunstancias propicias las que facilitaron esa economía para colocarla al nivel de los bolsillos más modestos: el escaso costo del papel y el volumen de cada tirada, pues un libro resulta más barato cuanto más ejemplares salen de las prensas. Los márgenes de ganancia eran reducidos, pero multiplicados por un alto número de ventas, crecían hasta alturas insospechadas. Ganar poco para ganar mucho, supone, pues, una inteligente táctica casi desconocida entre nosotros. Zamora la comprendió porque no estaba apurado por enriquecerse del día a la noche. (Barcia 1981: 19).

Sin embargo, si bien Zamora llevó más lejos que ninguno la política de bajo precio, como acabamos de mencionar, numerosos emprendimientos estaban asentados sobre esas bases debido a que era la única forma de acceder a ese nuevo público que no se definía, precisamente, por un alto poder adquisitivo. Muy tempranamente, el diario La Nación lanzó en noviembre de 1901- "La Biblioteca La Nación", cuyos libros se caracterizaban por tener un costo relativamente bajo: entre cincuenta centavos y un peso (De Diego 2009). Sin embargo, se necesitará el paso de algunos años para que los costos bajen aún más y la oferta editorial eclosione en un sinnúmero de emprendimientos editoriales. A mediados de la década de 1910 ya se puede apreciar la circulación de folletos, novelas por entrega y narraciones semanales cuyo costo no superaba los veinte centavos; por esa misma época, las publicaciones de Tor rondaban ese precio. A esto debemos sumar revistas y magazines, en cuyo interior se destinaba un espacio al contenido literario, tales como Caras y Caretas, Plus Ultra, Atlántida, El Hogar, etc. En 1924, el diario Crítica decidió sumarse a esta tendencia y creó una Biblioteca que editaba un libro por mes a un peso el ejemplar (Saítta 1998). Todos estos emprendimientos se colocan por fuera del circuito comercial de las librerías e instauran reglas de funcionamiento propias que contribuyen a la configuración de un nuevo mercado editorial.

Sin embargo, la coincidencia de públicos, modalidades de edición y bajos costos implica nuevas formas de competencia en el mercado, como así también fricciones y desencuentros entre los diversos proyectos editoriales. Un buen ejemplo de ello es el caso de la lucha que entabló Claridad con las narraciones semanales y los textos que incluían

\footnotetext{
${ }^{138}$ Comúnmente, el precio de cada ejemplar oscilaba entre veinte y cincuenta centavos, y se vendían por fuera del circuito comercial de las librerías. (Ver Barcia, 1981).
} 
lunfardo y cocoliche. Este tipo de literatura entorpecía la misión pedagógica y formadora que Claridad se había adjudicado para con sus lectores. Este dato no es menor porque es el que vertebra buena parte de los argumentos con que Claridad ataca al diario de Botana.

Debemos considerar también el auge del tango como un fenómeno importante durante los años veinte, y central en la discusión que la revista de Zamora entabla con el diario Crítica, dentro del cual este género musical tiene un lugar destacado. Hacia mediados de los años veinte el tango tiene mucha vigencia y aceptación por parte de una importante masa de porteños, aunque también existen sectores que lo impugnan, sobre todo por el lenguaje que utiliza y las temáticas que muchas veces roza. Para Claridad, las letras de tango no sólo constituyen una fuente corruptora del idioma, sino también un muestrario de inmoralidades puesto que algunos de sus centros temáticos son la prostitución y la delincuencia.

Una amplia porción de la literatura de ese período encuentra en el arrabal un escenario privilegiado; naturalmente, el tango compartirá plenamente ese rasgo y hará de los márgenes prostibularios un espacio productivo. Beatriz Sarlo (2007) indica que durante la década del veinte, la literatura argentina realiza un viraje tendiente a poner en foco un punto de vista nuevo sobre los marginales, quienes se convierten en los insumos centrales para la construcción simbólica del arrabal, se tornan más visibles, cambian las formas de su representación y las historias que se inventan con ellos como personajes. Los márgenes sociales y geográficos prácticamente definen, entonces, la literatura de ese período; en la medida en que no sólo numerosos escritores encuentran en las periferias temas y motivos para su literatura, sino que además, algunos representantes del circuito "culto" tradicional no pueden obviar este rasgo, y se colocan entre el anatema, la crítica feroz y la representación y promoción del arrabal de acuerdo a sus propias creencias e ideologías. De esta manera, por ejemplo, Manuel Gálvez publica Historia de arrabal (1922) y, un par de años antes, escribe el prólogo para Las puertas de Babel (1920) de Héctor Pedro Blomberg en el que celebra que por fin Buenos Aires tenga "un narrador artista de sus barrios extraños y siniestros" (Gálvez 1920: 7); e imbuido en la fascinación que suele despertar la "barbarie", afirma:

Los puertos de Buenos Aires y los barrios que los rodean: la Boca, Dock Sur, el Paseo de Julio, son las puertas de Babel. Por ellas se entra a la ciudad monstruosa e inquietante donde todos los idiomas del mundo y todas las razas se confunden y se mezclan (Gálvez 9).

El tópico del arrabal y sus tipos literarios derivados -las Estercitas, el obrero, la prostituta, el loco, etc.- se ven reforzados por la incorporación, en los bordes del campo literario, de escritores de origen inmigratorio quienes mantienen con el suburbio una relación 
vivencial y convierten ese lugar simbólico en su principal espacio literario. Por este motivo, en los años veinte, el escenario de las orillas ya no es el lugar literario de los otros (Sarlo 2007). Esos otros se encuentran en condiciones de configurar un nosotros que los convierte a través de la escritura en uno mismo.

Cabe destacar también que este fenómeno de nuevo enfoque sobre los márgenes coincide con el momento en que las traducciones españolas de la novela rusa proporcionan marcos y procedimientos a los escritores rioplatenses, entre ellos a los escritores de izquierda, cuyo tema primordial era la pobreza.

En pocos años, el arrabal se convierte en uno de los tópicos principales de la literatura argentina. Las barriadas de Buenos Aires pronto se transforman en materia poética por excelencia, hasta el punto de segregar una retórica nueva, clásica ya por el prestigio y la circulación de numerosos hallazgos. De esta manera, la búsqueda de color local criollista resulta una variante de la vanguardia literaria de Florida (Prieto 1964). Paralelamente, la izquierda literaria se propone una literatura crítica y de denuncia a partir de la tematización de los humildes y los sumergidos, pero con la configuración de un arrabal que dista de las elaboraciones martinfierristas. Por lo tanto, diversas y contradictorias configuraciones de los barrios se sobreimprimen en un abigarrado espacio textual. Comienza, entonces, una disputa por la representación de los suburbios, y de esa confrontación participa casi todo el campo letrado. El arrabal como tópico literario interesa a los efectos de la campaña de Claridad contra Crítica -que analizaremos más abajo-, puesto que podemos leer en las acusaciones que esgrime la revista de Zamora una disputa por ese espacio. Según Claridad, Crítica vino a desvirtuar los suburbios poblando sus textos de prostitutas y delincuentes y restando espacio al componente obrero. Así como Crítica "contaminó" la lengua con jergas y vocabularios "deleznables", también deformó, merced a la "inmoralidad" que contienen sus páginas, un espacio primordial para los escritores de izquierda.

En los años veinte, el espacio de la vanguardia argentina estuvo signado por los enfrentamientos entre Boedo y Florida. Si bien resulta conveniente reducir el maniqueísmo con que fue tratado este tema, las fuentes documentales indican que ambos grupos se cruzaron en numerosas rencillas literarias. No obstante, cabe mencionar que los argumentos que sostienen la existencia de diferencias radicales entre ambas facciones reenvían a esencialismos que es preciso revisar. En este sentido, Adolfo Prieto (1964) asegura que las características de Boedo parecen muy netas cuando se las deduce de sus autores más representativos pero, al igual que ocurre con Florida, se desdibujan cuando se observan las figuras secundarias o cuando se aplica un lente de aumento al menudo trajín de las revistas. La campaña iniciada por Claridad contra Crítica puede ser entendida como un capítulo más 
de ese, por momentos, difuso enfrentamiento entre Boedo y Florida. Se sabe que hacia 1925 varios martinfierristas ingresan a la redacción del diario de Botana. ${ }^{139}$ Esta alianza, en cierto modo, incompatible debido a los presupuestos estéticos, ideológicos y lingüísticos que sostenían esos escritores resulta posible gracias a las oportunidades que ofreció Crítica a los jóvenes vanguardistas de acceder a un público mucho más amplio que el que podrían haber alcanzado únicamente desde las revistas en las que colaboran (Saítta 1998). ${ }^{140}$ De acuerdo con las fuentes relevadas, Claridad ve a Crítica como un nuevo espacio de confrontación gracias a estas incorporaciones. Resultan numerosas las referencias negativas al nuevo staff vanguardista y los nombres de varios colaboradores de la revista Martín Fierro resuenan en las críticas que la revista de Boedo le realiza al diario de Botana.

\section{A propósito de una encuesta del diario Crítica: ¿Llegaremos a tener un idioma propio?}

Durante los años veinte, el lunfardo adquiere notoria relevancia en el marco de las discusiones sobre el idioma nacional. Si bien este vocabulario, en el discurso literario, puede ser rastreado a partir de 1880 (Soler Cañas 1965), es durante la década de 1920 cuando se producen ciertas transformaciones y desplazamientos que hacen que se incorpore en las disputas sobre la lengua literaria: en primer lugar, por aquellos años, muchos de los jóvenes escritores encuentran en el lunfardo un material estético para su literatura. De este modo, emergen una serie de autores que, sin ser lunfardescos, ${ }^{141}$ "colorean" sus obras con pinceladas extraídas de este vocabulario. Pero también aparecen, en las inmediaciones de la segunda y tercera década del siglo XX, poetas que utilizan plenamente el lunfardo: Juan Francisco Palermo, Yacaré y Dante A. Linyera. Y es, precisamente, en los últimos años de la década del veinte cuando aparece la obra más representativa de la literatura lunfardesca: La crencha engrasada (1928) de Carlos de la Púa. En segundo lugar, el tango es el género que, desde comienzos de siglo y paulatinamente, introduce en sus letras el lunfardo y se configura como su mayor difusor (Salas 2004). ${ }^{142}$ En tercer lugar, y gracias a la visibilidad que este vocabulario va adquiriendo en la literatura, en las letras de tango y la prensa, en los años veinte encontramos ya maduro el proceso por el cual el lunfardo lentamente se introduce en

\footnotetext{
${ }^{139}$ Por ejemplo, los hermanos González Tuñón, Çonrado Nalé Roxlo, Nicolás Olivari, Santiago Ganduglia, Cayetano Córdova Iturburu, Pablo Rojas Paz y Jorge Luis Borges, entre otros.

${ }^{140}$ Para profundizar la alianza entre Crítica y el martinfierrismo, ver Saítta (1998: 157-188).

${ }^{141}$ Para distinguirlo del uso real, José Gobello propone llamar "lunfardesco" al uso literario (1965: 11). Dentro de la categoría de autores no lunfardescos que, no obstante, utilizan el lunfardo pero con una menor intensidad, Soler Cañas menciona a Roberto Arlt, Enrique González Tuñón, Florencio Sánchez, Félix Lima (1965: 13).

${ }^{142}$ Esa difusión deriva del proceso de "limpieza y modernización" al que fue sometido el tango, proceso que culmina hacia 1920 (Garramuño 2007).
} 
los conventillos, se hace lenguaje usual para hablar entre los hombres, se enriquece en el uso diario y llega a transformarse en "seña de identidad de lo argentino" (Salas 183). ${ }^{143}$ Por último, cabe mencionar el teatro, sobre todo aquél que marca la transición del sainete al grotesco asainetado de Armando Discépolo, en el cual el lunfardo se instala de un modo central. $^{144}$

Ante este panorama resulta comprensible, como veremos, que Crítica, y sus encuestados, coloquen en primer plano, y de manera casi exclusiva, el papel del lunfardo como principal insumo y motor del cambio idiomático.

El 11 de junio de 1927, el diario Crítica lanza su encuesta “¿Llegaremos a tener un idioma propio?". La pregunta, con la que son inquiridas dieciséis personalidades del ambiente intelectual (escritores, gramáticos, periodistas), da por sentado algunas cuestiones, en apariencia, no sujetas a discusión: por un lado, se entiende que el "idioma propio" no se encuentra todavía formado y que, por ende, su constitución habrá de realizarse en un futuro. Por otro lado, la idea de un "idioma propio" parecería implicar la negación del español peninsular como idioma apropiado para la Argentina. La idea de una lengua propia supuso, sobre todo a partir del libro de Lucien Abeille, la mezcla como operación básica para su conformación. De allí que, por ejemplo, en la encuesta, el lunfardo sea el principal enemigo o aliado de las tesis conservadoras o rupturistas. Lunfardo, cocoliche, lenguaje gauchesco, indigenismos, galicismos, anglicismos: diversos ingredientes que los consultados aceptan o rechazan convenientemente.

El diario Crítica se caracterizó por adoptar posturas poco conservadoras con respecto a la lengua. Debido a que su público estaba conformado por los sectores populares, mayoritariamente inmigrantes, o hijos de estos, en ocasiones el diario editó ejemplares en diversos idiomas, lo cual iba en contra de las políticas de estado que, desde comienzos del siglo XX, procuraban nacionalizar a este sector de la población a partir, principalmente, de la homogeneización lingüística, a cargo del sistema educativo. ${ }^{145}$ Así, por ejemplo, el 1 de

\footnotetext{
${ }^{143}$ En la encuesta “¿Llegaremos a tener un idioma propio” (1927) que lleva adelante Crítica, y que en breve abordaremos, José María Monner Sans da cuenta, con ostensible indignación, de este proceso.

${ }^{144}$ Ver "Armando Discépolo: grotesco, inmigración y fracaso" de David Viñas (2005b).

${ }^{145}$ En La restauración nacionalista, Ricardo Rojas advierte sobre la necesidad de una enseñanza que "revista carácter de nacional" puesto que la gran masa de extranjeros que pueblan el país trata de "perpetuar sus tradiciones y hasta su credo político entre sus hijos, con peligro para nuestras instituciones y para el elemento nativo, que perdería poco a poco su espíritu de nacionalidad y viviría en un medio cosmopolita" (1922: 149150). Y señala que la escuela primaria necesita una sólida preparación de castellano para evitar la "corrupción" del idioma, que la "horda cosmopolita" produce (210). En los años veinte, la función homogeneizadora que se le asignaba a la escuela a principios de siglo continúa vigente y es puesta de manifiesto por autores importantes que se ocuparon de los problemas idiomáticos en Argentina. De este modo, por ejemplo, Arturo Costa Álvarez (1922) afirma que el progreso de la patria depende de la educación del pueblo. En este sentido, la escuela es la encargada de conformar una lengua común en todo el país, es decir, un "verdadero idioma nacional" que sea capaz de imponerse a todas las hablas regionales, las jergas locales y los idiomas extranjeros. Por otro lado,
} 
septiembre de 1927, aparece un artículo titulado "Crítica saluda a todos los hombres de todas las razas y todas las nacionalidades". Un subtítulo aclara: "En sus distintos idiomas hablaremos a nuestros lectores extranjeros" (“Crítica saluda..." 1927: 1). Con motivo de la triple celebración del nuevo edificio, las nuevas máquinas y el nuevo formato, el diario señala que hablará a sus lectores en sus mismas lenguas, para llegar mejor a sus espíritus: "órgano de Buenos Aires, intérprete de la ciudad cosmopolita, Crítica tiene acostumbrado su oído a todos los acentos extranjeros" (1), y por tal motivo asume la tarea de traducir "las voces y las inquietudes de las colectividades extranjeras radicadas en la Argentina.” (1).

Los posicionamientos del diario Crítica con respecto al lenguaje resultan inherentes a sus intereses y estrategias de mercado. Hacia 1920 la ampliación de la industria cultural implicó la solidaridad entre espectáculos y materiales impresos (Rogers 2012c). El diario de Botana no sólo intervino en el mercado cultural con la edición de bibliotecas populares, ${ }^{146}$ sino que además estaba muy vinculado con la industria del espectáculo (sainete, tango, revistas de teatro, etc.). Durante estos años, muchas revistas y diarios como Crítica "contribuyeron a la difusión de la cartelera porteña e instalaron la imagen pública de actores y actrices" (Rogers 5). Crítica se proclama "la voz del pueblo" porque a través de sus diversas especies literarias y periodísticas recupera las hablas populares al mismo tiempo que las reelabora en función de las exigencias de los géneros de mercado. ${ }^{147}$

En noviembre de 1920, se inaugura el concurso "Contrapunto Nacional" destinado a "los payadores, milongueros, versificadores y poetas espontáneos" (Saítta 1998: 144). Estos concursos, que se repitieron a lo largo de la década, no sólo favorecen la participación de determinados sectores tradicionalmente excluidos de los ámbitos públicos, sino también constituyen una impronta sobre el terreno de la escritura. José Antonio Saldías, al igual que Roberto Arlt, participa de la sección policial en donde la combinación de delitos, bajo fondos y marginalidad genera una escritura que, sobre los moldes del folletín, incluye el lunfardo y los diversos registros populares urbanos (Saítta). En otras palabras, los nuevos formatos periodísticos trabajan sobre la base de los géneros exitosos en el mercado cultural. Vale decir entonces que la escritura literaria/periodística se encuentra supeditada a las estrategias de mercado. En La inolvidable bohemia porteña, Saldías dice:

Arturo Capdevila (1954) señala que la escuela es la encargada de "extirpar" los italianismos y todas aquellas formas del lenguaje provenientes de la inmigración.

${ }^{146}$ Como hemos mencionado, en diciembre de 1924, Crítica anuncia la creación de una Biblioteca que editará un libro por mes, a un peso cada ejemplar. La iniciativa pretende acercarle a los sectores populares un material de lectura con el cual pueda descansar luego de las jornadas laborales. En este sentido, el emprendimiento de Crítica se ubica en consonancia con otros proyectos editoriales similares (Claridad, Tor, las narraciones semanales, etc.) que buscan configurar una propuesta cultural alternativa al restringido circuito de las librerías. Ver Saítta (1998: 74-76).

${ }^{147}$ Para profundizar en el auge y consolidación del mercado de bienes simbólicos en Buenos Aires, ver De Diego (2006, 2009), Rivera (1998), Prieto (1956, 2006). 
Botana había ideado una página policial sui generis. Policial inclusive en su parte literaria, pues debía ser escrita en el lenguaje orillero. Era una novedad (...) La página debía contener una composición en verso, una escena callejera a la manera de Félix Lima, y una gran nota que resultó ser después "El diccionario lunfardo" (1968: 133-134).

A lo largo de la historia de Crítica, existieron múltiples secciones en las que, además del costumbrismo y el criollismo, jugaba un rol preponderante el lunfardo. Para ilustrar, podemos mencionar "Sonetos rantifusos" y "Voces y expresiones del arrabal porteño". José Antonio Saldías y Juan Francisco Palermo dan forma al "Novísimo diccionario lunfardo", reemplazado luego por la "Gramática del Chamuyo Rantifuso", a cargo de Yacaré, "miembro de la Real Academia Arrabalera". Todos estos novedosos formatos periodísticos, destinados a introducir las voces atribuidas a los sectores populares en la literatura y el periodismo, se configuran en franca oposición al academicismo de criterios conservadores. En algunos títulos de estas columnas se puede rastrear el uso de la ironía, al instalar un campo semántico perteneciente al ámbito académico: "gramática", "novísimo diccionario", "Real Academia", "grafológico", etc. De la misma estrategia de distanciamiento irónico, y contraste grotesco, hace uso, como veremos, Roberto Arlt en sus aguafuertes dedicadas al idioma. ${ }^{148}$

Con estos antecedentes, el diario Crítica lanza una encuesta que se pregunta sobre la existencia de un idioma propio. No obstante, en su mayoría, quienes responden no son los martinfierristas que formaban parte del staff del diario. De la llamada Nueva Generación, sólo interviene Jorge Luis Borges. Y también se puede mencionar a Arturo Cancela, escritor cercano al martinfierrismo. Tampoco se registran intervenciones de los escritores de izquierda, enemigos acérrimos del diario. La encuesta consulta a personalidades cuya centralidad en el campo literario es notoria: Enrique Larreta, Ricardo Rojas, Roberto Payró, Alberto Gerchunoff, entre otros. Llama la atención la ausencia de aquellos escritores que, trabajando para Crítica en ese momento, elaboran su literatura a partir de la utilización de un lenguaje potente y heterogéneo. Nos referimos, por ejemplo, a Roberto Arlt, quien para esa época se ocupaba de la sección policial del diario, y que sí entrará de lleno en estas disputas como veremos en el capítulo quinto- al publicar en 1930 el aguafuerte "El idioma de los argentinos". Otro caso es el de Nicolás Olivari, cuyos poemas fueron publicados y comentados de manera muy positiva por Crítica; o el de Enrique González Tuñón y Carlos

\footnotetext{
148 "El 'Furbo"” (17 de agosto de 1928), "El origen de algunas palabras de nuestro léxico popular" (24 de agosto de 1928), "Divertido origen de la palabra "squenun"” (7 de julio de 1928), “Cómo quieren que les escriba?" (3 de septiembre de 1929), "El idioma de los argentinos" (17 de enero de 1930). Aguafuertes, todas publicadas en el diario El Mundo.
} 
de la Púa quienes escribían las glosas de tango. A partir de 1925, González Tuñón inicia sus glosas, y al año siguiente De la Púa dará origen a los "Poemas glosados de la ciudad", basados en los mismos procedimientos inaugurados por el primero. Estas producciones darán forma a los libros Tangos (1926) y La crencha engrasada (1928). Ante este escenario, no son extraños los resultados finales de la convocatoria. En el artículo que cierra la encuesta, el diario explica:

\begin{abstract}
Es casi unánime la opinión de que no llegaremos nunca a tener un idioma propio, más aun, hay quienes han profetizado las calamidades que este suceso nos acarrearía en todos los órdenes de la vida. (“Terminó la encuesta..." 1927: 6).
\end{abstract}

Y se consigna que el lunfardo, uno de los tópicos principales de la encuesta y de los debates sobre la lengua de fines de los años veinte, "ha sido, pues, ampliamente derrotado" (6). Los argumentos que impugnan este vocabulario son de lo más variado: José Antonio Saldías, viejo hombre de Crítica, propulsor de varias secciones cuya materia prima era el lunfardo, cambia su posición con respecto a esas prácticas discursivas ${ }^{149}$ y señala que si bien es posible la formación de un “idioma nacional, en cuyo caso el pueblo será su 'hacedor'”, advierte que

no se crea que por todo lo expuesto yo propicio la adopción o incorporación del 'lunfardo' (...) El lunfardo carece de alcurnia suficiente para expresar la belleza que enseña a amar a un idioma (1927: 7).

En referencia al teatro, más adelante agrega que "no es imprescindible escribir con propiedad para confeccionar una obra de éxito popular"; sin embargo, advierte sobre el peligro de que "los irresponsables que abundan en esta tierra de atropelladores e improvisados y al amparo del apoyo y el aplauso simple del pueblo, lo intoxiquen con el exceso del lunfardo llorón y sentimental" (7, destacado nuestro). En la cita se infiere que Saldías considera el lunfardo más que nada como un lenguaje del mercado cultural y, en este sentido, pone de manifiesto su condición de construcción o elaboración literaria y no un "aporte del pueblo". En todo caso,

\footnotetext{
${ }^{149}$ La contradicción de Saldías entre su trabajo con el lunfardo en Crítica y sus afirmaciones en la encuesta pueden explicarse, a modo de hipótesis, a partir del contexto en el que interviene en la convocatoria: en su mayoría, los consultados son escritores, periodistas, dramaturgos y gramáticos de renombre, legitimados, que manifiestan su rechazo hacia el lunfardo. En su respuesta, Saldías apoya la lengua popular, pero no obstante se separa del lunfardo probablemente condicionado por este marco. ¿Acaso el concepto "popular" resulta más apropiado, más versátil y acomodaticio que la idea de lunfardo, que parecería ser más estrecha, en el sentido que reenvía a valoraciones negativas por sus vinculaciones con lo delincuencial? Como veremos enseguida, un caso parecido sucede con Last Reason: pese a ser un escritor muy vinculado con el uso del lunfardo, en su respuesta también prefirió distanciarse de este vocabulario.
} 
critica el "exceso" del uso letrado de este vocabulario por parte de aquellos que buscan el "aplauso (...) del pueblo".

Por su parte, Ricardo Rojas, quien no cree en -y no desea- la formación de un idioma argentino, ${ }^{150}$ afirma:

El argot popular, que existe en todas las grandes ciudades y mucho más en los grandes puertos cosmopolitas; este habla del suburbio y del bajo fondo policial, aunque pase al sainete y a la prensa burlesca, no tiene más consistencia que la de esos pequeños hongos que proliferan en las tierras húmedas, debajo de grandes rocas (1927: 6).

Como casi todos los encuestados, Rojas considera el lunfardo como una forma primitiva, inherente a todos los pueblos. Su primitivismo se define en función de su aparente vinculación con los sectores populares ("habla del suburbio") y con el mundo del hampa ("bajo fondo policial"). ${ }^{151}$ No obstante reconoce su penetración en la literatura y el periodismo o, mejor dicho, en el mercado cultural, pero le quita importancia en relación con los problemas del idioma.

Roberto Payró basa su rechazo del lunfardo en el carácter rápidamente mudable de éste, y en la imposibilidad de su fijación. Explica que el vocabulario callejero, "en el lapso de tiempo que llevo vivido, he observado que varía. Si yo escribiera con el lunfardo de cuando era niño, los arrabaleros de hoy no me comprenderían.” (1927: 5). En este sentido, comparte con Rojas la idea de que el lunfardo resulta cambiante. Según Payró, este vocabulario está

\footnotetext{
${ }^{150}$ Para Rojas, la fuerte presencia inmigratoria hacía necesaria la intensificación de los "estudios nacionales". Para ello, sostiene que es fundamental conocer nuestro territorio, nuestra historia y "cultivar el idioma histórico del continente", es decir el castellano (1922: 193-194). Cuando Rojas se refiere al idioma argentino o nacional, piensa en el castellano peninsular, aunque enriquecido con los aportes de la realidad americana, pero siempre la norma es el idioma culto heredado.

${ }^{151}$ Si bien la idea de que el lunfardo supone una jerga carcelaria o de ladrones ha perdido validez (Gobello 1965), durante los años veinte resultaba un lugar común. La opinión de Rojas y otros encuestados resulta del arrastre de conceptualizaciones ya esbozadas en el pasado. Por ejemplo, Antonio Dellepiane, en su célebre $E l$ idioma del delito (1894) encontraba en el ambiente delincuencial la razón y fundamento del primitivismo del lunfardo: "los criminales [dice Lombroso], se crean un lenguaje propio,especial, que tiene numeroso puntos de contacto con los idiomas de las tribus salvajes, porque, en realidad, son salvajes extraviados en medio de la floreciente civilización contemporánea, porque son hombres que han vuelto, en virtud de la herencia regresiva, al estado de barbarie primitivo. Si el criminal es un salvaje, natural es que piense y sienta como un salvaje, y que su idioma, que es la manifestación de su pensamiento y corazón, ofrezca analogías marcadísimas con el idioma de los pueblos salvajes o primitivos" (1967: 51). Ernesto Quesada también da cuenta del mismo origen unos años después: "la jerga de ese género criollo-compadrito-orillero usa un lenguaje en el cual son visibles las infiltraciones del vocabulario lunfardo, o sea el de gente de mal vivir. (1983: 161). Esta tesitura también se encuentra en uno de los mayores defensores de un idioma rioplatense: Vicente Rossi. Este autor sostiene que el lunfardo es "el argot de nuestros delincuentes profesionales" (1926: 399).
} 
compuesto por "términos transitorios", aunque reconoce que algunos pocos vocablos pueden quedar "definitivamente incorporados al idioma". ${ }^{152}$

Jorge Luis Borges tampoco cree "en la mucha colaboración del lunfardo en la formación del idioma argentino"; ni en la de su derivación, el arrabalero ("mezcla de lunfardo trasnochado y habla vulgar"). Para Borges, el lunfardo es una "jerga artificiosa de ladrones", y usarlo es "condenarse a hablar solamente de cárceles, furcas, comisarías, etc." (1927: 3). Al igual que muchos escritores del pasado y del presente, Borges vincula el lunfardo con el mundo del hampa y en esa filiación funda su estrechez. Costa Álvarez, en Nuestra lengua, ya le había asignado al lunfardo un campo muy limitado de temas y de usuarios, lo cual contravenía la idea de que un nuevo idioma pudiera forjarse a partir de él: "el lunfardo y guirigay compadrito están confinados a un círculo estrecho" (1922: 147). No obstante, Borges aclara que cree en el idioma argentino. Y piensa que es deber del escritor "el aproximarlo". Con esta recomendación, Borges desestima el lunfardo como lenguaje literario, lo cual constituye una referencia negativa al amplio frente de escritores contemporáneos que se valen de este vocabulario para escribir sus obras. "Digamos cosas que no le queden chicas a Buenos Aires y hablaremos el idioma nuevo que será nuestro" (1927: 3), propone finalmente.

Por su parte, en su respuesta a la encuesta, Manuel Gálvez no cree en la conformación de un idioma propio, y mucho menos que en dicho fenómeno intervenga de manera decisiva el lunfardo: "el argot no tiene importancia filológica. Existe en muchos países, y no por eso los idiomas correspondientes han cambiado", sentencia (1927: 6). Al igual que Payró, Gálvez recupera la idea de que el lunfardo no tiene estabilidad, ${ }^{153}$ vale decir que carece del potencial para formar parte de los insumos del idioma propio: "sus voces van y desaparecen con la misma facilidad con que vinieron" (6). Estas tesis son opuestas a las sostenidas una década atrás, en su novela El mal metafísico (1916). En varias oportunidades, en esta obra, pone en boca de los personajes reflexiones en relación con la lengua literaria y con los problemas del idioma en las que se evidencia una postura más bien anti-académica y refractaria a España y hacia su injerencia en materia lingüística. ${ }^{154}$ En la encuesta sostiene que no existe "ninguna diferencia entre el castellano de España y el nuestro" (1927: 6), mientras que en la novela el

\footnotetext{
${ }^{152}$ Este argumento también es compartido por Vicente Rossi quien, en Cosas de negros (1926) sostiene: “en el Plata no existe léxico lunfardo impreso, ni podrá existir, porque sus vocablos son transitorios y no alcanzarían para llenar dos pájinas; corren un tiempo, gozan de un período de popularidad, pasan y se olvidan" (1926: 400).

${ }^{153}$ Pese a esta observación, años después, en sus memorias literarias, Gálvez declara: "cuando escribí Historia de arrabal no me preocupó 'el idioma del delito'. Aunque algo había cambiado en veinte años, los viejos términos de 1900 seguían usándose." (1961: 179, destacado nuestro).

154 “Qué Orloff empleaba palabras no admitidas por el diccionario, pero usadas por todo el país? Pues hacía perfectamente. Una palabra usada por ocho millones de hombres libres que hablan castellano, era tan castellana como cualquier palabra usada en España. Era ridículo que una nación independiente, como la Argentina, dependiese de otra en cuanto al idioma y aceptase el gobierno de una institución extranjera sobre sus escritores" (Gálvez 1922: 207).
} 
personaje, cuya caracterización e ideología resultan más afines al autor, afirma justamente lo contrario:

\footnotetext{
-Niego que nuestro idioma sea exactamente el castellano - dijo Riga. - Nosotros tenemos una psicología distinta de la española y por consiguiente nuestro idioma (...) resultará a la fuerza algo diferente del castellano. Es siempre castellano, pero un matiz nuevo que con los siglos llegará a convertirse en otro idioma (1922: 206-207).
}

La idea incluida en la novela, aunque más moderada, no sólo recuerda a las formulaciones de Lucien Abeille y Vicente Rossi en relación con la supuesta conformación de un castellano diferenciado y autónomo del peninsular, ${ }^{155}$ sino también a la opinión que Borges (1994) emitirá diez años después cuando sostenga que la diferencia entre el castellano peninsular y el argentino es sólo de "matiz". Sin embargo, a diferencia de Borges, el matiz que evoca Riga será el responsable de una evolución radical del idioma. La idea de lo moderno, en el Gálvez de 1916, resulta muy parecida a la manera en que muchos escritores jóvenes de los años veinte entendieron la lengua literaria: la ruptura de toda tutela idiomática con España y el antiacademicismo delimitan las coordenadas de un lenguaje literario novedoso. ${ }^{156}$ Además, en algunos pasajes de El mal metafísico, Gálvez postula ${ }^{157}$ el borramiento de la división entre lengua cotidiana y lengua poética y, de este modo, se aproxima a las concepciones de la zona más renovadora del campo literario de los años veinte. ${ }^{158}$ Sin embargo, la lengua literaria de Gálvez nunca siguió estas ideas. Su postura en la encuesta, conservadora y refractaria a los registros populares, se condice mucho más con su práctica literaria, lejos de las tesis progresistas que postulan sus personajes bohemios.

\footnotetext{
${ }^{155}$ Ver capítulo I.

${ }^{156}$ Gabriel Quiroga sostiene: "Los escritores españoles, en su mayoría, no vivían en nuestro tiempo. Sus giros, su adjetivación, su vocabulario pertenecía (sic) a épocas muertas, definitivamente muertas. La vida moderna, tan compleja, tan viviente, tan 'americana', exigía un idioma nuevo, un idioma civilizado, un idioma libre que fuese 'conductor de ideas', como decía Sarmiento. En nuestra época, había que dejar a un lado toda preocupación de casticismo idiomático, olvidar la gramática (...)

-Eso es verdad -interrumpió Rueda- En los países civilizados como Alemania, Inglaterra y Estados Unidos, nadie se preocupa de si una palabra está o no en el diccionario; y si no está la inventan. Sólo en los países bárbaros como España, existe la preocupación gramatical.” (Gálvez 1922: 325-326).

157 Si bien entendemos que adjudicar los dichos de los personajes al pensamiento del autor puede resultar, muchas veces, una forma equivocada de interpretación, en el caso de Gálvez, quienes formulan estas ideas en relación con la lengua literaria y el idioma son personajes con los cuales Gálvez se identifica y sobre los que diseña una suerte de autofiguración: Carlos Riga y Gabriel Quiroga.

158 "Cuando él [Gabriel Quiroga] veía un libro donde se decía do en vez de donde, Natura en vez de Naturaleza y se empleaban palabras del falso, estúpido, libresco y retórico lenguaje poético de los casticistas, mandaba al libro y al autor a cualquier parte. Los decadentes también tuvieron un lenguaje poético convencional, y había llegado la hora de acabar con eso. No había palabras poéticas, señores. Todas las palabras eran buenas. Necesitábamos convencernos de que nuestro lenguaje de todos los días podía expresar los más profundos sentimientos y las más sutiles bellezas" (Gálvez 1922: 260, destacado nuestro).
} 
Otro de los encuestados, Enrique García Velloso, coincide con Gálvez y Payró: los "barbarismos idiomáticos, vengan del lunfardo o del cocoliche, viven afortunadamente poco (...) La traza lunfarda vive lo que dura un 'berretín"” (1927: 9). Florencio Garrigós (hijo) no se encuentra lejos de estas apreciaciones cuando afirma que los giros populares -entre los cuales el lunfardo constituye un pilar importante- están "destinados a desparecer del caudal de la lengua" (1927: 17).

Curiosa resulta la intervención de Arturo Cancela quien descentraliza un poco el eje de la discusión: cuando aborda el tema de la lengua, no piensa solamente en Buenos Aires. De hecho, afirma que el idioma no lo hacen las grandes ciudades, y recomienda fijarse en "el castellano pintoresco y a ratos arcaico que se habla en Salta, en Jujuy, en La Rioja, etc.” (1927: 9). Como puede verse, centra su atención en el interior del país, en donde, según él, se habla un castellano más cercano a las formas (arcaicas) peninsulares. ${ }^{159} \mathrm{Y}$ agrega: "no creo que se pueda llegar a tener un idioma propio pero sí un estilo peculiar de los argentinos” (9). En este pasaje, Cancela se aproxima a la postura de Borges quien ve, entre el español peninsular y el argentino, una diferencia de "matiz"; Cancela dirá "de estilo". A su vez, ambos niegan las influencias del lunfardo. De hecho, Cancela ni lo menciona en su respuesta, y se limita a esquivar el problema y restarle importancia a los cambios lingüísticos producidos en una Buenos Aires "babélica". Aunque, no obstante, expresa su preocupación y angustia por el presente que le toca vivir, el cual le produce "un terror difuso a las masas irresponsables [que] sobrecoge el ánimo de los hombres civiles de este país" (Capelli 2007: 21). Como en los casos de Borges, Girondo o Güiraldes, el estilo de Cancela se construye de espaldas a las influencias inmigratorias. Con una prosa moderadamente castiza y sutilmente erudita, se coloca a caballo de las tendencias vanguardistas y del circuito "culto" tradicional, puesto que si bien no pertenece a la tradición literaria, sino más bien a la nueva camada de escritores que viven de lo que producen (Capelli 2007), sin embargo, por su forma y estilo, podría compartir un espacio como el de la revista Nosotros.

\footnotetext{
159 En Historia funambulesca del profesor Landormy (1944), la viuda de un diputado roquista refiere lo siguiente: "Los que atiendan a estos personajes [los intelectuales viajeros] han de ser todos gente de primera agua y han de hablar francés o inglés tan bien como ellos, y, si es posible, mejor. Si el viajero es español (parece que también hay algunas personas importantes entre los españoles de España) si el viajero es español, repito, que hablen como se les dé la real gana, porque éste es un idioma de entrecasa, si es que se le puede llamar idioma al español, que es la lengua nacional. (Me parece que idioma se les dice a los extranjeros, pero no estoy segura...). (1944: 36). Cancela ironiza sobre el desprestigio que en algunos sectores de la sociedad argentina -la oligarquíatiene la cultura hispánica. La viuda pone de manifiesto el valor que tienen las lenguas prestigiosas (francés e inglés) en detrimento del castellano, considerado como una lengua inferior, a punto tal que parecería no tener siquiera el rango de idioma. Cabe recordar que si bien esta novela se publica completa, por primera vez, en 1944, Cancela la comenzó a escribir en 1925, y desde entonces se pudo leer por entregas en el diario La Nación, bajo el título de "Los coloquios del M. Landormy" y, posteriormente en La vida literaria (1928-1931), revista dirigida por Samuel Glusberg.
} 
La respuesta de José María Monner Sans ${ }^{160}$ constituye un ataque directo al lunfardo: "lo repudiable y de mal gusto es la formación del lunfardo, idioma del delito que, por rara coincidencia, aparecen hablando las clases aparentemente cultas." (1927: 7). La utilización de ciertos vocablos lunfardos por parte de las clases no populares espanta a Monner Sans y califica el fenómeno como "un contagio, ${ }^{161}$ una impregnación de abajo hacia arriba" (7). Manifiesta el descontento ante un mercado cultural en expansión que constituye uno de los signos del proceso modernizador que experimenta Buenos Aires. De este modo, la difusión que adquiere el lunfardo en tangos, folletines y obras teatrales posibilita ese "contagio" entre los distintos estratos sociales que tanto lo alarman.

Dentro de la encuesta, el lunfardo cuenta con unos pocos defensores: Last Reason, ${ }^{162}$ Félix Lima ${ }^{163}$ y Alberto Nin Frías. ${ }^{164}$ No es casualidad que los dos primeros -además de haber pertenecido al grupo de colaboradores del diario de Botana- se hayan ocupado de escribir una literatura en la cual el lunfardo tuvo una presencia insoslayable. Félix Lima cree que, a la larga, habrá una escisión entre el español peninsular y el rioplatense. Llegará un momento - dice- en el que "un peninsular, arropado de casticismo terminará por no comprender[nos]" (1927: 17). Entre los escritores que reivindican una lengua nacional y un lenguaje literario autónomo, se repite esta idea de que la evolución del castellano en Argentina será tan pronunciada que los españoles tendrán que traducirlos para poder entenderlos. Casi al mismo tiempo, pero en la revista Martín Fierro, Nicolás Olivari decía: "hablamos su lengua [la de España] por casualidad, pero la hablamos tan mal que

\footnotetext{
160 José María Monner Sans (1896-1984) es el hijo del célebre gramático Ricardo Monner Sans (1853-1927).

${ }^{161}$ En esta misma encuesta, Larreta habla del "contagio cosmopolita" para referirse a la incorporación al español de vocablos provenientes o derivados de las lenguas de los inmigrantes. Garramuño explica que el primitivismo adjudicado al tango y, por extensión, al lunfardo, fue concebido como sinónimo de salvaje y considerado, a partir de metáforas relacionadas con el discurso científico heredado del positivismo, "una "enfermedad' para la nación" (2007: 45).

${ }_{162}$ El uruguayo Máximo Sáenz (1886-1960), más conocido como Last Reason, fue un escritor y periodista que colaboró a lo largo de su vida en diversos diarios y revistas, como por ejemplo Crítica, La Nación, La razón, Leolpán, Caras y Caretas, Noticias Gráficas, entre otros. En la década de 1920, escribió en el diario de Botana dos columnas: una sección fija que aparecía los días sábados, y otra, titulada "El consultorio patológico de Last Reason", que salía los martes. En estos artículos, daba forma a una suerte de cuadros costumbristas del ámbito de las carreras de caballos, en las que mezclaba el lenguaje lunfardo y el argot del turf. En 1925 publicó su obra principal, $A$ rienda suelta, que consiste en una selección de estas crónicas hípicas.

${ }^{163}$ Félix Lima ha sido uno de los más famosos cronistas populares, "el mejor cronista de Babel: Buenos Aires" (Soler Cañas 1965: 87). Si bien Lima "no fue un escritor específicamente lunfardesco, algo del ambiente y del vocabulario de la lunfardía se pegó a sus crónicas y a su prosa, en la que viven con sabroso humor los más variados modismos y expresiones de prosapia y costumbre popular" (88). Entre esos modismos, también se cuenta el cocoliche.

${ }^{164}$ Alberto Nin Frías nació en Montevideo, el 9 de noviembre de 1882. Se desempeñó como profesor y periodista. También llevó adelante tareas como diplomático, al igual que su padre. Debido a esto es que pasa su infancia en distintas ciudades de Europa, como Londres, Bruselas y Berna. A comienzos del siglo XX, se aleja de su Uruguay natal y se nacionaliza argentino. Escribió novelas, cuentos y ensayos. Fue un defensor de la homosexualidad y dedicó algunos libros sobre el tema, tales como Alexis o el significado del temperamento Urano (1932) y Homosexualismo creador (1933). Murió en la pobreza, en un pequeño pueblo de la ciudad de Santa Fe, Suardi, en 1937.
} 
impertinentemente nos estamos haciendo un idioma argentino. Dentro de unos pocos años nos tendrán que traducir si quieren gozar de nuestro lírico influjo" (1927: 6). Por su parte, Pablo Rojas Paz, desde la misma tribuna de Florida, frecuenta la misma idea: "nuestra ilusión debe ser la de echar a perder de tal manera el castellano que venga el español y no entienda nada de lo que le digamos." (1927: 6). Esto demuestra la firme creencia de algunos escritores acerca de que, en el Río de la Plata, la evolución del castellano, y por consiguiente de su literatura, se encuentra sobre una huella que lo alejará de manera definitiva y radical del idioma común.

Según Félix Lima, "el argot callejero está logrando expresión artística"; y atribuye a Last Reason la virtud de haber sido uno de los escritores que "no solamente lo ha popularizado, sino enriquecido." (1927: 17). Last Reason remonta su ascendencia lunfarda a Evaristo Carriego, lo cual muestra una operación de construcción de genealogía. Lima cita una carta que le enviara el poeta en 1908, plagada de lunfardismos. Y señala: "como usted ve, el pobre Carrieguito fue un precursor famoso del lunfardo." (17). Finalmente, puntualiza que “al paso que vamos no es aventurado pronosticar el advenimiento de un idioma propio." (17). De todas maneras, si bien Lima se refiere a una carta personal de Carriego, cabe aclarar que en la literatura del autor de Misas herejes no predomina el lunfardo. Al respecto, Borges afirma que pese a que conocía este vocabulario, Carriego lo "soslayó" y sólo se "entretuvo" utilizándolo "en alguna décima en broma y se desentendió de firmarla" (1994: 139).

En abril de 1920, el diario Crítica añade un par de columnas fijas, firmadas por Martín Fierro y por Last Reason las cuales, tomando como modelo la crónica costumbrista, privilegian el ámbito turfístico, su lenguaje y sus anécdotas. Junto a estas columnas, los jueves se publica el "Consultorio patológico, de Last Reason", donde el periodista responde las cartas enviadas por sus lectores. En sus respuestas, establece lazos de complicidad y proximidad con sus lectores a través de un lenguaje coloquial que abunda en términos provenientes tanto del lunfardo como de la jerga del turf. En la encuesta, sienta su posición no solamente a partir de lo que dice, sino también de la forma o el estilo que asume su lenguaje: un coloquialismo lunfardo que lo diferencia de todas las demás intervenciones de la encuesta, realizadas en correcto castellano. Allí, entiende que Ricardo Rojas y Enrique Larreta opinen del modo en que lo hacen,

pero que usted -le dice al periodista que lo encuesta- tenga la irreverencia de preguntarme a mí, si creo en la formación de una lengua que es chamuyada actualmente por una ciudad que cuenta con dos millones de zabecas eso es una cosa que entra entre las catalogadas de gilerías. (1927: 3). 
Se defiende del ataque de "los bacanes" -o como también los llama: "los príncipes de la literatura"- señalando que ellos "no van a admitir de ningún modo que la parla nuestra sea otra cosa que una simple compadrada nacida en el suburbio" (3). No obstante, no está de acuerdo en llamar a ese argot, del que hace uso en sus cuadros costumbristas, "lunfardo" y rechaza el mote de lunfardesco con que lo tildan: "¡la bronca que me da cuando me baten que parlamos en lunfardo!” (3). Como sucede en los primeros diccionarios y reflexiones sobre el lunfardo, ${ }^{165}$ Last Reason asocia este vocabulario con lo delincuencial, por eso trata de separarse de ese concepto, y se pregunta: “por qué ha de ser lunfardo el sentir íntimo de toda una ciudad que aborrece al chorro que le chupa el jugo y que la asalta entre dos luces? ¡Lunfardo, no! ¿Arrabalero? Puede ser.” (3). La vinculación entre el lunfardo y lo delincuencial se encuentra muy extendida (ya hemos visto ejemplos de esto en Borges, Monner Sans, Rojas, Costa Álvarez), aún en aquellos escritores que, como Last Reason, simpatizan y utilizan estas formas en sus textos. En este caso, al proponerlo como ingrediente principal del idioma argentino, resulta evidente que el autor de $A$ rienda suelta quiere despegarlo de su origen espurio o de cualquier vínculo o valoración negativa. Según Last Reason, el idioma argentino encontrará en el lunfardo -“arrabalero"- su materia prima; y gracias a él crecerá, “será el producto de esa parla inarmónica, bastarda, rea... que hoy le quema la boca a los doctores, y mañana será la bocina poderosa que grite a las naciones carcomidas y decrépitas el advenimiento de una grande y gloriosa nación” (3).

Entre los defensores de este vocabulario, y en el marco de la encuesta, Alberto Nin Frías constituye el último eslabón. Clara y brevemente afirma que “el 'lunfardo' depurado será ese idioma futuro." (1927: 10). Como Félix Lima, observa en Last Reason la figura que contribuye a la fijación de ese futuro idioma nacional a partir de la literatura. De hecho, propone un recorrido muy interesante por el canon literario:

\footnotetext{
Para tener una sensación intensa de argentinidad no leería la admirable "Gloria de Don Ramiro" (sic) (1908, Larreta), la cervantina "Aljofaina maravillosa” (sic) (Gerchunoff, 1922), el ingenuo e ingenioso "Libro fiel" (sic) (Lugones, 1912), o el altamente poético "Cascabel del halcón" (sic) (Banchs, 1912) -escritos deleitosos todos ellos y que honrarían a cualquier literatura- sino a las prosas entretejidas con los sentires del ambiente, amasadas en el instinto popular que se funde como copos de purísima nieve en el arroyuelo cantor de "Rienda suelta" (sic) (Last Reason, 1925). (10).
}

Este pasaje nos brinda una idea de la dimensión de los problemas que depara la cuestión del lenguaje en los años veinte. Las querellas sobre la lengua implican marcadas intenciones por

\footnotetext{
${ }^{165}$ Ver Dellepiane [1894] (1967).
} 
legitimar y deslegitimar diversas escrituras, pero también promueven la construcción y reconstrucción del canon literario a partir del concepto de "argentinidad", con un alto grado de injerencia del mercado cultural. Nin Frías cuestiona las obras de los escritores consagrados, aunque sin atacarlas ni agraviarlas, y les opone las nuevas escrituras que disputan un lugar en el campo letrado, al mismo tiempo que introducen nuevas formas en la lengua literaria. La escritura que escoge Nin Frías es la que recupera el lunfardo y los registros populares, y Last Reason parece ser el que mejor realiza esas operaciones. Además, de todos los ejemplos mencionados, A rienda suelta es la obra que se encuentra más próxima al presente; lo que también implica un gesto despreciativo hacia buena parte de la tradición literaria argentina.

En cuanto al ámbito de los estudios filológicos, la encuesta sólo ofrece dos nombres: José María Monner Sans, el mismo con el que polemizará Roberto Arlt en su famosa aguafuerte; el otro es Arturo Costa Álvarez quien, en la Argentina, es la figura de más peso en el tema, y de quien ya nos hemos ocupado en el capítulo primero de este trabajo. De todos los encuestados, Costa Álvarez es el único que discute con otro participante: Last Reason. ${ }^{166} \mathrm{El}$ 16 de junio, el autor de $A$ rienda suelta dejaba sus impresiones acerca del idioma; unos días después, el 22 del mismo mes, es consultado Costa Álvarez. En un procedimiento consistente en reponer la autoridad que Last Reason les había quitado a Rojas y a Larreta, Costa Álvarez comienza diciendo que este autor se ha "pegado una espantada de la madonna" al ver las figuras "solemnes e imponentes" de estos dos escritores (1927a: 6). Como ocurre con cierta parte de la crítica del momento que, al juzgar la obra de un escritor que usa una lengua literaria "plebeya", lo degrada hasta confinarlo en el terreno de los "escritores bárbaros", ${ }^{167}$ Costa Álvarez opera de un modo similar: barbariza a Last Reason a partir de la animalización; lo llama "redomón celoso", y lo acusa de que anda por ahí "bufando, corcoveando y atropellando". Más adelante arremete: “Chis, chis, sosiéguese, amigo, nadie le va a hacer nada..." (6). Costa Álvarez no niega la existencia del orillero o lunfardo; pero se opone a la idea -sustentada por Last Reason y Nin Frías, como hemos visto- de que esos vocabularios puedan dar forma al idioma nacional. Para el autor de El castellano en la Argentina, la lengua de un país es aquella normalizada por las academias, enseñadas en las escuelas y utilizadas por los sectores cultos de la población:

El orillero, ¿quién ha negado o discutido esta rama lateral y baja del castellano, que por cierto no existiría si no sacara del tronco su substancia? (...) No; negar el orillero sería como negar el

\footnotetext{
${ }^{166}$ Si bien Last Reason se refirió a Ricardo Rojas y a Enrique Larreta en su respuesta, Costa Álvarez lo interpela directamente.

${ }^{167}$ Ver el capítulo IV, dedicado a Nicolás Olivari.
} 
sol de Mayo... Pero, ¿qué tiene que ver el orillero con el idioma nacional? Vamos, vamos, Last Reason, no atropelle... La lengua de un país es la común, la oficial, la escolar, la culta; no es la síntesis imposible de sus diversas hablas populares, regionales y locales, y mucho menos es una sola de ellas. (6).

Florencio Garrigós opina de manera parecida al sostener que, cuando se piensa en el posible idioma de los argentinos, nos tenemos que referir más a lo culto que a lo popular (1927). Tanto Costa Álvarez como Garrigós refutan las tesis abiertas por Lucien Abeille quien vio en lo popular -ya sea en su faz exótica ${ }^{168}$ o autóctona- las bases de ese idioma. En Nuestra lengua, su autor afirma:

La aparición de esta obra (El idioma nacional de los argentinos) importa el triunfo y la apoteosis de nuestra incultura popular en el lenguaje. Este libro proclama la necesidad de favorecer la corrupción de la lengua entre nosotros: el autor pide que se suprima la enseñanza del castellano en nuestras escuelas y se la reemplace por el guaraní, el quechua, y una dosis mayor de francés (1922: 106, destacado nuestro).

Desde la perspectiva de Costa Álvarez, para Abeille toda la lengua culta ha desaparecido entre nosotros (115); y cierra la idea del siguiente modo: "nuestra incultura no es para Abeille deformación de cosas viejas sino creación de cosas nuevas" (116).

Si bien en la encuesta la postura de Costa Álvarez se basa en el rechazo de cualquier forma popular de habla cuya pretensión sea constituir el idioma nacional, no debemos adjudicarle el extremismo purista de otros. Sostiene la idea de que el idioma argentino se forjará a partir de la normalización de la lengua, libre de la tutela única de España. Por eso dice creer "firmemente que los argentinos llegaremos a tener un idioma propio. Este idioma será el castellano" (1927a: 6); e indica que esto se logrará cuando "apliquemos la altivez argentina a emanciparnos de la tutela extraña en cuanto al régimen de nuestra lengua; el día que suficientemente preparados para ello hagamos nuestra gramática y nuestro diccionario del castellano que hablamos y escribimos" (6).

Tardíamente, a fines de septiembre de 1927, Crítica agrega dos artículos sobre la encuesta: el primero recoge las observaciones de Amado Alonso con respecto al idioma propio; el segundo, constituye una extensa opinión del diario sobre el tema planteado. En el artículo dedicado a Alonso, Crítica comienza señalando que "cobra actualidad en

\footnotetext{
${ }^{168}$ El concepto "exótico" para referirse a todo aquello que remite a la inmigración es muy recurrente en las primeras décadas del siglo XX. Por lo general, siempre conlleva un valor negativo o una carga peyorativa: "Para restaurar el espíritu nacional (...) salvemos la escuela argentina, ante el clero exótico, ante el oro exótico, ante el poblador exótico, y ante el libro también exótico, y ante la prensa que refleja nuestra vida exótica sin conducirla..." (Rojas 1922: 187).
} 
conferencias, encuestas y publicaciones diversas el tema referente a la formación de un idioma propio hecho a base de argentinismos y sostenido especialmente por la conversación, como medio especial para difundirse" ("En Buenos Aires se habla bien el español” 1927: 5); por ello, sostiene, "las opiniones de un filólogo español tenían, pues, que interesarnos" (5). Alonso desestima la formación de un idioma nuevo, y explica que su aparición en un territorio determinado sólo se cumple cuando sus habitantes viven en el aislamiento y oscuridad cultural de la alta Edad Media (5). No obstante, reconoce que las repúblicas americanas, en cuanto al idioma, deben sustituir el estado de dependencia por el de independencia con respecto a España. En cierta medida, esta postura lo acerca a la sustentada por Costa Álvarez quien, más allá de su simpatía por el mundo hispánico, reclama la autonomía americana para poder legislar sobre la lengua. Con respecto al lunfardo, sostiene que, por sus caracteres intrínsecos, "da la impresión de un habla de campamento, con numerosos elementos lexicales de aluvión, pero respetando en absoluto la estructura interna de la lengua que lo acoge" (5). Al igual que Ricardo Rojas, afirma que el procedimiento de "mutilación” de palabras y la inversión de sílabas es común a los argots de cualquier otra gran ciudad cosmopolita. Pero advierte que en Argentina "hay una atención simpatizante, bastante extensa, por estas formas jergales" (5). Al ser una intervención tardía dentro de la encuesta, Alonso puede evaluarla: “... según se ve por la misma encuesta (...), fuera de algún escritor colorista que utiliza esa modalidad como instrumento de trabajo, los argentinos de alta cultura se han manifestado en contra" (5). Observación que rubrica el rechazo casi general de los encuestados hacia las formas populares, como el lunfardo o el cocoliche; y que el mismo diario Crítica puso de manifiesto una vez culminada la ronda de consultas.

Al día siguiente se publica "La encuesta de Crítica: ¿Llegaremos a tener un idioma propio? Y D. Américo Castro”. En este artículo, sin firma, se expresa la línea editorial sobre la formación de un posible idioma nacional. Si bien Crítica, como acabamos de decir, una vez finalizada la encuesta, se había manifestado al respecto a través de un pequeño artículo, en esta nota sienta sus posicionamientos de forma explícita y extensa. El nombre de Américo Castro es apenas mencionado, y su presencia se justifica como punto de partida del texto:

En el suplemento literario de nuestro colega "La Nación" del último domingo el eminente gramático y filólogo Américo Castro escribe pulcramente, como él sabe hacerlo, en torno al posible idioma nacional de los argentinos. Sin nombrar a Crítica se ve a las claras que su sesuda digresión ha sido motivada por la encuesta que hiciera nuestro diario a mediados del año corriente (“La encuesta de crítica...", 1927: 7). 
Más adelante, Crítica repone los motivos que impulsaron la encuesta y evalúa su resultado final. En estos primeros párrafos ya se puede observar la marcada posición anticasticista del diario con respecto a la lengua:

nuestro periódico (...) invitó a los escritores a opinar sobre un tema de palpitante interés. Resultó de la encuesta que, en su mayoría, hablistas y escritores, decidieron impugnar a quienes se resistían a abrevarse en la formación del lenguaje en otra fuente que la hispana (7).

La defensa de escrituras legitimadas por su vínculo con la oralidad popular, frente a la lengua dominante del circuito "culto" tradicional, resulta explícita: "por más que busquen los doctos y las clases cultas, o simplemente adineradas, inspirarse en la cultura idiomática hispana, siempre existirá (...) el idioma del coloquio íntimo, flor del terruño y de la originalidad circundante" (7). La cita guarda notable afinidad con aquello que Borges escribe sobre el idioma por esos mismos años. En este caso, Crítica define el idioma argentino en relación con la idea de una intimidad cifrada en lugares tales como el terruño -que en Borges también puede ser el barrio-, y en relación además con cierta idea de lo originario y de los elementos que nos son propios "por naturaleza". De un modo muy similar, Borges, en el final del ensayo "El idioma de los argentinos", expone los rasgos de la lengua que desea:

Pero nosotros quisiéramos un español dócil y venturoso, que se llevara bien con la apasionada condición de nuestros ponientes y con la infinitud de dulzura de nuestros barrios y con el poderío de nuestros veranos y nuestras lluvias y con nuestra pública fe (...) Escriba cada uno su intimidad y ya la tendremos. Digan el pecho y la imaginación lo que en ellos hay, que no otra astucia filológica se precisa (1994: 150, destacado nuestro).

Las coincidencias que se observan entre ambas citas no radican en la definición concreta de los elementos idiomáticos que conformarían nuestra lengua, sino en la formulación poética de sus condiciones y propiedades. Sin embargo, como hemos señalado, Borges, en su respuesta a la encuesta, rechaza el lunfardo por considerarlo muy limitado como para convertirse en fundamento del idioma de los argentinos. En este sentido, se separa de las tesis del diario de Botana el cual ha demostrado aproximaciones con el lunfardo, no sólo en sus columnas y en el perfil de algunos de sus colaboradores, sino en la línea editorial que acompañó la encuesta. Para Borges el lunfardo es el idioma de los ladrones, pero también de los saineteros; es decir que no sólo es el vocabulario de un tipo social sino también de una "lengua de mercado" que Crítica, por su parte, explota y fomenta desde sus páginas. Cuando Borges reseña La crencha engrasada, de Carlos de la Púa, se pronuncia en este sentido puesto que pone de manifiesto 
que el uso deliberado del lunfardo no debe confundirse con la poesía popular. Las descripciones y la versificación de los suburbios no corresponden a las intenciones de ese tipo de poesía, sostiene (Borges 1997a).

Desde las últimas décadas del siglo XIX, el avance del hispanismo en Argentina, en algunos casos, se constituye como reacción nacionalista, pero también se lo evalúa como síntoma de un imperialismo cultural cuya mejor encarnadura se encuentra en la cuestión del idioma. Representantes de esta última lectura resultan, por ejemplo, las intervenciones de los martinfierristas en el debate sobre el meridiano intelectual. Pero también el diario Crítica se vale de argumentos que apelan a una identidad nacional con el fin de sustentar la defensa de la "lengua popular", cuya preferencia se relaciona, como ya hemos expresado, con los intereses de Crítica en torno al mercado cultural. Desde las páginas del diario, el "argot" se erige como la base "para una nueva lengua del porvenir, de genuino cuño nacional" ("La encuesta de crítica...", 7, destacado nuestro). Este artículo de Crítica duplica las apreciaciones de Last Reason cuando, en el marco de la encuesta, afirmaba que "los príncipes de la literatura" jamás podrán aceptar "la parla (...) nacida en el suburbio" (1927: 3). En este mismo sentido, la línea editorial del diario opina:

La intención de constituir un nuevo idioma, derivado del ítalo-español, no parte ni podrá partir jamás del argentino de neta ascendencia hispana, o bien del argentino consciente: ella deriva de la turbamulta que encuentra en la letra del tango, en la vida sinuosa del malevo o del buscón, en una palabra, del iliteratismo del inmigrante, una expansión para el corazón y para el alma (“La encuesta de Crítica...", 1927: 7).

Hay que destacar que en esta cita, Crítica reduce el hipotético nuevo idioma a la fusión del italiano con el español, y no tiene en cuenta otras vertientes que pueden nutrir el cambio. Esto se debe, como hemos dicho, a que el lunfardo aparece en la encuesta como el centro gravitatorio de las modificaciones del idioma. ${ }^{169}$

La búsqueda de un idioma propio es presentada como una empresa netamente popular, en tanto que esta idea siempre supone la participación de registros y variedades que las elites ilustradas rechazan. Pero además, de esa búsqueda también participan los géneros populares del mercado, puesto que es allí donde se producen las reelaboraciones de un lenguaje popular que sirve, muchas veces, para reflexionar sobre las condiciones y propiedades del idioma. En

\footnotetext{
${ }^{169}$ El lunfardo se conformó, en gran medida, a través de un amplio sistema de préstamos: italianismo, anglicismos, galicismos, lusismos constituyeron, al menos, el cincuenta por ciento del total de los términos que lo componen. El resto de las voces lunfardas encontraron su origen en aborigenismos, ruralismo y fundamentalmente españolismos (Conde 2011: 147). Sin embargo, los aportes más definitorios provinieron del italiano. Esto se debe a la numerosa cantidad de inmigrantes procedentes de Italia que acogió Argentina: antes de 1920, llegaron al país dos millones de italianos.
} 
este sentido podemos observar cómo, en ocasiones, los polemistas superponen las categorías de idioma y lengua literaria.

Por último, resulta conveniente pensar este artículo en relación con el evidente populismo de mercado de Crítica. Existe una adhesión explícita hacia los pocos defensores del lunfardo consultados en la encuesta, como por ejemplo Last Reason y Félix Lima quienes participan activamente dentro de ese mercado cultural que impulsa y diseña el diario de Botana.

\subsection{El rol de la escuela}

En la encuesta, la función de la escuela en relación con la lengua se convierte en un tópico de confrontación. En la historia de nuestro país, la conformación de un sistema educativo estuvo subordinada a la empresa mayor consistente en la construcción de la nacionalidad. ${ }^{170}$ A partir de 1880, comienzan a visualizarse tensiones entre diversas colectividades instaladas en nuestro país - principalmente la italiana- y el Estado Nacional. Ya Sarmiento, en 1881, había publicado una serie de combativos artículos en los que consideraba inadmisible que se diera a niños argentinos una educación italianizante. Unos años después, en 1887, Estanislao Zeballos, por entonces Presidente de la Cámara de Diputados de la Nación, alertó en un informe al Consejo Nacional de Educación sobre una inquietante realidad de las escuelas: el descuido del cultivo de la adhesión a la patria. El principal obstáculo cultural del Estado estaba dado por la "corrupción del idioma" que suponía la presencia de la inmigración. La alta proporción de inmigrantes que hablaban otras lenguas convirtió en serio desafío el logro de una buena enseñanza del idioma nacional (Bertoni 2001). ${ }^{171}$

\footnotetext{
${ }^{170}$ Ver La restauración nacionalista [1909] de Ricardo Rojas (1922).

${ }^{171}$ En consecuencia, ese mismo año, se anunciaron un conjunto de medidas para regularizar la situación de la instrucción pública: se confeccionaron nuevos planes y programas, se mejoraron los contenidos y métodos, se otorgó mayor importancia a la enseñanza de la historia y a la realización de actos escolares; todo ello apuntando a acentuar el carácter nacional de la educación (Bertoni 2001: 45). Por supuesto, estos nuevos programas ponían énfasis en "el idioma nacional", puesto que incluían el estudio de la gramática elemental, que comprendía elocución, recitaciones, análisis lógico, redacción y ortografía: "se trataba de una 'reacción favorable', pues suponía un mejor conocimiento del idioma nacional" (47). Estas operaciones no podían sino acarrear un encarnizado debate en torno a la cuestión de las escuelas de los extranjeros. Durante toda la década del 80 se producen múltiples debates que se trasladan a los diarios, tanto argentinos como italianos, lo cual amenazó con que este problema se convirtiera en un conflicto internacional (66-67). El punto más encumbrado de estas polémicas podemos rastrearlo a partir de 1894, cuando Indalecio Gómez, diputado por Salta, presenta un proyecto de ley sobre la exclusividad del idioma nacional en todo tipo de escuelas. En Gómez están presentes los temores de que las escuelas extranjeras alimenten la formación de otras 'nacionalidades', y tiendan hacia la autonomía y la segregación del conjunto de la nación. Para Gómez, las escuelas extranjeras forman "niños extraños a nosotros", en la medida en que "no hablan ni quieren hablar nuestro idioma". (190). No obstante, y pese a una segunda presentación en 1896, el proyecto de ley es rechazado. Evidentemente, para ese entonces todavía no había ganado terreno la "paranoia cultural" que dominaría en la década siguiente (Di Tullio 2003:
} 
En la década del veinte, la cuestión no cambia sustancialmente. Ernesto Quesada, por ejemplo, en 1923, no modifica la postura que tenía veinte años antes, cuando fustigaba el libro de Abeille:

es la lengua usada por los buenos escritores (...) lo que caracteriza el lenguaje nacional (...) La lengua oficial de un país es la únicamente enseñada en sus escuelas, usada en sus funciones públicas, y empleada en sus libros y periódicos (...). El mayor número de hablantes emplea dicha lengua con las recordadas variantes dialectales (1923b:193).

En Nuestra lengua, Costa Álvarez marca una distinción inconciliable: la lengua culta y la lengua popular. ${ }^{172}$ Según este autor, lo irreductible de este binomio se manifiesta en la capacidad o incapacidad "natural" del hombre para discernir y apreciar la belleza,

capacidad o incapacidad que se observa en todos los campos del arte y que, en el caso del lenguaje, no aparece o desparece con la difusión de la escuela pública, ni con la pretendida nivelación de clases a la que aspiran los regímenes democráticos de gobierno (1922: 72, destacado nuestro).

Vale decir que Costa Álvarez naturaliza las diferencias culturales en torno a la utilización del idioma y, haciendo uso del determinismo, agrega que ni la escuela pública ni la democracia pueden revertir tal situación. En este sentido, su voz ingresa en franca disidencia con el discurso que hace de la escuela un dogma de fe capaz de exorcizar un mal cada vez más presente: la inmigración.

Estos discursos sobre las características y funciones de la escuela alcanzan el año 27 e ingresan en la encuesta del diario Crítica. En ella, Vicente Mercante le asigna a la escuela una acción homogeneizadora: "la escuela vela por la pureza de la lengua, la limpia de voces extrañas" (Mercante 1927: 9). De este argumento se vale para afirmar que no es posible que surjan nuevos idiomas. La escuela oficiaría de reproductora de un castellano apegado a sus normas. Manuel Gálvez también comparte esta visión cuando afirma que "lo que ha hecho aquí la escuela por la depuración del lenguaje es una obra magnífica” (Gálvez 1927: 6). Por su parte, Ricardo Rojas sostiene que la escuela, así como los textos oficiales, o los "principales" escritores argentinos (menciona a Larreta y a Lugones) transmiten un castellano muy castizo; y que ya se pueden ver nuevos autores de apellidos extranjeros utilizando ese castellano

103). A partir de 1880, hasta bien entrado el siglo XX, se le confiará a la escuela la tarea de erradicar del plano cultural e idiomático todo vestigio de la inmigración. El objetivo es "lograr un Estado unicultural y monoglósico" (6); vale decir, "la consigna era recuperar la identidad nacional preinmigratoria" (Di Tullio 105).

${ }^{172}$ La idea no es nueva, puesto que ya se encontraba en los polemistas de principios de siglo, como por ejemplo Ernesto Quesada. Ver Rubione (1983). 
(1927). En su respuesta, Rojas le adjudica a la escuela el rol de haber formado no solamente un amplio público lector -condición necesaria de la modernización del campo literario-, sino también una nueva camada de escritores. Lo que no dice Rojas es que muchos de esos "escritores de apellidos extranjeros" se constituyeron en un frente caracterizado por el uso del "argot popular" y el "habla del suburbio y del bajo fondo policial" que él mismo tanto critica en la encuesta.

Enrique García Velloso responde que cuanto más babilónica se hace la ciudad, más se perfecciona el idioma en la escuela por espíritu de la propia conservación nacional (1927). Durante estos años, las "deformaciones" del idioma se perciben, principalmente, en la manera de pronunciar las palabras. El cosmopolitismo o "babelismo" encuentra su manifestación singular en un conglomerado de acentos, entonaciones y dicciones reveladores de múltiples orígenes que los sectores conservadores juzgan "espurios”. Es por esto que a García Velloso le preocupa mucho el tema de la "prosodia" ("la pronunzia exótica", dirán los martinfierristas), más que cualquier otro aspecto idiomático; por eso recomienda a las escuelas primaria y secundaria "leer en voz alta, leer y leer y oír leer a los maestros de la dicción" (9).

Contrariamente, Félix Lima y Last Reason niegan y relativizan la función homogeneizadora y trasmisora de la norma lingüística de la escuela. El primero no sólo señala su poca efectividad en su función reproductora de un español "puro", sino que también advierte en esta institución la difusión de un habla heteróclita, que se encuentra lejos de los modelos esperados por los pedagogos: "nuestras escuelas difunden bastante el habla callejera, por la naturaleza diversa y heterogénea del alumnado" (Lima 1927: 17). En este sentido, según se desprende de lo dicho, los estudiantes hijos de inmigrantes se encontrarían lejos de comportarse de acuerdo con la tesis dominante, según la cual éstos estarían sujetos a una rápida asimilación idiomática y cultural. Entonces, Lima se distancia del discurso de la escuela como instancia de homogeneización lingüística, adjudicándole más bien su rol opuesto: por más que uno desee que el hijo se exprese con los cánones clásicos -indica el autor- por conducta de los compañeros aprende infinidad de palabras. Y, de acuerdo con el tema de la encuesta, afirma que "la escuela, tanto en los barrio ricos como humildes, resulta un vehículo poderoso para la difusión del nuevo idioma" (17).

Last Reason, en cambio, si bien coincide en algunos puntos con Lima, no descarta del todo la influencia del sistema escolar sobre el idioma. Reconoce que "en determinadas situaciones (...), el hablante o escritor se prende al castellano y echa mano a su bagaje del colegio" (1927: 3). No obstante, sostiene que lo aprendido en la escuela resulta por demás efímero, si se lo compara con las formas incorporadas en el habla de todos los días: en 
situaciones más cotidianas "vamos a ver a dónde queda lo aprendido en las escuelas e instituciones". Vale decir, pone en duda que el influjo de la institución escolar propicie la conservación de ciertas pautas idiomáticas.

Cuando Crítica anuncia la encuesta el 8 de junio de 1927, anticipa que la consulta “dará lugar a una sensacional polémica" ("Llegaremos a tener un idioma propio” 1927: 6). Sin embargo, de polémica no tuvo demasiado dada la prevalencia de las tesis que señalaban la inviabilidad de la formación de un idioma propio. Pese a que Crítica ponía de manifiesto la amplitud de la encuesta, dado que en ella se intentó que participaran "todos los sectores literarios (...) desde el autor proclive al clasicismo y el gramático hasta el escriba lunfardizante" (6), lo cierto es que, como hemos dicho, la mayoría de los autores consultados provinieron del circuito "culto" tradicional y, por consiguiente, sus posturas con respecto al “idioma propio" eran más bien refractarias. No obstante ello, el lunfardo se configura como tópico común en casi todas las respuestas de la encuesta, lo cual demuestra que -además de considerárselo como uno de los probables insumos de ese idioma en ciernes- se constituye como un problema para la lengua literaria.

La importancia asignada al lunfardo en relación con la constitución de un idioma de los argentinos aparece antes de que comience a publicarse la encuesta, puesto que en el anuncio promocional del 8 de junio se afirma: "el castellano de España, el de la Argentina y el lunfardo librarán una quijotesca y descomunal batalla" ("Llegaremos a tener un idioma propio" 1927: 6). Esto señala la envergadura que asume el lunfardo en el marco de los problemas de la lengua puesto que, pese a que se trate de un vocabulario, se lo coloca en pie de igualdad junto a las variedades hispánica y argentina del castellano. ${ }^{173}$

El balance que el diario realiza de los resultados arrojados por la encuesta coloca como el dato más relevante la idea de que "un nuevo idioma nos aislará, no solamente de Europa sino del resto de América, pues es de presumir cuerdamente que los países hermanos no compartirían en ningún momento el artificioso vocabulario nacido en el tal caso de un deseo efímero y no de una necesidad vital" ("Terminó la encuesta de Crítica" 1927: 6). Sin embargo, las tesis mayoritarias no se cierran sobre un purismo recalcitrante -parece querer dejar en claro el diario- puesto que todos los encuestados están de acuerdo en que "los vocabularios típicos, americanismos, argentinismos, etc." se incorporen al Diccionario de la

\footnotetext{
173 "En torno al origen del lunfardo circulan una gran cantidad de fantasías. La más grande y disparatada de todas dice que el lunfardo es un idioma. Se trata de un grave error conceptual, cuyas raíces pueden hallarse en el siglo XIX, en la vieja aspiración argentina de estar forjando una lengua nacional." (Conde 2011: 27-28).
} 
Real Academia Española. Más aún: algunos "han llegado a conceder que el castellano en la Argentina llegue a adquirir un tono diferencial sin perder su naturaleza primitiva, al contrario de otros -los menos- que no han trepidado en afirmar que acá se habla el español mejor aun que en el país de origen" (6). Según Crítica, lo que vino a demostrar la encuesta es que "existen en el país hombres empeñados en velar por la pureza y la salud del idioma que hablamos sin oponerse por cierto a la evolución que necesariamente sufre a través de años, climas y regiones" (6).

Cabe preguntarse por qué el lunfardo tiene tanto protagonismo en esta encuesta, por qué se coloca en relación tan directa con la formación de un idioma propio. El interrogante podría responderse en parte si tomamos en cuenta la masividad que adquiere este vocabulario en los años veinte, a través de los productos culturales (tango, teatro, folletines, novelas y poesías) que vehiculiza el mercado. La encuesta no demuestra tanto el grado de purismo o los alcances del conservadurismo lingüístico de los escritores argentinos, sino más bien la importante presencia que tiene el lunfardo en los bienes simbólicos que consumen las franjas cada vez más amplias de los nuevos lectores. Si este vocabulario ha sido desestimado y/o rechazado de manera unánime en la encuesta, hay que notar también su centralidad en el debate puesto que casi todos los encuestados se refirieron a él, instalando la idea de una posible identificación entre lunfardo e idioma propio. La encuesta sugiere que ese vocabulario se encontraba muy presente en el repertorio léxico de una masa importante de hablantes, gracias a su difusión por parte de la cultura impresa de mercado, y que de allí provenga su vinculación con una lengua propia.

\section{La campaña de Claridad contra Crítica}

Entre los años 1926 y 1928, en las páginas de la revista Claridad, tuvo lugar una fuerte campaña de desprestigio contra uno de los diarios más importantes de Buenos Aires de aquel entonces: Crítica. ${ }^{174}$ Las pujas entre los grupos de Boedo y Florida; las polémicas en torno al idioma y los juicios que despierta el lunfardo, en tanto lengua literaria; las disputas acerca del rol que estaba llamada a cumplir la prensa masiva en relación con un nuevo y amplio horizonte de lectores; y las derivaciones morales que supuso el ejercicio de una determinada

\footnotetext{
${ }^{174} \mathrm{El}$ relevamiento de las fuentes documentales de esta polémica, no advertida hasta entonces por la crítica, se llevó a cabo durante el año 2010. Fruto de este trabajo son las ponencias y artículos escritos por Oliveto (2011) y Rogers (2011b; 2012a).
} 
forma de periodismo y literatura; todo esto enmarca el conflicto desatado entre la publicación de Zamora y el diario de Botana.

La campaña de Claridad contra Crítica se inserta en un momento histórico en el que las viejas polémicas en torno al idioma nacional, con sus correspondientes improntas sobre las lenguas literarias, cobran renovada vigencia. Como podremos ver, en una amplia proporción, las acusaciones que dispara Claridad contra el diario de Botana involucran aspectos del orden lingüístico. Casi se podría decir que estas intervenciones constituyen una suerte de cruzada contra el lunfardo y el cocoliche.

En febrero de 1927, Claridad publica un artículo titulado "Aclaración editorial y política, periodismo y teatro". Allí se sostiene que con la incorporación de Horacio Rega Molina, Enrique González Tuñón, Roberto Arlt, Nicolás Olivari y Jacobo Fijman, el diario de Botana "se ha prostituido":

Lo peor que trae Crítica es el suplemento. Allí el señor Rega Molina se desahoga como marrano, haciendo epitafios contra lo que él llama sus “enemigos literarios” (...) El señor Rega Molina - prototipo del plumífero sietemesino- ha constituido con otros escritores como él: Olivari, Tuñón, Arlt, Fijmann- un grupo de afinidad (sic). No vamos a defender la moralidad del diario, pero con la incorporación de estos elementos el diario se ha prostituido ("Aclaración editorial...", 1927: 1).

A eso se le suma la inclusión de Carlos de la Púa, "cultor cínico del compadraje y malevaje literarios" (1). Como veremos más adelante, la denominada "literatura maleva" resulta una de las fórmulas principales con que Claridad define el espíritu de Crítica. El artículo sostiene la tesis de que el diario de Botana ha brindado un espacio excesivo a la delincuencia, la prostitución y a todo tipo de "fauna marginal":

Estos muchachos que imitan pésimamente el estilo de Castelnuovo y lo plagian pésimamente, se han largado a exaltar la mugre y la roña de los mugrientos. Uno le canta perpetuamente a los piojos y otro escribe perpetuamente sobre las liendres. Cada uno por su parte descubrió un género nuevo de literatura: el género piojoso y el género liendrudo. El diario del pueblo se ha convertido, en poco tiempo, en el diario del hampa (1).

Claridad no comparte el retrato que estos escritores han hecho del arrabal. La revista de Zamora ve en estos nuevos colaboradores de Crítica no sólo la corrupción del lenguaje periodístico, sino también una tergiversación de las coordenadas que definen los márgenes en el plano literario. 
En cuanto a Nicolás Olivari, se dice que "introdujo en Crítica el cocoliche" (1). Adjudicación un tanto excesiva ${ }^{175}$ y motivada, seguramente, por el posible despecho que Boedo siente ante uno de sus fundadores debido a las opciones literarias que asumió a partir de 1924 cuando, a raíz de su Amada infiel (1924), es expulsado del grupo.

En síntesis, el artículo manifiesta que Crítica no hace más que poner en primer plano "todas las lacras del bajo fondo" (2) y que, por lo tanto, sus columnas "están al servicio de la delincuencia" dado que "alimenta la sangre del crimen" y "glorifica a las prostitutas y asesinos" (3). También deja en claro que "Botana no debe sentirse orgulloso de semejante cuerpo de redacción que ha transformado el diario en un tacho de basura donde va a parar toda la resaca social de los bajos fondos" (3). Queda bien explicitado, entonces, que el foco del ataque hacia Crítica se encuentra en su staff de periodistas, el cual reúne a numerosos enemigos de la izquierda literaria: escritores de Florida, viejos colaboradores de Boedo que concluyeron en muy malos términos sus relaciones con el grupo, escritores cultores del lunfardo y el cocoliche. Sin embargo, el artículo tiene una importancia extra, y es la de haber sido el que motivó uno de los episodios más escandalosos de la literatura argentina del período: el "atentado" sufrido por Antonio Zamora a manos de Enrique González Tuñón y Carlos de la Púa. ${ }^{176}$ Las impugnaciones y críticas que Claridad realiza al diario de Botana pueden ser sintetizadas de la siguiente manera: en primer lugar, el artículo se constituye como una ofensiva contra la unión de Crítica con un amplio sector de la vanguardia martinfierrista. En segundo término, Claridad pone de manifiesto una serie de actitudes lingüísticas negativas hacia el lunfardo y el cocoliche. En tercer lugar, el artículo vincula este lenguaje "sucio" con las temáticas que promueve: delincuencia, prostitución, juego. Vale decir que el lenguaje es vehículo de una serie de categorías en la que los juicios estético-literarios se entremezclan con valores morales. De este modo, queda establecida la relación entre un determinado lenguaje popular y una serie de temas vinculados con la representación de espacios y sectores de la sociedad que también forman parte de la temática de Boedo. Claridad rechaza que Crítica superponga, en un espacio "propio" de los obreros -y, literariamente, de la izquierda-, el lumpen, la delincuencia, la prostitución. Claridad se adjudica, en cierto modo, la representación de esos sectores populares, y se arroga el derecho de preservarlos de la “contaminación” temática y lingüística que ejerce Crítica con las columnas de estos escritores.

\footnotetext{
${ }^{175}$ En las obras principales que Olivari publica en los años veinte, prácticamente no se registra el cocoliche.

${ }^{176} \mathrm{Al}$ mes siguiente, en marzo de 1927, Claridad publica el artículo "Para que nos asalten otra vez", en el que se reproduce íntegramente la editorial comentada líneas arriba.
} 
El ataque sufrido por Zamora motivó que la campaña contra Crítica se torne más agresiva, y en cierta manera desmedida puesto que el número 131, de marzo de 1927, contiene al menos cinco artículos que comentan el incidente y profundizan las invectivas contra el diario de Botana.

El primer artículo de este número, referido al tema, se titula "Crítica pretende amordazar a Claridad”. La revista denuncia explícitamente a Enrique González Tunón y a Carlos de la Púa como los agresores de Zamora. Cabe aclarar que, gracias a la intervención policial, el "asalto" fracasa, al igual que "el proyecto que perseguían [que consistía] en quemar la redacción de la revista” (“Crítica pretende...” 1927: 1). Así se narran los hechos:

El 24 del mes pasado, redactores del diario Crítica, agredieron a nuestro director, Antonio Zamora. De buena fuente sabemos que se proponían incendiar nuestra casa; pero esto no pasó del proyecto. Uno de los 'hermanos Karamasoff', Enrique González Tuñón llevó al malo Carlos de la Púa (...). Armado este de una piña americana, le amagó un golpe a Zamora y la cosa no pasó a mayores porque cayó un vigilante. El bardo De la Púa fue preso; pero gracias a la intervención de Botana pronto recuperó su libertad (1).

Las acusaciones son graves, puesto que también se lo involucra a Natalio Botana como el ideólogo de las agresiones: "no queremos incluir en estas consideraciones a todos los redactores del diario, sino a los que participaron del asalto y particularmente al señor Botana que los dirige" (1). Por este ataque, se acusa a Crítica de fascista; de no tolerar la libertad de prensa, sobre todo cuando se habla en contra del diario; de ser incoherente al combatir la violencia desde sus páginas para luego ejercerla contra quienes no piensan como ellos. Destacar este asunto no sirve más que para profundizar una idea ya esbozada en el editorial el "suelto", como la llaman desde la revista-, y que se vincula con la supuesta veta delincuencial de Crítica: no sólo se le da amplia cabida a los temas policiales en sus páginas, sino que además de eso algunos colaboradores del diario, según Claridad, practican actividades ilícitas, al igual que su director, que las fomenta y conduce: por ejemplo, se acusa Crítica de robar información y de tomar notas de la revista sin permiso y sin indicar la fuente. Ya en noviembre de 1926, en el artículo "Para el de "Hoy", Claridad manifiesta que Crítica publica versos extraídos de la publicación sin poner "debajo de cada transcripción el nombre de nuestra revista" ("Para el de "hoy”" 1926: 3). El "segundo aviso" - así se titula la breve nota - llega en febrero de 1927, cuando nuevamente Claridad reitera su queja: "muchas publicaciones se sirven de nuestro material sin dar noticia de dónde proviene. Nos parece que por lo menos, honestamente deberían mencionar nuestra revista. Esto va para el diario Crítica y para la revista Crítica Social” ("Segundo aviso" 1927: 2). 
El ataque frustrado también fue comentado por el propio Zamora, quien en el número 131, en un artículo titulado "Fue víctima de una tentativa de asalto el director de Claridad", publica una carta relatando los hechos. Señala haber sido atacado por "una banda de malevos que está al servicio del diario boycoteado (sic) Crítica" ("Fue víctima..." 1927: 26). Y detalla: “... me encontraba yo esperando un tranvía en la calle Independencia y Santiago del Estero, cuando a la voz de: 'ese es el director de Claridad', dada desde un automóvil, por el cocainómano González Tuñón, fui agredido por el sujeto Carlos R. Muñoz” (26). Según denuncia Zamora, De la Púa

tenía el proyecto de asesinarme y quemar las oficinas de la editorial que dirijo, como acto de venganza por la campaña contra la mala literatura que se realiza desde las columnas de Claridad (sic) en cuyo último número se publicó un suelto reflejando la catadura del diario venenoso de la tarde y de algunos de sus secuaces. (26)

Como se puede apreciar, la "mala literatura" se ejerce desde Crítica. Y esa será una de las acusaciones principales de Claridad.

Además de esto, Zamora denuncia la "parcialidad" de la policía que protegió al acusado (Carlos de la Púa) y lo liberó rápidamente. Esto sucede, según Zamora, porque Crítica es un diario "amigo" de la policía; rasgo que se suma a la semblanza criminal y corrupta que Claridad se propone realizar del diario de Botana.

En esa misma carta, Zamora se reserva unas líneas para Enrique González Tuñón, quien

se dice escritor y que pertenece a la vanguardia literaria conocida con el nombre confuso de la 'nueva sensibilidad', no sólo carnereó -y qué vieja es la sensibilidad crumira- sino que se creyó en el caso de defender al amo hasta con asaltos. Esta sería la famosa vanguardia literaria! (sic) (26).

La relación entre González Tuñón y la "nueva sensibilidad" deja en claro que nunca se pierde el horizonte que marca la polémica entre escritores de izquierda y martinfierristas. Este es un buen ejemplo para observar de qué manera el foco de esa polémica se ha desplazado y enriquecido gracias a la masiva incorporación de martinfierristas en Crítica. Además, se arrastran ingredientes que se creían ajenos al espíritu de Florida, como por ejemplo la vinculación de la "nueva sensibilidad" con los usos literarios del lunfardo. En cierto sentido, podría considerarse el incidente entre Zamora y los periodistas como el enfrentamiento más material y violento entre las dos jóvenes parcialidades literarias. 
Leónidas Barletta, por su parte, escribe otra carta -también en el número 131-, esta vez dirigida al propio Botana, en la que le reprocha el cambio que ha sufrido el diario. El punto de inflexión, según Barletta, es el hecho "incomprensible" de que Botana se "ha[ya] largado a trabajar con crumiros intelectuales" (1927: 14), en referencia a los jóvenes martinfierristas. Para Barletta, la "nueva generación" ha encontrado refugio entre "pederastas, morfinómanos y jugadores", hecho que le ha valido al diario "hacerse moralmente insignificante" (14). Finalmente, repite las acusaciones contra González Tuñón y De la Púa, y agrega: "si no fuimos a las manos cuando Crítica nos injurió y calumnió, fue porque consideramos que es una brutalidad obligar a nadie a que no diga lo que piensa poniéndole un puño en la boca" (14).

En este mismo número se publica otro artículo, titulado "Claridad y Crítica", que si bien deja de lado este incidente, no obstante se ocupa de atacar a los agresores González Tunón y De la Púa. El artículo comienza diciendo que lo que le molesta a Crítica es que "la pequeña Claridad esté atenta y vigilante y no deje pasar ninguno de sus errores sin la consabida reprimenda"; y luego agrega que otra cosa que incomoda al diario de Botana es que "los redactores de Claridad -gente que no vende por dinero su pensamiento- estén con el dedo índice acusando todas las porquerías que hacen" (“Crítica y Claridad” 1927: 5). Si, como afirma Sarlo (1997b) los ejes del lucro y del arte definen la actitud martinfierrista frente a la literatura como mercancía, en la medida en que hacer dinero con ella resulta una aspiración vinculada explícitamente al origen de clase del escritor, con la incorporación de los martinfierristas a Crítica estos parámetros varían. Según Florida, quienes habían unido literatura y mercado eran justamente los boedista a través de sus publicaciones más importantes, Los Pensadores y Claridad (Sarlo). Sin embargo, según se desprende de este artículo de Claridad, parece ser que quienes "venden por dinero su pensamiento" son los redactores del diario de Botana, entre los que se cuentan numerosos hombres de Florida. No obstante, hay que señalar que tanto unos como otros persiguieron los réditos económicos de un mercado editorial en expansión: por un lado, Zamora escoge una política comercial basada en la baratura de los libros y de los ejemplares de las revistas que edita, hecho que redunda en una venta masiva cuyos beneficios económicos son muy grandes; por el otro, los martinfierristas, al mismo tiempo que dividen al público y rechazan el mercado como espacio de consagración, desarrollan hacia adentro y hacia afuera del periódico estrategias tendientes a conquistar espacios cada vez más amplios dentro del mercado editorial. De esta manera, en el número 34 de Martín Fierro podemos leer un artículo -“Editoriales Proa y Martín Fierro"en el que se presentan las dos editoriales dependientes del periódico. Fundada en mayo de 1924 por Oliverio Girondo, Ricardo Güiraldes y Evar Méndez, la Sociedad Editorial Proa, 
además del objetivo central de publicar a los “jóvenes argentinos de timbre y esencia moderna", persigue los propósitos de conquistar un mercado y mejorar la economía de los escritores que publican en ella. Se declara que se establecerá el pago de derechos de autor, "cosa inusitada en el país" y "el registro del libro como propiedad del autor" ("Editoriales Proa...” 1926: 5). Pero lo que es más relevante aún: los martinfierristas se ponen a tono del momento en que viven, en el que "la competencia en el mercado y por el público es una de las formas modernas de la competencia estética" (Sarlo 1997b: 228), y declaran:

A esto se le agregó el designio de abaratar el libro nacional, revolucionando el mercado al lanzar a la plaza ediciones al menor precio posible, de un tipo de libro especialmente estudiado, con carácter propio, de primera calidad como papeles, tipografía, impresión, estilo, y en las mejores condiciones de presentación por medio de prospectos críticos, fajas anunciadoras, carteles de propaganda, organización de exposición en vitrinas de librerías, garantizando de tal modo una excelente difusión, beneficiosa para autor, librero y editor ("Editoriales Proa..." 1926: 5, destacado nuestro).

Y la Editorial Martín Fierro, traza los mismos objetivos:

Martín Fierro, agrupación y periódico, además de la Editorial Proa, cuenta con la editorial de su nombre, destinada a circular volúmenes de largo tiraje a reducido precio (...) Por medio de la Editorial Martín Fierro desearíamos llevar a la gran masa de público la obra de los martinfierristas, producción de indole popular, propaganda de ideas nuevas, páginas de humorismo, colecciones satíricas, selecciones poéticas, todo aquello que más caracteriza al periódico, en suma. (5, destacado nuestro).

Como puede verse, los emprendimientos editoriales de Florida se colocan en consonancia con los proyectos ubicados en sus antípodas: "volúmenes de largo tiraje a reducido precio". Sin embargo, la diferencia va a estar dada por la calidad de los productos y por el circuito de comercialización, puesto que Martín Fierro prolonga la tradición de la venta del libro en librerías, y deja en claro que los nuevos puntos de venta -kioscos, puestos de diarios, peluquerías, etc.- abiertos por los emprendimientos populares no constituyen un espacio de disputa para los martinfierristas. Estos rasgos concernientes a la calidad de los libros y a los modos de su comercialización son los que diferencian la propuesta de Florida de otras. Sin embargo, todas comparten un marcado interés por acrecentar las ventas y conquistar franjas cada vez más amplias de lectores.

Si en el movimiento hacia adentro, tendiente a ganar nuevos espacios en el mercado, los martinfierristas fundan editoriales e inician campañas publicitarias en el propio periódico, 
hacia afuera entablan la alianza con Crítica. El uso de las páginas de un diario masivo se convierte en otra de las estrategias de la vanguardia para crear su público (Saítta1998). Claridad supo aprovechar estos desplazamientos del martinfierrismo, y utilizó los mismos argumentos de los que se sirvió Florida para segregar a la izquierda: el mercantilismo al servicio de la literatura.

De regreso a "Claridad y Crítica", el artículo continúa la misma estrategia de inversión de argumentos y acusaciones: así como Florida imputó a Boedo el hecho de mercantilizar la literatura, también atacó su estilo y ubicó a este grupo de escritores en el estigmatizado lugar de la "mala escritura". Ayudado por la heterogeneidad que comporta la vanguardia martinfierrista, en la que revistan tanto escritores con posiciones conservadoras con respecto al idioma como otros que asumen el lunfardo como herramienta literaria, Claridad devuelve el golpe y lanza la misma piedra cuando afirma:

Los redactores con que cuenta [Crítica] son en su mayoría poco menos que analfabetos. Se han creado una situación a base de puercas concesiones al mal gusto del populacho. ¿Es otra cosa esa sección de comentarios tanguísticos, en la que se exalta el puro malevaje? Enrique González Tuñón, que es el autor de esas porquerías, estaría bien en 'El alma que canta' ${ }^{177}$, pero nunca en un diario que desea conseguir el respeto del público. Le podrían acompañar Carlos de la Púa y Nicolás Olivari, dos pedestres ejemplares de la cursilería arrabalera. Si por lo menos tuviera la gracia gruesa de Last Reason. Pero a Olivari, por ejemplo, es facilísimo reconocerlo por su prosa de escolar de tercer grado (“Claridad y Crítica” 1927: 5).

Los nombres mencionados, naturalmente, no son gratuitos. En primer lugar, se centra la atención en los dos implicados en el incidente con Zamora. En segundo término, Claridad ataca una vez más a Olivari, con quien los escritores de izquierda mantienen una saña particular puesto que su aproximación hacia la vanguardia estética, en tanto movimiento complementario a su deserción de las filas del boedismo, fue considerado como una suerte de traición. Más adelante se afirma que el poeta “tiene todavía - parece mentira después de tres años- las mismas barbaridades idiomáticas de cuando nos visitaba y poníamos todo de nuestra parte un poco de buena voluntad (sic) en corregirle" (5).

En cuanto a Enrique González Tuñón, éste tiene la particularidad de reunir dos ingredientes que la izquierda literaria rechaza: el tango y el lunfardo. Ambos elementos se fraguan en las glosas semanales que escribe para Crítica -a partir de junio de 1925-, las que

\footnotetext{
${ }^{177}$ El Alma que Canta fue una revista fundada en 1916 por Vicente Buchieri, que registró la historia de la música popular rioplatense. Por sus páginas pasaron las obras de famosos poetas y las canciones de numerosos autores de tangos, fox trots, milongas, chacareras y otros ritmos. Puso al alcance del público las letras de las canciones más populares.
} 
consisten en "ejecutar originales variaciones sobre los temas y los tópicos planteados en las letras de tango, expandiendo algunos de sus versos, que funcionan como punto de partida en las narraciones de una historia de vida" (Saítta 1998: 106). El otro imputado del delito contra Zamora, Carlos de la Púa, se suma al género al año siguiente, cuando inicia en Crítica la serie de "Poemas glosados de la ciudad". González Tunón resulta ser la quintaesencia de todo aquello que Claridad rechaza de Crítica, puesto que no sólo hace uso del tango y del lunfardo, sino que también incorpora aquellos elementos del arrabal que Boedo no está interesado en representar, o al menos no de la manera en que parece hacerlo el autor de Camas desde un peso: las glosas trabajan con el origen prostibulario del tango y reconstruyen un arrabal malevo, sede del delito, el juego y el crimen (Saítta). La vinculación entre el tango y una literatura (maleva) apoyada sobre este género brinda el marco para caracterizar un tipo de escritura predominante dentro de Crítica. Con respecto a la presencia de González Tuñón en las páginas del diario, Claridad reproduce una brevísima carta, bajo el título "Solicitud", dirigida a Natalio Botana en la que se le exige la inmediata supresión de sus glosas. De esta manera, en el número 5, de noviembre de 1926, se puede leer:

Los que suscriben esta nota, en representación de un setenta por ciento de los lectores de ese diario, velando por la salud moral de la población, por el buen gusto y por la dignidad del periodismo, solicitan que suprima usted del diario que dirige, los comentarios de los tangos que aparecen periódicamente y que constituyen una muestra de analfabetismo, de malevaje, y de mugre espiritual que tiene que desparecer de nuestro ambiente ("Solicitud" 1926: 7).

Sobre el final, la revista de Zamora señala que ha recibido esa carta y que se ha publicado tal cual. En muestra de adhesión agrega que "[la] firmaríamos gustosos los de esta casa" (7).

Tanto en "Claridad y Crítica" como en esta carta aparece la palabra "analfabetismo" con la que se pretende desacreditar un determinado tipo de escritura, mayormente la que explota el lunfardo y el cocoliche. Si del lado de Martín Fierro se adjudica la "mala escritura" a la extranjería de los escritores, desde Claridad se la explica a través de la falta de instrucción. Naturalmente, los escritores de izquierda no pueden utilizar el mismo argumento que los martinfierristas puesto que la mayoría de los escritores nucleados en torno a Claridad son de origen inmigratorio. ${ }^{178}$ Las críticas vertidas por Boedo con respecto a los usos del

\footnotetext{
${ }^{178}$ En este sentido, podría pensarse la actitud de la izquierda frente al problema de los inmigrantes y la lengua como una forma de plegarse, parcialmente, al proyecto oficial. Si bien utiliza el realismo con el fin de denunciar la explotación sobre la clase obrera, ese mismo rechazo no se materializa en lo que respecta a la lengua y la literatura. Al igual que muchos inmigrantes de décadas pasadas, la izquierda asume posturas de asimilación, procura borrar todo vestigio de extranjería e insertarse en la sociedad sin diferenciarse de ella, al menos en lo que respecta a la lengua.
} 
idioma demuestran claramente la adhesión del grupo a la normativa que rige los parámetros de la corrección idiomática, como así también una reasignación de valores a la literatura popular.

Todo lo que sirva para desacreditar al tango será aplicado mecánicamente para desprestigiar al diario de Botana, tal parece ser la identificación que se entabla entre los dos términos. Por ejemplo, en febrero de 1927, aparece una breve nota titulada "Noticia para el periodista milonguero" en la que se reproduce una nota sobre la prohibición del tango en Rusia por considerarlo "indecente y un producto de la grosera burguesía americana" ("Noticia para..." 1927: 2). A la inmoralidad inherente y a las "deplorables" formas lingüísticas y literarias que promueve, el tango parece ser interpretado también desde categorías políticas, en la medida en que se lo caracteriza como un producto de la burguesía. Crítica resulta un emprendimiento popular pero que, según Claridad, se define desde los marcos de la burguesía en tanto no sólo importa colaboradores ajenos a cualquier preocupación social, sino que además promueve géneros y textualidades que lejos de educar al pueblo, lo embrutece y reproduce las condiciones de dominio de una clase sobre otra.

José Picone, en un artículo titulado "El periodismo nacional", publicado en agosto de 1927 en Claridad, elabora una síntesis de la situación del periodismo en la Argentina. La primera distinción que hace es entre periodismo culto y popular. Del primero, afirma que "posee buenos periodistas, periodistas de primer orden, escritores y poetas muchos de ellos" (1927: 18). Leopoldo Lugones, Roberto Payró y Alberto Gerchunoff vendrían a ser los baluartes de este periodismo; y puntualiza que La Nación es el diario culto por excelencia. Sin embargo, afirma que si bien son buenos periodistas desde el punto de vista estético, desde la perspectiva social "su valor resulta negativo porque (...) no pueden ser más que retrógrados" (18). Esto sucede porque los grandes diarios (La Nación, La Prensa, La Razón) “defienden a los terratenientes argentinos, a los capitalistas extranjeros que en nuestras extensiones hincan los garfios del imperialismo destructor; defienden los juegos y el vicio; defienden a la Iglesia Católica; defienden al militarismo servil" (18). De acuerdo con Picone, luego de la Primera Guerra Mundial "se producen en el mundo transformaciones fundamentales que hacen comprender a ciertos sectores de la clase culta la necesidad, o acaso la conveniencia, de acercarse al pueblo, a la clase popular". Y agrega que esta aproximación resulta posible "a condición de connaturalizarse con sus sentimientos, con sus ideas, con sus orientaciones y propósitos" (18). Picone describe los usos de la cultura popular por parte de los sectores cultos, una práctica que, según este autor, definió prácticamente toda la literatura argentina del siglo XIX; y, en los años veinte, el criollismo martinfierrista se constituye en una reedición de esas operaciones: "la inclinación del periodismo culto hacia la izquierda literaria 
carece a mi entender de valor positivo"; y puntualiza: "tal [es] la actuación de la revista Martín Fierro" (18). En cuanto al periodismo popular, señala que es demagógico; y afirma que por cada noticia policial novela "un burdo folletín". Además de la valoración negativa de este género, muy en boga durante los años diez y veinte, Picone no se equivoca en la caracterización que hace de la crónica policial en ciernes. En plena etapa de formación, la crónica policial ensayada por Crítica resulta un formato a caballo entre el periodismo y la literatura. El modelo de crónica policial elaborado por Crítica durante los años veinte busca adaptar los datos suministrados por la policía y las investigaciones periodísticas a los procedimientos de la literatura policial. A su vez, para construir este tipo de crónicas, los periodistas incorporan rápidamente el imaginario del tango como intertexto (Saítta 1998). Protagonistas de los bajos fondos, amantes, ladrones, maritormes y apaches, cancioneros y suicidas; todos se dan cita en la crónica policial, la cual sigue el modelo periodístico típico de las publicaciones populares: "más literaria que informativa, atiende más a lo ficcional que a lo 'realmente ocurrido"” (189). Como observa muy acertadamente Picone, la sección policial de Crítica explicita sus referentes y la intención de convertirse en la página popular de un diario que busca interesar a un público consumidor de folletines y revistas populares.

En la cartografía del periodismo nacional que hace Picone, se encuentran los argumentos centrales esgrimidos por la línea editorial de Claridad con respecto al diario de Botana. Y, como no podía ser de otro modo, también se reserva un espacio para referirse a temas vinculados al lenguaje: "a los redactores de Crítica se [les] deberá un día el haber introducido definitivamente en la literatura nacional los más bajos valores lingüísticos, como el lunfardo, antes conocidos únicamente en las tablas" (1927: 18, destacado nuestro). Dada la cantidad de periodistas de Crítica que también son escritores, y el hecho de que muchos encuentren en las mesas de redacción un espacio para la experimentación y creación literarias, se puede comprender la influencia "negativa" -según Picone- que tiene, sobre el cuerpo de la literatura, la inclusión del lunfardo en el seno del diario de Botana.

Casi todo el periodismo popular en Argentina corre la misma suerte que Crítica, sostiene este autor. Sin embargo, “en medio de esta pobreza de periodismo popular", existe "una excepción": Claridad (18). A diferencia de lo que ocurre con el diario de Botana, se destacan en Claridad tanto "sus valores sociales como sus valores estéticos, entre ellos los literarios". Y concluye: “es para mí el valor periodístico positivo por excelencia de la actualidad argentina" (18). La oposición entre Crítica y Claridad, que Picone realiza sobre el final de su artículo, responde más a la coyuntura contextual en la que se enmarca el artículo la campaña contra Crítica- que a rasgos diferenciales y oponibles entre ambas publicaciones. Las diferencias entre la revista y el diario son notorias: la más básica y obvia es que Claridad 
es una publicación principalmente literaria y cultural en la que, a diferencia del diario, la presencia de la información periodística es nula. Pero queda muy en claro que Claridad se opone a Crítica principalmente en todo aquello que está referido a los aspectos literarios y, de manera indirecta aunque no menos determinante, lingüísticos. Como ya hemos señalado, el lunfardo es un elemento que la publicación de la izquierda rechaza categóricamente, y define sus políticas lingüísticas a partir de una borradura de todas aquellas formas provenientes del contacto de lenguas y de la oralidad, así como de la adscripción a las pautas de corrección de la lengua española, aunque salte a la vista las serias y parejas deficiencias que tiene Claridad en ese terreno.

Otro flanco por donde ataca Claridad a Crítica es el de las supuestas inexactitudes y desprolijidades en las que incurre el diario de Botana a la hora de brindar información sobre determinados hechos. Si bien cambia el eje de las acusaciones, los argumentos siguen siendo los mismos: la incorporación a las mesas de redacción de un grupo de martinfierristas el cual, además de ser responsable de traer la "inmoralidad" y una lengua corrompida al diario de Botana, su escaso valor periodístico deviene en "falta de seriedad informativa". Con este título se publican en Claridad dos artículos, entre mayo y junio de 1927, cuyo principal propósito es poner en evidencia las serias faltas en las que incurre Crítica al momento de informar a sus lectores. ${ }^{179}$ Según Claridad, las noticias falaces e imprecisas son moneda corriente en las páginas del diario; y responsabiliza de estos inconvenientes a su director, Natalio Botana, quien

con un sentido ridículo de la economía ha contratado en el mal paso de una huelga, a una docena de muchachos sin responsabilidad periodística de ninguna clase. La presencia de estos literatos en ciernes en esa casa, sólo la explica la exigüidad de sus sueldos. Son los periodistas de la neo-sensibilidad y se diferencian principalmente de los otros en que cobran menos ("Falta de seriedad..." 1927: 9).

\footnotetext{
${ }^{179}$ En el artículo titulado "El diario de las planchas", publicado en junio de 1927 en Claridad, se escogen, con cierta ironía, algunos ejemplos de las falencias de Crítica en relación a la manera de informar: por ejemplo, Crítica anuncia el arribo del aviador Nungesser, cuando este había desaparecido en el mar; o, en otro momento, se refiere al gato que acompañó a Lindberhg en su famosa travesía, cuando en realidad el piloto viajó solo. A su vez, pone de manifiesto algunas distorsiones en el manejo de la información, tal es el caso cuando brinda la noticia de que un grupo de afamados escritores internacionales colaborarán en el diario, cuando en realidad recibirá los artículos, ya publicados por otros medios, merced a un convenio celebrado entre varios rotativos incluido Crítica - y el Pallas Features Syndicate, el sindicato de grandes autores conformado por los dos hermanos Sepúlveda, George Bernard Shaw , Guillermo Ferrero, la Reina María de Rumania y Gilbert K. Chesterton, quienes empezaron a rodar entonces por todos los diarios de la América hispanoparlante ("El diario de las planchas", 1927: 3).
} 
Como puede observarse en esta y en otras citas, en el marco de esta campaña aparece la referencia a un conflicto gremial que devino en una huelga. ${ }^{180}$ De hecho, este episodio no es menor y permite explicar mejor la actitud beligerante que la revista de Zamora tiene para con el diario durante los años 1926 y 1927: en marzo de 1926 estalla un conflicto entre Crítica y la Federación Gráfica Bonaerense, que agrupa a varias ramas del gremio gráfico, como tipografía, imprenta, litografía, fotograbado, etc. Saítta explica la situación:

\begin{abstract}
De acuerdo a los comunicados del gremio, Botana propone a los obreros suprimir un turno de trabajo y aumentar una hora en la jornada de los dos turnos restantes para balancear la actividad; hecho que redunda en el despido de dieciocho obreros gráficos. El gremio no acepta la medida y se inicia una huelga que se mantiene hasta el 26 de marzo, fecha en que Botana firma el pliego de condiciones juntamente con el reglamento de trabajo. Sin embargo, el 12 de junio el conflicto se desata nuevamente: el gremio denuncia que Crítica ha violado el reglamento al despedir a dos obreros del taller con el pretexto de una página mal impresa y reemplazarlos con obreros no sindicalizados (1998: 226).
\end{abstract}

El resultado del conflicto es que, el 5 de julio, la Federación declara el boicot contra Crítica. De este modo, los militantes gráficos inician una campaña en donde se explican los motivos que los condujeron a tomar esa medida. Numerosos afiches son expuestos a la opinión pública en calles, canchas de fútbol, plazas, cines y teatros. En medio de este conflicto, Crítica incorpora nuevos colaboradores -muchos, martinfierristas- que no se encolumnan con los reclamos del resto de sus compañeros. La campaña de Claridad puede leerse como una de las manifestaciones de ese boicot. La revista de Zamora aúna sus motivaciones políticas de defensa de los trabajadores con la aversión que siente por los "crumiros"181 de la Nueva Sensibilidad. De hecho, muchos argumentos vertidos en varios de los artículos comentados en este trabajo parecen extraídos de esos carteles colgados en espacios públicos que daban forma al boicot contra Crítica. Así, por ejemplo, dice uno de ellos, reproducido en La Vanguardia, en octubre de 1926:

\begin{abstract}
Defienda a sus hijas de la obra de perversión que realiza Crítica con su idealización de la Milonguita y otras mujeres semejantes. Hay columnas enteras dedicadas a corromper conciencias. A la prostituta la convierten en heroína. ¡No permita que Crítica entre en su hogar! ¡No la compre! (Saítta 1998: 226-227).
\end{abstract}

\footnotetext{
${ }^{180}$ Como hemos visto, Antonio Zamora se refiere al "diario boicoteado" ("Fue víctima..." 1927: 26), mientras que Leónidas Barletta habla de "crumiros intelectuales" (1927: 14) en clara referencia a Crítica y a los martinfierristas, respectivamente.

${ }^{181}$ El Diccionario de la Real Academia Española define la palabra "crumiro" como aquella persona que no acata la huelga dispuesta por el sindicato.
} 
Claridad acusa a Crítica de ser un diario inmoral no sólo por esa supuesta promoción de la prostitución, sino también por la exaltación del mundo del crimen y del juego. La inmoralidad, antes que nada, parte de sus redactores

porque un diario moderno, insistimos, no se hace con improvisaciones, ni se contenta al lector que lo sostiene, con vaciedades cursis y con los insultos y groserías que provocan las rencillas literarias y de que se hizo vehículo 'el pasquín al cianuro', como lo ha bautizado el inteligente literato que hay en el despreciable Leopoldo Lugones ("Falta de seriedad informativa" 1927: 7).

Y cuando se refiere a los redactores de Crítica, Claridad piensa en la nueva cohorte de jóvenes escritores devenidos en periodistas, muchos de ellos adscriptos al martinfierrismo, quienes "creen que el diario no es otra cosa que un vehículo de sus antojadizas opiniones literarias, de sus desatinos idiomáticos, de sus injurias para los que no les van a la zaga" ("Falta de seriedad informativa" 1927: 9, destacado nuestro). Y, nuevamente, como sucede en otros artículos, se escoge a Olivari como blanco de las críticas. Le reprocha, por ejemplo, que se haga "el Tristán Corbier (sic) de Villa Crespo, después de haber escrito un estupendo elogio pasatista, en un tomo de 200 páginas, del inmarcesible Manuel Gálvez (¡Oh, la neosensibilidad)..." (9). ${ }^{182}$

\section{Literatura maleva}

Si desde la revista Claridad se señaló que el conflicto con Crítica -o más precisamente, el ataque contra Antonio Zamora por parte de dos periodistas del diario- se inició a raíz del editorial "Aclaración editorial y política, periodismo y teatro", publicada en febrero de 1927, y en la que se formulaba una nutrida variedad de críticas contra el diario de Botana, o mejor dicho, contra su nuevo staff de periodistas, cabe aclarar que el antecedente directo de todas las impugnaciones que partieron desde Claridad se encuentran en un artículo que se publica unos meses antes de esa editorial: en noviembre de 1926, aparece el artículo "Literatura maleva". Este texto sienta las bases de la polémica que se extenderá durante todo el año de 1927. Los problemas entre Claridad y Crítica tienen que ver, en buena medida, con

\footnotetext{
${ }^{182}$ Se refiere a Manuel Gálvez. Ensayo sobre su obra, publicado en 1924 y escrito en colaboración con Lorenzo Stanchina.
} 
maneras opuestas de concebir la lengua literaria. Además, implican una serie de posicionamientos que involucran juicios acerca del contacto de lenguas, la oralidad y las formas esperables de eso que algunos sectores denominaban "idioma nacional rioplatense" o "idioma de los argentinos".

Según el artículo, "desde un tiempo a esta parte se cultiva entre nosotros un género de literatura incalificable al que vamos a calificar eventualmente de literatura maleva" ("Literatura maleva" 1926: 1). Y agrega que dicha literatura "pretende encarnar el alma del arrabal y reproducir su lenguaje característico" (1, destacado nuestro). En el centro de la discusión se coloca el lunfardo, puesto que lo que define a la "literatura maleva" es ese vocabulario. La literatura que se sirve de estas formas "se ha encaramado en el teatro primero, después en los diarios y revistas y, finalmente, reclamó el concurso de la música, y sentó sus reales en el libro" (1). Claridad llama la atención sobre un fenómeno propio de esos años: la extensión del lunfardo a diversas manifestaciones escritas. Por ejemplo, se instala primero en el teatro y en algunas formas de periodismo, como el de Crítica; pronto ingresa en la música a través del tango, en las revistas, y en la literatura de escritores como Enrique González Tuñón, que lo practican desde sus columnas periodísticas. ${ }^{183}$ Además de ello, la literatura lunfardesca y/o lunfarda se desprendió de los círculos marginales y si bien continuó siendo rechazada por las esferas oficiales de la cultura argentina, parte de la vanguardia martinfierrista, por ejemplo, además de ejercerla -caso Nicolás Olivari- la legitimó parcialmente. ${ }^{184}$ A eso se le debe sumar que muchas palabras lunfardas son incorporadas por el hablante medio porteño; hecho que motiva que, por ejemplo, el diario de Botana, en el mismo momento en que es fuertemente criticado desde Claridad por promocionar estos usos lingüísticos en el periodismo y la literatura, lleve a cabo una encuesta en la que se propone preguntar a "escritores y gramáticos de todas las tendencias" si "llegaremos a tener un idioma propio". Como hemos visto, la pregunta presupone el lunfardo como la base de ese idioma propio. La encuesta de Crítica se anuncia el 8 de junio de 1927, y el núcleo fuerte de ataques contra el diario por parte de Claridad se ubican, principalmente, entre febrero y marzo de ese año. Entonces, se podría habilitar la hipótesis que permite pensar la convocatoria como una réplica indirecta a los cuestionamientos realizados desde la revista de Zamora a un lenguaje que, evidentemente, resulta bien valorado por Crítica. Pero no sólo es: como hemos visto, desde Claridad se acusa a Crítica de ser un diario delincuencial y prostibulario, promotor de una

\footnotetext{
${ }^{183}$ Cabe recordar que Tangos, el libro en el que González Tuñón reúne sus glosas escritas en Crítica, se publica en septiembre de 1926, apenas dos meses antes de que aparezca "Literatura maleva". No sería descabellada la hipótesis de que ese artículo estuviese motivado por la publicación de este libro, sobre todo por el hincapié que hace el texto de Claridad en la articulación que existe entre el tango y la literatura.

${ }^{184}$ En septiembre de 1926, Ricardo Güiraldes le escribe a Enrique González Tuñón una afectuosa carta privada en la que lo felicita por haber escrito un libro como Tangos. (Güiraldes 1962b: 785-786).
} 
lengua viciosa y degradada. En respuesta, el diario de Botana, con su encuesta, parecería querer demostrar que es capaz de instalar un debate serio, de amplio alcance, sobre el idioma, eje central de las diatribas de Claridad. Para ello, según hemos señalado, convocará, en su mayoría, a personalidades que podrían adscribirse al circuito "culto" tradicional. Crítica prescinde casi por completo de todos aquellos autores que conforman la constelación rea y plebeya de los escritores que utilizan el lunfardo, prescinde también de las vanguardias exceptuando a Borges- y de los impulsores del rupturismo. Luego de los ataques de la izquierda, Crítica prefiere adecentar el diario con los nombres que convoca la encuesta, y demostrar que es capaz de darle forma a un debate que bien podría haber aparecido en las páginas de la revista Nosotros o en el suplemento dominical de La Nación. En este sentido, con su encuesta, Crítica pretende erigirse como un espacio de representación de toda la nación, puesto que cuando se pregunta por el "idioma propio" parecería estar refiriéndose a un problema que involucra a todos, y el protagonismo que tiene el circuito "culto" tradicional en la encuesta estaría dando cuenta de la amplitud y el alcance que tiene el problema, el cual no se limita a lo que puedan pensar sobre el tema los autores más afines a las posturas idiomáticas del diario, esos mismos autores de los que se ocupa Claridad en sus ataques.

La ecuación para Claridad es sencilla: "sin lenguaje malevo no hay literatura maleva" (1). Según el artículo,

la primera preocupación de un escritor del género es, entonces, la terminología lunfarda. Se almacena una carrada de expresiones más o menos soeces y con ellas se procede a la construcción de la canción o del cuento. Esta preocupación es, sin duda, una preocupación de forma; de la peor forma, claro está, se cultiva la mala palabra con el mismo tesón con que el preciosismo cultiva la palabra bonita (1).

La identificación del lunfardo con la "mala palabra", lo soez y lo feo resulta explícita. Y ese es el camino por donde se ingresa a la conclusión de que el lunfardo resulta "inmoral": "la literatura maleva sacrifica todo a las palabras, a las palabras roñosas y apestosas, empezando por lo moral y terminando por la gramática" (1). Se puede apreciar, entonces, el doble impacto que supone el lunfardo o cualquier otra forma lingüística que atente contra la corrección idiomática, ya que su violación implica, además, no sólo el detrimento de aspectos estéticos sino también morales.

La izquierda literaria traslada, en reiteradas oportunidades, la polémica en torno al idioma y a las lenguas literarias al terreno de la moral. Para el grupo nucleado alrededor de Claridad, "el contenido de la literatura maleva es un verdadero veneno espiritual" porque 
"fomenta la emulación. Sabido es que la literatura ejerce una influencia poderosa en las masas y que contribuye poderosamente a modelar el carácter de los hombres, que son como los monos, seres imitativos" (1). Para los escritores de izquierda, más que un objeto estético en sí mismo, la literatura constituye una herramienta pedagógica modeladora de los sujetos. En este sentido, conciben un público lector inerme, a merced de un mercado editorial en constante ampliación que no siempre propone textos acordes a los parámetros que ese lectorado, con escasa formación, requiere. De acuerdo con la opinión de este grupo, según la cual la nueva masa de lectores establece una relación imitativa con la literatura, se puede comprender el celo que pone en la calidad de los textos que deben llegar a ese lectorado, como así también en advertir sobre los peligros morales y lingüísticos que emanan de cierta literatura. ${ }^{185}$ Como se puede apreciar en el capítulo II, escritores como Castelnuovo o Yunque, en sus prácticas literarias concretas, refuerzan la utilización de una lengua literaria regida por la norma culta, correcta, en la que prácticamente no existe espacio para el lunfardo u otras voces populares.

El artículo asegura que "la literatura maleva fomenta el malevaje. Allí se exalta, en primer término, al canfinflero. Luego a la prostituta. Milonguita es el prototipo de la prostituta maleva. No es una figura literaria, sino una mujer de café-concierto o lupanar" (1). El rechazo de la prostituta, no sólo como tipo literario sino como tipo social, continúa:

Milonguita o Estercita son dos atorrantas sin cacumen, que prefieren lavarse el útero a cada rato antes que ponerse a lavar pisos, que es para lo único que sirven (...) No viven más que para fornicar con taxímetro. Fuera de la fornicación, Milonguita no sabe siquiera remendarse la ropa (...) Milonguita hace todo lo que hace, para no hacer nada (1).

Sin lugar a dudas, la "literatura maleva" se asocia con la prostitución debido a la frecuente aparición que tiene este tipo de mujer en los textos de varios escritores populares; muchos de ellos, como hemos vistos, colaboradores del diario Crítica. Para la izquierda, la prostituta constituye la otra cara de la moneda de la obrera, también llamada "fabriquera" en la literatura de la época. La prostitución se configura como una salida espuria para la obrera o para la mujer pobre de los barrios; también, en su huída hacia las luces del centro, suele representar la traición a su origen, al arrabal. Como se puede apreciar en la cita, la prostitución, además de significar una actividad inmoral, connota vagancia. En cierto modo, podría trazarse un paralelo entre el gaucho del siglo XIX y la prostituta de las primeras décadas del siglo XX,

\footnotetext{
${ }^{185}$ Dice Castelnuovo en sus memorias: “en el teatro, por ejemplo, prevalecía el sainete. No el del mal gusto. El de la más baja estofa. Tras que los héroes de este género, no eran nunca los mejores, sino los peores sujetos de la sociedad -ladrones, vagos, prostitutas, proxenetas, etc. -, se repetían siempre idénticos modelos, como si en la Argentina, fuera de ellos, no hubiese habido personas dignas de ocupar el escenario" (1974: 124).
} 
puesto que comparten una construcción discursiva que los estigmatiza, básicamente, sobre dos ejes: la vagancia, es decir su colocación por fuera del aparato productivo capitalista, y el lenguaje "plebeyo" o "inculto".

Además de la prostituta, la "literatura maleva" trabaja sobre otros dos tipos literarios: el compadrito, que siempre es "un caften con todos los vicios y bajos apetitos de un mercachifle de mujeres"; y "la pobre madre querida (...) A nadie se le oculta que la viejita, la pobre viejita, inocente, buena, etc. es un pretexto lírico-sentimental" (1).

Como ya hemos dicho, las polémicas entre la izquieda literaria y otras zonas tienen que ver, en parte, con una disputa que se establece por la representación del arrabal. La construcción literaria de este espacio, los tipos que lo pueblan y los lenguajes que le dan vida no siempre resultan coincidentes. Es por eso que el artículo deja bien en claro que el arrabal construido por la literatura maleva "no es más que una figura retórica". Pese a que se arrogue la cualidad de ser "el alma del arrabal", este tipo de literatura no hace más que nutrirlo de "gente de baja estofa" (2). El arrabal de la izquierda, por el contrario, es el de "los obreros que no conocen otro sitio de la ciudad más que ese", es el de "la gente pobre que vive allí" (2). "Todo eso que se dice en las letras de los tangos", y que constituye el aliento principal de esa literatura maleva, "tras de ser relajado, es falso" (2).

El tango es un "mal" que parece haber "atacado" a una parte de los jóvenes escritores; y la literatura inspirada en el tango encuentra un ejercicio pleno en las redacciones de los diarios populares como Crítica. En un artículo de septiembre de 1927, titulado "Sobre el tango", desde Claridad se sostiene:

\footnotetext{
¿Cómo serán los libros de esta nueva generación que se inspira en el tango! (...) No podemos admitir que el tango haya sido un deslumbramiento para Borges, Güiraldes, Piñero, Rojas Paz, etc., etc. La cultura de estos escritores no puede tener un origen tan 'lunfardo'... Un periodista, y sobre todo un periodista de un diario popular, puede tener como base de su cultura al tango; pero un escritor que se respeta, no. ("Sobre el tango", 1927: 2).
}

Lo que pone de manifiesto este pasaje es la distinción que se establece entre los jóvenes escritores en relación con el tango. Dicha distinción estaría funcionando sobre cierta idea de "alta cultura" propia de la izquierda, con toda su carga moral y pedagógica, que diferencia bien a los escritores vanguardistas provenientes de familias patricias, adineradas y con una sólida formación, de aquellos sectores poseedores de un capital cultural endeble. La izquierda rechaza los "lenguajes populares" y se aferra a la norma lingüística puesto que de ese modo se asegura una inscripción en el espacio de la cultura dominante. 
Por lo general, el tango está vinculado a un vocabulario "bastardo" -el lunfardo- que supone, necesariamente, un origen extranjero. De este modo, se afirma en el artículo que los autores de tango son en su mayoría italianos -y se los menciona a Canaro, Maglio, Firpo y, como no podía ser de otro modo, a Olivari-; mientras que sus comentaristas, españoles; y se brinda los ejemplos de Enrique González Tuñón y Evaristo Carriego. Estas argumentaciones se aproximan a la perspectiva xenofóbica del martinfierrismo que, paradójicamente, utiliza argumentos similares para desprestigiar la literatura de la izquierda. Valga como ejemplo el siguiente pasaje de "Literatura maleva" que bien podría haberse extraído de un texto proveniente de la vanguardia estética: "los pocos argentinos -jahijuna!- que hacemos literatura, sabemos que el tango es la roña de nuestra ciudad" (2). Parecería ser que al igual que no son nítidas las fronteras entre el martinfierrismo y la izquierda, tampoco lo son los ejes del lucro-arte / argentinos-inmigrantes que define la actitud de Florida frente a la literatura mercantilista y "mal escrita” de Boedo (Sarlo 1997b). El rechazo que este grupo siente hacia el tango genera, en algunos textos como "Sobre el tango", una ilusoria eliminación de asperezas y una falsa proximidad del boedismo con respecto al martinfierrismo.

El tango vendría a ser un desprendimiento de la literatura del malevaje. Es por esto que en "Literatura maleva" se analiza la letra de un tango llamado "Ladrillo" para concluir: "la letra de todos los tangos se parece por su vacuidad y ramplonería. Si nosotros le consideramos tanto espacio es porque consideramos a la literatura maleva un veneno espiritual, de más tristes consecuencias que el cianuro de potasio" ("Literatura maleva" 1926: 2). Las críticas esbozadas a la "literatura maleva" coinciden con las realizadas posteriormente al diario de Botana, de hecho ciertos elementos léxicos confluyen y brindan la idea de que una y otro se implican mutuamente. Crítica cobija la literatura maleva, le da forma periodística y la convierte en varias de sus columnas más conocidas. La comparación de esta especie literaria con una "pastilla de cianuro", debido a las consecuencias nefasta que tiene sobre el lectorado popular, hace recordar que al diario de Botana se le aplica la misma metáfora, cuando se lo bautiza como "El pasquín del cianuro" ("Falta de seriedad informativa" 1927: 7).

Como hemos visto, la campaña que inicia Claridad contra el diario Crítica está motivada por múltiples factores. En primer lugar, con el ingreso de varios martinfierristas, el diario de Botana se convierte en un nuevo escenario de las disputas entre las dos facciones jóvenes que dominaron el escenario literario de los años veinte. El foco de atención no está puesto en los martinfierristas "clásicos" o centrales, sino más bien sobre aquellos 
colaboradores periféricos o marginales ${ }^{186}$ del periódico de Florida que se apartan del nacionalismo lingüístico dominante en Martín Fierro e incorporan variedades populares y formas de la oralidad en sus textos literarios y periodísticos. Esto permite apreciar las notorias diferencias existentes dentro del martinfierrismo con respecto a la lengua literaria. La alianza entablada con la vanguardia hace de Crítica el mejor adversario para Claridad porque trabaja con una lengua literaria de mercado y con algunos géneros, como el tango, que la izquierda rechaza. Además, ambas publicaciones participan de una disputa por el público, en este sentido la polémica podría estar dando cuenta también de disputas en relación con una franja del mercado cultural.

En segundo lugar, se puede entender esta campaña como una afirmación, por parte de un sector de la izquierda literaria, de las políticas lingüísticas a las que aspira. Recordemos que en el capítulo anterior hemos podido ver que los textos de Castelnuovo, Yunque y Tiempo encuentran en la corrección lingüística y en el concomitante rechazo de las variedades coloquiales urbanas rioplatenses los parámetros de su lengua literaria. En este sentido, las críticas contra el diario de Botana pueden ser pensadas como una suerte de cruzada contra el lunfardo y el cocoliche, y a favor de un relativo purismo idiomático cuyo propósito se encuentra en la asimilación de los extranjeros a los parámetros (idiomáticos) de la nacionalidad establecidos por las políticas educativas oficiales: la escolarización, la opción de una lengua española desagregada de las particularidades otorgadas por el contacto de lenguas y el establecimiento de una literatura "correcta" y moralmente edificante conforman las coordenadas con que la izquierda piensa sus intervenciones en el cada vez más amplio lectorado. Además, esta orientación de Claridad responde también a los ideales ilustrados propios de la izquierda. Finalmente, la polémica con Crítica explicita la postura de Boedo con respecto a un determinado conjunto de escrituras literarias y periodísticas. Pero sobre todo significa la manifestación de una disputa por el público.

Al mismo tiempo que Claridad lleva a cabo su campaña contra el diario de Botana, Crítica lanza la encuesta acerca del "idioma propio". La consulta, que excluye a los escritores de izquierda, puede considerarse en parte como una suerte de réplica a los ataques lanzados desde la revista de Boedo, ${ }^{187}$ puesto que, si Claridad denuncia la promoción de un vocabulario "espurio" e "inmoral" por parte de Crítica, el diario intensifica sus posicionamientos con respecto a la lengua a partir de la realización de esta encuesta cuyo

\footnotetext{
${ }^{186}$ Por ejemplo, Nicolás Olivari, Santiago Ganduglia, Enrique González Tuñón.

${ }^{187}$ La encuesta de crítica se inicia el 11 de junio de 1927, con la intervención de Enrique Larreta. Concluye el 29 del mismo mes. Las respuestas de los consultados aparecen casi diariamente. Por su parte, la campaña se inicia algunos meses antes: en noviembre de 1926; y se intensifica durante febrero y marzo de 1927.
} 
resultado, más allá del que se desprende de la consulta en sí misma, no es otro que el de convertir en tópico durante varias semanas el tema del lunfardo. Además, la encuesta muestra al diario como institución capaz de poner en escena un debate relevante para la cultura nacional y de convocar para ello a importantes representantes de posiciones diversas, e incluso muy diferentes, a las que sustenta Crítica. Esto contrasta con la caracterización meramente maleva y delictual del diario, como lo presenta Claridad.

Si los escritores de izquierda durante la campaña intentaron demostrar no sólo los efectos perniciosos del lunfardo, tanto en el idioma como en la lengua literatura, sino también el nulo papel que este vocabulario jugó en relación con la formación de un idioma propio, Crítica responde con su encuesta que coloca en un lugar destacado de su agenda al lunfardo. Tanto defensores como detractores del supuesto idioma de los argentinos encuentran en este vocabulario su germen y las condiciones de su transformación, como así también una amenaza que es preciso neutralizar.

La encuesta y las polémicas en el ámbito del periodismo sobre la lengua resultan de suma relevancia para la literatura, puesto que ponen en el centro del debate el lenguaje literario. Cabe remarcar la importancia que reviste el hecho de que una institución del mercado cultural, pero muy importante en relación con la renovación literaria y con los escritores vinculados con la vanguardia, como lo es el diario Crítica, instale de manera tan contundente un criterio de independencia respecto de las normas propiciadas por el Estado y por el sistema educativo, en relación con el uso de la lengua en general, pero también de la lengua literaria. Por el contrario, los escritores y las instituciones de la izquierda apoyan el respeto de las normas, fomentan la "corrección" y sostienen la lengua estatal como modelo.

La "literatura maleva" entrelaza lo malevo/criminal mediante el uso del lunfardo. De este modo, los sectores de izquierda establecen una dicotomía que asocia estética y moral, y que les sirve para posicionarse frente al idioma y la lengua literaria: la corrección vendría a ser una manifestación del "bien", mientras que el "delito" y sus formas lingüísticas espurias asociadas estarían vinculadas a cierta inmoralidad. Esta dicotomía, que expresa una forma de conservadurismo literario e idiomático, se da tanto en los sectores hegemónicos de la cultura, como así también en la izquierda. Frente a esto, emerge una configuración más novedosa, en la que tanto la literatura como el lenguaje literario tienden a desprenderse de las regulaciones del Estado, del "bien", del "buen decir" y de la "corrección" con el objeto de hacer productiva una autonomía (Casanova 2001) respecto de la moralidad y de la ley; autonomía posible gracias a la asociación entre el mercado cultural y la vanguardia, cuya representación más acabada, como hemos indicado, es Crítica. Los mejores escritores de vanguardia de los años 
veinte conformaron su literatura en el marco de este diario, tanto en sus páginas como en su sociabilidad.

En los siguientes capítulos nos ocuparemos de escritores como Nicolás Olivari y Roberto Arlt quienes trabajan con una lengua literaria construida a partir de la transgresión de las normas, de los lenguajes delictuales y "criminales", y del "mal" literario encarnado tanto en sus universos de representación como en los escritores que recuperan: François Villon, Charles Baudelaire, Joris-Karl Huysmans, etc. 


\title{
CAPÍTULO IV
}

\section{Lengua literaria en el proyecto creador en Nicolás Olivari}

\author{
"Cada mala palabra rectifica nuestra puntería" \\ Nicolás Olivari ${ }^{188}$
}

Nicolás Olivari fue hijo de padres italianos y aprendió a escribir español en la escuela primaria. No obstante, su lengua también se conformó escuchando a los inmigrantes del barrio de Once, que a comienzos del siglo XX todavía era un barrio periférico (Bosoer 2012). Bosoer advierte que "esta dualidad y el conflicto del recién llegado constituirán sus textos desde los comienzos" (2012: 195). En cuarto año, abandonó el Colegio Secundario "Nicolás Avellaneda", pero a diferencia de Arlt, no se esforzó por construir una imagen de escritor reacio por completo al sistema escolar.

Durante los años veinte, Olivari fue un escritor que participó activamente en el mercado cultural, transitó por varias zonas del campo literario y practicó diversos géneros: además de componer poesía de vanguardia, escribió letras de tango, narraciones semanales, obras de teatro, trabajó en diarios como Crítica, colaboró en algunas revistas literarias, y transitó, por muy poco tiempo, por la zona de la izquierda literaria.

El objetivo que persigue este capítulo es analizar el lenguaje literario de Nicolás Olivari, al mismo tiempo que nos proponemos reponer la recepción de su obra en los años veinte, con el objetivo de caracterizar el lugar que ocupó su figura en las disputas en torno a la lengua literaria. Las fuentes documentales consultadas indican que la escritura de Olivari ha sido una de las más sancionadas. Esto se debe a que es uno de los escritores del período que llevó más lejos las apuestas sobre un lenguaje nutrido por la rica situación de "babelismo" que atravesaba Buenos Aires por aquellos años. Se sirvió del contacto de lenguas de una manera muy provechosa: puso en cuestión, a partir de la parodia y la ironía, las formas literarias canónicas y elaboró una literatura que reivindicaba no sólo la argamasa lingüística producto de la inmigración, sino también las formas escriturarias "espurias", "incorrectas", que trasgredían las prescripciones del "buen decir". Olivari conviertió estos rasgos en ejes de su proyecto poético, cuestionando la estética y los preceptos tradicionales que regían las zonas legitimadas e institucionalizadas de las letras argentinas. Para este autor la elaboración de una lengua literaria original y contestataria constituía la mejor herramienta para abrirse paso y disputar espacios en el seno del campo letrado.

\footnotetext{
188 “La vía láctea”, en La musa de la mala pata (1926).
} 


\section{Lengua literaria}

La lengua literaria de Nicolás Olivari guarda muchos rasgos comunes con aquellos escritores que durante los años veinte comenzaron a escribir una literatura renovadora, anticanónica, cuestionadora de las estéticas dominantes. Olivari -al igual que Roberto Arlt, Enrique González Tuñón, Carlos de la Púa, entre otros- percibió en el coloquialismo urbano y en aquellas formas lingüísticas consideradas "plebeyas" por los autores y críticos conservadores, una fuente productiva de recursos. A continuación, repasaremos los rasgos principales de su estilo y analizaremos el modo en que su lengua literaria interviene en la construcción de su figura de autor.

En primer lugar, los textos de Olivari se plantean como una escritura del descuido, en el sentido de que su proyecto creador parece postular la "incorrección" formal como signo y fundamento de un valor estético novedoso. Al recorrer su producción narrativa y poética de los años veinte, ese "descuido" se manifiesta, por ejemplo, en signos ortográficos que abren pero no cierran, y a la inversa; ausencia de acentos y/o signos de puntuación; etc.: "cuando tocas con tu aire lánguido y sufrido / sueñas acaso que te llega un beso?” (2006: 43); "mira como sube la angustia, como sube!" (48). Por momentos, se confunde el error deliberado con la errata, a punto tal de que en ciertos casos resulta difícil establecer con seguridad si se trata de uno o de la otra: "este hombre se debría suicidar..." (84, destacado nuestro); o bien, "tra... la la... rilamolirina... / -con su carina ${ }^{189}$ en harina / la violinista se empina / en dos flatos / de can can" (85, destacado nuestro). Las construcciones ripiosas y la sintaxis enrevesada son el correlato de esta escritura "descuidada": "aspiró toda la revelación, adivinó el misterio del sexo, la diferencia del mismo, la finalidad del mismo, preciosa, de oasis, de la mujer" (2009a: 35). Las faltas de ortografía, por ejemplo, son muy habituales en sus cuentos y poesías: “animalizastes", "producistes" (2006: 107), “tibiesas", “acesibles” (2009a: 63), "exausta" (64), “extremecida" (56), "hisócrona" (47), “absención” (69), "razgos" (75), "dedicastes" (77).

El repertorio léxico olivariano también incluye la creación de neologismos y el uso de cultismos o arcaísmos. Con respecto a los primeros podemos citar: "ardencias" (35), “anhelancia” (37), "probabilicé”, “amargueado" (2006: 43), "madrigalizar" (46). En cuanto a los cultismos, cabe ponerlos en relación con otro rasgo propio de su lengua literaria: la mezcla

\footnotetext{
189 En 2006, se editan los tres poemarios que Olivari publica durante la década del veinte: La amada infiel (1924), La musa de la mala pata (1926), El gato escaldado (1929). Los editores advierten: “Gentileza de Juan Carlos Olivari, el ejemplar consultado [se refieren a La musa...] posee correcciones manuscritas del poeta. Las mismas se incluirán a un lado del verso y deben leerse como modificaciones del texto subrayado." (Olivari, 2006: 67). La palabra "carina" es corregida por el poeta y se convierte en "carita", y así aparecerá en ediciones posteriores (Ver Olivari 1992: 25). Según Sara Bosoer (2005), estas correcciones manuscritas fueron realizadas cuando preparaba la segunda edición de La musa... en 1956.
} 
de estilos. De este modo, palabras provenientes de la tradición literaria son desacralizadas cuando se las mezcla con expresiones de la más llana oralidad, con vocablos provenientes del lunfardo o de la conversación cotidiana. Con respecto a los cultismos y arcaísmos podemos citar los siguientes: "ludibrio" (77), "beguina" (79), "sinecura" (79), "ebúrnea”, "veneranda" (86), “coyunda" (97), “invaginadas" (107), “ajorcas", "barotas" (110), “flexuosa" (147), “gárrida”, “dogaresa”, “enjaretada” (2009a: 36), “febricitante”(37), “pitanza” (45), etc. Dichas palabras conviven sin mediaciones ni diferenciaciones de ningún tipo con lunfardismos como “yiranta" (2006: 58), "mina” (114), “atorranta" (115); o bien con expresiones coloquiales que transgreden la idea de "corrección" desde el sentido, ronda lo prohibido y lo bajo: “amueblada" (58), "putear" (73), "puteada" (113 y 119), "hembra lasciva" (113), "roce obsceno del pantalón" (113), etc. El juego que establece Olivari entre lo "alto" y lo "bajo", lo "culto" y lo "popular", lo lírico y lo prosaico se manifiesta muy tempranamente y continuará siendo uno de sus recursos predilectos a lo largo de toda la década. En sus relatos se pueden encontrar ejemplos como el siguiente: "la amó ahí, al contemplarla en el estrado, amplia y hermosa, llena de luz, como una Venus, toda palpitación de carne joven, toda anhelancia de ensueños tibios, sugeridora y henchidora de deseos, de todos los deseos machos de la concurrencia" (2009a: 37, destacado nuestro). Muchos de los pasajes de estilo refinado remiten a la estética modernista, escuela que marcó, no sin ciertas tensiones, ${ }^{190}$ a los escritores jóvenes de los años veinte. Las referencias a la mitología grecorromana, una de las marcas del modernismo, son copiosas en Carne al sol: "Diana" (2009a: 59 y 91), "Citérea" (sic) (62), “Juno" (70), "Mercurio", “musas" (73), "Venus" (86), “Apolo" (86), “Afrodita" (87), "Quimera" (89), "fauno" (93), etc. Las referencias al Cantar de los cantares también reenvían a la estética modernista: "el mozo incansable bebía la vida y el alma en la boca granadina, crátera infinita de dulcedumbre, salmodiando muda, con la sola hesitación del labio rojo mil nuevas ediciones del Cantar de los Cantares..." (61). El epígrafe que lleva el cuento "Sol de mediodía" es una cita directa del libro bíblico: "mel et lac sub lingua tua" (81), frase utilizada por Rubén Darío en su poema "Que el amor no admite cuerdas reflexiones”, incluido en Prosas profanas y otros poemas (1896). Otra mención al Cantar...: "me sentía hermoso, potente y bueno, e iba hacia mi amada en un inconsciente plagio del Cantar de los Cantares" (88). Sara Bosoer señala estos préstamos y referencias para indicar que Olivari ejerce "una apropiación de imágenes cargadas de resonancias y las abarata, sin que por eso pierdan su capacidad de seguir remitiendo, aunque de un modo desviado, a las retóricas en que fueron pensadas" (2009: 5), en este caso el modernismo. Para esta autora, la mezcla de estilos que venimos señalando se lleva a cabo "entre el acuerdo y la resistencia a los cánones

\footnotetext{
${ }^{190}$ Ver, en el capítulo II, el caso de Elías Castelnuovo.
} 
dominantes" (1); es decir -agregamos-, a partir de una lengua literaria tensionada entre lo residual y lo emergente, entre la fascinación y el rechazo de las formas legitimadas. Esta tensión no es privativa de Olivari, puesto que también se puede observar en otros escritores del período. ${ }^{191}$

Las referencias sexuales constituyen otro rasgo de su lengua literaria. La voluntad de transgredir en este sentido ya se halla plasmada tempranamente: Carne al sol encuentra en el erotismo su tema primordial, rasgo que lo vincula con las narraciones semanales -género que también frecuentó- puesto que la temática erótica o sexual aparece con suma frecuencia en ellas. $^{192}$ En este volumen de cuentos, aparecido el mismo año que los Veinte poemas... de Girondo -otro poeta que también encontró en la sexualidad nuevas potencialidades para su lengua literaria-, ${ }^{193}$ trabaja con un erotismo que procura escandalizar al lector y producir un rechazo con el cual Olivari construye su figura de autor. Algunos ejemplos: "enorme falo de vidrio" (2009a: 40), "se encendió todo en un orgasmo" (40), "los riñones doloridos del empuje vital que dio" (41), "el vaho tenía un olor sanamente viril de semen" (62). En estos relatos, desarrolla un realismo transgresor debido a las referencias directas y sin eufemismos del acto sexual. El lenguaje que utiliza para representar la sexualidad se encuentra tensionado puesto que, como explica Bosoer, está tramado por una sensibilidad modernista. La confluencia de un estilo dual o bifronte produce una lengua literaria moderna a partir del contraste entre lo sublime y lo terrenal o carnal.

La lengua literaria de Olivari tiene como función primordial desacralizar la tradición literaria y la noción de literatura, que en los años veinte establecía la lengua culta como modelo, guiada por propósitos morales y educativos (Bosoer 2012). Para ello, el poeta se servirá de palabras consideradas como "vulgares" u "obscenas". Por ejemplo, en el poema "Esta bestia magnífica y clinuda", perteneciente a El gato escaldado (1929), se puede leer: "Esta bestia magnífica y clinuda / (...) con el ano empotrado en la nostalgia / de su tribu cafre..." (2006: 181). O bien en "La dactilógrafa tuberculosa", de La musa... (1926): "Bella burguesita que a mi lado pasas, cambiá de acera, / porque voy a putear” (73). Además de las

\footnotetext{
${ }^{191}$ Algo similar ocurre con Enrique González Tuñón, Elías Castelnuovo y Roberto Arlt. Ver capítulos II y V.

${ }^{192}$ Los cuentos y las novelas breves que Olivari escribe a comienzos de los años veinte -como, por ejemplo, "La carne humillada" (1922), "Bésame en la boca Mariluisa!" (1923), "Historia de una muchachita loca" (1923)participan del espacio del mercado cultural de las narraciones semanales. Sara Bosoer señala al respecto: "tanto los cuentos, pero sobre todo las novelas breves, participaban del circuito de producción ampliado: son relatos sobre los comienzos en el mercado escritos en el mercado. Es decir que participaban de un espacio, como precisó Sarlo, dominado por 'el imperio de los sentimientos', en tanto las historias estaban sujetadas a la anécdota sentimental. Olivari, que escribió estas primeras narraciones para la zona de las novelas semanales y de las ediciones baratas, también eligió historias de amor, pero las escribió eróticas y burlonas a través de la parodia del personaje masculino, y trocó, podríamos decir, ese imperio de los sentimientos por el imperio del capital al desplazar el conflicto amoroso e individual y poner en el centro el conflicto económico, o mejor, el del escritor y del artista en una cultura mercantilizada" (2012: 34-35).

${ }^{193}$ Ver capítulo VI.
} 
señaladas, Olivari también desafía el decoro y la moral a través de referencias sexuales: "el sexo hediondo de mi alimaña" (45), "al compás del piano onanista / que se masturbaba siempre en el mismo vals" (101), "monograma en el viejo escritorio / que eyacula ${ }^{194}$ tinta" (119). Por último, hay que anotar que no sólo enfrenta la tradición literaria, sino también el discurso histórico hegemónico liberal al incluir referencias degradadas de algunos próceres nacionales: en "Antiguo Almacén 'A la ciudad de Génova", encontramos una escatológica humorada en relación con el General Roca: "tu recuerdo se viene en pareja / con el recuerdo de mi lejana infancia (...) cuando el General Don Julio Argentino Roca, en coche, / inauguró la máxima cloaca / que en su entraña Cangallo encierra” (152-153). O bien, en el poema "Canción de la Plaza Lavalle", se ridiculiza la figura del militar unitario:

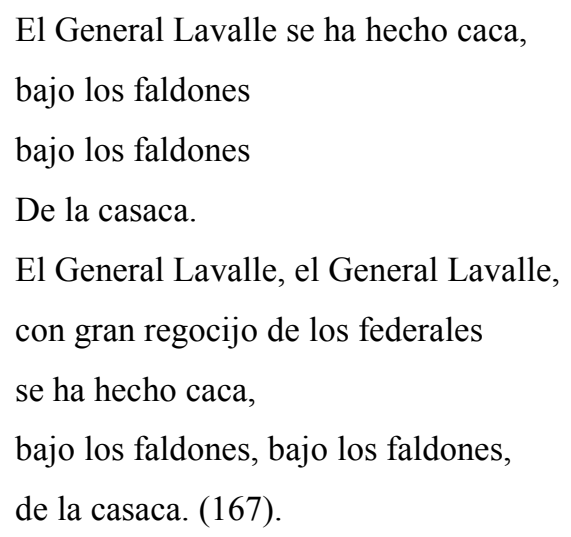

\section{Figura de autor}

Al igual que otros escritores jóvenes, sin formación tradicional y de procedencia inmigratoria, el rechazo y la exclusión de las zonas legitimadas del campo literario es una condición desde la cual Olivari construye un lugar propio. Lejos de constituir una dificultad, el lugar desventajoso desde donde parten estos autores se convierte en un espacio ideal para entablar las disputas contra los sectores consagrados y plantear innovaciones estéticas. Es decir, la subalternidad se convierte en un valor que define nuevas figuras de autor, pero también nuevos espacios de sociabilidad e intercambio entre los escritores.

Este lugar desventajoso que ocupan los escritores jóvenes y no tradicionales de los años veinte resulta un elemento fundamental en la construcción de la figura de autor. Olivari convertirá el fracaso, los rechazos sistemáticos de la crítica y de algunos de sus pares, la imposibilidad de sostenerse únicamente con su actividad de escritor y, por supuesto, su lengua literaria (auto)proclamada como "defectuosa" en un valor que encierra las cualidades del

\footnotetext{
${ }^{194}$ Nótese la reminiscencia girondiana de este último ejemplo. “[Las chicas de Flores] van a pasearse por la plaza para que los hombres les eyaculen palabras al oído..." (Girondo 1999: 15).
} 
artista nuevo, moderno y transgresor. ${ }^{195}$ Olivari se manifiesta a sí mismo como "el escritor subalterno de la decadencia” (2006: 70). Sus versos siempre son “cojos” (61), procedentes de una musa "tuerta" (71) o "estéril" (72). Si las musas tradicionales son seres etéreos, las de Olivari resultan sumamente terrenales y suelen estar asociadas a un tipo literario muy frecuentado en la década: la prostituta: "musa transparente / hueso solamente / cutis puramente / yo fui tu cliente / hay que pagar!” (129); “igratitud de poeta que ha encontrado su musa de carne... ¡de carne!" (108). Desde Baudelaire, la prostituta ingresa en la poesía moderna con la función de musa del poeta. ${ }^{196}$ Olivari toma esta tradición con el objeto de utilizar a la musa-prostituta como un elemento ligado a la desacralización del poema. Sara Bosoer (2012) explica que esa desacralización es doble: por un lado, sirve para cuestionar las jerarquías de temas poéticos y de las reglas morales del decoro; por el otro, forma parte de su trabajo con materiales desprestigiados, asociados a los circuitos ampliados.

La prostituta olivariana establece similitudes con la situación de todos aquellos escritores nuevos que ingresan a contrapelo del campo literario y de sus normas de funcionamiento. Por lo general, proviene de los sectores de origen inmigratorio y se define principalmente por su situación de marginal y explotada. En el poema "Hermana", de $L a$ musa ..., Olivari destaca no sólo el vínculo de la prostituta con la inmigración, sino el que mantiene con "los trovadores de la decadencia", es decir con el tipo de escritor que Olivari encarna: "tu apellido es gallego sino es italiano / pero tú eres la carne de los corazones / de todos nosotros, artistas, los nuevos / que tenemos el orgullo malevo / de ser los mejores!" (116). Vale decir entonces que la figura de autor promovida por Olivari encuentra en la marginalidad su fundamento: su musa, humana y plebeya, se configura como una réplica del poeta, el cual se ubica y recrea una marginalidad literaria y social que muchas veces se ve reforzada a partir del énfasis puesto en su precariedad laboral y en las dificultades económicas: "el poeta ha venido a beberse una copa (...) / como siempre tiene raída la ropa / y la angustia inquilina de su corazón" (84). Poeta y prostituta comparten un enemigo: el burgués, el cual no sólo se define en relación con una clase social, sino también con el conservadurismo estético y reaccionario. Por ejemplo, en 1932, Enrique Amorim le escribe a Girondo una carta en la que le dice: "has hecho un libro [Espantapájaros] con el cual

\footnotetext{
${ }^{195}$ Frente a la instauración de un mercado que puso en cuestión la función y utilidad del poeta modernista, se produce una reacción de hostilidad y de aislamiento del poeta frente a esa sociedad: "al desprecio se le respondió con desprecio, a la ignorancia provocativa con burla destemplada, al desinterés masivo con la ironía y el apartamiento aristocrático" (Rama 1970: 62-63). Lejos del endiosamiento que supuso la figura del poeta romántico, el poeta modernista se convertirá en autotema de sus obras con el propósito de indagar en su cuestionada función específica. Estas coordenadas que definen no sólo la figura de autor sino los vínculos de este con el público y el mercado continúan vigentes en los años veinte: Olivari, por ejemplo, indagará sobre su imagen y rol de poeta en muchas de sus composiciones.

${ }^{196}$ Ver, por ejemplo, "La musa venal", poema incluido en Las flores del mal (1857).
} 
pasamos por las armas a todos los burgueses juntos. No queda uno solo sin afeitar" (Schwartz 2007: 399). En tanto perteneciente a una clase social elevada, Girondo bien podría ser considerado un burgués, pero no es con ese sentido que utiliza la palabra Amorim, sino más bien como una referencia a aquellos que no comprenden el arte, aquellos sectores conservadores y filisteos de la sociedad. ${ }^{197}$ La miseria de la prostituta y la del poeta siempre termina por encontrarse con el burgués, que ayuda a definir la ubicación desventajosa tanto de una como del otro, ya sea en el entramado social o dentro del campo literario: "la miseria te obligará a mostrar la hilacha; / escucha este consejo: / entrégate a un burgués /¡Si será imbécil ese muchacho que te acompaña, /-cuarenta cuadras a pie y además sus versos- / (...) a ese lírico mándalo a pasear...!" (81).

Tanto para los escritores legitimados como para los nuevos, el origen resulta una construcción frecuente. Una de las tareas de los autores que provienen de la inmigración fuente señalada como "espuria", "bárbara", "plebeya", "babélica”, etc. por los sectores conservadores- consiste en revalorizar ese origen y ponerlo en consonancia con la idea de renovación estética. Olivari lo representa no sólo con orgullo sino como un correlato de su lengua literaria. En el poema "Antiguo almacén “A la ciudad de Génova”", explicita su origen inmigratorio a partir de la evocación de sus años de infancia: "antiguo almacén 'A la ciudad de Génova' / de Cangallo y Ombú. / tu recuerdo se viene en pareja / con el recuerdo de mi lejana infancia" (2006: 152). El escenario del poema se compone, principalmente, por grupos sociales provenientes de la inmigración: "los malevos, los italianos, buenos y borrachos / de mis recuerdos. / Miquelín, grande como una estatua, / que se iba a la cosecha y volvía rico dos semanas" (153). El universo referencial del tango ingresa en la vida temprana de Olivari, antes que como una forma artística, como un componente vivencial. Los malevos que pueblan los tangos viven en su barrio, los conoce y es testigo de los episodios que protagonizan: “...el malevo Julio / el que mató al cabito Ibañez" (154). Pero este género, en el poema, se define como una suerte de lenguaje fundacional puesto que el poeta reconoce que del tango -uno en particular, en realidad, "La morocha" - ${ }^{198}$ provino la "primera palabra argentina" que escuchó. Olivari define su origen a partir de una mezcla de inmigración y de criollismo emanado de "La Morocha" dado que la letra ${ }^{199}$ de este tango recupera el mundo criollo que

\footnotetext{
${ }^{197}$ La oposición entre el escritor y el burgués se encuentra en la ideología de artista desde el romanticismo europeo; ver al respecto Bourdieu (1995). En el contexto americano, el sentido negativo del vocablo burgués proviene del modernismo; ver Rama (1970).

198 "Muchos de los tangos producidos por descendientes de italianos elaboran (...) tangos de estirpe claramente "criolla", acentuando los rasgos gauchescos del tango por sobre los inmigratorios (...) 'Betinotti' o 'La morocha' son dos de los más claros y tempranos ejemplos" (Garramuño 2007: 98).

${ }^{199}$ En el tango "La Morocha" no hay lunfardismos sino gauchismos (cimarrón, redomón, ranchito, etc.).
} 
muchos inmigrantes asumieron como estrategia de asimilación. ${ }^{200}$ Establece un vínculo entre su madre y el tango dado que es ella quien se lo cantaba cuando era niño: "te recuerdo Cangallo y Ombú: / Mi madre era entonces tan joven y tan bella! / -la más hermosa de todas las mujeres- / Me acunaba con 'La Morocha'. / Fué esta canción la primer palabra argentina que escuché en el / dulce dialecto de su boca" (153). Habría, entonces, una mezcla entre lo inmigratorio, lo primitivo y lo nacional, porque mientras se evoca el universo social de los inmigrantes, aparecen acontecimientos y nombres de la historia nacional (Roca, Mitre, las "elecciones nacionalistas", etc.), junto con el canto a Buenos Aires, ciudad a la que el poeta hace suya y la termina comparando con su madre:

\footnotetext{
Buenos Aires, loma del diablo, Buenos Aires, patria del mundo,

Buenos Aires ancha, larga y grande,

como aquella primera palabra en argentino que le oí a mi madre:

'Yo soy la morocha,

la más agraciada...'

Buenos Aires morocha de río de hierro y asfalto!

¡ Buenos Aires! Seguís siendo la más agraciada de todas las poblaciones! (155).
}

En este origen, ligado al tango y a una suerte de "criollismo cosmopolita", se puede apreciar la diferencia que separa al poeta de los escritores de izquierda: mientras estos trabajan con un lenguaje literario supeditado a funciones sociales, pedagógicas o morales, Olivari persigue la intención de construir una lengua literaria autónoma.

Su identidad como poeta siempre se define en oposición a los valores y parámetros legitimados y legitimadores del campo literario, por eso los escritores como Olivari crean instancias de legitimación, lenguajes, formas de socialización y acreditaciones alternativos a los vigentes en el circuito "culto" tradicional. Si como afirman Altamirano y Sarlo (1997), hacia 1910, con la profesionalización del escritor aparecen "nuevas formas de iniciación cultural" que conectan a jóvenes escritores, hijos de inmigrantes, con los intelectuales tradicionales, algunos años después Olivari se convierte en un ejemplo de esto al criticar las formas tradicionales de iniciación literaria. En el prólogo de su primer libro de cuentos, Carne

\footnotetext{
${ }^{200}$ Adolfo Prieto explica que hacia fines del siglo XIX se respira en Buenos Aires un aire de extranjería y cosmopolitismo y que, pese a esto, "el tono predominante fue el de la expresión criolla o acriollada; el plasma que pareció destinado a unir los diversos fragmentos del mosaico racial y cultural se constituyó sobre una singular imagen del campesino y de su lengua (...) Para los grupos dirigentes de la población nativa, ese criollismo pudo significar el modo de afirmación de su propia legitimidad y el modo de rechazo de la presencia inquietante del extranjero. Para los sectores populares de esa misma población nativa, desplazados de sus lugares de origen e instalados en las ciudades, ese criollismo pudo ser una expresión de nostalgia o una forma sustitutiva de rebelión contra la extrañeza y las imposiciones del escenario urbano. Y para muchos extranjeros pudo significar la forma inmediata y visible de asimilación..." (2006: 18).
} 
al sol (1922), sostiene: “es moda en nuestra incipiente literatura, que al publicarse un primer libro, se haga bajo la égida paternal de un prólogo de alguien ya consagrado. Yo me lanzo solo, sin prólogos ni palabras liminares de nadie..." (2009a: 29). Aún entre los mismos escritores jóvenes y vanguardistas se producen desencuentros con respecto al origen, básicamente porque la vanguardia de los años veinte, en un sentido amplio, se compone de autores provenientes de diferentes sectores sociales: mientras que Borges, Güiraldes o Girondo, por ejemplo, refuerzan sus lazos de pertenencia a un origen patricio y/o a una clase social dominante, Olivari enseñará con orgullo su procedencia extranjera ${ }^{201}$ y marginal. $^{202}$

\section{El caso de la revista Nosotros}

En 1926, Nicolás Olivari edita su segundo libro de poemas, La musa de la mala pata. La revista Nosotros, en junio de ese año, publica un comentario crítico, "Barbarización literaria. La musa de la mala pata”. El texto aparece en la sección principal de la publicación y se desconoce su autor, pero la dirección de Nosotros, en nota al pie, advierte que se trata de "un conocido hombre de letras, de sólida reputación como estudioso y escritor" (“Barbarización literaria...” 1926: 261). Y, a continuación y en la misma nota, la publicación respalda los dichos del autor:

La dirección de Nosotros, coincidente con estas apreciaciones, confiesa que libros como el de que se trata, no debieran llamar por un solo instante la atención de la revista; por lo tanto, si da a conocer este artículo es porque él tiene un carácter general, muy oportuno en estos momentos (261).

Pese a que Nosotros cultivó una sociabilidad literaria marcada por la horizontalidad y la hermandad, con el propósito de cohesionar tanto a los escritores jóvenes como a aquellos pertenecientes a otras promociones; es decir pese al pacto intergeneracional basado en la continuidad y en la no exclusión (Delgado 2006), la revista advierte que no debería prestarle atención a un texto como el de Olivari. De este modo, Nosotros se alinea con la crítica que juzgó de manera desfavorable la obra del poeta, debido a la utilización poco ortodoxa de una lenguaje que nada parecía tener que ver con el literario. Según Francine Masiello, Nosotros "propone una forma conciliadoramente abierta" basada en

\footnotetext{
201 "Este cansancio que por mis venas flota / no es más que el cansancio de la raza mía / sombras heroicas de los argonautas / hombres de mi raza marina" (Olivari 2006: 38).

202 "Pero no encabrite / la sedicente crítica / su alharaca. / Mi Musa de la Mala Pata / sólo vive en la campana pneumática, / de los puestos de periódicos..." (Olivari 2006: 148).
} 
la necesidad de una integración del gusto literario, que incluya con amplitud los mayores talentos de Argentina y América Latina. Su llamado no es excluyente; al contrario, en [la] revista dan la bienvenida a todas las voces y estilos polémicos (1986:68, destacado nuestro).

Sin embargo, la actitud fundacional, plasmada en el prólogo ${ }^{203}$ del primer número de la revista, en 1907, resulta diametralmente opuesta al espíritu que anima a la reseña anónima sobre Olivari, pero sobre todo a la nota al pie en la que la publicación adhiere a las tesis allí expresadas, contradiciendo los postulados originarios de la revista. Esto estaría marcando las limitaciones que encuentra esa "integración del gusto literario", al menos en la década del 20, debido a las concepciones, al parecer, irreconciliables sobre la lengua literaria.

El autor anónimo comienza su texto diciendo que lo escribe debido a que duda que la "crítica oficial" se encargue de una obra como La musa de la mala pata. Pese a que nos encontramos frente a una crítica muy negativa del texto de Olivari, el autor aclara que " $L a$ musa de la mala pata me gusta, en sí misma, y relativamente a las musas 'bien' de que ésta se burla". No obstante, se apresura a agregar que ve "en ese librito un síntoma de barbarización literaria" (1926: 261).

La principal intención del artículo consiste en señalar la "atroz ignorancia del autor", que se manifiesta en las serias deficiencias expresivas, o como prefiere decir el articulista anónimo, citando al mismo Olivari: en "las depravaciones más exageradas del lenguaje" (262). ${ }^{204}$ Mientras Olivari destaca como valor positivo la idea de un lenguaje depravado, puesto que no es otra cosa que un signo de su condición de artista original y novedoso, el autor del artículo se sirve de la misma palabra para leer esa explícita intención poética como un rasgo negativo, como un pecado confeso por parte de Olivari, que sólo puede ser interpretado de esa manera si se ignora tanto el potencial irónico que hay en la frase como la decidida confrontación que esta afirmación implica en relación con las escrituras legitimadas. Para el autor del artículo, Olivari es un poeta sin cultura que, amén del uso "bárbaro" que hace del lenguaje, manifiesta su carencia en diferentes niveles. Por ejemplo, trae a cuento el prólogo del poemario, en el que el poeta "pretende explicar, bajo forma de una supuesta carta de Jorris (así, con dos erres) Karl Huysmann (así, con dos enes y sin $s$ )", las manifiestas irregularidades formales del libro. El crítico se concentra en la "semejante manera de ortografiar" el nombre de Joris-Karl Huysmans, e infiere de ello que Olivari no lo ha leído jamás. Finalmente concluye que “de estas reminiscencias literarias vagamente oídas (...) está

\footnotetext{
203 "Esta revista no será excluyente. No desdeñará las firmas desconocidas. Si lo hiciere, renegaría de éste su origen, humilde como el lector ve. (...) Ningún otro anhelo anima a sus directores, que el poner en comunión en sus páginas, las viejas firmas consagradas con las nuevas ya conocidas y con aquellas de los que surgen o han de surgir." ("Presentación" 1907: 5-6).

${ }^{204}$ La cita corresponde al prólogo a La musa de la mala pata.
} 
plagado el librito" (262). La ignorancia y la incultura literarias son las causas de un verso libre que se confunde con "la mala prosa entremezclada con las malas rimas" (262).

En el prólogo a La musa de la mala pata, Olivari convierte a Joris-Karl Huysmans en el autor ficticio del texto. Allí Olivari expone los rasgos del poeta nuevo, moderno y transgresor con el que pretende construirse como autor. Postula la "incorrección" y un lenguaje "depravado" como signos de una lengua literaria novedosa y relativamente autónoma; y manifiesta con sentido positivo la condición de "subalterno" y "decadente" del modelo de escritor al que aspira. ${ }^{205}$ Huysmans circulaba mucho entre algunos escritores jóvenes del período. Por ejemplo, Castelnuovo (1974) señala que Arlt era lector de este “novelista satánico". Last Reason (1929), por su parte, también lo menciona en un comentario sobre Los siete locos de Arlt. En Argentina, a través del modernismo, Huysmans se convierte en un autor de referencia constante hasta las primeras décadas del siglo XX: por un lado, José Asunción Silva escribe De sobremesa (1925), una suerte de remake de Á rebours; por el otro, Rubén Darío menciona a Huysmans en Los raros y le dedica algunos poemas. ${ }^{206}$

En tanto modelo del escritor decadente, Huysmans representa una actitud de artista aristócrata, en el que la rareza deviene en una excentricidad refinada. Parece extraño, entonces, que en Argentina los escritores "plebeyos" o de escaso capital simbólico, llegados desde "abajo" al campo literario, se identifiquen con su figura. Sin embargo, no rescatan de Huysmans su dandismo extravagante sino más bien el rechazo hacia la sociedad, ${ }^{207}$ el fracaso como signo del artista moderno, los poetas malditos, ${ }^{208}$ pero sobre todo la conciencia de que la lengua literaria debía ser un espacio de experimentaciones en donde las transgresiones y las “incorrecciones" (las “depravaciones") vendrían a ser la piedra de toque de una literatura en busca de autonomía.

\footnotetext{
${ }^{205}$ Citamos el breve prólogo: "Hasta la imperfección le gustaba, con tal que no fuera parásita ni servil, y acaso hubiera una dosis de verdad en su teoría de que el escritor subalterno de la decadencia, el escritor todavía personal, aunque incompleto, alambica un bálsamo más irritante, más aperitivo, más ácido que el artista verdaderamente grande, verdaderamente perfecto de la misma época. Entre los turbulento esbozos de esos mismos escritores era donde se advertían las exaltaciones más sobreagudizadas de la sensibilidad, ,los caprichos más morbosos de la psicología, las depravaciones más exageradas del lenguaje, obligado en último término a contener, a arropar las sales efervescentes de las sensaciones y de las ideas" (2006: 70).

${ }^{206}$ Ver D'entremont (1963).

207 "En la Francia del siglo XIX se prolongó casi ininterrumpidamente el enfrentamiento del artista con la burguesía. En muchos casos el motivo del desacuerdo fue social y político, pero cada vez con mayor intensidad la causa de insatisfacción tuvo un origen moral y estético: el poeta trató de reivindicar su autonomía con respecto a una sociedad a la que percibía dominada por el conformismo y la hipocresía (...) Nadie hizo tan evidente el conflicto como Huysmans, cuando en 1884 publicó Al revés, libro que proclamaba el tedio de su protagonista ante la conducta juzgada 'natural' y exponía la sistemática evasión lograda con ayuda de un programa de artificios esteticistas que se nutría de una vasta cultura" (Rest 1977: 21-22).

${ }^{208}$ Ver el capítulo 14 de Á rebours (1884) en el que se mencionan a los poetas malditos que lee Des Esseintes, el protagonista de la novela: Charles Baudelaire, Tristán Corbière, François Villon, Edgar Allan Poe, Stéphane Mallarmé, Paul Verleine, etc. Todos ellos aparecen con frecuencia mencionados en los poemas de Olivari.
} 
El prólogo de Olivari está basado en Á rebours (1884), obra maestra del llamado arte decadente. ${ }^{209}$ Des Esseintes, el protagonista de la novela, mientras lee "una serie de libros que lo subyugaron", se da cuenta de que le habían gustado "en virtud de sus mismos defectos [los cuales] significaban un agradable cambio en relación a la perfección de los libros de escritores de primera fila". Luego, el personaje concluye que "la imperfección misma le agradaba, siempre que no fuera parásita ni servil, y quizás hubiera cierta dosis de verdad en su teoría según la cual un escritor menor de la decadencia, el escritor que es incompleto, pero que posee su propia personalidad, destila un bálsamo más irritante, más excitante y más ácido que el autor de la misma época que verdaderamente es grande y perfecto". A su vez, lo que más pondera Des Esseintes de estos escritores son "las más extravagantes aberraciones del lenguaje" que dan forma a su literatura (Huysmans 1997, destacado nuestro). Como se puede ver, los pasajes resaltados son retomados por Olivari en su prólogo. Después de todo, la firma de Huysmans en el texto olivariano resulta mucho menos irónica, y más literal, que lo que sugiere su encabezado. ${ }^{210}$

De lo señalado, y en relación con el artículo "Barbarización literaria...", queda en claro que quien parece no haber leído a Huysmans es el propio autor del artículo, puesto que afirma que Olivari lo ignora sólo por haber escrito mal (¿adrede?) su nombre, sin reparar en todos estos elementos que el poeta toma de modo casi literal de su obra cumbre.

La "barbarie literaria" no sólo es producto de la ignorancia sino, como más abajo el crítico manifiesta, del "desprecio de la retórica tradicionalista", que lo obliga a caer en una serie de "vicios" expresivos que se pueden resumir en un rebuscamiento consistente en "la mala retórica guaranga sin sintaxis, plagada de neologismos insensatos y de grotescos idiotismos (...) y de palabras francesas casi siempre fuera de lugar y de las más resobadas por los poetillas monos de Rubén Darío" (262). Para el comentarista, el problema de Olivari radicaría en el uso de un español indeseado por aquellos sectores que creían firmemente en que la lengua literaria debía alinearse con el español peninsular o, en todo caso, con un uso culto del idioma. Olivari no sólo utiliza palabras provenientes de las variedades populares, sino que además crea un lenguaje literario particular a partir del neologismo, recurre a italianismos y vulgarismos, mezcla el lenguaje elevado con el vulgar. ${ }^{211}$

\footnotetext{
${ }^{209}$ Ver Ritvo (1996).

210 "Para la Musa de la mala pata que Jorris Karl Huysmann envió al autor minutos antes de convertirse al catolicismo" (2006: 70).

${ }^{211}$ Eduardo Romano define la estética de Olivari como realismo grotesco, y sostiene: “Grotesco nos parece la mejor calificación para su discurso, aficionado a las imágenes carnavalescas, a las mezcla de lo serio, respetable, con lo despreciable e ínfimo, a los violentos contrastes, a las escenas guiñolescas" (1990: 113). No obstante, es el propio Olivari quien califica a su segundo poemario de grotesco. Leemos en la Dedicatoria: "Dedico este libro, grotesco, rabioso e inútil a todos los empleados de Comercio de mi ciudad" (2006: 68).
} 
El crítico dedica buena parte del artículo al relevamiento de ejemplos que ilustran no sólo la ignorancia del poeta, sino también una de sus consecuencias: la utilización "hermética" del lenguaje. El "rebuscamiento" verbal de Olivari, al que denomina "culteranismo inculto", es el que determina la "confusión entre la libertad de forma y la anarquía delirante de la métrica y de la sintaxis" (265). Como hemos visto en el capítulo II, Castelnuovo también se quejará de los "ruiditos" de la lengua literaria de vanguardia, de su condición opaca y "embrollada”. Lo que critica el autor de este artículo es la experimentación con el lenguaje, reacciona contra las tentativas de autonomía, de liberar al lenguaje de las servidumbres que las normas literarias y gramaticales le imponían.

La barbarización literaria no es una apreciación unilateral; vale decir, una lectura que corre por cuenta únicamente de la crítica conservadora. El proyecto creador de Olivari contiene como intención fundamental operaciones autobarbarizantes, cuyo objetivo responde a un gesto de oposición hacia las tradiciones literarias preexistentes así como hacia las zonas centrales del campo literario de la época, configurando de esta manera un movimiento típico de la vanguardia. La crítica dominante no supo leer esta intencionalidad, y adjudicó repetidas veces esta acción deliberada a "ignorancia", "falta de cultura”, o a cualquier otro motivo ajeno a la voluntad del autor.

Si la Dedicatoria ${ }^{212}$ de La amada infiel busca ubicar al escritor en una zona marginal, desacralizada y a contrapelo de la figura de escritor de la élite y tradicional, es en La musa de la mala pata cuando la intencionalidad de autobarbarización comienza a hacerse explícita. Para ello, los paratextos iniciales resultan cruciales. La Dedicatoria define al libro como "groteso, rabioso e inútil" (2006: 68), mientras que el apócrifo prólogo de "Karl Huysmann", como vimos, señala "las depravaciones más exageradas del lenguaje" (70) que se dan cita en el texto. En "Palabras que se lleva el viento", suerte de prólogo o de manifiesto francotirador de su último poemario de la década, El gato escaldado (1929), las formas autobarbarizantes se revelan como un meditado "Knock-Out lírico" tendiente a derribar "el lirismo bobalicón y miedoso" (140). Allí se explicita la transgresión renovadora cuando Olivari afirma que hará uso de "los idiomas bajos" con el fin de superar "las sonoras y bellas palabras gastadas" (142).

La revista Nosotros también abordó su tercer poemario: M. López Palmero escribe un comentario en la misma línea del artículo anterior. Con esta obra, Olivari obtiene el tercer premio de poesía en el Concurso Municipal de Literatura, y eso constituye el punto de partida de la intervención de López Palmero. El comentarista vincula de manera no problemática

\footnotetext{
212 "Dedicatoria: A la Compañía de tranvías Anglo-Argentino y Lacroze, en cuyos mugrientos y faraónicos coches, transcurren oscuramente las mejores horas de mi alegre juventud" (2006: 32)
} 
autor y obra; y señala que, al momento de premiar el libro, el jurado debe haber tenido en cuenta "la personalidad" del autor. Pero agrega que esa personalidad es la de "un hombre basto hasta lo inconmensurable, grosero hasta lo infinito, vulgar hasta lo inconcebible" (1929: 398). La "grosería" y la "vulgaridad" definen al poemario debido a propiedades inherentes al poeta: “...un hombre cuyo comercio con el mundo exterior se reduce al contacto furtivo, a la percepción del olor nauseabundo, al ruido estridente, las manifestaciones más groseras de la vida de los sentidos" (398). La vulgaridad que pone de manifiesto López Palmero encuentra su mejor encarnadura en el lenguaje literario: “y nada digamos de su idioma, por el que se vuelca el burdel y la más supina ignorancia de lo trascendental y de lo elemental en gramática y en decencia lingüística" (399). Al igual que en el comentario anónimo antes analizado, la ignorancia aparece nuevamente como la manifestación principal de una lengua literaria que prescinde de la normativa, y como la expresión evidente de la "barbarie literaria". Sin embargo, no sólo incomoda el alejamiento de un lenguaje "correcto", sino también la aproximación de ese lenguaje a las formas extranjeras. López Palmero crea una suerte de identidad, o de sistema cerrado, entre el universo referencial de los poemas y la lengua empleada en ellos: "para el autor el idioma debe parecerse a las mujeres de su frecuentación, que por lo visto no le hablan sino en polaco" (399). El comentario de López Palmero recuerda a algunos argumentos vertidos en la revista Claridad cuando ésta se refiere a la literatura maleva y sus representaciones (inmorales) del arrabal, poblado de prostitutas, cafishos y delincuentes. De este modo, se puede ver cómo este tipo de evaluaciones conservadoras, moralizantes de la lengua literaria, planteadas por la izquierda aparecen también en el circuito "culto" tradicional; en este caso, en la revista Nosotros. De este modo, en lo que respecta al lenguaje literario, se pueden apreciar las coincidencias que se establecen entre los sectores dominantes de la cultura y la vanguardia de izquierda.

Para muchos de los escritores adscriptos al proyecto cultural y pedagógico de la izquierda, las lenguas literarias "bárbaras" (se detienen, particularmente, en aquellas que utilizan el lunfardo) son, antes que nada, inmorales. Esto sucede por las referencias que los escritores de izquierda creen que comportan: delincuencia, juegos, prostitución. ${ }^{213}$

La barbarización literaria se vincula con lo inmigratorio en la medida en que los lenguajes "bárbaros" o "plebeyos" siempre se definen por el grado de relación que establecen con otros idiomas, con la inmigración y el contacto de lenguas. No es extraño, entonces, que el artículo de López Palmero, al igual que el antes analizado, ponga de manifiesto cierta extranjería en la poesía de Olivari. En la reseña de La musa de la mala pata, se menciona el

\footnotetext{
${ }^{213}$ Esta suerte de moralización de las lenguas literarias se puede ver con mucha más claridad y desarrollo en el capítulo III, dedicado a las reyertas entabladas entre Claridad y el diario Crítica.
} 
(mal) uso de palabras francesas; mientras que López Palmero destaca el polaco, en boca de prostitutas, como un ingrediente deleznable más de su configuración poética. Estos señalamientos resultan una buena muestra de la manera en que el contacto de lenguas comienza a tener una importante injerencia en la literatura del período. Los escritores cultos descubren que hay dos tipos de lenguas extranjeras o que la misma lengua extranjera tiene dos realizaciones:

Están, por una parte, las lenguas extranjeras escritas y leídas por letrados; por la otra, las lenguas extranjeras escritas y leídas por la masa inmigratoria (las lenguas de los carteles, de los anuncios comerciales, de los periódicos de inmigrantes, de los volantes políticos).Y también están las lenguas extranjeras que hablan los letrados (...), quienes tienen un español 'bien' adquirido; y las lenguas extranjeras habladas por los inmigrantes, cuyo español es precario...

De manera acelerada y espectacular, se produce una reasignación de un cosmopolitismo legítimo y un cosmopolitismo babélico. Sobre estos dos ejes se organiza el imaginario: importaciones culturales legítimas e ilegítimas, traducciones buenas y traducciones peligrosas... (Sarlo 1997a: 274).

En una dimensión diferente, podemos ubicar un artículo previo a los analizados hasta el momento: nos referimos a la reseña que realiza Rafael De Diego de La amada infiel en el número 181 de Nosotros. La violencia con la que ha sido tratado Olivari en la revista de Giusti y Bianchi contrasta notablemente con este artículo que pretende ser un espaldarazo para un escritor que, como señala De Diego, aún antes de publicar sus revolucionarios poemarios "ya [era] conocido por una serie de pequeñas obras en prosa, obras que merecen los juicios más contradictorios..."214 (1924: 230).

Los duros señalamientos acerca del uso "impropio" de la lengua literaria no logran disolverse en las edulcoradas aprobaciones: si, por un lado, De Diego remarca el talento y las condiciones de Olivari, por el otro advierte algunos problemas expresivos: "en ese libro hay verdaderos aciertos, si bien la forma es deficiente, no por no responder a cánones determinados, sino por insuficiencia de expresión" (231). Pero la diferencia que hay con las otras críticas es que De Diego resulta benévolo con Olivari y lo disculpa de estos yerros:

Por ahora debe respetarse la despreocupación del poeta ante la retórica establecida, y respetársele por su decisión para decir lo que se le ocurre con entera libertad y hasta con entero libertinaje, ya que ello favorecerá la formación de una valiosa personalidad (231, destacado nuestro).

\footnotetext{
${ }^{214}$ Se refiere a los relatos que Olivari escribió a comienzos de la década del veinte. Varios fueron reunidos en el libro Carne al sol (1922).
} 
La principal diferencia que separa a De Diego de los demás comentaristas radica en el hecho de que parece estar captando mejor que los otros el carácter intencional del lenguaje olivariano. Según este autor, no hay ignorancia en Olivari, como afirmaban los articulistas anteriores, sino "decisión" y una deliberada búsqueda expresiva. Es decir, de lo que se estaría dando cuenta el crítico es de las búsquedas de una lengua literaria autónoma que lleva adelante el poeta.

En su libro Modernidades primitivas, Florencia Garramuño (2007) aborda el concepto de primitivismo en relación con los procesos de modernización y construcción de una cultura nacional en la Argentina y el Brasil de los años veinte. Si bien sus aportes están referidos al tango y al samba, podrían resultar aplicables de igual manera a otros productos culturales del período -novelas, ensayos, poemas, filmes, cuadros y representaciones iconográficas- que también constituyen representaciones complejas de lo primitivo y lo exótico. Como otros escritores del período, Olivari hace del primitivismo ${ }^{215}$ su principal rasgo estético y el fundamento de su figura de autor. Esto se puede ver con claridad en muchos de sus poemas, como por ejemplo, "Mi mujer", en el cual tanto el yo lírico como su amada son caracterizados a partir de rasgos que tienen que ver con lo primitivo y con lo grotesco: ${ }^{216}$

llegaste vos, bruta y sencilla como una vaca, con apenas cinco años de la escuela primaria (...) me animalizastes a tu nivel y te bendigo porque la coraza orinada de mi cultura aflautaba mis pulmones en el grito ocarinesco del pedagogo (...) eres tan del arrabal que tienes olor a tango y sabor al yuyo de la calle donde tus antepasados jugaban a los cobres (Olivari 2006: 106-107).

A su vez, como hemos podido ver, la crítica del período considera a Olivari un autor "bárbaro" y "salvaje" debido al lenguaje, los temas y las formas literarias que utiliza en sus textos. Durante la década del veinte, explica Garramuño, se produce una condensación entre lo primitivo y lo moderno; es decir que muchos escritores, sobre todo de vanguardia, hallaron en determinadas formas "primitivas" el camino hacia una modernidad que, gracias a ese primitivismo, también se definió como nacional. ${ }^{217}$ Garramuño explica que las letras de tango,

\footnotetext{
215 Para Garramuño (2007), lo primitivo se define en relación con la barbarie, con lo salvaje "en un sentido denigratorio", como así también con lo obsceno.

${ }^{216}$ Para profundizar sobre el grotesco en la poesía de Olivari, ver Romano (1990) y Carbone-Ojeda (2006).

${ }^{217}$ Garramuño sostiene que el tango y el samba son productos anfibios puesto que apuntan "a lo nacional que vendría de un pasado "originario" y a lo moderno de una forma que ha tenido éxito en París y en los ambientes internacionales (2007: 40). Aunque a fines del siglo XIX su costado primitivo es precisamente la razón para expulsar al tango y al samba de la nación, continúa la autora, cuando se producen sus respectivas canonizaciones será ese primitivismo el que se esgrima para señalarlos como símbolos nacionales. A esta suerte de paradoja, Garamuño la denomina "modernidad primitiva" (16). Resulta posible, entonces, describir una parábola desde el impulso de expulsión del primitivo salvaje y exótico que no se reconoce como propio hacia un primitivismo
} 
al apelar al mundo del arrabal y sus personajes más característicos -milonguita, compadritovan a construir también un juego entre lo "primitivo" de estos contenidos y un tipo de poética autorreferencial que es un rasgo claramente moderno. Estos mismos elementos pertenecientes a la poética del tango se encuentran también en las obras de escritores como Olivari, Enrique González Tuñón, Arlt, etc. Al mismo tiempo que estos autores aúnan lo primitivo con lo moderno, el primitivismo los ayuda a definir un origen (el inmigratorio) y su pertenencia a una cultura popular que los ayuda a oponerse y diferenciarse estética e ideológicamente de los grupos dominantes. Si en Europa el primitivismo implicó un distanciamiento de la tradición y de lo nacional (De Micheli 1993), en América Latina comprendió una inmersión en el pasado nacional (Garramuño 2007). Tal vez esto resulte claro en los casos de la literatura gauchesca o el tango, pero en lo que respecta a las lenguas literarias de los años veinte asociadas con lo primitivo puede pensarse que, en lugar de sumergirse en el pasado, estuvieran actualizando y reivindicando, a partir de su uso "moderno" (la literatura de vanguardia), un presente y un pasado relativamente cercanos signados por el contacto de lenguas producto de la inmigración y la consolidación de una cultura popular-masiva. ${ }^{218}$

El primitivismo de algunos escritores de vanguardia argentinos se entiende mucho mejor si se da cuenta de lo que había sucedido en Europa, desde mediados del siglo XIX hasta el surgimiento de las vanguardias europeas en las primeras décadas del XX. En Europa, el arte oficial o arte burgués, aun manteniendo una apariencia realista, no podía ser más que antirrealista o pseudorealista puesto que "cubría con un velo de agradable hipocresía las cosas desagradables" (De Micheli 1993: 50). Hacia mediados del siglo XIX, se produce entonces un distanciamiento de los mejores intelectuales de las posiciones políticas y culturales de su propia clase en señal de rechazo del "mundo burgués" (costumbres, moral, modo de vida, etc.). Ese distanciamiento asumirá la forma de la evasión: en muchos artistas del período se produce una fuga de la civilización, con el objeto de reencontrarse con sí mismos, fuera de la hipocresía, los convencionalismos y la corrupción de su medio. Escritores y pintores (Rimbaud, Mallarmé, Eluard, Gauguin, Kandinsky, Klee, etc.) emprenden búsquedas sociales, culturales, y estéticas en lugares remotos (África, las islas de Oceanía, América Central, etc.). Se "hacen salvajes" con el objeto de evadirse de una sociedad que se ha vuelto insoportable (De Micheli). En esta situación encuentra su origen gran parte de la vanguardia artística europea, cuyos miembros también abandonan "el terreno de su clase y al no hallar otro al que trasplantar sus raíces (...) se transforman en déracinés" (56). De este modo, una parte

formalmente concebido como afín a lo moderno y símbolo de una identidad nacional. Se establece de esta manera un trayecto que va desde la exotización de la nación hacia la nacionalización de lo exótico.

${ }^{218}$ Ver Gutiérrez-Romero (1995). 
importante de la vanguardia europea (decadentismo, cubismo, expresionismo, dadaísmo, futurismo, abstractismo) encuentra en el primitivismo no sólo una forma de rechazo del mundo burgués, sino también esa "novedad" que Baudelaire, Rimbaud y Leconte de Lisle reclamaban. ${ }^{219} \mathrm{Al}$ entroncarse con la vanguardia europea, el primitivismo se convierte, para muchos de los jóvenes vanguardistas argentinos, en signo de modernidad, de un arte verdadero que aspira "la voluntad de hallar un lenguaje virgen, al margen de la tradición contaminada y convertida en patrimonio del arte oficial" (64).

Si lo bárbaro-primitivo se relaciona con lo moderno, autores como Olivari recurren al primitivismo con el objeto de liberar su lengua literaria, otorgarle una autonomía que se manifiesta en la experimentación formal, pero también en la oposición a las propiedades tradicionales de la literatura. En casos como los de Olivari, sirve para degradar los cánones, para edificar nuevas percepciones acerca de lo literario pero reivindicando cierta idea de lo nacional que se define a partir de lo popular, lo inmigratorio y lo moderno. Se trata, en definitiva, de una reformulación global que involucra no sólo a la lengua literaria, sino también a la figura de autor, la relación con la tradición literaria y la construcción de nuevos espacios poetizables.

\section{Nicolás Olivari y Martín Fierro: desencuentros y acuerdos}

De todas las revistas de la época, Martín Fierro parece ser una de las publicaciones en la que mayor participación tuvo el poeta. En lo que respecta a los usos literarios del lenguaje, existían notables diferencias entre Olivari y el núcleo principal de martinfierristas: las ideas conservadoras de Martín Fierro contrastan con la heterogeneidad lingüística que propone Olivari en sus poesías. Por ejemplo, en el "Suplemento explicativo de nuestro Manifiesto", se acusa a los escritores de izquierda de emplear una "jerga abominable, ramplona y plagada de italianismos", jerga que Olivari utilizaba en sus poemas; ellos, en cambio, se definían como "argentinos sin esfuerzo, porque "no tenemos que disimular ninguna pronunzia exótica"” (“Suplemento..." 1924: 2). No obstante, en el número 14/15, Martín Fierro publica un poema inédito de Olivari, “Adiós a Buenos Aires”, en donde manifiesta que la única publicación que lo ha aceptado ha sido la de la calle Florida: ${ }^{220}$ "poeta informal y crudo / creído sólo por MARTIN FIERRO” (1925: 8).

\footnotetext{
${ }^{219}$ De Micheli cita Voyage (1859) de Baudelaire, el prólogo de los Poèmes antiques (1852) de Lenconte de Lisle y algunas impresiones de Rimbaud acerca de su viaje por África (1993: 50-53).

${ }^{220}$ No se descarta cierto componente irónico en la frase de Olivari dado que "la única" publicación a la que se refiere es la principal y más moderna revista argentina de vanguardia.
} 
Pese al hecho de que Olivari se presenta como una síntesis superadora del conflicto artepurismo/ arte social que parecía dividir a los poetas del veinte, y más allá de que nunca renunció a ciertos presupuestos estéticos desgajados del naturalismo boedista y los articuló en seguida con otros procedentes del vanguardismo (Romano 1990), la filiación de Olivari con los martinfierristas -es decir, con su núcleo principal-, por momentos puede resultar dudosa. Comparten el sarcasmo, la ironía burlona y la voluntad de ruptura. Pero las formas lingüísticas marginales, que se incrustan en la poética de Olivari, lo separan de los martinfierristas más representativos, como Borges, Girondo, Güiraldes, Méndez, etc. No obstante eso, Martín Fierro dedicará varios artículos a sus libros, aunque las diferencias entre la publicación y el poeta saltan a la vista a partir de los señalamientos acerca del uso de la lengua literaria en sus poemas.

En agosto de 1926, Martín Fierro publica una reseña sobre La musa de la mala pata, firmada por Leopoldo Marechal. Pese a ser un comentario positivo, los rasgos destacables se opacan cuando el autor del Adán Buenosayres expresa ciertas reservas en relación con la lengua literaria de Olivari.

Para Marechal el poemario se define por su tono sentimental. A esto se le suma el humorismo como otro de sus rasgos principales, el cual "se confunde a veces con la sal gruesa del habla criolla" ${ }^{221}$ (1926: 10). En ese mínimo comentario, se trasluce el presupuesto del núcleo martinfierrista con respecto a la lengua. Parecería que a Marechal no le resultara del todo aceptable esa “confusión". No obstante, su estilo peculiar, atravesado por lo "salado" del lenguaje, aporta la originalidad que todos los defensores del poeta invocan. Marechal dirá mejor que esa combinación “constituye el rasgo personal de Olivari”. (10).

Las coincidencias entre las críticas positivas y negativas acerca de la poética olivariana encuentran un lugar común: lo "desordenada y variable" que la obra puede resultar. Pero la diferencia radica en los modos en que son leídos esos ripios: "yo también diré que su obra es

\footnotetext{
${ }^{221}$ Ese "habla criolla" es el que se pondrá en funcionamiento mucho tiempo después en el Adán Buenosayres (1948). Según Julio Cortázar, "el velorio del pisador de barro de Saavedra está contado con un idioma de velorio nuestro, de velorio en Saavedra allá por el veintitantos. Si el deseo de jugar con la amplificación literaria de una pelea de barrio determina la zumbona reiteración de los tropos homéricos (...) la llegada de la Beba para ver el padre muerto y la traducción de este suceso barato y conmovedor halla un lenguaje que nace preciso de las letras de 'Flor de fango' y 'Mano a mano'”. Para Cortázar, el Adán... es un libro que tiene su propia prosa: "estamos haciendo un idioma, mal que les pese a los necrófagos y a los profesores normales en letras (...). Es un idioma turbio y caliente, torpe y sutil, pero de creciente propiedad para nuestra expresión necesaria. Un idioma que no necesita del lunfardo (que lo usa, mejor), que puede articularse perfectamente con la mejor prosa 'literaria' y fusionar cada vez mejor con ella -pero para irla liquidando secretamente y en buena hora. El idioma de Adán Buenosayres vacila todavía (...) pero (...) ha logrado en los pasajes citados (...) la aportación idiomática más importante que conozcan nuestras letras desde los experimentos (¡tan en otra dimensión y en otra ambición!) de su tocayo cordobés". (1999: 884). Jaime Rest, por su parte, retoma esta reseña que Cortázar realiza de la novela de Marechal, puesto que le permite observar el significativo esfuerzo que representa el intento del autor del Adán Buenosayres de construir una prosa "asentada en el lenguaje real" (Rest 2010: 157).
} 
desigual e improvisada; le aconsejaré un severo contralor de sí mismo y una sana prudencia en el uso de los vocablos" (Marechal 10, destacado nuestro). Remarcamos ese "también" porque Marechal nota que su recomendación se pliega a otra ya realizada, desde las páginas de la revista Nosotros, y de la cual quiere separase: Marechal añade que no hace estos señalamientos a Olivari "como cierto señor que debe ser diputado, ya que tantos lugares comunes frecuenta, y que, no bastándole una, necesitó dos equis para esconderse en la revista "Nosotros"” (10). Marechal se refiere al artículo, ya abordado, "Barbarización literaria. La musa de la mala pata". No obstante, lo que diferencia al comentarista de Nosotros y a Marechal no es la opinión sobre la estética olivariana, que bien mirado resulta en muchos puntos coincidentes, sino los lugares opuestos desde los cuales enuncian. Se trata de un caso en que sitios antagónicos ocupados por diversos agentes dentro del campo literario neutralizan posiciones afines con respecto, en este caso, a la lengua literaria.

Frente a la poesía de Olivari, Marechal vacila puesto que, como buen vanguardista valorador de lo nuevo que es, encuentra en el poeta un escritor de valía en este sentido, sin embargo, le resulta demasiado audaz, a punto tal de ocasionar esta ambigüedad que le impide aceptarlo de manera completa. Todo esto hablaría de la importancia de la transgresión realizada por Olivari, es decir, mostraría no sólo la radicalidad de sus propuestas estéticas a punto tal de que un vanguardista como Marechal se sienta incómodo o manifieste alguna forma de rechazo por su obra, sino que además enseñaría el grado de conservadurismo que legisla el campo literario en el que Olivari interviene.

En ocasión de la edición de La amada infiel, Martín Fierro publica una reseña a cargo de Roberto Mariani. Su crítica resulta demoledora. En primer lugar, la impugnación del poemario se apoya en la forma: sostiene que los versos que componen la obra, minimizada como "apuntes más o menos largos que constituyen algo así como un libro", están "mal medidos" y son "versos cojos" cargados de "fallas más graves que de las que suelen imputarse a despreocupación o apresuramiento" (1924a: 10). Mariani destaca el feísmo de la estética olivariana como un defecto que invalida cualquier emprendimiento poético: "sin la belleza formal no hay obra de verso que resista a un análisis severo. La poesía sin ritmo ni música no ha sido, no es, ni será nunca poesía" (10). El "desaliño" con que está escrito el libro malogra todas las virtudes que Mariani señala rápidamente: "sensibilidad moderna", "salud literaria", "buen humor". Pero esto que el autor de Cuentos de la oficina indica como defecto, como hemos dicho, en Olivari resulta intención. Su poética impone nuevas formas que tanto Mariani como muchos otros no pueden asimilar. En "Palabras que se lleva el viento", de 1929, suerte de poética en donde Olivari reflexiona sobre la literatura en general, y 
sobre su poesía en particular, dice: "todo será absorbido por el poema. No otra cosa es la tendencia moderna en poesía, libertada de la forma clásica, la rima y ritmo" (2006: 140). ${ }^{222}$

Roberto Mariani y Nicolás Olivari integraron, en un principio, las filas de Boedo. Sin embargo, las "transgresiones" realizadas por el segundo, justamente, en su poemario de 1924, le valen la expulsión del grupo. Esta reseña puede ser leída como una ampliación de esa sanción. En ese momento, Raúl González Tunón oficia de puente con Martín Fierro, y así lo recuerda el propio Olivari:

\begin{abstract}
Se indignaron [mis compañeros de Boedo] y en cierto modo me consideraron traidor al movimiento y me expulsaron sin más (...) Como en el tango, salí a la calle desconcertado, y dio la casualidad que me encontré en la puerta de la librería a Raúl González Tuñón, quien había leído mi libro y le gustaba. Me abrazó, y al saber de mi cuita, ya tuteándome, me dijo: 'No importa. Te llevo a Florida.' Y así fue (2009b: 2).
\end{abstract}

No obstante, es posible leer esta expulsión como un rasgo remarcado por el propio Olivari, como una maniobra para justificar su desplazamiento hacia la vanguardia estética y, de ese modo, legitimarse allí. En otras palabras, si bien existieron críticas hacia el poeta en la revista Claridad, como veremos en el apartado siguiente, la radicalidad con que Olivari refiere su alejamiento de la izquierda literaria también puede ser pensada como una estrategia más de su construcción de figura de autor.

En el artículo "Martín Fierro y yo", sin embargo, Mariani recupera la figura de Olivari:

He aquí una voz, una voz de muchacho porteño, de hoy y aquí: Nicolás Olivari.

Mientras que los redactores de MARTíN FIERRO se alejan de nuestra sensibilidad (¡comienzan por negarla!) y adhieren a mediocres brillantes como Paul Morand, francés, y Ramón Gómez de la Serna, español, he aquí un escritor argentino que en su libro se denuncia habitante de su ciudad y conciudadano de sus conciudadanos, entroncado, por consiguiente, con el auténtico y genuino Martín Fierro (1924b: 2).

En las páginas de Martín Fierro, Olivari resulta un caso singular. En primer lugar, por el espacio que ocupa en la revista: si bien es apenas un colaborador externo, resulta curiosa la

\footnotetext{
${ }^{222}$ Como hemos dicho, "Palabras que se lleva el viento" pertenece a su último poemario de la década del veinte. Este dato no es menor puesto que permite comprender el camino recorrido por el poeta durante estos años. La transgresión, la construcción de su figura de autor y el enfrentamiento contra las "odiosas jerarquías intelectuales" (Olivari 2006: 143) que rigen el campo literario de ese momento, hacia 1929 ya parecen haberse asentado, es decir aquello que comenzaba a delinearse en La amada infiel, hacia el final de la década ha madurado de modo tal que posibilita la aparición de este prólogo que hace las veces de una suerte de manifiesto.
} 
atención que se le brindó a sus obras. Si “en la revista de Evar Méndez, no era común que un libro recibiera más de una reseña" (Ojeda 2004: 2), La musa de la mala pata recibe tres. Y, en segundo lugar, porque el poeta constituye una suerte de pieza en disputa: contrasta el tratamiento que recibe en "Martín Fierro y yo" con la demoledora crítica que Mariani realiza en la reseña de su primer libro. Parecería que cuando Mariani defiende el espacio de Boedo, Olivari se convierte en su estandarte; mientras que cuando lo juzga como a un poeta colaborador de Martín Fierro, lo defenestra en nombre de la supuesta traición que significó para la izquierda La amada infiel. Los ataques y defensas hacia Olivari están en función de los mecanismos de apropiación y distanciamiento que se ponen en juego en relación con su figura.

Ana Ojeda indica que interesa "constatar de qué manera la literatura de Olivari se ubicó en el margen, tanto de uno como del otro grupo, tal vez porque ese espacio resultaba funcional a su propuesta estética, que combinó elementos de ambos polos" (3). Se podría completar la idea diciendo que también sucedía a la inversa: Olivari resultaba funcional a dos proyectos culturales opuestos, precisamente por la utilización de un lenguaje literario que ponía en jaque los presupuestos de ambas zonas, al mismo tiempo que se servía de ellos.

Roberto Mariani construye parte de "Martín Fierro y yo" a partir de la dicotomía nacional/extranjero. Esta integra un núcleo importante de las polémicas sobre el idioma y la lengua literaria. Los martinfierristas se definen, según Mariani, por la extranjería manifiesta en su cultura europea, preferentemente francesa. Nótese que cuando Mariani menciona a los intelectuales a los que adhiere Martín Fierro (Paul Morand y Gómez de la Serna) destaca su cualidad de extranjeros. En este contexto, Olivari vendría a representar una voz porteña, “de aquí y de hoy", que se "entronca" con la tradición del poema de Hernández. Los ripios en el lenguaje y las falencias formales son dejados de lado al momento de postular a Olivari como una voz propia, si no de la Nación, al menos de Buenos Aires.

Sobre la misma dicotomía, Martín Fierro funda sus críticas a los sectores de izquierda. En respuesta al artículo de Mariani, la redacción publica "Suplemento explicativo de nuestro 'Manifiesto'. A propósito de ciertas críticas” (1924c). En primer lugar, allí se deja en claro una de las debilidades de la argumentación de Mariani: ubicar a Olivari como un término opuesto de la revista, justamente cuando el poeta es un colaborador asiduo. Y a continuación, la redacción monta su estrategia discursiva sobre el par nacional/extranjero, y acusa a Mariani, y con él a todo el arco de la izquierda literaria, de extranjero: "el señor Mariani se nos antoja un eco, un eco indignado con cierta deformidad de pronunciación" ("Suplemento..." 1924: 2).Como puede verse, el nacionalismo anti-inmigratorio de Martin Fierro (Bosoer 2012) viene a apuntalar argumentos cuyo objetivo es impugnar una voz, un 
lenguaje literario que siempre aparece asociado a la deformación, la barbarie y/o lo plebeyo. $^{223}$

La incidencia sobre la literatura de las polémicas sobre la lengua puede verse muy bien en la siguiente cita, cuando la redacción martinfierrista señala que

Sabemos, sí, de la existencia de una sub-literatura (...) relatada en una jerga abominablemente ramplona, plagada de italianismos, cosa que provocaba en nosotros más risa que indignación pues la existencia de tales engendros se justifica de sobra por el público a que están destinados (2).

El pasaje no sólo pone de manifiesto las concepciones sobre la lengua literaria de la principal revista de la vanguardia estética, sino que además hace evidente su rechazo hacia la influencia de la inmigración sobre la literatura.

La poesía de Olivari, como hemos dicho, se nutre de múltiples registros y variedades lingüísticas. Entre ellos, recoge las voces que circulan en el ámbito de los inmigrantes, que es también el suyo puesto que es hijo de italianos. Signo de la heterogénea conformación del martinfierrismo resulta su rechazo de los italianismos a la vez que acepta y pondera a un escritor como Olivari, quien se sirve de ellos para elaborar su lenguaje literario.

Ricardo Güiraldes escribe un artículo en Martín Fierro, "Carta a Nicolás Olivari" (1926), en el que elogia la "Buena Mano" (así, con mayúscula) que tiene La musa de la mala pata. Con apenas algunas menciones grises al estilo del poeta, el texto celebra los poemas de Olivari ("Los amores albinos", "Cuarteto de señoritas", "La dactilógrafa tuberculosa", entre otros). En esta amistosa carta, Güiraldes reclama para sí un Olivari que, en manos de Mariani, es rechazado por espurio a la vez que convertido en bandera nacionalista. El texto de Güiraldes se convierte en un campo de batalla y los tiros por elevación a Mariani resultan evidentes:

¡Qué dedicatoria cariñosa y despreciativa! Para mí contiene una sorpresa. Comprendería que fuera la del libro de Mariani, lleno de tedio y de minucias oficinescas y lleno también de una sumisión perruna (hablo naturalmente de los sujetos y tipos pintados), pero el suyo no es así. (1926: 8).

\footnotetext{
223 "Dentro de la voluntad renovadora del grupo martinfierrista existe una suerte de "nacionalismo literario", pero entendido tal como puede leerse en el Manifiesto [de Martín Fierro]: no aferrarse a lo tradicional sino tomar lo europeo y extraer de allí lo necesario. Esta tarea implica utilizar los elementos esencialmente argentinos con una óptica nueva (...) Martín Fierro retorna el tema de la pureza lingüística (...) de la tradición cultural y del ser nacional" (Legaz 1999: 30).
} 
El nombre de Mariani no tiene razón de ser en el texto de Güiraldes, a no ser que se lo vincule con la reseña que el autor de Cuentos de la oficina publica en los primeros números de Martín Fierro. Güiraldes, a la vez que ensalza La musa de la mala pata, rechaza la lectura que Mariani hizo de La amada infiel. Esta suerte de apadrinamiento de Olivari por parte de Güiraldes permite repensar la figura del autor de Don Segundo Sombra en relación con sus compañeros de vanguardia, en la medida en que supo respaldar, en varias oportunidades, proyectos literarios renovadores en los que la lengua no se identifica con los criterios de corrección tradicionales, y que suelen apartarse de los presupuestos estéticos y lingüísticos de los martinfierristas principales. Güiraldes fue muy importante para otros autores "plebeyos", puesto que resultó sensible para captar el valor novedoso de algunas escrituras que parecían encontrarse en las antípodas de sus preferencias estéticas. No sólo apadrinó a Olivari; mayor fama tiene su relación con Roberto Arlt, de quien fue su corrector y facilitó la publicación de los pre-textos de El juguete rabioso en Proa; ${ }^{224}$ también se conoce el apoyo brindado a Enrique González Tuñón y a su libro Tangos. ${ }^{225}$ Las tensiones y heterogeneidades dentro del martinfierrismo no sólo se manifiestan en la amplia diversidad de los colaboradores, sino también en el núcleo fundador de la revista. Señalar que el conjunto principal de Martín Fierro estaba compuesto por autores, si bien muy diferentes entre sí, pero que coincidían en el rechazo de toda lengua literaria vinculada con la inmigración, puede resultar parcialmente falso si tomamos en cuenta la actitud receptiva de Güiraldes para con aquellos escritores que el mismo cenáculo martinfierrista, al que pertenecía Güiraldes, rechazaba.

Tres fueron los comentarios dedicados a La musa de la mala pata en Martín Fierro. E1 primero, el de Marechal; el segundo, la recién abordada carta de Ricardo Güiraldes; y el tercero, al cual nos referiremos a continuación, fue publicado en el número 37, bajo el título "Un poeta de Buenos Aires" (1927), escrito por Luis L. Franco. El texto comienza con un ataque hacia el proceder de la "crítica nacional" a raíz de la "generosidad" y "benevolencia" que dispensa a la mayoría de los libros que aparecen en la sección "bibliografía, o similar", de las publicaciones del medio. Cuando esta crítica, que elogia textos de poco valor, se opone a una obra determinada, Franco advierte que "hay que sospechar" cierta "personalidad" en el poeta (1927: 9). Olivari vendría a ser un ejemplo de esos escritores maltratados por un crítica parcial, y con un valor que Franco se propone recuperar en su artículo. La parcialidad se pone de manifiesto cuando los críticos expresan: "si yo soy el primero en reconocer la libertad de acción de cada artista... pero vea, qué quiere que le diga, lo que no está de acuerdo con mi estética es un mamarracho" (9). Este defecto de la crítica que denuncia Franco constituye la

\footnotetext{
${ }^{224}$ Ver capítulo V.

225 “A Enrique González Tuñón”, Güiraldes (1962b).
} 
explicación más sencilla, pero no por eso menos verdadera, de la suerte que Olivari, y otros poetas, han corrido en manos de la mayoría de las revistas literarias de los años veinte. Esa estética, agregamos nosotros, se completa con un ideal que críticos y escritores tenían sobre la forma que debía tener la lengua literaria. Los críticos "sobones" no sólo elogian los textos de un "poeta abortado o tronado"; sino que avalan una determinada utilización de la lengua y el seguimiento de ciertas preceptivas literarias. Desde estos parámetros, Olivari -como Carlos De la Púa, Enrique González Tuñón o Dante Linyera, para mencionar algunos- jamás podría haber sido motivo de elogios por parte del aparato crítico al que se refiere Franco.

Las críticas sobre la obra de Olivari, aún las favorables como la de Franco, señalan la existencia de un estilo deficiente. Así, éste dirá de los versos del poeta que son "espinudamente defectuosos", y que no intentará "disimularle ciertas fallas mayores". El caso de Franco es interesante porque, pese a que logra advertir que existe una disputa a nivel de estéticas y lenguajes enfrentados, condensados en los juicios y silencios que denuncia, no puede librarse de esos marcos conservadores de los que se sirve el discurso crítico que él mismo impugna. Las opiniones vertidas por Franco se alinean con las sostenidas por Marechal. Incluso, Franco repite ciertos aspectos, como por ejemplo la idea de que el sentimentalismo y el humorismo constituyen los rasgos destacables de la poesía de Olivari.

Como lo hizo Mariani en su comentario a La amada infiel, o Marechal en el dedicado a La musa de la mala pata, se destaca el valor del poeta; y en ese valor se fundan los permisos y licencias para el ejercicio de la crítica: “...si llegamos hasta el fariseísmo de tirarle la primera piedra es porque lo creemos uno de nuestros tres o cuatro poetas de mejor materia prima y tenemos derecho a exigirle cosas magníficas" (Franco 10).

Para concluir, los comentarios críticos acerca de la obra de Olivari, realizados en Martín Fierro, se conducen bajo un mismo patrón: se destaca el valor del poeta, un valor a futuro y que en el presente se ve entorpecido por una escritura "ripiosa" vinculada al uso de un lenguaje "poco literario" y a la subversión de las formas tradicionales de la poesía. Aún en el artículo escrito por Ricardo Güiraldes, en el que prácticamente no existe ninguna impugnación para la lengua literaria del poeta, se señala: “... sus versos [son] desarrapados como una tristeza acostumbrada a romperse el alma en todas las esquinas de los barrios dolorosos e intensos" (8, destacado nuestro). Cuando Güiraldes afirma que "sus versos dan la sensación de que van caminando, siempre caminando, con un paso algo bichoco, en busca de un amor respirante y simple como un pan fresco" (8, destacado nuestro), enseguida pensamos en los "versos cojos" de Roberto Mariani. Al igual que sucede con la frase "las depravaciones más exageradas del lenguaje", utilizada en primer lugar por Olivari, en referencia a su lengua literaria, con una clara intención provocativa y de autoafirmación, y retomada por sus 
detractores desde un sentido literal ("Barbarización literaria" 1926: 262) con el objetivo de impugnar su literatura, algo similar ocurre también en este caso puesto que es el propio Olivari quien señala la "mala pata" de su musa, también como gesto desafiante y de diferenciación. La derivación metafórica que facilita esta caracterización de su musa es utilizada también con un sentido literal y negativo por algunos de sus comentaristas.

Los dichos de Güiraldes, así como los de Franco, se diluyen en muchos otros argumentos que ponderan los versos del poeta. Dice el autor de Don Segundo Sombra: "Tengo la sensación de que ciertas obras se desprenden de su origen habiendo conseguido una realización formal que las faculta para bastarse a sí mismas" (8, destacado nuestro).

De lo expuesto, podemos concluir lo siguiente: por un lado, en el tratamiento de la poesía de Olivari en las páginas de Martín Fierro, aun en aquellas críticas más positivas, la cuestión de la lengua literaria resulta un tópico inevitable. Esto sucede, principalmente, porque Olivari hizo del lenguaje literario la sede de la novedad, su singularidad como un escritor cuya intencionalidad primera consistió en procurar la autonomía de la lengua literaria respecto de las regulaciones heterónomas de la corrección moral o gramatical propiciada por el Estado a través de la escuela y por los sectores más tradicionales de la cultura. Duras y leves admoniciones atraviesan las lecturas de sus poemas. Por otro lado, la estética de Olivari ha generado expulsiones y apropiaciones incompletas. Es decir, si Güiraldes o Franco no pueden terminar de ponderar los poemas debido a la existencia de ciertos versos "defectuosos", Mariani tampoco puede completar el gesto de Castelnuovo que expulsaba a Olivari del boedismo.

La lectura dispar que Martín Fierro hizo de Olivari evidencia su condición marginal dentro de la publicación o, en todo caso, la dificultad para aceptar de manera consensuada su literatura. Las propuestas estéticas del poeta se apoyan en una audacia y una radicalidad de difícil asimilación, aún para una revista de vanguardia. ¿Pero qué vieron los martinfierristas en Olivari para querer incorporarlo en sus filas de colaboradores? Probablemente, su actitud netamente vanguardista: el juego con las formas lingüísticas y con los géneros literarios, la desacralización de lo serio, su humorismo, etc. En cierta medida, todos estos rasgos participan del espíritu martinfierrista; sin embargo, Olivari no deja de ser un elemento extraño dentro de la revista. La principal distancia se establece a partir del componente inmigratorio, popular, cosmopolita que existe en sus textos. De manera concomitante, su lengua literaria, cargada de “incorrecciones" y transgresiones, es lo que más lo distancia del núcleo del martinfierrismo. Por estos motivos, su presencia en la publicación complejiza el programa estético-cultural de la revista. 


\section{Claridad y Nicolás Olivari}

Como hemos adelantado, las críticas negativas también se hicieron presentes en la zona de la izquierda literaria. Cuando Claridad realiza el balance literario del año 1926, publica un artículo sin firma en el que sostiene:

Raúl González Tuñón en El violín del diablo tiene buenos aciertos; no podemos decir lo mismo de Nicolás Olivari que pretendiendo imitar a los modernistas franceses dio en la ridiculez de un librito titulado La musa de la mala pata, lleno de barbarismos y pavadas. El caso de este autor merece considerarse por tratarse de un hombre joven, reincidente. Ya cuando apareció La amada infiel, se le hicieron atinadas observaciones que echó en saco roto. (...) Esperamos con interés su regeneración ("El año literario" 1926: 21, destacado nuestro).

La crítica principal de Claridad radica en la lengua "incorrecta" que utiliza en sus obras, esa "prosa de escolar de tercer grado" ("Claridad y Crítica" 1927: 5) que define un lenguaje literario muy lejano del modelo pedagógico que la izquierda se propone para sus lectores. Además, molestan las influencias vanguardistas de la poesía de Olivari: en aquellos años, los comentaristas solían reenviar las influencias del poeta a autores como François Villon o Charles Baudelaire, en parte porque el mismo Olivari los menciona y les rinde tributo en algunos de sus poemas. En la reseña que el diario Crítica dedica a La musa ..., se afirma: "Tristán Corbiere resucita en Buenos Aires" ("Ha aparecido un extraño libro..." (1926: 10), en referencia a Olivari. Eduardo Romano recupera esa misma filiación cuando afirma que la fuente del lenguaje particular del poeta debe buscarse en Tristán Corbiere:

Corbiere desmitificó el lenguaje poético con una convocatoria al vocabulario popular y aun vulgar, con una sedicente despreocupación por la perfección métrica. La disposición tipográfica y la abundancia de guiones, paréntesis y dos puntos, otorgan a su escritura un ritmo peculiar que no pasó desapercibido a la sensibilidad de Olivari (1990: 102).

La valoración que hace Claridad de Olivari incurre en el lugar común de la crítica contemporánea de su obra: el castigo a un lenguaje que es visto como bárbaro. Y también se destaca otro elemento compartido por la mayoría de los artículos que se refieren al poeta: muchos ven en él un autor talentoso, pero malogrado por sus elecciones lingüísticas y estilísticas.

Además, "El año literario" remite a lo delictual puesto que los sentidos de "reincidencia" y "regeneración" reenvían a ese universo de significación. Como se ha podido apreciar en el tercer capítulo de este trabajo, en la campaña de Claridad contra Crítica, esta 
revista recurre frecuentemente al argumento de la delincuencia para descalificar al diario de Botana y a sus colaboradores. Olivari no sólo escribe con un lenguaje que desde Claridad se rechaza, sino que incorpora los mismos ejes temáticos por los que Crítica es duramente cuestionado: la prostitución, el tango, la "vulgaridad" y "las lacras de los bajos fondos". En este artículo, además, se recuerda el episodio que le valió al poeta la expulsión del grupo de Boedo: las "atinadas observaciones" que hicieron los escritores de izquierda sobre su primer libro de poemas, y que Olivari “echó en saco roto" (“El año literario” 1926: 21).

La "regeneración" de Olivari que aguardaban en Boedo no llegó jamás. Sus obras posteriores continuaron -y profundizaron- el derrotero estético ya trazado por sus dos primeros poemarios, lo cual evidencia el carácter programático de su estilo y de su obra inicial. La vigencia del rechazo de esta revista hacia el poeta se observa en dos artículos de fines de la década del veinte: en el primero de ellos -"La producción literaria de 1929"-, a cargo de Ramón Doll, no se menciona la obra que Olivari publica ese año, El gato escaldado. La ausencia es aún más notable si se tiene en cuenta que por ese libro recibe el tercer premio en poesía del Concurso Municipal. El segundo artículo señala al respecto que "Olivari premiado, es otro yerro" ("El fallo de un jurado" 1930: 4). Como en el texto citado de 1926, "El año literario", se sostiene que "es un calco de enfermizas corrientes" (4) y se insiste en cierto valor como poeta que lo coloca por sobre Marechal (primer premio), no obstante se afirma que su obra no prospera debido a que se encuentra "plagada de cuanto atenta contra su vigor humano, salpicada de negaciones" (4) Para Claridad, Olivari "no es hoy, tal como avanza, un valor. Está aún bailando en la cuerda floja de las posturas" (4).

Las negaciones, silencios y ataques dirigidos hacia el poeta a lo largo de buena parte de la década del veinte quedaron plasmados en su propia poesía, como así también en prólogos, dedicatorias y entrevistas; ${ }^{226}$ es decir que Olivari, como dijimos, convierte en valor el rechazo porque, al igual que Arlt, entiende que ser rechazado por la institución literaria lo convierte en un artista moderno, original y transgresor. ${ }^{227}$ En el primer poema de La musa de la mala pata -“Canción con olor a tabaco, a nuestra buena señora de la improvisación"leemos una suerte de autofiguración en esa situación:

\footnotetext{
${ }^{226}$ Esto se puede apreciar mejor en sus dos primeros poemarios. De La amada infiel se pueden mencionar los siguientes poemas: "Te quiero", "Elegía a mi novia, muerta en olor de juventud", "Autorretrato". De La musa... se destacan: "Canción con olor a tabaco...", "Canto a la dactilógrafa", "Domingo burgués", etc.

${ }^{227}$ Durante los años veinte, la carrera literaria de Olivari parecería describir una curva de ascenso puesto que al inicio se encuentra vinculado a las zonas más desprestigiadas del campo letrado para luego, sobre el final de la década, ubicarse en espacios más centrales. Sin embargo, Bosoer advierte que el derrotero de Olivari no debe entenderse como un simple ascenso puesto que el poeta participa simultáneamente de los circuitos de producción ampliados y restringidos (2012: 7). El momento de mayor reconocimiento sucede, como acabamos de señalar, en 1929 cuando obtiene un premio municipal por El gato escaldado. El galardón le valió la "consagración" y su "indiscutible" pertenencia a "las capas más prestigiosas del campo letrado" (Bosoer 2012: 127).
} 
-Y de ese Olivari ¿qué opinan?, me aferro

a la crítica, ese mocito es un informal...

-Ese muchacho va de yerro en yerro...

-...puesto que ni figura en la Antología

Del Señor Doctor Don Julio Noé... ${ }^{228}$ (2006: 71)

El rechazo y/o la omisión ejercidos por buena parte de las publicaciones de la época ${ }^{229}$ excepción hecha de Martín Fierro-, además de las referencias al errático camino que estaba trazando y de la imposibilidad de acceder a instancias de legitimación tales como la Antología de Julio Noé, están condensados en esos pocos versos.

La participación simultánea de Olivari en circuitos ampliados y restringidos hizo que se lo critique desde diversos, y a veces opuestos, sectores del campo literario. Por ejemplo, las revistas Nosotros, Martín Fierro y Claridad, muchas veces envueltas en crudas disputas, coincidieron en criticar, con diversas intensidades, el lenguaje literario que utilizaba en sus obras. El rechazo de una lengua literaria heterogénea, compuesta por las variedades "ítalocriollas”, evidenció las puntuales coincidencias que la izquierda y la vanguardia estética tenían en relación con la lengua literaria.

Asimismo, Claridad realiza una lectura de la obra de Olivari con ribetes nacionalistas, algo ciertamente impensado entre los escritores de izquierda, cuya visión sobre la nacionalidad tenía como eje central la presencia del inmigrante. Desde ese espacio, se rechazó la influencia francesa de su poesía; y, en este sentido, esas críticas pueden ser leídas como una

\footnotetext{
${ }^{228}$ La Antología de la poesía moderna argentina (1900-1925), a la que se refiere Olivari, no se caracterizó justamente por una amplia cabida a la joven generación vanguardista. Salazar Anglada se refiere a una conferencia que Noé brinda en 1926, previa a la publicación de la Antología, en la que da pocas noticias sobre "las nuevas perspectivas que se abren hacia 1922 en el ámbitode la cultura nacional (...) apenas dedica unas líneas a algunos de los poetas coetáneos -Güiraldes, Girondo, el Borges ultraísta- que por estos años participan de lleno en la nueva estética. Este hecho se corresponde con la escasa representatividad que tiene la promoción vanguardista en la antología, sobre todo en comparación con la atención que se presta a la poesía de los primeros cuatro lustros." (2007: 185). Tampoco parece simpatizar con el ala izquierda de la joven promoción: "[En la conferencia] Noé dedica también un apartado a los poetas sociales afectos a Boedo influidos por la revolución político-social. No parece, sin embargo, tener en mucha estima a estos escritores minados de ideología, cuya poesía no resulta ni valiosa ni eficaz, en palabras del crítico. De hecho en su día no tuvieron cabida en la antología, en ninguna de sus dos ediciones. Sí fue llamado a participar Álvaro Yunque, cuyas diferencias ideológicas con Noé le llevarían a rechazar su participación.” (2007: 186). Ante este panorama, no resulta extraño la ausencia de Nicolás Olivari en las páginas de la Antología.

${ }^{229}$ Al respecto, Bernardo Koremblit, quien escribe un entusiasta libro sobre Olivari, explica que la introducción a El gato escaldado, en donde el poeta hace explícitos su poética y sus consiguientes rechazos y adscripciones, "le cerró las puertas de las revistas 'serias', los suplementos literarios de los diarios y las tarimas de las 'edificantes' salas de conferencia” (1957: 24).
} 
velada ofensiva hacia los escritores de Florida, acusados de francófilos tempranamente por Roberto Mariani. ${ }^{230}$

Las críticas elaboradas por Claridad contra Olivari -y sobre las que nos hemos detenido en estas páginas- ponen de manifiesto las diferencias existentes entre la lengua literaria del poeta, transgresora y en búsqueda permanente de autonomía, y las funciones que la izquierda le adjudica a la literatura: su tarea formadora, educativa y edificante. En este sentido, más que en la idea de formación, el lenguaje literario del poeta insiste en la transgresión y deformación.

\section{La subversión del lenguaje como novedad}

Los comentarios críticos acerca de las obras de Nicolás Olivari contienen juicios que, ya sean negativos o positivos, están tipificados: los primeros parecen coincidir en que los defectos de su obra se concentran en el terreno de la expresión. Los segundos sostienen la originalidad y la novedad como la principal fortaleza. En la crítica contemporánea de su obra, defecto y originalidad no sólo resultan ser dos lugares comunes, sino también las resultantes de la valoración de su lenguaje literario.

El rasgo de la literatura de Olivari que más llama la atención de los comentaristas parece ser la originalidad. La única certeza que los sostiene es la de saberse frente a una obra que se destaca, en un primer momento, por su novedad. A favor o en contra de ella, los textos críticos estructuran sus argumentos. Los juicios negativos leen esa novedad como un defecto absoluto. Así, en el ya mencionado artículo de Claridad, "Barbarización literaria" (1926), se sostiene que la originalidad de Olivari consiste en la desorganización formal, o mejor dicho en su conformación espuria; y lo expresa, metafóricamente, de la siguiente manera: "la originalidad en el vestir no se consigue metiéndose en un cambalache judío con los ojos vendados y sacando de trecho en trecho la primera prenda que caiga a mano" ("Barbarización literaria", 266). Luego señala que Olivari no necesita esa originalidad, puesto que "podría limitarse a decir lo que entiende con su vocabulario corriente”. De manera algo contradictoria, el autor del artículo propone que el poeta persiga su originalidad pero por fuera de aquello que lo convierte en original, es decir su lengua literaria. Por último, termina por desacreditar definitivamente la originalidad olivariana diciendo que: “...es una originalidad en un estado peor que en bruto: deformada por pegotes de falsa cultura literaria de vigésima mano, hundida bajo un fárrago de nociones falsas a guisa de cultura general" (266).

\footnotetext{
${ }^{230}$ Mariani (1924b).
} 
López Palmero, por su parte, hace hincapié en su "personalidad", la cual bien puede ser entendida también como originalidad. La supuesta personalidad es rápidamente demolida a través de la "bastedad", "vulgaridad" y "grosería" que le adjudica a Olivari. El procedimiento es similar en los dos artículos comentados: destacar la peculiaridad del escritor para, acto seguido, convertirla en su defecto fundamental.

El artículo de Luis Franco, publicado en Martín Fierro, también retoma la idea de la "personalidad". Sólo que aquí el sentido que se le adjudica a ese vocablo es opuesto al esbozado por los articulistas de Nosotros. Franco cree que la personalidad tiene un costo para Olivari, y es el rechazo que el grueso de la "crítica nacional" ha ejercido sobre él. La "benevolencia vegetariana del crítico", explica Franco, cae sobre escritores que carecen justamente de ese condimento que se destaca en el autor de El gato escaldado.

En cuanto a la crítica de Roberto Mariani, queremos destacar la valoración negativa que éste hace de la originalidad. Comienza su artículo:

El señor Nicolás Olivari ha escrito un libro de versos mal medidos donde se burla, a veces con gracia y otras - las menos- sin ella, de lo que todos los poetas suelen tomar en serio. Dicha jovial originalidad se inicia en el simpático desenfado con que dedica su libro a las compañías Anglo Argentino y Lacroze... (1924a: 10).

El uso de la ironía connota la originalidad a partir de su asociación con los "versos mal medidos" y las burlas que Mariani tanto va a repudiar en su texto.

Para Marechal la originalidad se desprende de la combinación de diversos elementos que el poeta utiliza para dar forma a su obra. Se refiere al humorismo y al tono sentimental, pero también a eso que, de modo poco específico, denomina "habla criolla". El lenguaje atraviesa todas las variables que tienen como resultante la singularidad, uno de los atributos destacados del poeta. Citamos, a continuación, el pasaje en donde Marechal pone de manifiesto esa cualidad: "el autor junta estos elementos [tono sentimental y humorismo] y realiza una combinación cuya receta muchos han buscado inútilmente; a mi juicio, esta combinación constituye el rasgo personal de Olivari” (1926: 10).

En síntesis, la particularidad del lenguaje literario de Olivari -su asociación con la barbarie, la incorrección, la transgresión de las normas, lo bajo y lo feo- es el rasgo fundamental que invalida la escritura o se transforma en la principal virtud del escritor, según la orientación que la crítica adopte al respecto. 


\section{Poética}

En esa suerte de poética que es "Palabras que se lleva el viento", el autor señala la mezcla como uno de sus principales procedimientos literarios: "mezclar en la antinomia del lirismo puro los elementos de la realidad, exagerados hasta la irrealidad para quitarles su sabor a fábrica, será la única y suprema labor” (2006: 139). La ironía y el humor, la burla hacia las tradiciones, temas y formas literarias, ${ }^{231}$ y la utilización de una lengua alejada de lo culto, más bien próxima a los registros populares y vocablos vulgares y/o escatológicos, se compendian y dan forma, según el poeta, a "la literatura del mañana":

Retazos de diálogos sin la lógica estúpida de la vida (...) rictus humoristas de deslenguados y tristes por dentro, rabia a lo normal y neutro, estocadas de ironía líricas a lo epiceno de las antologías, contradicción en cada párrafo (...) he ahí la única literatura del porvenir (Olivari 139).

Esa literatura del futuro constituye una fuerte intervención en las condiciones en que se redefine la lengua literaria. Olivari no sólo escribe poemas contra las preceptivas y normativas defendidas por los sectores más conservadores, sino que también elabora su metadiscurso -el prólogo en cuestión, en este caso- con el objeto de responder a esos sectores. La idea de una literatura poderosa y bien construida está desgajada de las preceptivas de la corrección idiomática:

El primero que ose escribir, al disponerse a redactar un cuento, una metáfora en lugar de un lugar común, una visión humorística en lugar de una frase gramaticalmente intachable pero vacía y fofa como un merengue, ese habrá dado el gran paso (Olivari 139-140, destacado nuestro).

Al respecto, en una entrevista realizada por la revista La literatura argentina, señala: "a mí no me importa nada la literatura como instrumento de perfección idiomática o sentimental" (“Nicolás Olivari tiene la palabra..." 1929: 134). Pese a su activa participación en la industria cultural, sostiene que el poema del futuro debe estar liberado de las ataduras del mercado. La contradicción en la que incurre aquí Olivari se mitiga si se tiene en cuenta que los lugares institucionales desde donde un sujeto enuncia, condiciona sus opiniones y valoraciones sobre determinados hechos u objetos. ${ }^{232}$ Es decir, en este caso, se posiciona contra el mercado porque propone su poemario como vanguardista y, en este contexto, el Arte se enfrenta con el

\footnotetext{
${ }^{231}$ Mariani se quejó de eso en su reseña a La amada infiel, aparecida en Martín Fierro: "[Olivari] se burla de lo que todos los poetas suelen tomar en serio." (1924a: 10).

${ }^{232}$ Ver Pierre Bourdieu (1997).
} 
mercado. Si el contexto hubiera sido otro, por ejemplo el del diario Crítica, tal oposición se disuelve.

Propone una modernización de la literatura que, para ser llevada a cabo, requiere abandonar los "cold creams de los academicismos" con que el "lirismo usado" está maquillado. Y agrega: "su vejez es espantosa ante las nuevas fórmulas. Fórmulas sin fórmulas" (140). Para Olivari, la tendencia moderna de la poesía consiste en la liberación de la forma clásica, de la rima y ritmo. Esta afirmación puede ser leída como una respuesta general a las acusaciones recibidas en múltiples reseñas y comentarios bibliográficos en donde se lo acusa, como lo hace Mariani, de escribir "versos mal medidos", entre otros “barbarismos". En definitiva, su poética resulta un claro ejemplo vanguardista, más allá de que haya confesado no entender a los escritores que conforman ese movimiento:

Soy adversario decidido de la poesía de vanguardia. Soy muy amigo y aprecio mucho el talento de Molinari, de Bernárdez, pero no los entiendo. Sus poesías para mí son chino. Esto seguramente es a causa de que usan solamente la imagen y la metáfora en sus poesías (Olivari 2006: 132).

La cita pone en evidencia la relación conflictiva que mantiene también con la vanguardia estética. La cercanía con Martín Fierro está dada por sus colaboraciones y por la evidente atención que la publicación dedica a sus obras, pero también por las búsquedas formales que lo aproximan a esta zona. Sin embargo, al referirse al lenguaje de la poesía de vanguardia como algo incomprensible ("chino"), expresa la distancia que lo separa de esos programas estéticos. Hay que tener presente que la poesía que él escribe no se caracteriza justamente por un lenguaje limpio, claro y entendible. Pero, en realidad, lo que cuestiona fuertemente es la falta de contenido, la metáfora per se como dice Romano (1990: 99). Si con los martinfierristas lo une la experimentación formal, al mismo tiempo lo separa la sustancia que sirve para esas experimentaciones:

La musa literaria despojará a todas sus hermanas, las otras musas, y se producirá en la turbulencia de la independencia sonora y agresiva. Tomará las malas palabras de los idiomas bajos para enaltecer las sonoras y bellas palabras gastadas por el roce en los cráneos de los líricos piangentes (Olivari 142, destacado nuestro).

Los "idiomas bajos", es decir los registros populares y las mixturas extranjeras, son rechazados por Martín Fierro. Esto lo hemos podido ver, por ejemplo, en el artículo publicado por la redacción de la revista, "Suplemento explicativo de nuestro "Manifiesto", 
como así también en las opiniones que Borges brinda en sus textos referidos al tema. ${ }^{233} \mathrm{La}$ distancia que Olivari guarda con la vanguardia estética es la misma que lo separa de los sectores conservadores, y esto se explica justamente porque, como dijimos en el capítulo II, el martinfierrismo expresa cierto grado de conservadurismo con respecto a la lengua literaria.

Con la zona de la izquierda comparte la preocupación por la conflictiva realidad social del momento. En este sentido, a veces elabora posicionamientos en relación con la lengua literaria afines con este sector: “¿qué le vamos a ir con palabras bonitas a quien está rabiando y blasfemando por el puerco oficio de vivir?” (135, destacado nuestro). En la entrevista que le hace La literatura argentina, después de realizar la afirmación anterior, vuelve a alinearse con los principios de la vanguardia estética, aunque pensando el público de modo distinto: "debemos usar nuestros elementos de renovación literaria para extenderlos a todo el mundo" (135).

La combinación de un lenguaje popular y cosmopolita con técnicas literarias propias de la vanguardia lo convierte en una suerte de paria: “[debemos] hablar a nuestros semejantes no con expresiones de clave ni con lenguaje de hermenéutica. (...) De otro modo, vamos a hacer como los curas que rezan en latín cuando los fieles piden a Dios, en honesto castellano, salud y plata" (135). Para Olivari, la literatura debe hablar el mismo "idioma" de los lectores. Por eso impugna la poética a veces "oscura" de la vanguardia estética. Al igual que Castelnuovo, ${ }^{234}$ propone una literatura llana, de fácil comprensión para un público ampliado. Sin embargo, para ello, y a diferencia de la izquierda, se sirve de los registros populares y de las voces de los inmigrantes. Las experimentaciones formales lo hicieron optar por una escritura que se alejaba cada vez más de la lengua literaria normada de Boedo.

\section{Olivari en Crítica}

En el artículo de la revista Nosotros, "Barbarización literaria", se acusa al diario Crítica de ser un promotor de Olivari: "si Olivari se resolviera a leer más y de todo (...) se libraría de envanecerse demasiado por el éxito que ha de dar a su librito la propaganda de Crítica" ("Barbarización literaria" 1926: 267). Como hemos señalado en el capítulo II, el diario de Botana recortó su perfil sobre la base de un público masivo y popular al que se dirigió “en su misma lengua”. El tono coloquial de sus artículos, las crónicas policiales que reponían el universo de los bajo fondos, el lunfardo en las crónicas de turf de Last Reason, las glosas de Enrique González Tuñón y de Carlos de la Púa que recuperan las orillas y el universo del tango, la incorporación de mujeres escritoras en secciones especializadas y los

\footnotetext{
${ }^{233}$ Ver capítulo I.

${ }^{234}$ Ver capítulo II.
} 
concursos de payadores son algunas de las innovaciones del diario Crítica (Saítta 1998). A su vez, el hecho de que muchos de los nuevos escritores utilizaran el espacio del diario para escribir su literatura en esos años y en los que siguieron, como así también la amplia difusión que les brindó a través de reportajes y reseñas de sus libros, lo convierte en un actor de relieve dentro de las polémicas en torno al idioma y a la lengua literaria. ${ }^{235}$

Pero Crítica -y obviamente Olivari- no constituye el único frente del artículo "Barbarización literaria". La vanguardia estética también aparece aludida. El "atraso" que evidencia Olivari "en su desarrollo" se debe, principalmente, al "pueril desprecio por todo lo pasado, hoy de moda entre tantos de los que se pretenden 'nueva generación"” ("Barbarización literaria" 1926: 267). Pese al moderatismo de muchos martinfierristas en materia de lenguaje, la vanguardia no escapa de las críticas. Los poemas de Oliverio Girondo, las tesis de Borges a favor de un idioma argentino, las colaboraciones de los hermanos Tuñón y las de Olivari en las páginas de Martín Fierro explican la referencia negativa del comentarista hacia la vanguardia estética. Según el crítico, Olivari no es un escritor subalterno, como supo autodefinirse en el "Prólogo" de La musa de la mala pata. Ni siquiera le concede la indulgencia del calificativo "semiculto". Nada de eso, Olivari es, directamente, "un escritor bárbaro" (267).

El 11 de mayo de 1926, Crítica publica una reseña del libro de Olivari. Pese a los buenos ojos con que el diario de Botana juzgaba la producción literaria de uno de sus periodistas, los síntomas de rareza aparecen enseguida: Crítica titula el artículo "Ha aparecido un extraño libro de versos: La musa de la mala pata". Y predice, desde muy temprano, que "es un libro llamado a encender discusiones". La reseña, que también incluye algunas palabras de Olivari, pone en evidencia la relación conflictiva del autor con las publicaciones literarias de la época: "Proa y Nosotros me rechazaron dos poemas", se queja. Sin embargo, se deben poner estos rechazos en sintonía con el elogio del fracaso propio que ha realizado Olivari a lo largo de toda su obra literaria. Ser rechazado por Nosotros, es decir por los viejos representantes de una literatura que la vanguardia juzga anquilosada y perimida, puede ser indicio de modernidad; mientras que el rechazo de Proa puede entenderse como un autoafirmación frente a los escritores "bien", es decir aquellos que detentan cierto poder económico y un origen que se hunde en las raíces de la nación.

\footnotetext{
${ }^{235}$ Los vínculos entre los nuevos escritores y el diario de Botana se materializan en 1925, cuando muchos de ellos ingresan a la redacción de Crítica: Raúl y Enrique González Tunón, Conrado Nalé Roxlo, Nicolás Olivari, Roberto Arlt, Sixto Pondal Ríos, Pablo Rojas Paz, Edmundo Guibourg, Horacio Rega Molina, Cayetano Córdova Iturburu, Santiago Ganduglia, Ulyses Petit de Murat, Luis Cané, Emilio Pettoruti, entre otros.
} 
El 21 de julio de 1925, Crítica había publicado una entrevista con Olivari. Desde las primeras líneas, se ponen de manifiesto esas extrañezas ya mencionadas en la reseña, sólo que esta vez aparecen de manera más específica: "Nicolás Olivari es porteño. Porteño en sus versos desaliñados y atrevidos, como los 'cirujas' que juntan huesos y malas palabras en la Quema...” (“Habla un tránsfuga...” 1925: 6, destacado nuestro). En este artículo, Olivari vuelve sobre el rechazo de la mayoría de las revistas. De Proa dice que es una revista aristocrática: "es la revista de los universitarios líricos y distinguidos que odian a la chusma de los 20.000 ejemplares" (6). Y agrega: “aquí entre nosotros, compañero, le diré que Proa me rechazó dos poesías porque en ellas mi musa tenía el cuello sucio” (6).

Si resulta comprensible que las opiniones vertidas en Nosotros vayan acompañadas de indignaciones y rechazos, no se tiene la misma impresión cuando las sanciones provienen del diario Crítica o de Martín Fierro. Sin embargo, la explicación acerca de por qué las sanciones sobre la lengua literaria olivariana provienen de lugares tan diversos, incluso opuestos, del campo letrado puede encontrarse en las actitudes lingüísticas sustentadas por estos sectores, las cuales resultan medianamente compartidas. De este modo, sabemos que en torno a Nosotros se nuclea la crítica afín con el conservadurismo literario e idiomático. Como ya hemos visto, también conocemos que el núcleo del martinfierrismo sustenta un nacionalismo lingüístico, "en un sentido anti-inmigratorio" (Bosoer 2012: 6). Del mismo modo, los escritores de izquierda, merced a sus propósitos pedagógicos, sustentan posturas conservadoras en el terreno de la lengua. El ingreso de Olivari en los diversos círculos literarios, aun los más rupturistas, siempre se realiza a fuerza de señalamientos que encuentran en su lenguaje una forma que muchas veces remite al orden de la incorrección lingüística y de los desatinos literarios.

Su incómoda posición en el campo letrado ha llevado a la conclusión de que no existe órgano difusor que sirva de marco para su poética. Fue colaborador de Martín Fierro, pero ya hemos visto que la asimilación del poeta no fue completa, debido a la existencia de zonas de su poesía que el núcleo de la vanguardia estética no compartía.

Encuentra en Crítica un espacio afín con su poética dada la apertura que tenía el diario de Botana con respecto a las formas populares del lenguaje. Dice Olivari en "Palabras que se lleva el viento":

\footnotetext{
Nosotros escribimos iniciando la revuelta, el motín, el cuartelazo contra la guarnición vieja que se iba disecando dentro de su uniforme de académicos ante las puertas de la academia. Trajimos la voz del pueblo, del hombre argentino de hoy, del tipo racial nuevo donde sólo había profesionales de libros. Al literato de salón opusimos el poeta joven, hambriento y desesperado (2006: 144-144).
} 
Queremos recuperar de la cita, en primer lugar, la identificación que hace Olivari de la generación anterior con ciertos usos literarios adscriptos al academicismo y a los rigores normativos. Desde ese lugar, se puede afirmar que los problemas de la lengua literaria, en los años veinte, se plantean también en términos generacionales. La idea de lo nuevo y moderno, en algunos de los jóvenes escritores, implicó no sólo un cambio en la manera de concebir la literatura, el público, las instituciones, el mercado, las tradiciones literarias y el canon, sino también representó una nueva forma de trabajar con la lengua. En segundo lugar, al igual que Crítica, Olivari invoca "la voz del pueblo" como la sustancia principal de su literatura. Hacia 1923, cuando el diario de Botana se muda a la calle Sarmiento e ingresa en un momento de refundación, incorpora nuevos tópicos de identificación, otro modo de interpelación al lector y una novedosa presentación de su staff de redacción. En ese marco, el diario se instituye a sí mismo como "la voz" de la masa ciudadana transformando el éxito de mercado en criterio de legitimación (Saítta 1998). A partir del 18 de abril de 1923, se presenta como "la voz del pueblo", como así lo hará Olivari hacia el final de los años veinte. Dice Crítica:

Nuestra única satisfacción (...) es la de haber entrado en el alma del pueblo (...) pensamos con la mente del pueblo y proclamamos valerosamente su pensamiento: hablamos con su voz, y es su alma, grande y noble, la que presta elocuencia a nuestra voz ("Hoy hace un año...” 1923: 1).

Correlacionar estas dos declaraciones implica pensar los posicionamientos de Crítica, por un lado, y los del mismo Olivari, por otro, como partes integrantes de una perspectiva afín con respecto al lenguaje. ${ }^{236}$ La idea de que una voz silenciada -cuando no apropiada-, la voz de los otros, encuentre un medio que le otorgue presencia e identidad a través del periodismo y la literatura indica la existencia de nuevos marcos y frentes desde los cuales los nuevos actores culturales ingresan en el terreno de las disputas lingüísticas y/o estéticas. Si bien no resultan lo mismo las elecciones lingüísticas en el marco de un proyecto poético particular que las llevadas a cabo por un diario comercial, dado que las variables de mercado intervienen fuertemente en este último cuando no siempre sucede así en el primero, lo cierto es que las opciones en relación con la lengua literaria que asumen los escritores y periodistas pertenecientes al staff de Crítica están atravesadas por variables comunes y, de manera diversa, participan en las mismas disputas que determinan las propiedades de los proyectos poéticos individuales que estos escritores y periodistas, incluido Olivari, llevan adelante. De hecho, Crítica se presenta como un espacio ideal para autores que incorporan elementos

\footnotetext{
${ }^{236}$ Olivari ingresa a Crítica a mediados de 1925, junto con otros escritores, en su mayoría colaboradores de Martín Fierro.
} 
"plebeyos" y "delictuales" a sus lenguajes literarios, dentro del cual pueden ejercer su literatura con mucha más libertad y autonomía. En el marco de las tensiones y transformaciones de la lengua literaria, el diario de Botana, sin dudas, representa un nuevo actor que condensa todo un arco de nuevos agentes culturales. Las transformaciones que inicia Crítica en el mercado cultural a mediados de la década del diez suponen un cambio en el lenguaje periodístico y crean las condiciones nuevas para la transformación de la lengua literaria.

Dentro del campo letrado de los años veinte, se suele asociar las nociones de "nueva sensibilidad", "juventud" o "renovación" al movimiento de vanguardia conocido como grupo de Florida. Sin embargo, Crítica condensó muchos de los elementos con los que se identifica a los movimientos de vanguardia, por ejemplo la idea de juventud (Saítta 1998). El diario puso mucho empeño en señalar que estaba formado, y hecho, por jóvenes periodistas con estilo renovador. En sus páginas, se crea la imagen de "la muchachada de Crítica". Nicolás Olivari, en "Palabras que se lleva el viento", afirma: "contra los fenicios de la forma clásica, propongo que se llame poema u obra poemática todo lo que escriba la nueva generación." (2006: 144). Cuando el poeta menciona a la nueva generación no se refiere exclusivamente a los martinfierristas. Piensa en una vanguardia desde el punto de vista de las estrategias literarias y del uso particular de la lengua. Es decir, utiliza un sentido de vanguardia más amplio, puesto que éste excede al grupo de Florida: su universo referencial, sus formas lingüísticas, así como su contenido no siempre coinciden con los del martinfierrismo.

Los nuevos escritores para Olivari son sus contemporáneos que adscriben a los patrones formales explicitados por él. La nómina es larga y muchos conforman el staff de periodistas de Crítica. La nueva generación para Olivari es aquella que, como él, recorre los barrios, participa activamente de su bohemia y reelabora su lenguaje.

Sylvia Saítta (1998) describe una operación realizada por Crítica, y que bien puede ser leída como propia de la vanguardia: el diario de Botana se sirve del juvenilismo y de la exaltación de lo nuevo para presentarse a sus lectores y consolidar una imagen que lo diferencie del resto de los vespertinos. Crítica se ve a sí mismo como la obra de un grupo juvenil que funciona como la expresión de una nueva generación. En el terreno periodístico, se presenta como una vanguardia en la medida en que propone un nuevo público, nuevos modos de enunciación y rompe con las tradiciones periodísticas precedentes. A diferencia de los grandes diarios que encuentran en el peso de su tradición el núcleo original de legitimación, Crítica funda su valor en la ausencia de un pasado al que rendirle cuentas. El diario establece una suerte de homología con los nuevos escritores que disputan un lugar en el campo literario, desde posiciones desfavorables dadas por la carencia de un capital simbólico 
legítimo. En este sentido, Crítica adopta la actitud típica del recién llegado que, si bien acepta las reglas de funcionamiento que rigen el campo al cual se incorpora, desarrolla ciertas estrategias de subversión. La identificación entre escritores como Olivari y el diario de Botana permite señalar la emergencia de una vanguardia literaria y periodística, más amplia que el martinfierrismo pero que, como sucede con Olivari, no reniega de ella, sino que incluso allí encuentra puntos de reunión y colaboración. Crítica capta de inmediato la aparición de las vanguardias estéticas y velozmente las convierte en un espacio de divulgación e información de los procesos de modernización del período, e incorpora gran parte de sus protagonistas a su comité de redacción, reestructurando de este modo las complejas relaciones entre masividad y vanguardia (Saítta).

Pese a sus tendencias populares, Crítica saluda muy pronto la salida de Inicial (1923) y Martín Fierro (1924), pero omite en sus páginas la aparición de Extrema Izquierda (1924), Nativa (1924) y Los Pensadores (1924). Este dato podría pensarse como el ingreso del diario de Botana en las querellas entre las vanguardias estética y de izquierda, y como una toma posición en ese conflicto: el diario publica un artículo en donde señala que la producción de los realistas dista mucho de ser nacionalista -como lo es Martín Fierro- debido a que "escriben sugestionados por los grandes escritores rusos" (Saítta 1998: 161). El argumento que sirve para deslegitimar la literatura de los escritores de izquierda es el mismo que utiliza la publicación de Florida en tanto inscribe la diferencia en el binomio nacional-extranjero. La discusión entre Crítica, la izquierda y los martinfierristas no es sólo estética, además involucra la propiedad de un lenguaje, una nacionalidad y un origen de la escritura.

Pero más allá del vínculo entre el martinfierrismo y Crítica, el diario recorta un lenguaje y un universo referencial diferente -y a veces opuesto- al de Martín Fierro. La representación del arrabal, la inclusión del mundo del tango y del trabajo, el manejo del lunfardo, los registros populares y extranjeros constituyen fenómenos que Crítica incorpora en sus páginas como sello de su identidad y modernidad. En pleno proceso de expansión desde la periferia hacia las luces del centro, Crítica asumió el imaginario del tango como intertexto a la hora de construir la crónica policial, y también como un novedoso tema sobre el cual informar. El diario combina suburbio, lenguaje heterodoxo y experimentación formal, los elementos y mecanismos que pone en juego Olivari para escribir su literatura.

A lo largo de este capítulo, hemos indagado la lengua literaria de Nicolás Olivari, su proyecto creador y las tensiones que establece en los años veinte entre la vanguardia estética, la izquierda literaria y la industria cultural. 
La "incorrección” y el "descuido" formal resultan las propiedades más visibles y más señaladas de su escritura. Su obra ha sido interpretada, desde diversos sectores, como la manifestación del "error", la "ignorancia" o el desconocimiento de las reglas del arte literario. Sin embargo, su estética persigue el propósito de transformar el lenguaje y dotarlo de nuevas formas expresivas. Su lengua literaria, autoproclamada como defectuosa, tiene su correlato en la construcción de una figura de autor que encuentra en el fracaso, el rechazo y la transgresión a las normas (entre ellas a los lenguajes literarios aceptados) los fundamentos de su valor artístico, de su originalidad, potencia y modernidad.

Las críticas hacia los libros que publica en la década del veinte, y que hemos abordado en este trabajo, representan ejemplos de barbarización literaria, la cual consiste en las apreciaciones negativas que la crítica conservadora realiza sobre la lengua literaria. Para este tipo de aparato crítico, vendría a ser una suerte de "perversión" de las formas estéticas, el ejercicio de una violencia formal sobre los textos. La barbarización literaria es un conjunto de mecanismos discursivos tendientes a desacreditar determinadas poéticas que no se ajustan a las configuraciones estéticas e ideológicas de una parte del campo literario. De esta manera, constituye una forma de desprecio hacia determinados escritores que se posicionan de manera heterodoxa con respecto a las normas literarias dominantes, vinculadas, en cierta medida, al purismo y a las formas cultas y escritas. Valiéndose de este procedimiento, una parte de la crítica señala anomalías formales en los versos de Olivari, y lo deposita en el terreno de la "mala escritura". "Versos extraños", "desaliñados" y "atrevidos", "torcidos", "bichocos", "rengos", "malas palabras": algunos de los epítetos y calificaciones que logra su obra, muchos de los cuales son creados por el propio poeta con la intención de diferenciarse de las tradiciones literarias pasadas y presentes. No interesa si la reseña o el comentario es favorable o no; importa señalar que, en grado variable, los dispositivos de la barbarización literaria se encuentran siempre presentes. La barbarie, a veces, suele asumir la forma de una "originalidad" o "personalidad" anómalas, en virtud de que siempre están sujetas a lo "raro" o "extraño". Ni Crítica ni Martín Fierro -dos de los pocos órganos que acogieron al poeta y que sirvieron de reducto de un importante arco de la vanguardia estética- escapan de señalar ese rasgo en su escritura.

Por su parte, las críticas que le dedica la izquierda literaria deben interpretarse como parte de la cruzada contra determinados géneros y lenguajes, provenientes de un sector del mercado. Como hemos analizado en el capítulo II, la izquierda rechaza las diversas formas de "lo popular" que pone en circulación la industria cultural. Al igual que sucede con el caso de Crítica, las lecturas de la obra de Olivari, realizadas por estos escritores, no son más que la manifestación de sus pautas estéticas e idiomáticas. Para la línea editorial de Claridad, y para 
algunos de sus colaboradores más importantes, Olivari compendia la parte espuria que comporta "lo popular", como así también el cosmopolitismo dado que su literatura se nutre de las estéticas vanguardistas europeas.

En el marco de los problemas de la lengua literaria que se suscitan en los años veinte, Nicolás Olivari representa una pieza fundamental puesto que su literatura pone en entredicho los presupuestos de las estéticas más tradicionales y conservadoras, como así también las posiciones referidas a la lengua literaria que buena parte del arco vanguardista sustenta.

La transgresión, la incorrección deliberada, la degradación de los cánones literarios y las experimentaciones formales constituyen las condiciones necesarias de una lengua literaria en procura de su autonomía relativa. 


\section{CAPÍTULO V \\ Roberto Arlt: el "idioma porteño" como lengua literaria}

\section{Comienzos y autofiguración}

Como hemos visto en los capítulos anteriores, los problemas del idioma no sólo se manifiestan en el terreno de la discusión gramático-filológica, periodística, institucional, etc., sino que además tienen un correlato en la lengua literaria. El mercado, por su parte, permitió la ampliación del debate -algo hasta entonces inédito- debido a que éste se instaló en diarios, libros y publicaciones masivas. Además, que es durante esta década cuando se amplía el campo literario a partir del ingreso de una cohorte de escritores no tradicionales, de relativo capital cultural, muchos de ellos hijos de inmigrantes. Algunos de estos escritores lograron acceder a determinadas instancias de consagración oficial, como por ejemplo el Premio Municipal de Literatura; ${ }^{237}$ publicaron textos en revistas prestigiosas, como Nosotros; dictaron conferencias; etc. También se destacaron por una oposición a "los conservadores de la cultura", quienes los rechazaban por su origen "espurio", pero también por las nuevas textualidades que proponían, muchas veces reñidas con el ideal de lengua literaria que esos sectores tradicionales sustentaban. Como acabamos de ver, éste es el caso de Olivari, pero también de otros como Roberto Arlt.

Como es sabido, Arlt provenía de una familia de inmigrantes europeos. Su padre, Carlos Arlt, había nacido en la provincia prusiana de Posen y su madre, Catalina Iobstraibitzer, en una aldea cercana a Trieste. Instalados en el barrio de Flores a comienzos del 1900, la familia Arlt estaba lejos de tener un buen pasar. Pese al asedio de las penurias económicas, debido a la inestabilidad laboral del padre, la familia nunca vivió en conventillos ni los hijos precisaron salir a trabajar. Desde niño, Arlt convivió en un hogar signado por el mismo poliglotismo que, poco a poco, iba cubriendo la urbe y definía sus márgenes.

Al igual que otros escritores recién llegados al campo literario de los años veinte, se caracteriza por cierta informalidad en su preparación escolar y académica. Esa condición

\footnotetext{
${ }^{237}$ Algunos escritores logran alcanzar el premio más o menos rápidamente, como por ejemplo Elías Castelnuovo, quien lo gana en 1923, por su libro Tinieblas; otros demoran un poco más, como es el caso de Nicolás Olivari y Roberto Arlt quienes lo obtienen en 1929. En el año 1926, además de editarse varias obras importantes de la década, muchas de ellas pertenecientes a los jóvenes escritores del momento, un grupo importante de autores se presenta al concurso. Ellos son Nicolás Olivari, Jorge Luis Borges, Enrique González Tuñón, Eduardo Mallea y Roberto Arlt. Ninguno obtiene el premio. Frente a este rechazo, los cinco reciben un "banquete de desagravio" de parte de sus jóvenes colegas, en lo que se configura como una nueva -y paralela-instancia de legitimación, a espaldas de los circuitos tradicionales. La invitación al evento puede leerse en la edición del 6 de mayo de 1927, del diario Crítica.
} 
influye en las posibilidades, elecciones y usos lingüísticos que determinarán su escritura periodística y literaria, como así también los posicionamientos -en ocasiones, explícitos- en torno a los problemas del idioma que la década depara. Pero no siempre una "mala" o "incorrecta" escritura responde a carencias del orden cultural, aún en un escritor como Arlt.

Como también se pone de manifiesto en el caso de Nicolás Olivari, la lengua literaria de ambos escritores se vincula con una intencionalidad estética -y política- que les sirve no sólo para instaurar una escritura propia y alternativa a las vigentes, sino también para consolidar un lugar en el campo literario y configurar una nueva figura de autor. Al respecto, Paul Verdevoye señala que, en los "malabarismos con la sintaxis" de Arlt, entraba a veces "la intención de repudiar la rigidez académica, para entregarse a la fantasía de la espontaneidad, acercarse al lenguaje vulgar que suele seguir más bien el impulso vital que las reglas gramaticales" (2002a: 352). Por su parte, Viviana Gelado (2007) le concede a las "fallas" de la escritura arltiana cierta intencionalidad parcial. Muchas de las escrituras contrahegemónicas y/o heterogéneas de la década del veinte deben entenderse como parte de un proyecto deliberado de oposición a la cultura conservadora. Lo que muchos leyeron como error, puede entenderse como intención. $^{238}$

En el libro El escritor en el bosque de ladrillos, Sylvia Saítta se propone "cuestionar la difundida imagen romántica que identifica a este escritor con los atormentados personajes de su ficción y comenzar a desmitificar la construcción de una imagen de escritor advenedizo en la literatura, poco reconocido y relegado por sus pares o la crítica” (2008: 10). Saítta pretende discutir, entre otras cosas, la construcción que hizo el propio Arlt de sí mismo, un escritor subalterno y "sin más patrimonio cultural que unas lecturas desordenadas y un tercer grado inconcluso, una representación que conjuga en sí misma marginalidad y falta de reconocimiento público" (11). Tarea nada sencilla, puesto que no sólo fue el creador de su propio mito, sino también porque una parte de la crítica se ha ocupado de repetir y cimentar ese discurso. Arlt no estudió solo hasta tercer grado, como el mismo escritor difundió en diversos testimonios. He aquí la cronología de su formación escolar:

Arlt repite tercer grado, pero no lo echan de la escuela como orgullosamente afirmará después, sino que vuelve a cursar y aprueba tercer grado en la misma escuela (...) cursa y aprueba

\footnotetext{
238 "Sin duda, no es posible decir que el carácter de las transgresión por el error sea completamente deliberado en Arlt, pero siendo consciente como lo era de esta cualidad de su escritura y, sobre todo, siendo deliberada y calculada su agresividad discursiva, tampoco puede dejarse de considerar como deliberado su uso, por lo menos parcialmente, junto con las otras formas de violencia y las figuraciones de la humillación y del fracaso presentes en su narrativa" (Gelado 2007: 301, destacado nuestro).
} 
cuarto grado. Por último cursa y aprueba el quinto grado (...) A los catorce años, Arlt da por finalizado sus estudios primarios (Saítta 19-20).

Arlt hizo de la falta de instrucción, y de su fracaso en la escuela, materiales con los cuales diseñó su figura de autor, desprolija y reñida con la noción tradicional dominante de literatura. Tal vez deba buscarse en esa construcción el argumento central que habilita la producción de una escritura "incorrecta", producto, efectivamente, de sus propias carencias, pero también, parte integrante de una voluntad consciente de transformación del lenguaje literario.

El aguafuerte "El viejo maestro" - publicada el 20 de julio de 1930 en el diario El Mundo- puede pensarse como una de las piezas que contribuyeron a formar esta imagen de escritor desaliñado, en pie de guerra permanente con las instituciones. En ese texto se puede rastrear una suerte de elogio del fracaso, en el que la indisciplina escolar se adhiere a una posterior imagen de escritor-periodista. "Me echaste del grado" (Arlt 1998: 424), le recrimina, amistosamente, a su maestro de escuela primaria, Emilio Valassina, ${ }^{239}$ con quien recursa y aprueba el tercer grado. A través de la voz de su maestro, Arlt construye su prehistoria de niño indomable y díscolo: "pocos alumnos he tenido tan burros como vos. Era imposible hacerte entender nada, ni la regla de tres ¡Qué cosa bárbara, si habré sufrido y me habré hecho malasangre con vos!" (424). La desprolijidad física que se atribuye invocando la voz de su maestro -"no te lustrabas nunca los botines. Venías a la clase con los botines sucios de barro, las uñas más sucias todavía..." (424)- se acopla al incipiente interés por la literatura: "y yo me decía: este chico me indisciplina el grado. En vez de atender las clases, estabas con un libro sobre la falda. Eran siempre libros de Salgari o de Carolina Invernizzio.” (424). La configuración de esta imagen de escritor no formado se corresponde con ciertos mecanismos de autobarbarización que el propio Arlt repitió a lo largo de su carrera de escritor y periodista; es decir, tanto en sus notas y entrevistas como en los prólogos de su obra: "eras un salvaje; ese es el término. Yo, muchas veces, mirándote, me decía: a dónde diablos irá a parar este muchacho con el carácter que tiene. Para obrero, no sirve. Para empleado, tampoco va a servir." (425, destacado nuestro).

Si bien el aguafuerte se estructura a partir de la distinción entre el pasado -la expresión “¿te acordás?” se repite cuatro veces, y se acompaña con expresiones del tipo “Sabés que hace ya 19 años que pasó todo esto?”- y el futuro, parece no haber un cambio sustancial en la forma de ser de Arlt con el correr de los años: desde las páginas del diario El

\footnotetext{
${ }^{239}$ Nicolás Olivari también recupera la figura de su maestro Emilio Alonso Criado. Le dedica, por ejemplo, su primer libro de cuentos, Carne al sol. Y lo vuelve a recordar en la autobiografía que precede a Historia de una muchachita loca (1923). Para profundizar en el vínculo entre Alonso Criado y Olivari ver Bosoer (2012: 23-31).
} 
Mundo, continuará con la indisciplina de entonces. Ante el anuncio "voy a escribir una nota sobre vos”, el maestro le replica: “bueno, pero no vayas a decir ninguna barbaridad, ¿eh?”; Arlt contesta: "Y si la digo, no va a extrañar a nadie. Ya están acostumbrados a oírme decir barbaridades." (425, destacado nuestro). Cabe remarcar que Arlt dice "oírme”, en lugar de "leerme", lo cual puede explicarse a partir de la concepción de una escritura fijada en la oralidad, más que en el registro escrito.

En los años de madurez, la figura del maestro de escuela primaria será reemplazada por la del director del diario, Carlos Muzio Sáenz Peña, quien corrige continuamente sus columnas, ${ }^{240}$ y a quien Arlt desafía sistemáticamente desde las páginas de sus aguafuertes. ${ }^{241}$

El aguafuerte "El viejo maestro" cobra una rica significación puesto que Arlt construye una suerte de escena con la autoridad, con su maestro quien representa el lugar que ocupa el padre, la generación anterior, la tradición y/o las normas. Es Valassina quien, desde un inicio probable como proto-escritor, se ocupa de señalarle a Arlt su "barbarie" y sus comportamientos díscolos. En el maestro bien podrían cifrarse las reglas de las cuales el escritor de vanguardia debe diferenciarse y mostrar la novedad. La ideología de artista plantea que, en un campo autónomo, es éste quien crea sus propias normas, se niega a adaptarse a las preexistentes y no admite otros jueces que no sea él mismo (Bourdieu 1995).

\section{Las aguafuertes y las disputas en torno al lenguaje}

Cuando Arlt comenzó a publicar sus aguafuertes en 1928, en el diario El Mundo, la discusión sobre la lengua estaba ya instalada en la cultura de masas desde comienzo del siglo XX, por ejemplo en Caras y Caretas. ${ }^{242}$ Como ya hemos analizado en el capítulo III, el diario Crítica muestra la importancia del problema del idioma al lanzar su encuesta sobre el tema. También cabe mencionar la campaña que la revista Claridad inició contra el diario de Botana, en cuyo centro gravitaban estas cuestiones. En el seno de la izquierda, las discusiones sobre el lenguaje literario configuraban otra manifestación importante. Sirvan de ejemplo los casos de Olivari o de Enrique González Tuñón, y el modo en que la revista Claridad los criticó casi hasta la injuria. O el de Castelnuovo y su lengua atravesada de tensiones. ${ }^{243}$

El lenguaje que Arlt utiliza en sus notas periodísticas y en sus obras ficcionales constituye indirectas intervenciones en las discusiones que, en diversos sectores, suscitaban las cuestiones del idioma. Sin embargo, existe un pequeño pero significativo número de

\footnotetext{
${ }^{240}$ También podría pensarse en Ricardo Güiraldes quien oficia de corrector de sus textos, sobre todo de su primera novela El juguete rabioso.

${ }^{241}$ Ver "La censura" (Arlt, 1930).

${ }^{242}$ Ver Geraldine Rogers (2008).

${ }^{243}$ Ver capítulo II.
} 
aguafuertes que abordan la problemática de manera explícita y directa. Por tales motivos, estas notas constituyen una fuente importante para su estudio.

Como es sabido, durante la década del cincuenta, los jóvenes pertenecientes al grupo de Contorno rescataron la figura de Arlt quien, después de su muerte, en los años cuarenta, había sido prácticamente olvidado (Sebreli 2005). David Viñas dedica el segundo número de la revista Contorno al autor de Los siete locos y, por su parte, Juan José Sebreli publica, en 1953, un ensayo sobre su obra en Sur. Luego, afirma Sebreli, los contornistas Oscar Masotta y Carlos Correas escriben "los mejores estudios sobre Arlt" (86). Se refiere a Sexo y traición en Roberto Arlt (1965) y a Arlt literato (1995), respectivamente. En este último texto, Correas dedica unas páginas a las aguafuertes y su lenguaje. Según Correas, la "porteñidad” literaria que se puede observar en sus artículos periodísticos representa

una reacción contra otros escritores, adefésicos y momentáneos, irrisoriamente pretensiosos: Capdevila, Lugones, Larreta, Rojas (...) Frente a esta 'argentinidad hidalga' el 'nosotros' porteño tiende a una comunión entre hombres plebeyos a través de un estilo plebeyo que oscuramente aspira a ser crónica de época (1996: 277).

Correas grafica muy bien el lugar que ocuparon las aguafuertes en el marco de las luchas que se libran en el seno del campo literario entre los nuevos agentes culturales y aquellos pertenecientes al circuito "culto" tradicional, pero también pone en evidencia la función primordial que le cabe al lenguaje en esas reyertas, puesto que se convierte en un tópico importante sobre el que advenedizos y legitimados intercambian ideas. El lenguaje "plebeyo" no sólo procura desestabilizar al lenguaje legitimado y "elevado", sino también busca poner en crisis determinadas certidumbres acerca de la escritura literaria y la lengua nacional.

Desde diversos sectores del campo literario se producen textos que tienen como finalidad explicitar qué debe entenderse por lengua y literatura nacionales. Las aguafuertes se suman a ese conjunto de voces crispadas y muchas veces gritonas; y persiguen el objetivo de descifrar "la identidad porteña mediante la focalización no sólo de ciertos personajes sino también de la lengua que hablan y que los describe" (Rodriguez Pérsico 1993: 6). Pero los debates sobre la lengua no se agotan en la problemática de la nacionalidad, puesto que para algunos escritores son también una manera de posicionarse como artistas autónomos, de vanguardia. Es decir, la lengua literaria asume una coincidente superposición con las figuras de autor que los escritores diseñan durante este período.

Escritores como Arlt, Enrique González Tuñón, Carlos de la Púa, Nicolás Olivari, entre otros, reelaboran los registros populares en la literatura, la que hasta hace pocos años 
atrás era dominio casi exclusivo de las élites preocupadas por mantener el modelo normativo: la literatura culta como modelo de lengua. $^{244}$ Pero esa tarea va acompañada del descubrimiento de nuevas geografías. La escritura de estos autores va unida a una voluntad de exploración porque "caminan" los suburbios y los sectores marginales de la gran ciudad, y en ese recorrido recrean literariamente la heterogeneidad del habla popular. ${ }^{245}$

En el vértice que une el periodismo con la literatura, Arlt, con sus aguafuertes, se inserta en la tradición periodística de los escritores costumbristas que lo preceden: Fray Mocho, Last Reason, Félix Lima, quienes, algunos de ellos, participaron a su vez en las disputas en torno al lenguaje durante los años veinte. ${ }^{246}$ Según Rodríguez Pérsico, con sus notas, "reformula la identidad lingüística y cultural sobre la base de lo excluido por la cultura oficial” (9), al poner en duda la lengua hegemónica y al atacar a la Academia.

El 17 de enero de 1930, el diario El Mundo publica el aguafuerte "El idioma de los argentinos", centro gravitatorio de la breve constelación de intervenciones de Arlt sobre los problemas del lenguaje. ${ }^{247}$ Además de brindarle el título a un aguafuerte, la locución "el idioma de los argentinos" sintetiza la coyuntura sobre la cual se apoyan las diversas posturas y apropiaciones en torno a la lengua; y constituye un eslabón más de una cadena de textos que también utilizaron esa frase como título, ${ }^{248}$ entre los que se cuentan, principalmente, el escandaloso libro de Lucien Abeille y la conferencia y el posterior ensayo homónimo de Jorge Luis Borges. ${ }^{249}$ Cuando Abeille publica Idioma nacional de los argentinos, en 1900, el título de la obra ya se encontraba cimentado en el pasado y daba cuenta no sólo de los planteos

\footnotetext{
${ }^{244}$ En 1902, Carlos Estrada afirmaba: "se comenzó en la literatura gauchesca (con) su restringido y degenerado vocabulario. Vino después la novela terrorífica (...) el Juan Moreira. Después se pasó al teatro (...). Hidalgo, Ascasubi y Hernández fueron sustituidos por Eduardo Gutiérrez (...). El inmigrante, de la más baja extracción social por lo común, fundido con el compadrito y el gaucho (...) ha producido el tipo del lector cocoliche de la producción 'cocoliche'. Fuera de la difusión de la enseñanza, un solo remedio puede oponerse a esta barbarización del gusto: la buena literatura" (1983: 240).

245 "El narrador [de las aguafuertes] combina formas de recorrido: deambula indistintamente por las calles porteñas y por los sentidos del lenguaje. Topografías y etimologías sirven para trazar los mapas que circunscriben territorios sociales y lingüísticos" (Rodríguez Pérsico 1993: 6).

${ }^{246}$ Ver, en el capítulo III, el apartado dedicado a la encuesta "¿Llegaremos a tener un idioma propio?", organizada por el diario Crítica, en la que intervienen Félix Lima y Last Reason, entre otros escritores.

${ }^{247}$ Ver el análisis de Naomi Lindstrom (1980), quien aborda las aguafuertes desde la perspetiva de los problemas del idioma.

${ }^{248}$ Gerardo Oviedo señala que a partir de la Generación del 80 "la expresión 'idioma nacional argentino' cobra vigor" (2005: 50).

${ }^{249}$ Cabe agregar en nómina de autores que hicieron uso de esta locución a Ramón C. Carriegos, uno de los representantes del rupturismo idiomático (ver capítulo I). Carriegos publica un libro titulado El idioma argentino. Sin embargo, no hemos podido dar con él puesto que no figura en los catálogos de las bibliotecas más importantes (Academia Argentina de Letras, Biblioteca Nacional, Biblioteca del Congreso de La Nación, etc.). No obstante, sabemos que el libro se publicó antes de 1910 dado que en las solapas de Minucias gramaticales, editado ese año, se lo menciona entre las obras publicadas por el autor. Muy posiblemente, el libro date del año 1905 dado que, en 1940, cuando Carriegos publica Criticas $i$ críticos, señala que "hace siete lustros que publiqué en el diario El Pais, de la Capital Federal, el primer capítulo de mi libro titulado El idioma argentino" (Carriegos 1940: 164).
} 
iniciados por la Generación del 37, sino también de las determinaciones institucionales manifestadas al momento de organizar la nación a partir de la década de $1880 .^{250}$

En los años veinte, como lo demuestran el ensayo de Borges y el aguafuerte de Arlt, los discursos que vinculan lengua y nación persisten. No obstante ello, la filiación con Abeille desaparece ya que ninguno de los dos escritores lo menciona en sus respectivos textos. Oviedo (2005) afirma que esa ausencia en el libro de Borges es una omisión, una tachadura. Y eso se explica por la lejanía existente entre la propuesta borgeana -que, si bien no adscribía a la hispanofilia tampoco apoyaba las lenguas "plebeyas"- y la de Abeille, quien "vindicaba al criollismo de su exclusión de la gramática preceptista académica $\mathrm{y}$, sobre todo, daba fueros patrios al habla coloquial plebeya, que entretanto decantaban las camadas inmigratorias" (24). Arlt, por su parte, "probablemente ignora que existió" el profesor francés (22). De todos modos, el nombre de Abeille parece haber desaparecido de las referencias de casi todo el campo letrado: "no lo vemos en la saga de la exégesis martinfierrista. Ni a Lugones, ni a Rojas, ni siquiera a Martínez Estrada (...) le merecen atención” (22).

Tanto Abeille como Arlt sufrieron los embates de los sectores conservadores. Según afirma Gerardo Oviedo (2005), el profesor francés fue tratado del mismo modo que sus predecesores gauchescos; esto es, como un escritor menor o un intelectual bajo, a pesar de no provenir de un estrato social popular; lo cual indica que no siempre existe una superposición automática entre la clase social del escritor y la lengua literaria. Abeille habría sido visto como un inculto, como un remedo científico de un Eduardo Gutiérrez, o como su versión académica (Oviedo). Sabemos que el autor de Los siete locos también fue señalado como inculto y bárbaro; y esa visión se mantuvo en todas las épocas, ya sea para invocar su "barbarie literaria" como para poner de manifiesto su "genialidad". En sus memorias, Alberto Pineta recurre al motivo de la "mala escritura" arltiana: el autor cuenta cómo, un día, se encuentra con Arlt y le pregunta qué le había parecido su último libro, La inquietud del piso al infinito (1931). Arlt "me contestó que el libro le había parecido poco menos que una basura". Pineta responde, malicioso: “¿Le encontraste muchas faltas de ortografía y de sintaxis? (...) ¿Cómo hiciste para descubrirl[as]?” (1962: 145). La maledicente e irónica respuesta de Pineta resulta toda una evaluación de la escritura de Arlt. Por su parte, Eduardo González Lanuza repite que el autor de El juguete rabioso "escribió hasta el fin de sus días

\footnotetext{
250 “Al relacionar 'Lengua y naciones' en el primer capítulo de su estudio, Abeille no hacía más que ajustarse a una costumbre que se remontaba al menos a la Gramática y ortografía de la lengua nacional (1817), de Antonio J. Valdés. Costa Álvarez señala la existencia de una Gramática Argentina en 1852. Noemí Ulla (...) recuerda que, desde 1852, se establece la asignatura 'Idioma nacional', que también aparece en los decretos de 1884, 1887, 1888, 1898 y 1900, frente a los nombres: Lengua castellana (1886), Idioma castellano (1891 y 1893), Idioma patrio (1901 y 1902)." (Verdevoye 2002b: 322).
} 
sin preocuparse por unas faltas de ortografía capaces de hacer sonrojar a cualquier colegial de la escuela primaria, e incurrió en cuanto dislate sintáctico le vino a la mente" (1971: 29); mientras que Raúl Larra, su primer biógrafo, afirma que "hablaba como escribía" y que se le podía adjudicar, en este sentido, las cualidades de ser "rápido, espontáneo y sincero", aunque no descarta que "a veces, 'componía' su frase” (1998: 54).

Gerardo Oviedo (2005) se refiere a la lengua literaria de Arlt como "populismo plebeyo lingüístico", poniéndola en relación con las tesis planteadas por Lucien Abeille treinta años antes: “el anticanónico y plebeyo Arlt está convencido de que la fuerza está siempre del lado de la creación idiomática (...) Este realismo le permite propiciar un autonomismo populista que está muy cercano al de Abeille" (74). En aquellas aguafuertes en las que se propone dilucidar "el origen de algunas palabras de nuestro léxico popular" (74) o en el uso de frases que celebran la soberanía lingüística popular se trasluce el espíritu abeilliano.

El origen de "El idioma de los argentinos" se encuentra en las afirmaciones de José María Monner Sans, quien en una entrevista para El Mercurio de Chile había señalado:

\begin{abstract}
hoy nadie defiende a la Academia ni a su gramática. El idioma, en la Argentina, atraviesa por momentos críticos... La moda del 'gauchesco' pasó; pero ahora se cierne otra amenaza, está en formación el 'lunfardo', léxico de origen espurio, que se ha introducido en muchas capas sociales pero que sólo ha encontrado cultivadores en los barrios excéntricos de la capital argentina. Felizmente, se realiza una eficaz obra depuradora en la que se hallan empeñados altos valores intelectuales argentinos (Arlt 1998: 161).
\end{abstract}

Como es sabido, Monner Sans (h) se alarmaba principalmente porque, durante los años veinte, el lunfardo había pasado de ser un registro exclusivo de los suburbios a convertirse en un componente idiomático de toda la geografía social porteña. ${ }^{251}$ Así como el tango se desplazó desde la periferia hacia el centro de la ciudad, el lunfardo se abrió paso desde los márgenes hacia las zonas y las clases más acomodadas de Buenos Aires. Desde principios del siglo XX, los sectores que adscribían a una lengua literaria conservadora percibieron este fenómeno como una amenaza. La extensión del lunfardo preocupó a filólogos, periodistas y escritores quienes pensaban que ese vocabulario influiría de manera decisiva en la formación de un idioma nacional, desprendido del castellano heredado de España. Otro fenómeno concomitante a éste-, y que también preocupó a los más conservadores, fue la elaboración de

\footnotetext{
${ }^{251}$ Monner Sans (h) ya había esbozado esta misma idea en 1927, cuando fue consultado por Crítica en ocasión de la encuesta “¿Llegaremos a tener un idioma propio?”: “... repudiable y de mal gusto es la formación del lunfardo, idioma del delito que, por rara coincidencia, aparecen hablando las clases aparentemente cultas (1927: 7). Ver capítulo III.
} 
una literatura que se sirve de las formas coloquiales y populares, y que podría fijarlas y dar así origen a una lengua bien diferenciada del castellano peninsular. Resulta claro, entonces, el vínculo entre el idioma y la lengua literaria en este punto: el "babelismo" en el que se encuentra inmersa Buenos Aires podría ingresar en la literatura, degradándola. Se trata del fenómeno que Ernesto Quesada ya había denunciado en 1902, cuando afirmaba que

en los últimos años, parece acentuarse (...) la tendencia a considerar únicamente como genuina producción de la literatura argentina lo escrito en el lenguaje diario de las clases populares que moran en el Río de la Plata. Esa tendencia literaria neo-patriótica quiere reconocer tan solo como argentino lo que lleve el sello criollo (1983: 107, destacado nuestro).

Quesada y Cané, entre otros, ${ }^{252}$ vieron que el peligro de una lengua nueva -alternativa al castellano peninsular, cuyo sustrato era la argamasa idiomática de los inmigrantes, y que se basaba en los lenguajes "de las clases populares"- se hacía inminente puesto que además de existir una literatura que fomentaba estas formas -el criollismo-, había aparecido también su "gramática", el libro de Abeille. En la década del veinte, esas amenazas, lejos de mermar, recrudecieron a través del auge de un periodismo popular y de otras formas de la cultura de mercado (colecciones de literatura barata, el tango, el teatro, etc.), pero también de la obra de muchos escritores quienes elaboraron sus textos a partir del lenguaje coloquial rioplatense, entre cuyas formas se contaba el lunfardo. Hacia fines de los años veinte, quien encendió las alarmas, entre varios otros, fue Monner Sans (h). Si bien Arlt menciona explícitamente a este gramático, en sus textos sobre el idioma discute con las posiciones conservadoras que, como vimos, ya habían sido esbozadas por la élite de principios de siglo, y las cuales desestimaban el valor y la necesidad de incluir la oralidad en las lenguas literarias. Monner Sans (h) actualiza las tesis de los conservadores de 1900, las que luego Arlt rebatirá al reivindicar el lenguaje popular en la literatura.

La respuesta de Arlt se inicia con una burla hacia el gramático, en consonancia con el espíritu paródico e irónico con que escribe otras aguafuertes dedicadas al tema de la lengua. A la demostración que realiza Monner Sans en su artículo, opone un breve y conciso giro popular, en cuyo centro aparece una palabra lunfarda: “¿quiere usted dejarse de macanear?" (1998: 161, destacado nuestro). De este modo, devuelve el golpe, porque si-como veremosen su aguafuerte "El furbo" decía que lo habían acusado de, justamente, ser "un solemne

\footnotetext{
${ }^{252}$ Ver Rubione, Alfredo (1983).
} 
"macaneador"” (63), a raíz de las etimologías lunfardas que fijaba a varios vocablos, ahora es Arlt quien procede del mismo modo. ${ }^{253}$

Arlt afirma que un idioma "puro", como sostienen los gramáticos, es un idioma sin vida que produce textos "aburridores". ${ }^{254} \mathrm{El}$ efecto inmediato es la ausencia casi total de lectores, quienes, desde la visión de Arlt y otros, venían a mensurar el éxito y calidad de la literatura. En este sentido, podemos observar un punto en común entre este autor y los escritores de izquierda: tanto uno como otros veían en el público y en la cantidad de ejemplares vendidos un índice importante de legitimación, que no se reducía sólo al éxito comercial, sino que además comprometía una noción de calidad artística que incluía la valoración por parte de un público amplio. En este sentido, Arlt señala que los escritores consagrados no tienen lectores: “... me acordé que a esos 'valores' ni la familia los lee, tan aburridores son" (162). Aquí vincula la cuestión del idioma con el discurso literario y el mercado editorial. Una tríada que vertebra buena parte de los argumentos que dominan las disputas entre los diversos frentes del campo letrado.

Arlt se posiciona frente a Monner Sans (h) como un igual, un igual cuyos alcances resultan muy efectivos gracias a los mecanismos paródicos e irónicos de los que se sirve para contrarrestar las intervenciones del gramático. Se sabe que creía fervientemente en la calidad de su literatura, pese a que era consciente de que su escritura poseía muchas imperfecciones de construcción; ${ }^{255}$ lo cual, sin embargo, no pensaba que pudiera ir en contra de los atributos de sus textos: "[Arlt] reivindica así el derecho de hablar de manera eficaz, aunque a veces antigramatical" (Di Tullio 2009: 580).

Como hemos visto, en sus aguafuertes, Arlt brinda su opinión acerca de que Argentina es un pueblo nuevo y, como tal, debe aspirar a un idioma que pueda manifestar esa novedad. Por eso escribe en "porteño", porque así es la única forma de dar cuenta de la realidad que representa en sus textos. El "idioma puro" de los casticistas no podría jamás expresar lo porteño, por esa razón se pelea con Monner Sans. En este sentido, la lengua literaria y periodística de Arlt es tributaria de sus ideologías y actitudes en torno al idioma.

Otro que resulta un guardián del idioma es el poeta cordobés Arturo Capdevila, quien en 1928 publicó un texto central para los debates en torno al lenguaje: Babel y el castellano.

\footnotetext{
${ }^{253}$ Como había ocurrido ya en 1927 en "A un meridiano encontrao en una fiambrera": "Espiracusen con plumero y todo, antes de que los faje. Che, meridiano, hacé a un lao, que voy a escupir" (Ortelli y Gasset 1927:7).

${ }^{254}$ Pocos meses antes de que Arlt esboce estas ideas, en octubre de 1929, Nicolás Olivari brinda una entrevista a La Literatura Argentina en donde sostiene: “yo le preguntaría a Capdevila, a Fermín Estrella Gutiérrez, a González Arrili, etc.; porque (sic) escriben libros si nadie se va a tomar el trabajo de leerlos ("Nicolás Olivari tiene la palabra..." 1929: 61). Como se puede observar, la relación entre el conservadurismo idiomático y el poco éxito de mercado resulta una ecuación muy recurrente en este tipo de escritores.

${ }^{255} \mathrm{La}$ declaración más ostensible al respecto es la que realiza en el prólogo a Los lanzallamas en donde reconoce que escribe mal, pero al mismo tiempo afirma que "para hacer estilo son necesarias comodidades, rentas, vida holgada" (1980: 8).
} 
Según Ángela Di Tullio (2009), en "El idioma de los argentinos", Arlt también aludió a este autor, en el siguiente pasaje: “tenemos un escritor aquí -no recuerdo el nombre- que escribe en purísimo castellano y para decir que un señor se comió un sándwich, operación sencilla, tuvo que emplear todas estas palabras: ‘y llevó a su boca un emparedado de jamón”" (1998: 162).

Arlt se construye como un experto en "filología lunfarda". Escribirá algunas aguafuertes en donde lo demuestra, hecho que lo habilitará para decirle al gramático: "querido Monner Sans: La gramática se parece mucho al boxeo. Yo se lo explicaré:...” (162, destacado nuestro).

La tesis rupturista de Abeille, que parecía definitivamente superada en la época del Centenario, reaparece vigorosa en la década siguiente, sostenida por jóvenes intelectuales pertenecientes a diferentes corrientes (Di Tullio 2009). Entre ellos, Arlt retoma algunas posiciones sostenidas por el profesor francés, sobre todo cuando afirma que el idioma refleja el grado de "evolución" de un pueblo. ${ }^{256}$ Uno de los principios de Abeille señala que en la Argentina tiene lugar el proceso de formación de una nueva raza, lo cual trae aparejado la evolución del español cuyo resultado final es la aparición de un idioma nuevo. Arlt comparte esa idea y señala que si bien hay "pueblos bestias" que no necesitan palabras nuevas para expresarse puesto que carecen de ideas novedosas, "en pueblos como el nuestro, en continua evolución", afirma, "se sacan palabras de todos los ángulos" (1998: 162-163, destacado nuestro). En sintonía con Nicolás Olivari, Arlt tacha de inútil el intento de detener la evolución de la lengua. ${ }^{257}$ Enuncia categóricamente su decisión de escribir "en porteño", apoyado en su propia genealogía y en su capacidad de llegar a un gran número de lectores. Pero esa escritura siempre se realiza sobre un espacio que le es adverso: Arlt manifestará que la crítica oficial no lo reconoce. Por eso, afirma que "un pueblo impone su arte, su industria, su comercio y su idioma por prepotencia" (1998: 163, destacado nuestro). Y utiliza esa prepotencia contra quienes opinan de forma negativa sobre sus textos. Así, por ejemplo, finaliza una conversación que mantiene con Elías Castelnuovo, quien rechaza El juguete rabioso (todavía titulado Vida puerca) por sus "errores de ortografía y redacción":

\footnotetext{
256 Antes que en Abeille, estas ideas ya se encontraban en Sarmiento: “iMire usted, en países como los americanos, sin literatura, sin ciencia, sin arte, sin cultura, aprendiendo recién los rudimentos del saber, y ya con pretensiones de formarse un estilo castizo y correcto, que sólo puede ser la flor de una civilización desarrollada y completa! Y cuando las naciones civilizadas desatan todos los andamios para construir otros nuevos, cuya forma no se rebela aún, nosotros aquí apegándonos a las formas viejas de un idioma exhumado ayer entre los escombros del despotismo político y religioso" (citado en Rosenblat 1984: 276).

${ }^{257}$ Ver el artículo "Madrid, meridiano intelectual Hispano America", en donde Olivari afirma que la evolución de la lengua será tal que hará falta que se traduzcan a los poetas porteños para que los españoles puedan leerlos (1927: 6).
} 
"Está bien -le dice Arlt-. Usted dice que mi novela es mala. Glusberg dice que mi novela es mala. Gleizer dice que mi novela es mala. Pero yo y mi mujer decimos que mi novela es buena. Muy buena. ¡Muy buena! -repitió-. ¡Chau! Y se retiró violentamente” (Castelnuovo 1974: 134).

Arlt opina que, en lo referente a la formación del idioma, la labor de los escritores se encuentra por sobre la de los gramáticos. Para demostrarlo, apela al panteón de autores que, en diversa medida, escribieron una literatura popular, nutrida de lunfardismos y expresiones coloquiales, la cual, según este autor, se constituyó en modeladora de las formas de la lengua: "Last Reason, Félix Lima, Fray Mocho y otros, han influido mucho más sobre nuestro idioma, que todos los macaneos filológicos y gramaticales de un señor Cejador y Frauca, Benot y toda la pandilla polvorienta y malhumorada de ratones de biblioteca..." (1998: 163). En esta cita, podemos ver el modo en que se interceptan las cuestiones vinculadas al idioma con las referidas a la lengua literaria. Y agrega: "este fenómeno nos demuestra hasta la saciedad lo absurdo que es pretender enchalecar en una gramática canónica, las ideas siempre cambiantes y nuevas del pueblo" (163). Palabras que recuerdan a las proferidas por Sarmiento en 1842 cuando tiene lugar la famosa disputa con Andrés Bello. En un artículo publicado por El Mercurio -"Ejercicios populares de lengua castellana"- el sanjuanino afirma:

La soberanía del pueblo tiene todo su valor y predominio en el idioma; los gramáticos son como el senado conservador, creado para resistir los embates populares (...) Son el partido retrógrado, estacionario, de la sociedad habladora (...) Su derecho está reducido a gritar, desternillarse contra la corrupción de los abusos, contra las innovaciones (Donoso 1927:50).

Ideas como la de Sarmiento se encontraban circulando en los ambientes literarios y periodísticos de la época. Cabe recordar que en 1927, Armando Donoso publica un estudio sobre las polémicas en las que se vio envuelto el autor de Facundo, referidas a los problemas de la lengua, junto con un corpus de los textos sarmientinos que alumbraron esos debates. Entre ellos, se cuenta el artículo citado más arriba. Se trata del mismo año en que tiene lugar la polémica en torno al meridiano intelectual de Hispanoamérica, junto con otros debates sobre el tema dados a conocer en la prensa y en diversas publicaciones. Las aguafuertes que tratan el problema del idioma y que reflexionan sobre la lengua literaria se ubican, prácticamente, en el mismo período: entre 1928 y $1930 .{ }^{258}$

\footnotetext{
${ }^{258}$ Por ejemplo, "El origen de algunas palabras de nuestro léxico popular" se publicó el 24 de agosto de 1928. “¿Cómo podemos escribir así?” apareció el 13 de septiembre de 1930.
} 
Cuatro meses antes de la aparición de "El idioma de los argentinos", el 3 de septiembre de 1929, Arlt publicó otra aguafuerte, “¿Cómo quieren que les escriba?”, en la cual se refería a ciertas críticas recibidas por parte de sus lectores en cuanto al lenguaje que utilizaba en estas notas. Allí se defiende diciendo:

Yo las escribo [las aguafuertes] así nomás, es decir, converso así con ustedes, que es la forma más cómoda dirigirse a la gente. $\mathrm{Y}$ tan cómoda que hasta algunos me reprochan, aunque gentilmente, el empleo de ciertas palabras. Uno me escribe: ¿'Por qué usa la palabra 'cuete' que estaría bien colocada si la hubiera puesto un carnicero?' Pero yo tomo el volumen dieciséis de la Enciclopedia Universal Ilustrada y encuentro en la página 1042: "Cuete, m. Americanismo Cohete" (1998: 370, destacado nuestro).

Arlt reivindica la incorporación de la oralidad al discurso escrito periodístico y/o literario, cuando afirma que escribe las notas como si conversara con sus lectores. Pero tal incorporación supone una reelaboración literaria de la oralidad, ${ }^{259}$ distinción no siempre admitida por los escritores que -como en el caso de Arlt- concebían su lengua literaria en gran medida como un reflejo directo de los registros orales. De este modo, se refiere a "nuestro amplio y pintoresco idioma porteño" (68) como el registro privilegiado de su lengua literaria. Por su parte, aunque en otro sentido, Jorge Luis Borges también señala a la oralidad como sustrato principal sus obras. De este modo, en el prólogo a Luna de enfrente (1925), afirma que "muchas composiciones de este libro hay habladas en criollo" (1925a: 4, destacado nuestro). Comparte con Arlt la idea de una literatura "conversada", "hablada", pero las concepciones que cada uno tiene sobre la oralidad resultan diferentes, en la medida en que Borges se apura a agregar que de esa lengua criolla quedan excluidos "el gauchesco" y "el arrabalero". Este último supone el lunfardo, vocabulario de suma importancia en la escritura de Arlt.

En la década del veinte, la oralidad se encuentra en la raíz de la mayoría de los debates que movilizan los problemas de la lengua, y su influencia en el terreno de la literatura es muy profunda. En esta aguafuerte, como hemos visto, Arlt intenta transmitir o representar en su escritura formas de la oralidad, y desde ese lugar oponerse a las críticas que reciben sus textos. Sin embargo, ciertas ambigüedades o contradicciones recorren sus posicionamientos.

\footnotetext{
${ }^{259}$ Existe una diferencia notoria entre el lenguaje literario y el periodístico de Roberto Arlt: en el primero, observamos el registro refinado, la zona del lenguaje elevado (Jitrik 1987), que se entrevera con la lengua oral, la zona "rústica" o "baja". En cambio, en sus aguafuertes, por ejemplo, Arlt parecería ser consciente de que aquello que está escribiendo no pertenece a la esfera de literatura, o que en todo caso es una escritura diferente a la que ensaya en sus cuentos y novelas. Por esta razón, el "estilo literario" no aparece en estos textos. Las notas periodísticas se asientan preferentemente sobre la base de un lenguaje oral y flexible.
} 
De esta manera, cuando en su aguafuerte “Cómo quieren que les escriba?” hace la defensa del uso de la palabra "cuete" (1998: 371), observamos que -dejando de lado la posible intención irónica- recurre a la instancia normalizadora -el diccionario- para legitimar ese uso popular. Si bien este recurso podría pensarse como una estrategia de Arlt para responderle a estos lectores desde los parámetros en que encuadran sus críticas -la asociación del lenguaje literario con el lenguaje "correcto"-, también puede ser observada como una manifestación más de esa ambigüedad que ubica a su escritura en una permanente tensión entre la innovación y la corrección. Tensión que se duplica en el rechazo hacia la cultura oficial, a la vez que aspira a su reconocimiento (Saítta 2008).

Como hemos dicho, los lectores que critican sus notas tienen como modelo el lenguaje "correcto". Así se pone de manifiesto en el siguiente pasaje en el que el autor cita a uno de estos lectores: "por favor, señor Arlt, no rebaje más sus artículos hasta el cieno de la calle..." (1998: 371). La cita de autoridad del diccionario, para decir que la frase "al cuete" puede ser utilizada sin por ello dejar de hablar "en puro castellano" (371) sirve para poner de manifiesto, con cierta ironía, que la lengua popular no siempre supone apartarse de las normas. Las palabras del lector dejan en evidencia dos figuras de escritor contrapuestas a partir del uso de la lengua, porque si afirma que las expresiones que utiliza Arlt están bien usadas por un carnicero y, sugiere, resultan un uso impropio en un escritor-periodista, Arlt afirma:

y yo tengo esta debilidad: la de creer que el idioma de nuestras calles, el idioma que conversamos usted y yo en el café, en la oficina, en nuestro trato íntimo, es el verdadero. ¿Que yo hablando de cosas elevadas no debía emplear estos términos? Si yo no soy ningún académico. Yo soy un hombre de la calle, del barrio... (371).

Podría haber dicho "un escritor de la calle, del barrio", porque tanto su literatura como sus notas periodísticas trazan la geografía y la sociabilidad de los suburbios, puesto que su intención es la de elaborar una literatura alternativa a las propuestas ya existentes, como las de Borges o la de algunos autores de Boedo. Arlt legitima sus usos idiomáticos y, al igual que Olivari, le confiere a los lenguajes "bajos", un status literario sin precedentes: ${ }^{260}$

\footnotetext{
Yo he andado un poco por la calle, por estas calles de Buenos Aires, y las quiero mucho, y le juro que no creo que nadie pueda rebajarse ni rebajar el idioma usando el lenguaje de la calle, sino que me dirijo a los que andan por esas mismas calles y lo hago con agrado, con satisfacción (371).
}

\footnotetext{
${ }^{260}$ Ver el prólogo a El gato escaldado (1929), “Palabras que se lleva el viento”, abordado en el capítulo anterior.
} 
Con estas palabras, Arlt no sólo contribuye a redefinir su figura de escritor, sino también hace explícito el público al que se dirige; y, en función de ello, el lenguaje que utiliza. En este punto, incurre en otra contradicción puesto que, en ocasiones, rechaza ese mismo público que "anda por las calles" por considerarlo "inculto". Esto se debe a que no sólo está atravesado por sus aspiraciones a la alta cultura, como también podemos ver en el caso de Castelnuovo, sino además por los deseos de ser legitimado por la crítica. En el aguafuerte "Por qué dejé de hablar por radio", publicada el 3 de abril de 1932, se queja de que quienes lo escuchan son “incultos”. En marzo de ese año, Radio El Mundo le ofreció un programa semanal, que saldría al aire todos los jueves. Arlt sólo hablará tres veces y expone sus razones en el aguafuerte mencionado. En la nota evoca la conversación que tiene con un amigo cuando el autor le comenta que comenzará con las emisiones:

- Lamento no poder felicitarte... pero hacés una macana.

- ¿Macana?... ¿Por qué?

- La gente que te lee, no escucha a los que dicen algo inteligente u original por radio...

- ¿De dónde sacás esa invención?

- El receptor de radio se ha convertido en un mueble decorativo que, cubierto con un tapiz sirve para sostener un florero, nada más.

- Pero ¿por qué?

- Convencéte, Arlt... Escucha radio únicamente aquella gente que no tiene qué hacer ni a dónde ir; gente que, por lo tanto, posee un mínimo poder adquisitivo... y un mínimo poder adquisitivo significa, a veces, mínimun de cultura. ¿Te interesa ese público a vos?

- No...

- ¿Qué público es el que te interesa?

-El público culto... Aquel que pueda interesarle mis libros...

Según su amigo, a Arlt no sólo no lo escucharían sus lectores de El Mundo, quienes tampoco son "cultos", sino que su programa sería consumido por personas con muy escaso capital simbólico. Comprueba esto luego, cuando comienza a recibir cartas de sus escuchas:

[Las cartas] eran muestrario de la papanatería elevada a la enésima potencia: una me pregunta qué opino yo acerca de la melenita 'ventarrón'; otra que me dice 'qué es lo que piensa acerca de una amistad espiritual' entre un tío que habla por broadcasting y ella que le escribe (...); una tercera, cursi y ramplona hasta decir basta, me habla de las aves canoras... (430). 
En el aguafuerte también queda en claro que no pensaba su literatura para un público "inculto", necesitado de instrucción, como era el caso de Boedo. ${ }^{261}$ Arlt buscaba fervientemente el reconocimiento, no sólo de sus pares contemporáneos, sino también de los sectores dominantes de la cultura. Queda tensionado, entonces, en la imposibilidad de legitimar una escritura "bastarda", reñida no sólo con los textos literarios modélicos, sino también con los posicionamientos lingüísticos que la crítica a la que aspira sustenta. Al respecto, Saítta señala:

su posición en el campo cultural está lejos de ser la de un vanguardista: Arlt desdeña el reconocimiento de los pares - pues no lo considera suficiente-, y busca un reconocimiento que la crítica oficial no está dispuesta a otorgar. ¿Cómo ser rupturista y buscar, al mismo tiempo, el aval de la tradición? Esta paradoja describe, mejor que ninguna, la ubicación siempre incómoda de Roberto Arlt (Saítta 2008: 64).

En el aguafuerte “¿Cómo quieren que les escriba?”, sostiene que el lenguaje alejado de las formas populares "tiene el horrible defecto de no ser natural" (1998: 371). Y por eso mismo, una literatura escrita de acuerdo con esa artificiosidad tiende a ser aburrida y poco expresiva. Los registros populares en la literatura no son un invento de los costumbristas del 900, ni de los saineteros, como así tampoco de algunos de los jóvenes escritores del veinte, parece decir Arlt. Muchos grandes escritores -argumenta- escribieron sus obras en un lenguaje popular: François Villon, Miguel de Cervantes, Jean Richepin, Charles Louis Phillipe. En el periodismo sucede cosa parecida: su director le ha dicho que en EE.UU. las historietas de los periódicos están escritas en "el caló o 'slang' de la ciudad" (372). De este modo, Arlt respalda su lenguaje periodístico y literario no sólo con su propia opinión, sino también con las citadas autoridades.

En este mismo aguafuerte, Arlt critica un artículo de Américo Castro, publicado en El Sol de Madrid, en el que el español se pregunta "a dónde iremos a parar con este castellano alterado por frases que derivan de todos los dialectos" (372) ilustrando estos "males" lingüísticos con el ejemplo de Last Reason. ${ }^{262}$ La réplica de Arlt es sencilla: con este "castellano alterado iremos a parar a la formación de un nuevo idioma, más sonoro y flexible", el cual "sustituirá a un[o] rígido [...] que no corresponde a nuestra psicología"

\footnotetext{
${ }^{261}$ Graciela Montaldo señala que uno de los ejes sobre el que se apoya el grupo de Boedo es la educación del pueblo: los textos literarios, para estos escritores veristas -continúa Montaldo- "tienen un afán didáctico que se realiza a través de las moralejas y la explicación de todo aquello que se quiere decir” (2006b: 330).

${ }^{262}$ Por aquellos años, Last Reason gozaba de mucho prestigio entre los autores de tendencia popular. Así queda demostrado, como hemos visto en el capítulo III, en la encuesta del diario Crítica acerca del idioma propio. Allí, tanto Nin Frías como Félix Lima lo consideran como el punto más alto de la literatura lunfarda; y esa opinión la confirma Arlt cuando sostiene que Last Reason es "lo mejor de nuestros escritores populares" (1998: 373).
} 
(372). Esta respuesta bien podría haberse incluido en la diatriba que dos años antes los martinfierristas y la vanguardia española sostenían en torno al meridiano intelectual. De acuerdo con su contestación, Arlt coincide con las tesis de Abeille: ambos expresan la idea de que el destino lingüístico de Argentina -o al menos de la zona rioplatense- está dado por la emergencia de un idioma nuevo: "lo que es hoy el caló, mañana se convierte en idioma oficializado" (Arlt 1998: 373). Pero también se pueden observar discrepancias con respecto a la postura del profesor francés: ambos encuentran en las influencias extranjeras los materiales centrales del idioma de los argentinos, pero Arlt rechaza las fuentes gauchas/gauchescas que Abeille considera en alto grado. ${ }^{263}$ Por otro lado, la herencia indígena, a la que Abeille dedica numerosas páginas, ${ }^{264}$ no es tenida en cuenta por Arlt.

\section{Lunfardo y comillas: usos y tensiones}

Con respecto a la obra literaria de Roberto Arlt, hay un consenso entre los críticos: se afirma que su escritura se entrama a partir de dos estilos, uno "elevado" y otro "bajo" o popular. Se sabe también que el primero de ellos obedece a una traslación de vocablos y giros tomados de las traducciones españolas de los escritores clásicos que supo leer en las bibliotecas de barrio, como así también en los folletines que solía comprar en las librerías de viejo de Flores. ${ }^{265}$ Pero, fundamentalmente, el estilo "elevado" muchas veces encuentra su fuente en la estética modernista-decadentista, muy apreciable en sus primeras narraciones. ${ }^{266}$

David Viñas advierte en la escritura de Arlt este conglomerado heterogéneo de formas lingüísticas que configuran una de las escrituras más singulares de la literatura argentina. De acuerdo con los aportes de Viñas, se podría pensar que la lengua literaria de este escritor viene a ilustrar su incómoda posición dentro del campo letrado:

El espacio literario inicial permanece abierto: arriba se sitúa la mirada de los humilladores, allí residen los académicos, los que dominan las inflexiones y los adverbios, la literatura oficial, los propietarios de la casticidad y las buenas conciencias; frente a ellos, debajo de su mirada, el escritor humillado, el novelista y el dramaturgo porteño al margen del tú, el "vosotros tenéis" y

\footnotetext{
${ }^{263}$ Abeille detalla, parcialmente, la larga "lista de expresiones figuradas usadas por los gauchos", muchas de las cuales se encuentran presentes en el castellano de principio de siglo XX. (Abeille 2005: 343). Además, repasa una serie de vocablos que constituyen arcaísmos españoles, pero que a partir de determinadas alteraciones en vocales y consonantes cobran vida en la lengua popular. La mayoría de esas voces, Abeille las extrae de "los poetas populares como Ascasubi, Del Campo y Hernández" (380-411).

${ }^{264}$ Abeille demuestra la existencia de un contagio del español con diversas lenguas indígenas, lo que produjo una intensa producción de neologismos (Abeille 2005: 165-189).

${ }^{265}$ Para profundizar en las lecturas de Arlt ver Saítta 2008: 21-23.

${ }^{266}$ Laura Juárez (2004) realiza un análisis de los modos en que las estéticas modernista y decadente se hacen presentes, no sin tensiones y ambigüedades, en los escritos de Arlt que van desde sus inicios, a comienzos de la década del veinte, hasta el año 1932.
} 
el diccionario pugna por salir de su encogimiento hinchándose con un lenguaje seudocastizo (1971: 71).

Así como Arlt aguarda los juicios del circuito "culto" tradicional sobre sus obras, su escritura se pliega a ese deseo y refleja todas las contradicciones inherentes en el plano lingüístico. No obstante, parece tomar partido y "se vuelca asomándose sobre los sumergidos y emplea el lunfardo" (Viñas 71). Pero las contradicciones no se diluyen con esa toma de posición, y su escritura ingresa en el cenagoso terreno de la ambigüedad.

Para Noé Jitrik, resultan evidentes estos "dos bloques muy diferenciados estilísticamente": el lenguaje "bajo" o "rústico" se ubica en "una estructura de intercambio (diálogo)", mientras que "la fase ascética", el "lenguaje "elevado", se corresponde con lo "idealizado" (1987: 80). Lo que diferencia a estas dos formas lingüísticas, entre otras cosas, es el vínculo que establecen con las pautas de corrección prescritas para el "buen escritor". Arlt construye sus textos entre lo aceptable y aquello que no lo es, entre la mímesis de eso que entiende como el lenguaje literario "alto" -el de los libros que lee- y su subversión. Jitrik afirma que la zona de lo idealizado se ajusta a las reglas, a la gramática de la lengua. Como contrapartida, ese "idioma porteño" del que se ufana en sus aguafuertes, "connota el lenguaje de los marginales, de los que aspiran a salir de pobres" (81). Jitrik subsume estas dos superficies textuales al uso de los pronombres, en tanto indica que habría dos zonas correlativas, en una predomina el tú -“es interna, deseo postergado, pura imagen"-, y otra en la que abunda el $\operatorname{vos}^{267}$-“es inmediatez, crudeza, representación” (81)-. La escritura de Arlt estaría determinada por un mecanismo de apropiaciones y ofrecimientos: se apropia de "palabras que, evidentemente, no son de uso corriente en la Argentina de 1925" (98) básicamente, vocablos utilizados en España, muchos de ellos arcaicos- ${ }^{268}$, mientras que, al mismo tiempo, ofrece "términos propios no leídos, atesorados por una experiencia vital: son las palabras del lunfardo, empleadas con toda propiedad y espontaneidad"269 (98).

La lengua literaria de los años veinte se define, entre otras cosas, por la relación problemática que en ella entablan oralidad y escritura, y con las influencias lingüísticas

\footnotetext{
${ }^{267}$ Los escritores del período fluctúan, vacilan y están sometidos a una tensión constante en relación con diversas normas y/o tendencias literarias. La zona del "vos" y del "tú" sintetizas dos tipos de lenguas literarias en disputa, pero también en el entramado de la escritura. El voseo en la literatura argentina de los años veinte se convierte en un tópico de los problemas acerca de la lengua literaria. Arturo Capdevila dedica varias páginas a este tema en su Babel y el castellano, en donde afirma: "los argentinos estamos enfermos de este sucio mal (...) El voseo es la viruela del idioma" (1954: 61 y 64).

${ }^{268}$ Sylvia Saítta retoma algunas ideas vertidas por Beatriz Sarlo y agrega otra apropiación realizada por el discurso literario y/o periodístico del autor de Los siete locos: "Arlt combina el uso de las voces de la calle con la exhibición constante de un saber literario, al que se suma la apropiación de discursos ajenos a la literatura, esos "saberes del pobre" que incorporan el léxico de la química, la geometría, las ciencias ocultas, etc." (2008: 8182). Esto que describe Saítta se presenta de manera muy similar en el caso de Castelnuovo. Ver capítulo II.

${ }^{269}$ En esta misma dimensión ingresan los neologismos, muy utilizados por Arlt.
} 
provenientes de la inmigración. En este sentido, Ricardo Piglia señala como contraste a Leopoldo Lugones, quien se propone con su estilo "borrar cualquier rastro del impacto, o mejor, de la mezcolanza que la inmigración produjo en la lengua nacional" (2001: 125), ${ }^{270}$ lo que también se puede verificar en el martinfierrismo. En cambio, en el discurso crítico incluido en su ficción, Piglia sostiene que, en cambio, Arlt opera en un sentido absolutamente opuesto:

trabaja con los restos, los fragmentos, la mezcla, o sea, trabaja con lo que realmente es una lengua nacional. No entiende el lenguaje como una unidad, como algo coherente y liso, sino como un conglomerado, una marea de jergas y de voces. Para Arlt la lengua nacional es el lugar donde conviven y se enfrentan los distintos lenguajes, con sus registros y sus tonos. Y ése es el material sobre el cual construye su estilo (...) Arlt transforma, no produce. En Arlt no hay copia del habla (...) Arlt entonces trabaja esa lengua atomizada, percibe que la lengua nacional no es unívoca, que son las clases dominantes las que imponen, desde la escuela, un manejo de la lengua como el manejo correcto (125).

La hipótesis de Piglia permite establecer conexiones relevantes entre las lenguas literarias de Arlt y de Castelnuovo. Como señalamos en el capítulo II, el autor de Tinieblas también la concibe como algo heterogéneo, sin unidad y coherencia debido a las diversas fuentes de las que se sirve para elaborarla: términos que provienen del modernismo, palabras que nombran los "saberes del pobre", formas de la oralidad y la escritura castiza. Sin embargo, Castelnuovo, a diferencia de Arlt, no establece una relación beligerante con una lengua "alta" o "correcta"; muy por el contrario, esa es la norma a la que aspira para sus textos y para los que conforman la literatura social de la izquierda.

Por su parte, Noemí Ulla (1990) desbroza aún más el estilo arltiano cuando afirma que en él se pueden encontrar dos formas de escritura combinadas: en primer lugar, una sintaxis coloquial frecuente en los diálogos; en segundo término, una sintaxis narrativa o descriptiva que tiene como modelo los textos escritos o traducidos en España y frecuentados por Arlt como lector. A esto hay que agregar la presencia, en el habla cotidiana de Buenos Aires, de la oralidad inmigratoria española, que ofrecía un repertorio disponible de usos y modismos castizos, junto con los italianos, también presentes. La escritura literaria de Arlt, altamente sensible al contexto de la oralidad contemporánea inmigratorio, fue a la vez, en parte por eso mismo, una escritura original y transgresiva en el contexto literario de esos años.

Los deseos de ser legitimado por lo crítica dominante hace que su escritura asuma un estilo bifronte cuyos elementos opuestos, lejos de convivir pacíficamente, se tensionan y, por

\footnotetext{
${ }^{270}$ Los aportes de Piglia están extraídos de su novela Respiración artificial (1980), y pertenecen a los personajes Marconi y Renzi.
} 
momentos, se contaminan, dando forma a numerosas ambigüedades que no se pueden resolver. Sabemos que la dimensión coloquial de su lenguaje está dada, entre otras formas, por el lunfardo. Al respecto, es posible sostener la siguiente hipótesis: el modo vacilante en que muchas veces opera el entrecomillado resulta un síntoma de los mandatos contrapuestos que tensionan su escritura. La fluctuación de las comillas en los vocablos lunfardos ha generado múltiples interpretaciones, que repasaremos. Al mismo tiempo, y dentro del registro “elevado", en el cual parece haber poco lugar para la invención o creatividad lingüística, por momentos Arlt parece sentirse constreñido en su expresión y recurre al neologismo pretensioso o a palabras poco usuales que aparecen sin entrecomillar, quizás porque piensa, en el caso de los neologismos, que esas palabras existen; o quizás porque utilizando un vocabulario en desuso busca otorgar a su escritura el prestigio del cultismo. Por ejemplo, en Los siete locos leemos palabras tales como "rojidez", la cual no se registra en el diccionario; o vocablos de uso poco frecuente, tales como "azulenca", "carminosa" o "verdinoso" (Arlt 2000: 73).

La utilización de las comillas en Arlt ha originado varias explicaciones, algunas de ellas opuestas entre sí. David Viñas (1971) ha manifestado que el entrecomillado obedece, en principio, a su ambigua posición en el campo letrado. Para el crítico, esta situación particular se manifiesta plenamente en la lengua literaria:

Pero ocurre como al hacer el amor con la Bizca o al sentirse pringosamente querido por el Rengo: el miedo a "la caída", el terror a quedar pegado. Antes el conjuro se lograba con el toque sobre algo duro; era la forma de distanciarse; con las palabras lunfardas el procedimiento es semejante: se escribe chorro y guita, pero entre comillas. Es decir, si me atraen desciendo montando un espectáculo alrededor de mi lenguaje. Pero con cautela, entrecomillándolas y tomándolas con la punta de los dedos, no sea que me quede pegado en ellas y me desmorone en eso que presiento un tembladeral (1971: 71-72).

Se podrían hacer dos consideraciones al respecto: en primer lugar, según Viñas, Arlt incorpora el lenguaje popular pero lo manipula con cierta aprensión y temor. Las comillas vendrían a funcionar como profilaxis o antiséptico de un lenguaje rechazado por las élites y que, evidentemente, lleva implícito el costo de ser cuestionado por ese sector. En segundo lugar, resulta obvio que Arlt "marca" sobre lo que ya se encuentra "marcado". Es decir, duplica la acción, el gesto, que ya la cultura hegemónica ha realizado sobre ese lenguaje. Pone las comillas sobre aquellos elementos marcados por la polémica y que nutre los principales ejes de discusión en torno a la literatura, la identidad nacional y los problemas de la lengua. Si Arlt es quien verdaderamente entrecomilla las palabras lunfardas -porque hay otros críticos 
que, como veremos enseguida, afirman que las comillas no corren por su cuenta- entonces no habría mucha distancia entre él y, por ejemplo, Manuel Gálvez, quien también marca las voces lunfardas de los protagonistas de Historia de arrabal (1922) para diferenciarlas de la voz del narrador; o Ricardo Güiraldes quien encierra entre comillas las voces gauchas de sus reseros en Don Segundo Sombra (1926). De todos modos, el lugar de Arlt en el campo letrado lo ubica en una tensión con respecto a su propia lengua literaria que los otros dos escritores no tienen, porque si Gálvez o Güiraldes entrecomillan voluntariamente, sin vacilaciones ni conflictos, él lo hace de forma despareja, sin un criterio uniforme, "olvidando" a veces las comillas en aquellos lugares donde deberían ir, o colocándolas en el medio de una sintaxis chueca, de una ortografía dudosa o de un neologismo revestido de ultracorrección.

Viñas sintetiza su hipótesis al respecto de las comillas cuando señala que Arlt se encuentra "ambiguamente seducido y frustrado por el lenguaje oficial y sus valores correlativos, a la vez que tentado por el populismo y temeroso de sus consecuencias" (1971: 72); es decir, Viñas cruza la variable social, de clase, con la lengua literaria ${ }^{271}$ al afirmar que el lenguaje de Arlt está determinado por su condición de "escritor de clase media humillado por las academias, el prestigio y el poder" que intenta "hacerse cargo de lo popular para seducir con sus elementos pero temeroso de 'caer' y quedarse adherido en ese nivel" (72). Además, Viñas se cuida bien de separar esta tensión en la que se encuentra Arlt del lenguaje de los autores más representativos de Boedo, quienes no sólo rechazan el lunfardo, sino que además ajustan su escritura a las pautas de corrección que rigen la literatura oficial: "Boedo reitera el asunto de la caída pero ya no es el riesgo ni condena; no hay pegoteo ni comillas y el ‘ascenso' no es seducción ni mística ni escalafón. Por lo menos entre el 20 y el 30” (Viñas 72).

En cuanto al uso de las comillas en términos lunfardos, Viviana Gelado señala dos hipótesis al respecto, incomprobables en cierta medida, puesto que la falta de ediciones críticas a partir de manuscritos impide iluminar los usos del entrecomillado en los textos de Arlt. No obstante, indica que, en primer lugar, el uso de comillas puede estar dado por la intencionalidad de "marcar un distanciamiento irónico" (2007: 302), aunque resulta improbable que este autor se permita la ironía sobre un "idioma" que toma tan en serio. Otra hipótesis, más plausible, es la de pensar que este uso "estuviera supeditado al objetivo de alcanzar un público mayor"272

\footnotetext{
${ }^{271}$ Un profundo análisis sobre la relación entre clase y lengua literaria puede leerse en Piglia (2004). La vinculación entre estas dos variables ya se encuentra aboradada por el propio Arlt en el prólogo a Los lanzallamas.

${ }^{272}$ De acuerdo al contexto, con la expresión "público mayor" Gelado se refiere evidentemente a la intención de Arlt de alcanzar un público masivo.
} 
(302). Hipótesis que resulta casi un apéndice de las ideas esbozadas por Viñas, porque si Arlt, por un lado, funda su contradicción en una textualidad que pretende evitar el rechazo de los conservadores de la cultura, al mismo tiempo que cuestiona su literatura anquilosada, por el otro sabemos que la cantidad de lectores que un escritor puede tener resulta algo fundamental para el autor de Los siete locos. De hecho, y como ya hemos dicho, según las aguafuertes concretamente, "El idioma de los argentinos"- Arlt piensa en los escritores puristas, de estilo esmerado y "correcto", como autores que al colocarse en una perspectiva estético-idiomática lejana al uso popular, carecen de lectores. Arlt se ufana de ser leído por miles de personas desde su página seis en El Mundo, y en ese mismo gesto reivindica el "idioma porteño" en el que escribe. Las comillas pueden ser pensadas como una estrategia para captar público. En El juguete rabioso, Arlt entrecomilla y explica en notas a pié de página el lunfardo y el vésrico. Cabe suponer que esas notas y las comillas están motivadas, en parte, por el hecho de que ese gran público de clase media escolarizado -al menos, con nivel primario- lector de Arlt, fluctuaría, al igual que él, entre la familiaridad que supone el lenguaje coloquial y las formas “adecuadas" para un lenguaje escrito y literario que la escuela prescribía.

Otro sector de la crítica desestimó las hipótesis de Viñas sobre el entrecomillado y propuso que las comillas no corrían por cuenta del autor sino de los editores. Raúl Larra es el primero que escribe un libro dedicado enteramente a su figura. En 1950, publica Roberto Arlt, el torturado, obra que conoce varias reediciones (1956, 1960, 1973, 1986 y 1992), y en cada una de las cuales tiene lugar no sólo correcciones sino también agregados y quitas significativas; tal es así que estas modificaciones redundaron en el aumento de un tercio del texto, respecto de la primera edición (Lafforgue 1998). Entre esos agregados, se cuenta la breve réplica de Larra a las ideas expuestas por Viñas. Según Larra, las comillas deben adjudicarse al editor, afirmación que intenta invalidar de un plumazo las hipótesis de Viñas:

Viñas (...) en su nihilista De Sarmiento a Cortázar le reprocha a Arlt, tan luego a Arlt, que entrecomillara las palabras lunfardas. A Viñas, que le parece revolucionario escribir "peuyó" por "Peugeot", se le escapa que Arlt fue de los primeros en lunfardear en nuestra literatura. Las entrecomillas (sic) corrieron por cuenta del editor o del diario El Mundo, que no admitía que cuando se hablara del furbo o del squenun se tipografiaran como palabras corrientes. ¿Y aún entrecomillándolas, significa desmedro por la palabra lunfarda o por los vocablos populares frecuentemente utilizados por Arlt? (1998: 55).

Larra, además de adelantar una hipótesis dudosa con respecto al entrecomillado, como lo es la expresada en la cita, coloca al autor en una relación con el lunfardo que prescinde del contexto de producción literaria de aquellos años, puesto que comillas, pronombres enclíticos, 
alternancias entre el "tú" y el "vos" resultan muy frecuentes aún en los textos más rupturistas de la época. Es decir, la escritura vacilante y por momentos contradictoria de Arlt no es exclusiva de este autor sino de un momento en que la lengua literaria está siendo replanteada y redefinida. En 1926, cuando edita su primera novela, publican sus obras numerosísimos escritores que conforman una constelación de textualidades diversas y por demás nutridas; ${ }^{273}$ y que, junto con Arlt, incorporan formas escritas derivadas del lenguaje popular y de la oralidad. Por este motivo, Rita Gnutzmann advierte que la diversidad que se manifiesta en los textos publicados hacia mediados de los años veinte "debe inducir al crítico a cierta prudencia antes de ver en Arlt el iniciador exclusivo de la 'modernidad' en la literatura rioplatense" (1996: 127). Pero al margen de esta aclaración, Gnutzmann comparte la hipótesis de Larra con respecto al entrecomillado del lunfardo. Sin embargo, a diferencia de él, esta autora afirma que no fue uno de los primeros en usar este vocabulario en la literatura:

...el lunfardo se usaba ya en textos anteriores, por ejemplo en Cambaceres o en el teatro, preferentemente en los sainetes, pero también en alguna obra teatral de Florencio Sánchez y Armando Discépolo e indiscriminadamente en los artículos costumbristas de Fray Mocho, Last Reason y Félix Lima y en ciertas antologías de poesía lunfarda... (137).

Pero sí señala que con Arlt "por primera vez la jerga tiene cabida en la novela sin ningún prejuicio (si aceptamos que las voces lunfardas entrecomilladas fueron marcadas por sus editores)" (137, destacado nuestro). Sin embargo, resulta del todo inviable el condicionamiento que Gnutzmann pone entre paréntesis. Puede entenderse que haya existido una misma censura ${ }^{274}$-el entrecomillado del vocabulario "bárbaro"- a lo largo de toda su obra. Más aún, esta censura guarda coherencia con las políticas lingüísticas de las editoriales y publicaciones donde Arlt publica muchos de sus textos, que por lo general rechazan el lunfardo: Proa, Claridad, El Mundo, El Hogar. Pero es poco probable que todos los editores,

\footnotetext{
${ }^{273}$ En ese año, publican obra Ricardo Güiraldes, Enrique Larreta, Eduardo Mallea, Horacio Quiroga, Álvaro Yunque, Elías Castelnuovo, Jorge Luis Borges, Raúl González Tuñon, Nicolás Olivari, Enrique González Tuñón, Armando Discépolo, entre otros.

${ }^{274}$ Utilizamos esta palabra en el mismo sentido que le da Arlt en su aguafuerte "La censura", publicado en el diario El Mundo, el 23 de julio de 1930. En este texo, Arlt se refiere a la censura en tanto modificación y recortes que sufren sus artículos a manos del director del diario El Mundo, Carlos Muzio Sáenz Peña. En la nota, relata la manera en que somete a juicio sus textos, como si se tratase de una humillante escena extraída de Los siete locos: "[Muzio] lee despacio, poniendo los puntos y las comas que yo me he olvidado, las ' $h$ ' que me traspapelado, las 'c' y las 's' transpuestas del más fantástico modo." Luego del examen, el director le dice: "¿es posible que todavía no hayas podido aprender que 'haber' se escribe con 'h'? Vos sos la falta de ortografía en persona."( 1930: 6). En el marco de los problemas en torno a la lengua literaria, resulta muy significativo que Arlt tematice estos asuntos vinculados con su escritura. El autor de Los siete locos se muestra en clara oposición a la corriente normalizadora del lenguaje, aunque por momentos se adapte a ella. Sin embargo, lo que no deja de hacer es mostrar el conflicto, tematizar su "mala" escritura y sus desencuentros con los "guardianes" del "buen" decir. Esta parece ser una estrategia -de la que también se vale Olivari- cuyos objetivos consisten en autoafirmarse en un estilo propio y opuesto a las estéticas vigentes, y también en construir una imagen de autor basada, merced a ese lenguaje "plebeyo", en la idea del artista nuevo, original y transgresor.
} 
esos mismos a quienes Larra y Gnutzmann responsabilizan de las comillas, hayan usado un criterio de entrecomillado tan arbitrario, dejando algunos lunfardismos marcados, mientras que otros (incluso las mismas palabras dentro de los mismos textos) hayan quedado sin marcar. Por ejemplo, en el aguafuerte "El 'furbo", Arlt emplea alternativamente la palabra "furbo" con y sin comillas, sin ningún tipo de criterio que permita evidenciar dos o más usos diferentes de la misma palabra:

En resumen, el 'furbo' es el hombre que quebranta todas las leyes, sin peligro de que éstas se vuelvan contra él, el furbo es el jovial vividor que después de habernos metido en un lío, saqueado las escarcelas, os da unos palmetazos amistosos en la espalda y os invita a comer un 'risotto', todo entre carcajadas bonachonas y falsas promesas de amistad ${ }^{275}$ (1998: 65).

En Los siete locos podemos apreciar que algunas palabras lunfardas aparecen entrecomilladas, mientras que otras no. Este fenómeno, incluso, se produce dentro de un mismo capítulo. Así, por ejemplo, en el capítulo I, en el apartado "Las opiniones del Rufián Melancólico”, Arlt escribe: "la mantenida desprecia a la mujer de cabaret, la mujer de cabaret desprecia a la yiranta, la yiranta desprecia a la mujer de prostíbulo..." (2000: 46). Más abajo se lee: "si un sábado a la mañana oyera usted a una mujer decirle a su 'marlu', 'Mon cheri, hice cincuenta latas más que la semana pasada" (46). Luego: "la mayoría de ellos habían vivido como grandes bacanes y sabían qué animalito es" (47); y por último: "por aquí caminarás, frente a esta esquina no debes pasar, a tal 'fioca' no hay que saludarlo" (47). "Yiranta", "marlu", "bacanes" y "fioca" son por igual palabras pertenecientes al lunfardo. Sin embargo, no todas aparecen entrecomilladas. Evidentemente, esta irregularidad no puede ser achacada a un editor en misión de marcar lunfardismos. Estas inconsistencias, que se extienden en el tiempo y en las distintas obras, deberían adjudicarse más probablemente al propio autor.

Como hemos indicado, Jitrik sostiene que en El juguete rabioso existe un "mecanismo de apropiaciones y préstamos" que se puede observar con mayor detalle en el terreno del vocabulario (1987: 98). Del lado de las apropiaciones, encontramos aquellas provenientes de las lecturas de diversos autores europeos, realizadas sobre la base de traducciones españolas. Jitrik ofrece ejemplos: “zarandaja”, “yacija”, “mercar”, “cofrades”, “doncellas”, “gentecilla”, “quisquillosidad”, “donaire”, “churrigueresca”, “regañones”, “bigardón”, etc. (98). Según el autor, estas apropiaciones se complementan con

\footnotetext{
${ }^{275}$ Nótese que el entrecomillado de los lunfardismos convive con el de las palabras extranjeras. En el caso de la cita, "risotto". De todos modos, debido a la anomia en la que se encuentra el procedimiento del entrecomillado, resulta aventurado formular afirmaciones en torno a si Arlt utiliza con un mismo criterio o sentido las comillas en las palabras lunfardas y extranjeras. No obstante ello, las comillas parecen estar puestas siempre en función de vocablos o expresiones ajenas al discurso literario tradicional.
} 
un movimiento inverso de ofrecimiento de palabras, de términos propios no leídos, atesorados por una experiencia vital: son las palabras del lunfardo que empleadas con toda propiedad y espontaneidad, son como presentadas al público mediante entrecomillados: 'cana', 'te la voglio dire', 'bondi', 'reló', ‘jetra', ‘yuta', ‘cachan', ‘laburado', ‘minga', etc. (98).

Y agrega que estos lunfardismos, en virtud de las comillas, actúan como "cartelitos anunciadores, convirtiendo el texto en una plaza pública en la cual hay un activo intercambio verbal, por un lado se pide y por el otro se ofrece" (98). Pese a que Jitrik entiende el entrecomillado como una operación llevada a cabo por el propio Arlt, y no por los editores o correctores, el crítico prefiere distanciarse de las hipótesis de Viñas al señalar que podemos entender el ofrecimiento de palabras

no tanto como una ambigua y avergonzada declaración de propiedad lingüística sino como una significación bifurcada: en un sentido, revela la acción del 'intercambio' en la producción del texto; en el otro, asume dos fuentes culturales cuyo resumen es el texto y trata de situarse en la problemática de las relaciones entre la escritura (de donde se toma el préstamo) y la voz (en donde se experimenta el lunfardo) en busca de una síntesis entre lo universal (la escritura) y lo nacional (la voz) de nuestra cultura (98, destacado nuestro).

Para Jitrik, las comillas no representan un "distanciamiento avergonzado" o un "tomar con la punta de los dedos" esas palabras, como sostiene Viñas, sino más bien todo lo contrario: configuran un destacado, un ofrecimiento de esas palabras que no pertenecen a la literatura (legitimada). Más allá de la validez o no de la hipótesis, las comillas siguen poseyendo una misma función: la de marcar una otredad, una extranjería lingüística, un escritura "bárbara" con la cual Arlt entabla tensiones que no resuelve. Jitrik observa este fenómeno como una síntesis cultural que se plasma en su primera novela. El ofrecimiento, es decir el "idioma porteño", puede ser pensado como una nueva textualidad propuesta al conjunto de la literatura; lo que significa, también, la postulación del lunfardo como parte integrante -y preponderante- de un asediado idioma nacional.

Se puede estar de acuerdo con Jitrik en cuanto a que es Arlt quien entrecomilla las palabras lunfardas; pero lo que el crítico no puede explicar con su hipótesis -y que en cierta medida la pone en cuestión- es la irregularidad con que aparece ese ofrecimiento, es decir el entrecomillado. ¿Acaso Arlt prefiere algunos lunfardismos en detrimento de otros, y es por eso que el ofrecimiento resulta parcial o incompleto? Su escritura es, en sí misma, una 
escritura vacilante, como si hubiese prescindido de las instancias de revisión y corrección: ${ }^{276}$ como hemos dicho, se confunde el voseo con el tuteo; muchos signos de interrogación o exclamación se abren pero no se cierran, o a la inversa; abundan errores ortográficos y erratas -todo lo cual relativiza aún más las posibles intervenciones de los editores-. Pero a esto se le suman las ambigüedades que se observan en el lenguaje literario de Arlt, producto de la confluencia en su escritura de estilos opuestos; escritura que al mismo tiempo se orienta a la cultura "alta" y a la cultura popular, como destinatarias simultáneas de sus textos, ${ }^{277}$ lo que podría explicar el uso tan errático de las comillas. En este mismo sentido se ubica el aporte de Walter Berg quien sostiene:

Si bien Arlt, hace un constante uso de terminología lunfarda en sus aguafuertes, el entrecomillado señala cierta imposibilidad de asimilar del todo ese vocabulario al texto literario y periodístico. Hay una ambigüedad e inconsistencia en el uso de estas palabras a partir de un entrecomillado que es fluctuante puesto que, si bien la mayoría de las veces señala una distancia con respecto a las palabras de procedencia bastarda, las comillas no siempre aparecen (1999: 84).

Otra hipótesis similar a la de Jitrik es la que plantea Ricardo Piglia, quien afirma que en la escritura arltiana existe una "apropiación degradada de las palabras lunfardas". Estos vocablos, al ingresar en la literatura -es decir, en un espacio adonde, en cierta medida, resultan ajenos-, deben ser señalados (2004: 69). Las comillas vienen a cumplir con esa función. De acuerdo con Piglia, Arlt actúa como un "traductor" de una lengua menor, ${ }^{278}$ y eso se puede apreciar en las notas al pie que pone en la primera edición de El juguete rabioso, las cuales explican y definen los términos lunfardos. Del mismo modo que para Jitrik este vocabulario resulta el único patrimonio lingüístico que Arlt está en condiciones de ofrecer a la literatura y a sus lectores $-\mathrm{y}$, en este marco, las comillas cumplen con el objetivo de ostentar ese ofrecimiento-, Piglia dice algo parecido cuando afirma que el lunfardo "es el único lenguaje cuya propiedad Arlt puede acreditar" (69). Al igual que la hipótesis de Jitrik, la de Piglia tampoco puede explicar el complejo procedimiento de entrecomillado de los textos de este autor. Las comillas estarían dando cuenta de que, al momento de escribir, Arlt

\footnotetext{
${ }^{276}$ La textualidad de Arlt pertenece también a esa "escritura del descuido" de la que hablábamos en el capítulo anterior, en referencia a Nicolás Olivari.

277 Así como David Viñas (1971) o Sylvia Saítta (2008) ubican a Arlt en una posición ambigua o problemática en el campo letrado de los años veinte, Berg repite la idea: "Roberto Arlt, al dominar perfectamente todos los matices del lunfardo, no dejaba de sentir envidia por la cultura 'aristocrática' de sus colegas mejor ubicados en la jerarquía social” (1999: 113). Esta tensión también se pone de manifiesto en un escritor como Elías Castelnuovo. Al respecto, ver el capítulo II.

${ }^{278}$ Seguimos la idea de lengua menor de Deleuze y Guattari (1975), para quienes no significa una lengua hablada por pocos sino una operación desterritorializante de la lengua dominante.
} 
se sitúa desde parámetros propios de la cultura conservadora, la cual sustenta la corrección lingüística como una de las marcas definidoras y legitimadoras del discurso literario. Las irregularidades en el marcado del lunfardo encontrarían una vía de explicación si tomamos en consideración que los valores de esta cultura constituyen un espacio rechazado por el autor. Pero también es un espacio marcado por la contradicción en tanto que si por momentos asume sus valores, también procura subvertirlos. Su problema radica en cómo lograr la legitimación de su escritura sin renunciar a su lenguaje vivencial. En cierto modo, se sirve de las estrategias utilizadas por los escritores "cultos" que introducen en sus textos diversas voces populares. Pero en Arlt los procedimientos de inclusión de estos registros son inconstantes, parciales y descuidados lo cual permite diferenciar sus textos literarios de los de aquellos autores.

Como hemos dicho, el ingreso del coloquialismo urbano rioplatense en el discurso literario no es privativo de Arlt -aunque sea él uno de los autores más emblemáticos al respecto- sino que se da también en otros escritores del período, como por ejemplo en Enrique González Tuñón. Si por un lado los personajes de Tuñón intentan reproducir el habla de los suburbios, por el otro, el narrador se distancia de ese lenguaje y se reserva para sí el uso de metáforas o el tuteo. Las vacilaciones textuales -manifestadas, entre otros aspectos, en el entrecomillado- no sólo tienen que ver con la relación que su escritura establece con las instituciones literarias y con el público, sino también con las condiciones en que se produce el discurso literario de la época. La ruptura con las textualidades modélicas no se realiza de modo coordinado y acabado, sino a merced de tensiones y ambigüedades que van definiendo la aparición de nuevas formas dentro del discurso literario. El entrecomillado ${ }_{-} \mathrm{O}$ su equivalente, la bastardilla-, destinado al señalamiento del lenguaje popular, no es privativo de Arlt y no responde únicamente a las explicaciones de Viñas o Jitrik, sino a los condicionamientos que ejercen límites y presiones sobre su escritura. Sin embargo, las operaciones lingüísticas que lleva a cabo el autor -entre las que naturalmente se cuenta la particular forma de realizar el entrecomillado- hacen que su caso resulte singular. Cuando entrecomilla el lunfardo somete a su propia lengua, a su lenguaje vivencial, y lo "normaliza" según las reglas conservadoras. Las comillas son la manifestación ortográfica de un deseo de legitimación legible en la escritura.

Si tomamos en cuenta la mayoría de las críticas que abordan la obra de Arlt, se puede apreciar un consenso en juzgarlo como un escritor carenciado, pobre, sin un pasado prestigioso, sin cultura, sin un dominio y autoridad sobre la lengua, acuciado por el trabajo 
periodístico. ${ }^{279}$ Piglia marca este rasgo cuando afirma que "habría [en Arlt] una carencia 'natural', irremediable: una fatalidad. ${ }^{280}$ Para Arlt esta carencia es económica, de clase: en esta sociedad, la cultura es una economía, por de pronto se trata de tener una cultura, es decir, poder pagar" (2004: 59). Pero rápidamente, Piglia advierte que eso que fue visto, hasta no hace mucho tiempo atrás, como una carencia, es en realidad intención: "ahora bien, ¿y si esto que sirve para desacreditarlo fuera justamente lo que él no quiso dejar de exhibir? Quiero decir, ¿y si el mérito de Arlt hubiera sido mostrar lo que no hay, hacer notar la deuda que se contrae al practicar -sin títulos- la literatura?" (59). Con estas palabras, Piglia encuentra los elementos necesarios para definir la noción de intención en Arlt, aunque en su artículo no se detenga particularmente en este aspecto. No obstante, se podría completar la idea si se señala que Arlt no escribe "mal" como una forma alternativa al escribir "bien". Es decir, debido a las efectivas carencias en su formación, no puede optar en el terreno del lenguaje o, en todo caso, sus opciones son muy limitadas. ${ }^{281}$ Pero lo que sí puede hacer es promover deliberadamente un estilo "descuidado", no poniendo su centro de atención en las instancias de corrección ni en la búsqueda de la expresión "perfecta". Es una escritura apresurada destinada a mostrar la proletarización del escritor -quien produce su literatura en los ratos libres que le permite su oficio de periodista-, las desigualdades generadas en el seno del campo literario, las limitaciones en torno a la noción de literatura que encuentra en aquellas escrituras legitimadas y, sobre todo, los posicionamientos con respecto al idioma en el marco de los debates sobre la lengua.

Para muchos escritores y estudiosos de principios de siglo XX, el lunfardo no forma parte del llamado idioma nacional porque, justamente, lleva en sí el origen "espurio" del extranjero y de lo delincuencial, planos que muchas veces se superponen. Arlt es consciente

\footnotetext{
${ }^{279}$ En el prólogo a El escritor en el bosque de ladrillos, Sylvia Saítta afirma que los críticos literarios han colaborado con la mitificación de la figura de Arlt, repitiendo datos falsos y reproduciendo la imagen del escritor torturado e incomprendido que el propio Arlt forjó en sus textos (2008: 9-13).

${ }^{280}$ No obstante su excelente estudio Habla y literatura en Argentina (1974), Rodolfo Borello explica el estilo de Arlt a partir de sus "fallas culturales" e "incapacidades": "Roberto Arlt mostró una extraña incapacidad para captar las diferencias de niveles y tonos entre el lenguaje escrito-literario, el habla coloquial y los términos que había aprendido en las traducciones españolas de obras extranjeras. Aquí es donde se delatan las fallas culturales de un escritor nato que, a pesar de tales caídas, elaboró una obra que todavía sigue interesándonos" (1974: 54, destacado nuestro).

${ }^{281}$ Piglia explica las operaciones sobre el lenguaje que realiza Arlt, en relación con la cuestión del idioma: "el estilo de Lugones [está] dedicado a borrar cualquier rastro del impacto, o mejor, de la mezcolanza que la inmigración produjo en la lengua nacional. Arlt trabaja en un sentido absolutamente opuesto (...) trabaja con los restos, los fragmentos, la mezcla, o sea, trabaja con lo que realmente es una lengua nacional. No entiende el lenguaje como una unidad, como algo coherente y liso, sino como un conglomerado, una marea de jergas y de voces. Para Arlt la lengua nacional es el lugar donde conviven y se enfrentan los distintos lenguajes, con sus registros y sus tonos. Y ése es el material sobre el cual construye su estilo (...) Arlt transforma, no produce. En Arlt no hay copia del habla (...) Arlt entonces trabaja esa lengua atomizada, percibe que la lengua nacional no es unívoca, que son las clases dominantes las que imponen, desde la escuela, un manejo de la lengua como el manejo correcto (2001: 125).
} 
de ello, y si la mayoría de las veces se reserva las comillas para este vocabulario, en otras oportunidades las aplica a palabras provenientes de otras lenguas. Aunque, en este caso, la operación también es fluctuante. En otras ocasiones, emplea las comillas en el lenguaje de la clase media. En una de las notas de la edición crítica de Los siete locos y Los lanzallamas, a cargo de Mario Goloboff, Ana María Zubieta señala: "las comillas ponen distancia entre el lenguaje del narrador y el de otros grupos sociales. Se utilizan tanto para el lunfardo como para las palabras propias del mundo pequeño burgués; pero su uso es irregular y fluctuante" (Arlt 2000: 54). El pasaje que motiva la nota es el siguiente: “usted me dirá cómo siendo pobres alquilábamos una casa, pero éste era un antojo de mi esposa, que recordando tiempos mejores no se avenía a no 'tener armado' su hogar” (54). Otros casos se repiten a lo largo del texto, como por ejemplo: "Sí... ella, en cambio, cree en la felicidad, en el sentido de 'eterna felicidad' que estaría en su vida si pudiera pasar los días entre fiestas..." (56-57). Pero estos casos son muy aislados.

En síntesis, la creación de una lengua literaria “popular”, en el caso de Arlt, presenta problemas, tensiones y ambigüedades, muchas veces derivados de los contradictorios vínculos que establece con los diversos sectores del campo literario. Si, por un lado, tiende a la construcción de un lenguaje literario autónomo a partir de la transgresión de las normas que rigen la literatura más tradicional, del corte de amarras con la gramática y con la concepción de la literatura como espacio de una escritura prolija y cuidada; por el otro, modera estas rupturas, y se sirve del lenguaje y de las reglas que le proporciona la literatura ya legitimada en el campo literario.

\section{Lunfardo y corrección en un pasaje de El juguete rabioso}

Como se sabe, a lo largo de su carrera, Arlt realizó numerosas colaboraciones en distintos diarios -El Mundo, Crítica, La Nación- como así también en varias revistas: Don Goyo, El Hogar, Claridad, Babel, entre otras. En los meses de marzo y mayo de 1925, publicó dos adelantos de El juguete rabioso -novela todavía llamada Vida puerca ${ }^{282}$ - en la revista Proa, dirigida por Ricardo Güiraldes. Uno de ellos llevaba como título "El Rengo", y formaría parte del capítulo cuarto, "Judas Iscariote", cuando la novela sea publicada al año siguiente por la editorial Latina. A los efectos de analizar el lenguaje arltiano, este relato cobra mucha importancia puesto que existen diferencias sustanciales entre la versión aparecida en Proa y la que finalmente integró la novela. Esas diferencias -correcciones, enmiendas, agregados y supresiones- se distribuyen en varios niveles, dentro de los cuales se

\footnotetext{
${ }^{282} \mathrm{Si}$ bien suele aparecer este primer nombre como La vida puerca, en los capítulos publicados en Proa se lee: “Capítulo de la novela 'Vida puerca' que aparecerá próximamente." (Arlt 1925: 28).
} 
reserva uno al entrecomillado de las palabras lunfardas. Viviana Gelado (2007) advierte que el texto publicado en Proa representa un buen ejemplo de la "escritura heterogénea" de Arlt: además del lunfardo, abundan las reproducciones fonéticas como así también el uso del voseo. Y aclara que ninguna de estas formas aparecen con comillas, sino que lo harán recién en las ediciones en libro. Gelado hace mención a estas diferencias, pero no las analiza detenidamente. De la confrontación entre el texto aparecido en Proa y la versión que finalmente se edita en el cuerpo de la novela, concluimos: mientras que en "El Rengo" ningún lunfardismo aparece entrecomillado, en "Judas Iscariote" las comillas marcan sólo algunos vocablos lunfardos, muchos continúan sin diferenciación, siguiendo los parámetros de la irregularidad propia de los textos de Arlt en este aspecto. En la novela, ${ }^{283}$ cabe destacar que salvo un caso, del que nos ocuparemos luego- ningún vocablo lunfardo desaparece. Las modificaciones, en este terreno, consisten en el entrecomillado de sólo algunos de ellos: "milonguero", "shofica", "gill", "grelunes", “retobabas", “fajaban", “cachó”, "cacharon”, "biaba", "manyá" son las palabras que sufren la marca de las comillas; pero junto a ellas, aparecen otras que no tienen ninguna modificación: "garrón”, “amuré”, "rajando", "mango", "bagayito", “matingo", “junado", "brodo", "bulín”, "afile”, “matungo", "lungo", "cana”, "requechar", "otario". No es cierto que -como dice Gelado- todas las expresiones en lunfardo de "El Rengo" pasen a tener comillas en la novela, como si se tratase de una modificación mecánica. La operación de entrecomillado se realiza con las fluctuaciones y vacilaciones que se pueden apreciar en otros textos de Arlt. De hecho, la palabra "manyar", en la novela al igual que en "El Rengo", aparece dos veces, sólo que en la edición del libro puede leerse con comillas en una sola oportunidad.

No se conoce muy bien la forma en que Arlt se relaciona con Ricardo Güiraldes y termina siendo su secretario, pero sí se sabe el importante rol que juega el autor de Don Segundo Sombra no sólo en la publicación de su primera novela, sino también en la corrección de sus textos. Sylvia Saítta piensa que Güiraldes ejerce sobre Arlt una suerte de "protección familiar":

Güiraldes ocupa alternativamente el lugar de padre o hermano mayor, y nunca el de un igual. Porque Güiraldes asume el rol de padre cuando resuelve, en alguna medida, la economía maltrecha del hijo convirtiéndolo en su secretario; cuando lee paternalmente los borradores de la novela que Arlt lleva consigo a todas partes, y también cuando corrige con paciencia su sintaxis enrevesada y un léxico exuberante (2008: 43, destacado mío).

\footnotetext{
${ }^{283}$ Seguimos la edición a cargo de Ricardo Piglia (Arlt, 1993), que respeta el original de 1926.
} 
De acuerdo con estos datos, no parece descabellada la idea de que las comillas en el lunfardo corran por cuenta de Güiraldes, más aún si tomamos en consideración que, a su vez, se encarga también de entrecomillar el lenguaje gauchesco que él mismo utiliza en Don Segundo Sombra. Sin embargo, como ya hemos visto, no existen comillas en el relato de Arlt publicado por Güiraldes en Proa. Es decir, no se explica muy bien el hecho de que -si tenemos en cuenta que, como demuestra Saítta, la mano de Güiraldes estuvo muy presente en El juguete rabioso- Güiraldes haya marcado el lunfardo en los borradores de la novela y no lo haya hecho en "El Rengo", texto que lo involucraba de manera mucho más directa que la novela puesto que se publica en la revista de la cual él era director. Siempre en el terreno de las hipótesis, se podría decir que las correcciones de Güiraldes no se encuentran todavía muy presentes en ese texto puesto que, en Proa, aún se menciona la novela en preparación como "Vida puerca", y no con el nombre que finalmente sugirió Güiraldes. No obstante, el cambio de título, probablemente, forme parte de los últimos ajustes de los borradores, más aún si tenemos en cuenta que entre la publicación de "El Rengo" y la presentación de El juguete rabioso en el concurso organizado por la editorial Latina -que finalmente premiará y publicará la novela- median, por lo menos, siete meses. Sostenemos, entonces, la hipótesis de que las correcciones de Güiraldes no se ocuparon de marcar el lunfardo ni de depurar el texto de su coloquialismo urbano, sino que su tarea estuvo centrada en los aspectos ortográficos y sintácticos del borrador, además de la realización de diversas sugerencias, como el título de la novela. ${ }^{284}$

El entrecomillado de algunos vocablos lunfardos no es la única diferencia entre "El Rengo" y el texto incluido en la novela. Cuando se cotejan ambas versiones se pone en evidencia la aplicada operación de corrección a la que estuvo sujeto el relato. Se contaron ciento cincuenta y cuatro correcciones de diversa índole, pero que se podrían catalogar, en su mayoría, como correcciones de estilo. No hay grandes modificaciones, y las enmiendas sólo responden al objetivo de corregir su prosa descuidada. Sabemos que Ricardo Güiraldes, posiblemente, haya sido el responsable principal de estos cambios. No obstante, las correcciones no son todas del mismo tipo y suponen la presencia de otra mano, tal vez la del propio autor. Veamos un poco la naturaleza de los cambios que sufre el relato, según el análisis que hemos realizado: como hemos dicho, la mayoría de las correcciones

\footnotetext{
${ }^{284}$ Si bien Güiraldes, por un lado, asumirá una posición lingüística muy diferente a la de Arlt -El juguete rabioso y Don Segundo Sombra, como se sabe, se publican en el mismo año, 1926-, por el otro, cuando lee a los escritores que incluyen en sus textos el lenguaje popular rioplatense, no alza su voz en franca oposición, como cabría esperar de un autor que escribe con un estilo cuidado y "correcto" y que se separa, gracias a las comillas, de las formas populares, sino que les brinda un gran apoyo. Así lo hizo con Arlt, pero también es el caso de la positiva recepción que hizo en Martín Fierro de La musa de la mala pata, de Nicolás Olivari (Güiraldes 1926); o de la carta privada que le envía a Enrique González Tuñón (Güiraldes 1962b: 785-786) brindando su "voto a favor" de Tangos. Ambas obras se editan en 1926 y comparten la fuerte presencia del lunfardo.
} 
corresponden a cuestiones de estilo, y se pueden agrupar de la siguiente manera: ${ }^{285}$ en primer lugar, un grupo importante de rectificaciones radica en el uso de los verbos: "más allá las mondongueras raían (raen) los amarillentos mondongos en el estaño de sus mostradores(,) o colgaban (cuelgan) de los ganchos inmensos hígados rojos" (Arlt 1925: 28). O bien: "pedazos de hielo encubiertos (cubiertos) de aserrín rojo se derretían (derriten) a la sombra lentamente encima del lomo de los pescados encajonados" (29). En segundo lugar, otras correcciones tienden a reacomodar o mejorar las frases a partir de elisiones y sustituciones: "(terminadas sus historias) antes de que fuera la hora reglamentaria para deshacerse la feria, el Rengo me invitaba:..." (33); "a veces, cuando terminaba (terminado) mi recorrido, y (si) quedaba en (mi) camino, iba a echar un parrafito con el cuidador de carros..." (28). En tercer lugar, otro conjunto de correcciones consisten en el agregado de signos de exclamación, de interrogación y guiones: “- (i) pero date cuenta (!)... Una tarde veo que sale. (¿)Adónde vas(?,-) le digo." (35). En cuarto lugar, se observa un meticuloso trabajo sobre los signos de puntuación: se agregan comas, punto y comas, se juntan y separan párrafos a través del punto seguido y punto aparte. Otro conjunto de cambios -bastante menos numerosos que los anteriores- consiste en la morigeración de cierto lenguaje, es decir en el reemplazo de determinados vocablos o expresiones que podían resultar un tanto rudos o vulgares: "se adornaba el cogote (cuello) que dejaba libre su elástico negro...” (30); “... de pronto se iba(,) guiñando (de paso y) al soslayo un ojo a los peones (de) carniceros, que con los dedos de las manos le hacían el obsceno gesto de la fornicación (obscenos gestos)" (29). En este mismo grupo se pueden ubicar aquellos cambios que intentan moderar las reproducciones fonéticas de la oralidad, muy marcadas en "El Rengo". De este modo, leemos en ese texto la palabra "bení" en lugar de "vení". Se descarta la errata porque aparece en cuatro oportunidades. Gelado piensa estos casos -y otros: "Pibeee", "Pejerreeyes frescos"- como un intento de reproducción fonética, que vendría a dar forma, junto con el uso del voseo, a la oralidad predominante en el relato (2007: 297). Pero en las páginas de El juguete rabioso, de los cuatro "bení" sólo sobrevive uno -en los otros tres casos se cambia la "b" por "v"- que, a diferencia de lo que sucede en "El Rengo", queda encerrado entre comillas.

Si estas correcciones estuvieron a cargo de Güiraldes, queda en claro que su lectura del texto se mantuvo al margen de cuestiones referidas al lunfardo. Como ya hemos dicho, ningún lunfardismo -fuera de un caso particular- fue eliminado, sino al contrario, existen pasajes que señalan la sustitución de una frase o palabra por algún término lunfardo, fenómeno que pone en duda la presencia de un solo corrector del texto. ¿Quién puede sumar

\footnotetext{
${ }^{285}$ Citamos el relato publicado en Proa. Entre paréntesis colocamos los cambios introducidos en la novela, y marcamos con cursiva la palabra o frase removida.
} 
más lunfardos al texto sino el propio Arlt?: “ ¿no es cierto, che, Rubio, que tengo trazas de apache (pinta de 'chorro')"; "me compré una damajuana, porque plata que no se gasta se va al monte ("escolaza")" (Arlt 1925: 34). Pero estas no son las únicas marcas de otro posible corrector, que sería el propio autor. Existen otro tipo de modificaciones que difieren del criterio predominante en los más de ciento cincuenta cambios. Por ejemplo, si, como ya indicamos, se observa una voluntad de suavizar el lenguaje del relato a partir del reemplazo de frases o palabras rudas o vulgares, evidentemente la siguiente enmienda corre por cuenta de otro corrector, o bien forma parte de otro criterio de corrección: “- (i) che, hijos de una gran señora (puta) qué hacen ahí (?) (32). La coexistencia de un corrector, o de un criterio de corrección, más ligado a un registro culto y correcto con otro -en menor grado- que continúa fomentando el lenguaje popular queda evidenciada en el siguiente pasaje, en el que el agregado de la "d" final a "majestá" contrasta fuertemente con el agregado de una frase lunfarda: “... le juego una redoblona a Su Majestá (Majestad), Vasquito y la Adorada... y todo al muere (Su Majestad me mandó al brodo)...” (31). Estos casos chocan con la única eliminación de un término lunfardo: “... la miseria y toda la experiencia de la atorrantería (vagancia) habían lapidado arrugas indelebles" (34). Si el o los corrector/es culto/s ${ }^{286}$ no sustituye o elide ningún caso de lunfardismo, y la otra mano -si la hubiera- lejos de quitar, agrega nuevos términos del caló porteño, ¿cómo se explica esta modificación? Posiblemente, el corrector cambia "atorrantería" por "vagancia", pero no porque rechazara las formas lunfardas en sí mismas, sino porque Arlt elabora un neologismo sobre la base de la palabra lunfarda "atorrante", cuestión que quizás no convenció mucho al corrector. También pudo haber sucedido que eliminara la palabra "atorrantería" porque a continuación aparece otra palabra con "rr" (arrugas), lo cual podría haber resultado cacofónico.

En conclusión, sabemos que "El Rengo" fue sometido a un fino proceso de corrección, a cargo -según señalan varios críticos- de Ricardo Güiraldes. Sabemos también que los cambios, en su mayoría, se centraron en el arreglo del estilo y en la puntuación. En cuanto al lunfardo, las únicas modificaciones se centran en el entrecomillado de algunos -y no todosvocablos; lo que indica con alto grado de probabilidad que Güiraldes, corrector implacable y puntilloso, fue del todo ajeno a ese procedimiento irregular y vacilante. De acuerdo a la naturaleza de las enmiendas, se puede deducir que muy probablemente un mínimo de esos cambios estuvo a cargo de un corrector (o criterio) diferente, tal vez el propio autor.

El contraste entre el título original y el que lleva la novela habla a las claras de los criterios utilizados por Güiraldes al momento de corregir los borradores. Si el nombre Vida

\footnotetext{
${ }^{286}$ El corrector "culto" bien podría ser también el propio Arlt, puesto que es probable que ambos criterios contrastantes de corrección coexistan en él.
} 
puerca muestra "con mayor precisión el lugar de enunciación desde el cual Arlt pensaba al escribir" (Saítta 2008: 43), además de definir una estética y una lengua literaria particulares, el título El juguete rabioso "señala desde afuera el lugar que a esta literatura le asigna" Güiraldes, detalle que no pasa inadvertido para un indignado Elías Castelnuovo que lo acusa de ser "quien se encargó de proceder a su profilaxis con tal rigor que hasta le cambió un título claro y contundente, de proyección social, por otro bastante turbio, carente por completo de claridad y de contundencia" (1974: 134). Si bien Castelnuovo y Güiraldes se ubican en sectores diferentes -y casi opuestos- en el campo letrado y en los modos de concebir la estética literaria, en lo que respecta a los criterios de lectura y revisión del texto arltiano encuentran algunas coincidencias. La principal: pensar el texto de Arlt como una forma inacabada que debía ser sometida a un proceso de corrección. Los fundamentos del rechazo de Castelnuovo para publicar la novela en la colección Los Nuevos de Claridad son los mismos de los que se sirve Güiraldes para revisar los borradores y realizarle diversas modificaciones, algunas muy radicales como es el cambio de título. El mismo Castelnuovo da cuenta de esto:

le dije [a Arlt] que así como estaba la obra no se podía publicar. Que la tenía que arreglar. Se la llevó entonces a Ricardo Güiraldes, y él se encargó de efectuar la limpieza que necesitaba. Le cambió hasta el título dado que inicialmente se llamaba De la vida puerca y más tarde se llamó El juguete rabioso" (Zas 1968: 23-24, destacado nuestro).

Chispazos de las disputas sobre la lengua literaria se ponen de manifiesto en estas declaraciones de Castelnuovo; mientras tanto Arlt, con su texto, queda en el medio de una confrontación - la vanguardia estética y la izquierda - que en cierta medida lo excede debido a su particular ubicación con respecto a estas dos zonas. Remarcamos, entonces, las coincidencias en relación con la corrección que se presentan en dos escritores que conciben de manera muy diferente la lengua literaria. Esto pone en evidencia que cierta idea modélica de la escritura literaria atraviesa, y condiciona, a los diferentes sectores del campo literario, incluso aquellos que presentan diferencias estéticas irreconciliables. No obstante, cruces como estos, sumados a la permeabilidad de Arlt con respecto a las lecturas que Güiraldes hace de sus textos; las gestiones que éste realiza para publicar la novela, concomitantes con el rechazo de Castelnuovo de editarla; los adelantos publicados en Proa; la dedicatoria a Güiraldes y la presencia de Arlt en las páginas de Crítica Magazine lo ubican en un espacio cercano al de la vanguardia estética (Saítta 2008). De hecho, la revista Claridad no hace sino nombrarlo en el bando de sus enemigos, los escritores de Florida, muchos de ellos colaboradores de Crítica: Rega Molina, Tuñón, Olivari, Fijmann, y obviamente Arlt, todos son mencionados como 
parte integrante de un conjunto del que la izquierda literaria procura diferenciarse (“Aclaración editorial y política...” 1927: 1).

Como hemos dicho al principio de este apartado, en el mes de mayo de 1925, Arlt publicó nuevamente en Proa: "El poeta parroquial", otro adelanto de su próxima novela, Vida puerca, sólo que en este caso el capítulo no formará parte de la primera edición de El juguete rabioso, debido a "las continuas correcciones a que es sometido el manuscrito" (Larra 1998: 51). Este texto resulta interesante para señalar el uso irregular del lunfardo puesto que, a diferencia de la mayoría de sus textos, no registra ninguna palabra proveniente de este vocabulario. A su vez, el lenguaje popular, lejos de la presencia que tiene en "El rengo", parece estar controlado. "El poeta parroquial" refiere el encuentro del narrador y su amigo Juan con el poeta Alejandro Villac. ${ }^{287}$

Cabría preguntarse por qué en la edición del texto en forma de libro aparecen comillas que no estaban en "El rengo". Puede encontrarse una explicación probable si consideramos los cambios que supone este cambio de formato: la ampliación de público, el posible incremento de las lecturas críticas, y no hay que olvidar que El juguete rabioso logra su publicación merced a los juicios del tribunal del "Concurso literario de prosa y verso para escritores inéditos sudamericanos", organizado por la editorial Latina. Estas nuevas mediaciones y condiciones de recepción y circulación del texto hizo, tal vez, que Arlt se haya visto en la necesidad de separarse de un lenguaje que bien podía llegar a impedirle el reconocimiento que tanto ansiaba.

\section{La recepción crítica contemporánea}

En los años veinte, la crítica literaria no fue indiferente a la obra de Roberto Arlt, contrariamente a lo que él mismo se encargó de manifestar una y otra vez. Durante estos años, tuvo una fuerte visibilidad en diarios y revistas, ya sea gracias a sus notas en El Mundo y a los relatos que publica, como a las reseñas y comentarios de sus novelas provenientes desde diversos sectores del campo literario. La queja en Arlt responde más a "la construcción de su figura pública como la de un escritor siempre postergado" (Saítta 2008: 11) que a un dato real. El temprano reconocimiento de sus pares altera y desmitifica una imagen de autor que la crítica posterior se encargó de repetir y consolidar. Por ejemplo, cuando se edita El juguete rabioso, su recepción estuvo marcada por numerosos elogios provenientes de la fracción de escritores más jóvenes. Las revistas y los suplementos culturales donde escribían estos autores

\footnotetext{
${ }^{287}$ Este nombre ficcional se corresponde con el de Félix B. Visillac, "el poeta del barrio" de Flores, quien organizaba tertulias literarias en el diario barrial La Idea, a las que concurría Arlt (Saítta 1998: 23).
} 
dieron cuenta de la irrupción de una narrativa nueva. En un movimiento típico de esos años, los pares avalaban una literatura anómala en el sistema literario existente, sin el consentimiento de los mayores (Saítta). No resulta extraño, entonces, que la primera reseña dedicada a El juguete rabioso haya provenido del suplemento literario del diario Crítica, en el que colaboran, principalmente, escritores pertenecientes al grupo de Florida. ${ }^{288}$ El comentario, sin firma, publicado en un diario como el de Botana, vigorosamente instaldado en el mercado cultural, inscribe la novela de Arlt en el circuito comercial. ${ }^{289}$

El artículo sostiene que la obra "ha revelado un novelista vigoroso, de una sola pieza" ("Una semana de vida literaria..." 1926: 14). También hace referencia a que la obra "fue rechazada por las editoriales Babel y Claridad, cuyo asesor literario, el señor Castelnuovo asesoró a Arlt, coincidiendo con el de Babel, que se dedicara a la venta de legumbres" (14). $\mathrm{Si}$, por un lado, la reseña pretende reivindicar una obra literaria que se presenta como novedosa, por el otro se propone denunciar los avatares por los que Arlt tuvo que pasar para poder publicar el texto. En este sentido, la crítica hacia el sector de la izquierda literaria, el cual no supo apreciar las virtudes del nuevo escritor y su obra, se inserta en la polémica mayor que enfrenta a escritores de izquierda y martinfierristas y que, ya por ese entonces, se duplica en las discusiones que mantienen Claridad y el diario de Botana. ${ }^{290}$ El denuesto al grupo de izquierda es explícito: "toda la literatura de Boedo no cabe en tres páginas de las ciento sesenta de El juguete rabioso" (14). Esta primera reseña puede pensarse como un primer intento, por parte de la vanguardia concentrada en Crítica, pero también por parte del mercado, de apropiarse de Arlt, y sobre todo de evitar que su textualidad, por sus temas y estilo más cercanos a Boedo, quedara emparentada con el grupo liderado por Castelnuovo.

A continuación se dará cuenta de los distintos comentarios que suscitó la obra de Arlt en diferentes publicaciones. Como sucede con autores como Nicolás Olivari, la mención al particular uso del lenguaje resulta una referencia obligada, hecho que demuestra la activa intervención de su obra en los irritados terrenos del problema de la lengua literaria.

\subsection{La izquierda literaria y Roberto Arlt: entre el rechazo y la aceptación}

La relación de Roberto Arlt con la editorial Claridad estuvo atravesada por los extremos del rechazo y la aceptación. Entre mediados de la década del veinte y los primeros

\footnotetext{
${ }^{288}$ La sección de Crítica Magazine en donde sale publicada la reseña -“Actualidad del mundo literario"- se encuentra en manos de un sector de la vanguardia martinfierrista, y se encarga de difundir, principalmente, textos literarios de vanguardia (Saítta 2008: 59).

${ }^{289}$ Ver capítulo III.

${ }^{290}$ Ver capítulo III
} 
años del treinta, realizó colaboraciones esporádicas. Claridad realizó una recepción despareja de su obra, dando lugar a la coexistencia de detractores y promotores de sus textos. La forma en que fue tratado durante estos años por esta revista revela la multiplicidad de perspectivas que convivían en el seno de la izquierda literaria. El año 1925 marca el inicio de la ambivalencia con que fue juzgado Arlt porque si, por un lado, Elías Castelnuovo le negó la posibilidad de editar su primera novela -todavía llamada Vida puerca- en la colección Los Nuevos, de la cual era director, arguyendo deficiencias en el estilo y en el lenguaje; por el otro, hacia fines de ese año, Los Pensadores publicó un cuento suyo, "La Tía Pepa". Hay que señalar, no obstante, que pese al rechazo de El juguete rabioso, Claridad reseñó la obra rápidamente. De esta manera, en noviembre de 1926, en la sección "Notas bibliográficas", apareció un comentario muy breve y anónimo sobre la obra de Arlt. En primer lugar, el autor del artículo señala que la novela "ha recibido la aprobación de Julio Noé y Enrique Méndez Calzada" (“El juguete rabioso..." 1926: 31); dos nombres que, con autoridad desigual, avalan la novela de Arlt y justifican la inclusión de la reseña. El sucinto artículo no ejerce una mirada crítica sobre la obra; sólo se limita a la síntesis rápida: "se trata de la vida de los muchachos del suburbio, de sus pillerías y aventuras" (31). No obstante, se detiene en el título de la novela, al que se refiere en estos términos: "es un tanto caprichoso y modernista y no condice con el espíritu del libro". Para la vanguardia de izquierda, el término "modernista" es un calificativo despreciativo que remite a aquello que obtura el sentido de las palabras en lugar de volverlo claro.

Naturalmente que el comentario no va dirigido contra Arlt exclusivamente, sino también contra Ricardo Güiraldes quien, como hemos dicho, entre las numerosas correcciones que le hace a la novela, sugiere su título. Claridad impugna la influencia del autor de Don Segundo Sombra sobre El juguete rabioso por considerarla como una forma de desviación de los propósitos estéticos de Arlt. ${ }^{291}$ Años después, cuando la editorial de Zamora se reconcilia con el autor y reedita su primera novela, desaparecerá la dedicatoria de la primera edición con la que Arlt agradecía a Güiraldes.

Luego se abre una suerte de meseta de cuatro años en los que el autor no volvió a publicar en ningún número de Los Pensadores / Claridad, y durante los cuales "mira con igual distancia la existencia de los dos grupos [Boedo y Florida] y no se reconoce en ninguno" (Saítta 2008: 62). Sin embargo, en 1929 rompió el silencio y se autoincluyó -explícita y extemporáneamente- en el grupo de Boedo, cuando en una entrevista realizada por $L a$ Literatura Argentina declaró: "en el grupo llamado de Boedo encontramos a Castelnuovo, Mariani, Eandi, yo y Barletta" ("Roberto Arlt sostiene...” 1929: 26). En esta misma

\footnotetext{
${ }^{291}$ Ver Castelnuovo (1974: 134).
} 
entrevista, Arlt se refirió a algunas de las revistas literarias más importantes del período Nosotros, Síntesis y Criterio- y señaló que no las había leído nunca. Sin embargo, con respecto a Claridad, dijo que "aunque está mal escrita, peor compuesta y sin un método inteligente, tiene un público obrero y desempeña una útil misión social.” (26, destacado nuestro). La referencia a la "mala escritura" de Claridad pone de manifiesto las tensiones que atraviesan el lenguaje literario de Arlt, puesto que si bien manifiesta afinidad con una literatura "popular", transgresora y sin demasiados miramientos de las normas, los comentarios vertidos acerca de la revista de Boedo guardan muchas similitudes con aquellas críticas que recibe su obra por parte de los sectores (lingüísticamente) más conservadores. Pero también, y por tratarse justamente de la editorial de Zamora, Arlt, en un acto vengativo, repite los mismos juicios de que fue víctima en 1925, y que le valieron el rechazo de su primera novela. Se podría pensar que, en esta entrevista, asume los valores estéticos y lingüísticos de la crítica dominante, de la cual aguarda su reconocimiento. Señalar la "mala escritura" del órgano principal de los escritores de izquierda resulta una estrategia de diferenciación y autoafirmación equivalente a la utilización de las comillas en el lunfardo de sus textos, es decir un evitar "caer y quedarse adherido", como dice Viñas, a una lengua, pero sobre todo a una fracción del campo literario de escasa legitimación.

Durante el año 1929 se reanudaron las relaciones entre Arlt y Claridad a partir de la publicación de un adelanto de Los siete locos: "Naufrágio (sic). Un cuento de locos". Hacia enero de 1930, la figura negativa de Arlt parece revertirse gracias a un artículo que publica Ramón Doll en el que lo rescata como "novelista de gran valor". En un repaso por la obras editadas en 1929, Doll destaca muy enfáticamente Los siete locos y señala que la obra “constituye la mejor novela que se ha escrito en este país en los últimos años" (1930: 27). El lenguaje pasa a constituir el elemento principal de diferenciación porque Doll marca como virtud la escritura arltiana que prescinde de lo que "sus compañeros de generación" referencia evidente a Florida- entendieron como "buena" escritura. En lo que Castelnuovo observó como un lenguaje que “ofrecía innumerables fallas de diversa índole” (Zas 1968: 23), Doll encuentra la principal virtud de Arlt.

Otra manifestación del cambio de actitud en algunos representantes de la izquierda literaria para con el autor de El juguete rabioso es la antología que Guillermo Miranda Klix publicó en 1929, Cuentistas argentinos de hoy. Muestra de narradores jóvenes (1921-1928). La recopilación se abre con "El humillado", el mismo fragmento de Los siete locos que Barletta adaptará en 1932 para el Teatro del Pueblo. La inclusión del texto de Arlt y la jerarquía que le otorga el hecho de que sea este relato el que abre el libro habla a las claras del nuevo posicionamiento del autor frente a los escritores de izquierda. Se debe tener en cuenta 
que la antología es publicada por la editorial de Zamora y que además Miranda Klix es un asiduo colaborador de Claridad.

Sin embargo, la figura de Arlt dentro de Claridad continúa siendo ambigua e imprecisa puesto que, pocos meses después de que Doll defendiera fervorosamente al autor de Los siete locos, el propio Antonio Zamora publica un comentario, en mayo de 1930, sobre los premios literarios otorgados en 1929 y señala a Arlt como uno de los tantos ganadores que no se merecían el galardón: “una vez más los premios municipales a la producción literaria han sido adjudicados a autores de obras de poco valor y de escaso interés social" (1930: 1). A este artículo, debemos sumar otro -"El fallo de un jurado"-, sin firma, aparecido un mes después, donde se retoma el tema de los premios literarios municipales de 1929. Las críticas principales caen sobre Arlt y Olivari. La nota afirma que los premios dedicados a la prosa constituyen una "barrabasada [que] colmó el límite". En referencia a Los siete locos, se afirma que es "una novela de segundo orden (...) en la que se resumen todos los vicios de un temperamento desordenado, oscuro y desorientado" ("El fallo de un jurado" 1930: 4-5).

Entre 1930 y 1932 tuvo lugar, tal vez, el período de mayor intensidad en la relación entre Claridad y Arlt. No tanto por sus colaboraciones, que se reducen a apenas una más -“El bloque de oro", un adelanto de Los lanzallamas, publicado en enero de 1931-, sino por la edición y reedición de sus obras llevadas a cabo por la editorial de Zamora. ${ }^{292}$ Durante 1931, Claridad también le realizó un homenaje cuando publicó en la portada del número 238 su fotografía, acompañada del siguiente texto: "autor de Los siete locos y Los lanzallamas con cuyas obras ha alcanzado el primer puesto entre los novelistas de la nueva generación”. Ese mismo año marca el regreso a la revista de otra figura conflictiva para el núcleo de los escritores de izquierda: Nicolás Olivari. No obstante, su desvinculación de este grupo no supuso la ruptura total con sus miembros; tal es así que, en 1925, Olivari ofició de puente entre Arlt y Castelnuovo: "mientras estuve a cargo de esa colección (Los Nuevos) -sostiene el autor de Tinieblas-, no esperaba que los escritores nóveles vinieran a buscarme. Los iba a buscar yo. Así sucedió con Roberto Arlt mediante invitación cursada a través de Nicolás Olivari que lo conocía" (Zas 1968: 23). Esa relación tal vez explique por qué Olivari publica una encendida y afectuosa reseña sobre Los lanzallamas en noviembre de 1931. El comentario del poeta se configura, más que como un elogio, como una defensa en función de los ataques sufridos por Arlt a lo largo de estos primeros años como escritor. Olivari da cuenta del desacomodo que constituye Arlt en el panorama de las letras argentinas: "tu gran

\footnotetext{
${ }^{292}$ En 1930, la Editorial Claridad publica la segunda edición de Los siete locos, y la tercera tendrá lugar en 1931. En ese año se reedita también El juguete rabioso. Estas reediciones estarían dando cuenta de una revalorización de Arlt y de una "ostensible mea culpa" (Saítta 2008: 61) por parte de esta publicación de Boedo.
} 
crimen es haber escrito eso [Los lanzallamas] aquí. Tu lugar no es América. No serás nunca juzgado como debes. No te darán ni siquiera el $1^{\circ}$ municipal (sic) y no recomendarán tu libro como el mejor del mes" (1931: 46). En cierta medida, se podría pensar que cuando Olivari habla de Arlt no hace otra cosa que hablar de sí mismo porque si algo comparten ambos autores es la posición marginal en el campo literario; pero, sobre todo, comparten la voluntad de ocupar un sitio a fuerza de poner en entredicho las estéticas y los lenguajes que determinaban la legitimidad de los textos literarios. Incluso, una misma figura de autor parece ponerse en funcionamiento: la del escritor incomprendido que pese a su talento, pasa inadvertido: "es trágico tu destino. Porque teniendo tu talento bestial, seguís caminando por la calle como un vulgar transeúnte" (Olivari 46). ${ }^{293}$ El parentesco entre Arlt y Olivari no nace de la exposición de estas hipótesis, sino que es el propio autor de La musa de la mala pata quien establece la relación: "pero vos, como yo, con mis poemas retorcidos y rabiosos, te agarrás a la misma complacencia de lo dicho. Es nuestra satisfacción vengativa" (47, destacado nuestro). En este pasaje, se ponen de manifiesto tres elementos centrales que les son afines: en primer lugar, la idea de un lenguaje literario que no obedece a los modelos de la literatura tradicional, y que Olivari denomina "retorcido" y "rabioso". Ese lenguaje, en segundo lugar, es producto de una decisión relativamente consciente que la convierte en intención, de ahí los señalamientos de Olivari acerca de que la puesta en práctica de esa lengua produce una "satisfacción" que podría interpretarse como artística. Y, por último, el calificativo de esa satisfacción - "vengativa”- reenvía no sólo a la idea de intención, sino a la voluntad de cobrar algunas cuentas pendientes con los sectores más institucionalizados del campo literario, que no se mostraron dispuestos a reconocerlos como escritores nuevos, relegándolos al subestimado reducto de la "mala" escritura o literatura "barata".

Finalmente, en 1932 Arlt se alejó de Antonio Zamora por motivos políticos y económicos, pero también personales. Había descubierto nuevos mundos, entre ellos el teatro, al cual estará entrañablemente unido hasta el fin de sus días (Ferreira de Cassone 2002).

\subsection{Otras recepciones}

En 1926, Leónidas Barletta publicó, en la revista Nosotros, una reseña sobre El juguete rabioso. Este artículo puede ponerse con ese grupo de comentarios sobre Arlt que elabora una crítica altamente positiva al mismo tiempo que desliza observaciones en torno al

\footnotetext{
${ }^{293}$ Al respecto, Viviana Gelado sostiene: "invadiendo un espacio que les estaba vedado por el origen y por la clase, Arlt y Olivari tomarán efectivamente el verbo por asalto y expondrán la corrosión del modernismo hispanoamericano instituido en la tradición 'artística' local por la política lugoniana. La nueva musa, hambrienta, enferma y gangosa, introduce una estética de la fealdad (Olivari) y de la crueldad (Arlt) que se adecua mejor a las expectativas y fracasos de estos 'advenedizos' en el campo literario y social”' (Gelado, 2007: 312).
} 
particular uso del lenguaje. Desde el comienzo, Barletta deja en claro que El juguete rabioso "es una buena novela" y que su autor, merced a "un seguro instinto", es guiado "por el intrincado campo" de este género literario (1926: 553). Por estas razones -continúa Barlettaesta obra resulta "espontánea y extraordinariamente interesante. Ardiente en la pintura, discreta en la medida, aunque no siempre sobria en la expresión (553, destacado nuestro).

Sabemos que, en su mayoría, los escritores de izquierda rechazan el uso del lunfardo. Eso puede leerse también en la reseña de Barletta, aún cuando el autor reseñado sea uno de los principales exponentes de la década en el uso de este vocabulario. No obstante, Barletta recortará una figura positiva de Arlt, pese a la utilización de un lenguaje que sólo en él parece resultar apropiado:

El caló que pone en boca de sus personajes no es postizo como lo es en casi todos los intentos de novela de suburbio que hasta aquí se han hecho. El autor maneja con propiedad estas expresiones y siempre que ellas completen el retrato de un personaje. Por manera que este peligroso escollo de la novela donde se han estrellado novelistas de la fama de Gálvez, Arlt lo ha salvado felizmente (1926: 553).

Si bien Barletta justifica la utilización del lunfardo en la novela de Arlt, se apresura a dejar en claro que su uso no tuvo resultados felices en la literatura argentina. La referencia negativa hacia una "novela del suburbio" responde no sólo con una reafirmación de los temas y propósitos del boedismo, sino también al rechazo explícito de aquellos autores que toman el arrabal como tópico principal de alguna de sus obras, sobre todo si esos autores se ubican en un lugar central del campo literario, como es el caso de Manuel Gálvez.

La reseña pone de manifiesto que en el seno de la izquierda literaria existen diversas perspectivas sobre el idioma y su relación con la literatura: si, por un lado, Castelnuovo, tan sólo unos pocos meses antes de la fecha en que aparece la reseña de Barletta, rechaza $E l$ juguete rabioso para su publicación a raíz de sus deficiencias de lenguaje, por el otro, el autor de Royal circo -como hemos visto- leerá la novela desde una perspectiva muy diferente a la de su compañero de grupo.

Carlos Pirán escribió para Mundo Argentino, en diciembre de 1926, una reseña sobre El juguete rabioso. Allí sostuvo que "sin ningún reparo" se puede comparar a Arlt "con un gran novelista argentino que desapareció prematuramente (...) Me refiero a Juan Palazzo"294

\footnotetext{
${ }^{294}$ La analogía entre Palazzo y Arlt no es gratuita: se sabe que Palazzo fue para los escritores de izquierda una influencia muy importante; muerto prematuramente antes de que se conforme la vanguardia social, fue autor de La casa por dentro (1921), novela donde se relatan las miserias de la vida en los inquilinatos. A su vez, Elías Castelnuovo deja constancia de esta influencia en el cuento "Lázaro", de Malditos (1924), cuyo protagonista guarda marcadas reminiscencias con el escritor muerto.
} 
(1926: 24). Al ponerlo en relación con un escritor como Palazzo, Pirán no hace otra cosa que vincular al autor de El juguete rabioso con la estética boedista, o al menos con uno de sus pilares fundacionales. Según Pirán, la mayor coincidencia entre estos dos escritores se produce a nivel del lenguaje:

Su autor [Arlt], y esto es en lo que más se asemeja a Juan Palazzo, afanado en expresar las imágenes que acuden a su cerebro, se despreocupa sensiblemente del lenguaje. De ahí que sea éste algunas veces desaliñado y aparezca ocasionalmente reñido con la sintaxis. Pero ya sabemos que cuando un hombre tiene algo que decir -y es este el caso con el señor Arlt- elige la manera más clara y más fácil. Y es esto el libro que tratamos de comentar: fácil de leer y claro de comprender (1926: 24).

Pirán adjudica al estilo de Arlt un linaje, rastrea y encuentra en el pasado inmediato un escritor que, como él, "descuida" la lengua literaria en beneficio de una literatura centrada en el contenido y en las rudimentarias destrezas lectoras del público al que, supuestamente, iban dirigidas estas obras. Vale decir que Pirán no sólo disculpa el lenguaje de Arlt y lo ubica en una breve pero fuerte "tradición", sino que además hace coincidir esas “deficiencias" literarias con la función pedagógica que Boedo asigna a la literatura: Pirán no sanciona su lenguaje de forma vehemente porque se corresponde con la claridad y la facilidad para comprender el mensaje literario, principio fundamental de la izquierda literaria. También destaca que las narraciones están escritas en un "idioma casi vernáculo" - como ya hemos dicho, el propio Arlt hablará de "idioma porteño" para referirse a su lenguaje- y corren el peligro de caer "en la jugosa y áspera crónica policial o pintoresca con que aún los grandes rotativos suelen diariamente entretener y ruborizar a sus lectores" (24).

En febrero de 1930, Luis Emilio Soto publicó en el diario La Prensa un comentario sobre Arlt, en ocasión de la reciente publicación de Los siete locos, en el que se refiere a la lengua literaria:

$\mathrm{Su}$ expresión tiene un ritmo lento, su lenguaje es bastante preciso, aunque sin elegancia literaria: lo característico de su escritura es el desaire; su idioma es una mezcla de palabras castellanas y vocablos del caló orillero o lunfardo o modismos populares (1930: 33).

La concepción de Soto en torno a la escritura literaria -evidente en estos comentarios- se basa en los presupuestos que hacen de lo "correcto" y "elegante" condiciones sine qua non para su definición. Naturalmente, los textos de Arlt no pueden pasar por el tamiz con que los cierne Soto. De hecho, la escritura arltiana resulta tan peculiar a sus ojos que la particulariza como 
un “idioma” privativo del autor. No obstante, más allá de estas críticas, Soto agrega: “a pesar de todo, obtiene el Sr. Arlt una pintura eficaz de los medios que evoca, de perdularios y gente de bajo fondo con características locales..." (33). En cierta medida, es como si encontrara en sus personajes la justificación de la utilización de ese lenguaje "poco literario" con el que, evidentemente, no está de acuerdo.

El caso de Antonio Vallejo - colaborador de Martín Fierro- resulta mucho más radical, y representa la visión cabal que los escritores más conservadores tienen de la obra de Arlt. Vallejo afirma que "de conocer el idioma en que escribe, podría llegar a conquistar nombre y fortuna escribiendo novelas de aventuras: ésa es su verdadera vocación" (Arlt 2000: 733). Otro comentario que señala los ripios gramaticales de la escritura de Arlt, al mismo tiempo que enfatiza sus virtudes, es el realizado por Alberto Hidalgo en La Literatura Argentina, ${ }^{295}$ en noviembre de 1929. Para Hidalgo, este escritor "es un caso único" puesto que pese a que "no conoce la gramática elemental (...) tiene imaginación y un léxico exuberante que hacen de Los siete locos una obra poderosamente sugestiva" (“Alberto Hidalgo..." 1929: 73). No obstante, a la inversa de la postura de Soto, Hidalgo afirma que Arlt habría ganado mucho más "publicándola con todos los errores de ortografía, según se lo aconsejé cierta vez" (73). A diferencia de otros comentaristas, Hidalgo observa en esa escritura "anómala" una gran virtud, hasta el punto de ver en las correcciones a las que fue sometido el texto un desmedro de su calidad. La condición de Hidalgo de escritor "moderno" y vanguardista explica estos comentarios a favor de una lengua literaria autónoma.

Pocos son quienes han visto en el lenguaje de Arlt una virtud en sí misma. Alberto Hidalgo es uno de ellos. ${ }^{296}$ Se puede sumar a la breve lista una reseña, publicada en noviembre de 1929 en La Literatura Argentina. Allí se saluda la aparición del "extraordinario libro" de Arlt, y se agrega:

en Los siete locos la impetuosidad, la indisciplina lexicográfica y sintáctica del desorden de todo un caudal de elementos, dicen paladinamente de un instinto formidable, de un genio

\footnotetext{
${ }^{295}$ Alberto Hidalgo (1897-1967) fue un escritor peruano de vanguardia, inventor del simplismo. En la década del veinte se instala en Buenos Aires, adonde entabla relaciones con los martinfierristas. Francisco Luis Bernárdez refiere su llegada al país: "Hidalgo llegó a Buenos Aires entre estas dos fechas: la construcción del pasaje Barolo y la inauguración de los semáforos luminosos en nuestras bocacalles. Ahora, completamente asimilado a nuestras cosas, ha montado una honrada industria espiritual (Lafleur et al. 2006). Bernárdez se refiere a la creación de la Revista Oral, creada en 1926 y de la cual Hidalgo fue su director. En ella participaron numerosos martinfierristas, tales como Macedonio Fernández, Emilio Petorutti, Norah Lange, Brandán Caraffa, Eduardo González Lanuza, Leopoldo Marechal, Jorge Luis Borges, Raúl Scalabrini Ortiz, entre otros. Su ubicación netamente vanguardista explica mejor la opinión vertida sobra la escritura de Arlt: Hidalgo poee una concepción moderna de la lengua literaria, autónoma de la gramática y de cualquier otro factor de sujeción o condicionamiento estético-lingüístico.

${ }^{296}$ Ya hemos mencionado los casos de Ramón Doll (1930) y Nicolás Olivari (1931).
} 
innato, salvaje, que no ha sabido sentarse en la escuela. Un genio sin acomodadores (" $\operatorname{Los} 7$ $\operatorname{locos} . . . " 1929: 88)$.

De todas maneras, aún cuando la intención sea manifestar adhesión, el lenguaje de Arlt queda encerrado en los dominios del error, la "barbarie" o la falta de instrucción. Este tipo de comentarios recuerdan las palabras de Muzio Sáenz Peña quien festejaba su "gran talento" mientras tachaba y corregía muchas de sus aguafuertes. "Impulsividad", "indisciplina", "desorden”, "instinto", "salvaje” forman parte del campo semántico que define la escritura de este autor y que la pone en violenta relación con la literatura tradicional. ${ }^{297}$

Como hemos visto en el capítulo cuarto, en relación con la figura de Nicolás Olivari, Roberto Arlt construye una imagen de autor vinculada al fracaso y a las carencias en su formación como escritor y lector. En la literatura argentina, estas privaciones se convierten en nuevas coordenadas para la definición del valor y de la autonomía del artista. Mediante la construcción de una lengua literaria "incorrecta", "desprolija" y al margen de las normas que rigen la literatura dominante, logra definir su figura de escritor "maldito", pero también “popular" y muy “moderno".

Hemos dedicado una parte importante de este capítulo a analizar el procedimiento de entrecomillado de los textos de este autor. En este sentido, hemos presentado algunas hipótesis explicativas acerca de las razones y los posibles agentes responsables de llevar a cabo esa tarea. Más allá de su difícil corroboración, dado que los manuscritos de esos textos de Arlt no se encuentran disponibles, las vacilaciones y las posibles intervenciones en sus textos constituyen uno de los mejores ejemplos para poder observar las tensiones y reconfiguraciones a las que la lengua literaria ha estado sometida hacia mediados de los años veinte.

También nos hemos ocupado de señalar el vínculo entre los postulados de Lucien Abeille y los de Arlt a propósito del idioma, coincidentes en lo que respecta a su necesaria evolución: como afirmaba Abeille a propósito del español hablado en el país, la lengua literaria de Arlt -aquello que él llamaba "idioma porteño"- es el correlato de una evolución particular y local del castellano en Argentina.

En líneas generales, la crítica literaria le fue favorable. Más allá de algunos pocos artículos, los comentarios y reseñas siempre destacan la presencia de un escritor novedoso,

\footnotetext{
${ }^{297}$ Como ya hemos comentado en el caso de Olivari, ser "salvaje", "bárbaro" o "primitivo" en los años veinte formaba parte de una fuerte condensación con lo moderno (Garramuño 2007: 100).
} 
potente y cargado de creatividad. No obstante $-\mathrm{y}$ como ya lo hemos puesto de manifiesto en el caso de Olivari-, aún en aquellos textos que se extienden en largos elogios, los señalamientos en torno al uso "incorrecto" y transgresor del lenguaje literario se convierten en una constante que determina no sólo uno de los lugares comunes acerca de la imagen de Arlt como escritor -la "mala escritura"-, sino también las ambigüedades que deparan las nuevas textualidades en un contexto de emergente modernización y cambio cultural generalizado. El tópico de la "mala escritura", además de servir para la construcción de una figura de autor moderno, no formado por instituciones escolares o academias literarias, un escritor que privilegia las ideas por sobre el lenguaje, configura la pieza clave para poder entender el proceso de autonomización literaria que, al igual que Arlt, otros jóvenes escritores buscan llevar adelante. Esa imagen se fue cimentando no sólo gracias a las propias declaraciones del autor, sino también a los discursos críticos y a los comentarios y testimonios de sus pares. En este sentido, ya hemos mencionado, al comienzo de este capítulo, las evocaciones de Alberto Pineta y Eduardo González Lanuza, que no cesan de marcar la particularidad del lenguaje de Arlt como falla o anomalía. Con los años, esa particularidad dejó de significar una carencia para convertirse en una virtud, en el ingrediente principal de una escritura singular. Pocos contemporáneos señalaron este rasgo como un valor -hemos visto los casos de Ramón Doll, Nicolás Olivari y Alberto Hidalgo-, pero lo cierto es que aún en aquellos comentarios favorables, el problema de la lengua en Arlt siempre se encuentra presente, ya sea bajo las formas de la salvedad, la recomendación o la simple impugnación o condena.

La lengua literaria de Arlt resulta una clave de lectura de su posición en el campo literario: en ella se puede observar sus intenciones vanguardistas de construir una literatura diferente a la tradicional, aunque también deja en evidencia las tensiones que el escritor mantiene con el circuito "culto" tradicional y legitimador. Al mismo tiempo, el mercado implica cierta modernidad -que autores como Arlt valoran mucho, según hemos visto- en el sentido de la relación que establece con las nuevas formas de reconocimiento masivo que el escritor logra a través de su participación en los nuevos medios.

Arlt ensaya una literatura que coincide con otros proyectos estéticos que encuentran en el fracaso, la incorrección y la transgresión estrategias que concentran diversas intenciones: por un lado, le permiten construirse como un escritor moderno; por el otro, posibilita que Arlt encuentre la manera de crear una lengua literaria más autónoma de las regulaciones del lenguaje literario vigente; finalmente, convierte en armas sus propias carencias, es decir, encuentra en la intencionalidad -con elementos conscientes e inconscientes- de la incorrección la base de su identidad como escritor pero también una nueva modalidad de concebir la literatura. 


\section{CAPÍtULO VI}

\section{Oliverio Girondo y la correcta incorrección}

En este capítulo centraremos la atención en la obra que Oliverio Girondo escribió durante los años veinte ${ }^{298}$ y analizaremos de qué manera su estética se imbrica con los problemas del idioma y de la lengua literaria. En primer lugar, se analizará su relación ambigua con España. Esta cuestión no está libre de complejidades dado que si el poeta, por un lado, cuestionó la autoridad lingüística de la vieja metrópoli, por el otro estableció relaciones empáticas con distintos elementos de la cultura española. Esta suerte de contradicción no es exclusiva de Girondo, sino que afecta al martinfierrismo en general. ${ }^{299}$ Sin embargo, creemos que este poeta es quien mejor encarna esa situación ambigua.

${ }^{298}$ El corpus de análisis está formado por los Veinte poemas para ser leídos en el tranvía (1922), Calcomanías (1925) y, pese a que escapa del período estudiado en esta tesis, Espantapájaros (1932). Hemos decidido incluir esta última obra dado que la consideramos como parte integrante de este primer ciclo poético de Girondo.

${ }^{299}$ Martín Fierro estableció una relación ambigua con España puesto que si, por un lado, entabló un estrecho vínculo con la vanguardia española; por el otro, el periódico fue escenario de la crisis de esa relación, hacia 1927, cuando se produjo la polémica en torno al meridiano intelectual del Hispanoamérica. Los martinfierristas encontraron en Francia el modelo cultural por excelencia; mientras que, al mismo tiempo, observaron en España el retraso político y cultural. Pero la historia de la vanguardia martinfierrista no comenzó en Francia, sino en España. De allí Borges importó el ultraísmo, estética que se encuentra en las bases del programa martinfierrista. Este comienzo funda las tensiones que determinarán la amplia recepción que el martinfierrismo hizo de la cultura española. En su artículo "Ultraísmo" (Nosotros, 1921), Borges pone de manifiesto la vinculación de la vanguardia argentina con la española: allí elabora una suerte de mínimo parnaso peninsular, realza la figura de Rafael Cansinos Assens y cita algunos ejemplos de poetas ultraístas españoles. Además, menciona a los escritores que han colaborado en las publicaciones ultraístas, muchos de ellos también españoles: Ramón Gómez de la Serna, José Ortega y Gasset, Ramón del Valle-Inclán, Juan Ramón Jiménez, etc. Las páginas de Martín Fierro participan de la tensión entre la auspiciosa recepción de determinados escritores españoles y el crudo rechazo hacia todo lo que provenga de España. Con respecto a lo primero, se puede señalar la figura señera de Cansinos Assens, introducida por Borges en el número 12-13. Allí el autor de Fervor de Buenos Aires le dedica un laudatorio artículo, titulado "Definición de Cansinos Assens". En el número 19, se le realiza un homenaje a una de las figuras españolas más encomiadas por los martinfierristas: Ramón Gómez de la Serna. Martín Fierro se encargó también de reseñar y presentar poetas españoles. Así, por ejemplo, en el número 20, Borges reseña de manera amable un libro de Guillermo de Torre, Literaturas europeas de vanguardia. Por su parte, Eduardo Mallea, en el número 39, le dedica un artículo a Benjamín Jarnés, en el que comenta, elogiosa y extensamente, su libro El profesor inútil (1926). Otro ejemplo tiene lugar en el número 41, cuando aparece, a doble página, un artículo titulado "La nueva poesía de España - Inéditos para Martín Fierro", en donde se publican poesías de algunos de los escritores de la vanguardia española, muchos de los cuales, al mes siguiente, polemizarán fuertemente desde La Gaceta Literaria con los martinfierristas; como por ejemplo Gerardo Diego y Antonio Espina. Entre otras positivas recepciones de la cultura española, podemos mencionar el homenaje a Góngora $\left(\mathrm{N}^{\circ}\right.$ 41), como así también un artículo de De Torre, titulado "Tres poetas jóvenes de España" -publicado en el mismo número- en el que aborda las figuras de Federico García Lorca, Rafael Alberti y Gerardo Diego. La figuración de una España inculta y semi-bárbara atravesará, por momentos, determinados flancos del periódico de Florida. No obstante, no es esta la representación que predomina. Numerosos escritores españoles tuvieron una buena acogida en la revista, tal es el caso de Miguel Unamuno. En el segundo número, se le dedica al escritor un artículo -"El caso Unamuno"- en el que se rescata su valor al oponerse públicamente al régimen de Primo de Rivera. En ese mismo número, Evar Méndez le escribe un poema -"Baldada"- con el mismo motivo. Con respecto al rechazo que los martinfieristas sentían por España, se puede mencionar la prédica anti-hispánica que realiza Girondo en los textos programáticos del grupo. De este modo, por ejemplo, en su "Carta abierta a 'La Púa", el poeta afirma: "es necesario declararle la guerra a la levita (...) con que se escribe en España" (1924a: 4). En el "Manifiesto de Martín Fierro", Girondo cree en la importancia del "aporte intelectual de América" nótese que no dice Hispano-América, como querían los españoles-, "previo tijeretazo a todo cordón umbilical" (1924b: 1). Esto puede ser leído como la voluntad de relativizar la autoridad de España, principalmente en el 
En segundo lugar, se intentará demostrar que la escritura de Girondo configura un fuerte cuestionamiento hacia las formas y cánones literarios aunque, a diferencia de lo que ocurre en la escritura de otros compañeros de generación, dichos cuestionamientos no implican violaciones a las normas idiomáticas. La creación de una nueva lengua literaria, en este caso, no implica necesariamente la destrucción y/o subversión de las reglas del idioma. La renovación estética de Girondo tiene que ver sobre todo con la incorporación de nuevos referentes y con un peculiar manejo de los significantes.

Finalmente, a partir del rastreo de fuentes primarias, reconstruiremos la recepción crítica que tuvieron sus primeras obras con el objetivo de poder establecer los modos en que las polémicas sobre el lenguaje se hacen presentes en estos documentos.

\section{Entre la renovación estética y el conservadurismo idiomático}

En el plano literario, la década del veinte se caracterizó por una amplia producción de nuevas escrituras; muchas de ellas reñidas con las posturas idiomáticas y literarias hegemónicas. El caso de Oliverio Girondo merece una atención particular debido a que la radicalidad de su renovación estética no se vio involucrada en los tópicos principales de los problemas de la lengua literaria: el lenguaje popular, las “jergas” de la inmigración, la corrección gramatical, la disyuntiva entre la aceptación de los modelos lingüísticos recibidos de España y la conformación de un idioma nacional, entre otros. Pero sí produjo un cuestionamiento de los cánones literarios y estéticos heredados a partir de la incorporación de un lenguaje que, sin incurrir en la "mala escritura", 300 propone nuevos materiales lingüísticos para ser incorporados al discurso literario.

Lo novedoso del lenguaje de Girondo puede ser rastreado en sus elementos léxicos, puesto que deja de lado los materiales tradicionalmente poéticos y se sirve de un campo semántico ajeno a la poesía, vinculado al proceso modernizador el cual no sólo rediseña el

terreno de la lengua literaria, autoridad que ya había sido puesta en cuestión, según este mismo texto, por Rubén Darío. El auge de las polémicas en torno al lenguaje encontró en el martinfierrismo un actor fundamental. Su nacionalismo anti-inmigratorio, entreverado con la admiración por la cultura europea, con una hispanofobia casi anacrónica y con diversas tensiones con la cultura popular, dio como resultado un amplio abanico de intervenciones acerca de los problemas de la lengua literaria y del idioma. Su relación ambivalente con la vanguardia española tal vez constituya uno de los capítulos centrales con respecto a estas discusiones, junto con las querellas establecidas con los escritores de izquierda. La promoción y ruptura con la joven guardia española no sólo determina las contradicciones propias del martinfierrismo, sino también el acelerado pulso que los debates en torno al lenguaje van teniendo a lo largo de la década.

300 Cabe recordar que la "mala escritura", a la que ya hemos hecho mención en capítulos anteriores, está determinada por un castellano "contaminado" con las lenguas de contacto y con una supuesta carencia de capital simbólico por parte de los escritores enmarcados en ella. Estos autores, como por ejemplo Roberto Arlt, Enrique González Tunón, Nicolás Olivari, Carlos de la Púa, etc., se caracterizan, principalmente, por el uso de una lengua literaria que reelabora formas asociadas con lo popular. 
paisaje urbano, sino que redefine las formas del discurso literario. La modernización y el progreso abren, entonces, nuevos campos léxicos que la literatura explota. Sin estos cambios contextuales no es posible comprender la literatura de este autor, pero tampoco la de muchos otros escritores jóvenes de los años veinte.

A esto se debe sumar la incorporación de la cotidianeidad como elemento literaturizable, que apunta evidentemente a la elaboración de una lengua literaria que tiene como objetivo primordial dar con lo que los formalistas rusos denominaron "extrañamiento" (ostranenie). ${ }^{301}$ La incorporación de la "lengua prosaica" en los niveles de la "lengua poética" -distinción que corresponde también a Shklovski- rige la ruptura literaria de Girondo. La noción de extrañamiento, como también la utilizó Boris Eichenbaum, ${ }^{302}$ permite explicar las operaciones realizadas por su poesía y comprender su particularidad en el panorama literario de los años veinte.

El vínculo entre arte y vida -rasgo característico de los textos de Girondo- propone una poesía que se define por el principio de "mezcla" y "contaminación” de lenguajes. Este procedimiento instala "una palabra que desmenuza y desacraliza la autoridad de la doxa moral, religiosa, estética; mezcla de lo sublime y lo profano, lo bajo y lo alto, abre para la poesía argentina el espacio de lo prohibido" (Muschietti 2009: 126). La mezcla entre lo "alto" y lo "bajo" habilita - como veremos más adelante- los conceptos de carnavalización y grotesco para realizar el abordaje de la obra girondiana. Sin embargo, lo "bajo" no se define en relación con la cultura o los lenguajes populares, sino con la cotidianidad, en ocasiones con lo escatológico, y muchas veces con la sexualidad.

Graciela Speranza (2006) afirma que los referentes de sus primeros poemarios se construyen a partir de la abolición de distancias entre los objetos estéticos y no estéticos. Este procedimiento configura la matriz fundamental en la elaboración de la lengua literaria de Girondo y, además, representa el mejor ejemplo de rechazo al modernismo, principal estética contra la que reacciona la vanguardia martinfierrista en general. En los "Nocturnos", que desde el título remiten a un género marcado por el lirismo romántico y el artepurismo, el lenguaje acude con mayor insistencia a lo antipoético: "alambres", "cañerías", "mingitorios" provocan una "des-sublimación" del espacio poético. Estas ideas, si bien hoy forman parte de

\footnotetext{
${ }^{301}$ De acuerdo con Viktor Shklovski, el procedimiento de extrañamiento se define según la relación que el procedimiento artístico establece con la esfera estética disponible del receptor, en la cual el objeto artístico rompe con los procesos automatizados de percepción y genera así ostranenie (Amícola 2001: 59). Rose Corral (1999b) se refiere al lenguaje experimental de Espantapájaros -particularmente, toma como muestra el texto número 4- y señala que está constituido por operaciones que tienden a la desautomatización lingüística.

${ }^{302}$ Eichenbaum aplicará la terminología que propone el pionero del movimiento (Shklovski) de modo diferente, a saber, la de "hacer extraños" los cánones literarios consagrados (Amícola 2001: 58).
} 
un lugar común de la crítica especializada, fueron puestas en funcionamiento muy tempranamente para la elaboración tanto de lecturas negativas como positivas. ${ }^{303}$

En Girondo, lo sagrado se funde con lo profano, las esferas de lo público, lo privado y lo secreto se dislocan, y la ciudad de los poemas se transforma en un escenario en el que la mezcla y la transgresión se visualizan (Speranza 2006). No obstante, pese a la eliminación de jerarquías y a la horizontalidad a la que somete estos materiales diversos, ${ }^{304}$ la escritura de sus primeros libros no conforma una masa lingüística homogénea, puesto que muchas palabras cosmopolitas o extranjeras -como "jazz-band", "rugby", "foxtrot", “cocottes", “champagne”, etc.- aparecen entrecomilladas. ${ }^{305}$ Por más cosmopolitas que resulten los dos primeros libros, el cosmopolitismo encuentra un límite, que es el del idioma. Girondo "contamina" el discurso literario a través de la incorporación de un sinnúmero de elementos "extraliterarios", pero lo que no puede hacer es "contaminar" la lengua. Las comillas funcionan de manera aséptica, separando aquellos materiales "extranjeros" o "espurios" que no se pueden integrar a la escritura dominada por el castellano. Entrecomillar las palabras cuya procedencia es extranjera o evidentemente popular es un recurso propio de los escritores que sustentan, parcial o totalmente, posturas conservadoras en relación con la lengua literaria. ${ }^{306}$ Las comillas, en este autor, son una inscripción de clase, un posicionamiento explícito desde dónde se enuncia. Habría, entonces, una clara consciencia lingüística que impide que el cosmopolitismo se manifieste directamente en la lengua. En Veinte poemas y Calcomanías, la vertiente cosmopolita se reduce a la referencialidad, a la alusión a monumentos, edificios o paisajes europeos; pero nada de esa extranjería puede penetrar en la lengua literaria sin ser marcada como una otredad. ${ }^{307}$

\footnotetext{
${ }^{303}$ Así, por ejemplo, en una entrevista que le realiza la revista Columbia $\left(\mathrm{N}^{\mathrm{o}} 3\right.$, junio de 1925), se puede leer: "alguien decía a nuestro lado, mientras leíamos sus veinte poemas que todo su arte se circunscribía a fijarse en el detalle insólito que todo el mundo había visto a diario sin darle importancia. Si la frase fue dicha con un sentido de crítica negativa, erró el blanco, porque, de entrañar un fondo de verdad, expresó únicamente la suma condición que hace de la obra de Proust o Joyce dos monumentos de la literatura contemporánea" (Nahuelpán 1925: 12).

${ }^{304}$ Al respecto, Adriana Rodríguez Pérsico afirma: "el predominio de las mezclas desplaza jerarquías, fomenta una infinidad de alianzas y posibilita la coexistencia de elementos dispares que convocan sin cesar una relación de horizontalidad entre ellos" (1999: 381).

${ }^{305}$ En Veinte poemas aparecen las siguientes palabras entrecomilladas: "champagne", "cocotte" (Girondo, 1999: 8); "dandys", "campanile" (14); "fox-trot" (19); "Manneken-Pis" (23); "chewing gum" (26); "bidé" (27). Aparecen también algunos italianismos, como "piccoli canalí" (14), pero son rápidamente neutralizados de su asociación ilegítima debido al referente prestigioso al cual se vinculan, como por ejemplo Venecia. En Espantapájaros: "rugby" (41); "jazz-band" (41); "upper-cut" (42); "kiff” (42); "sherry-brandy" (43).

${ }^{306} \mathrm{Si}$ bien encontramos en el período a escritores populares que utilizan el entrecomillado en sus textos, como por ejemplo Roberto Arlt, en este caso en particular, Arlt se sirve de este procedimiento como una forma de lograr que sus textos no queden excluidos del reconocimiento de la crítica legitimadora a la que, de alguna manera, aspira. Ver Saítta (2008: 64) y el capítulo V de este trabajo.

${ }^{307} \mathrm{Un}$ análisis fundamental de las lenguas extranjeras en la literatura argentina es el que realiza Beatriz Sarlo (1997a). Según esta autora, con los románticos argentinos se inicia la promoción de las lenguas extranjeras como lengua de los letrados. Esta tendencia puede verse con mayor intensidad en la literatura de la Generación del 80 . A partir de la llegada masiva de la inmigración -continúa Sarlo-, se produce una redefinición del
} 


\section{Entre la hispanofilia y la hispanofobia}

A partir del pasaje de la hispanofobia liberal de la primera mitad del siglo XIX al redescubrimiento y apelación espiritualista a España, a partir de 1890, este país aparece como un nuevo espacio del viaje estético (Viñas 2005a). Una renovada visión de la vieja metrópoli atraviesa y define a buena parte de la generación del Centenario y alcanza a muchos escritores jóvenes de los años veinte, los cuales refuerzan su vínculo con la Península mediante la importación del ultraísmo y de los frecuentes intercambios con la vanguardia madrileña. Oliverio Girondo no será la excepción: en julio de 1924 emprende un viaje por el continente americano $^{308}$ que lo llevará, finalmente, a España. Más tarde, en 1925, publica Calcomanías, poemario dedicado enteramente a este país. Sin embargo, los martinfierristas se reservan un vínculo complejo y contradictorio con España. Y es Girondo, precisamente, quien manifiesta esto porque si, por un lado, en su segundo libro fija su vista allí, motivado posiblemente por la calurosa recepción de su primer poemario por parte de los jóvenes escritores españoles; por el otro, continúa viendo al país europeo como una fuente de tradicionalismo y de atraso literario.

Durante los años de vida de Martín Fierro, sus integrantes y colaboradores más cercanos establecieron una estrecha relación con la vanguardia española, y se le dio una buena cabida a muchos autores y temas españoles dentro de sus páginas. Pero, a mediados de 1927, los vínculos se rompieron abruptamente a raíz del artículo publicado por Guillermo de Torre en La Gaceta Literaria de Madrid, en el que proponía a la capital española como meridiano intelectual de Hispanoamérica. Como afirma Schwartz (2002b), desde el seno del martinfierrismo se organizó una rápida respuesta colectiva que unió a escritores con posturas estéticas e ideológicas muy diferentes: autores que circulaban por las zonas de las vanguardias estética y de izquierda coincidieron en una suerte de cruzada anti-española. Sin embargo, en la relación del martinfierrismo con España, Girondo se anticipa a sus compañeros de ruta. Tanto la "Carta abierta a 'La Púa"” (1922) como el posterior "Manifiesto de Martín Fierro" (1924) constituyen una declaración de independencia cultural e idiomática con respecto a la vieja metrópoli. En la "Carta abierta", declara:

es necesario declararle (...) la guerra a la levita (...); a la levita con que escribe en España, cuando no se escribe de golilla, de sotana o en mangas de camisa. Porque es imprescindible

cosmopolitismo: por un lado, se encuentra aquél considerado legítimo y que remite a las lenguas extranjeras prestigiosas, y por el otro, está el babélico, que se vincula con las lenguas de la inmigración. En la literatura de Girondo se manifiesta este cosmopolitismo legítimo: no sólo incluye voces provenientes de los idiomas en que lee y escribe la alta cultura, sino también paisajes y referencias que remiten a ese mismo universo.

${ }^{308}$ Girondo visita Chile, Perú, Cuba y México. 
tener fe (...) en nuestra fonética, desde que hemos sido nosotros, los americanos, los que hemos oxigenado el castellano, haciéndolo un idioma respirable, un idioma que puede usarse cotidianamente y escribirse de 'americana', con la 'americana' nuestra de todos los días (1924a: 3).

Por su parte, en el "Manifiesto" afirma:

Martín Fierro cree en la importancia del aporte intelectual de América, previo tijeretazo a todo cordón umbilical. Acentuar y generalizar, a las demás manifestaciones intelectuales, el movimiento de independencia iniciado, en el idioma, por Rubén Darío, no significa, empero que habremos de renunciar, ni mucho menos, finjamos desconocer que todas las mañanas nos servimos de un dentífrico sueco, de unas tohallas de Francia y de un jabón inglés (1924b: 1).

La fórmula de Girondo comprende un anti-hispanismo que se combina con la voluntad de no renunciar al cosmopolitismo que se cifra en las toallas francesas o en el jabón inglés. No obstante, esa declaración de principios, con la vehemencia con que la expone, no se concretará sino en los números finales de Martín Fierro, pero para ese entonces su figura ya ha perdido espesor en el seno del grupo ${ }^{309}$ y, llamativamente, no participa de la polémica del meridiano en ninguno de los dos números que la abordan. Sin embargo, la actitud que el poeta muestra con respecto a España en los primeros números de Martín Fierro se mantiene con el tiempo. A fines de la década del treinta, cuando el debate sobre el meridiano se encontraba cerrado desde hacía años, realizó unas afirmaciones que bien podrían entroncarse con esa vieja querella. Hacia 1939, convocó a Alfonso Reyes para colaborar con él en un emprendimiento editorial como director de una colección de "clásicos latino-americanos". 310 Sin embargo, Girondo le aclara a Reyes que el mejor nombre para la proyectada colección no debe ser "hispano" ni "iberoamericana", sino "latinoamericana" puesto que ese título "ofrece la ventaja de dejar sentada nuestra mayoría de edad, con respecto a España" (Corral 1999a:

\footnotetext{
${ }^{309}$ Dentro de Martín Fierro, la figura Girondo durante los primeros números resultó crucial. Sin embargo, poco a poco, su figura va siendo marginada. En 1925, le escribió una carta a Guillermo De Torre explicando su función dentro de la revista en sus primeros momentos y su posterior alejamiento. Señala que "al poco tiempo de llegar [a la revista] me comprometí a dirigir tres números, para vivificarlo financieramente y darle la orientación que consideraba oportuna" (2007: 358). Después del tercer número, el poeta comenta que se fue "retirando como lo había anunciado desde el primer número". Y prosigue: "Continuar era materialmente imposible a no ser resignándose a renunciar a todo. Solo en el primer número tuve que dibujar las letras del título, las viñetas (sacadas de las telas peruanas) escribir leyendas, comentarios y tres artículos (...) Mi presencia, por lo demás, ya ha dejado de ser indispensable, pues, mal que mal, el periódico ha adquirido una orientación definida, cuenta con recursos y tiene cada día más influencia" (358). Más allá de estas afirmaciones, lo cierto es que la presencia de Girondo en Martín Fierro continuó siendo importante después del tercer número: además de escribir el "Manifiesto" en el cuarto, participó de la encuesta acerca de la nueva sensibilidad en el quinto, obtuvo un lugar destacado en el sexto a raíz de su gira por Latinoamérica, y siguió escribiendo membretes, aunque su alejamiento se tornó cada vez más evidente.

${ }_{310}$ Rose Corral (1999a) supone que esta colección pertenece a la editorial Sudamericana que se crea en ese mismo año, 1939.
} 
465). Cuando Guillermo de Torre publica el artículo que da pie al debate sobre el meridiano, impugna el nombre de Latinoamérica y propone otro más "lícito", el de Hispanoamérica, puesto que el primero implica "hacernos cómplices inconscientes de las turbias maniobras anexionistas que Francia e Italia vienen realizando respecto a América" (Croce 2006: 67); aunque, en realidad, lo que le preocupa a De Torre es la pérdida de hegemonía cultural de la Península sobre la América de habla hispana.

Durante los años veinte, el martinfierrismo mantuvo aceitados intercambios con la vanguardia española. No obstante, este vínculo no estuvo exento de desencuentros y de momentos de crisis. Si bien Borges ya había introducido el ultraísmo en 1921, cuando Girondo escribe la "Carta abierta" a fines de 1922 "parece no haberse enterado de la existencia del movimiento ultraísta" y "sigue viendo a España como fuente de la tradición y de la esclerosis literaria" (Schwartz 2002b: 70). Sin embargo, en 1924, la perspectiva de Girondo, como hemos visto, no cambia sustancialmente puesto que es en el "Manifiesto" donde radicaliza esta posición con mayor violencia y sarcasmo. En lo tocante a la relación con España, el programa del martinfierrismo, propuesto en ese texto, se lleva a cabo recién en el número 42, cuando estalla la polémica sobre el meridiano intelectual: "el número de Martín Fierro $\mathrm{N}^{\mathrm{o}} 42$ representa el 'tijeretazo a todo cordón umbilical' previsto por Girondo en su 'Manifiesto', y sirve como afirmación de la 'argentinidad', en cuanto oposición a una supuesta influencia estética madrileña (Schwartz 97).

El recorrido de Girondo evidencia las contradicciones o conflictos culturales con España, los cuales pueden rastrearse en otros martinfierristas. Tal es el caso de Borges, quien si bien, por un lado, trae el ultraísmo, por el otro escribe un texto como "A un meridiano encontrao en una fiambrera", que manifiesta, como se sabe, una postura antihispánica.

El poeta inicia su periplo literario auspiciado por un antihispanismo visible, no solamente en "La carta" y el "Manifiesto", sino en la edición de un libro como Veinte poemas..., que además de estar editado en París -recordemos que De Torre luchará en su editorial de 1927 contra la influencia cultural de Francia sobre Hispanoamérica- no se rige por los preceptos ultraístas. Si bien se cuenta con pocos datos acerca de las actividades previas a la publicación de su primer poemario en la capital francesa, se evidencia en su poesía el contacto con los diferentes "ismos" existentes en París. ${ }^{311}$

En los Veinte poemas..., las referencias cosmopolitas se reparten entre el escenario preponderante de Francia (Douarnez, Brest, Biarritz, París), algunas ciudades argentinas

\footnotetext{
${ }^{311}$ Al respecto, señala Schwartz: "el estilo de Veinte poemas... refleja nítidamente la asimilación de las teorías cubo-futuristas de composición (...) El posible contacto de Girondo con algunos elementos de la élite parisina lo acercaría al último de los grandes movimientos de vanguardia, el surrealismo..." (2002: 120).
} 
(Buenos Aires, Mar del Plata) e Italia (Venecia, Pallanza, Verona). No obstante, dos de los poemas están dedicados a la ciudad española de Sevilla: "Croquis Sevillano" y "Sevillano". Según estos poemas, el rasgo que parece definir a España -o, al menos, a Sevilla- es la fuerte identificación con la Iglesia, cuyos eclesiásticos están levemente ensombrecidos, ya sea por cierta valoración moral negativa - "Un cura de Zurbarán, que vende a un anticuario una casulla robada en la sacristía" (Girondo 1999: 17) -; o bien por el contraste entre lo sacro y lo profano-moderno: "el cura mastica una plegaria como un pedazo de "chewing gum"” (26). Sin embargo, su intención no es criticar a España, sino integrarla al horizonte cosmopolita, a esa geografía cuyos límites abiertos colocan en una misma escala jerárquica los centros europeos con algunas ciudades latinoamericanas como Buenos Aires o Río de Janeiro. Todo forma parte de ese sincretismo cosmopolita que proclama apenas se abren los Veinte poemas..., cuando en la dedicatoria "A 'La Púa" escribe sobre el "estómago ecléctico" de los latinoamericanos, capaz de "digerir bien, tanto unos arenques septentrionales o un kouskous oriental, como una becasina cocinada en la llama o uno de esos chorizos épicos de Castilla" (Girondo 1999: 4, destacado nuestro).

Sin embargo, los Veinte poemas... también se relacionan con España a través de la favorable y amplia recepción que suscita el libro entre los críticos españoles. El primero en celebrarlo es Ramón Gómez de la Serna, quien lo reseñó en El Sol de Madrid, el 4 de mayo de 1923, meses antes de conocer personalmente al poeta. Desde La Veu de Catalunya, el 8 de junio del mismo año, Alfonso Maseras también se ocupó de la obra en términos muy elogiosos. Gabriel Alomar lo recogió en su crónica para El Imparcial, el 2 de septiembre; y el día 8 del mismo mes, Enrique Díez-Canedo hizo lo propio para la revista España. Muchas de estas reseñas fueron conocidas en Buenos Aires a través de las reproducciones que los diarios locales, como La Nación, hicieron de ellas. A estos comentarios se le suma el de otro español, Guillermo de Torre, quien escribió un largo artículo sobre los versos de Girondo para el número doce de la revista Proa.

No resulta descabellado pensar entonces que el emplazamiento poético de su segundo libro, Calcomanías, situado completamente en España, haya sido estimulado por esta muy favorable recepción que los españoles hicieron de sus Veinte poemas... De hecho, en Calcomanías, los primeros tres poemas están dedicados a tres de los entusiastas comentaristas de su libro anterior. ${ }^{312}$ También hay dedicatorias para otros críticos y escritores españoles, como Eugenio D’Ors, José Ortega y Gasset, Alfonso Maseras y Margarita Nelken.

\footnotetext{
${ }^{312}$ Enrique Díez Canedo (“Toledo"), Ramón Gómez de la Serna (“Calle de las sierpes”) y Gabriel Alomar ("El tren expreso").
} 
Sin embargo, no se puede explicar el lugar que tiene España en sus dos primeras obras por la sola simpatía que ese país pudo haberle despertado en algunos de sus viajes por Europa, o por los avatares de la recepción crítica. En el poeta parecen convivir las dos fuerzas que tensionaron y dieron forma a los vínculos que la Argentina estableció con la Península a lo largo de todo el siglo XIX: por un lado, una reactualización de la herencia de los hombres del 37, quienes identificaban a España con el retraso y la barbarie, con el anquilosamiento cultural y literario. Esta valoración de lo hispánico se pone de manifiesto, como hemos visto, desde muy temprano, en la "Carta abierta a 'La Púa"”. Por otro lado, Girondo participa de la revalorización de España y de los intercambios intelectuales que los hombres de fines de siglo XIX y, con mayor intensidad, los escritores del Centenario supieron fomentar. ${ }^{313}$ Esta contradicción es la que tiene lugar, con mucha claridad, en los Veinte poemas... y Calcomanias, para luego disolverse en Espantapájaros. Según Luis Martínez Cuitiño (1998), más allá de sus propósitos de autonomía con respecto a España en el terreno idiomático, siente un apego especial por el idioma español debido al prestigio emanado del contraste que establece esta lengua con las formas "babélicas" que dominan en Buenos Aires; fenómeno que se enmarca en una creciente hispanofilia asumida fundamentalmente por "los conservadores de la cultura". Si bien el autor alardea en la carta a "La Púa" de tener fe en "nuestra fonética", sigue muy apegado a veces al referente hispánico, lo que se observa en el empleo de vocablos como "gulusmea", "gélido" o en giros como "a guisa de" y en diminutivos como "calleja", "olorcillo", “vientecillo" (Martínez Cuitiño). Aunque cabe

\footnotetext{
${ }^{313}$ La revalorización de la cultura española por parte de Argentina se acompaña con fructíferos intercambios intelectuales. En este sentido, fue clave el papel desempeñado por la Generación del 98, con cuyos miembros muchos escritores argentinos, a comienzos de siglo XX, traban excelentes relaciones. Sabido es que Gálvez y Rojas parten para Europa en 1905 y 1907, respectivamente. Ambos comparten la idea de la trascendencia que tiene España y su cultura en la vida y en el pensamiento americanos. Cárdenas-Paya aseguran que esta actitud resulta sin duda novedosa a principios de siglo, cuando aún predomina la influencia positivista que cubriría todo lo español con los motes de oscurantista y atrasado (1978: 66). Según estos mismos autores, el nacionalismo cultural que marca el rasgo primordial de la Generación del Centenario proviene, en buena medida, de España, dado que "aprendieron de los españoles del 98 que el conocimiento profundo y sin eufemismos del propio país era la clave para restaurar su personalidad espiritual (69). Y enseguida comienzan los vínculos entre estos jóvenes y los escritores españoles: por ejemplo, Rojas traba amistad con Ramiro de Maeztu en Londres, en 1907, pero también conoce a Unamuno, Menéndez y Pelayo, Menéndez Pidal y Pérez Galdós; y, por su parte, Gálvez se vincula con Ramón del Valle Inclán, entre otros. (73). En su libro La literatura argentina y sus vínculos con España (1948), Rafael Arrieta demuestra que desde comienzos de siglo las relaciones con España fueron cada vez más intensas. Por ejemplo, menciona que en mayo de 1900, Américo Llanos pronunció, en el Círculo de Prensa de Buenos Aires, una conferencia sobre La obra de Miguel de Unamuno y el pensamiento ibérico, en la que advierte que tiene el propósito de "iniciar por sobre las antiguas consanguinidades históricas, no un mero intercambio de vana afectuosidades sino un intercambio de análisis intelectual para reanudar en lo posible los abandonados parentescos del Espíritu" (Arrieta 1957: 182). A su vez, se establece lo que Arrieta denomina "embajadas intelectuales", que no eran sino las visitas al país de eminentes universitarios y escritores europeos, invitados para que brinden conferencias. Se inician en 1908, con las presencias de Guillermo Ferro y Enrique Ferri (193). Las relaciones entre España y Argentina también se tradujeron en diversas iniciativas de editoriales españolas, como la casa Maucci o la Biblioteca Sempere, encargadas de promocionar los parnasos hispanoamericanos en Europa (Arrieta 185). Tampoco se debe olvidar la visita de la Infanta Isabel en ocasión de los festejos del Centenario de la Revolución de Mayo. Junto a la Infanta, venía Eugenio Sellés, quien traía la misión oficial de fundar en Buenos Aires una academia correspondiente (Arrieta 197).
} 
agregar que el acercamiento del poeta hacia España no sólo se reduce a estos elementos léxicos, sino también a referencias a ciudades, obras literarias, escritores, aspectos históricos, etc. El mejor ejemplo de ello es Calcomanías, en donde dominan los escenarios españoles. Girondo manifiesta explícitamente la necesidad de autonomía lingüística frente a España y defiende la evolución del idioma ya que la aparición de nuevas ideas requiere nuevas expresiones. ${ }^{314}$ No obstante, en el primer ciclo de su obra, es refractario a las operaciones habituales en los escritores con ideas similares: el trabajo literario por fuera de los parámetros normativos o, directamente, desde la deliberada "incorrección" de sus formas; la incorporación del lunfardo y de aquellas voces que remiten a la inmigración; el lugar central asignado a la cultura popular. Otro factor que determina el acercamiento de Girondo hacia España es el lugar que ocupa ese país en relación con la vanguardia argentina. Ya hemos mencionado el lazo que une a los martinfierristas y los ultraístas españoles. De este modo, si Ramón Gómez de la Serna se convierte en una personalidad de culto para algunos escritores que circulan en la zona de la vanguardia estética, Girondo fomentará ese vínculo muy personalmente. Así, en su segunda estancia en España, en 1923, asistirá a las tertulias ramonianas en el célebre Café Pombo; y se iniciará entre ambos escritores una amistad profunda cargada de admiración y respeto mutuo que se afianzará aún más cuando Gómez de la Serna se instale en Buenos Aires, en 1936 (Barrera 1999). Cabe agregar que, en los años veinte, Madrid funcionó como "una especie de traductor hispánico del movimiento parisino", puesto que las vanguardias europeas fueron conocidas en la Argentina a través de publicaciones que llegaban desde París y Madrid (Schwartz 2002b: 60).

En síntesis, tres serían entonces los factores que definen el acercamiento de Girondo a España: en primer lugar, la muy buena recepción crítica de su primer libro probablemente incide en la hispanofilia evidenciada en el segundo; luego, Girondo encuentra en el idioma español una compensación de la argamasa lingüística producto de la inmigración; y por último, los tradicionales síntomas de anquilosamiento y retraso cultural asignados a España

\footnotetext{
314 Algunos años antes de que escribiera la "Carta abierta a "La Púa" y el "Manifiesto de Martín Fierro", Girondo presentó, en 1916, su tesis doctoral "Warrants agrícolas. Legislación argentina a su respecto. Juicios críticos sobre los mismos". Allí afirma lo siguiente con respecto a la lengua: "Las lenguas, pese a los esfuerzos de anquilosados, gramáticos y linguistas (sic), siguen la lógica evolución de la vida y al evolucionar, se renueva (sic). Es terca necedad esa de oponerse sistemáticamente al empleo de voces extrañas a una lengua, pues si, a veces son justificadas, por tener el equivalente exacto, en otras ocasiones, al significar ellas cosas o ideas nuevas, son del todo punto irremplazables, y el 'warrant' se hallaba en este caso. La Cámara hizo bien en aceptar el neologismo y su aceptación fue el triunfo del sentido común, tan poco común desgraciadamente” (Artundo 1999: 517-518). Las valoraciones que realizan los escritores sobre el idioma suelen tener su correlato en el lenguaje literario, aunque muchas veces se puedan observar tensiones o contradicciones al respecto, como sucede en los casos de Arlt o Castelnuovo, por ejemplo. En este sentido, la cita de Girondo prefigura las reflexiones sobre el lenguaje literario que el poeta formalizará unos años después en el "Manifiesto" y/o en "Carta a la Púa", y que pondrá en práctica en sus poemarios. La apertura con respecto a las "voces extrañas", si bien en este caso aluden a los vocablos en otros idiomas, también resultan un punto de partida para poder pensar el material lingüístico, ajeno a la tradición literaria, que Girondo utiliza en su lenguaje poético.
} 
aparecen matizados por la renovación estética que propone la vanguardia española y su imbricación en el movimiento martinfierrista.

\section{La correcta incorrección}

Como hemos señalado en el apartado anterior, Girondo realiza un trabajo poético sobre España, un referente algo insólito en el marco de una vanguardia argentina que se reivindicaba como independiente. Pero su lengua literaria reenvía a los "ismos" europeos, principalmente parisinos. Es posible, entonces, que esa tensión haya determinado su particular lengua literaria, que puede caracterizarse como "incorrecta" desde el punto de vista del sentido transgresor de los términos -en tanto eluden a la sexualidad, a lo escatológico, al humor, al feísmo- pero llevada a cabo desde una considerable corrección formal, acorde con las prescripciones normativas. La idea de "incorrección" hay que pensarla como una forma de transgresión de las tradiciones literarias vigentes y de los parámetros de la lengua literaria aceptada. Por su parte, la "corrección" nos reenvía a la noción de moderatismo porque el poeta no rompe con las normas gramaticales, sintácticas y morfológicas del lenguaje literario. Es decir, la "incorrección” o transgresión, o sea aquella dimensión de su escritura que fue muy cuestionada por determinados sectores, ${ }^{315}$ no radica en el nivel de la norma lingüística sino en el de la norma estética o literaria. ${ }^{316}$ Jan Mukarovsky (2000) define la transgresión en el campo de la estética como la relación entre una norma precedente en el tiempo y una norma diferente de la anterior, que apenas se está formando. En este caso, el poeta demuestra que la transgresión de la norma estética no supone indefectiblemente una transgresión de la norma lingüística. Sus marcadas “incorrecciones” radican en la desidealización del lenguaje poético; hecho que se manifiesta con mucha claridad en su tercer libro, Espantapájaros, en el que se derriban jerarquías y solemnidades: el poeta habla con la lengua "sucia", nombra las partes siempre veladas del cuerpo y sus funciones, y suele utilizar referentes inusuales para la poesía, muchas veces escatológicos ("meadero", “culo de botella", "tachos de basura”). Estas ideas, ya expuestas por Delfina Muschietti, resultan centrales para nuestro abordaje puesto que la voluntad de desidealizar el espacio poético implica, necesariamente, llevar a cabo

\footnotetext{
${ }^{315}$ Ver, sobre todo, las reseñas y comentarios de Espantapájaros... Por ejemplo: "Espantapájaros por Oliverio Girondo" (1932), Godoy (1932), Delio (1932), López de Molina (1932). En estos textos se critica el uso cómico, burlón y desenfadado de la lengua literaria de Girondo, así como las referencias sexuales y escatológicas de algunos poemas. Como señala Delfina Muschietti (2009), la repulsa y el asco serán una y otra vez el efecto que la escritura del "bárbaro" Girondo producirá en los centros de la cultura oficial. En el apartado 4 de este capítulo, se analizarán algunos de estos artículos.

${ }^{316}$ Para el concepto de norma estética, ver Mukarovsky (2000).
} 
diversas operaciones sobre la lengua literaria. Es decir, convertirla en otra cosa para hacerla ingresar nuevamente en el discurso literario; poblarla de nuevas referencialidades; importar, desde la cotidianeidad, nuevos vocablos al campo de lo literario. ${ }^{317}$ Girondo trabaja sobre las zonas-tabú (Angenot 2010) del discurso social aceptado en la Argentina de 1920: el sexo pertenece al dominio de los tabúes y sólo los "libertinos literarios" (Angenot 42) como Girondo están dispuestos a levantar el velo.

Beatriz Sarlo (2007) señala que los poetas de los que Girondo busca diferenciarse "sienten", "expresan", "imaginan"; cuando escriben, hacen pasar el mundo por la grilla de un yo lírico que Girondo prefiere evitar. En consecuencia, si no hay yo, la literatura puede librarse de varias servidumbres: del sentimentalismo, del recuerdo, de la nostalgia, del pasado, de la tradición, de la historia. El valor se funda en la novedad; los procedimientos trabajan, básicamente, con la percepción. Esta es la innovación en la lengua literaria que los críticos coinciden en destacar cuando se refieren al poeta. Se trata de una operación que se lleva a cabo en las modalidades de la representación literaria. Por eso, podemos pensar a Girondo como un escritor que subvierte el lenguaje literario sin poner en peligro su escritura ante los puristas y los guardianes de la cultura. Si escandaliza, no lo hace porque mancilla con voces plebeyas, bajas o vulgares la impoluta superficie del idioma, sino porque provoca una torsión en el seno de la lengua literaria misma, a partir de una suerte de desliteraturización de sus textos, basada en la incorporación de campos léxicos y referentes considerados como no literarios; además utiliza voces o ideas rechazadas desde el pudor -por ejemplo, vocablos como "eyacular"- por las poéticas tradicionales. En síntesis, trabaja con un vocabulario que hasta entonces estaba excluido de lo poetizable. Y es precisamente aquí donde reside su gesto vanguardista más genuino y provocador.

En el caso de Girondo, entonces, podemos hablar de una lengua "incorrecta", pero no en el mismo sentido en que lo hacemos, por ejemplo, para referirnos a los textos de Roberto Arlt, Nicolás Olivari o Enrique González Tuñón. En referencia a Espantapájaros, Martínez Cuitiño señala que "de todos los niveles de la lengua, el más estable es el sintáctico, pese a que algunas oraciones se quiebran o aparecen inconclusas o el hipérbaton las resemantiza" (1988: 166). La estabilidad, que el crítico observa en el orden sintáctico, separa los textos de Girondo de otros innovadores del período quienes, muchos de ellos, ya sea de manera deliberada o no, incurren en numerosos "errores" de construcción, como una forma manifiesta de desdén por las formas legitimadas. Sin embargo, el poeta, sin hacer trastabillar las normas de la escritura, se las arregla para romper por momentos ese orden imperante. De todos modos, esas rupturas de ninguna manera pueden adjudicarse a descuido o ignorancia, como

\footnotetext{
${ }^{317}$ Ver al respecto, Speranza (2006).
} 
podría ocurrir en el caso de Arlt u Olivari, ${ }^{318}$ sino que son el resultado de un evidente trabajo sobre la norma. De allí que ningún comentario del período se refiera a Girondo como un autor que escribe "mal". No obstante, algunos críticos perciben que en su escritura existe algo que se encuentra dentro de lo "incorrecto". Por ejemplo, en una reseña no firmada de Espantapájaros, aparecida en el diario Crítica (7 de agosto de 1932), ${ }^{319}$ se hace referencia a la obra como "un libro bien escrito y mal hablado" ("El último libro de Girondo" 1999: 622). Esta es una buena fórmula para definir su tercer poemario porque, en cierta medida, ilustra la particular configuración de su lenguaje literario, tensionado por una adecuación sintáctica y ortográfica que se combina con la innovación estética. La reseña de Crítica brinda la clave que luego las lecturas más actuales se encargaron de repetir y analizar: "Girondo (...) busca elementos poéticos allí donde otros creen que no deben buscarse, vale decir, donde otros no saben hallarlos" (623). Es allí donde radican los "desvíos" y donde su lenguaje "correcto" comienza a ser impugnable por sectores más conservadores.

$\mathrm{Su}$ transgresión no es gramatical, sino contextual o referencial, pero sobre todo literaria. En los Veinte poemas, por ejemplo, podemos observar su competencia cultural manifiesta en un léxico "culto", cosmopolita, al que el fluido manejo de lenguas extranjeras confiere prestigio social (Muschietti 1985). Estas propiedades de la textualidad literaria del poeta hacen que se distinga de los escritores "populares", cuyos vínculos con la lengua son muy diferentes. ${ }^{320}$

Cuando nos referimos a la "corrección" de la escritura de Girondo, de ninguna manera queremos significar que el poeta trabaja con una lengua convencional. Muy lejos de ello, crea una de las lenguas literarias más vanguardistas y singulares del período. Si hablamos de "corrección", lo hacemos con la intención de contrastar su lenguaje poético con otras escrituras innovadoras del período las cuales, muchas veces, se elaboran a partir de estructuras agramaticales, cargadas de lunfardismos o giros populares.

Espantapájaros es una invitación a la rebelión en contra de las conductas esclerosadas, de las costumbres y las instituciones, pero también en contra de un lenguaje acartonado (Corral 1999b). Sin embargo, en la mayoría de los textos que conforman Espantapájaros se "respetan la estructura sintáctica normal de la oración a la vez que [se] desprecian y burlan el significado usual de las palabras" (599, destacado nuestro). La corrosión lingüística se

\footnotetext{
${ }^{318}$ La supuesta ignorancia o descuido en los casos de Arlt y Olivari constituyen los argumentos centrales de la crítica que los barbarizó y los ubicó en el dominio de las "malas escrituras", sin poder ver que, muchas veces, la escritura "desprolija" de estos autores forma parte de una intencionalidad cuya función, en los proyectos creadores respectivos, resulta central. Ver los capítulos IV y V, en los que se analizan a estos escritores

${ }^{319}$ Muy posiblemente, el artículo haya sido escrito por Raúl González Tuñón o Ulises Petit de Murat, críticos habituales del diario ("El último libro de Girondo" 1999: 622).

${ }^{320}$ Ver Sarlo (1997a).
} 
ejerce sobre las relaciones semánticas; sobre la mezcla de lo "alto" y lo "bajo", lo escatológico y lo sublime; sobre la experimentación con los géneros literarios, etc.; pero dicha corrosión se ejerce siempre dentro de los límites del diccionario, o bien a partir del uso de palabras extranjeras que no poseen la impronta negativa de las palabras derivadas de la inmigración. ${ }^{321}$ Todos estos juegos no involucran la normativa de la lengua, o si lo hacen, ocurre en muy pocas ocasiones y de modo tangencial. La esclerosis del lenguaje que Girondo denuncia en algunos de sus textos programáticos no radica en el código lingüístico en sí, en el idioma propiamente dicho, sino en los usos que la literatura hegemónica ha hecho de ese código. En 1923, recibe una carta de un amigo, en respuesta al envío de los Veinte poemas..., en la que le objeta algunas expresiones utilizadas en el libro. El poeta responde:

\begin{abstract}
Ahora en cuanto a lo de 'Becasina' siento no poder estar de acuerdo contigo. Admito todas las transformaciones morfológicas, y hasta sintácticas del lenguaje que quieras; no podemos pretender que sigamos expresando nuestras ideas modernas con nuestra mentalidad moderna en la misma forma que lo hicieron Cervantes o Lope de Vega; pero la ortografía y la propiedad del lenguaje son dos cosas que a mi juicio no pueden ni deben variar, so pena de perderlo (Artundo 1999: 518, destacado nuestro).
\end{abstract}

El pasaje ilustra su concepción sobre la lengua literaria. Si bien admite como imprescindibles las modificaciones del lenguaje con el objeto de renovar la literatura, las tensiones entre los parámetros innovadores y conservadores quedan explicitados con claridad. ${ }^{322} \mathrm{Si}$, por un lado, admite transformaciones en la lengua, por el otro evidencia un conservadurismo en lo referente a la alteración de la ortografía y recomienda no alejarse de "la propiedad del lenguaje". De ese modo, la expresión de las "ideas modernas" no debe atentar, necesariamente, contra algunos marcadores de corrección lingüística.

De esta manera, se explica por qué Girondo no alienta, por ejemplo, un idioma de los argentinos, como sí lo hicieron Arlt, Olivari o buena parte del martinfierrismo cuando estalló el debate sobre el meridiano intelectual. El poeta, en cambio, prefiere construir una nueva lengua literaria con los elementos lingüísticos heredados, enriquecidos por el aporte del lenguaje coloquial y por la importación y combinación de recursos considerados, tradicionalmente, como no literarios; procura socavar las bases de la literatura canónica

\footnotetext{
${ }^{321}$ Un ejemplo de uso de vocablos extranjeros "legítimos", provenientes de cierto cosmopolitismo prestigioso, es el poema "Tánger", de Calcomanías, en la que aparecen palabras como "jazz-band", "rugby", "sherry-brandy", entre otras (Girondo 1999: 41-44).

${ }^{322}$ Jorge Schwartz afirma que la apuesta de Girondo es "inventar una lengua que abarque las tradiciones y lo nuevo" (Rodríguez Pérsico 1999: 382).
} 
haciendo un uso subversivo con sus mismos materiales. De esta manera, construye sus textos "antilegalistas":

Si toda cultura requiere para su constitución la mutua presuposición de lo alto y lo bajo, Oliverio trastrueca los cánones estéticos cuando desconoce los límites de las culturas. En Espantapájaros, la desaparición de un sentido segundo propone una práctica de lo concreto que desata las fuerzas reprimidas del lenguaje. El énfasis en la literalidad desatiende lo referencial (...) Al dar vuelta los usos del lenguaje, se subvierte la creencia que ve univocidad en la lengua cotidiana y polivalencia en el arte. En vez de reforzar los sentidos figurados del lenguaje poético, la escritura se complace, a menudo, en recoger sintagmas sociales provistos de un sentido figurado único (Rodríguez Pérsico 1999: 389-390).

Rodríguez Pérsico señala una de las operaciones literarias más importantes de Girondo. Mediante este procedimiento, transforma radicalmente la lengua poética a partir de la incorporación no sólo de los usos cotidianos del lenguaje, sino también de una transformación de esos usos basada en brindarle espesor poético a aquello que tradicionalmente no lo tenía. De este modo, el lenguaje continúa inalterado desde el punto de vista normativo, pero dentro de la lengua literaria se producen importantes innovaciones.

En obras posteriores, como Persuasión de los días (1942) y En la masmédula (1954), el sujeto poético penetra el lenguaje al modo de una violación. En este último libro, la violencia se ejerce sobre una lengua a la que se despoja de la función comunicativa, que se hace opaca mediante las acumulaciones, la destitución de los significados y el quiebre de la sintaxis o la semántica (Rodríguez Pérsico). Las propiedades que asume el lenguaje literario de Girondo, en estos dos libros, se distancian bastante de las prácticas escriturarias del poeta de los años veinte. Existe, entonces, una gradual "descomposición" del lenguaje poético que se inicia de manera sutil con su primer libro pero, con el correr de los años, sus propuestas estéticas se radicalizan. Durante los años veinte, la "descomposición" comienza a darse en los aspectos semánticos del lenguaje, mientras que el quiebre de las normas sintácticas y/o morfológicas sucederá mucho después. No obstante, Espantapájaros es la obra que marca la apertura hacia las rupturas posteriores. Sirva como ejemplo el texto $\mathrm{N}^{\circ} 4$ :

Abandoné las carambolas por el calambur, los madrigales por los mamboretás, los entreveros por los entretelones, los invertidos por los invertebrados. Dejé la sociabilidad a causa de los sociólogos, de los solistas, de-los sodomitas, de los solitarios. No quise saber nada con los prostáticos. Preferí el sublimado a lo sublime. Lo edificante a lo edificado. Mi repulsión hacia los parentescos me hizo eludir los padrinazgos, los padre-nuestros. Conjuré las conjuraciones más concomitantes con las conjugaciones conyugales. Fui célibe, con el mismo amor propio 
con que hubiese sido paraguas. A pesar de mis predilecciones, tuve que distanciarme de los contrabandistas y de los contrabajos; pero intimé, en cambio, con la flagelación, con los flamencos... (Girondo 1999: 82).

Girondo expone la materialidad del lenguaje, lo conduce a asociaciones que tienen que ver más con la plasticidad de los significantes, con sus encuentros fonéticos, que con la coherencia que posibilitan las correspondencias entre significados y significantes. Utiliza, principalmente, asociaciones que están regidas por su efecto humorístico. Estos juegos con el lenguaje se encuentran determinados por la voluntad de negación y de rechazo de las formas establecidas. De esta manera, "abandona", “deja", "no quiere", "siente repulsión”, "conjura" y "se distancia" de todo aquello que tiene la forma de la certeza, de lo instituido y aceptado. En su lugar, propone un lenguaje transgresor de la tradición pero no de las normas lingüísticas.

\section{La recepción crítica}

En la década del veinte, tal vez Oliverio Girondo haya sido el martinfierrista con mayor proyección en el exterior del país. Así lo demuestran las numerosas reseñas dedicadas a sus libros -sobre todo a los Veinte poemas...-publicadas fuera de Argentina. Las repercusiones internacionales de su obra constituyen un correlato de su intensa actividad de viajero. Como es muy bien sabido, en julio de 1924, inició un periplo por el continente americano que lo llevó a Chile, Perú, Cuba y México. Luego de una estancia en New York, llegó finalmente a España. Los motivos de esta larga gira se explican desde las páginas de Martín Fierro: con su viaje, emprendió una "trascendente misión de confraternidad artística e intelectual de la juventud de América y Europa latina” (“Oliverio Girondo en misión intelectual" 1924: 3). ${ }^{323}$ El viaje se focalizó en la ampliación del público lector y en una campaña de promoción de los escritores rioplatenses de vanguardia; además, obviamente, del interés por difundir su propia obra. ${ }^{324}$

\footnotetext{
323 "Por iniciativa suya (...) y decididamente apoyado por MARTIN FIERRO, Oliverio Girondo logró formar el frente único de la juventud intelectual argentina (...), con los camaradas del Uruguay, lleva de Buenos Aires, en su viaje, la representación de este periódico, de "Inicial" (...), "Noticias Literarias" (...), "Valoraciones" de La Plata, "Cruz del Sur" y "Teseo", de Montevideo, además de la representación de una librería que aspira a hacer efectivo el intercambio de libros americanos, la de La Facultad, de Roldán, y de una recién fundada sociedad la "Editorial Proa", para designar sus agentes" ("Oliverio Girondo en misión intelectual" 1924: 3).

324 “... llegaremos al verdadero intercambio de producciones, revistas y libros; ideas, poesía, arte. Y nosotros, y los escritores a quienes nos dirijimos (sic), formando un bloque formidable, contaremos con veinte o treinta órganos de publicidad en todo el mundo y un público de varias decenas de miles de lectores. Huelga insistir en la importancia de esta empresa (...) que, generosamente, se prestó a realizar, con medios propios, nuestro distinguido compañero fundador de MARTIN FIERRO..." (“Oliverio Girondo en misión intelectual" 1924: 3).
} 
Fruto de las relaciones establecidas por Girondo en su gira son los artículos, aparecidos en Martín Fierro, dedicados a escritores y artistas mexicanos, como por ejemplo "La poesía de los jóvenes en México" ( $\left.\mathrm{N}^{\circ} 17\right)$ o "Arte infantil mejicano" ( $\left.\mathrm{N}^{\circ} 18\right)$. A medida que recorría Latinoamérica brindaba entrevistas, presentaba sus Veinte poemas y recogía reseñas muy auspiciosas en varios diarios y revistas. Entre septiembre y octubre de 1924, permaneció en México, adonde su primer poemario recibió una calurosa recepción. El 17 de septiembre, el diario Excelsior hizo un comentario sobre el arribo del poeta al país y le realizó una entrevista. Allí se afirma que los Veinte poemas "han tenido un éxito clamoroso en Buenos Aires" (Corral 1999a: 458). Por su parte, unos días después, el diario El Universal Ilustrado, señala que "el prestigio" de Girondo en Argentina "es muy grande" (460). Esta visión del poeta que se tiene en el exterior contrasta notablemente con las afirmaciones que Evar Méndez vuelca en las páginas de Martín Fierro siete meses atrás:

El cretinismo de las revistas anquilosadas y los magazines cursis, la estupidez de los grandes rotativos y su hipocresía (...) no ha querido hasta hoy comentar ni emitir juicio sobre los Veinte poemas para ser leídos en el tranvía, de Oliverio Girondo. Individuos de letras de otros países, ajenos a nuestro espíritu y nuestra sensibilidad, son los únicos que nos han dado su impresión sobre esta obra originalísima y vigorosa, que entra por la puerta más ancha en la literatura argentina (1924b: 4).

Méndez, en efecto, tiene razón puesto que buena parte de las reseñas de los Veinte poemas... provinieron de España. De hecho, el primero en festejar el libro es Ramón Gómez de la Serna, quien publica un artículo -"La vida en el tranvía"- en el diario El Sol de Madrid, en mayo de 1923. Al año siguiente, el texto se reproduce en la revista porteña Nosotros, pero bajo otro título: "Veinte poemas para ser leídos en el tranvía, de Oliverio Girondo". De la Serna procura, en primer lugar, destacar el valor del libro al señalarlo como "original", "gracioso", “interesante” y "revelador" (1924: 137). En segundo término, deja en claro que el poeta no imita a nadie puesto que Veinte poemas es "un libro sin falsedades y sin repugnantes tatuajes de estampilla ajena"; y puntualiza: "este libro (...) que sin necesidad de imitar como un tití o un salvaje a nadie, traza imágenes rotundas y greguerías que le pertenecen” (137).

La Nación publica un artículo -“Oliverio Girondo: Veinte poemas para ser leídos en el tranvía"- que no lleva firma pero corresponde, seguramente, a la mano de un escritor español, no sólo porque se encuentra entre una serie de artículos provenientes de ese país, y que el diario argentino recoge de diversas publicaciones peninsulares, sino también porque la nota incluye al libro de Girondo en el panorama de las letras no sólo americanas, sino también españolas. El autor de esta reseña coloca la obra del poeta en una nueva era literaria. Frente a 
Rubén Darío, que “cierra una época”, Girondo inaugura una nueva manera de hacer poesía en español: “después [de Rubén Darío] los poetas se han dado a reconstruir, de las ruinas del concepto antiguo, una poesía escueta, con el mayor ahorro posible de Gramática (sin analogía, sintaxis, prosodia ni ortografía académicas)..." (“Oliverio Girondo...” 1923: 9). El articulista valora positivamente las rupturas llevadas a cabo por el poeta y percibe los cambios que produce en la lengua poética. Así como, desde Martín Fierro, Girondo destacó el quiebre idiomático que significó la poesía de Darío, la reseña ubica al poeta argentino en línea de continuidad con respecto a las innovaciones lingüísticas del nicaragüense. Según la reseña, los Veinte poemas "nos muestran a Oliverio Girondo como poeta finísimo y atento a conseguir (...) la perfección del gusto nuevo" (9). De este modo, Girondo es definido como "el mayor representante, en una nueva corriente expresiva que no pone tanto el acento en la normativa" (9).

Evar Méndez escribe para Martín Fierro un artículo cuyo título es "Oliverio Girondo" ( $\mathrm{N}^{\mathrm{o}}$ 2, marzo de 1924). Allí, como ya hemos puesto de manifiesto, Méndez denuncia el "cretinismo" y la "estupidez" de quienes no han querido "comentar ni emitir juicio sobre los Veinte poemas para ser leídos en el tranvía" (1924b: 3). Y, como contrapartida, resalta que "individuos de letras de otros países" fueron los únicos encargados de "dar su impresión sobre esta obra originalísima y vigorosa" (3). A su vez, Méndez procura insertar la figura y la obra de Girondo en el marco del nacionalismo anti-inmigratorio de Martín Fierro, caracterizado por la recuperación de una tradición heredada y enriquecida con aportes propios, pero raramente ensayada en las obras de los martinfierristas. De este modo, Méndez afirma acerca del poeta:

Se percibe además en la obra una sonoridad, un timbre de cosa netamente argentina, que hasta hoy no reflejo la literatura nacional: algo de franqueza gaucha mezclada con rudeza y desplante indígena en el estrépito de algunos pasajes, al arrojar palabras como boleadoras, al pintar con guapeza toda argentina nativa, ancestral (...) sus paisajes , sus cuadros y sus gentes de todo el mundo. Audacia que se funde con su aristocracia originaria, para convertirse en elegancia y en belleza de ley, regida por su irónico exceptismo (sic). Y, por fin, una gallarda insolencia... (3).

Este pasaje habla más de un discurso tendiente a construir una identidad nacional, en continuo debate, que de Girondo. Así, de acuerdo con Méndez, el gaucho y el indio definen la "argentina nativa y ancestral" que sirve para enmarcar y caracterizar la primera obra poética de Girondo, aunque esta carezca, notablemente, de indios y de gauchos. La "aristocracia originaria" es la que instaura las distancias y diferencias, la que separa convenientemente la ancestralidad -lo otro- de lo originario -el si mismo-; pero por sobre todas las cosas, ayuda 
a distinguir el espíritu martinfierrista de aquellos escritores centrales en el grupo -Borges, Girondo, Méndez, Güiraldes, etc.- respecto de aquellos otros que participan de la intención vanguardista, pero desde un costado más marginal y "espurio" -Nicolás Olivari, Raúl y Enrique González Tuñón, Santiago Ganduglia, etc.-. La aristocracia también funciona como asepsia lingüística, en tanto Girondo tamiza la supuesta herencia gauchesca e indígena con el cedazo de su cosmopolitismo legítimo. ${ }^{325} \mathrm{Si}$ su lenguaje "ahorra en gramática", como afirma el comentarista anónimo de La Nación, sus orígenes y patrones culturales lo preservan de la "mala escritura". La "elegancia” y la "belleza de ley" con las que Méndez se refiere a sus versos contribuyen a separarlos de la rusticidad de la tradición en la que, supuestamente, se insertan. Pero, además, los diferencian de ese otro lenguaje, también rústico pero ubicado en el presente: el proveniente de la inmigración.

La idea de la corrección en Girondo, unida a la intención de Méndez de entroncar su poesía con lo nacional, a partir de la evocación del gaucho, se podría pensar a partir de la opinión de Lugones sobre la lengua literaria que, dos años después, brindará desde las páginas de La Nación. El 12 de septiembre de 1926, en el suplemento literario del diario de Mitre, Lugones comenta Don Segundo Sombra de Ricardo Güiraldes y establece su modelo de lengua literaria nacional: aquélla que tome un tema argentino -el gauchesco-, pero supeditado a un lenguaje "correcto" o culto. En este sentido, para Lugones, la obra de Güiraldes cumple con estos requisitos. Cuando los gauchos de la novela hablan directamente, su lenguaje "es limitado y defectuoso, bajo el aspecto gramatical, o sea como expresión literaria”, sin embargo, el acierto de Güiraldes, según Lugones, consiste en que "el protagonista cuenta su historia con su propio lenguaje", es decir, culto. La "imperfección" que deriva de los personajes que dan forma a la temática nacional es subsanada con la intervención de un narrador que porta la "corrección" formal imprescindible para alcanzar una obra valiosa: "en arte no hay término medio ni capitulación posibles: lo que puede estar mejor debe estar mejor. Porque el deber de belleza impone la aspiración a lo perfecto (1926: 4, destacado nuestro). Como resulta evidente, el error gramatical se convierte en un defecto artístico para Lugones. Los escritores más novedosos de los años veinte (Arlt, Olivari, E. González Tuñón, etc.) reaccionan contra esta concepción del lenguaje literario. Sin embargo, Girondo, al menos en sus primeros libros, halló la manera de romper con los cánones literarios sin comprometer la gramática de su lengua literaria.

${ }^{325}$ Ver Sarlo (1997a). 
En 1923, Vicente Martínez Cuitiño reseñó los Veinte poemas en la revista Vida Nuestra (1917-1923). ${ }^{326}$ Al comienzo del artículo, traza las coordenadas que definen este primer momento del poeta: la lujosa primera edición francesa - “el suntuoso cuaderno de Argenteuil", la llama-, hecha en "papel de Velin puro hilo Lafuma", que ya desde su aspecto exterior la define como "una obra de arte" (1923: 49); su vinculación con "La Púa"; su afinidad con algunos poetas franceses, tales como Baudelaire, Laforgue, Rimbaud (51). En cuanto al lenguaje, Martínez Cuitiño sostiene que

algún exégeta hallaría reparos a la libertad de expresión que es tal vez uno de los encantos del libro. Y podría afirmar que asoma en los poemas con innecesaria frecuencia la diabólica burbuja sensual apenas disuelta por el chiflón helado del espíritu (52).

Si bien, como sabemos, Girondo no riñe con la gramática como lo hace Olivari o Arlt, en las primeras reseñas de los Veinte poemas se pone de manifiesto algo que incomoda, que necesita ser destacado y que se vincula con la lengua literaria. Como hemos afirmado, muchas veces se produce una correlación entre la "libertad de expresión" de la que se vale con la presencia del erotismo. El autor del artículo continúa:

Podría reprocharle algo más sin duda: cierta desigualdad en el estilo, por ejemplo; algún rebuscamiento que ha dejado su traza sobre esmalte, acaso. Y un dómine ceñudo iría más lejos: a censurarle, quizá, su evidente pasión por las nuevas maneras... (52).

Si bien se destacan las "desigualdades del estilo", Martínez Cuitiño no juzga las innovaciones en ese terreno como algo negativo. Lejos del "dómine ceñudo", el artículo configura un aval para las nuevas formas poéticas que entablan lucha con formas textuales más conservadoras. De esta manera, Martínez Cuitiño precisa que el idioma del poeta "es fuerte, como es rica su imaginación, como es olímpico su desdén por las formas anquilosadas en las cuales se precipita tanto lacayuelo literario" (53). Sin embargo, existe un aspecto que Martínez Cuitiño critica: el corte aristocrático que supo imprimir a, por lo menos, su primer poemario. Según el comentarista, a Girondo le resta cumplir con un deber:

el de democratizar un poco más sus ediciones para que todo el mundo pueda escuchar los acordes de su lira. De otro modo sus vibraciones se limitarán a herir la sensibilidad de

\footnotetext{
${ }^{326}$ Vida Nuestra fue una publicación mensual que adquirió cierta trascendencia en su época. Estuvo dirigida por Aarón Bilis, León Kibrik, E. Mizes y otros. Publicó 75 números entre julio de 1917 y septiembre de 1923. En ella colaboraron importantes intelectuales, tales como Ricardo Rojas, Leopoldo Lugones, José Ingenieros, Arturo Capdevila, Alberto Gerchunoff, Manuel Gálvez, Alejandor Korn, entre otros (Lafleur et al. 2006).
} 
determinados grupos, no siempre aptos ni atentos (...) El pueblo, tan calumniado por las capillas, atesora, entre la gran masa anónima de las intuiciones, una sensibilidad que le equivale, la ingenua, por lo que no solamente suele percibir con mayor rapidez las altas presencias, sino que hasta en la diatriba suele ser más espontáneo (53).

De acuerdo con Martínez Cuitiño, las innovaciones literarias y lingüísticas no debieron estar exentas de constituir un aporte importante para los sectores populares, puesto que estos grupos poseen una sensibilidad y una capacidad nada desdeñable para captar las nuevas formas artísticas. Martínez Cuitiño no estaba de acuerdo, en definitiva, con la concepción elitista que tendrá el futuro martinfierrismo -que Girondo encarna de manera ejemplar-, consistente en negar al pueblo el potencial para captar las nuevas estéticas, y en el menosprecio y la xenofobia con que buena parte de la vanguardia estética juzga a los sectores populares. La democratización de sus textos será parcialmente concretada tres años después de editados los Veinte poemas, cuando la Editorial Martín Fierro lanza la "edición tranviaria" de este poemario, en 1925.

Como ya hemos señalado, cuando publica Calcomanías, dedica varios poemas a la joven guardia madrileña. No es extraño, entonces, que las reseñas españolas se ocupen también de este segundo libro. ${ }^{327}$ De estos comentarios que ha recibido Calcomanías nos interesa, muy especialmente, el que escribe Guillermo de Torre para la revista Proa en julio de 1925. Su interés radica en que De Torre piensa la literatura de Girondo desde los parámetros que ofrecen los problemas en torno al idioma, temática dentro de la cual el crítico español está llamado a desempeñar un rol preponderante, en tanto antagonista de la intelectualidad argentina en general y del martinfierrismo en particular, ya que fue él quien dio pie a la extensa polémica sobre el meridiano intelectual de Hispanomaérica, en cuyo centro gravitan sus actitudes lingüísticas y en ellas se cifra la batalla sobre la supremacía cultural e idiomática de España.

De Torre señala que la poesía de Girondo "se nos aparece como proyecciones corroboradoras de la poesía más genuina de nuestro tiempo" (1925b: 18). Su propósito inicial en estas primeras páginas es dejar en claro que la poesía del argentino inaugura "una Nueva Era" (18) y que su figura se corresponde con la de un "verdadero poeta nuevo" (22). Sin embargo, cuando De Torre se ocupa del estilo, su visión no resulta tan amable. Afirma que podría hacérsele un "reproche (...) desde un punto de vista puramente técnico": se refiere a

\footnotetext{
${ }^{327}$ Por ejemplo, Benjamín Jarnés escribe para la madrileña Revista de Occidente un artículo en el que pondera al poeta de la siguiente manera: "Vimos trepar ágilmente por los viejos muros españoles a estas pupilas de gran niño de Oliverio Girondo, que buscan, en la luz o en las sombras, en El Escorial o en las Sierpes, la cartela más sugerente donde asirse y quemar desde allí su gavilla de imágenes" (1925: 255).
} 
"la dureza y el embarazo de su expresión verbal" (26). La "dureza" del estilo se explica mediante "las peculiaridades de su sintaxis" que, en ocasiones, hace que "las palabras pesen demasiado y los enganches sintácticos se [tornen] duros y difíciles". Y le recomienda: "debe aspirar, por tanto, a hacerlos más suaves, a dotar a su verbo de una fluidez lubrificadora y de un ritmo más grácil" (26). En cuanto al "embarazo" que producen los versos del poeta, De Torre no se explaya en ese terreno, pero evidentemente se refiere al contenido sexual, el otro punto que convierte en "problemática" la lengua literaria del poeta.

En primer lugar, De Torre ubica a Girondo como un impulsor del "americanismo literario". Lo positivo de esta postura, según De Torre, radica en que el poeta no enmascara su escritura "con afeites europeos". Si bien dice "europeos", De Torre quiere significar "franceses", puesto que en sus textos hay una insistencia por destronar la hegemonía cultural francesa y proponer la española. ${ }^{328}$ En segundo término, el americanismo conlleva una “imperfección": "un cierto sabor bravío, un encanto de cosa primitiva y fragante, derivada del manantial de Martín Fierro" (26, destacado nuestro). Como puede observarse, la idea de lo americano aparece ligada a cierto campo semántico relativo a la barbarie, lo cual resulta muy significativo para poder precisar las representaciones de la América hispana que De Torre proyecta sobre los campos de la lengua y la cultura. Según este autor, el americanismo literario puede tener como consecuencia inmediata la formación de un nuevo idioma español propio de Sudamérica; fenómeno que, en 1925, valora muy positivamente y que atribuye únicamente a los escritores reunidos en torno a Martín Fierro. Así, los precursores de estas innovaciones literarias e idiomáticas serían "Girondo con Güiraldes y otros pocos", puesto que son justamente ellos quienes tienen "fe en sus posibilidades fonéticas" (27). Y agrega:

\footnotetext{
Ya en otro lugar di mi vaticinio sobre la evolución, o, más bien, la creación de un nuevo idioma español, de un estilo autóctono sudamericano, que aspira salir de los cauces domésticos y a adquirir, depurado y ennoblecido, una nueva categoría literaria. Los signos de esta renovación son ya varios y merecedores de crédito. En ambas riveras del Plata, surge una falange de poetas y prosistas, desde los mismos Güiraldes y Girondo, con Borges hasta Ipuche y Silva Valdés, preocupados por hallar un nuevo cauce verbal a sus sentimientos más genuinos (27).
}

El artículo de De Torre, además de mostrar el modo en que los vanguardistas españoles consideran a Girondo, constituye una buena demostración de la imbricación que existe entre

\footnotetext{
${ }^{328}$ Recordemos que la editorial de De Torre -"Madrid, meridiano intelectual de Hispanoamérica"- discute la noción de "Latinoamérica", en tanto esta supone una filiación directa con Francia. Por eso propone el viejo nombre de "Hispanoamérica", el cual restablece los lazos entre América y España, de acuerdo con tres factores fundamentales: el origen étnico, la filiación lingüística y el carácter espiritual (Croce 2006: 67).
} 
la cuestión del lenguaje literario y los debates acerca del idioma. Durante estos años de fuertes discusiones en torno, por un lado, a las nuevas textualidades y, por el otro, a los problemas que depara el idioma, a la literatura, muchas veces, se le atribuye una función de modeladora y creadora de formas idiomáticas que trascienden el plano meramente literario y pasan a integrar el acervo idiomático común. En los momentos en que De Torre escribe este artículo, existe una buena relación entre los ultraístas españoles y la vanguardia martinfierrista. La idea de un idioma sudamericano, por entonces, no resulta tan incómoda a los madrileños como lo será en 1927, cuando el mismo De Torre publique la conocida editorial sobre el meridiano.

En este artículo sobre la obra de Girondo, De Torre afirma que ya son visibles los signos de una renovación. La percepción de que Argentina, a través de la eclosión literaria que suponen las nuevas escrituras que aparecen durante los años veinte, está fraguando una nueva lengua literaria, bastante alejada del español heredado y con una personalidad propia, se encuentra muy extendida. No sólo entre los martinfierristas, o entre los ultraístas españoles que se hacen eco de ese fenómeno proclamado por muchos de los escritores argentinos con quienes mantienen cotidiano contacto, sino también un autor como Valery Larbaud, muy cercano al martinfierrismo y amigo personal del matrimonio Güiraldes, hace referencia a este fenómeno de renovación literaria. Así lo afirma De Torre:

Hasta un vigía del 'Dominio Español' -tan constante y afinado como Valery Larbaudreconocía ha poco (...) la existencia de una nueva lengua literaria en trance de ser fraguada por los americanos 'más capaz de expresar lo que se tiene ante los ojos que la lengua tradicional y bastardeada que defienden en vano los casticistas' (27).

De Torre se refiere a un artículo que Larbaud publica en el octavo número de la revista Proa (1925). ${ }^{329}$ En ese texto, Larbaud explicita su posición con respecto a la lengua literaria. Además de impulsar y alentar la consolidación de un lenguaje literario autónomo, su tesis se configura como una reconvención hacia los escritores rioplatenses puesto que habrían cometido el error de descuidar las herencias y las buenas influencias culturales y literarias. Por este motivo, De Torre llama a Larbaud “vigía del dominio español”. Sin embargo, ese epíteto proviene de una tergiversación interesada de De Torre. Para Larbaud, las tierras americanas se encuentran bajo la hegemonía española puesto que resultan "una inmensa prolongación ultra atlántica del dominio español” (Larbaud 1925: 16), por lo que recomienda a los jóvenes escritores argentinos "acentuar el acercamiento intelectual que os lleva de nuevo hacia España, origen siempre fecundo de la lengua que habláis todos los días, y cuyo

\footnotetext{
329 "Carta a dos amigos" (Larbaud 1925).
} 
Renacimiento literario parece a punto para haceros desear ese acercamiento" (17). Se trata de reconocer un origen sobre el cual debe edificarse esa lengua literaria novedosa y "cosmopolita" que, según Larbaud, ya se está fraguando en el Río de la Plata y de la cual Ricardo Güiraldes representa uno de sus más conspicuos hacedores. Sin embargo, lejos de lo que De Torre presenta como una postura propia del purismo o hispanismo, Larbaud se interesa, más que nada, en los aspectos cultuales y literarios de España y desdeña la "lengua tradicional y abastardada" que defienden los casticistas.

Larbaud resulta clave en relación con los procesos de autonomía literaria dado que teoriza a mediados de los años veinte sobre la idea de que dicha autonomía sólo podía conseguirse a costa de eliminar los límites políticos y lingüísticos de las naciones. Deseaba la llegada de una "internacional intelectual", es decir de una élite supranacional encargada de realizar una crítica literaria capaz de destronar los nacionalismos literarios, responsables de crear la ilusión de unicidad, especificidad e insularidad. Esta "aristocracia", cuyo poder es meramente literario, tiene la facultad de ser indivisible: es nacional debido a que encarna la cultura que ha formado y agrupado la nación, pero también, y al mismo tiempo, internacional puesto que sólo puede encontrar sus pares o iguales entre las élites de las demás naciones (Casanova 2001). Esas relaciones intelectuales son para Larbaud garantes de las autonomías literarias ya que excede las divisiones políticas y lingüísticas e impone una definición autónoma (es decir, no nacional) de los criterios de legitimidad literaria. En este sentido, la búsqueda de una lengua literaria autónoma durante los años veinte, en Argentina, encuentra en las palabras de Larbaud una legitimidad, proveniente de un intelectual francés, que permite pensar el lenguaje literario menos ligado a las condiciones, filiaciones, prescripciones formales y tradiciones anudadas a criterios nacionales. A comienzos del siglo XX, se pensaba que la literatura debía consagrar el uso culto del idioma; es decir, la lengua literaria era considerada modelo de lengua nacional. En la década de 1920, se producen desplazamientos que hacen que la literatura ya no se perciba como un patrón de lengua estable y modélica, sino que algunos escritores empiezan a trabajar con sus límites. El lenguaje literario, lenta y parcialmente, abandona su condición de lengua modelo, de ejemplo idiomático en los libros de gramática o manuales escolares, para concebirse como campo de pruebas. Precisamente, las ideas Larbaud circularon en Argentina a través de los artículos publicados por la revista Proa, en 1925, y en los intercambios epistolares que entabla con Ricardo Güiraldes.

Lentamente, el espacio literario se desnacionaliza, explica Pascale Casanova, para quien, contradictoriamente, Francia, gracias a su gran capital literario acumulado, se conserva 
como el más autónomo y libre de las instancias político nacionales (121) ${ }^{330}$ El poder literario de este país se manifiesta, además de en su facultad de consagrar autores y convertir obras en clásicos, en la capacidad de invertir los valores literarios. De este modo, por ejemplo, Larbaud señala que las primeras novelas de William Faulkner ${ }^{331}$ llegaron a Francia con la etiqueta de "literatura campesina", género menor en la jerarquía de los géneros novelescos (Casanova). Sin embargo, gracias a la traducción e introducción de la novela, a cargo del mismo Larbaud, en la capital mundial de las letras, la obra de Faulkner accede a "la modernidad novelesca, asociada siempre con la vanguardia formal" (433). ${ }^{332}$

Las reflexiones de Larbaud sobre la autonomía ponen en juego la relación entre lengua nacional y lengua literaria. Si tradicionalmente la segunda servía de modelo prescriptivo para las configuraciones de la primera, la idea de la autonomía literaria tiende a cuestionar la forma tradicional de ese vínculo y el lenguaje literario comience, al menos en parte, a regirse por sus propias reglas.

Si tenemos en cuenta estas ideas, se comprende por qué no existe contradicción en el hecho de mirar hacia Europa con el objeto de definir, mejorar y consolidar la literatura del Río de la Plata, como propone Larbaud, puesto que, como acabamos referir, para este autor la autonomía literaria supone un desprendimiento de esa esfera intelectual respecto de las regulaciones políticas. Para el crítico y traductor francés las letras argentinas se hallan en una marcada relación de inferioridad con respecto a las letras europeas, sobre todo francesas. En el artículo de Proa, Larbaud justifica la atención que los argentinos deben prestar a España,

\footnotetext{
${ }^{330}$ En esta cita, la opinión de Casanova coincide con la de Larbaud: ambos resultan francocéntricos. Plantean la autonomía pero en realidad es una forma de establecer o legitimar el dominio o la superioridad de las letras francesas por sobre las del resto del mundo. A María Teresa Gramuglio le resulta "asombroso" el marcado francocentrismo de La república mundial de las letras (2013: 350) y no ahorra críticas: relama que los puntos que toca Casanova "a veces con bastante ligereza o de segunda mano en su desordenado libro", sean revisados desde perspectivas más rigurosas. Sobre su concepto principal de "literatura mundial" afirma que "es dable inferir la escasa atención prestada a un área tan vasta y dinámica como la de las literatura del mundo hispanohablante, o la dificultad de integrarla en una concepción tan sesgada de lo "mundial"” (367).

${ }^{331}$ Larbaud fue el encargado de introducir -y de traducir- en Francia a escritores como James Joyce y William Faulkner, entre otros.

${ }^{332}$ Algo similar podría pensarse en relación con Güiraldes: Don Segundo Sombra es una novela deudora, en parte, de la gauchesca, un género poco autónomo en el sentido de su inmediata conexión con lo político y lo social. Sin embargo, esta obra establece una tensión a partir de los criterios establecidos por Lugones, en el artículo del diario La Nación comentado más arriba, para quien, precisamente por su tema y por su lengua literaria, Don Segundo Sombra era una novela nacional. Güiraldes, enterado de las ideas de autonomía literaria de Larbaud, produce una obra moderna que participa de la vanguardia estética. La influencia de Larbaud en la novela se puede rastrear en los cifrados homenajes que le realiza Güiraldes. En una de sus cartas, le manifiesta:
}

Verá que el primer gaucho que ayuda al pequeño Cáceres en la vida es un tocayo de usted. No sin intención sucede esto, como tampoco es mera coincidencia que el apellido Lares lleve la inicial de Larbaud. Con gran cariño lo he hecho y con igual egoísmo se lo hago notar. (1962a: 789). 
pero la permeabilidad y el dominio de las letras francesas prácticamente no necesitan argumentación:

Considerad, sin embargo, que hubiera podido yo (...) predicar ante todo la necesidad, para ustedes los jóvenes, de estar más que nunca atentos a lo que se hace en Francia, es decir, predicar para mi santo, puesto que, gracias a su intermedio, tengo el honor de ser uno de los intérpretes -iy asalariado- de la literatura francesa en Argentina. Pero la influencia del arte francés en las letras de América latina, es sobre todo una cuestión de afinidad en ustedes y de mérito en nosotros. Ello cesaría el día en que nuestros escritores dejen de merecer vuestra atención. No hay nada que hacer (1925: 18).

De regreso al artículo de De Torre, sobre el final, cuando se refiere al problema del idioma, asume una postura similar a la que tiene, desde las páginas de Martín Fierro, Ramón Gómez de la Serna, quien preconiza "la libertad del pueblo nuevo y original" por sobre la "esclavitud" y la "solemnidad" (De la Serna 1925: 5). Esas concesiones se hacen siempre desde la superioridad que los vanguardistas españoles adjudican al idioma de su país; pero cuando ese liderazgo es puesto en duda -las réplicas de todo el arco martinfierrista a los planteos de De Torre acerca de Madrid como centro de irradiación cultural constituyen un buen ejemplo-, se colocan en el lugar de los casticistas criticados por Larbaud.

Finalmente, De Torre termina su artículo con unas últimas reflexiones de Larbaud sobre la lengua literaria americana:

En cuanto a las objeciones que frente a la legitimidad de esta lengua pudieran erigirse, el mismo crítico [Larbaud] se anticipaba sagazmente a pulverizarlos: “suponed, decía, que surja a vuestra zaga un escritor argentino, chileno o colombiano de la envergadura de un Withman o un Poe: esto bastaría para imponer de viva fuerza los mejores de vuestros americanismos y la mayor parte de vuestros galicismos e italianismos a la lengua literaria de la Península”. Pues bien: ya sea Güiraldes (...) o bien Girondo (...) en su ámbito creemos que está llamado a surgir ese gran espíritu de mañana, anunciador, encarnación y crisol al mismo tiempo de un nuevo estilo trasatlántico (1925b: 27).

Los problemas de la lengua literaria en relación con las discusiones en torno al idioma no son gratuitos en un texto cuyo tema principal es la obra de Oliverio Girondo. De todos modos, no hay que olvidar que pese a que De Torre afirma que la renovación idiomática resulta muy visible en el Río de la Plata y merecedora de crédito, los señalamientos relativamente negativos hacia el estilo del poeta, como así también hacia lo que denomina "americanismo literario" y hacia las posiciones del martinfierrismo, habla a las claras de una postura ambigua por parte del escritor español en relación con este tema; postura que, como ya hemos dicho, se tornará clara y definida hacia 1927. 
En Argentina, Calcomanías despertó algunos comentarios. En junio de 1925, su compañero de vanguardia, Jorge Luis Borges, escribió una reseña sobre este libro en el número 18 de Martín Fierro. En este artículo, el autor de Fervor de Buenos Aires contrasta la estética de Girondo con la suya propia. En cierto modo, al referirse a Girondo, Borges no hace otra cosa que hablar de sí mismo. Con una tonalidad agridulce constituida por certeros elogios detrás de los cuales se adivina una crítica velada, Borges afirma: "es innegable que la eficacia de Girondo me asusta. Desde los arrabales de mi verso he llegado a su obra" (1925b: 4). La mención de la palabra "arrabales" no es inocente: Borges contrasta su poesía del arrabal -ese arrabal intemporal, mítico, prolijamente limpio de la presencia del inmigrante- con el cosmopolitismo que ensaya Girondo en sus libros. Si bien el autor de Calcomanías tampoco es un cultor de la Buenos Aires "plebeya", no obstante recupera una ciudad inmersa en el acelerado proceso de modernización, dando así a su lengua literaria la riqueza y el dinamismo de un vocabulario novedoso y muchas veces considerado "anti-poético", en comparación con el sosegado y frugal lenguaje del joven Borges. Esta diferencia fundamental hace que Borges diga con ironía: "me he sentido provinciano junto a él" (4). En cuanto al estilo, señala: "Girondo impone a las pasiones del ánimo una manifestación visual e inmediata: afán que da cierta pobreza a su estilo (pobreza heroica y voluntaria, entiéndase bien) pero que le consigue relieve" (4). Las dudas que despierta en Borges el lenguaje de Girondo quedan transparentadas en este extraño elogio. Muchos años después, un Borges anciano precisa su opinión acerca del poeta y su lenguaje:

Las cartas de Oliverio no se entendían. Eran como Finnegan's Wake. Un día me dijo que había conseguido un español macanudo que le corregía los originales, porque cuando se los corregía Ricardo Güiraldes se los llenaba de paréntesis, comas, diéresis, etc. Y al pobre Oliverio, caramba, eso no le agradaba (1984: 10).

Si bien este comentario se encuentra al final del largo recorrido de la vida de Borges, interesa recuperarlo en la medida en que nos devuelve una opinión no muy diferente en torno a la escritura de Girondo a la que, hacia mediado de los años veinte, planteaba, sin duda con muchos escrúpulos. En una serie de apreciaciones, vecinas de la injuria, ${ }^{333}$ Borges se encarga de rebajar a Girondo de tal manera que, cuando se refiere a sus supuestas dificultades escriturarias, se podría pensar que está hablando de Roberto Arlt y no del autor de los Veinte

\footnotetext{
${ }^{333}$ En esta entrevista, Borges hace apreciaciones del siguiente calibre: "Oliverio simulaba libros que consistían sobre todo en páginas en blanco, carátulas. Si le publicaran las obras completas, bueno, no llegarían a una página. ¿Si hay un posible paralelismo conmigo? ¡Pero no!, yo alguna página rescatable creo haber escrito. Oliverio era un infeliz, Xul Solar en cambio era un hombre de ingenio. Él se reía de Xul Solar y después lo plagió tardíamente en un libro que se llama En la masmédula" (1984: 10).
} 
poemas... De esta manera, Borges deposita a Girondo en el terreno de la "mala escritura", de la escritura ciertamente "incorrecta" que requiere instancias de revisión ajenas al autor, imposibilitado de lograr un texto adecuado. Con el correr de los años, la figura de Güiraldes no se desdibuja del paternalismo que muchos jóvenes vanguardistas supieron otorgarle. En cierto modo, la imagen dispar de un Güiraldes corrigiendo por igual a Girondo y a Arlt, en los años veinte, habla a las claras de las dificultades y tensiones que encontraban los nuevos lenguajes literarios aún en el seno de los propios vanguardistas.

En 1932, publicó el último libro de la serie que se abrió diez años antes con los Veinte poemas...: Espantapájaros, (al alcance de todos). A diferencia de los textos que lo preceden, su recepción crítica fue casi nula. Entre los contados festejos, se encuentra el que Enrique Amorim le dispensa en una carta personal:

\footnotetext{
Mi gran Oliverio: Tu libro [Espantapájaros] brincaba de entusiasmo de mano en mano en la calle y el café. Eres el hombre de los hallazgos, de las definiciones, de todos los extravíos... Has hecho un libro con el cual pasamos por las armas a todos los burgueses juntos. No queda uno solo sin afeitar. Los amigos están entusiasmados con tu manera de espantar, y preparan artículos y noticias por radio, mientras dueños, aún analfabetos, siguen sin leerte (2007: 399).
}

Sin embargo, pese al panorama que describe Amorim, los pocos comentarios recibidos muestran que la obra no fue comprendida y que fue leída como un producto tardío de la generación martinfierrista (Corral 1999b). Una nota anónima de la revista La Literatura Argentina se refiere a Espantapájaros como "un libro desconcertante (...), la última bufonada de la generación que ya no tiene nada que decir" ("Espantapájaros por Oliverio Girondo" 1932: 351). Cabe mencionar algunos aspectos de este breve artículo: allí se señala que el poeta fue "de los primeros que removieron el ambiente nacional con sus poemas de nuevo y atrevido estilo" (351, destacado nuestro). Desde su inicio, ya se puede apreciar la dirección que va a tomar el comentario: la sanción explícita de una lengua literaria asociada con lo soez y procaz. Luego de citar el poema $\mathrm{N}^{\mathrm{o}} 1$ de Espantapájaros, afirma: "este tono desenfadado armoniza las 24 notas que componen el volumen. Aquí todo es burla ingeniosa, hecha de juego de palabras, disparates, imágenes sorprendentes y, de cuando en cuando, una suciedad para espantar" (351, destacado nuestro).

Las pocas reacciones en contra y los muchos silencios se explican en el hecho de que Girondo, con este libro, lleva hasta la crispación aquellos rasgos de su lengua literaria que muchos habían impugnado u observado en las críticas y reseñas correspondientes a sus obras precedentes. En este texto es donde el poeta experimenta con las sonoridades y las formas del 
significante, con fórmulas hechas y proverbios, y radicaliza la incorporación de un lenguaje antipoético y muchas veces procaz. ${ }^{334}$ Todo el libro es una saludable invitación a la rebelión en contra de las conductas esclerosadas, de las costumbres y las instituciones, en contra también de un lenguaje acartonado (Corral 1999b). A propósito del lenguaje de Espantapájaros, Delfina Muschietti agrega que en este texto

se da cita el espacio abigarrado y tumultuoso de la ciudad, allí resuenan en mezcla babélica todos los lenguajes: es la ciudad cosmopolita e inmigrante en la que se escuchan 'bataholas' surgidas de un 'conventillo de calabreses malcasados' (2009: 132).

En primer lugar, hay que señalar que la referencia a los inmigrantes, citada por Muschietti, perteneciente al texto $\mathrm{N}^{\mathrm{o}} 11$ del libro, es la única que aparece en toda la obra. Pese a las amplitudes que pueden rastrearse en Espantapájaros en relación con sus otras obras, el inmigrante continúa permaneciendo al margen de las búsquedas poéticas de Girondo. En segundo lugar, resulta difícil acordar con Muschietti con respecto a que en el libro "resuenan en mezcla babélica todos los lenguajes". Si bien el poeta menciona el costado inmigratorio de la ciudad -sólo es eso, apenas una mención-, la voz del inmigrante no aparece nunca, ni en éste ni en ninguna de las dos obras anteriores. Si, por un lado, Borges piensa una Buenos Aires hecha a medida de ese arrabal que procura restaurar un pasado pre-inmigratorio; por el otro, nos encontramos con la ciudad babélica, suburbana, de escritores como Roberto Arlt, Enrique González Tuñón o Nicolás Olivari, por mencionar algunos, quienes justamente intentan lo contrario: representar esos sectores que conforman el grueso de la población. Por su parte, Girondo retrata el proceso de modernización que va teniendo lugar en la ciudad, pero como Borges, prefiere obviar los sectores populares. Cada uno de los diseños urbanos propuestos por la literatura de los años veinte implica opciones sobre el lenguaje literario. Si existe alguna mezcla en Espantapájaros, de ninguna manera podemos llamarla babélica, y menos aún en el contexto de la década del veinte en la que lo "babélico" tenía una obligada y peyorativa referencia hacia los sectores inmigratorios de la población porteña.

No obstante, más allá de su rechazo por los sectores marginales de la sociedad, Girondo representa algunos espacios propios de las clases populares. Nos referimos, por ejemplo, a la milonga, que da el título a uno de los Veinte poemas:

\footnotetext{
${ }^{334}$ Los juegos poéticos centrados en las formas del significante pueden verse con claridad en el texto $4 \mathrm{y}$ en el 18. El entrecruzamiento entre frases hechas y dichos con novedosas referencias sexuales pueden rastrearse en el texto 14. En cuanto al lenguaje procaz, se puede señalar que se encuentra vinculado al uso de palabras que no tienen tanto que ver con lo erótico o pornográfico, sino más bien con palabras tabuizadas o utilizadas por el discurso médico, como "esperma", "secreciones", "espermatozoico", "pezones", "testiculares"; o bien lindantes con cierto mal gusto y del todo inusuales en el discurso literario de la época: "mujeres preñadas", "sexos usados", "enfermedades venéreas", etc.
} 


\section{Milonga}

Sobre las mesas, botellas decapitadas de «champagne» con corbatas blancas de payaso, baldes de níquel que trasuntan enflaquecidos brazos y espaldas de «cocottes».

El bandoneón canta con esperezos de gusano baboso, contradice el pelo rojo de la alfombra, imanta los pezones, los pubis y la punta de los zapatos.

Machos que se quiebran en un corte ritual, la cabeza hundida entre los hombros, la jeta hinchada de palabras soeces.

Hembras con las ancas nerviosas, un poquito de espuma en las axilas y los ojos demasiado aceitados.

De pronto se oye un fracaso de cristales. Las mesas dan un corcovo y pegan cuatro patadas en el aire. Un enorme espejo se derrumba con las columnas y la gente que tenía dentro; mientras entre un oleaje de brazos y de espaldas estallan las trompadas, como una rueda de cohetes de bengala.

Junto con el vigilante, entra la aurora vestida de violeta (Girondo 1999: 13).

Cuando se refiere a los ambientes en que se baila el tango, utiliza la perspectiva, muy presente en algunos martinfierristas como así también en las elites intelectuales, que concibe al tango a partir de sus rasgos "primitivos", en tanto refiere a una ubicación cultural pensada como bárbara o plebeya. Florencia Garramuño, quien ha trabajado en extenso sobre la relación entre el primitivismo y el tango, recupera un poema de Ricardo Güirlades ${ }^{335}$ sobre el que afirma: se trata de "un poema descriptivo sobre el tango pendenciero y sexual, el tango del prostíbulo". Y agrega que los personajes que aparecen en el poema

pertenecen a una misma clase, el hombre, 'guaso' y la mujer, una 'china guaranga', adjetivos que en la época denotaban a aquellos que no integran la clase patricia. Ambos son animalizados: se los nombra como 'macho' y 'hembra', movimiento que sirve para ubicar al tango y a sus representantes como seres primitivos (2007: 93-94).

Este mismo campo léxico es el que utiliza Girondo en el poema antes citado.

En su búsqueda por construir la Buenos Aires cosmopolita de los años veinte, representa estas reuniones populares, pero lo hace con la misma distancia de turista con que recrea algunos paisajes de España o Francia. El yo lírico apenas escucha; en cambio, observa

\footnotetext{
${ }^{335}$ Se refiere al poema "Tango", incluido en El cencerro de cristal (1915).
} 
la escena como desde la puerta. Si Borges y Girondo proponen dos maneras casi opuestas de construir literariamente la ciudad, ambos coinciden, sin embargo, en que eliden los registros populares, como así también los espacios en que viven y socializan los sectores proletarios.

En "Milonga", este espacio habilita a Girondo a realizar ciertas concesiones al lenguaje, manifiestas en algunos coloquialismos como "jeta", una jeta que se hincha de "palabras soeces", irreproducibles. Sin embargo, en lugar del lunfardo, vocabulario que utiliza por ejemplo el tango para describir estos mismos espacios, hace uso, por un lado, de palabras francesas, encerradas entre comillas; y por el otro, aparece un breve campo léxico que remite a lo sexual ("pezones", "pubis").

En este poema, Girondo ensaya una suerte de barbarización de los asistentes a la milonga. Por ejemplo, allí no hay hombres y mujeres sino "machos" y "hembras". La escena principal del poema es una riña que, merced a los artificios poéticos, se encuentra desagregada de su sentido más brutal y banal para transformarse en un pasaje altamente lírico en donde abundan los "fracasos de cristales" y las auroras "vestida[s] de violeta". La estetización de la "barbarie" resulta una operación literaria recurrente en algunos escritores del período, que en cierto modo se sienten fascinados por ella. Pongamos por caso a Ricardo Güiraldes o Manuel Gálvez, quienes mantendrán a sus narradores -los cuales tienden a ser identificados con la figura del autor- aislados del lenguaje "plebeyo" de sus personajes merced, por ejemplo, al uso de comillas. Generalmente, el primer rechazo que les despierta la "barbarie" se manifiesta en los usos de la lengua. De este modo, la estetización se configura como una forma particular de acercamiento -y en cierto modo, transformación- a ese mundo salvaje que atrae y fascina pero que es mirado desde lejos. Las denuncias contra el anquilosamiento del lenguaje académico, que supo explicitar en textos como el "Manifiesto de Martín Fierro", toman renovada forma en Espantapájaros. Decide romper definitivamente con la forma de la poesía: blancos textuales, prosas entreveradas con versos, rechazo de la rima y la métrica. En esta oportunidad, el poeta se sirve más que nunca de otros discursos, "descuartiza el lenguaje y conecta unos miembros con otros sin considerar estratificaciones sociales, genéricas, situacionales" ${ }^{336}$ (Muschietti 2009: 132). El muñeco que sirvió para la campaña publicitaria ha sido identificado, tanto por los testimonios como por la crítica

\footnotetext{
${ }^{336}$ Por ejemplo, aunque se podrían citar varios, en el texto número 13 se puede apreciar el modo en que Girondo recurre a una estrategia muy común en este poemario: despliega un vocabulario o un conjunto de referentes totalmente heterogéneos y los pone en relación a partir de diversas acumulaciones que producen el efecto no sólo de extrañamiento ante palabras consideradas ajenas al discurso poético, sino que además la descontextualización y yuxtaposiciones más o menos arbitrarias generan una suerte de desjerarquización dentro lenguaje, los valores de las palabras se alteran y se integran en significaciones novedosas: "Cuando empiezo a dar patadas, es inútil que quiera contenerme. Necesito derrumbar las cornisas, los mingitorios, los tranvías. Necesito entrar $-i a$ patadas!- en los escaparates y sacar - ¡a patadas!- todos los maniquíes a la calle (...) A patadas con el cuerpo de bomberos, con las flores artificiales, con el bicarbonato. A patadas con los depósitos de agua, con las mujeres preñadas, con los tubos de ensayo" (Girondo 1999: 94).
} 
literaria, con el académico, el hombre atado a las convenciones, a prejuicios, a normativas (Artundo 1999); pero también con aquel que lucha contra la vanguardia y, vistiendo el disfraz de la tradición, nace, irónicamente, bajo el signo de la muerte ya que su cuna es una carroza fúnebre (Schwartz 1984). La festiva "funeraria solemnidad" con que fue paseado por las calles de Buenos Aires en una carroza mortuoria y la voluntad final de quemarlo -hecho que no se consumó gracias a la mediación de Norah Lange- habla a las claras del posicionamiento de Girondo con respecto al conservadurismo que regía en buena parte del campo literario del momento. El muñeco tiene su antecedente directo en el "Señor Perita", un monigote que traería consigo Gómez de la Serna en 1925, y a quien increparía en una de sus conferencias en Buenos Aires: "el señor de perita simboliza a Calixto Oyuela, a Jorge Max Rodhe, a Luis María Jordán y a otros ejemplares de una fauna paleontológica" (Artundo 1999: 530); es decir, a los puristas del idioma, a los conservadores de la lengua literaria, a los "guardianes de la cultura". Este muñeco también representa al "rey burgués" que reúne, tanto para los poetas modernistas como para los jóvenes vanguardistas de los años veinte, características similares a las que Darío le asigna en su famoso cuento: "El rey burgués (...) se dedica a ensanchar su espíritu, leyendo novelas de M. Ohnet, o bellos libros sobre cuestiones gramaticales, o críticas hermosillescas" (Darío 1961: 12). Además, resulta un "defensor acérrimo de la corrección académica en letras, y del modo lamido en artes; alma sublime amante de la lija y la ortografía" (Rama 1970: 58).

Las lecturas de Espantapájaros ponen en la mira el vocabulario y las expresiones cuyas referencias se anclan en el erotismo y la sexualidad. Allí Girondo mezcla formas relativamente "correctas" con una innovación desaforada del lenguaje, cuyas aristas rozan aquello que se consideraba por fuera del dominio de la literatura. El resultado de ello, entonces, es un texto "bien escrito" en el que se incrustan discursos, en principio, ajenos al orbe literario canónico. En este marco, el poeta utiliza vocablos que remiten fuertemente a lo sexual, de allí la idea de que el libro resulte "mal hablado".

Desde la revista Nosotros, Arturo Capdevila también cuestiona el costado "grosero" de Espantapájaros, pese a que su comentario se esfuerza por renunciar a la sanción en pos de la valoración positiva. El artículo comienza recogiendo la impresión de una "dama católica, apostólica y bonaerense" que reproduce la voz de los sectores más conservadores: "Espantapájaros es un libro inmundo y a su autor habría que darle de palos" (1932: 108). Sin embargo, Capdevila señala: "yo no comparto esa opinión” (108). Y continúa:

Hay un capítulo en verso, capítulo constituido por un poema indecoroso, donde la riqueza y precisión verbales son dignas de aplauso. Algunos acoplamientos de voces, por lo imprevisto, 
suelen desconcertar; pero el ingenio del autor resulta indiscutible. Si Oliverio Girondo hubiese suprimido algunas palabras groseras (tres o cuatro) y el capítulo 17 , nada perderíamos y se hubiera evitado el escollo que acaso destroce la obra. Pero, ¿a qué la prudencia? Al autor nada le importa lo que la gente diga y, podríamos afirmarlo, le gusta escandalizar (108, destacado nuestro).

No obstante la buena predisposición de Capdevila para con el libro del poeta, el comentario resulta sancionador en lo que respecta a algunos usos del lenguaje. Por ejemplo, en el pasaje citado, el autor de Melpómene, aproximándose a la "dama católica", habla de "poemas indecorosos" como así también de "palabras groseras" que recomienda suprimir. Capdevila reconoce en estos usos una intención de escandalizar, la misma voluntad presente en otros escritores como por ejemplo Arlt y Olivari, aunque neutralizada por las supuestas ignorancia e impericia en el manejo del lenguaje de estos autores.

En el mismo número que aparece el comentario de Capdevila, Nosotros publica otro artículo sobre el tercer libro de Girondo: "El espantapájaros de Girondo", de H. B. Delio. El primer señalamiento que hace Delio radica en la nula evolución que ha tenido la literatura de Girondo. Entre los Veinte poemas y Espantapájaros "han transcurrido en vano diez años" puesto que el poeta no ha hecho otra cosa que repetirse: "el mismo ingenio, el mismo desenfado, la misma chabacanería, la misma gracia, los mismos trastocamientos, las mismas imágenes" (1932: 123). Como ocurre con la mayoría de sus detractores, las críticas apuntan al uso de un lenguaje "chabacano":

Quizás hace diez años Girondo podía creer de veras que irritaba al burgués con sus malas palabras y sus alusiones al sexo de las hijas. Hoy no. El burgués ha terminado por comprender que la literatura de la "nueva generación" no tenía algo de peligrosa, puesto que era literatura burguesa... (123).

La figura del burgués en los años veinte es un elemento residual del romanticismo ${ }^{337}$ y luego del modernismo, ${ }^{338}$ y se configura como el representante de lo canónico y legitimado, de lo conservador y anquilosado; en una palabra, el burgués sería aquel que se encuentra del otro lado de las tendencias literarias vanguardistas al mismo tiempo que se erige como defensor de

337 “... el presente se había vuelto insípido y vacío. La intelectualidad se aisló cada vez más del resto de la sociedad y los elementos intelectualmente productores vivían ya su propia vida. Se desarrolló el concepto del filisteo y del 'burgués' en contraste con el 'ciudadano', y lo curioso de esta situación sin precedentes es que artistas y escritores estaban llenos de odio contra la misma clase a la que debían su existencia material e intelectual" (Hauser 1969: 363).

${ }^{338}$ Para profundizar en las características del burgués en el marco del modernismo, ver Rama (1970), Real de Azúa (1977). 
las posturas idiomáticas puristas. Por eso, mucho se ha insistido en que el lenguaje de Girondo $-y$, por extensión, el cultivado por los jóvenes literatos del período- ha tenido la intención principal de "espantar al burgués” (M. C. 1925: 7). El modernismo pensó al burgués como el actante principal de un mercado y un público en emergencia cuyo rechazo hacia el poeta y el arte en general hizo que el escritor se replantee su función en una sociedad que los poetas juzgaban dominada por "un materialismo hostil al espíritu" (Rama 1979: 50). Es por eso que la vinculación del burgués con lo estéticamente conservador se realiza por sobre la extracción de clase de los escritores, como ocurre en el caso de Girondo, quien provenía de una familia rica y tradicional de Buenos Aires.

En el capítulo dedicado a los escritores de izquierda, hemos puesto de manifiesto la voluntad de estos autores de ceñirse a la corrección lingüística. Dos motivos explican esta actitud: en primer lugar, la intención de instruir a un público lector de escaso capital cultual. Leónidas Barletta señala al respecto: "los de Boedo creíamos en el pueblo y nos habíamos juramentado que lo serviríamos para enaltecerlo y elevar su nivel de cultura artística y política" (Ara 1970: 88, destacado nuestro). En segundo término, la intención de "mejorar" la escritura se debe a la voluntad de diferenciarse de las apreciaciones que parten desde la vanguardia estética y que tildan a los escritores de izquierda de "incultos" y de no conocer el idioma. Otra vez Barletta señala: "los de Boedo se aplicaron a escribir cada vez mejor y los de Florida fueron comprendiendo que no podían permanecer ajenos a la política” (1967: 41-42). De acuerdo con Barletta, habría una aproximación mutua entre ambas alas de la vanguardia, en la medida en que cada una incorpora a sus prácticas literarias elementos que parecen pertenecer, "por esencia", a la otra. Así, la vanguardia estética empieza a no desdeñar la política, mientras que la izquierda comienza a escribir "mejor". Como se puede apreciar, Barletta coloca en el lugar de los que escriben "bien" a los escritores de Florida, al mismo tiempo que, dándole la razón a este grupo, reserva para Boedo el lugar de los escritores inseguros en el terreno idiomático. Se sabe también de la aversión que sentía una parte importante de la izquierda hacia las narraciones semanales, sobre todo por su lenguaje y su contenido erótico. Por lo tanto, resulta posible que en la reseña que la revista Claridad le dedica a Espantapájaros -en noviembre de 1932, bajo la firma de López de Molina- habrá más impugnaciones que aprobaciones. López de Molina centrará la mira de sus ataques en la "obscenidad" y "suciedad" del libro: "todo en este libro es extravagancia y ridiculez hasta ese comezón irrefrenable por las palabras sucias y los tópicos no menos inmundos" (1932: 13). Luego añade que "es una lástima que un escritor que revela imaginación y dotes de observación, se detenga en cosas pueriles, cuando no obscenas y disparatadas" (13). Cabe destacar que si bien López de Molina observa con detenimiento el lenguaje de Girondo, en 
ningún momento se referirá a aspectos de índole gramatical o normativa. Su atención, como hemos señalado, no se correrá de la sexualidad. De este modo, continúa: “en Espantapájaros hay como una obsesión sexual, y casi siempre, llevado el autor por su manía, cae en la grosería más imperdonable" (13). Finalmente, López de Molina concluye el artículo diferenciándose de aquellos que, si bien no resultan numerosos, opinan de modo opuesto: “creemos que Espantapájaros es un error de Girondo, aunque adulones y críticos sin honestidad afirmen lo contrario" (13).

Las lecturas de Claridad suponen una concepción no autónoma sobre la literatura. Si debe servir a la formación lingüística, cultural, social y moral del lectorado al que se dirige, resulta entonces inadmisible que la literatura se dedique a cultivar "ruiditos" o un lenguaje poco edificante. En general, la idea que la izquierda tiene sobre la literatura no admite su autonomía, como así tampoco del lenguaje literario. Para esta zona, la lengua literaria debe subordinarse a las necesidades sociales (denunciar, esclarecer, formar un público responsable socialmente) y a la corrección gramatical (formación educativa del lector). Como se puede apreciar, la recepción de Girondo en el marco de la izquierda literaria está determinada por esa visión.

En el marco de las polémicas sobre el idioma y la lengua literaria, la figura de Girondo resulta sumamente peculiar. En primer lugar porque si, por un lado, tiene la intención manifiesta de romper con la subordinación idiomática hacia España; por el otro, sucede también que esa ruptura, evidenciada en el declarado deseo de renovación del castellano, no se manifiesta en el desafío de las normas del idioma, sino en la transgresión de la lengua literaria aceptada. A diferencia de otros escritores, no busca la autonomía de la lengua literaria en la confrontación con gramáticas y diccionarios. En todo caso, concibe la autonomía a partir de la transgresión y ampliación del lenguaje literario mediante la incorporación de vocablos y registros considerados hasta entonces como no literarios.

Como otros martinfierristas, Girondo se muestra refractario al imperante "babelismo" que vive la ciudad de Buenos Aires. La incorporación de voces provenientes del contacto de lenguas no constituye una opción estética para el autor; y si utiliza neologismos o extranjerismos (siempre derivados de lenguas prestigiosas) los entrecomilla.

En síntesis, la renovación del lenguaje poético que lleva adelante Girondo consiste en llevar la literatura a otros campos temáticos y léxicos, es decir librarlo de sus servidumbres habituales, y por medio de la transgresión encaminarlo hacia cierta autonomía. ${ }^{339}$

\footnotetext{
${ }^{339}$ La renovación poética de Girondo, sobre todo su lenguaje saturado de múltiples referencias sexuales, no pasó desapercibida para los escritores que vinieron luego. Además de las influencias que se pueden observar en un
} 


\section{CAPÍTULO VII}

\section{El género de la lengua literaria}

\section{Las polémicas sobre el lenguaje y el "discurso literario femenino"}

La participación de las mujeres en la escritura literaria y periodística tiene tanta historia como las mismas querellas en torno al idioma: la lucha de las mujeres para editar sus propios periódicos y ganar aceptación como escritoras comenzó en 1830 cuando dos diarios realizados por mujeres aparecieron en Buenos Aires: La Argentina y La Alajaba (Frederick 1998). Sin embargo, en la década de 1920, se consolida y amplía no solamente un lectorado femenino, sino también un grupo de escritoras que consigue ubicarse en inéditas posiciones dentro del campo literario.

Norah Lange y Alfonsina Storni son dos figuras emblemáticas que presentan diferencias significativas dentro del campo literario. Mientras que Lange está asociada a las tendencias de vanguardia, por su parte, Storni pertenece a un círculo vinculado con estéticas más residuales. Si Norah Lange piensa la literatura de modo renovador, Alfonsina Storni no puede ser otra cosa que una poetisa de mal gusto (Sarlo 2007), cuya literatura se sirve de estéticas tardías: romanticismo y modernismo. ${ }^{340}$ La perspectiva masculinista con que fue leída Storni juzgó su literatura como un producto estético menor y devaluado, en la medida en que no tomó en cuenta la modernidad y las inflexiones que introdujo, parcialmente, en algunos de sus poemarios.

Como hemos señalado en la introducción de esta tesis, resulta productivo abordar a las escritoras de los años veinte a partir del concepto de situación mujer (Rivero 1994-95). Más allá de las diferencias que existen entre las autoras, comparten un lugar subalterno en relación con su producción literaria, la cual es regulada por una norma diferente a aquellas que rigen las prácticas de los hombres. Este concepto permite evitar las perspectivas esencialistas vinculadas con lo femenino, y colocar a las escritoras en el entramado de poder en el que lo

autor como Cortázar, nos interesa rescatar un breve texto de Néstor Perlongher, titulado "Nena, lleváte un saquito" (1997), publicado en la revista Alfonsina, en el año 1983, bajo el seudónimo de Rosa L de Grossman. Allí, Perlongher recupera el desenfado sexual de Girondo, la libérrima expresión literaria que cultivó durante los años veinte. Sin embargo, a comienzos de la década del ochenta, con una represión sexual todavía vigente, la obra de Girondo adquiere nuevas resonancias. Perlongher construye su texto en una clara alusión al poema "Exvoto", cuyo contenido es politizado por la represión sexual y policial imperante.

${ }^{340}$ La opinión de Sarlo es parcialmente cierta, sin embargo ignora los aspectos más rupturistas de la poesía de Storni, tanto en lo que refiere a las cuestiones de género como así también a las estéticas. En sintonía con la lectura que la vanguardia masculinista hizo de ella, Sarlo no ve en su poesía más que un producto literario kistch o menor. 
masculino deviene en un eje central y regulador de las prácticas literarias. A partir de la noción de situación mujer, lo femenino permite ser pensado por fuera de cualquier tipo de homogeneidad, es decir, como un término pluralizador que "amalgama factores comunes de construcción cultural" (Rivero 28). De allí que podamos hablar de "literatura femenina" en el sentido en que lo haremos en este capítulo. ${ }^{341}$

La aparición en la escena pública de las escritoras mencionadas subsume las desigualdades que guardan entre sí en favor de una idea que comienza a circular en el discurso de la época y que se vincula con la consolidación de un "lenguaje femenino". Entendemos este concepto no como un atributo lingüístico esencial de las mujeres, sino como un discurso sometido a determinadas regulaciones que se establecen a partir de valoraciones de género (gender). En nuestras sociedades, existen procedimientos de exclusión en el plano de los discursos, y el más evidente de ellos es la prohibición (Foucault 1996). La lengua literaria femenina se encontraba fuertemente regulada y algunas escritoras se opusieron a las prohibiciones del poder patriarcal. De este modo, las autoras mencionadas, entre otras, trasgredieron reglas referidas al decoro, a los géneros literarios y a ciertos núcleos temáticos vinculados con el erotismo, el espacio urbano, y en general a la esfera de lo público (en detrimento del amor romántico, la intimidad y la clausura). En este sentido, durante la década de 1920 se produce una nueva forma de transgredir esas reglas a las que estaba sujeta la escritura de las mujeres, y no se puede pensar estas transgresiones por fuera de los debates y las reconfiguraciones que sufre la lengua literaria durante este período. Nos proponemos, entonces, por un lado, analizar qué alcance tienen las transgresiones de estas escritoras y, por el otro, determinar las limitaciones que regulan la utilización de su lenguaje literario.

Un objetivo importante que perseguimos en este capítulo es el de poner en consonancia la particular problemática de la "literatura femenina" con las disputas y las prácticas en torno a la transformación de la lengua literaria. Este encuadre es el que permite ubicar a las escritoras de la década del veinte en el mismo plano que los escritores recién llegados al campo acusados de barbarizar el idioma. Más allá de las operaciones concretas sobre el lenguaje literario, las mujeres y los escritores de nuevo tipo, provenientes de sectores criollo-inmigratorios en ascenso, constituyen las dos categorías sobre las cuales la barbarización literaria encuentra su mejor encarnadura.

En el orden del discurso literario, la función del autor se refuerza, a diferencia de lo que ocurre cuando los textos circulan bajo un anonimato al menos relativo. A los textos literarios se les pide que expliciten de dónde proceden, es decir quiénes los han escrito

\footnotetext{
${ }^{341}$ Toda vez que utilicemos los conceptos de "lenguaje femenino", "expresión femenina” y afines lo haremos en relación con el significado que acabamos de exponer.
} 
(Foucault 1996). El orden del discurso exige saber quién es el autor, es decir si se trata de un hombre o una mujer - como así también, el origen, la etnia y la clase- puesto que una porción de las regulaciones sobre el lenguaje se encuentran fuertemente "generizadas". El presente capítulo, y tal cual lo adelantamos en la introducción de esta tesis, tiene como objetivo general demostrar que la lengua literaria tiende a asumir un género y que esta "generización" se encuentra expuesta de manera muy explícita en la discursividad de la época. Un buen ejemplo de esto son los artículos analizados en el capítulo II, "Vaselina vaselina" y "Hay que escribir con dinamita", ambos publicados en 1926 en la revista Claridad-la izquierda literaria fue muy proclive a leer determinadas escrituras desde parámetros genéricos- en los que se plantea la existencia de una lengua literaria masculina y otra femenina o "amanerada".

Junto con la inquietud provocada por la emergencia inmigratoria, una nueva otredad, constituida y diferenciada justamente a partir del lenguaje, ingresa en el terreno de las disputas y valoraciones. Con el advenimiento de los procesos de modernización ${ }^{342}$ en Argentina, los hombres de letras comenzaron a reformular la imagen de la mujer, a la que consideraron, de forma alternativa, como adversaria o defensora de la nación, afirma Masiello (1997). Esta autora sostiene la hipótesis de que estos desplazamientos entre diferentes usos de lo femenino resultan sintomáticos de los conflictos experimentados por la intelligentzia en torno de los problemas de la modernización (188). Si la mujer se ubica, en este período, cada vez más en la intersección entre las actividades públicas y privadas, el grado de amenaza sentido por las élites (masculinas) se intensifica. Mujeres e inmigrantes son colocados por el discurso dominante en el polo de la barbarie, que amenaza el orden existente.

\section{Norah Lange: regulaciones y transgresiones de la lengua literaria}

Norah Lange ingresa al campo literario siendo muy joven. Este ingreso está sujeto a la voluntad y vigilancia masculinas, lo cual implica ciertos límites y una forma de legitimación controlada. La voz que introduce sus versos, vale decir aquella que los precede y les otorga legitimidad, proviene de un hombre: Jorge Luis Borges prologó su primer libro, La calle de la tarde (1925); ${ }^{343}$ A su vez, “un olvidado" (Sarlo 2007), Juan Julián Lastra, firmó el prólogo a La inquietud del rosal (1916), de Alfonsina Storni.

\footnotetext{
${ }^{342}$ Cuando Masiello se refiere a los procesos de modernización en Argentina, piensa en los primeros años del siglo XX, cuando "el desarrollo del capital ponía a prueba la estabilidad del Estado" y "la rápida urbanización trasformaba el paisaje de Buenos Aires" (1997: 187).

${ }^{343}$ Borges no sólo prologa su primer libro, sino que es una pieza fundamental en la iniciación literaria de Lange: "la alienta en su vocación poética, lee sus primeros escritos y los aprueba, le habla del ultraísmo, le recita el Lunario sentimental de Lugones y la vincula con los inicios de Prisma" (Legaz 1999: 15). Las influencias de Borges también se constatan en su producción poética, sobre todo en su segundo libro, Los días y las noches
} 
Al comienzo de su carrera como escritora, sobre todo en su primer libro, Norah Lange desenvuelve la subjetividad femenina a través de un yo poético que se ajusta a las pautas establecidas para la escritura de las mujeres, entre las cuales figura la deserotización del texto literario. Pero progresivamente va subvirtiendo dichas pautas a partir de la intensificación del deseo y de la construcción de personajes que contravienen las regulaciones que la masculinidad ha asignado tradicionalmente a la mujer.

Los textos de Norah Lange y de Alfonsina Storni constituyen una crítica contra las exclusiones a las que fue sometida la escritura de las mujeres, y contra su inclusión en formulaciones discursivas que tradicionalmente fueron asignadas a la sensibilidad femenina. Esta hipótesis no sólo crea una geografía que permite agrupar a estas escritoras de características muy diferentes, sino que además las inserta en el seno de los problemas de la lengua literaria que se suscitan, con particular intensidad, hacia mediados de la década de 1920.

¿Cuáles eran, entonces, los límites y las propiedades de ese lenguaje al que las mujeres del período estaban atadas? El discurso literario de estas escritoras se encontraba al margen de los temas que depararon los grandes cambios producidos por la modernización: urbanismo, inmigración y masas (Muschietti 2006), tres núcleos importantes en la literatura (masculina) del período. La restricción de estos tópicos que sufre la escritura producida por las mujeres define los criterios de distribución discursiva asignados a cada sexo.

De lo relevado en encuestas, correos y consultorios para los lectores aparecidos en diarios y publicaciones periódicas, nos encontramos en presencia de una polémica que ocupa velada o desembozadamente gran cantidad del espacio periodístico de entonces: la crisis del rol férreamente establecido por la sociedad para la mujer (Muschietti). La polémica produjo la inmediata reacción de los sectores conservadores. Estas manifestaciones hablan a las claras de que en la década del veinte nos encontramos frente a la emergencia de un nuevo sujeto social que intensifica las disputas iniciadas en el siglo XIX $^{344}$ por un nuevo espacio de inserción en

(1926), en el que aparecen algunos versos ligados al arrabal con reminiscencias borgeanas: "en las horas que engarza el silencio / tu rezo de arrabal es como una tarde /enaltecida con fiereza de puñales" (Lange 2005: 92); o bien, "tu ausencia se torna grande y sencilla, / como la noche que baja al arrabal cansado" (97).

${ }^{344}$ A modo de ejemplo, señalamos algunas intervenciones importantes de mujeres escritoras durante el siglo XIX: la editora de La aljaba, Petrona Rosende de Sierra (1787-1863) escribió vigorosamente en defensa de su sexo en las páginas de su diario. Luego, en abril de 1852, apareció La Camelia, cuyos editores "decidieron permanecer en el anonimato por razones de modestia". Su programa consistía en tres puntos: celebrar la caída de Rosas, interpretar ese momento histórico como una era de libertad que incluye la justicia para la mujer, y defender los roles tradicionales de esposa y madre: "entramos en una era de Libertad y no hay derecho alguno que nos excluya de ella", reza uno de sus artículos. Dos años después, Juana Manso (1819-1875) funda El Álbum de Señoritas (1854), el cual resulta aún más explícito que La Camelia en cuanto a la defensa de la educación femenina. El Álbum de Señoritas fue el primer periódico de mujeres que mezcló cuestiones políticas con secciones literarias. La Aljaba y La Camelia habían incluido poemas y cuentos, pero ellos afirmaban ideas de la feminidad tradicional y evitaban las cuestiones más candentes de la igualdad social y la educación de la mujer. 
la sociedad ${ }^{345}$, y en cuyo marco la escritura se revela como una estrategia muy importante. Debemos pensar los textos escritos por las mujeres durante el período 1916-1930 en relación con esa crisis y esa emergencia, así como con el desplazamiento con respecto a aquellos núcleos (inmigración-urbanismo) que señalábamos centrales en la literatura del período. Esos textos deben considerarse también como las manifestaciones de nuevas aristas y de nuevas intervenciones en las polémicas en torno al idioma y a la lengua literaria. Como ya hemos visto en capítulos anteriores, los núcleos principales de estas disputas durante aquellos años (purismo, lunfardo, cocoliche, lengua popular, vanguardismo, coloquialismo, etc.) atraviesan los textos literarios. Las estrategias desplegadas por estas mujeres se vinculan con la necesidad de legitimar una escritura que rompe los moldes de lo esperable por aquellos años. La misma necesidad que tuvieron otros grupos y escritores. En este sentido, se podría homologar la situación de estas escritoras con la de los intelectuales recién arribados al campo literario, quienes libran estrategias tendientes a autorizar una escritura vista como "bastarda", "anti-literaria" o "bárbara".

La deserotización del texto literario femenino se constituye como una propiedad fundamental de una escritura normada y subalterna (Muschietti 2006, Sarlo 2007). El clima erótico se disuelve en la estereotipada escena lánguida en la que los elementos léxicos referidos al cuerpo y al placer son permutados por una cadena de elementos abstractosimbólicos (silencio-amor-corazón) en donde lo sentimental se torna hegemónico. Además, las menciones al cuerpo siempre se realizan a partir de los lugares más apartados del sexo, entre ellos, los ojos y la mirada constituyen las focalizaciones más frecuentes del desplazamiento de lo erótico en el imaginario habitual de la época (Muschietti 2006). En el caso de Lange, esta forma de erotismo oblicuo o velado se puede ver con mayor claridad en su primer poemario, La calle de la tarde: "Él acogió mi tristeza. En sus labios el amor / era el

En los diez años siguientes a la caída de Rosas, Juana Manso publica su novela La familia del comendador (1854), Margarita Rufino Ochagavia, Un ángel o un demonio o El valor de un juramento (1857), y Rosa Guerra y Eduarda Mansillla escriben sendas novelas con un mismo título, Lucía Miranda (1860). En 1875, arriba a Buenos Aires desde Perú Manuela Gorriti quien nunca trató de ocultar el hecho de que era una profesional que escribía por dinero. Su distinguido linaje no inclúa riqueza y, a diferencia de otras como Eduarda Mansilla, Gorriti vivía de lo que ganaba con su pluma. En cierto sentido, Gorriti se configura como un prototipo del escritor profesional. Guiada por su deseo de expandir las oportunidades de publicación de las mujeres, Gorriti funda La Alborada del Plata en 1877. En 1895, Clorinda Matto de Turner, una escritora peruana que había sido miembro de los salones de Gorriti en Lima, llegó a Buenos Aires escapando de la persecución que su escritura había motivado en Perú. En 1896 funda El Búcaro Americano (1896-1901) (Frederick 1998: 16-42). Para profundizar en las escritoras del siglo XIX y comienzos del XX, ver Molina (1995), Frederick (1998), Lojo (2000), Batticuore (2005).

${ }^{345}$ En 1926 se sancionan los Derechos Civiles de la Mujer, ley impulsada por el socialista Joaquín del Valle Ibarlucea; derechos que para algunos resultan más importantes que el voto femenino o la patria potestad compartida: "este mojón histórico aparece en el contexto de una proliferación polimorfa y constante de discursos sobre la domesticidad y el matrimonio que hegemonizan el habla pública sobre las mujeres" (Giordano 2010: 100). 
alba. Sus palabras me besaban. Y / por el caminito suave de sus miradas, llegué / como una canción hasta su alma (2005: 34), "Yo me he asomado / a las ventanas de tus ojos / y he visto tu alma / envuelta en mi imagen" (47).

El "lenguaje femenino" también se define como una escritura de clausura. La ciudad no es atravesada por la mujer-sujeto de estos textos, sino que se contempla siempre desde una interioridad. En el caso de la poesía de Norah Lange, por ejemplo, el yo lírico femenino siempre se encuentra dentro de la casa, detrás de las ventanas, en el umbral de la puerta o en los jardines. Esa clausura se complementa con las restricciones que la mujer padece en su vida social:

\begin{abstract}
La mujer no sale de su casa, no trabaja fuera de ella (y si lo hace, está sujeta a procedimientos de extrema marginalidad), no puede disponer de sus bienes materiales ni ejercer la patria potestad sobre sus hijos, no puede votar, no puede caminar por la calle junto a un hombre que no sea su padre, marido o hermano, no puede reírse en público ni darse vuelta para mirar a nadie, no puede sino escribir "versos de amor". La escritura reproduce, entonces, la figura de un cuerpo disciplinado, vigilado entre las cuatro paredes de la casa, o en las redes de un poderoso corsé normativo (Muschietti1990: 91).
\end{abstract}

En los primeros poemarios, el yo poético de Norah Lange observa todo desde adentro, desde los dominios del ámbito doméstico. Sobre todo en La calle de la tarde, en donde abundan las rejas y las vantanas que sepran, a la vez que conectan, el interior con el exterior:

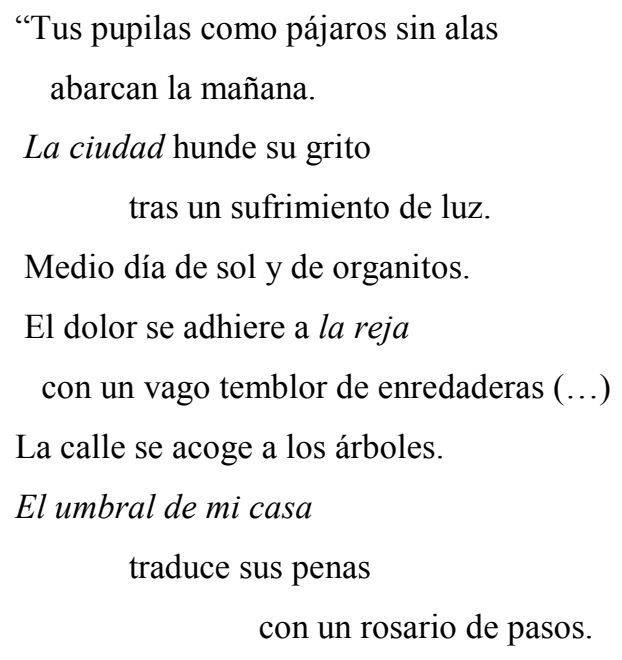

Mi corazón se abre a la tarde.

La tarde se oculta tras las rejas, como una mano hospitalaria (2005: 59, destacado nuestro). 
Esta clausura no significa que la ciudad esté ausente en estos primeros poemas. Lo urbano aparece con frecuencia, pero siempre mediado, del otro lado: los sonidos y el movimiento de la urbe son percibidos en la interioridad doméstica: "La ciudad deletrea su vida / con un grito de acero. / El bullicio se da a las ventanas abiertas / como un éxtasis" (65).

En este sentido, Los días y las noches (1926) es una obra de transición: se empiezan a percibir fisuras en lo que respecta a las regulaciones que rigen la escritura de mujeres. Si bien todavía el yo poético guarda clausura -"La noche agitada y mala / se agolpó en mi ventana" (96) - hay una tendencia a romper con el confinamiento. La ciudad aparece con mayor intensidad que en el poemario anterior. La lengua literaria se transforma al incorporar nuevos vocablos que ya no remiten al intimismo característico de La calle de la tarde. Se mencionan "plazas", “iglesias", “trenes”, “esquinas", “calles”, “arrabales”, "letreros luminosos", "tranvías". Sin embargo, el punto de vista sigue siendo el de la interioridad del hogar, el que le permite observar pero detrás de ventanas o rejas.

A diferencia de lo que ocurre en el caso de Storni (como veremos más adelante), el yo poético de Lange no transita la ciudad, no camina por su calles. O si lo hace, las metáforas y comparaciones le sirven para desmaterializar la urbe puesto que remiten a imágenes más bien abstractas, vinculadas con los sentimientos y/o el mundo interior y subjetivo: "he vuelto a la calle ahondada de esperas / rezando ausencias que ya no serán más. / Calle poblada de voces humildes" (87, destacado nuestro), "mi corazón es un calle blanca / por donde tu no pasas" (97).

La paulatina apertura de la clausura y la aparición de la ciudad moderna también se manifiestan en la apelación a los sectores pobres y marginados de la sociedad. Si bien no existe un desarrollo poético de este tópico, estas referencias parecerían estar indicando el intento por parte de Lange de integrar grupos sociales que los miembros centrales del martinfierrismo prefirieron evitar: "como la limosnita ingenua / que es presagio de dicha / en las manos de un pobre" (99), "lejos, el primer mendigo / traiciona el portal donde ha dormido" (100).

Entre las innovaciones que registra la lengua literaria de Lange en este segundo poemario, cabe señalar la intensificación del componente erótico, que se puede observar, por ejemplo, en un poema como "Ofrenda", en el que la mujer se ofrece (eróticamente) al deseo del hombre: "Voy a ti, como baja el sosiego / a la mar quejosa (...) / Con el corazón presintiendo una fiesta en tus labios / voy a ti, sufrida de dicha. / Hoy estás tú en mí..." (107)

En el primer texto narrativo de Lange, Voz de la vida (1927), la protagonista sale del hogar familiar, se alquila un departamento en el centro para escribirle las cartas de amor a 
Sergio, y funda así una suerte de subversión dada por el espacio que enmarca las distintas enunciaciones.

El "verso de amor" constituye el género literario permitido para la mujer del veinte. La escritora sufre una "doble clausura": por un lado, existe un encierro temático que caracteriza a la poesía romántico-sentimental; por el otro, un encierro retórico, con la reiteración obsesiva de predicaciones que dibujan una imagen estereotipada: la de la doncella emblemática a la que se le escamotea el deseo y el cuerpo (Muschietti 1990).

Ahora bien, la idea de un "lenguaje femenino" se encuentra tanto en el discurso dominante-masculino como en el de las propias mujeres, sólo que con valencias distintas. Según el primero, el lenguaje femenino normativo se caracteriza por la deserotización y el intimismo sentimental; mientras que algunas mujeres escritoras de los años veinte diseñan una nueva subjetividad, en la cual el deseo y la corporalidad contribuyen a definir sus principales rasgos.

El concepto de androcentrismo ${ }^{346}$ sirve para definir a una buena parte de la incipiente crítica literaria de las primeras décadas del siglo $X X$, en la que se señala con insistencia que las mujeres dedicadas a la escritura estaban ocupando un espacio masculino (Diz 2006). Un buen ejemplo de esta postura reaccionaria frente a la escritura femenina lo constituye la crítica de Ramón Doll, en la revista Nosotros, sobre la breve novela Voz de la vida (1927), la tercera obra publicada de Norah Lange. El texto de Doll resulta esclarecedor para poder observar de qué manera el discurso dominante censura un "lenguaje femenino" que subvierte las limitaciones impuestas.

Voz de la vida es una novela epistolar que narra el amor entre Sergio y Mila a través de las cartas que ella le escribe. ${ }^{347}$ La novela se mueve en el terreno de la subversión femenina, los límites normativos asignados a la mujer son transgredidos. Las cartas de Mila encuentran en el erotismo y en el deseo femeninos sus tópicos principales. Ciertas pautas morales, entonces, son puestas en entredicho: "sentí desde nuestra intimidad, que toda pureza es dolorosa, ya que implica la atenuación de cada deseo y, la quemazón de todo instinto" (Lange 2005:132). La lengua literaria de la novela, mediada por el lenguaje epistolar, pertenece a un registro culto y esmerado en su forma, sin marcas de oralidad ni de lo popular.

\footnotetext{
${ }^{346}$ Según Amparo Moreno, "(el androcentrismo) hace referencia a un punto de vista central, que se afirma hegemónicamente relegando a los márgenes de lo no-significativo o insignificante cuanto considera impertinente para valorar como superior la perspectiva obtenida." Esta perspectiva sería "propia de aquellos hombres que se sitúan en el centro hegemónico de la vida social, se autodefinen a sí mismos como superiores y, para perpetuar su hegemonía, se imponen sobre otras $y$ otros mujeres y hombres mediante la coerción y la persuasión/disuasión." (Diz 2006: 18).

${ }^{347}$ Sergio se ha alejado de Mila. Ella lo aguarda al mismo tiempo que le envía cartas. Pasa el tiempo y el mejor amigo del novio, Iván, se casa con la protagonista. Finalmente, Mila abandona a Iván para huir con el amor de su vida, Sergio.
} 
En relación con sus poemarios anteriores, se puede observar la continuidad de un lenguaje sentimental o intimista, que remite a los padecimientos del amor: "me ha dejado doliente como un sollozo, ante la amarga realización de saberme no amada" (159). En la novela, Lange no cambia sustancialmente su lengua literaria, sino que opera su transgresión a partir del género literario, del erotismo y, sobre todo, del modelo de mujer que propone su personaje Mila.

Desde una perspectiva de género, el perfil de Mila resulta conflictivo: trabaja (es enfermera), lee y escribe, es una mujer independiente en tanto abandona la casa familiar para mudarse al centro a los fines de escribir las cartas a Sergio. Su independencia surge, precisamente, en momentos en que el hombre está ausente: "Cuando él [Iván] no está, leo, escribo, pienso" (Lange 136). Además, un dato no menor: no es madre y la maternidad no está tematizada en la novela.

Doll censura que la autora "no se hubiese limitado a narrar la vida interior de Mila, sus sueños, sus depresiones" (1928: 87); vale decir, reprueba el haberse salido de la esfera de lo estrictamente personal e íntimo. Para Doll, existe un "lenguaje de la pasión femenina" que, por lo visto, Mila ${ }^{348}$ no ha aprendido. El lenguaje de la protagonista guarda un "estilo insexuado y cuando no, usa expresiones y giros varoniles" (90). Con el término "insexuado", Doll quiere significar aquello que está por fuera de las competencias femeninas. Para el autor, el único sexo posible es el femenino, en tanto la escritura masculina parece estar ubicada por fuera del eje de género; es una escritura no marcada, por lo tanto lo "insexuado" y lo varonil se asocian y resultan expresiones equivalentes en la reseña crítica.

Doll pasa revista a los "errores del libro": critica que la protagonista sea "una mujer vulgar atenaceada por el frenesí de la carne". Y condena también que sus deseos se manifiesten "en un decir que más bien expresa refinamiento intelectual, poesía conceptuosa, que se nutre en lo incorpóreo del intelecto, más que en el torrente sanguíneo de su corazón apasionado" (89). Lange, al parecer, comete dos infracciones: por un lado, escribe de forma "inteligente", es decir, "masculina”, y se aparta de lo sentimental propio de las mujeres. Y, por el otro, convierte esa intimidad femenina en un muestrario de sus deseos carnales. Vale decir que Doll encuentra un desajuste entre el contenido y la forma. Percibe como una falla el hecho de que "bajas pasiones" (femeninas) se expresen en un "lenguaje refinado y culto" (89) y varonil.

La "virilización" del discurso literario de ciertas escritoras se convierte, en los años veinte, en un lugar común de la crítica, sobre todo de aquella emplazada en las revistas más

\footnotetext{
${ }^{348}$ Cuando Doll se refiere a Mila, sus apreciaciones valen tanto para el personaje como para la autora puesto que confunde, constantemente, ambos niveles.
} 
conservadoras. ${ }^{349}$ El "lenguaje femenino" de Lange se transforma, según Doll, en una "lengua masculina" la cual, en la pluma de una mujer, constituye una infracción que el crítico condena con vehemencia: "el lenguaje de Mila es un lenguaje aprendido en una literatura sin sexo o del sexo masculino; lenguaje que en labios de mujer no tiene interés para el hombre" (90). De esta manera, el crítico asume la función de un juez que determina el interés o no que puede tener la palabra femenina. La crítica o el comentario literario, ejercido mayoritariamente por hombres en los años veinte, se constituye en una instancia importante de regulación del lenguaje utilizado por las escritoras.

Lo que Doll impugna, en definitiva, es el lugar que la vanguardia martinfierrista le otorgó a Lange dentro del campo literario. ${ }^{350}$ En este sentido, se puede afirmar que la discusión continúa siendo entre hombres, lo que constituye una estrategia para sustraer a la mujer del campo de las disputas en las cuales comienzan a insertarse. Ensayar un lenguaje vanguardista (masculino de por sí) en una literatura que debe enmarcarse dentro de lo que Doll considera un "lenguaje femenino", ocasiona los desajustes -tanto en el nivel del lenguaje como de los temas- que el crítico adjudica a la novela. Para él, Madame Noailles se convierte en el modelo de escritora que Lange debería seguir:

\begin{abstract}
Es que Mila, que se satisface con un ultraísmo o vanguardismo de aquí a la vuelta no más, no sabe que existe Le Visage Emerveillé de Madame Noailles, donde pudo aprender a expresar su temblor apasionado de doncella (90).
\end{abstract}

La referencia Anna de Noailles cobra funcionalidad en tanto representa a la escritora que enarbola cierto antifeminismo. ${ }^{351}$ Doll reclama para Lange el lenguaje femenino de Noailles, ${ }^{352}$ vale decir, el lugar subalterno dentro del campo literario preestablecido por la normativa masculina. El crítico concluye diciendo que la voz femenina de la novela es una "reminiscencia de nociones mal entendidas sobre los ideales modernos de la emancipación sexual de la mujer" (92). Hacia el final del texto sus propósitos quedan explicitados: condena

\footnotetext{
${ }^{349}$ Más adelante, veremos de qué manera los mismos argumentos que Ramón Doll utiliza para interpelar a Norah Lange, varios años antes, en 1919, y desde la misma revista Nosotros, se ponen en funcionamiento para referirse a la escritura de Alfonsina Storni.

${ }^{350}$ Voz de la vida es editada por editorial Proa.

${ }^{351}$ Victoria Ocampo se referirá al antifeminismo de Noailles en su conferencia de 1933 “Anna de Noailles y su poesía": "Comíamos juntas (con Anna de Noailles), una noche, en casa de una amiga. Éramos cuatro mujeres en torno de una mesa. La conversación vino a recaer sobre el genio o la ausencia de genio en las mujeres. Anna, arrebatada por su propia elocuencia, no cesaba de despotricar contra el sexo débil. Una de nosotras, feminista acérrima, trataba en vano de detener aquel torrente de invectivas (...) El antifeminismo de que ella hacía gala, ¿no era una de las formas de su orgullo?, me pregunto yo" (1981: 240-241).

352 Lenguaje que Victoria Ocampo, desde una posición diferente a la de la Norah Lange de 1927, se encargará de rechazar, en 1933, en la conferencia mencionada en la notar anterior, pronunciada en el Jockey Club.
} 
la liberación de la mujer y su inclusión en lugares del campo literario inéditos hasta el momento.

Para Doll, la "escritura femenina" se debería encuadrar en un discurso deserotizado y doméstico. Lo que escribe Lange se aleja de esos parámetros, por lo tanto, en la reseña crítica, lo femenino se anula gracias a la expresión de una subjetividad, propia de la mujer, que pone en primer plano la sexualidad. De este modo, se configura entonces una nueva dimensión de aquello que en capítulos anteriores hemos denominado "mala escritura": nuevas significaciones adquiere este concepto cuando lo aplicamos a los textos de algunas escritoras. Ya no se trata de una escritura "plebeya", "degradada" o "incorrecta", corroída por el lunfardo $\mathrm{u}$ otros registros de la oralidad popular, como en la literatura de Arlt, Olivari o Enrique González Tuñón. Se trata, en cambio, de una "mala escritura" definida como tal no por aspectos formales del lenguaje, sino más bien por aquello que subvierte los temas y las modalidades de expresión aceptadas para el género, por aquello que desordena la matriz impuesta por el orden del discurso, y que legisla lo que pueden y no pueden decir hombres y mujeres. En este sentido, se podría establecer un punto de contacto entre la escritura literaria de Lange o Storni y la de Oliverio Girondo, en la medida en que, en estos casos, la innovación no se encuentra en la "incorrección” del lenguaje en sí, sino más bien en la violación de aquellos preceptos (temáticos y genéricos) que controlan los discursos.

Con Voz de la vida, Norah Lange deja la poesía amorosa, deserotizada y de clausura, y se dedica a la novela. En la obra se destaca la contaminación de géneros: los versos de la introducción y el epílogo regresan a la escena amorosa, pero la novela está construida a partir de un epistolario que revela todas las violaciones a los mandatos discursivos de género de aquella época. Tal vez esta vacilación genérica, y que sin dudas señala cierto pulso dubitativo por parte de Lange al momento de abandonar el "lenguaje femenino" prescrito, sirvió para que Jorge Luis Borges reubicara la producción literaria de Lange en los cauces de los que jamás debería haberse salido. Desde las páginas de Síntesis, Borges afirma: “esta aparente narración epistolar o supuesta novela es, en verdad, el tercer libro de poesía de Norah Lange o una tercera parte del único largo poema que son todos los libros y todos los días de esta escritora" (1928b: 101). Borges pretende desagregar la irreverencia de Lange, en la medida en que no le permite que el ya asignado rol de "poetisa" de Norah se convierta en una incómoda y novedosa figura de novelista: “...por la buena exaltación de su tono, afirmo que el libro es un poema y no una novela" (102), sentencia.

Voz de la vida representa un desafío a los mandatos masculinistas, hacia la subvaloración, exclusión y confinamiento de las prácticas escritas femeninas. 


\subsection{Entre la vanguardia y las narraciones semanales}

En este apartado, abordaremos nuevamente Voz de la vida con el objeto de señalar que, además de las transgresiones que Lange lleva a cabo en relación con el erotismo y con la figura de mujer que construye con Mila, agrega otra operación de subversión: aproxima su novela, formal y temáticamente, a las narraciones hebdomadarias. Es decir, Lange toma un género propio de la literatura popular para inscribir una subjetividad femenina que contraviene no sólo las regulaciones androcéntricas, sino también las preferencias estéticas del núcleo principal del martinfierrismo.

En su poesía, Norah Lange se ciñe a la norma asignada para la literatura femenina. Su ingreso a la escritura tiene un costo que se evidencia, para Beatriz Sarlo (2007), en sus dos primeros libros, ${ }^{353}$ caracterizados por la ausencia de libertad sentimental y erótica, y por la trivialización de los sentimientos en el clisé simbolista o ultraísta. En su obra poética, hay un "continuo trabajo de borrado" de las cualidades eróticas. Así escribe una mujer que quiere ser poeta pero quiere también seguir siendo aceptada (Sarlo 77-78). El contacto físico, las caricias o los besos están invariablemente acompañados de un tropo que los aleja del cuerpo, desmaterializándolos, purificados por el recurso de la niñez (74). Desde la perspectiva de Sarlo, Lange borra lo que la mirada social de los padres no debe leer. Y para ello, el ultraísmo le da la irrestricta libertad de las imágenes, las cuales utiliza en su esfuerzo de tapar lo inconveniente (78). Así las cosas, el supuesto lugar preferencial que le otorga la vanguardia ${ }^{354}$ sirve de espacio legítimo desde donde ejercer la escritura, al mismo tiempo que sus herramientas estéticas contribuyen a fijar las lindes de una libertad controlada.

Distinto es el caso de Alfonsina Storni. Ella no borra su deseo ni su sensualidad, sino que los convierte en centro temático de su poesía. Desde el punto de vista biográfico, no había forma de practicar, con éxito, el borramiento que consigue Lange: recuérdese que Storni llega a Buenos Aires embarazada, soltera y en completa soledad. Su poesía será no sólo sentimental sino erótica:

Dame tu cuerpo bello, joven de sangre pura,

\footnotetext{
${ }^{353}$ La calle de la tarde (1925) y Los días y las noches (1926).

${ }^{354}$ Norah Lange es un caso singular en la literatura de los años veinte, en el sentido de que es la única mujer que participa activamente en un grupo intelectual conformado por hombres: publica sus obras, participa de reuniones y ágapes, brinda discursos, y participa del desenfado vanguardista. A partir de estos datos, se leyó a la vanguardia estética como un espacio que aceptaba a las mujeres. Sin embargo, el lugar que ocupa Lange dentro del martinfierrismo es subalterno: antes que como escritora, aparece como una "musa" o bien como la que animaba las veladas en su casona de la calle Tronador, a las que asistían los escritores principales del martinfierrismo.
} 
No moderno en el arte de amar, como en la hora

Que fue clara la entrega, en mi boca demora

Tu boca, de otra boca negada a la dulzura (1968: 282).

Como se sabe, Norah Lange y Alfonsina Storni representan dos alternativas diferentes en materia estética. Sin embargo, con Voz de la vida, Lange invierte su poética y se coloca en un espacio vecino al de Storni. De ese modo, reivindica para sí una forma de enunciación libre de los condicionantes de sus dos primeros libros.

Si observamos a través de la perspectiva de Doll, Lange pasa de un "lenguaje femenino" -es decir, acorde con las regulaciones que impone el discurso androcéntrico y legitimado por la intelectualidad masculina- a un "lenguaje masculino", que en la pluma de una mujer se transforma en "inmoralidad" y "mal gusto".

Ninguna de las características que Sarlo atribuye a la escritura de Lange puede observarse en su prosa, precisamente en su novela de 1927. Allí no hay borramientos ni autocensura, sino un registro que se distancia del anterior, un abandono de los condicionamientos que la clase y el género le imponen, y la inauguración de una escritura sin limitaciones, diferente a la que Doll receta para la mujer, deserotizada y circunscrita a la poesía.

Mila reproduce una figura femenina novedosa para la época y que, sin intención de forzar las relaciones, podríamos vincular con la imagen social que Alfonsina Storni construye sobre sí misma por aquellos años. A continuación, citamos un pasaje en el que Beatriz Sarlo se refiere a Storni, y que bien podría adjudicarse al perfil de Mila:

Independencia respecto del hombre, autoabastecimiento en el sostén de sí misma, afirmación de la intelectualidad (...) Todos estos rasgos, pioneros para la época e indicadores de un estadio 'salvaje' de la liberación femenina, diseñan una (nueva) imagen de mujer (2007: 80).

Los rasgos que definen una zona de la poesía de Storni comparten algunas propiedades con el nuevo costado que evidencia la prosa de Lange. Su novela puede leerse como una inflexión de la voz de la autora, en la medida en que parece querer suspender, al menos por un momento, esa operación de borramiento. Mila seduce a Iván y luego lo deja para huir con Sergio. Si bien, en la relación con él, Mila asume el rol de mujer sumisa y dependiente, la carnalidad con que impregna su deseo en las cartas relativiza esa posición tradicional de la mujer. Sarlo explica que Storni escribe para invertir la seducción: salir del lugar de la mujer seducida y 
abandonada, para ocupar el de la seductora y abandonante ${ }^{355}$ (84). Ese modelo femenino es el que sigue Norah Lange para construir a su protagonista, y lo acompaña con la asunción de un lenguaje particular que no sólo la arranca de los mandatos de género y clase, sino también de las poéticas que prescribe su círculo literario. Con Voz de la vida, Lange se aleja de la estética vanguardista para acercarse a un tipo de literatura diferente en su forma, propiedades y mecanismos de consumo: la literatura de folletín y la novela epistolar.

Ricardo Güiraldes llevó adelante una operación similar, pero inversa: escribió su relato breve Rosaura y lo publicó, por primera vez, en 1918, en la colección de narraciones semanales El cuento ilustrado, dirigida por Horacio Quiroga. ${ }^{356}$ Es decir, en lugar de inscribir la narración en su circuito literario -el de la vanguardia estética-, como lo hizo Lange, optó por participar activamente en el segmento de relatos hebdomadarios y someterse a las exigencias del mercado cultural. En este sentido, el caso de Güiraldes reviste interés para nuestro trabajo puesto que su participación en la publicación de Quiroga implicó un cambio importante en la lengua literaria. En primer lugar, reemplazó el título original por uno más acorde con la estética del folletín: Un idilio de estación. ${ }^{357}$ En segundo término, declara que utilizó un lenguaje de frecuente uso, "bajo" y lejano de la lengua literaria moderna y vanguardista de sus otras obras:

En El cencerro como en los Cuentos y Raucho había desterrado en absoluto las palabras emputecidas por el bajo uso, tales como suave, tierno, melancolía, y la generalidad de los vocablos de este tono. Eran para mí palabras manoseadas como nalgas y me encabritaba contra su atracción (...) En Rosaura me vengué de estas ausencias. Rosaura era intencionalmente tierna, cursi, melancólica, etc... La niña que se suicida por el mocito hermoso y cruel. Hice Rosaura en veinte días. En esos momentos, Horacio Quiroga, que empezaba a lanzar una edición popular de novelas cortas, me pidió colaboración. Le mandé Rosaura, a

\footnotetext{
${ }^{355}$ Si bien existe, en la poesía de Storni, el engaño y la infidelidad como rasgos que definen al hombre en muchas oportunidades, la mujer no asume su rol de abandonada y/o engañada de manera pasiva. En el siguiente ejemplo se puede apreciar que el engaño no resulta tal puesto que la mujer posee conocimiento sobre los hechos. Esto conduce a que la figura del hombre ligada al saber es puesta en cuestión por la mujer: "Soy tuya, Dios los sabe por qué, ya que comprendo / que habrás de abandonarme, fríamente mañana, (...) Pero tú sabes menos que yo, y algo orgulloso / de que te pertenezca, en tu juego engañoso / persistes, con un aire de actor del papel dueño. / Yo te miro callada con mi dulce sonrisa, / y cuando te entusiasmas, pienso: no te des prisa. / No eres tú el que me engaña, quien me engaña es mi sueño." (1968: 254-255, destacado nuestro). También, en ocasiones, se puede apreciar que las mujeres de Storni no siempre asumen un rol pasivo en la seducción: en el poema "Divertidas estancias a Don Juan", perteneciente a Ocre, se puede leer: "y hasta hay alguna hartera, / juguetona mujer / que toma tu manera [las de Don Juan] / y ensaya tu poder" (272).

${ }^{356}$ El cuento ilustrado se publicó entre abril y octubre de 1918. Editó treinta números, y en el cuarto apareció el relato de Güiraldes.

357 Cuando en 1922 se publique el relato en formato libro, es decir, cuando se sustraiga del circuito de las narraciones semanales, recobrará su título original, Rosaura.
} 
quien por motivos de venta se cambió de nombre, intitulándola: Un idilio de estación ${ }^{358}$ (Güiraldes 1962: 32, destacado nuestro).

En cambio, la operación de Lange consiste en tomar como modelo estas narraciones populares y sustraerla de los circuitos que el mercado traza para este tipo de literatura. Es decir, des-abarata el género al insertarlo en la experiencia vanguardista del martinfierrismo. Y desde la perspectiva de género (gender), también se aprecia una torsión que consiste en lo siguiente: mientras que las narraciones semanales pertenecen a un género escrito por hombres y que encuentra en el amplio público femenino una gran aceptación, ${ }^{359}$ Voz de la vida es una obra escrita por una mujer, dirigida para un restringido número de lectores masculinos, los vanguardistas.

Según Sarlo (1985), las novelas semanales se organizan de acuerdo a tres órdenes que, necesariamente, tienen que entrar en conflicto: el de los deseos, el de la sociedad y el de la moral; y su resolución suele ser ejemplarizadora. En Voz de la vida, a través del triángulo amoroso de Mila, Sergio e Iván, se puede apreciar el conflicto en el que entran estas tres dimensiones. Sin embargo, el final de la novela no es sancionador: Mila se va con su amante y abandona definitivamente a Iván, su marido, es decir, prima el deseo por sobre las convenciones sociales y morales. Tampoco es un final trágico, en el sentido de concluir con la muerte de la heroína, como sucede en el caso de Rosaura. Lange se separa de los moldes de las narraciones semanales y en esa desviación se puede leer la violación del género, entendido este en su doble acepción (gender y genre).

Si observamos las particularidades formales de las narraciones periódicas, veremos que la novela de Lange retoma algunas pautas de estos textos. En primer lugar, el amor, el deseo y la pasión constituyen tópicos centrales en las narraciones semanales. En segundo término, son relatos fuertemente erotizados, a tal punto que el erotismo se constituye en un eje narrativo y estilístico importante. ${ }^{360}$ Luego, las historias narradas tienen una repetida

\footnotetext{
${ }^{358}$ En 1918, Horacio Quiroga lanza las narraciones semanales El cuento ilustrado (1918). Un idilio de estación aparece en mayo de 1918, en el cuarto número. Esta fue la primera edición de Rosaura. Con este nombre se editará en 1922.

${ }^{359}$ Los anuncios que acompañaban este tipo de literatura -referidos a la belleza y a la salud- hacen pensar en un lector mujer y joven. Ver "Los lectores: una vez más ese enigma" en Sarlo (1985).

${ }^{360}$ Sarlo señala que las narraciones semanales estaban atravesadas por un fuerte erotismo del cual se servían los moralistas de la época para condenar estos textos. La autora define el tipo de erotismo: "las narraciones semanales cultivan el erotismo del lugar donde el vestido se entreabre: el erotismo del lenguaje de las miradas, de los roces, de las caricias furtivas, de los besos robados que anticipan y potencian el placer" (1985: 14). Veamos un ejemplo de uno de los títulos más famosos de La novela semanal (1917-1922), "La vendedora de Harrods" (1919), de Josué Quesada. A continuación, una de las descripciones de la protagonista, Carmen: "Era en el fondo Carmen una muchacha buena y honesta; el medio en que vivía no la había contaminado y conservaba sin esfuerzo una espontánea distinción, unida a la sencilla elegancia de su traje siempre negro, como lo establecía el reglamento de la tienda. Cuidadosa de sus manos, bien peinada siempre, ofrecía el encanto atrayente de una silueta gentil, que adquiría marcado relieve entre todas las compañeras de trabajo" (Quesada, 1919: 8). Citamos
} 
estructura funcional, que se manifiesta en las tramas altamente redundantes, donde un número restringido de núcleos definen el conflicto central. Y por último, la brevedad es otro de sus rasgos típicos (Sarlo 1985). Todas estas propiedades pertenecientes a las narraciones periódicas aparecen también en Voz de la vida. Sin embargo, la diferencia radica en el circuito de consumo por el que transita la novela de Lange y, por consiguiente, el segmento de lectores al que se dirige. Si las narraciones semanales consolidan no sólo una nueva franja de público, sino también un conjunto de lugares de comercialización y difusión alternativos a la librería, ${ }^{361}$ Voz de la vida es editada por Proa bajo condiciones -materiales y de circulaciónbien diferentes a las de las narraciones semanales: "de este libro se han impreso 20 ejemplares en papel de hilo numerado y firmados por la autora. Diez de los cuales fuera de comercio. Y 500 en papel pluma" (Lange 2005: 120). En Voz de la vida no existe gesto paródico de ningún tipo en relación con las narraciones semanales. En una suerte de treta del débil, Lange toma como modelo un género "bastardo" y popular y lo propone en un circuito diferente. En esto radica su principal gesto transgresor.

Pero más allá de estas consideraciones, nos interesa destacar que esta inflexión en la producción literaria de la autora comporta un cambio de lenguaje que la hace ingresar en un terreno de disputas.

A diferencia de Lange, Storni se encuentra, desde un comienzo, en un circuito popular, caracterizado por lo que los escritores tradicionales llaman "gusto plebeyo" o "mal gusto". Su poesía se lee con una facilidad y rapidez similares a las de la novela sentimental del mismo período (Sarlo 2007). Esas similitudes entre la poesía de Storni y las narraciones semanales, como ya hemos visto, se encuentran también en la primera novela de Lange la cual, con las salvedades hechas, bien podría incluirse dentro de ese corpus textual.

\footnotetext{
también el final del relato, momento en el que la relación de Carmen y Juan Manuel se consuma: “Carmen había transigido con las pequeñas exigencias de Juan Manuel, y en más de una oportunidad aceptó en llegar hasta las proximidades de su casa en automóvil. La primera vez, fue el pretexto de una lluvia torrencial; luego el de dar una vuelta, y por último ¿por qué no confesarlo? el deseo de los besos apasionados que bien pronto reemplazaron a las palabras. Y llegó el día en que Carmen, confiada en el cariño que él tantas veces le había jurado acudió a la cita en la "garconiere" que acababa de instalar... El sacrificio de su juventud y de su honor se cumplió sin que mediara una palabra, y así como sus almas se habían identificado en una pasión sin límites, así también se unieron ambos en un abrazo febril e inconsciente" (11).

${ }^{361}$ En realidad, los lugares de comercialización de esta literatura masiva y económica encuentra su antecedente en la prensa periódica de la década del ochenta. Adolfo Prieto señala que la prensa periódica constituyó un nuevo espacio de lectura, mientras que para la cultura letrada el libro continuó siendo la unidad vertebradora de su universo específico. También su circuito de difusión fue diferente: buscaron su propio circuito material de difusión. Lo hicieron fuera de las librerías: quioscos, tabaquerías, peluquerías, lugares de esparcimiento (2006: 15).
} 


\section{El caso de Alfonsina Storni}

Delfina Muschietti (1990) da cuenta de un problema en la producción literaria de Alfonsina Storni: afirma que existe una discontinuidad, un corte entre los textos periodísticos y los textos poéticos que la autora escribió en el período yrigoyenista. En los poemas, existe una orientación hacia la súplica y el ruego. El yo-mujer aparece como sumiso, postrado, en silencio, sin deseos. Los poemas trazan una voz-mujer mendicante que señala claramente desde dónde se habla: el lugar del débil (Muschietti 87). En cambio, los textos periodísticos escritos en ese mismo período van a contramano de los poemas, los cuales parecen funcionar casi a modo de ejemplo de la situación que los primeros se empeñan en denunciar: "mientras los poemas clausuran el horizonte textual en la intimidad mistificada de la escena amorosa, los artículos periodísticos hablan de una transformación colectiva en proceso, del surgimiento en definitiva de un nuevo sujeto social: la mujer" (87). Hasta el tercer libro de poemas Irremediablemente (1919)-, las transgresiones al mandato de género se sitúan en el discurso periodístico. El ensayo constituye un campo que, evidentemente, pertenece al hombre, según la reinterpretación cultural que nuestra sociedad hace de la diferencia biológica entre los sexos. Storni se muestra como una doble invasora: ocupa el terreno del adversario en el marco de las leyes de un género discursivo, la polémica, género público, del que la mujer se halla tradicionalmente excluida. Entonces se produce un travestimiento en Storni, consistente en ocupar un género discursivo ajeno, con un discurso que le está vedado a su género sexual. Las transgresiones se producen, simultáneamente, en el seno del bifronte concepto de género. En la producción de Storni, la primera batalla en torno al lenguaje se libra en el marco de los géneros discursivos. Salirse del encorsetamiento del género impuesto -poema de amorpermite asumir una voz que, sin renunciar a sus particularidades, se pone en pie de igualdad con respecto al registro masculino.

Los grandes cambios producidos en la década del veinte -urbanismo, inmigración y sociedad de masas- son materia de los textos y generadores de un modo de producción literaria en las obras más importantes del período (Muschietti 2006). Estos nuevos fenómenos no sólo dieron lugar a nuevos temas literarios, sino también a nuevas formas expresivas que contribuyeron a actualizar los debates sobre la lengua. Muschietti asegura que, en la literatura escrita por mujeres, estos nuevos núcleos temáticos no aparecen sino lateralmente en poemas aislados o como simple gesto retórico en la producción, que va hasta 1930, de las tres escritoras más importantes del período: Alfonsina Storni, Norah Lange y Nydia Lamarque (113).

Los textos escritos por mujeres durante la década de 1920 deben pensarse también como nuevas intervenciones en las polémicas sobre la lengua literaria, puesto que tienen que 
definir cómo escribir en un campo altamente regulado por prescripciones masculinistas. Las estrategias desplegadas por estas mujeres tienen que ver con la necesidad de legitimar una escritura, acorralada en formas y temas estereotipados. Los núcleos principales de las polémicas sobre la lengua en esos años tienen que ver con esa necesidad.

Las diversas operaciones que utiliza Storni -así como otras escritoras del períodopara construir un discurso subversivo desde la situación mujer, constituye un intento no sólo por legitimar una escritura -la de las mujeres- a partir de nuevas coordenadas que no son, precisamente, las impuestas por la normativa androcéntrica, sino también configuran una de las aristas de las disputas en torno al lenguaje de los años veinte. Si el purismo, la oralidad, el contacto de lenguas o las diversas configuraciones de lo nacional forman parte del principal nudo vascular por donde circularon las polémicas en torno al idioma y a las diversas escrituras literarias, la categoría de género (gender) también debe ser incluida en el entretejido de estas querellas en tanto que su análisis implica la puesta en cuestión de los usos y actitudes lingüísticos.

Un repaso por algunas reseñas y comentarios contemporáneos acerca de la obra poética de Storni permite observar los mecanismos que la crítica normativa utilizó para neutralizar una escritura contestataria, pero también posibilita ver cómo esa operación se inserta necesariamente en las polémicas sobre la lengua literaria.

En el año 1921, José Gabriel publica en la revista El Hogar un artículo ${ }^{362}$ en el que reflexiona acerca de la literatura escrita por mujeres, en general; y comenta, particularmente, el último libro publicado por Alfonsina Storni, Languidez (1920). Según José Gabriel, la literatura femenina tiene como característica esencial "el íntimo horror a expresar la vida real y ordinaria" (1921: 17). Sin embargo, como veremos más abajo, José Gabriel se asombra del modo en que Storni, en este poemario, rompe con esta característica general de la "literatura femenina". Además, agrega que "el primitivismo espiritual de las escritoras", las llevaba a suponer que la literatura tenía vocablos, giros y temas propios y eternos, fuera de los cuales no podía haber arte. Todas se ponían a escribir "en literatas" -continúa- y así, "todas cantaban al amado y todas, o bien lo inventaban, sencillamente, no habiendo tenido ni siquiera un festejante, o bien teniendo un amado, desfiguraban la realidad a tal punto que constituía también una invención" (17). Critica el encorsetamiento que sufre la literatura escrita por

\footnotetext{
362 "La literatura femenina en Sud América. A propósito de un nuevo libro de Alfonsina Storni” (Gabriel 1921). Muschietti toma nota de los comentarios de José Gabriel en este artículo, en el que afirma que "en la literatura femenina sudamericana campea cierta uniformidad"; las mujeres no conocen "otro mundo que el de los amores, ya en forma idílica o pasional" y "cuya característica esencial está constituida por un íntimo horror a expresar la vida real y ordinaria” (1921: 17). Ante la apreciación de José Gabriel, Muschietti señala que el comentarista parece atribuir esa uniformidad, equivocadamente, más a características inherentes al hecho de ser mujer que a las condiciones socio-históricas de producción de los textos (2006: 112).
} 
mujeres, para las cuales "no existía otro mundo que el de los amores, ya en forma idílica o pasional" (17). Hasta aquí, Gabriel parece criticar la "literatura femenina" por su sujeción a los modelos patriarcales que imponen temas, perspectivas y formas expresivas particulares. Sin embargo, su mirada se estrecha al no poder advertir los dispositivos de control y coerción que gravitan sobre la mujer al momento de escribir, y adjudica las condiciones y propiedades de esa escritura a la naturaleza femenina. La reclusión referencial de la "literatura femenina" impacta sobre la lengua, cuestión que José Gabriel destaca en su artículo. Para él, la mujer escribe con un lenguaje que no pertenece a la realidad, sino que es inventado, como el amor y el universo contextual que componen sus poemas. Formas, frases, locuciones y términos de estas escrituras "no reflejan la vida que las rodea", sino más bien "una actitud espiritual primitiva $^{363}$ de lo subjetivo puro en que la complejidad de la vida real cede el puesto al simplismo de la ficción" (17). Desde la perspectiva de José Gabriel, un lenguaje escasamente referencial, estereotipado e iterativo convierte a la "literatura femenina" en una copia de sí misma.

El traspaso de los límites que la separan de la oralidad constituye una seria infracción, ya no solamente para la literatura escrita por mujeres, sino para la literatura dominante en general. En el marco de los problemas de la lengua literaria, la incorporación de la oralidad, sobre todo de aquélla basada en los usos de los registros populares, será seriamente cuestionada por los sectores más conservadores del campo literario, generalmente adscriptos a algún tipo de purismo idiomático. A pesar de ello, José Gabriel critica la "literatura femenina" que se aferra ciegamente al registro escrito, al punto tal de desnaturalizar determinadas formas de expresión: “no se dirá 'te quiero', sino 'te amo’ ('¿te quiero?', eso se dice hablando)" (17).

No obstante estos señalamientos, José Gabriel menciona algunos nombres que rompen con el panorama de la "literatura femenina" que ha venido trazando a lo largo de su artículo. En primer lugar, y como al pasar, se refiere a "la iniciadora", a la uruguaya Delmira Agustini, quien, durante la primera y segunda década del siglo $\mathrm{XX}$, supo construir una poesía que contravenía los preceptos impuestos a la escritura de las mujeres por la lógica dominante. Básicamente, Agustini se aparta del poema de amor aséptico para dar forma a una lírica fuertemente erotizada. Duplicada esa voluntad en la realidad, existe un dato biográfico que plantea -al igual que su escritura en el plano literario- cuestionamientos a los mandatos sociales de la época: se divorcia de su esposo, Enrique Job Reyes, pocos días después de la

\footnotetext{
${ }^{363}$ Según se puede apreciar en las palabras de José Gabriel, las escritoras de los años veinte comparten con los nuevos autores surgidos en este período la condición de "primitivos". Para indagar la funcionalidad del primitivismo en este contexto, ver Garramuño (2007).
} 
boda. ${ }^{364}$ No obstante ello, y ya definitivamente separados, Agustini mantiene con él una ardiente relación amorosa que culmina trágicamente el 6 de julio de 1914, cuando Reyes la asesina de dos disparos.

Al igual que la Norah Lange de Voz de la vida - y, como veremos luego, al igual que Alfonsina Storni- la crítica literaria contemporánea "virilizó" a Agustini. Al respecto, se transcriben algunas palabras que el crítico uruguayo, Alberto Zum Felde, le dedicó a la escritora en su Crítica de la literatura uruguaya (1921), reeditadas luego en la compilación póstuma de Agustini, Los astros del abismo (1924):

Delmira Agustini une la mentalidad robusta de un varón, a la más sutil sensibilidad de mujer (...) casi siempre la cerebralidad prima en ella, convirtiendo toda sensación en idea (...) Los pensamientos enérgicos y originales que se hallan a cada estrofa, revelan una conciencia máscula... (Agustini 1924: 9, destacado nuestro).

El segundo nombre en el que se detiene José Gabriel es el de Alfonsina Storni. ${ }^{365} \mathrm{Al}$ leer Irremediablemente, se sorprende por el lenguaje utilizado allí por la escritora: lejos del vocabulario subjetivo, intimista y abstracto de las "poetisas", Storni le devuelve toda su materialidad a la lengua. Según Gabriel, antes de Languidez, Storni "imaginaba idilios y reyertas amorosas, trágicas: ahora habla de sus ansias de querer: esta es su realidad viviente y esto es aquello en que puede poner emoción y originalidad; antes parecía vivir fuera de este mundo" (17). E incluso agrega que en este poemario "hasta en Buenos Aires ha puesto atención". Si se toma en cuenta que la escritura de mujeres, en los años veinte, se encuentra excluida de los tópicos vinculados a los síntomas de una ciudad en pleno proceso de modernización, no resulta extraña la sorpresa de José Gabriel al notar el modo en que Buenos Aires se hace presente en el poemario de Storni. De este modo, podemos observar poemas como "Domingos", "Rosales de suburbio", "Tristeza" o "El obrero"366 en los que la ciudad aparece con fuerza y que, necesariamente, modifica el lenguaje literario de la poetisa, puesto que ingresan palabras más "materiales", prosaicas si se quiere, alejadas del lirismo modernista que caracteriza al grueso de sus poemarios de la década de 1910: ${ }^{367}$ "Metal", "piezas de género", “vereda”, “calles”, “paredes”, “negocios” (Storni 1968: 185-186).

\footnotetext{
${ }^{364} \mathrm{El}$ abandono del esposo o prometido por parte de la mujer constituía una acción osada en las primeras décadas del siglo XX. Como ya hemos visto, Norah Lange se ocupó de tematizar esta situación en su novela epistolar Voz de la vida.

${ }^{365}$ En su poemario Ocre, Storni le dedicará un poema a Agustini: “Palabras a Delmira Agustini" (1968: 258).

${ }^{366}$ Todos los poemas mencionados pertenecen a Languidez (1920).

367 Claudia Darrigrandi (2008) analiza con detenimiento la poesía de Alfonsina en relación con el espacio urbano.
} 
En el ya mencionado "Domingo", se describe un paseo por la ciudad. Dado el día, comercios y casas se encuentran cerrados, y es allí en donde el yo poético imagina los interiores, lo que sucede detrás de las paredes. El poema es un ejemplo de cómo Storni rompe con la reclusión destinada a la mujer escritora e invierte la situación dado que todo lo que observa en el poema, o mejor dicho lo que no puede observar, se encuentra recluido, encerrado, mientras ella camina libremente las calles del centro de la ciudad. Estos rasgos son indicios de una modernidad que rompe con ese "mal gusto" y esas formas residuales de las que habla Sarlo. Entonces, si las escritoras asumían una perspectiva intimista en sus obras, traducida en un enclaustramiento que se manifestaba, muchas veces, en un yo poético encerrado en la casa, el cual sólo tenía noticias de la ciudad mediante ventanas o umbrales que oficiaban de puentes entre la esfera privada y la pública, la obra de Storni de los años veinte modifica esa situación: "En los domingos, cuando están las calles / Del centro quietas, / Alguna vez camino/ (...) Vueltas y vueltas doy por esas calles” (1968: 185-186), "Sobre las pobres casas / De latas y maderas, / De los suburbios" (199), "Iba por la ciudad cuando un obrero / Me arrojó, como piedras, sus palabras" (204). ${ }^{368}$ El poema "Siglo XX" tematiza la ruptura de la clausura, en relación con su condición de mujer moderna: "Me estoy consumiendo en vida, / Gastando sin hacer nada / Entre las cuatro paredes / Simétricas de mi casa. / ¡Eh, obreros! ¡Traed las picas! / Paredes y techos caigan (...) Mujer soy del siglo XX” (220-221). Estas rupturas que comienzan a apreciarse hacia 1920 se van consolidando en sus libros sucesivos. De este modo, nos encontramos en Ocre con unos "Versos a la tristeza de Buenos Aires":

Tristes calles derechas, agrisadas e iguales por donde asoma, a veces, un pedazo de cielo, sus fachadas oscuras y el asfalto del suelo me apagaron los tibios sueños primaverales. Cuánto vagué por ellas, distraída, empapada en el vaho grisáceo, lento, que las decora. De su monotonía mi alma padece ahora. -¡Alfonsina!- No llames, ya no respondo a nada. Si en una de tus casas, Buenos Aires, me muero viendo en días de otoño tu cielo prisionero, no me será sorpresa la lápida pesada.

Que entre tus calles rectas, untadas de su río apagado, brumoso, desolante y sombrío, cuando vagué por ellas, y estaba yo enterrada. (1968: 255, destacado nuestro).

\footnotetext{
${ }^{368}$ Las citas corresponden a "Domingos", "Rosales del suburbio" y "El obrero" respectivamente. Todos pertenecientes a Languidez (1920).
} 
La virilización de Storni se puede entender mucho mejor si consideramos estos ejemplos puesto que el vagabundeo, el errar por la ciudad, se convierte en un procedimiento literario propio del escritor moderno. ${ }^{369}$

Por el contrario, la obra poética de Norah Lange se ciñe a los mandatos patriarcales en este sentido: ${ }^{370}$ en su primer libro de poemas, La calle de la tarde (1925), podemos apreciar el rol preponderante que tendrán las puertas y las ventanas de la casa familiar: "La noche entró por la ventana / Mi alcoba está suave de luna" (2005: 58). En el poema "Ciudad", todo lo que expone el yo poético parece provenir de lo que ingresa a través de las aberturas de la casa: "El bullicio se da / a las ventanas abiertas / como un éxtasis" (65). A la inversa de lo que ocurre con los poemas escritos por hombres que retratan la ciudad, la urbe de la "literatura femenina" se contempla desde la intimidad, no se la recorre con la mirada de flâneur suburbano. Salir del espacio íntimo para ubicarse en la escena pública implica un desafío a los límites que regulan la "literatura femenina", lo cual supone una modificación en las pautas que rigen a ese lenguaje literario. En este sentido, se puede comprender entonces la infracción que representan los poemas citados de Storni al configurarse a partir de la visión de un yo poético que, lejos de recluirse, rompe con la poesía de clausura y reconstruye la ciudad.

José Gabriel, ante el señalado desplazamiento producido en la poesía de Storni, repara en las formas expresivas utilizadas en Languidez: "apenas se hace creíble que esta escritora se haya atrevido a tener en cuenta las cosas que la rodean y a usar vocablos como 'ladrillos', 'maderas', 'veredas', 'latas', que parecían proscritos para siempre de su tradicional diccionario mitológico" (1921: 17). La cita pone de manifiesto que la gran distinción entre lo femenino y masculino, en el plano literario, asume una funcionalidad que se dirime en torno a la prohibición o el acceso a ciertas zonas del lenguaje. Franquear esos lindes constituye uno de los gestos primordiales de las mujeres escritoras en el plano de las disputas sobre la lengua. El crítico felicita a Alfonsina por desarrollar su escritura por fuera de una literatura estandarizada y repetitiva; piensa que con Languidez Storni "se humaniza" y considera la obra

\footnotetext{
${ }^{369}$ Roberto Arlt, Nicolás Olivari, los hermanos González Tuñón son algunos ejemplos de escritores que han desarrollado una literatura urbanamente trashumante, en la que el caminar y observar se asumen como perspectivas centrales de sus literaturas. En el caso de Arlt, por ejemplo, Noé Jitrik realiza un análisis del caminar como "traslado estructurante" (1987: 74-77).

370 "Ventanas, marcos y espejos se convierten en pautas de sus textos [los de Lange], como si se trata de una suerte de enunciado de un antes y un después, de un adentro y un afuera (...) Lo más importante es que los paneles de vidrio denotan una separación entre la esfera pública y la privada que se traduce como una experiencia dentro del lenguaje. Estos marcos se abren y se cierran según la voluntad de la narradora y proyectan una disposición interior que contrasta con el medio circundante (...) Por ejemplo, en Cuadernos de infancia y Personas en la sala (1950) la prosa de Lange se define a partir del aislamiento de sus protagonistas del entrono global. La casa, el patio, el ático o las celosías de las ventanas de la casa familiar protegen al narrador dentro de espacios limitados" (Masiello 1997: 200-201).
} 
como "un acto suyo loable" (17). En este sentido, parecería que la lectura que hace José Gabriel de Storni se coloca en una posición inversa a la que realizará, pocos años después, Ramón Doll sobre la novela epistolar de Norah Lange; pese a que, no obstante, ambos críticos comparten la misma perspectiva androcéntrica.

Ante una escritura en cierta medida anómala, si la comparamos con el conjunto en donde se la incluye, los argumentos que predominan en los problemas sobre la lengua literaria no tardan en aparecer. Sobre el final, el artículo de José Gabriel se sume en la contradicción cuando luego de festejar la voluntad emancipadora de los versos de Storni, la sanciona por el uso de esa misma liberalidad que, como hemos visto en otros autores como Olivari, se la vincula a la ignorancia y a la falta de pericia literaria. Luego de los elogios por el novedoso lenguaje de Languidez, el crítico expresa que "si bien la intención de este libro nos es ya muy simpática, su realización no nos merece acogida" (17), puesto que posee "un arte literario sumamente incorrecto, con un verso defectuoso y duro casi siempre y una sintaxis risueña", y agrega que no comparte "la opinión de todos esos figurones españoles y americanos que envían cartas laudatorias y plantan prólogos descabellados porque les atrae secretamente la relación femenina" (17). La refutación del aparato crítico que saludó la obra de Storni principalmente ubicado en la revista Nosotros - se realiza desde una perspectiva masculinista, al adjudicar los supuestos logros literarios de la autora más bien a una actitud galante de los comentadores frente a la presencia femenina que a los juicios formulados frente al texto literario en sí mismo. José Gabriel se desdice un poco al señalar que "todavía [Storni] no logra desprenderse de esa subjetividad de sus primeros textos, y no puede observar la realidad objetivamente" (17). Pero su crítica principal se centra en el lenguaje: "la autora descuida no sólo el arte literario, sino hasta la gramática". Y a continuación trata de salvar la contradicción que entraña propiciar una literatura libre de ataduras retóricas y, al mismo tiempo, pregonar la corrección idiomática:

Desde hace años venimos reclamando de los escritores el abandono resuelto de todo lo que sea retórica o literatura o purismo lingüístico. Parecerá, pues, que ahora nos contradecimos reprochando a la autora de Languidez su descuido literario. No sucede así, sin embargo, ni mucho menos. Hemos pedido, y pediremos siempre, la independencia artística. Más aún: sostenemos la necesidad de despreciar el "instrumento" del oficio; pero eso, sólo después de haberlo conocido y dominado a la perfección, y el caso de la Storni no es, por cierto, el de un escritor idóneo que se resuelve a ser libre por sentirse capaz de dominar y sobrepasar las reglas (17). 
Vale decir que para José Gabriel la “incorrección” es un valor para nada desdeñable; al contrario, la juzga necesaria para que surja una literatura nueva. Sin embargo, esa “incorrección" puede llevarse a cabo únicamente a costa de la "corrección”. Es decir, para que un texto literario, libre de tutelas gramaticales y de estilo, pueda ejercerse de manera "legítima", es necesario que el escritor domine la lengua "correcta", conozca sus reglas. El crítico piensa en un escritor que viole las reglas a sabiendas de lo que está violando, y no que lo haga como fruto de la ignorancia o del desconocimiento del idioma. Para ello, es inevitable pensar que el escritor, antes de proponer una lengua literaria alternativa a las normas vigentes, debe producir textos "correctos" para demostrar que su escritura "anómala" encuentra en el saber el sostén de su irreverencia. En este sentido, la escritura que "desprecia el instrumento" siempre es subsidiaria o parásita de ese mismo instrumento que desprecia. Los alcances de las palabras de José Gabriel exceden claramente la referencia a Storni, puesto que a quien parece estar haciendo referencia en estas últimas ideas es a los escritores "plebeyos", a aquellos que muestran una escritura reñida con las normativas del idioma. Cabe aclarar que este no es el caso de Storni, quien en sus poemarios evidencia una lengua literaria correcta, por lo menos desde el punto de vista gramatical. Lo que el crítico ataca en Storni no es el aspecto formal de su lenguaje -aunque así lo manifieste-, sino la violación de los órdenes del discurso a los que debía ajustarse una poetisa. Como decíamos, el tiro por elevación está destinado a aquellos autores que se construyen como escritores modernos a partir del desprecio de las reglas de la lengua sin conocerlas de antemano, debido principalmente a que muchos de ellos son escritores con escasa formación escolar. En el caso de Storni, podemos apreciar en su obra una evolución que va desde el tardorromanticismo y el modernismo hacia una postura más vanguardista, aunque esta no comporta el desprecio por la gramática, debido a que su formación como maestra podría haber influido en la construcción de su lengua literaria.

Como sucederá con buena parte de la crítica literaria contemporánea encargada de la obra de Nicolás Olivari, en las experimentaciones formales y en el uso de un lenguaje a contrapelo de las normas imperantes, los críticos han preferido ver ignorancia o torpeza antes que un deliberado proyecto creador encargado de subvertir determinados mandatos y mecanismos de control reguladores del discurso literario. Las incorrecciones gramaticales de Storni se suman a los "barbarismos y galicismos en abundancia", que se mixturan con un "manifiesto desconocimiento de algunas palabras usadas" (17) por Storni en sus poemas.

En enero de 1930, en la revista Claridad, aparece un artículo de Norberto Lavagnino, titulado "Literata", en el que se refiere a la producción literaria llevada a cabo por mujeres, entre las cuales se destaca el nombre de Alfonisa Storni. Lavagnino llama la atención sobre “un pequeño volumen de poesías en prosa sobre el amor", que Alfonsina publica en 1926; se 
refiere a Poemas de amor: "la delicada forma y el sentimiento de estas composiciones -señala el comentarista- no alcanzan a disimular la llama sensual que las ha inspirado" (1930: 18). Como en la crítica que Ramón Doll realiza a Voz de la vida, aquí Lavagnino juzga de manera muy negativa la pasión (sexual) encarnada en la poesía escrita por mujeres. En oposición a Storni, Lavagnino encuentra en María Isabel Biedma Martel "una nueva estrella de la poesía", en tanto que, además de mantenerse al margen de los arrebatos pasionales, "escribe sus versos en francés" (18); vale decir, acata el modelo normativo androcéntrico que regula la pluma femenina. Por estos motivos, el comentarista rescata a esta escritora del conjunto de sus contemporáneas.

A continuación, Lavagnino elabora una cartografía valorativa de las escritoras del período, pero antes precisa el concepto, muy en boga en la época, que da nombre a su artículo:

Literata es la mujer que desentendiéndose de la cocina $[y]$ de las 'labores propias de su sexo' se dedica a garabatear cuartillas (...) Si fuera el inolvidable Valbuena jugaría con el vocablo partiéndolo en dos trozos iguales: lite-ratas, aplicando la última partícula a la generalidad de las mujeres que en nuestro país se dedican a la literatura, para desgracia de los parientes y allegados. Pues ratas, y pobres de albañal suburbano, nos resultan las tales. Ratas conscientes de su misión de propagadoras de la mala peste que es la literatura, ora ramplona y cursi, ora obscena y pornográfica (20).

La carga peyorativa del vocablo es por demás explícita, y se anuda a la llana impugnación de un discurso -el de algunas mujeres-, si no novedoso al menos provocador, que irrumpe en el plano literario, entre otros. Lavagnino condena la escritura de las mujeres a partir de su asociación con lo pornográfico. La idea de una literatura pornográfica recorre las tesis de la izquierda literaria y, según esta zona, se encarna en los folletines y en las novelas por entregas, muy en boga desde 1917 hasta por lo menos $1925 .{ }^{371}$. Los argumentos que procuran estigmatizar determinadas escrituras que no se avienen a las normativas estipuladas por el "buen decir", resultan de suma vigencia. Podemos relacionar lo que ocurre con la "literatura femenina" -observada desde la perspectiva de la revista Claridad-con el caso de Nicolás Olivari: a través de argumentos parecidos a los de Lavagnino, la crítica detractora colocó su obra -particularmente su primer libro de cuentos, Carne al sol (1922)- en el terreno de la "obscenidad".

\footnotetext{
${ }^{371}$ Beatriz Sarlo señala el período de apogeo de estas publicaciones entre los años 1917 y 1925 (1985: 9-10); parecidamente opina Margarita Pierini, quien acota la etapa a los años 1917-1924 (2002: 43, 2009 13-14).
} 
Al igual que la "literatura pornográfica" de la época (las narraciones semanales), ${ }^{372}$ los poemas de Storni se leen con una facilidad y rapidez similares a las de la novela sentimental del mismo período (Sarlo 2007). La comparación -sin dudas prejuiciosa- no sólo se explica por la fuente estética común -el tardoromanticismo- que comparten tanto los "novelines" como la poesía de Storni, sino además por el lugar privilegiado que en ambos casos suele asumir la pasión amorosa que los sectores conservadores contemporáneos llamarán pornografía.

Luego de precisar lo que entiende por el término "literata", Lavagnino realiza una evaluación del conjunto de las autoras que escribieron sus poemas durante los años veinte. Se queja de cuán "difícil resulta pescar de entre el montón de poetrascas a una poetisa de veras" (1930: 20): al nombre de María Isabel Biedma Martel, debe sumársele el de Susana Calandrelli; "el resto no sirve". Si bien Lavagnino no precisa las virtudes de Calandrelli, fácil es suponer que la escritora se salva de los afilados juicios del comentarista porque, al igual que la otra rescatada, ajusta su escritura a los preceptos patriarcales que rigen los versos de las “poetisas". Ambas escriben y publican en francés: en 1921, Calandrelli edita su primer libro de poemas en esa lengua, Carillons dans l'ombre.

Las impugnaciones de Lavagnino siempre se refieren a un mismo punto: el tono marcadamente erótico y sexual que, según él, tenían los versos de muchas mujeres. ${ }^{373}$ De "Juana de Ibarborou" (sic) dice que "no es de nuestro tiempo" puesto que "pertenece al coro de las bacantes y siente el rito sagrado de su sexualidad exaltada por la actual hipocresía" (22). La comparación de Ibarbourou con las bacantes proyecta la crítica hacia el terreno del desenfado sexual y la prostitución. Afirma que Concepción Ríos "ha equivocado su vocación", puesto que "Dios la hizo para practicar esos poemas y sonetos exaltadores del sexualismo" (22); hecho que evidentemente no se ajusta a lo que el comentarista entiende por las formas expresivas de una escritora. Y agrega que "muchas poetisas (¿para qué nombrarlas?) cantan el amor materializado en el acto bestial que nos acerca a los animales" (23). El dispositivo barbarizador lentamente comienza a desplegarse, y en Lavagnino aparece combinado con dos principios: el más conocido consiste en la animalización: "lo más original de Emilia Bertolé son sus ojos de gata, su mirar de gata. Posee esa mirada de los felinos que se aprestan a dar el zarpazo..." (23). A éste se le yuxtapone el de prostituir a las autoras a partir de la moralización de su escritura, es decir, Lavagnino sanciona la violación de las

\footnotetext{
${ }^{372}$ Ver “Alcaloides de papel. Una encuesta argentina de 1923 sobre la literatura barata" (Pierini 2002). Ver nota al pie 131 .

${ }^{373}$ Como por ejemplo: Delfina Bunge, María Luisa Domínguez, María Eugenia Vaz Ferreira, Raquel Adler, Salvadora Medina Onrubia. De Nydia Lamarque llegará a preguntarse si realmente tiene inteligencia (Lavagnino 22).
} 
pautas escriturarias de la mayoría de las escritoras aplicándoles una lectura cuyo fundamento se encuentra en un juicio moral sobre las prácticas sexuales, homologadas a las prácticas textuales. ${ }^{374}$ Líneas más abajo, precisa el sugerente pasaje acerca de Concepción Ríos:

Supongo que han errado la vocación; pero, no. Recuerdo que ninguna de las mujeres que comercian con su cuerpo lo pregonan. Por el contrario, se avergüenzan de ello. ¿Debemos, entonces, considerar a tales 'poetisas' más despreciables que las citadas mujerzuelas? (23).

Además de Susana Calandrelli, María Isabel Biedma Martel y "la nueva y original poetisa" Clara Beter, ${ }^{375}$ Alfonsina Storni también se suma a la lista de las autoras cuya textualidad, según Lavagnino, las convierte en putas: “¿por qué Alfonsina Storni, en lugar de contarnos sus hallazgos de buenos mozos en los trenes y en los paseos, no se procura uno para su particular regalo?” (1930: 23). Finalmente, Lavagnino culmina su artículo con la humorada misógina: "apiádate Señor de los que tienen una novia dada a las letras (...) Odiosa por partida doble la mujer fea que comete malos versos" (23-24). Rata, pornógrafa y prostituta: triplemente barbarizada, en el texto de Lavagnino, la mujer escritora de los años veinte se asume como la difusora de una peste textual que debe ser silenciada/saneada.

La mirada que Lavagnino tiene sobre la "literatura femenina" coincide con la de otro artículo de Claridad, escrito por Ramón Doll en el mismo año de 1930 -“La producción literaria de 1929"- en el que se refiere a la "poesía femenina" como una "zona cenagosa (...) de raigambre ostensiblemente genital" (1930: 26). La genitalidad que tanto Doll como Lavagnino -éste la denomina "sexualismo", entre otros términos que utiliza- notan en muchas de las "poetisas" se refiere, básicamente, a la voluntad de salirse de los límites que el

\footnotetext{
${ }^{374}$ La idea de la "prostitución artística" tenía mucha circulación en las revistas de vanguardia de la época, y venía a significar el contacto determinante del mercado con la obra literaria. Interesa en este caso hacer notar que la prostitución se convierte también en un tópico del dispositivo barbarizador cuya funcionalidad consiste en impugnar las escrituras "sexualizadas" de las escritoras. De todas maneras, la "prostitución artística" comporta aspectos que también se vinculan con la lengua literaria en la medida en que con el afán de vender libros o ganar concursos sucede muchas veces que el escritor se ve inmerso en un condicionamiento estético que tiene como consecuencia "un estancamiento en los procedimientos consagrados y un almibarado refinamiento a fuerza de pulido, por temor a notas agrias o discordantes" (González Lanuza 1926: 3).

${ }^{375}$ Para cuando Lavagnino publica su artículo, la broma ya había sido descubierta y se conocía que debajo de la máscara de la prostituta se encontraba la "masculina presencia de César Tiempo" (20). En 1927, antes de que se descubra el engaño, Tiempo se encuentra ocupado en la tarea de acrecentar la figura de Clara Beter desde las páginas de Claridad. Allí publica un artículo, "La poesía de una mujer de la calle", en la que realiza una semblanza de su creación: "esta mujer alta como un alarido, de mirada dulce y penetrante, de una belleza firme y madura, gana el centro y es una gracia onerosa en el corazón de la urbe" (Zeitlin 1927: 15). Tiempo no ubica a su Clara Beter en el rol de escritora, puesto que "no se trata de una mujer que hace literatura (...), la que nos abandona su lacerante y subyugante confesión es una mujer de la calle, 'de la vida"' (15). En todo caso, Tiempo parece querer decir que esos poemas deben ser leídos más como testimonio que como literatura, y así evita ubicar a Beter en un terreno poco propicio para las mujeres, según la mirada no sólo de la izquierda literaria sino de gran parte del campo letrado de entonces.
} 
lenguaje y los temas fijan a la escritura de las mujeres, de acuerdo con la normativa androcéntrica vigente. Deseo y lenguaje conforman el vértice que la "literatura femenina" asume en el marco de las disputas acerca de la lengua. Veamos dos ejemplos de Ocre, en donde Storni construye mujeres sensuales, fuertemente erotizadas:

Tengo el cuerpo perfecto y la boca rosada,

Para el amor más alto yo fui seleccionada,

Pero escondo mi fuego bajo un velo de monja (1968: 253). ${ }^{376}$

O bien:

Pasó ayer a mi lado, las caderas redondas, Los duros muslos tensos soliviando las blondas,

Los labios purpurados, y miedo tuve de verla,

Pues, de tal modo es ella, ya la predestinada

Que, se comprende al verla, camina, abandonada,

Hacia el hombre primero que debe poseerla (269). ${ }^{377}$

En el primer ejemplo, el erotismo femenino aparece como algo que la mujer debe esconder, sin embargo el poema lo pone de manifiesto. Se encuentran, al mismo tiempo, la regulación que existe sobre los cuerpos y el deseo de la mujer, pero también su subversión. En el segundo también hay una clara intención de destacar el erotismo y el deseo femeninos. Si bien la mujer aparece en un rol pasivo, en tanto es el hombre quien la "posee", su actitud decidida y de búsqueda del objeto del deseo, tradicionalmente adjudicada al hombre, es asignada a la mujer. Además, Storni construye un lenguaje literario fuertemente erotizado a partir de la elección de palabras que crean imágenes muy sugerentes.

Sin lugar a dudas, una de las publicaciones que más tempranamente -y con mucha asiduidad- se ocupó de Storni fue la revista Nosotros. Alicia Salomone señala que la publicación era "portadora de un gesto innovador al acoger en 1916 la escritura de Alfonsina en el espacio de lo literario". ${ }^{378}$ No obstante esta "postura aperturista", las críticas que reciben las distintas obras de la escritora en el seno de la revista de Giusti y Bianchi -si bien es cierto que en su conjunto son muy positivas- no están exentas de señalamientos que tienen que ver

\footnotetext{
${ }^{376}$ La cita pertenece al poema "La otra amiga".

${ }^{377}$ La cita pertenece al poema "Una voz".

378 "Es la primera mujer cuyo libro se comenta. Ello establece una demarcación significativa: por un lado, se autoriza una voz que había sido descalificada por sectores conservadores que cuestionaban su modo de exponer públicamente la subjetividad femenina (...) con este gesto la revista legitima la presencia de la mujer en el espacio de la escritura literaria, asumiendo una postura aperturista ante un debate que se venía desarrollando desde el inicio de la publicación y que tenía por eje la relación entre mujer, cultura y literatura" (Salomone 2006: 53).
} 
con las modalidades de regulación de la "escritura femenina" que venimos observando, y que se configuran como dispositivos relevantes en el marco de los problemas de la lengua literaria.

Bajo el simple título “Alfonsina Storni”, Luis María Jordán reseña en Nosotros, en 1919, el poemario Irremediablemente. Resulta de suma importancia para nuestro trabajo este texto puesto que aquí Jordán esgrime uno de los argumentos centrales que la crítica contemporánea ha utilizado para deslegitimar la literatura escrita por mujeres: nos referimos al proceso de virilización de estas escritoras. ${ }^{379}$ Salomone entiende que la "virilización de ciertas escritoras" representa

una anomalía que hay que interpretar tanto en el sentido del desplazamiento sexo-genérico que implica respecto de las figuras de ellas mismas, como en lo que hace a la infrecuencia que este rasgo tendría en la producción literaria de mujeres de comienzos del siglo XX (2006: 56). ${ }^{380}$

Además de esta operatoria, a las llamadas estéticas femeninas en los años veinte se las suele vincular con lo europeizante, extranjero, degenerado y cobarde; mientras que a las masculinas, en cambio, se las liga con lo productivo, nacional, propio y vigoroso (Salomone 2006).

Jordán, desde el comienzo de su artículo, y entremezclada con los aspectos positivos, ${ }^{381}$ desliza la impugnación consistente en atribuir a la escritura de Storni aspectos sexo-genéricos no coincidentes con los de ella: “con la señorita Storni puede hablarse sin eufemismos, ya que ella misma nos da ejemplos de claridad en el decir, en las viriles y armoniosas estrofas de su verso..." (1919: 37, destacado nuestro). La identificación entre los lectores y el autor resulta una característica propia del discurso crítico de aquellos años. Así, por ejemplo, lo que se consideraba "baja" literatura, "inculta" u "obscena", se decía que era producto de la ignorancia del autor y encontraba su destino en un lectorado semi analfabeto. $^{382}$ La masculinización de determinadas "poetisas" no suponía solamente una transgresión a las reglas del género -entendido este término en su doble acepción-, sino

\footnotetext{
${ }^{379}$ Basta recordar el ya mencionado caso de la crítica que Ramón Doll (1928) realiza a Voz de la vida de Norah Lange.

${ }^{380}$ El dispositivo de virilización de las mujeres escritoras ya se había puesto en práctica a fines del siglo XIX. Un ejemplo de ello es lo que Mariano Pelliza, historiador perteneciente a la Generación del 80, señala acerca de Madame de Staël: "no era escritorcilla sedentaria, sin erudición, ni mundo, sin gusto ni talento: mujer por el sexo, fue hombre por el espíritu" (Maristany 1998: 52). Otro ejemplo, de algunos años después, es la presentación que realiza la revista Nosotros de un artículo de Ida Baroffio Bertolotti ("Cuando una mujer escribe", 1908) en la que se afirma que la escritora es "varonil por el pensamiento, femenina por la delicadeza" (Maristany 52).

381 "Irremediablemente es uno de los libros de versos más bellos entre las docenas de los aparecidos desde hace veinte años." (Jordán 1919: 41).

${ }^{382}$ Ver Pierini (2002: 43-63).
} 
también un cambio del supuesto lectorado al que, naturalmente, estaban dirigidos sus versos. Esto se puede apreciar claramente cuando Jordán sostiene: "bien es cierto que este poeta ${ }^{383}$ no escribe para ser leído por las Jeunes filles en los largos hastíos de las medias tardes, si no (sic) para hombres apasionados y violentos que hayan mordido la vida..." (37, destacado nuestro). En francés, la expresión "Jeunes filles" significa "chica" o "muchacha". Evidentemente, al estar en ese idioma, el término se connota para referirse a las jóvenes aristocráticas, quienes además de adjudicárseles una moral sexual impoluta, poseen la educación necesaria $-\mathrm{y}$ el ocio, como también se sugiere- para poder leer la "poesía femenina" en la lengua de Hugo, tal cual estipula la norma masculinista. ${ }^{384}$ Se desprende de las palabras de Jordán que Storni no escribe para la clase social ni para el sexo que, se supone, debe escribir. En contraposición, aparece la figura de los "hombres apasionados y violentos que ha[n] mordido la vida" como los destinatarios reales de sus poemas; es decir, los hombres que poseen experiencias en un sentido general, pero principalmente en el plano sexual, cosa que se supone las jeunnes filles están lejos de tener; y no deben tener: la lectura puede marchitar la inocencia de las jóvenes. Al poner en el mismo plano a la autora y a sus lectores, Jordán masculiniza y connota sexualmente a Alfonsina Storni y su escritura. Más adelante, el comentarista la compara con un marinero: "[Storni] se ofrece con la ruda camaradería de un marino..." (38).

Pese a la ascendencia europea de Storni, Jordán festeja la presencia en el medio de una "mujer fuerte de nuestra raza que nos dice, en bravos versos extraordinarios lo que nosotros mismos desearíamos decir todos los días" (39, destacado nuestro). Y agrega: "su idioma no tiene reminiscencias francesas, inglesas, italianas o latinas. Escribe en castellano, en nuestra sonora y armoniosa lengua peninsular, sin torturarla con afeites prestados y postizos (40, destacado nuestro). De acuerdo con esto, Jordán rompe con la homología entre lo extranjero y la mujer; aunque este corrimiento, tal vez, se deba adjudicar mejor a la posición heterodoxa que asume Storni con respecto al grueso de las escritoras. En esta última cita, se evidencia la postura que Jordán tiene con respecto al problema de la lengua, y el lugar en el que coloca a Storni al respecto. Su purismo idiomático hace que los juicios hacia los versos de la "poetisa" sean muy positivos al no estar incrustados de los extranjerismos propios de la literatura afrancesada de otras escritoras. No obstante, esta valoración positiva se engarza con el aspecto más negativo del artículo: la "virilización" de la escritora.

\footnotetext{
${ }^{383}$ Nótese que se refiere a Storni en masculino.

${ }^{384}$ Lo que está en juego aquí también, es el control sobre el otro polo de la producción literaria: se trata del control sobre las lecturas que pueden hacer las jóvenes y las mujeres en general, preocupación propia de esta época porque la lectura encierra peligros que es preciso advertir. Para profundizar sobre esta cuestión, ver Maristany (2008).
} 
Sin embargo, la analogía entre lo masculino y la figura de Storni no parte únicamente de los críticos sino también de la propia escritora. En septiembre de 1931, El Hogar publica una entrevista a Storni. Allí hace un repaso de su niñez en San Juan, de la acomodada situación económica que gozaba su familia y de la debacle que sufrió gracias a la crisis financiera de los años noventa. Debido a la pérdida de la fortuna familiar, Storni cuenta cómo, desde muy pequeña, tuvo que ingresar al mundo laboral: "a los once años me puse a trabajar manualmente (...) y a los doce ganaba el alquiler de mi casa" (Alcazar Civit 1931: 8). Luego, comienza a exponer su dificultosa formación como escritora: “trabajaba de día y leía de noche"; un esquema que se repite en muchas de las declaraciones autobiográficas de los escritores recién llegados al campo letrado, como por ejemplo Roberto Arlt, quien convierte la incompatibilidad entre el trabajo asalariado y las tareas literarias en un tópico de su obra. ${ }^{385}$

Debido a su temprana inserción en el mercado laboral y al rol que desempeñó en su núcleo familiar, Storni afirma que su vida se asemeja a la de un varón, y que ese rasgo, necesariamente, se vio reflejado en su literatura:

Usted comprenderá que una persona como yo, que se ha puesto en contacto con la vida de un modo tan directo, de un modo tan varonil, digamos, no podía vivir, pensar, obrar, como una niña metida en las cuatro paredes de su casa; y mi literatura ha tenido que reflejar esto, que es la verdad de mi intimidad: yo he debido vivir como un varón; yo reclamo para mí una moral de varón. Lo que la experiencia me ha dado es para mi superior a cuantas cosas me ha dicho lo que me rodeaba. Con ello no hago más que anticipar a la mujer que vendrá, pues toda la moral femenina se basa en el régimen económico actual. Nuestra sociedad todavía descansa en la familia; la familia es la autoridad del varón, que es quien legisla, es decir, quien ordena en forma intelectual los hechos y quien provee el sustento. Pero si la mujer provee el sustento, y no depende del varón alguno, y puede penetrar y superar con su inteligencia la red legal en que su sistema la aprisiona, adquirirá, automáticamente, derechos de varón, que a mi modo de ver son apetecibles por ser mayores y de más alta moral que los femeninos (8, destacado nuestro).

Vale decir que aquello que, en una primera instancia, se configura como un rasgo ofensivo en la prosa de los críticos -la "virilización" de la escritora-, en la de Storni se convierte en el

\footnotetext{
${ }^{385}$ Este desacomodo entre la función de escritor y la inserción en el mercado laboral a través del periodismo de numerosos escritores no es un fenómeno de los años veinte, sino que resulta heredero del proceso de "profesionalización" del escritor, iniciado a comienzos de siglo XX. Algunos poetas modernistas pusieron de manifiesto esta situación al señalar que "la exigencia que los llevaba al periodismo no era vocacional sino de orden económico, debido a que la sociedad no necesitaba de poetas pero sí de periodistas" (Rama 1970: 68). Los modernistas no se alegraron con esta transformación, puesto que vieron en su trabajo una imposición económica (Rama 68). No obstante, esta "crisis de las ilusiones perdidas" provocó diversos tipos de reacciones y respuestas: "para unos será la crisis con sus secuelas previsibles de anulación, marginación y suicidio intelectual (e inclusive físico). Otros, por el contrario, encontrarán vías de realización, adecuándose con gran plasticidad creativa a los nuevos medios" (Rivera 1998: 55).
} 
reclamo de un derecho y en una militancia, cuya habilitación se encuentra en determinados núcleos biográficos que despegan a Storni de los patrones tradicionales de género. Una de las manifestaciones de esa militancia se encuentra, principalmente, en su tarea como escritora y periodista. José Maristany advierte que es muy frecuente que las escritoras de las primeras décadas del siglo XX recurran a afirmaciones "exageradas y defensivas de feminidad" debido a que juzgan que el ejercicio de la escritura "las volverá masculinas a ojos del público" (1998: 52). Esa actitud defensiva es el resultado del dispositivo de virilización vigente que condena a las autoras que se apartan de las prescripciones patriarcales que regulan su lengua literaria. No obstante, como acabamos de ver, este no es el caso de Storni quien lejos de las actitudes defensivas y claudicantes, se asume en esa masculinización que parte de la cultura conservadora y, de esa manera, neutraliza y/o subvierte dicho dispositivo.

En 1925, el crítico y poeta Rafael de Diego escribe una reseña sobre Ocre para la revista Nosotros. Su postura es particularmente interesante porque se aparta de las apreciaciones dominantes de la crítica y revela un artículo en el que afirma y defiende el erotismo que la obra de Storni posee. Recordemos que Rafael De Diego es el mismo que comentó, de manera muy positiva, el primer poemario de Nicolás Olivari, La amada infiel, en esta misma publicación, en el mismo momento en que arreciaban los comentarios insultantes y despectivos hacia el poeta. No es raro, entonces, que este artículo sobre Storni desentone con los que, desde esta misma revista, y otras, se le dedicó a la poeta. De Diego abre su comentario diciendo:

\footnotetext{
No es, ciertamente, la que canta este libro, Ocre (...) aquella jovencita que hace años, componiendo y descomponiendo el tocado para las horas trémulas de la cita, se veía volver del encuentro desesperada y melancólica (...) La mujer que ahora nos dice en sonetos sencillos, y un tanto graves con palabras de confesión íntima, sus tristezas y ansiedades nacidas más allá del desengaño, ha vivido mucho, tanto que por momentos no sólo nos emociona su ternura maternal, sino esa dulce comprensión sabia en la que palpita el perdón más sincero (1925: 70).
}

Como se puede observar en la cita, junto a la perspectiva novedosa que se manifiesta a través de la reivindicación del erotismo de Storni surgen los elementos residuales con que la normativa patriarcal ha definido a la mujer. Aparecen expresiones que ubican a la poeta en el lugar destinado a las mujeres de las primeras décadas del siglo XX, en general: "nos emociona su ternura maternal"; y a las "poetisas", en particular: "palabras de confesión íntima". La convivencia de estos dos registros que señala De Diego es el resultado de la combinación que hace Storni del lenguaje público y privado, es decir, de la coexistencia del lenguaje estipulado para su género, pero permanentemente agredido por un referente que lo 
subvierte. A su vez, a lo largo de todo el artículo, De Diego hace mucho hincapié en las ideas de la confesión y la intimidad como fuentes primarias de Ocre -rasgos que se ajustan a las supuestas propiedades de la "literatura femenina" -; y, además de eso, lo maternal como otra de las propiedades que definen al poemario. ${ }^{386}$ Evidentemente, los viejos mandatos dirigidos hacia la mujer y su escritura permanecen, en buena parte, muy vigentes en el texto de De Diego.

No obstante, existen amplias zonas que se apartan de estas concepciones para oficiar una lectura que coloca el erotismo como una de las principales virtudes de Ocre:

\author{
Mira con inocencia y es dura su mirada. \\ Su sonrisa es tranquila y en el fondo es taimada: \\ Hay huellas en la fresca ternura de su pulpa. \\ Ya en la boca se pinta la blandura redonda \\ Que dan los besos largos y en su nariz la honda \\ Codicia de la especie. ¡Y carece de culpa! (1968: 250). ${ }^{387}$
}

Ocre representa, en la obra de Storni, un momento transicional marcado por la constitución de un "sujeto-mujer crítica". Poco a poco, va imprimiendo a su poesía un tono irónico-crítico: la puesta en discurso del deseo femenino y la presencia de un cuerpo más material, ${ }^{388}$ menos ingrávido que el de sus primeros poemas (Salomone 2006); el cuestionamiento hacia la naturaleza masculina; ${ }^{389}$ la aparición de espacios abiertos en desmedro de los cerrados e íntimos. ${ }^{390}$ Cabe mencionar también la confrontación que Storni entabla con determinadas autoridades literarias (masculinas): el primer poema del libro, "Humildad", pese a su título, comienza parodiando el verso inicial de Cantos de vida y

\footnotetext{
${ }^{386}$ Ver, por ejemplo, el poema "Ternura" (Storni 1968: 259).

${ }^{387}$ La cita corresponde al poema "Cara copiada".

${ }^{388}$ Ver, por ejemplo, "Una”: "Es blanca y es perfecta, de radiadas pupilas / azules, donde acecha, perezosa, una Eva. / Su piel es piel de fruta. Su blanca carne nieva / y sus trenzas se tuercen como gruesas anguilas" (Storni, 1968: 268); "Una voz": "Sonabas cálida y segura / como de alguno que domina / del hombre obscuro el alma obscura, / la clara carne femenina" (269); "La palabra": "Me salí de mi carne, gocé el goce más alto: / oponer una frase de basalto / al genio oscuro que nos desintegra" (271).

${ }^{389}$ Ver, por ejemplo, el poema "La otra amiga": "Y otra amiga me dice: -las mujeres mentales / perdedoras salimos en negocios de amores. / Tenemos, ciertamente, muchos admiradores: / buscan pequeños sorbos en caídas vestales. (...) piensan que las mejores / son aquellas plegadas a sus modos carnales. / Las mujeres mentales somos las plataformas: mejoramos los hombres, y pulimos sus normas; / refinan en nosotras su instinto desatado" (Storni: 253).

390 "La sujeto que predomina en Ocre (...) prefiere deambular por múltiples ciudades (Buenos Aires, Mar del Plata, Córdoba) (Salomone, 2006: 147). Ver, a modo de ejemplo, "Siglo mío": "Yo la invito: -del brazo vamos por esas calles, / jovencitas precoces de delicados talles, / no vírgenes, y hombres fatigados veremos." (Storni 1968: 257); "Encuentro": "Me abandonó. De prisa le vi cruzar la calle / y con su manga oscura rozar el blanco talle / de alguna vagabunda que andaba por la vía. / Perseguí por un rato su sombrero que huía... / después fue, ya lejana, una mancha de herrumbre. / Y lo engulló de nuevo la espesa muchedumbre (251).
} 
esperanza, de Darío, ${ }^{391}$ mientras que, en "Palabras a Rubén Darío", explicita su alejamiento de la estética modernista, la cual había guiado la elaboración de sus primeros poemarios: "tus libros duermen. Sigo los últimos autores: / Otras formas me atraen, otros nuevos colores..." (1968: 252). En determinados momentos, Storni realiza una lectura sexo-genérica de la literatura. El poema "Femenina" es un buen ejemplo de ello: allí, el yo poético realiza una evaluación de Baudelaire como hombre antes que como poeta: "Baudelaire: yo me acuerdo de tus Flores del mal / En que hablas de una horrible y perversa judía (...) Pero a su lado no eras tan pobre, Baudelaire (...) Hombre al cabo, lograbas un poco de placer...” (258). Por fuera de la poesía, Storni también se enfrenta con el canon al reescribir obras de Eurípides y de Shakespeare. $^{392}$

Las mujeres escritoras de los años veinte participan de los problemas de la lengua literaria desde un ángulo diferente al de los hombres en la medida en que ponen a consideración una escritura, la suya, con la que pretenden disputar una subalternidad mucho más arraigada que la de los escritores periféricos del campo letrado, marginados en gran medida no sólo por su origen sino también por sus posturas explícitas con respecto a la lengua literaria. La poesía de Storni puede ser considerada "como una larga reflexión sobre las falacias del lenguaje, cuya crisis suele expresarse con frecuencia en las metáforas de unión del yo y el amado o a través de la lucha por representar un cuerpo material en los registros del verso" (Masiello 248, destacado nuestro). La lucha de la que habla Masiello está dada, principalmente, por la voluntad de representar algo - una nueva subjetividad: el deseo erótico, la crítica hacia el hombre y la sociedad machistas, etc.- mediante un lenguaje que se encuentra encorsetado por los mecanismos de control patriarcal.

La vanguardia estética también se ocupó de la figura de Alfonsina Storni. Tal es el caso de Jorge Luis Borges quien, años antes de la fundación del periódico Martín Fierro, escribe desde la revista madrileña Cosmópolis acerca de la poeta. En ese artículo -“La lírica argentina contemporánea"- Borges niega todo tipo de virtud a sus versos:

La señorita Storni -que según atestigua el último verso del poema anterior es muy partidaria del susto en literatura- se lamenta de que motejen de eróticas sus composiciones. Yo las encuentro cursilitas más bien. Son una cosa pueril, desdibujada, amarilleja, conseguida mediante el fácil barajeo de palabras baratamente románticas -flor, ninfa, amor, luna, pasión-,

\footnotetext{
391 "Yo soy aquel que ayer nomás decía..." Storni escribe: "Yo he sido aquella que orgullosa...” (1968: 239).

392 Explica Francine Masiello que Storni toma al dramaturgo griego para realizar su Polixena y la cocinerita (1931), además hizo una parodia del Cymbeline de Shakespeare. Y agrega: "el compromiso de Storni con los textos de la tradición clásica está destinado no sólo a mostrar que las escritoras pueden desafiar el canon sino señalar la distancia fundamental que separa las exigencias de género y clase cuando se trata de crear la ilusión de un personaje unificado (1997: 254).
} 
y cuyo accidental erotismo se acendra vergonzante en símbolos espirituales o se diluye en aguachirle retórica (1997b:137).

El comentario de Borges se centra, principalmente, en la utilización del lenguaje por parte de Storni; un lenguaje perimido, asociado al romanticismo y al modernismo que el joven ultraísta encuentra muy residual. El estilo de Storni deriva en la "cursilería", la "puerilidad" y en una retórica gastada. Incluso los procedimientos poéticos también son impugnados: "muy habitual en sus poemas es la repetición de cualquier frase pedestre con la finalidad de enaltecerla" (137).

En 1925 y desde la revista Proa, Borges reseña el libro Telarañas (1925) de Nydia Lamarque. En el artículo, claramente puede observarse la alianza que establece entre clase social y estética literaria. La reivindicación de la figura de Lamarque parte de su lugar de residencia, Belgrano, sitio que se diferencia del resto de los barrios suburbanos debido a que “es maridaje, no de la ciudá con el campo; sino de la ciudá con los árboles" (1925c: 50). De este modo, Borges repone, algo transfigurada, la dicotomía civilización-barbarie para hablar de un sector de la ciudad que influye de manera muy positiva en los textos de la poeta: "Belgrano infundió el agua de sus fuentes y el cariño de sus canteros en los versos de Nydia" (50). El nombre de Alfonsina Storni no se demora en llegar y se ubica allí con la intención de exaltar a Lamarque. Borges afirma que Telarañas es una obra poética que no incurre "en las borrosidades y chillonerías de comadrita que suele inferirnos la Storni” (51). Su contrafigura será, en el campo de la comparación, Norah Lange: "El sujeto [de las poesías de Lamarque] es la espera del querer, la víspera segura del corazón, las luces sabatinas encendidas aguardando la fiesta. Es el idéntico sujeto que hay en La calle de la tarde por Norah Lange, tanto más grato cuanto más enfatizado" (50-51). De todos modos, y pese a los avales que otorga tanto a Lamarque como a Lange, Borges coloca a esas poetas por fuera del círculo literario masculino. Establece una distinción vinculada con cuestiones relativas a la lengua literaria: "Le gustan [a Lamarque] los luceros, los rosales, los atardeceres con pájaros, las violetas. A nosotros varones, obligados al verso pensativo, nos conmueven esos trebejos que tan justamente se avienen con la hermosura de las muchachas y que florecen en sus versos con la misma naturalidad que en las quintas" (51, destacado nuestro).

Los vanguardistas juzgan la poesía de Storni acusándola de un "mal gusto" que no esconde bien ciertos prejuicios de clase y de género sexual, característicos de buena parte de los martinfierristas. Así, por ejemplo, en el "Parnaso satírico" de los números 27 y 28 de Martín Fierro, se lee: “Al color de tus versos sólo en parte / es el título dado conveniente. / 
No es 'Ocre' por completo allí tu arte, Alfonsina, es medio ocre, solamente." ("Parnaso satírico"1926a: 12).

La activa participación de las mujeres en la sociedad de los años veinte y el surgimiento de algunas escritoras que reivindicaban los derechos femeninos, entre los que podemos contar el derecho a la escritura literaria sin restricciones, produjo tensiones en el plano de la lengua literaria: algunas escritoras diseñaron estrategias de transgresión de los mandatos masculinistas para poder elaborar una literatura en la que se pudiera expresar la subjetividad y la identidad femeninas sin condicionamientos. Tanto Norah Lange como Alfonsina Storni diseñaron escrituras cuya transgresión se vincula con la creación de yo líricos o personajes femeninos que expresan aquello que estaba vedado: una participación activa en la relación amorosa, la tematización del deseo y el cuerpo, pero también el abandono de la clausura, la ruptura con el ámbito doméstico y familiar, la exploración de la ciudad, etc.

La lengua literaria tiene un género desde el momento en que existen regulaciones y discriminaciones que se inscriben en las escrituras, a partir de la distinción femenino/masculino. A lo largo del capítulo, hemos podido ver los modos y tonos, géneros, temas, idiomas a los que las escritoras estaban sujetas. 


\section{CONCLUSIÓN GENERAL}

El presente trabajo estuvo orientado hacia tres objetivos concretos relacionados entre sí. En primer lugar, se analizaron las implicancias de la cuestión del idioma en las reconfiguraciones de la lengua literaria. Para ello, hemos analizado de qué modo pudieron articularse las transformaciones del lenguaje literario durante los años veinte con las ideas acerca de un idioma nacional y con los cambios de la lengua en un medio signado por el cosmopolitismo y por los procesos modernizadores. En segundo lugar, nos propusimos evidenciar las tensiones, contradicciones y ambigüedades implicadas en el lenguaje literario en distintos autores y zonas del campo letrado de los años veinte. Dichos fenómenos no tuvieron un carácter homogéneo ni pueden ser explicados a partir de las mismas variables. Las tensiones que se presentan en las lenguas literarias de Roberto Arlt, Elías Castelnuovo u Oliverio Girondo responden a motivos diferentes vinculados de manera compleja con su educación y formación, su extracción social, su mayor o menor tendencia a la autonomía respecto de regulaciones ajenas a la literatura misma, sus posicionamientos y sus relaciones con los otros agentes o sistemas de agentes del campo literario, con los lineamientos de los proyectos colectivos en los que se insertan, su relación con el mercado y con el público, etc. Por último, y en tercer lugar, esta tesis se propuso realizar un aporte significativo a través del relevamiento de fuentes documentales, muchas de ellas inexploradas, con el objeto de reconstruir las disputas y tensiones acerca del lenguaje literario.

Las transformaciones de la lengua literaria durante el período 1920-1930 no pueden entenderse sin tomar en cuenta las discusiones acerca del idioma desarrolladas tanto previamente como a lo largo de la década. Escritores como Olivari o Arlt ejemplifican muy bien esta situación dado que, al proponer un lenguaje literario relativamente autónomo, relativamente libre de ataduras normativas, y nutrido de materiales lingüísticos considerados "no aptos" para la literatura por los grupos conservadores en materia de lenguaje, cuestionan la autoridad y los criterios estéticos e idiomáticos de esos sectores. Arlt construyó una lengua literaria "porteña", que era en sí misma una refutación de los argumentos de autoridades del circuito "culto" tradicional, como Monner Sans (h) o Capdevila, en abierto desafío a las actitudes puristas y afirmación de la emergencia de un idioma argentino. Es decir, la construcción y defensa de un lenguaje literario de esta naturaleza implicó, en la mayoría de los casos, ingresar en la agenda y en los temas propios de los debates acerca del idioma, los cuales se concentraron en explotar brechas y diferencias para la construcción de la lengua literaria. Lo que se discutía, en estos debates, era su autonomía, la pertinencia del "color local”, la distancia que debía mediar (o no) con la oralidad (Di Tullio 2009: 571). 
Además de estas disputas, un segundo factor determinó en buena medida las condiciones de transformación de la lengua literaria: en la década de 1920, se persiguió una autonomía, es decir, un lenguaje específicamente literario, separado de la lengua comunicativa, que buscó en la violación y deformación de la norma algo específico de la literatura y un derecho derivado de la condición de artista (Valery 1999). Vale decir entonces que las tensiones del lenguaje literario no sólo se vinculan con las insoslayables discusiones acerca del idioma o del intenso contacto de lenguas producto de la inmigración, que venía desbaratando desde hace algunas décadas un cierto orden, una supuesta homogeneidad lingüística cuya pérdida las élites lamentan. En todo caso, estos fenómenos propiciaron la emergencia de una escritura que, en consonancia con las exploraciones vanguardistas, tendió a distanciar al escritor de los legisladores de la lengua. En otras palabras, la lengua literaria debía estar regida por leyes propias o, en todo caso, no depender de las reglas que regulaban el funcionamiento del idioma. Las tensiones y transformaciones del lenguaje literario pueden ser entendidas como la manifestación de un proceso de relativa autonomización literaria, iniciado a comienzos del siglo XX, en el marco de dos transformaciones vinculadas con la modernización: la emergencia de las vanguardias y la expansión del mercado cultural. La investigación ha dejado en claro que la tendencia conservadora en relación con la lengua literaria no se dió exclusivamente en la zona "culta" tradicional del campo letrado, integrada por intelectuales de mayor peso y autoridad. El conservadurismo en el lenguaje literario también estaba presente en zonas más o menos emergentes o en escritores recién llegados a las letras, tanto en la zona de la vanguardia estética como en la de la vanguardia de izquierda y del circuito de mercado.

El concepto de "mala escritura" sirvió a los puristas y conservadores para rechazar las propuestas más novedosas que disputaban la autoridad y centralidad de criterios más tradicionales. La transformación del lenguaje literario también implicaba la expansión de los límites de la literatura a partir del trabajo con formas "espurias" o "plebeyas", o bien con significantes y campos semánticos atípicos para el discurso literario de la época. En algunos de los capítulos de este trabajo, hemos registrado algunos de los principales términos que sirvieron para una descalificación que no estaba exenta de contradicciones: se tildó de "babélica" o "cosmopolita" a toda lengua literaria que encontrara su punto de partida en la argamasa lingüística producto del contacto de lenguas popular-inmigratoria, al mismo tiempo que otras formas del cosmopolitismo - como el uso del francés en los poemas de amor escritos por mujeres de la elite - eran consideradas perfectamente aceptables.

A su vez, existió una "mala escritura" de otra índole, que se manifestó en tópicos y palabras de orden sexual, y que expresaba otro tipo de transgresión o "corrupción” literaria. 
Los ejemplos más claros son los de Girondo y Olivari. En el segundo caso, confluyen las dos modalidades censuradas: la asociada a lo "babélico" y aquella otra que encontraba en la transgresión temática una nueva productividad estética, lo que se agravaba cuando las que se atrevían eran escritoras mujeres.

El análisis de las fuentes documentales ha demostrado que no sólo existieron disputas y discusiones entre segmentos opuestos del campo literario, sino que también tenían lugar aún dentro de una misma publicación, grupo o zona. Esto indica las tensiones respecto de la lengua literaria y da cuenta de la dinámica compleja que asumieron las querellas en torno suyo. Dichas tensiones responden a veces a la coexistencia conflictiva de criterios: mientras que uno de ellos apuntaba a conformar un lenguaje literario modélico apegado a las normas, el otro operaba a contramano de las reglas atribuidas a la "buena" literatura. La transversalidad de estas tensiones es tal que aún dentro de un mismo autor suelen existir ambigüedades, contradicciones y vacilaciones con respecto al lenguaje literario, como se ha visto en los casos de Arlt y Castelnuovo.

La investigación realizada en esta tesis muestra al año 1927 como el epicentro o el momento de mayor actividad de los debates acerca de la lengua literaria, dado que en él tuvieron lugar varios episodios relevantes en relación con la problemática. En ese año se inició la polémica sobre el "meridiano intelectual” entre Martín Fierro y La Gaceta Literaria, que puso en debate el grado de influencia en materia cultural de España sobre América y, sobre todo, representó una toma de posición de un grupo heterogéneo de escritores acerca de la gestación de modalidades del idioma desprendidas del castellano peninsular, con las cuales se estaba construyendo una nueva literatura, autónoma de cualquier servidumbre estética y lingüística. En segundo lugar, a mediados de ese año se publicó la encuesta del diario Crítica, “LLlegaremos a tener un idioma propio?”, en la que el lunfardo se convirtió en protagonista, dada la extendida impresión de que podría constituirse en insumo principal de un idioma argentino y de una literatura "rea" cuya notoriedad y circulación irritaba a más de un sector del campo letrado, desde fines del siglo XIX. En tercer lugar, durante 1927 se desarrolló la virulenta campaña iniciada por la revista Claridad contra el diario Crítica, y cuyo núcleo también será el lunfardo en la lengua literaria y periodística de entonces. En cuarto lugar, Borges dictó su conferencia El idioma de los argentinos, que luego dará forma al libro de ensayos homónimo, publicado al año siguiente. Finalmente, no podemos dejar de mencionar la publicación de los textos inéditos de Sarmiento, donde el sanjuanino abordaba el problema de idioma en relación con la creatividad del pueblo y con la función de los escritores.

Alfonsina Storni y Norah Lange, en los años veinte, participaron de los problemas y tensiones de la lengua literaria. Su inclusión en la tesis resultó imprescindible para poder 
apreciar un panorama más completo que diera cuenta de la relevancia de la escritura de mujeres en esta etapa. La bibliografía consultada en relación con las disputas sobre el idioma y el lenguaje literario casi nunca incluye en la cartografía de esas discusiones a las mujeres escritoras. Nuestra investigación demostró la importancia que algunas autoras de la década del veinte tuvieron en relación con modificaciones sustanciales que ejercieron sobre la literatura; pero, sobre todo, evidenció la productividad que asumieron dentro de las discusiones acerca de la lengua literaria. La literatura escrita por mujeres se encontraba regulada y legitimada por pautas estilísticas, temáticas e idiomáticas determinadas por el discurso androcéntrico. Al igual que ciertos escritores emergentes, algunas escritoras se constituyeron en "otros", en casos "atípicos" o "molestos", puesto que produjeron un lenguaje literario que contravenía los mandatos de género y que, por lo tanto, era preciso corregir, señalar, impugnar. La "virilización" de quienes escapaban de los criterios y modelos esperables para la escritura de mujeres se convirtió en un tópico muy frecuente en la recepción de sus textos. Las escritoras se integraron a los movimientos de renovación estética que atravesaron la literatura en los años veinte; se constituyeron en agentes culturales con intervención directa y determinante sobre las configuraciones estéticas del período. Ahora bien, la "otredad" de las escritoras "descarriadas" fue la forma de visualización que adquirieron para los intelectuales que se resistían a una participación literaria plena y, sobre todo, nueva por parte de estas autoras. Dicha participación las convirtió en agentes activos, que se eslabonaron en un proceso lento y gradual en el que fueron abandonando la marginalidad a la que estuvieron sometidas durante mucho tiempo. De este modo, empezaron a realizar actividades culturales y ganaron lugar en el periodismo, y desde allí -como Alfonsina Storni o Herminia Brumana, por ejemplocombatieron fuertemente el androcentrismo y reclamaron nuevos espacios y modos de producción cultural. Storni y, ocasionalmente, Lange se colocaron en un lugar diferente al que se esperaba de ellas: ese desplazamiento, como venimos diciendo, implicó sanciones y condenas de estas autoras y sus textualidades. El pensamiento androcéntrico caracterizó, en algunos casos, a la escritura femenina como literatura pornográfica, producto de un estro insuflado por pasiones “desbordadas", que ponían en duda la moral de las escritoras: se las llegó a acusar de "prostitutas" y se desplegó, en algunas oportunidades, diversas formas de animalización. En definitiva, al igual que algunos escritores hombres, las autoras estuvieron sometidas a procedimientos de deslegitimación por la utilización de una lengua literaria que violaba algún tipo de norma, en el caso de ellas las de género principalmente.

Con respecto a las escritoras analizadas, las transgresiones no se relacionaban con la introducción de formas populares, con el trabajo sobre una oralidad "plebeya" o con rupturas en el plano de la corrección gramatical. No se trataba de planteos vinculados con una 
experimentación con el lenguaje cuya ruptura se llevara a cabo antes que nada en las normas que regían el idioma, es decir en las regulaciones del "buen decir" gramatical. Se trataba en cambio de un lenguaje a contrapelo de los mecanismos de control discursivo -que determina zonas-tabú para algunos sujetos hablantes-, pero sin trastocar los diccionarios y las gramáticas. Sencillamente decían aquello que les estaba vedado. En este sentido, las modalidades de ruptura, trasgresión y reconfiguración de la lengua literaria son similares a las que llevó a cabo Oliverio Girondo, quien transformó el lenguaje literario sin subvertir los parámetros de corrección idiomática.

El trabajo de investigación que hemos expuesto en las páginas previas deja abiertas líneas futuras de investigación, las cuales pueden ser ubicadas en un eje diacrónico y en otro sincrónico. Con respecto al primero, valdría la pena investigar las continuidades y discontinuidades en las disputas acerca del lenguaje literario en décadas posteriores, y cuáles fueron las condiciones de transformación en los nuevos contextos de producción.

En cuanto al eje sincrónico, una línea de investigación productiva estaría dada por el análisis del problema de la lengua literaria en las provincias: ¿cómo se suscitan estas discusiones -centralmente rioplatenses- en las literaturas de otras zonas del país (en particular en las zonas de frontera o bilingües) y cómo repercuten en el lenguaje literario durante los años veinte en Buenos Aires?

Para finalizar, creemos pertinente señalar la zona del teatro como una línea de investigación futura, sumamente rica, que no hemos podido abordar en esta investigación dada su particular configuración y dinámica.

Nos hemos propuesto, en estas páginas, desarrollar algunas hipótesis que contribuyan a una mejor comprensión de las condiciones de transformación la lengua literaria y de sus diversas modalidades. Las disputas en torno al lenguaje literario -a veces explícitas, otras oblicuas, silenciosas pero con consecuencias manifiestas en las muchas escrituras del período- conforman una importante polémica constitutiva de nuestra literatura, al decir de Jorge Panesi: quizás la gran polémica de nuestras letras, cuyas ondulaciones dictadas por ausencias y reapariciones marca al período 1920-1930 como uno de los momentos de su emergencia más significativos. 


\section{BIBLIOGRAFÍA}

\section{Fuentes documentales}

“Aclaración editorial y política, periodismo y teatro" (1927). Claridad, No 130, 1-8.

"Alberto Hidalgo emitirá libremente su voto en el Jurado Municipal de Literatura" (Entrevista) (1929). La Literatura Argentina, A. II, No 15, 73-74.

"Barbaridades que se nos escapan al hablar, por Ricardo Monner Sans" (1924). Nosotros, № $186,369$.

"Barbarización literaria. La musa de la mala pata" (1926). Nosotros, No 205, 261-267.

“Cementerio de Martín Fierro" (1924). Martín Fierro, № 8-9, 12.

“Claridad y Crítica” (1927). Claridad., No 131, 5.

“Concurso literario femenino" (1929). La Literatura Argentina, № 7, 27.

"Contestaciones a la Encuesta de Martín Fierro: ¿cree Vd. En la existencia de una sensibilidad, de una mentalidad, argentina? En caso afirmativo, ¿cuáles son sus características?" (1924). Martín Fierro, No 5-6, 6-7.

"Conversaciones del momento. Paul Groussac al caer la tarde" (1926). La Nación, 19 de septiembre de 1926, 4.

"Crítica saluda a todos los hombres de todas las razas y todas las nacionalidades" (1927). Crítica, 1 de septiembre de 1927, 1.

“Crítica pretende amordazar a Claridad” (1927). Claridad, № 131, 1.

"Dios los cría y ellos se juntan" (1927). Claridad, № 130, 3-5.

"Editoriales Proa y Martín Fierro" (1926). Martín Fierro, No 34, 5.

“El año literario" (1926). Claridad, No 6, 19-22.

"El diario de las planchas" (1927). Claridad, No 137, 3.

“El fallo de un jurado" (1930). Claridad No 207, 3-5.

"El juguete rabioso, novela de Roberto Arlt" (1926). Claridad, N 5, 31.

“El primer mensaje” (1922). El Diario, 13 de octubre de 1922, 1 y 4.

"El último libro de Girondo" (Crítica 7 de agosto de 1932) (1999). Girondo, Oliverio (Antelo, Raúl Ed.) Obra completa. Madrid: Galaxia Gutember - ALLCA XX, 622-623.

“En Buenos Aires se habla bien el español” (1927). Crítica, 25 de septiembre de $1927,5$.

“Espantapájaros por Oliverio Girondo” (1932). La Literatura Argentina, № 48, 351.

“Extrema Izquierda” (1924). Martín Fierro No 8 y 9, 8.

"Falta de seriedad informativa" (1927a). Claridad, No 135, 9. 
"Falta de seriedad informativa" (1927b). Claridad, No 136, 7.

"Fue víctima de una tentativa de asalto el director de Claridad" (1927). Claridad, No $131,26$.

“Glorias nacionales” (1926). Claridad, No 5, 5.

"Ha aparecido un extraño libro de versos: La musa de la mala pata" (1926). Crítica, 11 de mayo de 1926, 10.

"Habla un tránsfuga de la Avenida de Mayo del arrabal" (1925). Crítica, 21 de julio de $1925,6$.

"Hay que escribir con dinamita" (1926). Claridad, № 5, 7.

"Homenaje a Ramón" (1925). Martín Fierro, N 19, 5.

"Homenaje a Ricardo Güiraldes" (1927). Martín Fierro, No 44-45, 3.

Homenajes tributados a los educacionistas señor Ramón C. Carriegos i señorita Aurora J. Carriegos al acogerse a la lei de jubilaciones (1947). Buenos Aires: Talleres Gráficos Argentinos L. J. Rosso.

"Horacio Rega Molina destaca que el movimiento intelectual argentino es un suceso contemporáneo" (1929). La Literatura Argentina, $\mathrm{N}^{\circ}$ 11, 18-22.

"Hoy hace un año que apareció triunfalmente el primer número de las $5^{\circ}$ edición de Crítica" (1923). Crítica, 18 de abril de 1923.

“Instantáneas. (Breves entrevistas de Variedades)" (2007). (Variedades, Lima, N 859, 16 de agosto de 1924). Schwartz Jorge. Nuevo homenaje a Girondo. Rosario: Beatriz Viterbo, 137-138.

"La encuesta de Crítica: ¿Llegaremos a tener idioma propio? Y D. Américo Castro" (1927). Crítica, 26 de septiembre de 1927, 7.

"Libros nuevos" (1926). Martín Fierro, № 33, 11.

"Literatura maleva" (1926). Claridad, № 5, 1-7.

“Los 7 Locos, por Roberto Arlt” (1929). La Literatura Argentina, № 15, 88.

"Llegaremos a tener un idioma propio" Crítica, 8 de junio de 1927, 6.

"Nicolás Olivari tiene la palabra..." (1929). La literatura argentina, No 14, octubre de 1929, 61-62.

"Notas" (1927). Síntesis, N 6, noviembre de 1927, 383-388.

"Noticia para el periodista milonguero" (1927). Claridad, N No 130, 2.

"Oliverio Girondo" (1924). Martín Fierro, № 2, 4.

“Oliverio Girondo: Veinte poemas para ser leídos en el tranvía” (1923). La Nación, 23 de diciembre de 1923, 9.

“Oliverio Girondo en misión intelectual” (1924). Martín Fierro, № 7, 3. 
“Otro que tira y erra" (1927). Claridad, № 130, 6.

"Para el de "Hoy"' (1926). Claridad, No 5, 3-4.

"Para que nos asalten otra vez. Este es el suelto que motivó el asalto. Denuncia contra Crítica" (1927). Claridad, № 131, 27.

"Parnaso satírico" (1926a). Martín Fierro, No 27-28, 12.

"Parnaso satírico" (1926b). Martín Fierro, a. III, No 34, 12.

"Pasatiempos lingüísticos, por Ricardo Monner Sans" (1926). Claridad, No 1, 43-45.

"Presentación" (1907). Nosotros, № 1, 5-6.

"Roberto Arlt sostiene que es de los escritores que van a quedar y hace una inexorable crítica sobre la poca consistencia de la obra de los otros" (1929). La Literatura Argentina, $\mathrm{N}^{\circ}$ Aniversario, 25-27.

“Segundo aviso" (1927). Claridad, No 130, 2.

“Sobre el tango" (1927). Claridad, No 143, 2.

"Solicitud" (1926). Claridad, № 5, 7.

"Suplementos explicativo de nuestro Manifiesto" (1924). Martín Fierro, No 8-9, 2.

"Terminó la encuesta de Crítica" (1927). Crítica, 29 de junio de 1927, 6.

"Una semana de vida literaria. El juguete rabioso, Roberto Arlt" (1926). Crítica Magazine, № 2, 22 de noviembre de 1926, 14.

"Vaselina vaselina" (1926). Claridad, № 5, 7

Abeille, Lucien (2005). Idioma nacional de los argentinos [1900]. Buenos Aires: Colihue.

Acuña, Angel (1932a). "Los factores de evolución de los idiomas". Ensayos. Buenos Aires: Espiasse, 39-45.

Agustini, Delmira (1924). Los astros del abismo. Montevideo, Máximo García Editor.

Alcazar Civit, P. (1931). "Las grandes figuras nacionales. Alfonsina Storni, que ha debido vivir como un varón reclama para sí una moral de varón”. El Hogar, № 1143, 8.

Alonso, Lisandro (1931). “Los Lanzallamas, de Roberto Arlt”. Megáfono, N 9, 125 129.

Alomar, Gabriel (1923). "A propósito de Veinte poemas para ser leídos en el tranvía". La Nación, 23 de diciembre de 1923, 9.

Amorim, Enrique (2007). "Carta a Oliverio Girondo" (Las Nubes, 1932). Schwartz Jorge. Nuevo homenaje a Girondo. Rosario: Beatriz Viterbo, 399-401.

Arlt, Roberto (1925). “El Rengo". Proa No 8, 28-39.

--- (1928). “Soy fotogénico?”, El Mundo, 7 de agosto de 1928, 6.

--- (1930). "La censura”. El Mundo, 23 de julio de 1930, 6. 
--- (1998). Aguafuertes. Obras, tomo II. Buenos Aires: Losada.

--- (1980). Los lanzallamas [1931]. Barcelona: Bruguera.

--- (1983). Estoy cargada de muerte y otros borradores. Buenos Aires: Torres Agüero.

--- (1993). El juguete rabioso [1926]. (Edición a cargo de Ricardo Piglia). Buenos Aires: Espasa Calpe.

--- (2000). Los siete locos. Los lanzallamas. (Edición crítica a cargo de Goloboff, Mario). París: Allca XX - Fondo de Cultura Económica.

Asunción Silva, José (1985). Obra completa. Barcelona: Biblioteca Ayacucho.

Barletta, Leónidas (1926). “El juguete rabioso, por Roberto Arlt”. Nosotros № 211, 553-54.

--- (1927). "El malevaje periodístico. Carta abierta al director de Crítica". Claridad, $\mathrm{N}^{\mathrm{o}} 131,14$.

--- (1932). “Crítica y ensayos. El amor brujo de Roberto Arlt”. El Hogar No 1196, 16 de septiembre de 1932, 16

--- (1967). Boedo y Florida. Una versión distinta. Buenos Aires: Ediciones Metrópolis.

Barbieri, Honorio (1929). "Nuestro ambiente de cultura bibliográfica y quienes la producen” (“Los 7 Locos de Roberto Arlt”). La Literatura Argentina, No 15, 87-91.

Beter, Clara (1998). Versos de una... [1926]. Buenos Aires: Ameghino.

Borges, Jorge Luis (1925a). “Al tal vez lector”. Martín Fierro, No 25, 4.

--- (1925b). “Oliverio Girondo - Calcomanías". Martín Fierro, № 18, 4.

--- (1927). “La encuesta de Crítica: ¿Llegaremos a tener idioma propio?”. Crítica, 19 de junio de 1927, 3 .

--- (1928a). “Idioma nacional rioplatense, por Vicente Rossi”. Síntesis, No 18, 361.

--- (1928b). “Voz de la vida, de Norah Lange”. Síntesis No 10, 101-102.

--- (1984). “Testimonios”. Xul. Signo viejo y nuevo. Revista de poesía. № 6, 10.

--- (1993). El tamaño de mi esperanza [1926]. Buenos Aires: Seix Barral.

--- (1994). El idioma de los argentinos [1928]. Buenos Aires: Seix Barral.

--- (1997a). “La crencha engrasada". Textos recobrados. 1919-1929. Buenos Aires:

Emecé, 377-378.

--- (1997b). "La lirica argentina contemporánea." Textos recobrados I (1919-1929). Buenos Aires: Emecé, 137.

C. I. (1924). "Versos de la calle, por Álvaro Yunque". Martín Fierro No 8 y 9, 10.

Cancela, Arturo (1927). "La encuesta de Crítica: ¿Llegaremos a tener idioma propio?". Crítica, 24 de junio de 1927, 9. 
--- (1944). Historia funambulesca del Profesor Landormy. Buenos Aires: EspasaCalpe.

Capdevila, Arturo (1932). "Espantapájaros (al alcance de todos), por Oliverio Girondo". Nosotros, $\mathrm{N}^{\mathrm{o}} 281,108$.

--- (1954). Babel y el castellano [1928]. Buenos Aires: Losada.

Carriegos, Ramón C. (1910). Minucias gramaticales. Tandil: El Progreso.

--- (1928). El porvenir del idioma español en la República Argentina. Frases $i$ palabras criollas. Tandil: El Imparcial.

--- (1940). Críticas i críticos. Temas filológicos, gramaticales i literarios. Corrientes: $\mathrm{s} / \mathrm{d}$.

Castelnuovo, Elías (1926). "Literatura criolla". Revista del Pueblo, a. I, No 1, 12.

--- (1927). “Bibliografía”. Izquierda, N 1, 46-48.

--- (1974). Memorias. Buenos Aires: Ediciones Culturales Argentinas.

--- (2003). Tinieblas [1923]. Buenos Aires: Librería Histórica.

Castro, A. (1927). "En torno al posible idioma argentino". La Nación, 15 de septiembre de $1927,11$.

Chaves, Roland [Castelnuovo, Elías] (1927a). Chaves, Roland. "Dramaturgia". Izquierda $\mathrm{N}^{\circ} 2,19-20$.

--- (1927b). "El ruidito musical”. Izquierda, $\mathrm{N}^{\circ} 2,17-18$.

--- (1927c). "La hora se acerca". Claridad, No 134, 3-4

--- (1998). "Prólogo a la primera edición". Beter, Clara (1998). Versos de una... Buenos Aires: Ameghino.

Córdova Iturburu (1930). "Resumen de 'Un nuevo novelista argentino: Roberto Arlt". La Literatura Argentina, Número Extraordinario, 329.

--- (1932). "Un nuevo novelista argentino: Roberto Arlt". Revista Jurídica de Ciencias Sociales. Buenos Aires: Centro de Estudiantes de Derecho, a. 49, No1, 30-58.

Coronado, Nicolás (1916). “La inquietud del rosal, por Alfonsina Storni”. Nosotros $\mathrm{N}^{\mathrm{o}}$ $83,406-407$.

--- (1919). “Irremediablemente, por Alfonsina Storni”, Nosotros $\mathrm{N}^{\circ} 121,91-93$.

Costa Álvarez, Arturo (1922). Nuestra lengua. Buenos Aires: Sociedad Editorial Argentina.

--- (1923). "El estudioso argentino y el catedrático importado ante la autoridad universitaria". Valoraciones $\mathrm{N}^{\mathrm{o}} 2,137-149$.

--- (1927a). “La encuesta de Crítica: ¿Llegaremos a tener idioma propio?”. Crítica, 22 de junio de 1927, 6 . 
--- (1927b). La obra de Monner Sans en nuestra lengua. Buenos Aires, Imprenta Mercatali.

--- (1928a). "Rudolf Grossmann: 'Das Ausländische Sprachgut im spanischen des Río de la Plata. Ein Beitrag zum Problem der argentinischen Nationalsprache'. Hamburg, Seminar für romanische Sprachen und Kultur, 1926”. Valoraciones $\mathrm{N}^{\circ} 12,241-244$.

--- (1928b). El castellano en la argentina. La Plata: Talleres de la Escuela San Vicente de Paúl.

--- (1929). “Groussac y la lengua”. Nosotros No 119-128, 118-128.

Darío, Rubén (1953). Obras poéticas completas. Buenos Aires: El Ateneo.

--- (1961). Azul. El Salvador: Ministerio de Educación de San Salvador.

De Diego, Rafael (1924). “La amada infiel, de Nicolás Olivari”. Nosotros, № 181, 230-233.

--- (1925). “Ocre”. Nosotros No 196, 70-77.

De Lucca, Carlos (1927). "El ocaso de la retórica". Claridad, N 149, 10.

De Torre, Guillermo (1925a). “Carta abierta A Evar Méndez”. Martín Fierro, a. II, No $19,10$.

--- (1925b). “Oliverio Girondo - un poeta consecuente". Proa No 12, 18-27.

--- (1954). "La buena doctrina". Capdevila, Arturo. Babel y el castellano. Buenos Aires: Losada, 165-171.

--- (2006). "Madrid, meridiano intelectual de Hispanoamérica”. (La Gaceta Literaria, Madrid, 15 de abril de 1927, Año I, No 8). Croce, Marcela (Comp.). Polémicas intelectuales en América Latina. Del "meridiano intelectual" al caso Padilla (1927-1971). Buenos Aires: Sigmur, 67-71.

Dellepiane, Antonio (1967). El idioma del delito [1894]. Buenos Aires: Compañía General Fabril Editora.

Delio, H. B. (1932). “El espantapájaros de Girondo”. Nosotros, No 281, 123-124.

Di Perle, Pascatore (1927). “¿Llegaremos a tener un idioma propio?”. El Hogar. No 907,66 .

Doll, Ramón (1928). "Literatura Femenina. Voz de la vida, de Norah Lange". Nosotros $\mathrm{N}^{\mathrm{o}} 230,87-94$.

--- (1930). “La producción literaria de 1929”. Claridad N 198, 23-32.

Donoso, Armando (Ed.) (1927). Sarmiento en el destierro. Buenos Aires: Gleizer.

E. K. (1924). “Un poeta que calla y un Cocoliche que parla”. Martín Fierro, No 1, 5.

E. P. (h) (1925). “Calcomanías, por Oliverio Girondo”. La Razón 21 de junio de 1925, 12. 
Echeverría, Esteban (1958). Dogma socialista de la Asociación de Mayo. Precedido de una oajeada retrospectiva sobre el movimiento intelectual en el Plata desde el año 37. Buenos Aires: Perrot.

Estrada, Carlos. (1983). “Carta al doctor Ernesto Quesada” [El Tiempo, octubre 21 de 1902]. Rubione, Alfredo (Ed.). En torno al criollismo. Textos y polémica. Buenos Aires: CEAL, 239-242

Franco, Luis L. (1927). “Un poeta de Buenos Aires”. Martín Fierro, № 37, 9-10.

Gabriel, José (1921). "La literatura femenina en Sud América. A propósito de un nuevo libro de Alfonsina Storni." El Hogar, N 588, 17.

--- (1927). "Vivir no es beber o la reforma de la ortografía", Caras y caretas $\mathrm{N}^{\circ} 1498$, año XXX, 18 de junio, 1927, 25-26.

Gálvez, Manuel (1920). "Prólogo". Blomberg, Héctor Pedro. Las puertas de Babel. Buenos Aires: Agencia General de Librerías y Publicaciones, 7-12.

--- (1922). El mal metafisico. Buenos Aires: Biblioteca de Novelistas Americanos.

--- (1927). “La encuesta de Crítica: ¿Llegaremos a tener idioma propio?”. Crítica, 20 de junio de 1927, 6 .

--- (1961). Recuerdos de la vida Literaria. El mundo de los seres ficticios. Buenos Aires: Hachette.

--- (2010). Nacha Regules. Buenos Aires: Eterna Cadencia.

Ganduglia, Santiago (1927). "Buenos Aires, metrópoli”. Martín Fierro, a. IV, № 42, 7.

García Velloso, Enrique (1927). "La encuesta de Crítica: ¿Llegaremos a tener idioma propio?”. Crítica, 21 de junio de 1927, 9.

Garrigós, Florencio (hijo) (1927). "La encuesta de Crítica: ¿Llegaremos a tener idioma propio?”. Crítica, 27 de junio de 1927, 17.

Gerchunoff, Alberto (1927). "La encuesta de Crítica: ¿Llegaremos a tener idioma propio?”. Crítica, 25 de junio de 1927, 6.

Girondo, Oliverio (1924a). "Carta abierta a 'La Púa”'. Martín Fierro, a. I, No 2, 4.

--- (1924b). “Manifiesto de Martín Fierro". Martín Fierro, № 4, 1-2.

--- (Antelo, Raúl Ed.) (1999). Obra completa. Madrid: Galaxia Gutember - ALLCA $\mathrm{XX}$.

--- (2007). "Carta a Guillermo de Torre", (Buenos Aires, septiembre de 1925). Schwartz Jorge. Nuevo homenaje a Girondo. Rosario: Beatriz Viterbo, 357-359.

Godoy, Lucas. "Hojeando los últimos libros. Oliverio Girondo. Espantapájaros". Mundo argentino, a. XXII, No 1144, 21 de diciembre de 1932, p. 45. 
Gómez de la Serna, Ramón (1924). “Veinte poemas para ser leídos en el tranvía, por Oliverio Girondo". Nosotros, a. 18, No 176, 137-138.

--- (1925). “Salutación”. Martín Fierro, № 19, 5.

--- (2007). "La vida en el tranvía", (El Sol, Madrid, 4 de mayo de 1923). Schwartz Jorge. Nuevo homenaje a Girondo. Rosario: Beatriz Viterbo, 461-462.

González Lanuza, Eduardo (1926). “Emoción y \$”. Martín Fierro, a. I, № 10-11, 3.

--- (1927). “Liquidando un meridiano". Martín Fierro, a. IV, № 44-45, 11.

Gonález Tuñón, Enrique (1967). Tangos [1926]. Buenos Aires: CEAL.

González Tuñón, Raúl (1927). “A Benjamín Jarnés”. Martín Fierro, Año IV, No $44 / 45,11$.

Grossmann, Rudolf (2008). El patrimonio lingüístico extranjero en el español del Río de la Plata. Buenos Aires: Biblioteca Nacional.

Güiraldes, Ricardo (1926). “Carta a Nicolás Olivari”. Martín Fierro, a. III, No 33, 8.

--- (1962a). Obras completas. Buenos Aires: Emecé.

--- (1962b). “A Enrique González Tuñón”. Obras completas. Buenos Aires: Emecé, 785-786.

--- (1991). Paul Verdevoye (Coord.). Don Segundo Sombra. Madrid: Archivos.

H. C. (1924a). “La levita gris, por Samuel Glusberg”. Martín Fierro No 7, 8.

Henriquez Ureña, Pedro (1928). Seis ensayos en busca de nuestra expresión. Buenos Aires: Babel.

Hernández, José (Edición crítica a cargo de Lois, Élida y Núñez, Ángel) (2001). Martín Fierro. Madrid: ALLCA XX.

Huysmans, Joris-Karl (1997). Contra natura. Barcelona: TusQuets.

Ibarra, Néstor (1930). La nueva poesía argentina. Ensayo crítico sobre el ultraísmo 1921-1929. Buenos Aires: Imprenta Vda. de Molinari e Hijo.

Jarnés, Benjamín (1925). “Oliverio Girondo: Calcomanías”. Revista de Occidente, Madrid, 255-257.

Jordán Luis María (1919). “Alfonsina Storni”. Nosotros No 121, 37-41.

Koremblit, Bernardo Ezequiel (1957). Nicolás Olivari poeta unicaule. Buenos Aires: Deucalión.

Lange, Norah (2005). Obra completa. Rosario: Beatriz Viterbo.

Larbaud, Valery (1925). “Carta a dos amigos”. Proa, a. II, No 8, 4-18.

Larreta, Enrique (1927). "La encuesta de Crítica: ¿Llegaremos a tener idioma propio?". Crítica, 11 de junio de 1927, 7. 
Last Reason (Máximo Sáenz) (1927). "La encuesta de Crítica: ¿Llegaremos a tener idioma propio?”. Crítica, 16 de junio de 1927, 3.

---(1929). "Firmas ajenas: Los 7 'colos' de Roberto

Arlt". El Mundo, 16 de diciembre de 1929, 6.

Lavagnino, Norberto (1930). "Literata". Claridad, N 199, 18-24.

Leblanc, Oscar (1924). "Vanguardismo de viaje. Una tarde con Oliverio Girondo". El Universal Ilustrado, México D. F., 30-46.

Lima, Félix (1927). "La encuesta de Crítica: ¿Llegaremos a tener idioma propio?”. Crítica, 18 de junio de 1927, 17.

López de Molina (1932). “Espantapájaros por Oliverio Girondo”. Claridad № 258, 13.

López Palmero, M. (1927). "Poemas de amor, por Alfonsina Storni”. Nosotros No 215, 103-105.

--- (1930). “El gato escaldado. Poemas de Nicolás Olivari”. Nosotros No 253, 398399.

Lugones, Leopoldo (1926). “Don Segundo Sombra, de Ricardo Güiraldes”, La Nación, 12 de septiembre de 1926, 4 .

--- (1959). Obras poéticas completas. Madrid: Aguilar.

--- (1991). El payador. Caracas: Biblioteca Ayacucho.

M. C. (1925). “Calcomanías, de Oliverio Girondo". La Vanguardia, Buenos Aires, 26 de julio de 1925, 7.

Machado, Antonio (1919). Soledades, galerías y otros poemas. Madrid: Calpe.

Mallea, Eduardo (1927). “Divagaciones en torno a Jarnés”. Martín Fierro, No 39, 2.

Mercante, Vicente (1927). "La encuesta de Crítica: ¿Llegaremos a tener idioma propio?". Crítica, 14 de junio de 1927, 9.

Marechal, Leopoldo (1925). "Luna de enfrente, por Jorge Luis Borges". Martín Fierro, $\mathrm{N}^{\mathrm{o}} 26,4$.

--- (1926). "Nicolás Olivari”. Martín Fierro, № 32, 10.

Mariani, Roberto (1924a). "La amada infiel por Nicolás Olivari”. Martín Fierro N. 7, 10.

--- (1924b). “Martín Fierro y yo". Martín Fierro № 7, 2.

--- (1924c). "Suplemento explicativo de nuestro "Manifiesto". A propósito de ciertas críticas". Martín Fierro, $\mathrm{N}^{\mathrm{o}}$ 8-9, p. 2.

Martínez Cuitiño, Vicente (1923). “Oliverio Girondo y sus Veinte Poemas”. Vida Nuestra. Publicación mensual israelita, a. VII, Nº 3, Buenos Aires, 49-54. 
Méndez, Evar (1924a). "Balada". Martín Fierro No 2, 3.

--- (1924b). “Oliverio Girondo", Martín Fierro, a. 1, No 2, 4.

--- (1924c). “Rubén Darío, poeta plebeyo”. Martín Fierro N 1, 2.

--- (1927). “Asunto fundamental”. Martín Fierro; Año IV, N 44/45, 1.

Monner Sans, José María (1927). "Encuesta de Crítica. ¿Llegaremos a tener un idioma propio?" Crítica 26 de junio de 1927, 7.

--- (1929). “Acerca de El actual momento literario". La literatura argentina, № 12 , $31-32$.

Monner Sans, Ricardo (1923). Disparates usuales en la conversación diaria. Buenos Aires: Agencia General de Librería y Publicaciones.

--- (1924). Barbaridades que se nos escapan al hablar. Buenos Aires: Agencia General de Librería y Publicaciones.

--- (1926). “La gramática rediviva y el nuevo diccionario”. Nosotros, № 200-201, 4765.

Nahuelpán (1925). "Diez minutos con Oliverio Girondo, fuerte mentalidad agridulce”. Columbia, Buenos Aires, a. 1, № 3, 12-14.

Nalé Roxlo, Conrado (1978). Borrador de memorias. Buenos Aires: Plus Ultra.

Nin Frías, Alberto (1927). "La encuesta de Crítica: ¿Llegaremos a tener idioma propio?”. Crítica, 23 de junio de 1927, 10.

Noé, Julio (1923). "Letras argentinas. Algunos libros de 1923”. Nosotros, № 175 , 471-479.

Ocampo, Victoria (1981). Testimonios. Primera serie (1920-1934). Buenos Aires: Sur.

--- (1983). De Francesca a Beatrice [1924]. Buenos Aires: Sur.

Olivari, Nicolás (1925). “Adiós a Buenos Aires”. Martín Fierro, No 14-15, 8.

--- (1926). “Tangos por E. González Tuñón”. Martin Fierro, № 33, 8.

--- (1927). “Madrid, meridiano intelectual Hispano América”. Martín Fierro, № 42, 6.

--- (1931). “Los lanzallamas, de Roberto Arlt”. Claridad, a. 10, № 239 (117), 44-47.

--- (1992). La musa de la mala pata. El gato escaldado. Buenos Aires: CEDAL.

--- (2006). Poesías 1920-1930. La amada infiel. La musa de la mala pata. El gato escaldado. Buenos Aires: El 8vo Loco.

--- (2009a). Carne al sol. Cuentos del escritor Nicolás Olivari. Buenos Aires: El 8vo Loco.

--- (2009b). "Mito y realidad del grupo Martín Fierro". (Revista Testigo No 2, 1966, Buenos Aires, 14-17). http://www.poesiaeljabali.com/bululu/bul_09.htm, 1-2. 
Ortelli y Gasset (Borges, Jorge Luis y Mastronardi, Carlos) (1927). “A un meridiano encontrao en una fiambrera". Martín Fierro, a. IV, $\mathrm{N}^{\circ} 42,7$.

Payró, Roberto (1927). “La encuesta de Crítica: ¿Llegaremos a tener idioma propio?”. Crítica, 17 de junio de 1927, 5.

Perlongher, Néstor (1997). "Nena, lleváte un saquito". Prosas plebeyas. Buenos Aires: Colihue, 25-27.

Petit de Murat, Ulises (1939). "Roberto Arlt, novelista”. Síntesis No 41, 161-164.

Picone, José (1927). "El periodismo nacional” Claridad, No 140, 1927, p. 18.

--- (1929). "La usurpación vanguardista y la literatura de izquierda". Claridad, No 181, 22-23.

Pineta, Alberto (1962). "Roberto Arlt y la deshumanización de la locura". Verde memoria. Buenos Aires: Antonio Zamora, 140-151.

Pirán, Carlos (1926). "Hojeando los últimos libros”, en Mundo Argentino, No 830, 24.

Quesada, Ernesto (1923a). "La evolución del idioma nacional”. Nosotros, N 164, 531.

--- (1923b). "La evolución del idioma nacional” (conclusión). Nosotros, No 165, 175207.

--- (1983). “El 'criollismo' en la literatura argentina” [1902]. Rubione, Alfredo (Comp.), En torno al criollismo. Buenos Aires:. CEAL, 105-219.

Quesada, Josué (1919). "La vendedora de Harrods". La novela semanal, Buenos Aires, $\mathrm{N}^{0} 69$

Rivera Reyes J. (1927). “Sobre hispanismo. En defensa del idioma”. Claridad, N 137, 23-24.

Rojas, Ricardo (1927) “LLlegaremos a tener un idioma propio?”. Crítica, 13 de junio de 1927, p. 6.

--- (1922). La restauración nacionalista. Buenos Aires: La Facultad.

--- (1948). Historia de la literatura argentina, Tomo I, Los Gauchescos. Buenos Aires: Kraft.

--- (1980). Eurindia. Buenos Aires: CEAL.

Rojas Paz, Pablo (1927). "Imperialismo baldío". Martín Fierro, № 42, 6.

--- (1925). “Hispanoamericanismo". Martín Fierro, a. II, No 17, 2.

Rossi, Vicente (1926). Cosas de negros. Los oríjenes del tango y otros aportes al folklore rioplatense. Córdoba: Imprenta Argentina.

--- (1928a). Folletos Lenguaraces $N^{o}$ 6. Idioma Nacional Rioplatense (argentinouruguayo). Primera evidencia. Córdoba: Imprenta Argentina. 
--- (1928b). "El señor Vicente Rossi, nos acaba de enviar un interesante folleto de estudio sobre asuntos relacionados con nuestra lengua y su influencia en nuestra literatura". Nativa, $\mathrm{N}^{\circ} 49,17$.

--- (1929a). Folletos Lenguaraces $N^{o}$ 7. Idioma Nacional Rioplatense (argentinouruguayo). Segunda evidencia. Córdoba: Imprenta Argentina.

--- (1929b). Folletos Lenguaraces $N^{o}$ 8. Idioma Nacional Rioplatense (argentinouruguayo). Tercera evidencia. Córdoba: Imprenta Argentina.

--- (1929c). Folletos Lenguaraces $N^{o}$ 9. Del trascendentalismo. Idioma Nacional Rioplatense (argentino-uruguayo). Primera evidencia. Córdoba: Imprenta Argentina.

--- (1969). Teatro nacional rioplatense. Contribución a su análisis y a su historia. Buenos Aires: Solar/Hachette.

Rubione, Alfredo (Ed.) (1983). En torno al criollismo. Textos y polémica. Buenos Aires: CEAL.

S. (1921). “Languidez, versos por Alfonsina Storni”. Babel, № 1, 4.

Saldías, José Antonio (1927). "La encuesta de Crítica: ¿Llegaremos a tener idioma propio?”. Crítica, 12 de junio de 1927, 7.

--- (1968). La inolvidable bohemia porteña. Buenos Aires: Freeland.

Sanín Cano, Baldomero (1927). “Kodak argentino”. La Nación, supl. lit., 12 de junio de $1927,12$.

Scalabrini Ortiz, Raúl (1927). "Despedida de un meridiano”. Martín Fierro, № 44-45, 11.

Selva, José Fernando (1967). Dolores, Bs. As.: sus hijos dilectos, sus varones ilustres, sus vecinos destacados. Dolores: Talleres Gráficos de "El Tribuno".

Selva, Juan B (1925). Guía del buen decir. Estudio de las transgresiones gramaticales más comunes. Buenos Aires: Librería de A. García Santos.

Soto, Luis Emilio (1930). “Los siete locos, por Roberto Arlt”. La Prensa, 9 de febrero de 1930,33 .

Storni, Alfonsina (1968). Obras completas I. Poesías. Buenos Aires: Sociedad Editora Latino Americana.

--- (1998). Nosotras y la piel. Selección de ensayos de Alfonsina Storni. Buenos Aires: Alfaguara.

Suárez Calimano, Eduardo (1925). “Calcomanías”. Sagitario, La Plata, a. 1, No 2, 232-233. 
Supervielle, Jules (2007). “20 poemas para ser leídos en el tranvía, por Oliverio Girondo", (Revue de l'Amérique Latine, París, marzo de 1924). Schwartz Jorge. Nuevo homenaje a Girondo. Rosario: Beatriz Viterbo, 471-472.

Tiempo, César (1974). Clara Beter y otras fatamorganas. Buenos Aires: A. Peña Lillo.

Unamuno, Miguel de (2001). “El gaucho Martín Fierro, poema popular gauchesco de D. José Hernández (argentino)". Hernández, José (Edición crítica a cargo de Lois, Élida y Núñez, Ángel). Martín Fierro. Madrid: ALLCA XX, 839-848.

Valéry, Paul (1999). "Los derechos del poeta sobre la lengua" (carta del 19 noviembre de 1927). Piezas sobre arte. Madrid: Visor.

X. (1925). “Ocre. Alfonsina Storni”. La Campana de Palo, № 2, 28.

Yunque, Álvaro (1976). Barcos de papel. Buenos Aires: Plus Ultra.

--- (1977). Versos de la calle. Buenos Aires: Rescate.

Zamora, Antonio (1930). “Cascotes". Claridad No 206, 1-2.

Zas, Lubrano (1968). Palabras con Elías Castelnuovo. Buenos Aires: Carlos Pérez Editor.

Zeitlin, Israel (1927). “La poesía de una mujer de la calle”. Claridad, No 130, 15.

\section{Bibliografía teórica}

Amícola, José (2001). De la forma a la información. Bajtín y Lotman en el debate con el formalismo ruso. Rosario: Beatriz Viterbo.

Angenot, Marc (2010). El discurso social. Los límites históricos de lo pensable y lo decible. Buenos Aires: Siglo XXI.

Bajtín, Mijaíl M. (1991). Teoría y estética de la novela. Madrid: Taurus.

Bourdieu, Pierre (1985). "La producción y la reproducción de la lengua legítima". ¿Qué significa hablar? Economía de los intercambios lingüisticos. Madrid: Akal, 17-39.

--- (1995). Las reglas del arte. Génesis y estructura del campo literario. Barcelona: Anagrama.

--- (2003). “Campo intelectual y proyecto creador". Araujo, Nara y Delgado, Teresa. Texto de teorías y crítica literarias: del formalismo a los estudios postcoloniales. México: Universidad Autónoma Metropolitana, 241-285.

--- (1997). "La ilusión biográfica”. Razones prácticas. Sobre la teoría de la acción. Barcelona: Anagrama, 74-83 
Casanova, Pascale (2001). La república mundial de las letras. Barcelona: Anagrama.

Deleuze, Gilles y Guattari, Félix (1997). Mil mesetas. Capitalismo y esquizofrenia. Valencia: Pre-Textos.

Eichenbaum, B. (1991). "La teoría del 'método formal”". Todorov, Tzvetan (Comp.). Teoría de la literatura de los formalistas rusos. México: Siglo XXI, 21-54.

Foucault, Michel (1996). El orden del discurso. Madrid: La Piqueta.

Hall, Stuart (1984). "Notas sobre la desconstrucción de 'lo popular'”. Samuel Raphael (Ed.). Historia popular y teoría socialista. Barcelona: Editorial Crítica - Grijalbo, 93-109.

Mukarovsky, Jan (2000). Signo, función y valor. Estética y semiótica del arte de Jan Mukarovsky. Bogotá: Universidad Nacional de Colombia.

Rivero, Eliana (1994-95). "Precisiones de lo femenino y lo feminista en la práctica literaria hispanoamericana". Revista INTI, No 40-41, 2-46.

Williams, Raymond (1980). Marxismo y literatura. Barcelona: Península.

\section{Bibliografía histórica y crítica}

Alemany Bay, Carmen (1998). La polémica del meridiano intelectual de Hispanoamérica (1927). Estudio y textos. Alicante: Universidad de Alicante.

Alfón, Fernando (2008a). "La exhumación de un raro: El patrimonio, de Rudolf Grossmann". Gossmann, Rudolf. El patrimonio lingüístico extranjero en el español del Río de la Plata. Buenos Aires: Biblioteca Nacional, 9-32.

--- (2008b). "Los orígenes de las querellas sobre la lengua en Argentina”. González, Horacio (Comp.). Beligerancia de los idiomas. Un siglo y medio de discusión sobre la lengua latinoamericana. Buenos Aires: Colihue, 43-77.

--- (2013). La querella de la lengua en Argentina. La Plata: Universidad Nacional de La Plata.

Altamirano, Carlos y Sarlo, Beatriz (1997). "La Argentina del Centenario: campo intelectual, vida literaria y temas ideológicos". Ensayos Argentinos. De Sarmiento a la vanguardia. Buenos Aires: Ariel, 161-199.

Ansolabehere, Pablo (2009). "La idea de lo nuevo en escritores de izquierda". Jitrik, Noé (dir.) Historia crítica de la literatura argentina. Manzoni, Celina (dir.) Volumen 7: Rupturas. Buenos Aires: Emecé, 49-70.

Ara, Guillermo (1970). Suma de poesía argentina (1538-1968). Buenos Aires: Guadalupe. 
Arrieta, Rafael Alberto (1957). La literatura argentina y sus vínculos con España [1948]. Buenos Aires: Librería y Editorial Uruguay.

Artundo, Patricia (1999). "Oliverio hombre, Oliverio poeta". Girondo, Oliverio (Antelo, Raúl Ed.). Obra completa. Madrid: Galaxia Gutember - ALLCA XX, 513-543.

Astutti, Adriana (2002). "Elías Castelnuovo o las intenciones didácticas en la narrativa de Boedo". Gramuglio Teresa (Dir.) Historia crítica de la literatura argentina. Vol 6. El imperio realista. Buenos Aires: Emecé, 417-445.

Barcia, José (1981). “'Claridad', una editorial de pensamiento”. Todo es historia, No $172,8-25$.

Barrenechea, Ana María (1953). "Borges y el lenguaje”. NRFH, № 3-4, 551-569.

--- (1967). "Borges y el idioma de los argentinos". La expresión de la irrealidad en la obra de Borges. Buenos Aires: Paidós, 205-229.

Barrera, Trinidad (1999). “"El gaucho que atrapa a lazo las greguerías criollas'. Oliverio Girondo en España durante la década de los veinte”. Girondo, Oliverio (Antelo, Raúl Ed.). Obra completa. Madrid: Galaxia Gutember - ALLCA XX, 445-453.

Batticuore, Graciela (2005). La mujer romántica: lectoras, autoras y escritores en la Argentina (1830-1870). Buenos Aires: Edhasa.

Berg, Walter B. (1999). “Apuntes para una historia de la oralidad en Argentina”. Berg, Bruno; Schäffauer, Markus Klaus (Eds.). Discursos de oralidad en la literatura rioplatense del siglo XIX al XX. Tübingen: Narr, 10-119.

Bertoni, Lilia Ana (2001). Patriotas, cosmopolitas y nacionalistas. La construcción de la nacionalidad argentina a fines de siglo XIX. Buenos Aires: Fondo de Cultura Económica.

Blanco de Margo, Mercedes (1991). Lenguaje e identidad. Actitudes lingüísticas en la Argentina (1800-1960). Bahía Blanca: Gabinete de Estudios Lingüísticos, Departamento de Humanidades, Universidad Nacional del Sur.

--- (1997). "Nacionalismo y ruptura lingüística en la Argentina: Luciano Abeille" Mendoza: Congreso Nacional de lingüística, Universidad Nacional de Cuyo, Facultad de Filosofía y Letras, 119-131.

Bombini, Gustavo (2004). Los arrabales de la literatura. Historia de la enseñanza literaria en la escuela secundaria argentina (1860-1960). Buenos Aires: Miño y Dávila.

Bordelois, Ivonne y Di Tullio, Ángela (2002). “El idioma de los argentinos: cultura y discriminación". Ciberletras: Revista de crítica literaria y de cultura, № 6 , Universidad de Buenos Aires, http://www.lehman.cuny.edu/ciberletras/v06/bordelois.html 
Borello, Rodolfo A. (1974). Habla y literatura en la Argentina. (Sarmiento, Hernández, Mansilla, Cambaceres, Fray Mocho, Borges, Marechal, Cortázar). Tucumán: Universidad Nacional de Tucumán. Facutad de Filosofía y Letras.

Bosoer, Sara (2005). "Los textos escondidos de Nicolás Olivari, aportes para redefinir su obra". Orbis Tertius $\mathrm{N}^{\mathrm{0}}$ 11, La Plata: Universidad Nacional de La Plata, 1-7. http://www.orbistertius.unlp.edu.ar/numeros/numero-11/5-bosoer-los-textos-escondidos-denicolas-olivari.pdf

--- (2008). “Algo más que hispanismo - antihispanismo en la polémica por el meridiano: lengua, nación y mercado a fines de la década de 1920”. I Congreso Internacional de literatura y cultura españolas contemporáneas. La Plata: Universidad Nacional de La Plata, Facultad de Humanidades y Ciencias de la Educación, 1-8.

--- (2009). “Olivari y la imaginación modernista: entre la sensibilidad erótica y el gargajo". II Congreso Internacional “Cuestiones Críticas”. Rosario: Universidad Nacional de Rosario, 1-7. Disponible en http://www.celarg.org/int/arch_publi/bosoer_c.pdf

--- (2012). La vanguardia plebeya de Nicolás Olivari. Mercado, lengua y literatura (1919-1929) [en línea]. Tesis de Posgrado. Universidad Nacional de La Plata. Facultad de Humanidades y Ciencias de la Educación. Disponible en http://www.memoria.fahce.unlp.edu.ar/tesis/te.765/te.765.pdf

Candiano, Leonardo y Peralta, Lucas (2007). Boedo: orígenes de una literatura militante. Historia del primer movimiento cultural de la izquierda argentina. Buenos Aires: Ediciones del CCC.

Capelli, Darío (2007). "Estudio preliminar". Cancela, Arturo. Historia funambulesca del profesor Landormy. Buenos Aires: Biblioteca Nacional-Colihue.

Carbone, Rocco y Ojeda, Ana (2006). "Estudio preliminar”. Olivari, Nicolás. Poesías 1920-1930. La amada infiel. La musa de la mala pata. El gato escaldado. Buenos Aires: E1 8vo Loco, 4-23.

--- (2008). “Con los botines de punta: la literatura de Roberto Mariani”. Mariani, Roberto. Obra completa 1920-1930. Tomo I. Buenos Aires: El 8vo Loco, 5-59.

--- (2012). “Malas lenguas. Un siglo de escrituras salvajes”. Carbone, Rocco (Comp.). Museo de las Lenguas de la Eterna. Los Polvorines: Universidad Nacional de General Sarmiento, 65-89.

Conde, Oscar (2011). Lunfardo. Un estudio sobre el habla popular de los argentinos. Buenos Aires: Taurus. 
Corral, Rose (1999a). "Notas sobre Oliverio Girondo en México. Introducción a un texto de Xavier Villaurrutia y a la correspondencia Reyes/Girondo". Girondo, Oliverio (Antelo, Raúl Ed.). Obra completa. Madrid: Galaxia Gutember - ALLCA XX, 454-474.

--- (1999b). "Relectura de Espantapájaros (al alcance de todos)". Girondo, Oliverio (Antelo, Raúl Ed.). Obra completa. Madrid: Galaxia Gutember - ALLCA XX, 587-599.

Correas, Carlos (1996). Arlt literato. Buenos Aires: Atuel.

Cortázar, Julio (1999). "Leopoldo Marechal: Adán Buenosayres" (Realidad No 14, marzo-abril 1949). Marechal, Leopoldo. Adán Buenosayres. Madrid: Colección Archivos ALLCA XX, 882-886.

Croce, Marcela (Comp.) (2006). Polémicas intelectuales en América Latina. Del “meridiano intelectual” al caso Padilla (1927-1971). Buenos Aires: Sigmur.

Cuitiño Martínez, Luis (1998). “Girondo y sus estrategias de vanguardia”. Filología, año 23, $\mathrm{N}^{\mathrm{o}} 1,151-176$.

Dalmaroni, Miguel (2006). Una república de las letras. Lugones, Rojas, Payró. Escritores argentinos y Estado. Rosario: Beatriz Viterbo.

Darrigrandi, Claudia (2008). "Ciudad, cuerpo, traje: la flaneuse en Buenos Aires". Revista Iberoamericana, $\mathrm{N}^{\circ} 222,85-99$.

De Diego, J. A. (1969). "Estudio preliminar". Rossi, Vicente. Teatro nacional riolplatense. Contribución a su análisis y a su historia. Buenos Aires: Solar/Hachette, 7-27.

De Diego, José Luis (Dir.) (2006). Editores y políticas editoriales y la Argentina 1880-2000. Buenos Aires: Fondo de Cultura Económica.

--- (2009). “Editores, libros y folletos". Manzoni, Celina (Dir.). Historia crítica de la literatura argentina. Vol 7: Rupturas. Buenos Aires: Emecé, 265-284.

De Micheli, Mario (1993). Las vanguardias artísticas del siglo XX. Madrid: Alianza.

Delgado, Verónica (2009). El nacimiento de la literatura argentina en las revistas literarias 1896-1913. La Plata: Universidad Nacional de La Plata.

D'entremont, Elaine (1963). "The influence of Joris Karl Huysmans Á Rebours on Rubén Darío". Romance Notes 5.1, 37-39.

Devoto, Fernando (2002). Nacionalismo, fascismo y tradicionalismo en la Argentina moderna. Una historia. Buenos Aires: Siglo XXI.

Di Tullio, Ángela (2003). Inmigración y políticas lingüísticas. El caso argentino. Buenos Aires: Eudeba.

--- (2006). “Organizar la lengua, normalizar la escritura”. Rubione, Alfredo (Dir.). Historia crítica de la literatura argentina. La crisis de las formas. Vol. 5. Buenos Aires: Emecé, 543-580. 
--- (2009). "Meridianos, polémicas e instituciones: el lugar del idioma". Manzoni, Celina (Dir.). Historia crítica de la literatura argentina. Rupturas Vol. 7. Buenos Aires: Emecé, 569-596.

Díaz Quiñones, Arcadio. (2006). "Pedro Henríquez Ureña (1884-1946): la tradición y el exilio". Sobre los principios. Los intelectuales caribeños y la tradición. Bernal: Universidad Nacional de Quilmes, 167-253.

Diz, Tania (2006). Alfonsina periodista. Ironía y sexualidad en la prensa Argentina (1915-1925). Buenos Aires: Libros del Rojas.

Echavarría, Arturo (1983). Lengua y literatura de Borges. Barcelona: Ariel.

Ennis, Juan Antonio (2008). Decir la lengua Debates ideológico-lingüísticos en Argentina desde 1837. Frankfurt: Peter Lang.

Espósito, Fabio (2009). La emergencia de la novela argentina. La prensa, los lectores y la ciudad (1880-1890). La Plata: Al Margen.

Farías, Víctor (1994). Las actas seccretas. Inquisiciones y El idioma de los argentinos, los otros libros proscriptos de Jorge Luis Borges. Madrid: Anaya \& Mario Muchnik.

Feinmann, José Pablo (2004). Filosofía y nación. Estudios sobre el pensamiento argentino. Buenos Aires: Seix Barral.

Ferreira de Cassone, Florencia (2002). "Roberto Arlt y Claridad". Revista de Literaturas Modernas, № 32, Universidad Nacional de Cuyo - Facultad de Filosofía y Letras, p. 49-66.

Frederick, Bonnie (1998). Wily Modesty. Argentine Women Writers, 1860-1910. Phoenix: Arizona State University.

Gamerro, Carlos (1989). "La gauchesca anarquista”. Filología XXIV 1, 2, Universidad de Buenos Aires, Facultad de Filosofía y Letras, 133-164.

Garramuño, Florencia (2007). Modernidades primitivas. Tango, samba y nación. Buenos Aires: Fondo de Cultura Económica.

Gelado, Viviana (2007). Poéticas de la transgresión. Vanguardia y cultura popular en los años veinte en América Latina. Buenos Aires: Corregidor.

Gilman, Claudia (2006). "Florida y Boedo: hostilidades y acuerdos". Viñas, David (Dir.) Yrigoyen entre Borges y Arlt (1916-1930). Buenos Aires: Paradiso, 44-58.

Giordano, Carlos (1986). "Boedo y el tema social". Historia de la literatura argentina. Tomo 4, “Los proyectos de la vanguardia”. Buenos Aires: CEAL, 1986, 25-48.

Giordano, Verónica (2010). "La ampliación de los derechos civiles de las mujeres en Chile (1925) y en Argentina (1926)". Mora N², 97-113. 
Gnutzmann, Rita (1996). “Los siete locos y Los lanzallamas en la renovación literaria de los años veinte". Texto Crítico. Nueva época № 3. Centro de Investigaciones LingüísticoLiterarias. Universidad Veracruzana, julio-diciembre, 125-141.

Gobello, José (1965). "Prólogo". Soler Cañas, Luis. Orígenes de la literatura lunfarda. Buenos Aires: Ediciones Siglo Veinte, 1965, 9-12.

González Lanuza, Eduardo (1971). Roberto Arlt. Buenos Aires: CEAL.

Gramuglio, María Teresa (2013). Nacionalismo y cosmopolitismo en la literatura argentina. Rosario: Editorial Municipal de Rosario.

Grillo, María del Carmen (2008). “La Campana de Palo (Buenos Aires, 1925-1927) y el periodismo porteño de los años veinte: un registro de tensiones". Ensayos sobre la prensa. Buenos Aires: Biblioteca Nacional, 293-383.

Gutiérrez, Leandro y Romero, Luis Alberto (1995). Sectores populares, cultura y política. Buenos Aires en la entreguerra. Buenos Aires: Sudamericana.

Hauser, Arnold (1969). Historia social de la literatura y el arte (tomo II). Madrid: Guadarrama.

Jitrik, Noé (1987). "Entre el dinero y el ser. Lectura de El juguete rabioso de Roberto Arlt”. La memoria compartida. Buenos Aires: CEAL, 68-103.

Juárez, Laura (2004). "Estética del 'cross a la mandíbula' y elementos modernistadecadentes en Roberto Arlt". Orbis Tertius No 10, La Plata: Universidad Nacional de La Plata, 1-6. http://www.orbistertius.unlp.edu.ar/numeros/numero-10/01.\%20Juarez.pdf

--- (2010). Roberto Arlt en los años treinta. Buenos Aires: Simurg.

Lafleur, H. et al. (2006). Las revista literarias argentinas (1893 - 1967). Buenos Aires: El 8vo. Loco.

Lafforgue, Jorge (1998). "Larra, una lectura pionera de Roberto Arlt". Larra, Raúl. Roberto Arlt. El torturado. Buenos Aires: Ameghino, 9-18.

Larra, Raúl (1998). Roberto Arlt. El torturado. Buenos Aires: Ameghino.

Legaz, María Elena (1999). Escritoras en la sala (Norah Lange. Imagen y memoria). Córdoba: Alción Editora.

Lindstrom, Naomi (1980). "La elaboración de un discurso contracultural en las Aguafuertes porteñas de Arlt”. Hispanic Journal, N 1, University of Pennsylvania, 47-55.

Lojo, María Rosa (2000). “El 'género mujer' y la construcción de mitos nacionales: el caso argentino rioplatense". Arancibia, Juana et. al (Eds.). La mujer en la literatura del mundo hispánico. California: Instituto Literario y Cultural Hispánico, 7-31.

Luch Prats, Javier (2008) Los trabajos y los dias de un editor rocambolesco: Vicente Blasco Ibáñez (En línea). Trabajo presentado en I Congreso Internacional de Literatura y 
Cultura Españolas Contemporáneas, 1 al 3 de octubre de 2008, La Plata, Argentina. Disponible en: http://www.memoria.fahce.unlp.edu.ar/trab_eventos/ev.406/ev.406.pdf

Ludmer, Josefina (1999). El cuerpo del delito. Un manual. Buenos Aires: Perfil Libros.

--- (2000). El género gauchesco. Un tratado sobre la patria. Buenos Aires: Perfil Libros.

Maristany, José (1998). “Maestras escritoras: el desafío de devenir 'autor' (19001930)". Mujeres en escena. Actas de las Quintas Jornadas de Historia de las Mujeres y Estudios de Género. Santa Rosa: Universidad Nacional de La Pampa, 49-59.

--- (2008). "Intoxicación literaria: dispositivos de lectura femenina en Argentina (1890-1930). Mora, $\mathrm{N}^{\circ} 1,43-56$.

Masiello, Francine (1986). Lenguaje e ideología. Las escuelas argentinas de vanguardia. Buenos Aires: Hachette.

--- (1997). Entre civilización y barbarie. Mujeres, Nación y Cultura literaria en la Argentina moderna. Rosario: Beatriz Viterbo.

Molina, Hebe Beatriz (1995). "Las mujeres escritoras en La Revista de Buenos Aires". Páramo, Martha Susana. Erase una vez la mujer... La mujer argentina en los siglos XIX y XX según fuentes históricas y literarias. Mendoza: Universidad Nacional de Cuyo, 111-131.

Montaldo, Graciela (1987a). "Los años veinte: un problema de historia literaria". Filología, XXII, 2, 129-144.

--- (1987b). "La literatura como pedagogía, el escritor como modelo". Cuadernos Hispanoamericano, $\mathrm{N}^{\mathrm{o}} 445$, pp. 41-64.

--- (2006a). “Consagraciones: tonos y polémicas”. Viñas, David (Dir.) Yrigoyen entre Borges y Arlt (1916-1930). Buenos Aires: Paradiso, 30-42.

--- (2006b). “Literatura de izquierda: humanitarismo y pedagogía”. Viñas, David (Dir.) Yrigoyen entre Borges y Arlt (1916-1930). Buenos Aires: Paradiso, 324-344.

Monteleone, Jorge (1988). "Inmigración y babelismo. La voz del otro en la poesía argentina, de Lugones a los poetas de los años veinte”. Filología, XXIII, 1, 109-126.

Muschietti, Delfina (1985). "La fractura ideológica en los primeros textos de Oliverio Girondo”. Filología, No 20.1 153-169.

--- (1990). "Las estrategias de un discurso travesti (género periodístico y género poético en Alfonsina Storni)”. Dispositio, XV, No 39, 85-105.

--- (2006). "Mujeres: feminismo y literatura". Viñas, David. Yrigoyen entre Borges y Arlt (1916-1930). Buenos Aires: Paradiso, 111-133. 
--- (2009). “Oliverio Girondo y el giro de la tradición”. Manzoni, Celina (Dir.) Historia crítica de la literatura argentina. Rupturas. Buenos Aires: Emecé, 121-145.

Myers, Jorge (1999). “La Revolución en las ideas: la generación romántica de 1837 en la cultura y la política argentinas". Noemí Goldman (directora del tomo) Revolución, república, confederación (1806-1852), Tomo 3 de Nueva Historia Argentina. Buenos Aires: Sudamericana.

Narvaja de Arnoux, Elvira (2001). "Disciplinar la lengua. La Gramática Casterllana de Amado Alonso y Pedro Henríquez Ureña”. Narvaja de Arnoux, Elvira y Di Tullio, Ángela (Eds.). Homenaje a Ofelia Kovacci. Buenos Aires: Eudeba, 53-76.

Narvaja de Arnoux, Elvira y Bein, Roberto (1999). "Posiciones de Jorge Luis Borges acerca del idioma nacional”. Borges, Buenos Aires: Biblioteca del Congreso Nacional, 19-30.

Ojeda, Ana (2004). “Olivari, entre fuegos” La posición. Revista de letras, cultura y politica, $\quad \mathrm{N}^{\mathrm{o}} \quad 5, \quad$ http://laposicion.blogspot.com/2008/01/olivari-entre-fuegos-ensayoscrticos.html

Olea Franco, Rafael (1993). El otro Borges, el primer Borges. Buenos Aires: Fondo de Cultura Económica.

Oliveto, Mariano (2011). "La campaña de Claridad contra Crítica y las puercas concesiones al mal gusto del populacho". IV Congreso Internacional CELEHIS de Literatura (Universidad Nacional de Mar del Plata).

Onega, Gladys (1982). La inmigración en la literatura argentina. Buenos Aires: CEDAL.

Oviedo, Gerardo (2005). "Luciano Abeille y el idioma nacional de los argentinos". Abeille, Lucien. Idioma nacional de los argentinos. Buenos Aires: Colihue, 11-88.

Panesi, Jorge (2003). "Polémicas ocultas". Boletín No 11, Rosario: Facultad de Humanidades y Artes, Universidad Nacional de Rosario, 7-15.

Payá, Carlos y Cárdenas, Eduardo (1978). El primer nacionalismo argentino en Manuel Gálvez y Ricardo Rojas. Buenos Aires: Peña Lillo.

Pellettieri, Osvaldo (2005). Historia del teatro argentino. Buenos Aires: Galerna Instituto Nacional del Teatro.

Pierini, Margarita (2002). "Alcaloides de papel. Una encuesta argentina de 1923 sobre la literatura barata". Revista de literaturas populares, $\mathrm{N}^{\mathrm{o}}$ 2, 43-63.

--- (2009). "Estudio preliminar. La novela semanal: un capítulo imprescindible en la historia de la literatura argentina". Doce cuentos para leer en el tranvía.Una antología de La novela semanal. Bernal: Universidad Nacional de Quilmes Editorial, 9-30.

Piglia, Ricardo (1998). "Sarmiento escritor". Filología XXXI, (1-2): 20-34. 
--- (2001). Respiración artificial. Buenos Aires: Planeta.

--- (2004).“Roberto Arlt, una crítica de la economía literaria”. Grupo de investigación de literatura argentina de la UBA (Comp.). Ficciones argentinas. Antología de lecturas críticas. Buenos Aires: Norma, 55-71.

Prieto, Adolfo (1956). Sociología del público argentino. Buenos Aires: Leviatán.

--- (1964). Antología de Boedo y Florida. Córdoba: Universidad Nacional de Córdoba.

--- (2006). El discurso criollista en la formación de la Argentina moderna. Buenos Aires: Siglo XXI.

Rama, Ángel (1970). Rubén Darío y el modernismo. (Circunstancia socioeconómica de un arte americano). Caracas: Biblioteca de la Universidad Central de Venezuela.

--- (1977). "El sistema de la poesía gauchesca”. AA.VV. La poesía gauchesca. Caracas: Biblioteca Ayacucho, IX-LIII.

--- (1982). Los gauchipolíticos rioplatenses. Buenos Aires: CEDAL.

--- (1984). La ciudad letrada. Montevideo: Comisión uruguaya pro Fundación Internacional Ángel Rama.

Ramos, Julio (1995). "El don de la lengua". Paradojas de la letra. Caracas: Universidad Andina Simón Bolivar - Ediciones Excultura, 3-21.

Rapalo, María Ester y Gramuglio, María Teresa (2001). "Pedagogías para la nación católica. Criterio y Hugo Wast". Historia crítica de la literatura argentina. El imperio realista. Buenos Aires: Emecé, 447-475.

Real de Azúa, Carlos (1977). "El modernismo literario y las ideologías". Escritura. Teoría y crítica literarias. $\mathrm{N}^{\circ}$ 3. Caracas: Universidad Central de Venezuela, 41-75.

Rest, Jaime (2010). Ensayos sobre cultura y literatura nacional. Bahía Blanca: 17 grises.

--- (1977). “Introducción”. Huysmans, J-K. Al revés. Buenos Aires: Ediciones Librerías Fausto, 7-28.

Rivera, Jorge (1996). "Notas sobre literatura y cultura popular en el "fin de siglo", Boletín de la Biblioteca del Congreso de la Nación, № 119, 53-66.

--- (1998). "La forja del escritor profesional: 1900-1930. Los escritores y los nuevos medios masivos". El escritor y la industria cultural. Buenos Aires: Atuel, 33-92

--- (2001). "Ingreso, difusión e instalación modelar del Martín Fierro en el contexto de la cultura argentina”. Hernández, José (Edición crítica a cargo de Lois, Élida y Núñez, Ángel). Martín Fierro. Madrid: ALLCA XX, 545-575. 
Rodríguez, Fernando Diego (2003). “Inicial (1923-1927). El frente estético-ideológico de la nueva generación”. Inicial. Revista de la nueva generación (1923-1927). Buenos Aires: Universidad Nacional de Quilmes, 7-43.

Rodriguez Pérsico, Adriana (1993). “Arlt: sacar las palabras de todos los ángulos”. Cuadernos Hispanoamericanos. Los Complementarios 11, 5-14.

--- (1999). “Girondo o el triunfo de una ética posagónica”. Girondo, Oliverio (Antelo, Raúl Ed.). Obra completa. Madrid: Galaxia Gutember - ALLCA XX, 379-403.

--- (2011). "Imágenes oscuras de la modernidad. Deshechos y mounstruos en la literatura de Elías Castelnuovo". Simposio Internacional Imágenes y Realismos en América Latina. Leiden, Holanda.

http://imagenesyrealismosleiden.files.wordpress.com/2012/01/imc3a1 genes-oscuras-de-lamodernidad-desechos-y-monstruos-en-la-literatura-de-elc3adas-castelnuovo.pdf

Rogers, Geraldine (2008). Caras y Caretas: cultura, política y espectáculo en los inicios del siglo XX. La Plata: Univ. Nacional de La Plata.

--- (2010). "La isla del arte martinfierrista". Santa Rosa: Revista Anclajes, N 14, $165-174$.

--- (2011a). "Ser políglota y trotamundo: los derechos del poeta sobre la lengua". La Plata: II Congreso Internacional de Literatura y Cultura Española Contemporánea, 1-7.

--- (2011b). "Claridad y los martinfierristas en Crítica". Mar del Plata: IV Congreso Internacional CELEHIS de Literatura. Universidad Nacional de Mar del Plata.

--- (2012a). “Claridad against avant-garde writers in Crítica (Argentina, 1926-1927)”. Dossier: Between folk and highbrow: popular culture and its functions in avantgarde magazines of the 1920s and 1930s. PhIN. Philologie im Netz, Berlin, (en prensa).

--- (2012b). "Entre la competencia por el público y la lucha por el pueblo: vanguardia estética, vanguardia de izquierda y mercado en la Argentina de 1920”. Congreso del Instituto Internacional de Literatura Iberomericana, Cádiz, 1-13.

--- (2012c). "Sufragio cultural: lo masivo en revistas argentinas en 1920". Iberoamericana. America Latina-España-Portugal. Berlín-Madrid: Ibero-Amerikanisches Institut and Iberoamericana/Vervuert, 1-15 (en prensa).

--- (2013). "La entrada a la escritura: Elías Castelnuovo y sus avatares literarios". Coloquio 2013 pip 0333. Idihcs (UNLP-CONICET): Redes intelectuales entre los universos letrado y popular en la cultura argentina 1920-1960: análisis de prácticas discursivas y archivos documentales. La Plata, 29 y 30 de agosto 2013. 
Romano, Eduardo (1990). "Transgresión y grotesco en la poesía de Nicolás Olivari”. Romano, Eduardo. Seminario Scalabrini Ortiz, Las huellas de la imaginación. Buenos Aires: Puntosur, 97-118.

--- (1991). "Lectura intratextual". Güiraldes, Ricardo. Paul Verdevoye (Coord.). Don Segundo Sombra. España: Archivos, 319-340.

Rosenblat, Ángel (1961). Las generaciones argentinas del siglo XIX ante el problema de la lengua. Buenos Aires: Universidad de Buenos Aires - Facultad de Filosofía y Letras Instituto de Filología Hispánica "Dr. Amado Alonso".

--- (1984). “Lengua literaria y lengua popular en América”. Estudios sobre el español en América (Tomo III), Caracas: Monte Ávila, 263-310.

Rubione, Alfredo (Ed.) (1983). En torno al criollismo. Textos y polémica. Buenos Aires: CEAL.

Saítta, Sylvia (1998). Regueros de tinta. El diario Crítica en la década de 1920. Buenos Aires: Sudamericana.

--- (2008). El escritor en el bosque de ladrillos. Una biografía de Roberto Arlt. Buenos Aires: Sudamericana.

--- (2009). "Nuevo periodismo y literatura de izquierda". Jitrik Noé (Dir.) Historia crítica de la literatura argentina. Monzoni, Celina (Dir.). Rupturas. Volumen 7. Buenos Aires: Emecé, 239-264.

Salas, Horacio (2004). El tango. Buenos Aires: Emecé.

Salazar Anglada, Aníbal (2007). "Julio Noé y la Antología de la poesía moderna argentina (1926): un punto de inflexión en la práctica antológica en Argentina. Anales de Literatura Hispanoamericana, vol. 36, Madrid: Universidad Complutense, 171-197.

Salomone, Alicia (2006). Alfonsina Storni. Mujeres, modernidad y literatura. Buenos Aires: Corregidor.

Santillán de, Diego (1956). Gran enciclopedia argentina. Buenos Aires: Ediar.

Sarlo, Beatriz (1983). "La perseverancia de un debate". Punto de vista, № 18, 3-5.

--- (1985). El imperio de los sentimientos: narraciones de circulación periódica en la Argentina, 1917-1927. Buenos Aires: Catálogos.

--- (1992). La imaginación técnica. Sueños modernos de la cultura argentina. Buenos Aires: Nueva Visión.

--- (1997a). “Oralidad y lenguas extranjeras. El conflicto en la literatura argentina durante el primer tercio del siglo XX". Altamirano, Carlos y Sarlo, Beatriz. Ensayos Argentinos. De Sarmiento a la vanguardia. Buenos Aires: Ariel, 269-287. 
--- (1997b). "Vanguardia y criollismo: la aventura de Martín Fierro". Altamirano, Carlos y Sarlo, Beatriz. Ensayos argentinos. De Sarmiento a la vanguardia. Buenos Aires: Ariel, 211-260.

--- (1998). "Victoria Ocampo o el amor de la cita". La máquina cultural. Maestras, traductores y vanguardistas. Buenos aires: Ariel, 95-194.

--- (2007). Una modernidad periférica: Buenos Aires 1920-1930. Buenos Aires: Nueva Visión.

Schäffauer, Markus-Klaus (1999). "Jorge Luis Borges y la escritura avant la voix". Berg, Walter Bruno y Schäffauer, Markus-Klaus (eds.). Discursos de oralidad en la literatura rioplatense del siglo XIX al XX. Tübingen: Narr, 204-217.

Schwartz, Jorge (1976). “Don Segundo Sombra: una novela monológica”. Revista Iberoamericana, $\mathrm{N}^{\circ}$ 96-97, 427-446.

--- (1984). “¿A quién espanta el espantapájaros?” Xul. Signo viejo y nuevo. Revista de poesía. $\mathrm{N}^{\mathrm{o}} 6,30-36$.

--- (2002a). Las vanguardias de América Latina. Textos programáticos y críticos. México: Fondo de Cultura Económica.

--- (2002b). Vanguardia y cosmopolitismo en la década del veinte. Oliverio Girondo y Oswald de Andrade. Rosario: Beatriz Viterbo.

--- (2007). Nuevo homenaje a Girondo. Rosario: Beatriz Viterbo.

Schvartzman, Julio (1996). Microcrítica. Lecturas argentinas (cuestiones de detalle). Buenos Aires: Biblos.

--- (2001). "El gaucho letrado". Hernández, José (Edición crítica a cargo de Lois, Élida y Núñez, Ángel). Martín Fierro. Madrid: ALLCA XX, 1156-1167.

Sebreli, Juan José (2005). “Cosmópolis y modernidad en Roberto Arlt”. Cuadernos Hispanoamericanos $\mathrm{N}^{\mathrm{o}}$ 661-662, 85-100.

Soler Cañas, Luis (1965). Orígenes de la literatura lunfarda. Buenos Aires: Ediciones Siglo Veinte.

Sorrentino, Fernando (1973). Siete conversaciones con Jorge Luis Borges. Buenos Aires: Casa Pardo.

Speranza, Graciela (2006). "Oliverio Girondo. El furor cosmopolita”. Montaldo, Graciela (Comp.) Yrigoyen entre Borges y Arlt (1916-1930). Buenos Aires: Paradiso, 164174.

Svampa, Maristella (2006). El dilema argentino. Civilización y barbarie. Buenos Aires: Taurus. 
Terán, Oscar (1993). "El payador de Lugones o "'la mente que mueve las moles"”. Punto de vista, Año XVI, No 47, 43-46.

Toscano y García, Guillermo (2009). "Materiales para una historia del Instituto de Filología de la Universidad de Buenos Aires (1920-1926)". Revista Internacional de Lingüística Iberoamericana. Madrid: Vervuert, 113-135.

Ulla, Noemí (1990). Identidad rioplatense 1930. La escritura coloquial (Borges, Arlt, Hernández, Onetti). Buenos Aires: Torres Agüero.

Verdevoye, Paul (2002a). “Aproximación al lenguaje porteño de Roberto Arlt”. Literatura argentina e idiosincrasia, Buenos Aires: Corregidor, 350-359

--- (2002b). "Hace cien años, una bomba lingüística en Buenos Aires: el libro de Luciano Abeille”. Literatura argentina e idiosincrasia. Buenos Aires: Corregidor, 321-331.

Vidal de Battini, Berta Elena (1966). El español en la Argentina. Buenos Aires: Consejo Nacional de Educación.

Viñas, David (1971). "El escritor vacilante: Arlt, Boedo y Discépolo". Literatura argentina y realidad política. De Sarmiento a Cortázar. Buenos Aires: Siglo XXI, 67-73.

--- (1986). "Prólogo". Teatro rioplatense (1886-1930). Caracas: Biblioteca Ayacucho, IX-XLIV.

--- (2003). “José Hernández, del indio al trabajo y a la conversión (1872-1879)". Indios, ejército y frontera. Buenos Aires: Santiago Arcos, 169-180.

--- (2005a). Literatura argentina y política. De los jacobinos porteños a la bohemia anarquista. Buenos Aires: Santiago Arcos.

--- (2005b). Literatura argentina y política. De Lugones a Walsh. Buenos Aires: Santiago Arcos. 